\title{
GENERAL AVIATION AND COMMUNITY DEVELOPMENT
}

(WEAS: -CF-145776) GENEFAL AVIATION ANL ACN. UNIIY LEVEICEMENT (Cld ECGinion Univ. Iorfolk. Va.) 268 E EC $\$ 9.00$ CSCI O1E

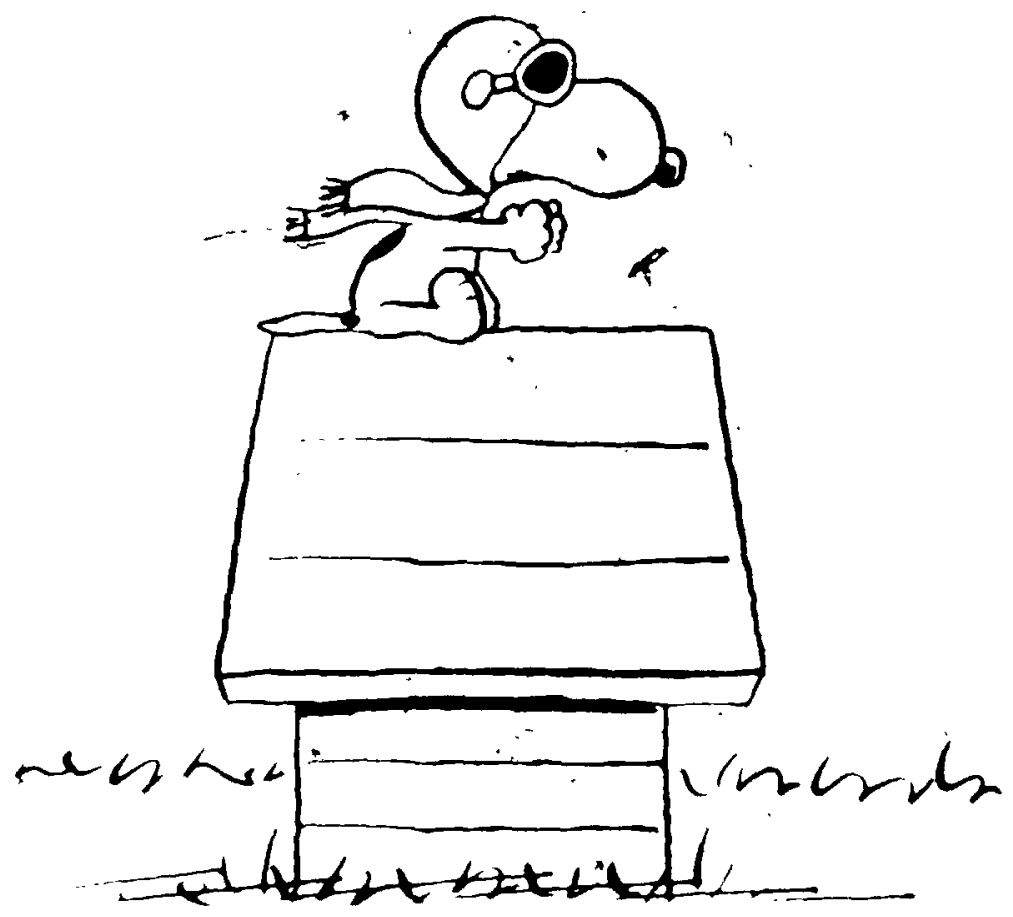

N76-11994 THRU N76-12005 unclas

5371004406

\section{NASA CONTRACT} NGT 47-003-028

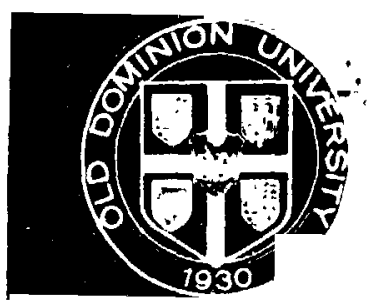

NASA Langley Research Center and Old Dominion Uniparsic 


\section{ORIGIHAL GOHTAIMS}

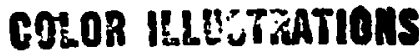

For Copies of this Report:

Dr. G. L. Goglia, Chairman

Department of Mechanical Engineering and Mechanics

Old Dominion University

Norfolk, Virginia 23508 


\section{THE AUTHORS:}

Michael Z. Sincoff, Ph.D., Project Director

Jarir S. Dajani, Ph.D., Assistant Project Director

Kay L. Antoniewicz, B.A.

John J. BernardJ, Ph.D.

Bernard F. B;rne, Ph.D.

Alexis Cenko, Ph.D.

Sybil da Groot, Ph.D.

Robert M. Eastman, Ph.D.

Joan Franklin, Ph.D.

Sander B. Friedman, Ph.D.

Gary W. Kiteley, M.A.

Clare F. Kosbab, M.A.

Timothy J. Kubiak, Ph.D.

Irwin B. Levinstein, Pn.D.

Henry L. Livas, M.S.

Charles L. Menges, B.A

Morris H. Mericle, Ph.D.

Wolfgang Pindur, Ph.D.

Robert L. Scott, J.D.

John J. Uhran, Jr., Ph.D

Robert K. Wattson, Jr., S.M.

Perry B. Wigley, Ph.D.

This report was compiled and writter, by the authors listed above, each of whom was a particifant in the 1975 NASAASEE Summer Faculty Fellowship Piogram in Engineering Systems Design. The authors represented seventeen different colleges and universities, and nineteen different academic disciplines. 


\section{GENERAL AVIATION \\ and \\ COMMUNITY DEVELOPMENT}

Editors:

Michael 2. Sincoff

Jarir S. Dajani

1975 SUMMER

FACULTY FELLOWSHIP PROGRAM IN ENGINEERING SYSTEMS

DESIGN

NASA-LANGLEY RESEARCH CENTER

AMERICAN SOCIETY FOR ENGINEERING EDUCATION

OLD DOMINION UNIVERSITY RESEARCH FOUNDATION 


\section{TABLE OF CONTENTS}

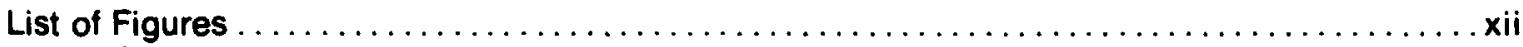

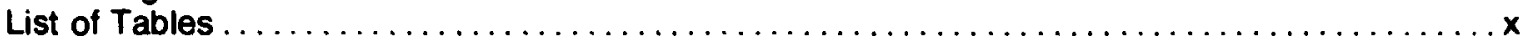

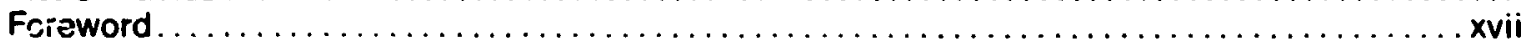

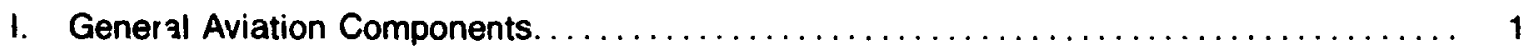

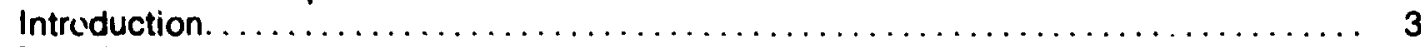

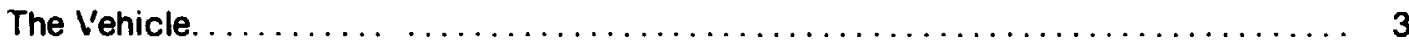

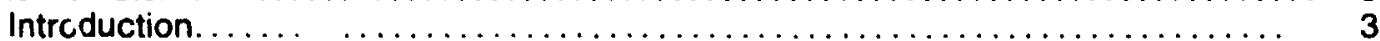

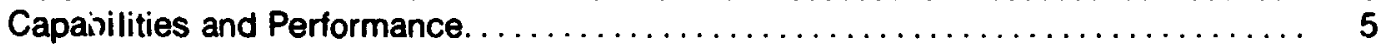

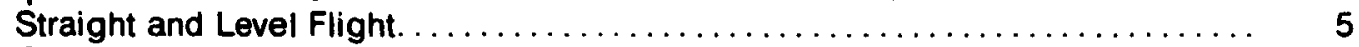

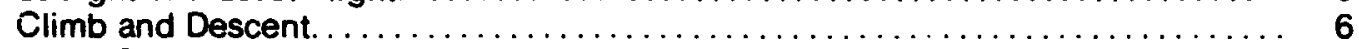

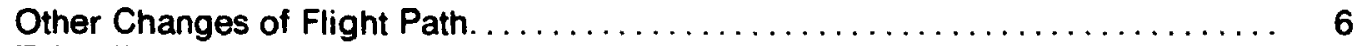

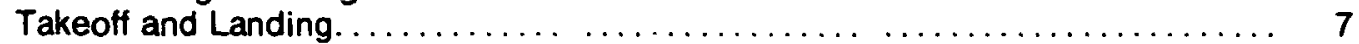

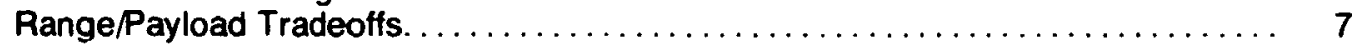

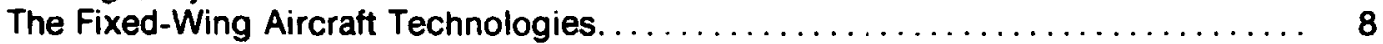

Aerodynamic Design. ................................... 8

Airfoil Development. . . . . . . . . . . . . . . . . .

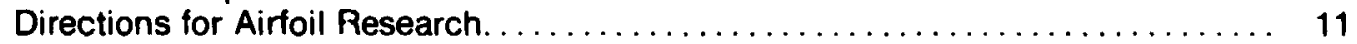

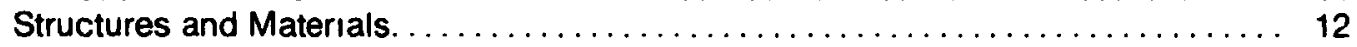

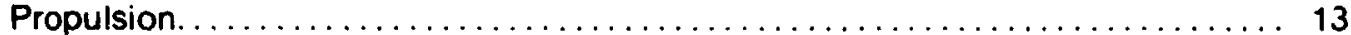

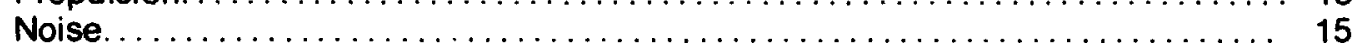

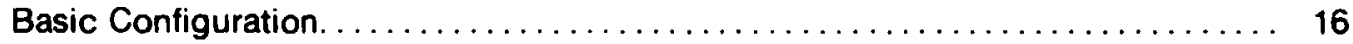

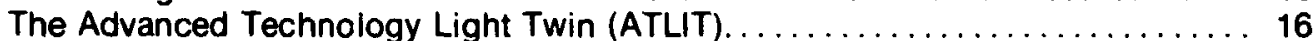

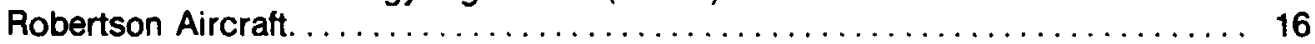

Short Field Aircraft. ...................................... 17-民

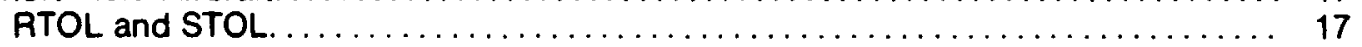

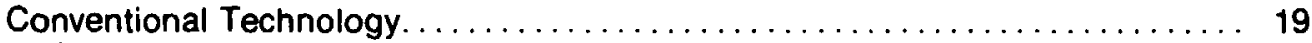

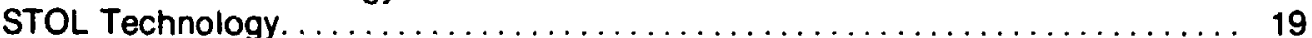

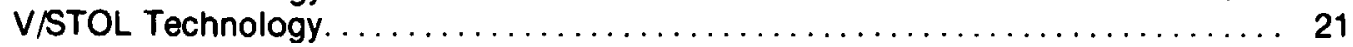

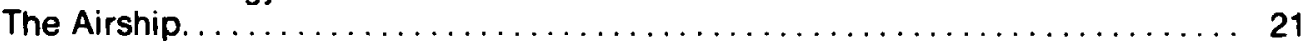

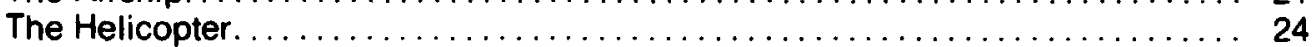

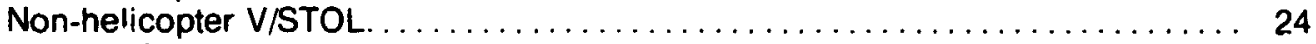

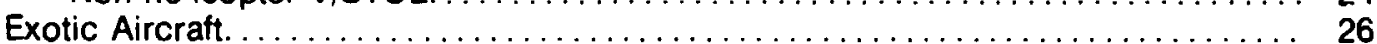

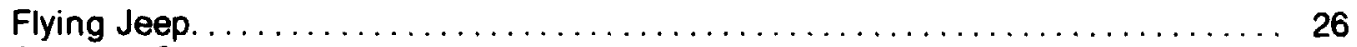

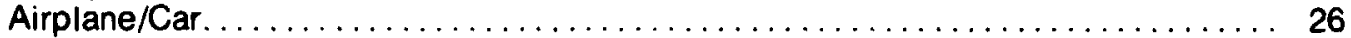

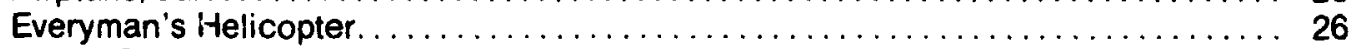

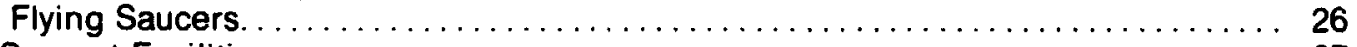

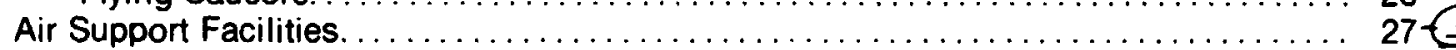

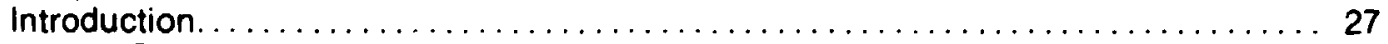

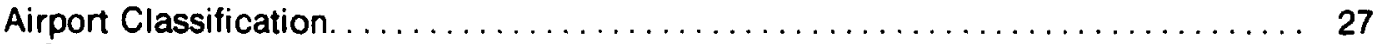

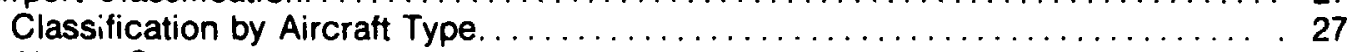

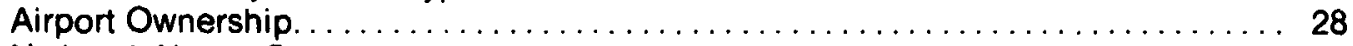

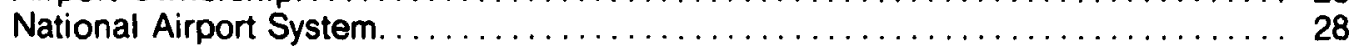

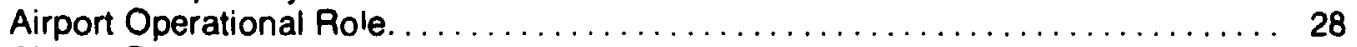

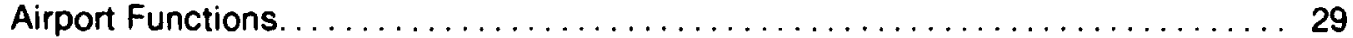

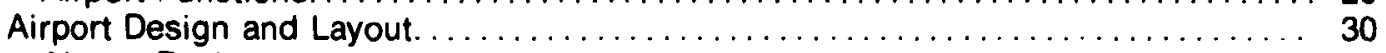

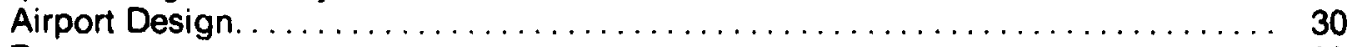

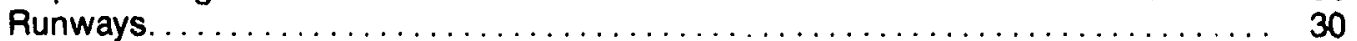

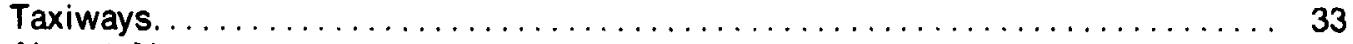

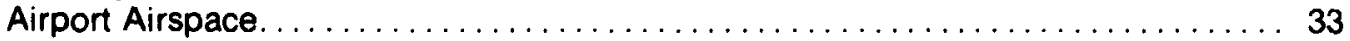

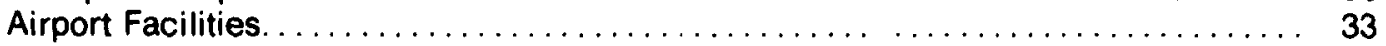

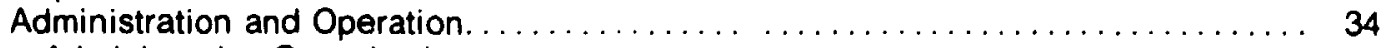

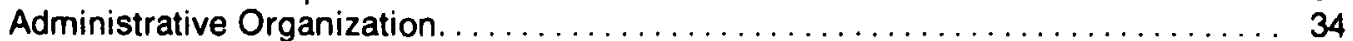

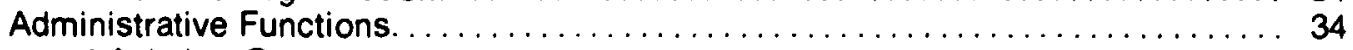

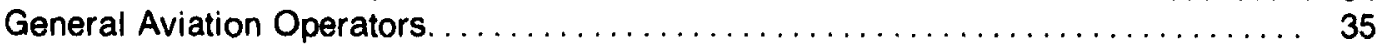


Aimways and Avionics. $\ldots \ldots \ldots \ldots \ldots \ldots \ldots \ldots \ldots \ldots \ldots \ldots$

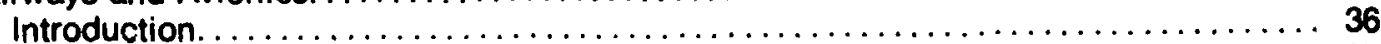

Air Traffic Control. . . . . . . . . . . . . . . . . . . . . . . . . . . . . . 37

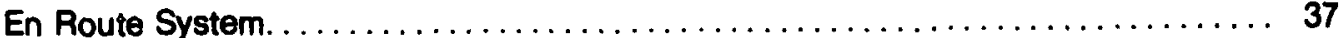

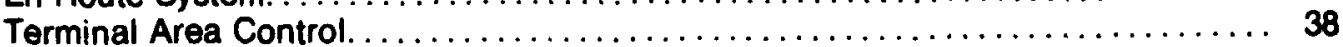

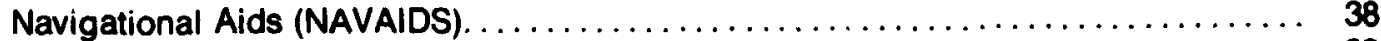

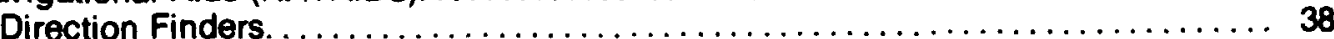

Satellite System. . . . . . . . . . . . . . . . . . . . . . . . . . . . . . 42

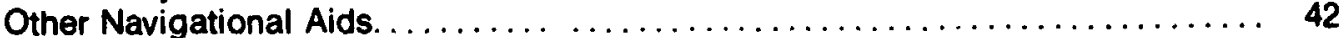

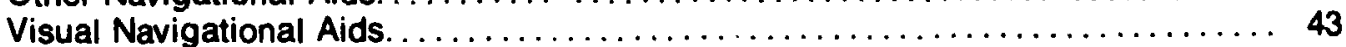

Computerized Area Navigation. . . . . . . . . . . . . . . . . . . . . . . 43

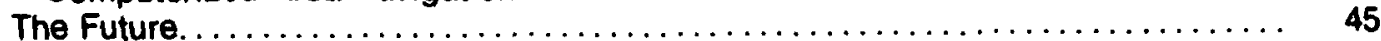

Human Factors in General Aviation. . . . . . . . . . . . . . . . . . . . . . . . 48

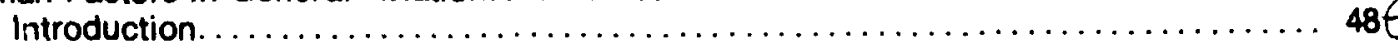

The Human Component: The Individual. . . . . . . . . . . . . . . . . . . . 48

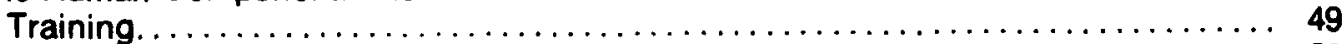

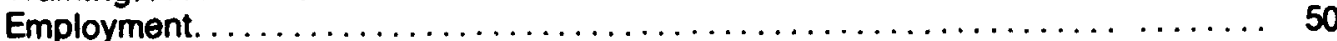

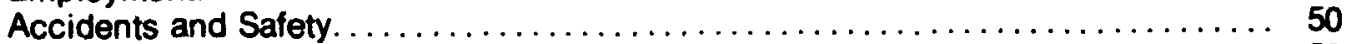

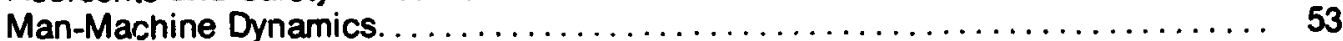

The Man-Environment Interface $\ldots \ldots \ldots \ldots \ldots \ldots \ldots \ldots \ldots \ldots \ldots \ldots \ldots$

II. The Ger.eral Aviation Environment. ............................ 57 .

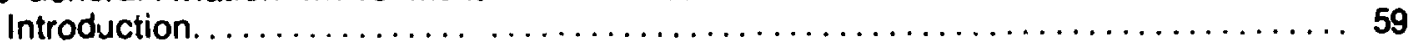

The Regulatory Environment. . . . . . . . . . . . . . . . . . . . . . . . 59

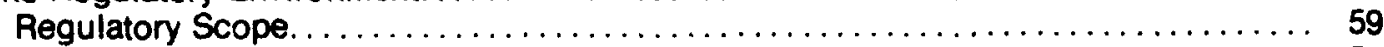

Legislative and Regulatory History. . . . . . . . . . . . . . . . . . . . . . 59

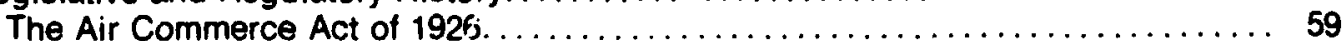

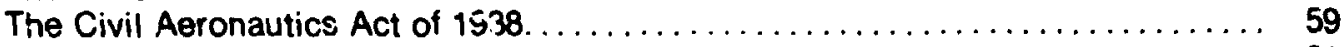

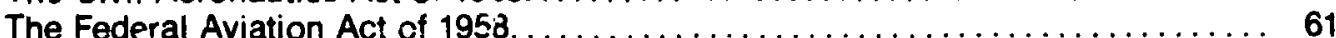

The Department of Transportation Act of 1970. . . . . . . . . . . . . . . . 61

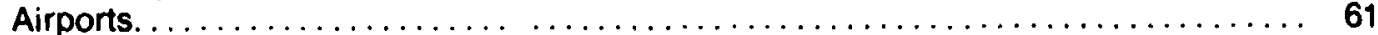

Legal Implications of Airport Planning and Land Use. . . . . . . . . . . . . . . 62

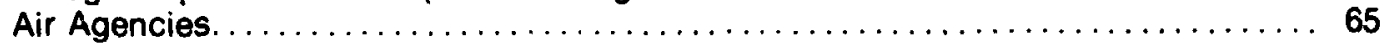

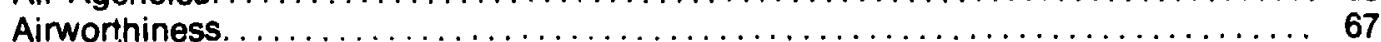

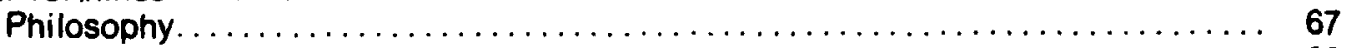

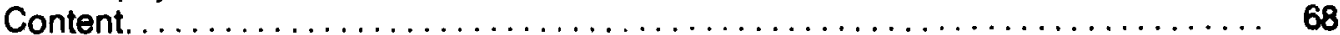

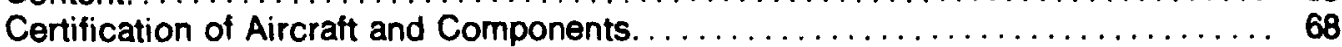

Changing Airworthiness Regulations. . . . . . . . . . . . . . . . . . . 69

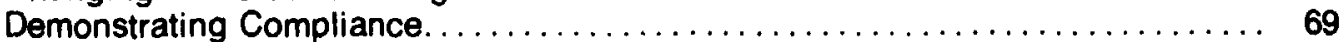

Airworthiness Directives. . . . . . . . . . . . . . . . . . . . . . . . . . 70

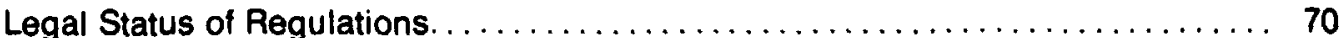

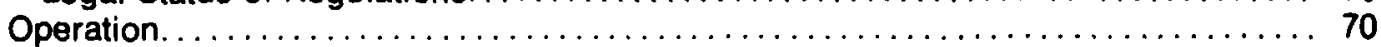

Interaction of Airworthiness and Operating Regulations. . . . . . . . . . . . . 71

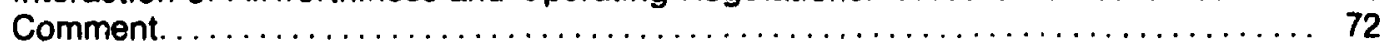

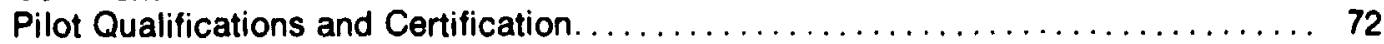

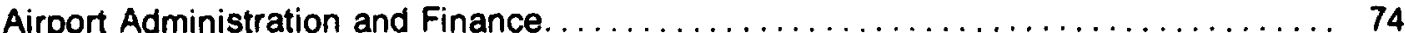

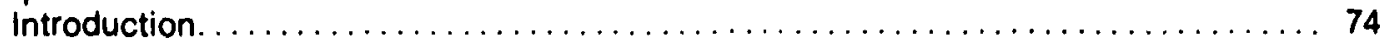

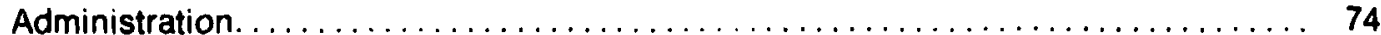

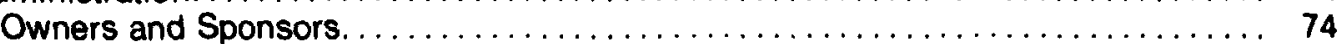

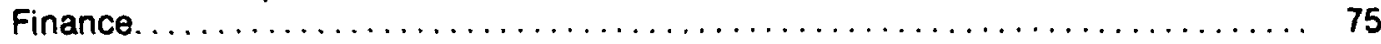

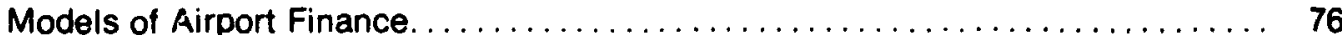

Airport Bonding and Sources of Capital. . . . . . . . . . . . . . . . . . . 77

Government Assistance. . . . . . . . . . . . . . . . . . . . . . . . . . . 77

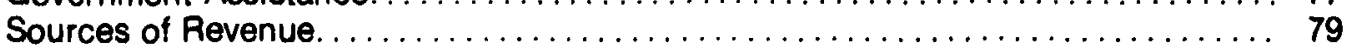

Conclusion. ..................................... 80 
Physical Environment ............................................ $81-\oslash$

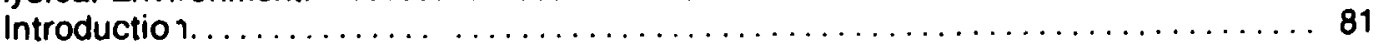

Environmental Legislation. . . . . . . . . . . . . . . . . . . . . . . . 81

Aviation Noise $\ldots \ldots \ldots \ldots \ldots \ldots \ldots \ldots \ldots \ldots \ldots \ldots \ldots \ldots \ldots \ldots, \quad 82$

Noise Scales. . . . . . . . . . . . . . . . . . . . . . . . . . . . . . . . . . . . 82

General Aviation Noise $\ldots \ldots \ldots \ldots \ldots \ldots \ldots \ldots \ldots \ldots \ldots \ldots \ldots \ldots, \quad 85$

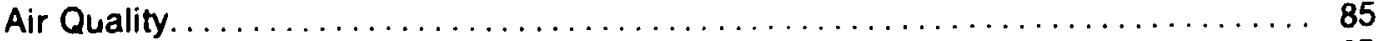

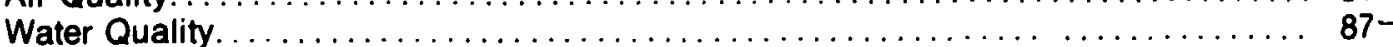

Alternative Modes and Travel Substitutes................................ 88 (8)

Introduction ....

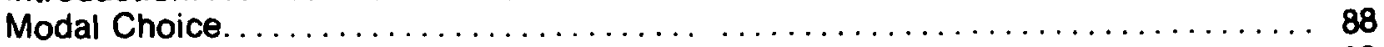

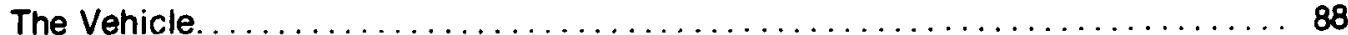

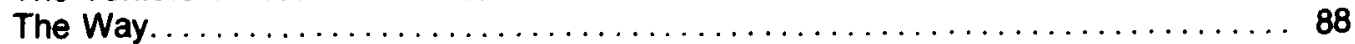

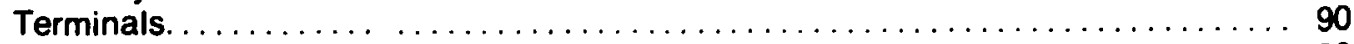

System Characteristics. ..................................... 90

Cost Comparisons.......................................... 91

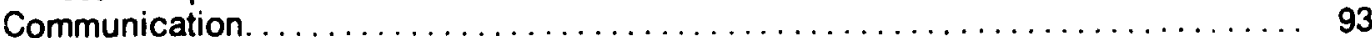

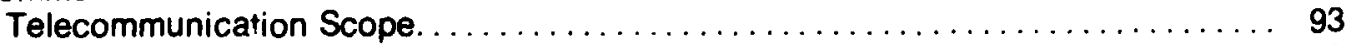

Telecommunicat:on Technology................................. 93

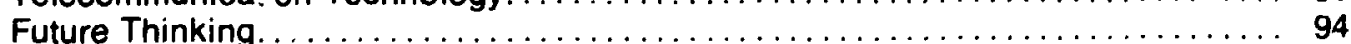

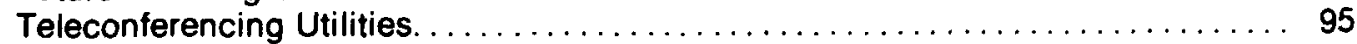

Conclusions......

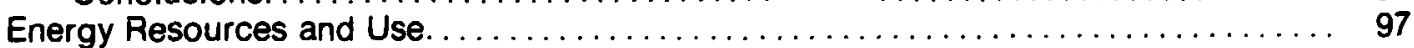

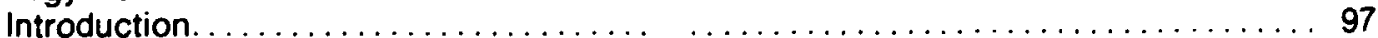

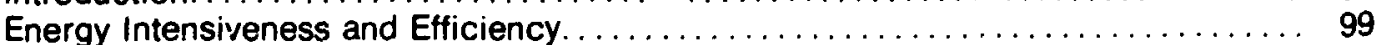

Future Research. . . . . . . . . . . . . . . . . . . . . . . . . . . . . . . 103

Conclusions . . . .

III. Community Perspectives................................................ 107-q

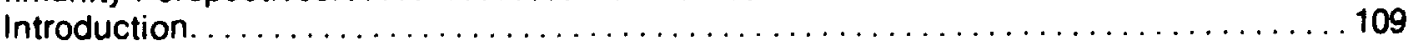

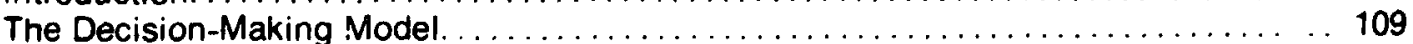

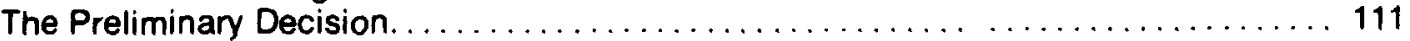

External Pressures. . . . . . . . . . . . . . . . . . . . . . . . . . . . . . . . . . . . . . . 112

Internal Pressures....................................................... 114

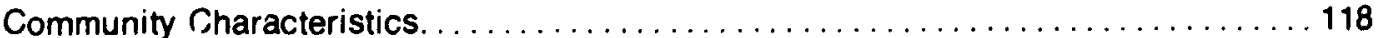

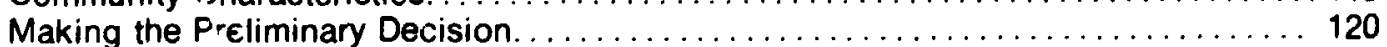

Forecastinc Demand...................................... 122

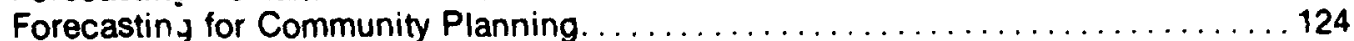

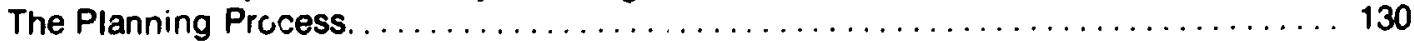

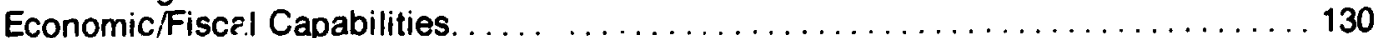

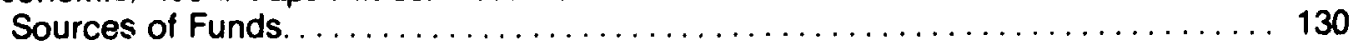

Alternatives. . . . . . . . . . . . . . . . . . . . . . . . . . . . . . . . . . . . . . . . 130

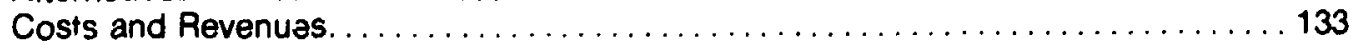

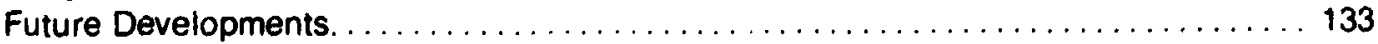

Population Dispersion. ........................................... 134

Cost of Aircraft Cwnership. . . . . . . . . . . . . . . . . . . . . . . . . . . . . . . . . . . 135

State and Local Plans.... .................................... 136

General Aviation Service Options. . . . . . . . . . . . . .

Transportation. ............................................. 136

Industrial and Community Service................................ 137

Sport and Recreational Flying . . . . . . . . . . . . . . . . . . . . . . . . . . . . 137

Ground Services. . . . . . . . . . . . . . . . . . . . . . . . . . . . . . . . . . . 138

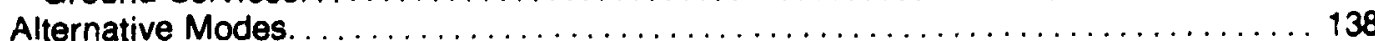

Developing the Plan ........................................ 139

Introduction . . . . . . . . . . . . . . . . . . . . . . . . . . . . . . . . . . . 139 


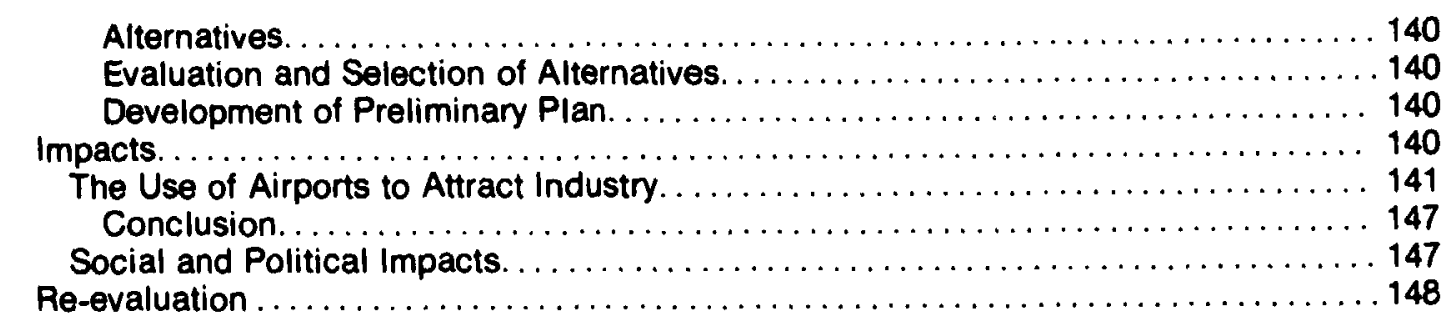

IV. Transportation and General Aviation in Virginia........................... 151

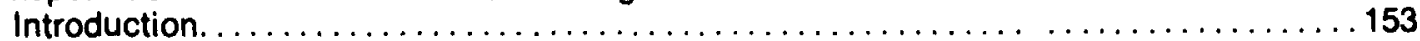

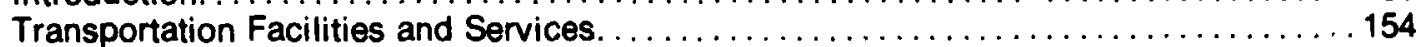

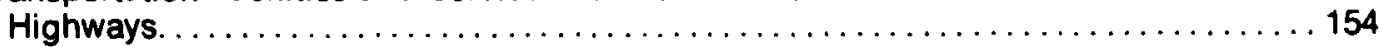

Intercity Bus. . . . . . . . . . . . . . . . . . . . . . . . . . . . . . . . . . . . 154

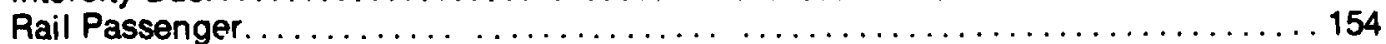

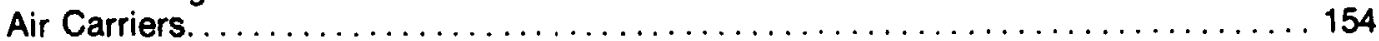

Virginia Airport Facilities. . . . . . . . . . . . . . . . . . . . . . . . . . . . 157

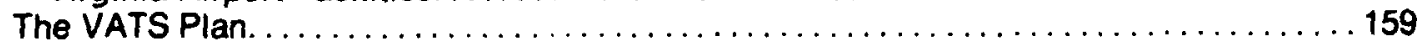

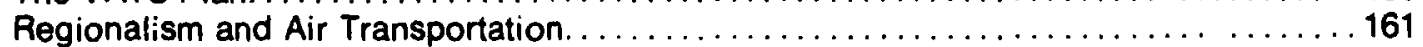

Selected Case Studies. . . . . . . . . . . . . . . . . . . . . . . . . . . . . . . . . . 168

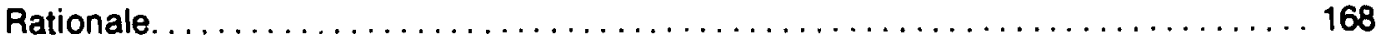

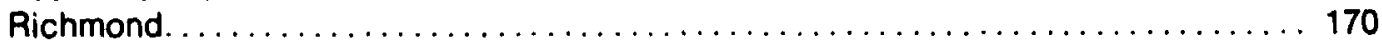

Introduction............................................... 170

Community Characteristics. . .................................... 170

Airport history and Development. .............................. 170

Airport Role and Support. . . . . . . . . . . . . . . . . . . . . . . . . . . . . . . 172

Commission or Authority. . . . . . . . . . . . . . . . . . . . . . . . . . . . . . . 173

Williams

Introduction ............................................... 174

Community Characteristics................................... 175

History and Development of Williamsburg Aviation Facilities............... 176

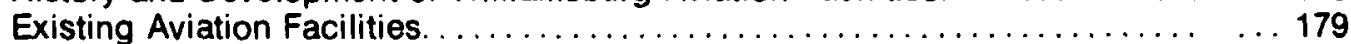

Support. .................................................. 180

Opposition.............................................. 181

Future Developments......................................... 181

Virginia Beach Case Study. . . . . . . . . . . . . . . . . . . . . . . . . . . . . 182

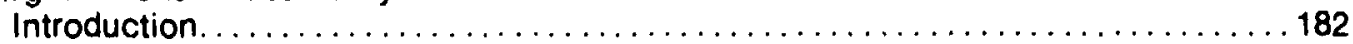

Community Characteristics. .................................. 184

History and Development........................................ 184

Existing and Proposed Aviation Facilities. . . . . . . . . . . . . . . . . . 189

Support. ... . . . . . . . . . . . . . . . . . . . . . . . . . . . . . . . . . . . . 190

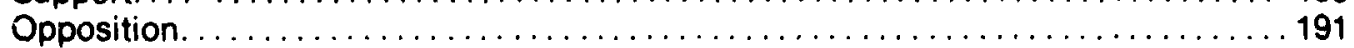

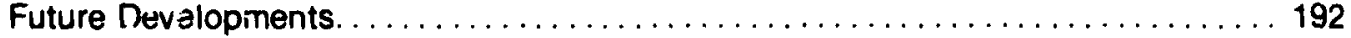

Chesapeake............................................... 192

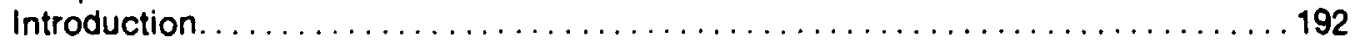

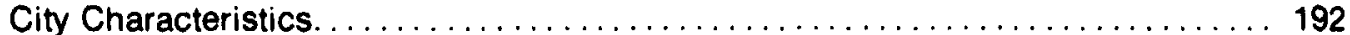

Existing Aviation Facilities.................................. 193

History and Development of Proposed Facility........................ 193

Support................................................... 195

Opposition............................................ 195

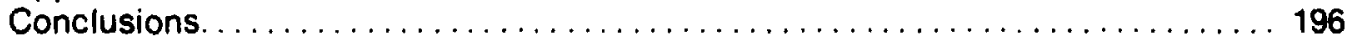

Summary and Conclusions.................................... 196

V. Aviation Service Analysis Guidebook. ... . ............................... 197

Introduction. ..................................................... 199

The Decision-Making Process................................... 200 


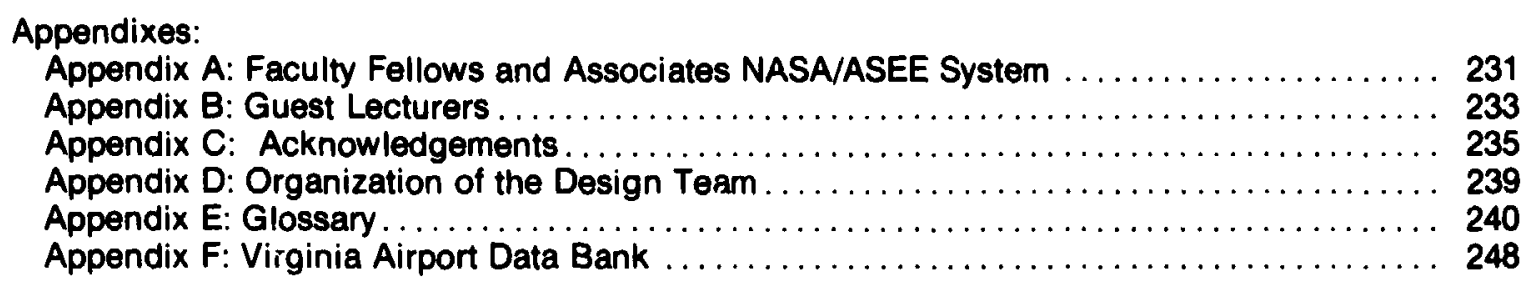




\section{LIST OF TABLES}

CHAPTER I

I-I Passenger and Cargo Traffic by Transportation Mode 1971

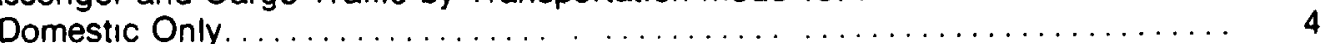

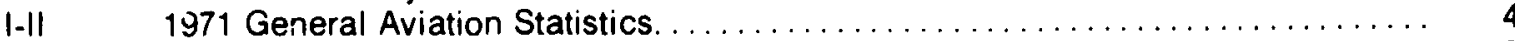

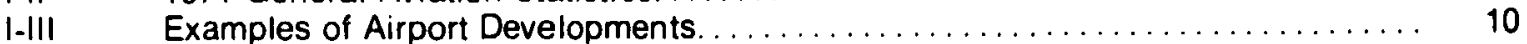

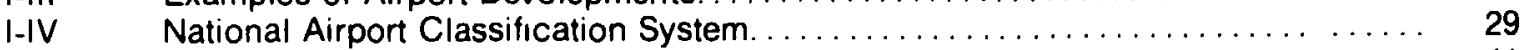

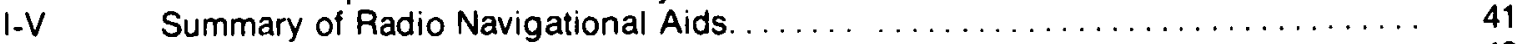

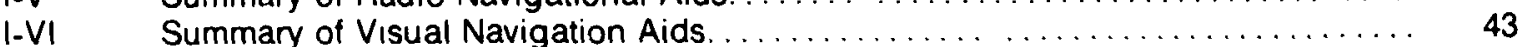

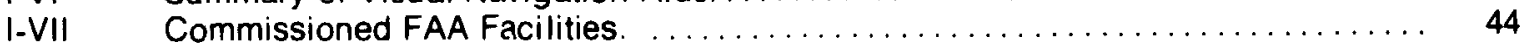

I-VIII Rate and Rank of Total Accidents per General Aviation

I-IX General Aviation Percent of Accidents Which Occur

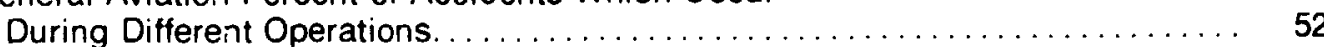

\section{CHAPTER U}

II-1 Federal Aviatıon Regulations for Certification As A

Private Pilot. Airplane Category. ........................... 73

II-II Chart for Estimating Response of Residential Communities

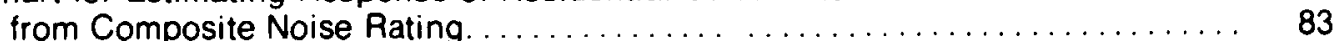

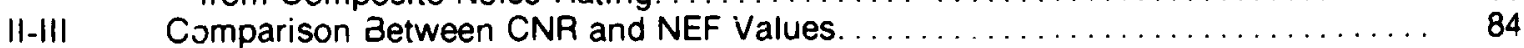

II-IV ASDS 85db(A) Contour Tables for Selected Aircraft. . . . . . . . . . . . . . . . . . 84

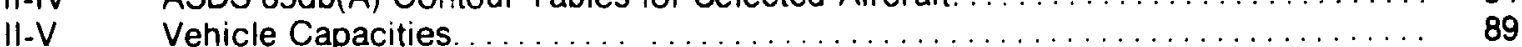

II-VI Highway and Railway Capacities. $\ldots \ldots \ldots \ldots \ldots \ldots \ldots \ldots \ldots \ldots \ldots \ldots \ldots$

II-VII The Use and Consumption of Energy \& Petroleum. . . . . . . . . . . . . . . . . . . 99

II-VIII The Energy Intensiveness of Alternative Transport Modes. . . . . . . . . . . . . . . 99

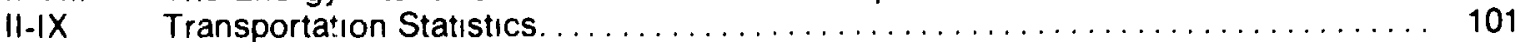

\section{CHAPTER III}

III-1 Demand Models Applicable to Forecasting A.rport Usage . . . . . . . . . . . . . . . . 122

III-II The Based Aircraft Factor . . . . . . . . . . . . . . . . . . . . . . . . . . 125

III-III Equivalent Single-Engine Aırplane Weıghts. . . . . . . . . . . . . . . . . . . . . . 127

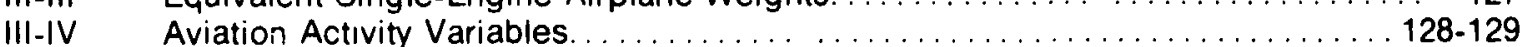

III-V Ranking of Location Factors in Nebraska. All Industries. . . . . . . . . . . . . . . . 144

III-VI Ranking of Location Factors in Minriesota: All Industries. . . . . . . . . . . . . . . . 145

\section{CHAPTER IV}

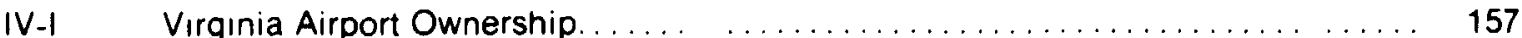

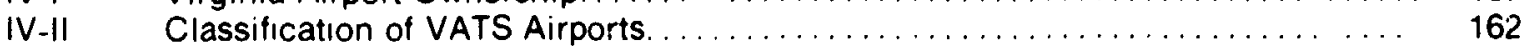

IV-II! Virginia Communities for Case Study. . . . . . . . . . . . . . . . . . . . . . . . . 169

IV-IV Demographic Characteristics of Upper Peninsula. . . . . . . . . . . . . . . . . 176

\section{CHAPTER V}

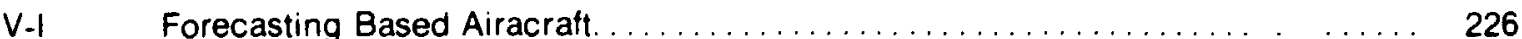

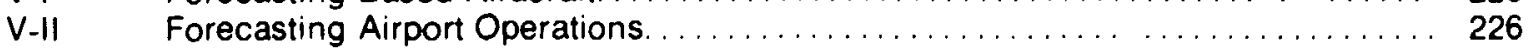

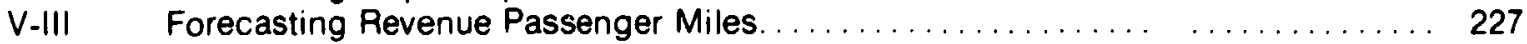

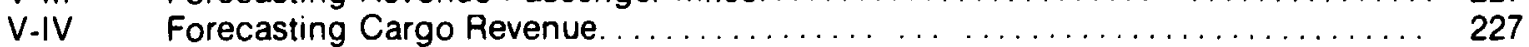




\section{APPENDIXES}

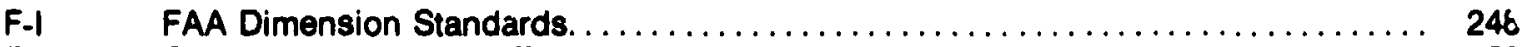

F-11 Operations by Aircraft Type (Virginia, 1937 and 1968:................. 253 


\section{LIST OF FIGURES}

CHAPTER 1

$1-1$

1.2

1.3

$1-4$

$1-5$

$1-6$

$1-7$

$1-8$

$1-9$

Capabilities: The Flight Envelope.

Ra:ıg-Payload Tradeotts.

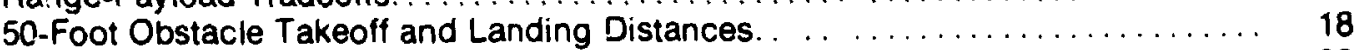

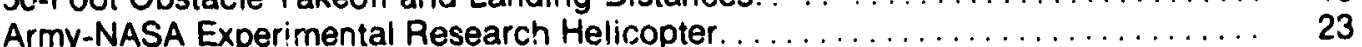

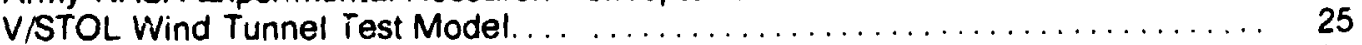

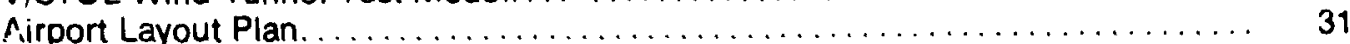

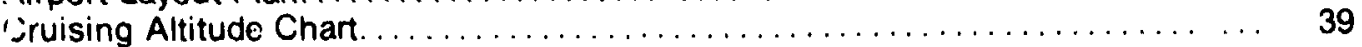

Isometric Diagram of Washington, U.C.

Terminal Control Area.................................... 40

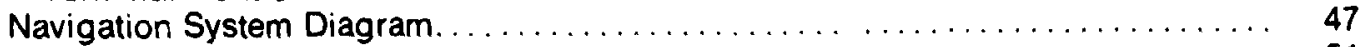

General Aviation Fatalities $1960-1973 \ldots \ldots \ldots \ldots \ldots \ldots \ldots \ldots \ldots \ldots \ldots$

\section{CHAPTER 2}

Major Aviatır: Controls: Legıslative and Regulatcry.................. 60

Summary of Characteristics of Air Agencies. . . . . . . . . . . . . . . . . . 66

Noise Levels for Propeller-Driven Small Airplanes

at Maximum Continuous Power. ............................ 86

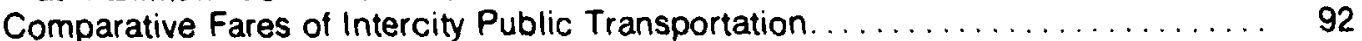

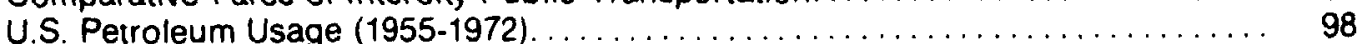

Transportation Load Factors for Class 1

Intercity Carriers.

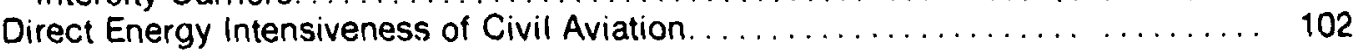

CHAPTER 3

Modes of Community/General Aviation Decision-Making Process. . . . . . . . . 110

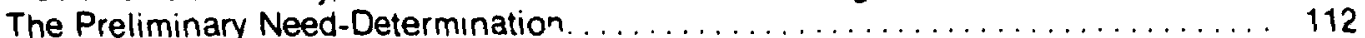

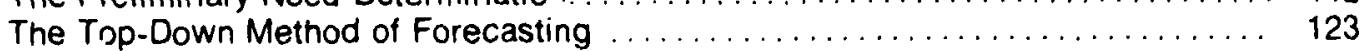

Based Aircraft Vs. Number of Households with

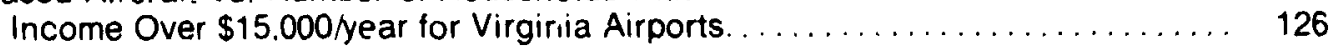

User Cost Vs. Number of Households with Income

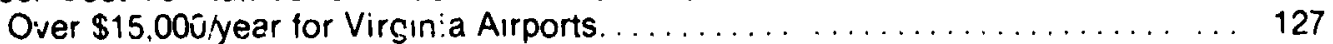

The Planning Process. ..................................... 131

CHAPTER 4

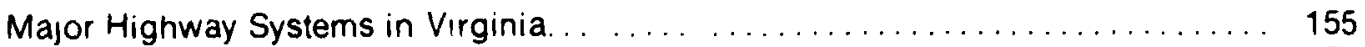

Rail Passenger and Intercity Bus Services in Virginia . . . . . . . . . . . . 156

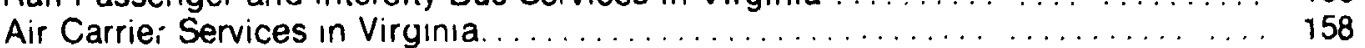

Classification of General Aviation Airports in Virginia . . . . . . . . . . . . . . 160-161

Virginia Air Transportation System and Population Density. . . . . . . . . . . . 163

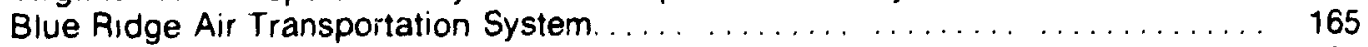

Roanoke Munıcipal (Woodrum) Airport $\ldots \ldots \ldots \ldots \ldots$

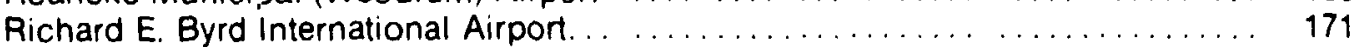

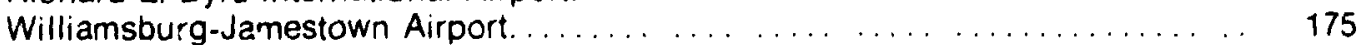

The Williamsburg Area. . . . . . . . . . . . . . . . . . . . . . . . . . 177

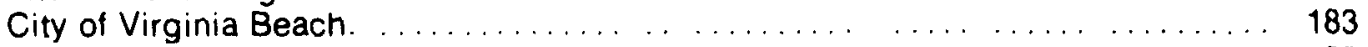

NAS Oceana Airspace Utılization. . . . . . . . . . . . . . . . . . . . . . . . 189

Airports in Cities South of Hampton Roads. . . . . . . . . . . . . . . . . . . . . . . 194

\section{CHAPTER 5}


APPENDIXES

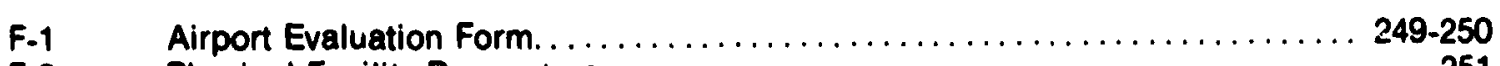

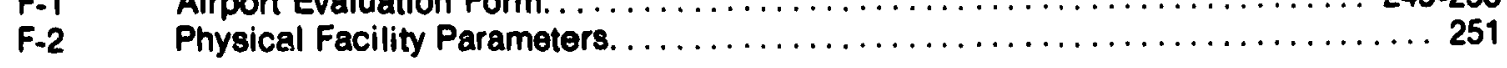

xiii 


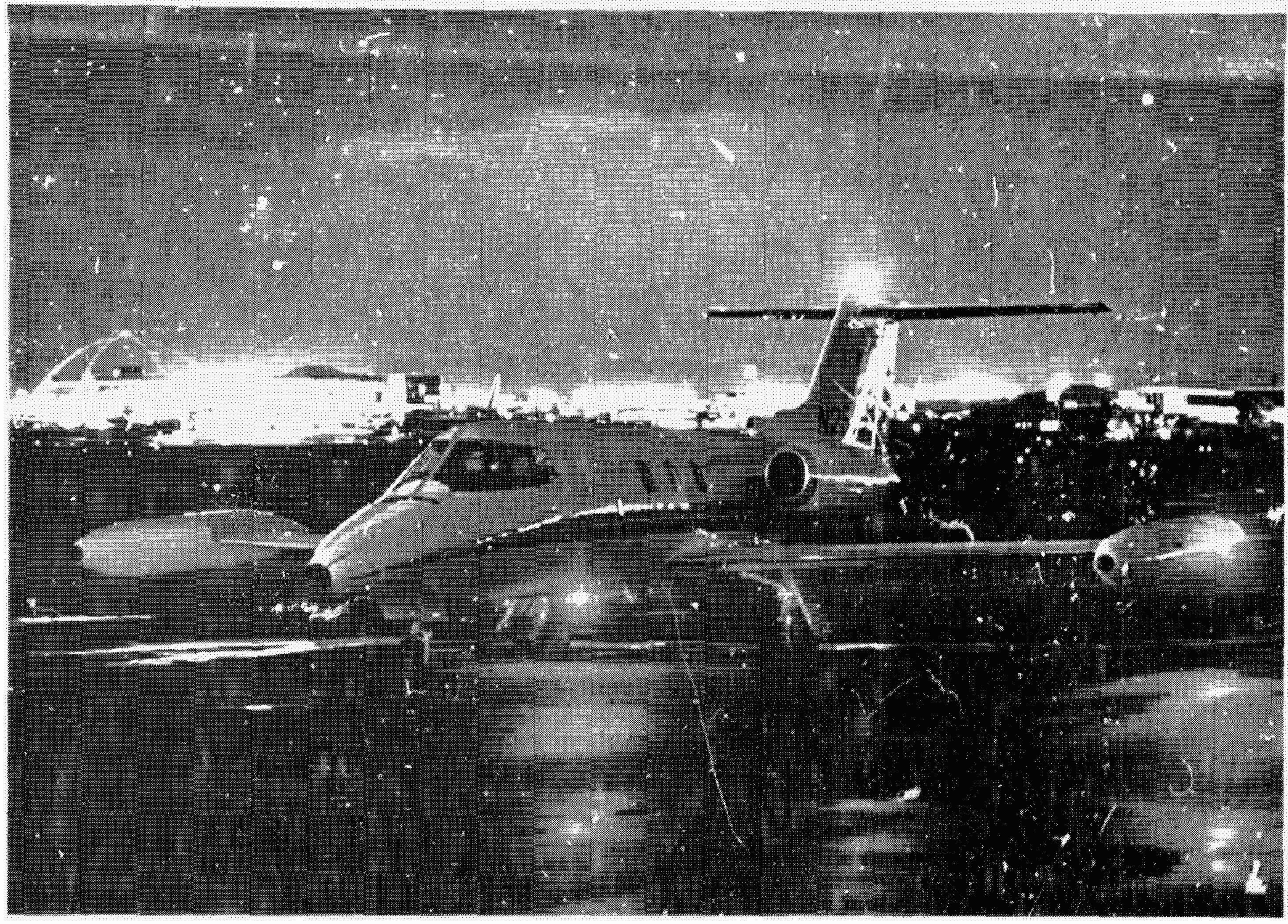




\section{FOREWORD}

This document summarizes the results of the 1975 NASA-ASEE Summer Faculty Program in Engineering Systems Design conducted at the NASA-Langıey Research Center in Hampton. Vi-ginia during the period June 2 through August 15. The program was sponsorec jointly by the National Aeronautics and Space Administration and the American Society for Engineering Education througil a contract by NASA (NGT 47-003-028) to the Old Dominion University Research Foundation of Old Duminion University.

Included among the objectives of this program v:are to: (1) provide a framework for communication and collaboration between academic personnel, research engineers, and scientists in governmental agencies arid nrivate industry; (2) provide a use'i ' studv of a broadly hased societal problem requiring the coordinated efforts of a multidisciplinary team; and. (3) generate participant experience In. and foster interest toward, the development of sustems c ssign activities and multidiscip!:nary programs at the participants' home institutions.

These three objectives we'e met through a study of general aviation and community development. characterized by intensive scrutiny of many ideas. philosophies, and academic perspectives on this multidimensional problem. To assure awareness and testing ct many points of view, and to achieve some convergence of best ideas. a group of 22 investigators was assembied. The design team represented 17 different colleges and universities, and 19 academic disciplines-architectural engıneering. aerodynamics. aeronautical engineering. air tiansportation law, civil engineerıng. community resource development, electrical engineering, envirorimental law. engineerirg psychology, geology, industrial educatıon industrıal ençineering. marketıng. mechanical engineering. organizational communication. political science, social thought. urban studies. and vocational educaticn

Althcugh the presence of a multidisciplinary team has been essential to the success of this study, the program itself has been enhanced by guest lecturers and consultants (see Appendixes $B$ and $\mathrm{C}$ ). Additionally. particular appreciation is expressed for the administrative support provided by the Co-Directors of the NASA-ASEE Summer Institutes. Dr. John E. Duberg of NASA-Langley, and Dr. G.L. Goglia of Old Dominion University. The assistance of Mr. John Witherspoon and ivir. Malcolm P. Clark, both of the NASA-Langley Personnel Training and Educational Services Branch. Personnel Division. was indispensable to the functioning of the program.

Mr. Joseph W. Stıckle and Mr. Alber! W. Hall of NASA-Langley served as teciınical advisors to the Design Team from its inception to its conclusion. For their assistance, the participants express appreciation.

Michael Z. Sincoff. Project Director

Jarir S. Dajani. Assistant Project Director

August 15. 1975

\section{PRECEDING PAGE BLANR NOT FIMMED}




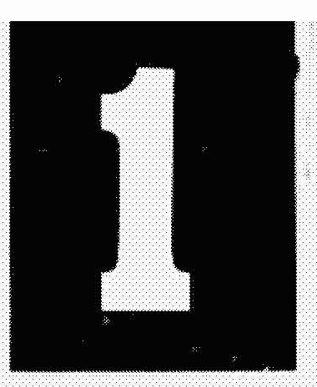

\section{GENERAL AVIATION COMPONENTS}

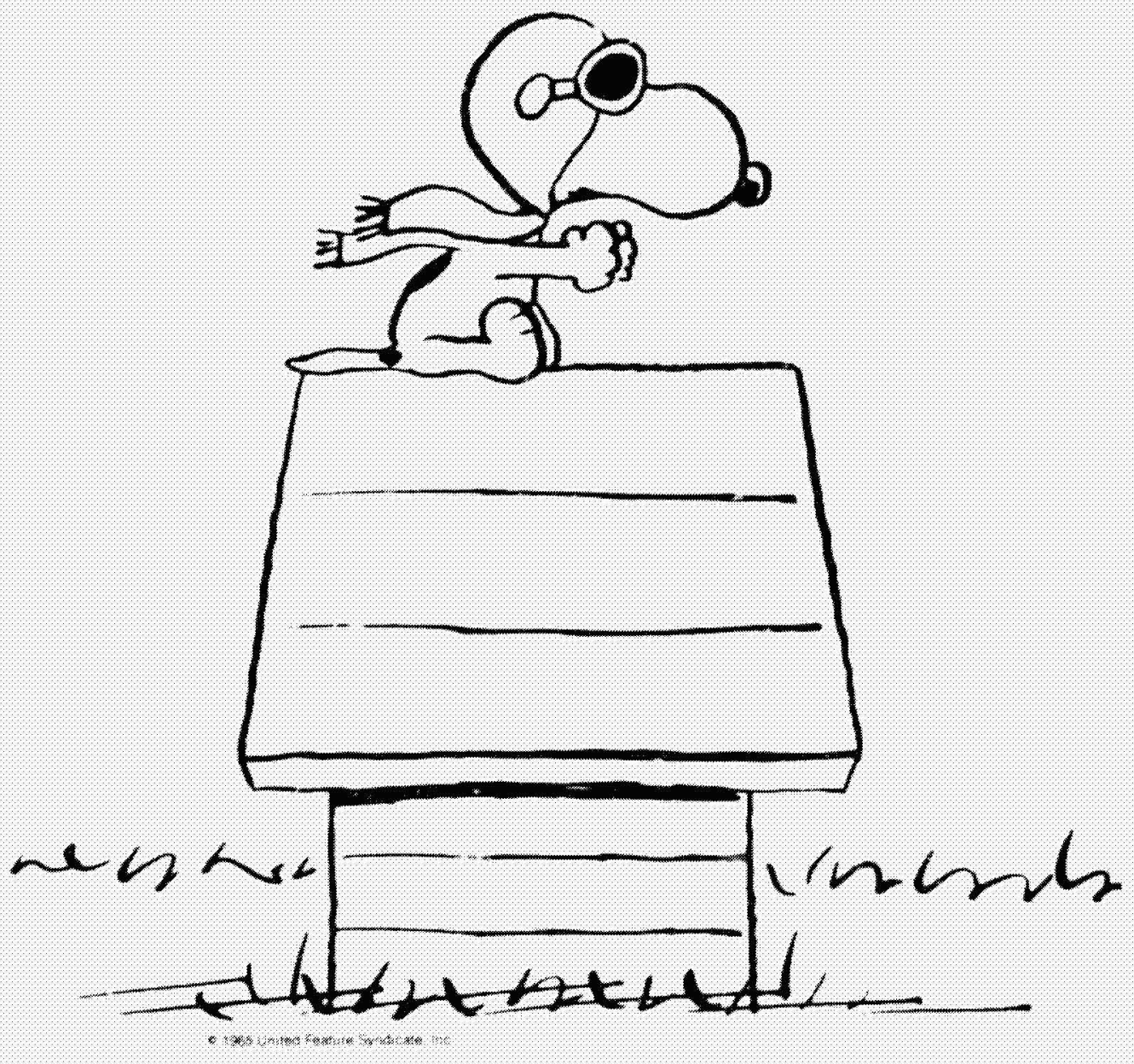



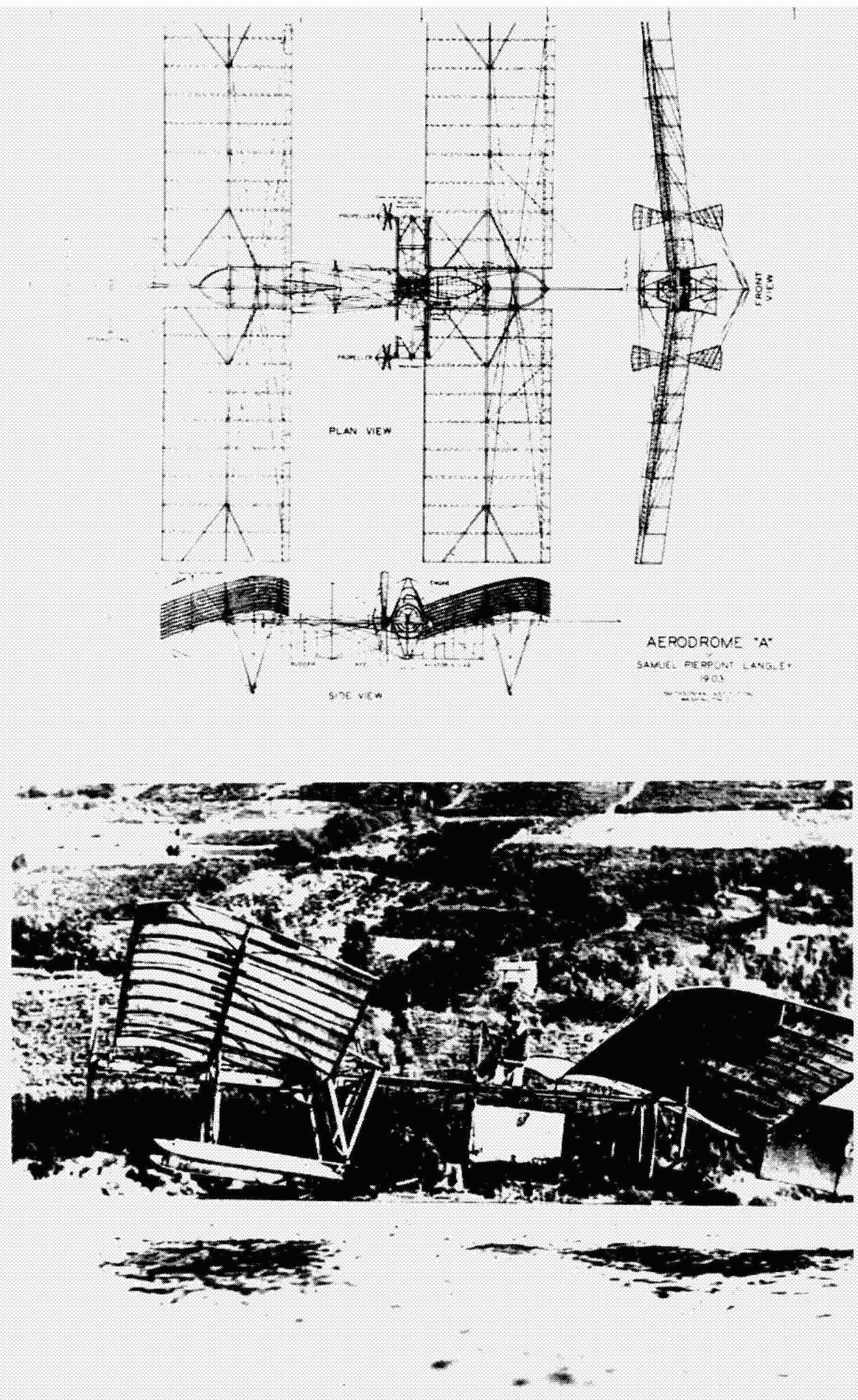


\section{N76 11995 Chapter I GENERAL AVIATION COMPONENTS INTRODUCTION}

daVinci conceived it in his early sketches. Popov claimed to have done it first. Langley's effort disintegrated over the Potomac River. And on December 17, 1903, Orville Wright piloted man's first successful powered flight in a heavier-than-air vehicle; a flight which if undertaken today could be compleied within the fuselage of a DC-10. His short 120 foot trip (0.02.3 of a passenger mile) marked the beginning of man's conquest of the sky, and the start of a multi-million dollar industry, which in 197 $i$ alone resulted in 120 billion passenger-miles. It freed man from the earth and started him on his way to the moon in less than 66 years.

The aviation industry has had a tremendous influence on the American way of life: in time, in mobility, in technology, in weaving our social fabric. Much of its influence, nevertheless, remains highly misunderstood and unexplored. Although aviation has touched the lives of millions of people, most of their contact with it has been either through the ise, or the image, of scheduled air carriers in operation around the world. Air carriers, however, represent only a small proportion of the total fleet of aircraft using the airspace, and serve only a small proportion of the landing facilities available around the country. Exclusive of the military, the other side of the civilian aviation coin is known as General Aviation, and is defined institutionally as incorporating all operating civilian aircraft other than the air carriers, which are certificated by the Civil Aeronautics Board.

Today there are approximately 3,000 aircraft being used by air carriers, while in excess of 130,000 make up the general aviation fleet. Of the 13,000 airports in the United States. only about 500 are served by air carriers in contrast to total use by general aviation vehicles. General aviation employs thousands of persons in this country in a wic'e variety of occupations, including aircraft cren's, direct and indirect ground support personnel, and manufacturers.

General aviation is assuming an increasingly important role in the national transportation picture: in 197: general aviation

' "Non-Business Planes Carried 90 N.' 'lion.' Newpon News Darly Press, July 25. 1975. p 42 aircraft flew 3.8 billion miles and carried 90 million people.'

General aviation provides a wide variety of functions, varying from the actual transportation of peuple and goods through charter, cargo, mail, executive transport, and air taxi operations; to sports, recreational, and instructional activities. Between these two poles lie a range of industrial and community services such as aerial photography, stock-herding, fish-spotting, advertising, corpse-flying. logging, law enforcement. fire fighting, environmental management, health care delivery, banking, and emergency services.

Table 1-I shows the number of vehiclemiles and passenger-miles travelled by general aviation, in comparison to other modes of transport. Table I-II presents some basic general aviation statistics. These show that it includes 98 percent of all aircraft, 60 percent of the total number of vehicle miles and 7 percent of all passenger miles flown.

This report examines the relationship between geneial aviation and community development. The first chapter discusses general aviation and its components. Later chapters will examine the environment in which general aviation operates, the process of analyzing community aviation needs, and selected Virginia community aviation issues. The final chapter is a guidebook which will enable community decision-makers to determine whether or not a general aviation service is needed and how to go about satisfying such needs.

The major components of the general aviation system discussed in this chapter are (1) the vehicle, (2) the air support facilities, (3) airways and avionics, and (4) human factors. These components combine to produce the dynamic category of General Aviation; ever moving toward increased safety and efficiency.

\section{THE VEHICLE Introduction}

The purpose of this section is to present an overview of selected aviation vehicles. The capabilities and performance of these vehicles are first presented, followed by a discussion of the aerodynamics, structures and materials, propulsion systems, noise, and configurations of fixed-wing aircraft. Finally the discussion focuses on the history, status, and future of attempts to provide vehicles capable of shortfield operations. Inclusion of the final section is due to the importance of such capabilities in general aviation aircraft. 


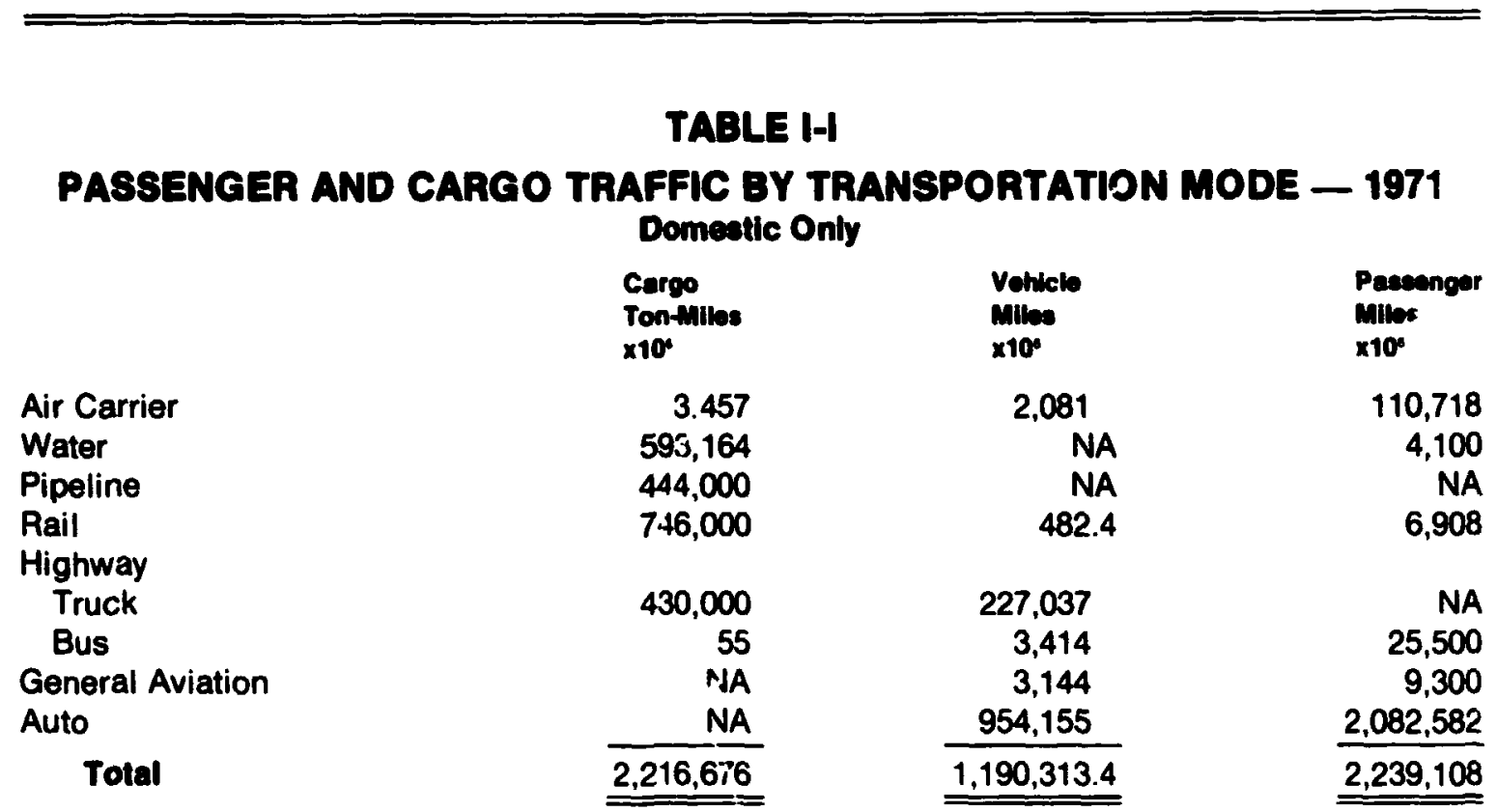

Note: NA may mean one of the following:
1) not available
2) not applicable
3) smaller than half the statistical unit used

Source: "Summary of National Transportation Statistics," DOT-TSC-OST-73-76, Washington, D.C., November, 1973.

TABLE I-II

\section{GENERAL AVIATION STATISTICS}

Genaral Aviation Category

Business

Commercial Instructional

Personal

Other

$\begin{array}{cr}\text { Vehicle } & \\ \text { Units } & \% \\ 33,314 & 25 \\ 9,327 & 7 \\ 19,750 & 13 \\ 68,475 & 52 \\ 4,282 & 3\end{array}$

1. Total expenditures and revenues

2. Passenger miles

3. Number of fatalities

4. Total number of vehicles

5. Total vahicle-miles

\begin{tabular}{cr}
\multicolumn{2}{c}{ Vehicle-miles } \\
Units & $\%$ \\
$1,130,000,000$ & 36 \\
$510,000,000$ & 16 \\
$650,000,000$ & 21 \\
$794,000,000$ & 25 \\
$60,000,000$ & 2
\end{tabular}

$\$ 2,206,000,000$ $9,300,000,000$ 1,322 131,148 $3,144,000,000$

$\begin{array}{cr}\text { Hours Flown } \\ \text { Units } & \% \\ 7,100,000 & 29 \\ 3,500,000 & 14 \\ 6,400,000 & 26 \\ 7,200,000 & 29 \\ 400,000 & 2\end{array}$

$21.4 \%$ of all air $7 \%$ of all air $87 \%$ of all air $98 \%$ of all air $60 \%$ of all air

Source: "Summary of National Transportation Statistics," DOT-TSC-OST-73-76, Washington, D.C., November, 1973. 
The airplane has been selected as the specific aircraft to be discussed because it has, since its invention, always been the dominant vehicle on the aviation scene, and there are no reliable indicators that its status will change. Other general aviation vehicles such as helicopters, balloons, airships, and gliders are discussed briefly. For cefinitions of these and other terms, see the Glossary (Appendix E)

\section{Capabilities and Performance}

The airplane is a specific type of flight vehicle or aircraft, propelled through the air by a powerplant which exerts its force preponderantly forward. It is sustained in the air by the forces created by differential pressures exerted on its exposed surfaces, mainly its fixed wings. due to its motion through the air

Fer purposes of considering its incorporatıon into an aviation system, the airplane can be considered as an imaginary box, the c.mensions of which portray a volume of air around it which is forbıdden to other aircraft; the airplane is at its center. The dimensions of the box (actually a rectangular figure) are variable individually with phase of operation !e.g., operation in a termınal area). The important point is that the airplane interdicts a sizeable airspace and ground area, and this space may be, and sometimes is, the same for a small airplane as for a large one.

The airplane is a moderately constrained vehicle in terms of its freedom to move in various directions relative to its own plane of symmetry. In flight its broadest-band capabilities are in that plane, and are those of steady or nearly steady movement. These capabilities are known collectively as its static performance, consisting of climbs, cruise flight, and descents.

\section{Straight and Level Flight}

The straight and level unaccelerated flight capability of an airplane may be portrayed by a graph showing true airspeed (not groundspeed) against altitude. Figure 1-1 illustrates the "flight envelope." The curved line

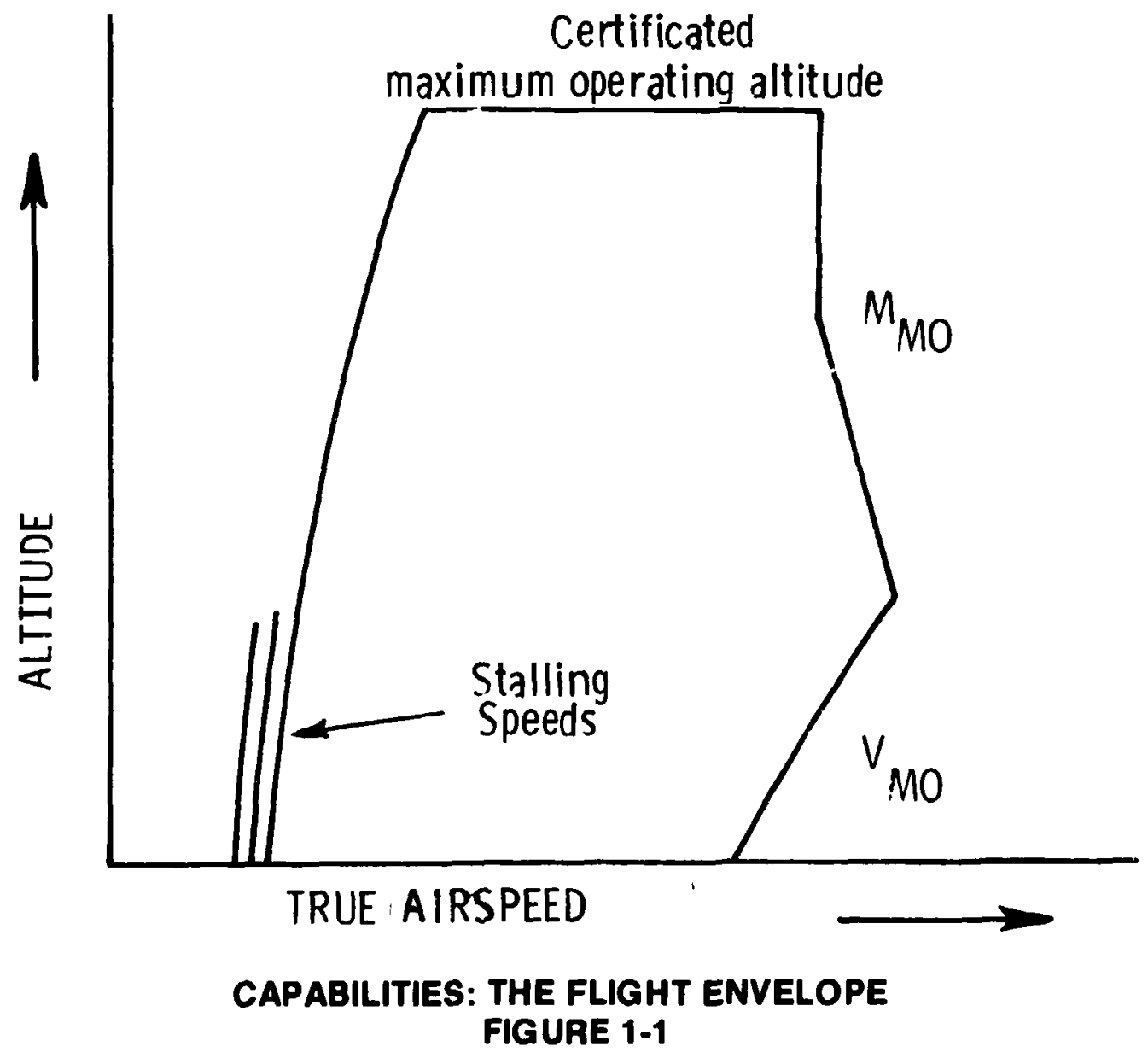


at the left represents the trend of stalling speed, the speed below which the airplane cannot be flown straight and level, because of insufficient aerodynamic lift. The long line is the stalling speed in "clean" (gear and high-lift devices retracted) configuration; the short lines give the stalling speeds for other configurations; takeoff, segmented climb, and landing.

The horizontal line at the top of the figure represents the maximum altitude for which the airplane is certificated. It may be well below the absolute ceiling of the airplane since reasons such as safety in event of a window blowout or oxygen requirements may govern the choice of the highest altitude for which certification is sought.

The crooked line on the right represents the highest speed or Mach number in normal flight for which the airplane is certificated. The symbol $V_{\text {mo }}$ means "maximum operating velocity" and Mmo means "maximum operating Mach number." These speeds are usually very close to the top speeds the airplane can attain, and are set by a combination of structural and handling-qualities requirements.

\section{Climb and Descent}

Generally, an airplane does not climb without first pitching its nose up; at its maximum speed it has no climb capability at all. The maximum rate of climb is generally realized at an airspeed about $2 / 5$ of the way between stalling speed and top speed.

The maxium angle of climb is important for takeoffs and for climbs which emergency conditions may necessitate performing near the ground. This can vary with size and type of aircraft, and with speed and flight configuration of a given iype. Small, slow airplanes may have clean-configuration maximum climb angles of perhaps 14 degrees or so; the business jets may achieve 40-degree angles.

An airplane may be caused to descend without pitching by retarding the throttle (the throttle is said by some flight instructors to be the basic climb-and-descent control, though this is oversimplistic). Except in air-carrier operation this is not an important maneuver. A more popular descent technique is to establish some fixed vertical speed while retaining cruising airspeed (approximately). In the cockpit of practically all modern airplanes there is an instrument called a Vertical Speed Indicator, and a popular vertical speed for descents out of ground proximity is 500 feet per minute, a rate for which the apparent nose-down arigle of the cabin is not disturbing to passengers, and
Which is satisfactory for use in flight on airways. Emergency descents of 1,500 feet per minute or even more can be made with reasonable pitch angle changes and within acceptable limits of operation, though in unpressurized airplanes there is risk of damage to passengers' ears.

The "best approach" angle at which landing approaches may be performed is that representing a power-off (engines idling) glide at an airspeed about 30 percent above that for stall, with flaps fully extended and landing gear down. The angle may be anywhere from about 5 to 9 degrees. Steeper approaches may be made, but some pilots consider that safety levels are reduced at the higher angles. The "ILS landing approach" angle of 2.5 to 3 degrees is established by the angle that the glide slope beam of an instrument landing system transmitter makes with the ground. This shallow angle almost always requires that engine power or thrust be above idle setting, and this increases the degree of control the pilot has over the glide angle (since the throttle is a climb and descent control).

\section{Other Changes of Flight Path}

The airplane is an awkward machine to turn; it must be turned and banked simultaneously, much as a car requires banked curves on roads. A conventional airplane cannot move directly sideways at all except by slipping, during which altitude typically must be lost because the aerodynamic drag (rearward) force on the airplane increases, and the airplane must either slow down or descend or do both. as a consequence. The slipping maneuver was popular years ago as a means of steepening landing approach paths, but its capability is very limited. The advent of trailing edge flaps in about 1940 made it largely unnecessary, except as an aid in making crosswind landings. Recently interest has revived in improving the ability of the airplane to move sideways, this time as a means of making adjustments in the lateral position of the final approach path relative to a landing field runway. This ability can be important for instrument flight operations.

In turning flight, the measure is the radius of turn, a function both of speed and of bank angle. As a general rule, the radius of a turn may be decreased (the turn made tighter) by increasing the bank angle. At a given bank angle a slow airplane is able to turn tighter than a fast one, so the minimum turning radii of small airplanes are generally in the hiundreds of teet. while those of fast airplanes such as fighters 
are generally thousands of feet long. Power is required to make a level turn, in excess of that required to drive the airplane straight. Consequently, as the speed of an airplane is increased toward its top speed, its ability to turn gradually deteriorates until at top speed it cannot make level turns at all, but must slow down to do so. Passengers will begin to take notice, and some will be disturbed if turns are made with bank angles more than 30 to 45 degrees.

Historically, there has been a fairly close relationship between the size and the maxium speed of airplanes marketed successfully in the United States. The smaller airplanes have maximum speeds near 100 knots. As gross weight rises, maximum speed also rises, until at the top of the weight range for six-passenger single-engine airplanes (about 3,800 pounds) it is on the order of 200-220 knots. Larger piston-engine airplanes, the twins, are only a little faster than this, because of the unavailability of engines of more than about 350 horsepower. The turbin powered twins use engines of $600-1,000$ horsepower, and so are considerably faster than piston twins of comparable size, with maximum speeds on the order of 250 knots. This size-speed relationship has not chariged much in recent years.

The turbofan and turbojet airplanes, whatever their weights, have maximum speed of 350-450 knots. The lack of size-dependence is due to the fact that the jet airplanes are limited by the effects of the compressibility of air on their ability economically to achieve high-speed flight. The speeds of the jet airplanes are well above those of propeller airplanes of any size, though military propeller airplanes during World War II were occasionally flown straight and level at speeds just above 430 knots, during development programs.

Little on the technological horizon has appeared to indicate that the above relationships will change much. New type piston engine development is moribund, the fuel economy of the Wankel engine is not outstanding, and there is a large region extending from about Mach 0.9 to about Mach 1.5 in which efficient airplanes are difficult to develop.

\section{Takeoff and Landing}

Airplanes can be built which will take off and land in any given distance, including zero. Takeoff and landing distances depend strongly on stalling speeds, but in general, power is required to fly slow, below a certain point, just as it is required to fly fast. This means that the available technology, as ivell as the market place, will establish whatever relationships exist between field performance and other design features.

Three identifiable technological levels have evolved into which marketed airplanes have been divided. (1) Conventional Takeoff and Landing (CTOL) technology is typified by simple flaps, such as appear on most general aviation airplanes. (2) Reduced Takeoff and Landing (RTOL) incorporates complex flaps and leading-edge high-lift devices called slots, slats, and Krügers, and perhaps a little powered lift. (3) Short Takeoff and Landing (STOL) airplanes use energy, in addition to that supplied to the main propulsive means (e.g., prop) to produce lift directly, through boundary layer control or lifting fans. Historically, STOL airplanes have not found a market except with the military. RTOL airplanes, such as the Boeing 727 , are in operation, but the only small airplanes in the category have beer. isolated single examples because of the expense involved in adopting the technology.

Field performance data on specific airplanes are given slsewhere, but it is instructive to look at what corporate and utility airplane operators have considered to be ade. quate field length requirements. Two surveys of such operators made some years ago, indicate that all operators would be satisfied with 2,000 foot-or-shorter field performance, but field length requirements of 5,000 feet or longer would satisfy no one.

\section{Range/Payload Tradeoffs}

Most airplanes, except very small ones, are weight-limited in such a way that full passengers and full fu?l cannot be loaded simultaneously without exceeding the maximum certificated gross weight. Figure 1-2 shows typical ranges for various types of aircraft starting with full tuel tanks. It also shows one of the informative ways in which range-payload information can be portrayed graphically. The empty airplane occupies a point at the origin of the graph, and eithe- fuel or payload must be loaded first. If, for illustrative purposes, payload is considered to be loaded first, the lefthand end of the top horizontal line represents the airplane when loading is completed but fueling has not started; the airplane can thus go nowhere. As fueling proceeds, the capability of the airplane is indicated by points on the horizontal line. Finally enough fuel has been added that the airplane is at its maximum certificated weight, and fueling must stop whether the tanks are full or not (point A). If the tanks are filled before the payload is ad. 


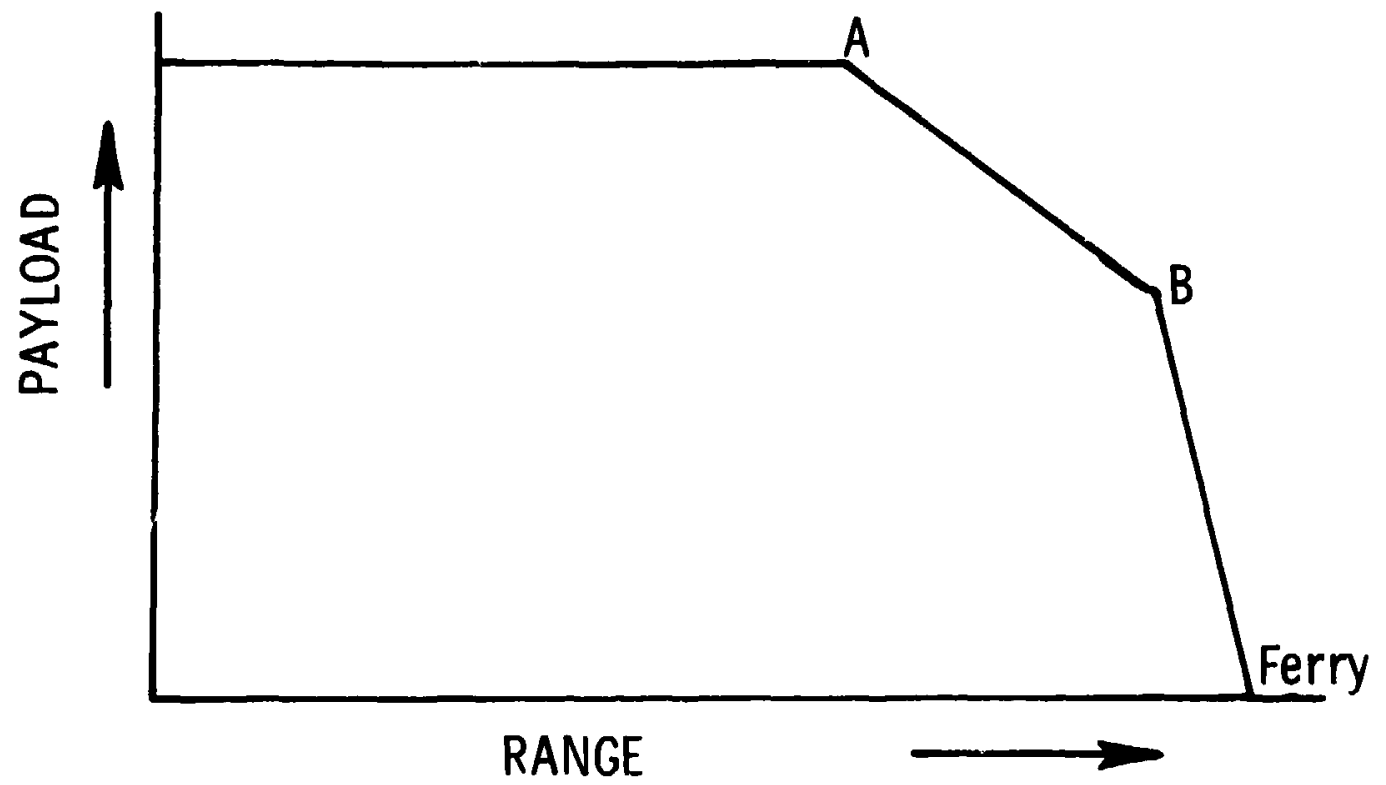

TYPICAL MAXIMUM RANGES (Nautical Miles)

General Aviation Aircraft

Light Airplanes

$300-900$

Business Jets

$2,000-3,000$

Airliners

Short-haul

$3,500-2,500$

Trunk and International

$4,000-6,050$

\section{FIANGE - PAYLOAD TRADEOFFS FIGURE 1-2}

ded, the airplane will be represented by points on the line between "Ferry" (the weight with nc payload) and $B$ (the point at which loading payluad must stop because the airplane has again reached its certificated weigh:). Between $A$ and $B$, fuel and payload must be traded to keep the gross weight constant.

\section{The Fixed-Wing Aircraft Technologies}

The history of the development of the airplane has been that of technological evolu- tion, with the occasiona! addition of major jumps in innovation which nevertheless Jid not change the definitive outlıne of the airplane itself.

\section{Aerodynamic Design}

The general outline of the airplane as a set of wings with stabilizing and control surfaces was definitive from the start. There were other concepts, but these disappeared rapidly.

Two changes took place within a decade after the first flight. replacement of wing-warping by allerons, and settlement on the conclu- 
sion that the tail-surface of an airplane belonged behind it. Nothing basic has occurred since then in the area of general aerodynamic configuration of small subsonic airplanes.

Combat airplanes underwent evolutionary growth during World War I, with both sides producing airframes using about the same technology until the Germans introduced the first all-metal monoplane, near the end of the conflict. General acceptance of the monoplane waited until the appearance of aluminum in sufficient quantities, and of acceptable properties, made the aerodynamically superior internally braced monoplane technically feasible. In the meantime, during the decade of the twenties, the biplane and strut-braced monoplane lived side-by-sids, with no singular advance in aerodynamic technology.

The next two significant improvements appeared almost simultaneously. The feasibility of the internally-braced monoplane resulted in higher wing loadings (thus higher stalling speeds) and in the increasing significance for drag of items which previously were of minor importance. Flaps and retractable landing gear appeared almost together, to make significant extensions to both ends of the speed range. The fighters of World War I could fly a little over twice as fast as their stalling speeds; by the 1930's "twice as fast" had become "over three times as fast."

At that point the major contributions to low subsonic aerodynamic art ceased. Since then there have been detail improvements-shaping refinements in ailerons, flaps, slats, airscoops, and so on.

General aviation includes high-subsonic airplanes, so the two most significant technical contributions to flight in the Mach-number range from 0.6 to 0.9 should be mentioned. The first of these was accidental. During the midthirties specially shaped families of airfoils were developed in an attempt to reduce wing skin-friction drag. Success in doing this was negligible for various reasons. Of interest. however, was the fact that the snecial airfoils had better high Mach characteristics than their predecessors. Maximum operating Mach number gains of more than 0.1 , or about 15 percent. were possible. The second development, that of the swept wing. was German, and was not known to the United States until the collapse of Germany in 1945. High-subsonic airplane aerodynanic design coasted along on the strength of these two developments untıl the late 1950's. whe'ı Boeing commenced utilizıng a further refiried airfoil series and tailoring near the junc- tions of wings and bodies, in accordance withthe Whitcomb "transonic area rule."

Aerodynamically, the modern airplane is ar extremely efficient device. Its propeller delivers thrust horsepower at an installed efficiency, typically, of over 85 percent. The "induced" drag which is an inherent theoretical penalty of the production of lift is exceeded by only about 10-15 percent in practice. The "parasite" drag which is the penalty for having a useful load that occupies space, is little more than that which would be experienced by a thin flat plate, equal in exposed area to that of the airplane's exposed skin, drawn through the air edgewise, at flight speed. This is approximately six times "cleaner" than a typical automobile (the above statements apply to "top-of-the-art" airplanes: unbraced-wing mono-planes with retractabl ₹ gear).

On the low speed end of the flight envelope the airpıane does not do so well. It cannot fly level at any speed below its "stalling" speed. which can be compared roughly with the cruising speed of an automobile. The safety implications of having to toucn down no slower than this are obvious and efforts to improve the situation have been continual. The market place typically has called for speed and efficiency, however, and has accepted the risks of fast touchdowns.

Indeed, striving for very low stalling speeds can be more dangerous than not. The reason lies in the fact that the aerodynamic force that a control surface (e.g., rudder) can exert, is proportional to the square of the speed with which it moves through the air. So an airplane configured for low speed handling can be oversensitive at high speeds $\partial r$ one con. figured for high speeds too s'uggish at low. Conventional general aviation airplanes of small-to-medium size are typically acceptable on both ends of the speed range. One of the ways in which power required for cruise flight can be reduced, however, is by reducing wing areas. The higher stalling speeds which result are undesirable, but can be lowered by increasing the maximum wing lift capability. Thus the energy crisis helps keep the pressure on for further development of high lift devices.

\section{Airfoil Development}

"Airfoil" refers to the shape and thickness of a cross-section of a wing. Three forward surges in airfoil development can be identified. First. the NACA low-speed programs of the 1920 's and 1930's which resulted in the four and five-digit airfoil serie 3 (each digit of a Jesigna. tıon such as 2412 gives the magnitude of an air- 


\section{TABLE I-III \\ EXAMPLES OF AIRFOIL DEVELOPMENTS}

\author{
Airtoll \\ NACA 24XX \\ NACA 230XX (1930's) \\ NACA 63-4XX
}

NACA 6716 (1974)

GA(W)-1 (1973)

- Defined as

\section{Maximum Uif Capability"}

$1.47-1.7$

$1.5-1.8$

$1.47 \cdot 1.77$

$\sim 2.0$

$\sim 2.1$
Romarks

4-digit series

5-digit series

"Lamingr-flow" airfoils

4-digit airfoil with high-loaded trailing edge

"Low-speed supercritical" thick airfoil

$\overline{\text { (Dynamic pressure) }} \overline{\text { (Area) }}$

foil shape parameter). The entire series used a type of thickness function based on only 2 airfoils: one designed by Col. Virginius E. Clark, and one very similar designed at Göttingen. The mathematical difinitions of thickness functions and mean lines were sys!ematized, but not on a thecretical physical jase-they were arbitrary, as were the Clark and Gottingen airfoils that served as the point of departure.

Second, the so-called "laminar flow" series, which as it turned out offered more to high-Mach flight than to low. There were several families of these, of which the suivivors are the so-called " 6 " and " $6 A$ " series. Airfoil contours were developed to match desired surface velocity distribution.

Third, various programs seeking further relief from high-subsonic-Mach number limitations of thick airfoils developed. The names connected with these programs are Sinnott and Pearcy in England, and Whitcomb in the United States.

Current work in the United States is of three kinds: (1) theoretical and experimental work on multi-element (f.apped and slatted) airfoils; (2) theoretical and experimental work on high-lift basic airfoils, notable among which is the GA(W) airfoil series to which Whitcomb's name has literally become attached; and. (3) continued wurk on the "supercriticai" slasses of airtoils.
The gains being sought are relatively small, and the cost of obtaining them sumetimes seems excessive. Table l-III illustrates the evolution of high-lift airfoil technology. The data are clouded by the fact that the later explorations have emphasized low test speeds.

There has been much attentio.1 devoted to raising the maximum lift capabilities of airfoil sections. This has taken the forms if (1) devising basic sections with high maximum lifts, and (2.) devising slat and flap configurations to apply to these sections to produce high maximum lifts in landing configurations (flap down, slat out).

Some of the recently-developed basic sections have had lower drag at high lift than have older sections of the same thickness ratio (thickness ratio is important because it indicates the depth of wing available for structure and tankage). A conventionally configured small airplane may be said to have "toc much" wing for economical cruise, since the wing size is determined by the requirement for low stalling speeds. The bencrit sought through use of the newer airioil sections is in that they allow smaller wings than usual, since their maxium lift capability is high. in climb and at cruise, the small wing opsrates at higher lift per unit area, and the shift of maximum weight/drag ratios to higher lift values is therefore favorable to the new sections. 
The classic approach to configuring multielement wings for takeoft, approach, and landing has been to start with a given basic airfoil, lay in flap and slat elements that will fit inside the airfoil contour, and then explore what the settings of these elements should be for lift maximizetion. However, an aiffoil designed for high lifting capability with no flap will not necessarily be exceptionally good when a flap system is added. This suggests that multi-element airfoil research might be directed toward finding airfoil sections and flap configurations that are best when the flaps are down.

Most of the multi-element aifoil developments of the past have been addressed to the landing configuration, where flap deflections are large and maximum lifts high. The most troublesome flight configuration remaining is that for climb. in particular the engine-out clin.hs of twin-engine airplanes. Feder.al Aviation Regulatirirs acknowledge the importance of climb performance by prescribing minimum values of climb gra "ients or rates, but implicitly acknowledge that truuble ex sts by setting the minimum values very low. ${ }^{2}$ Lwalopment of airfoil systems tailoiad for the clir:.i) regimes have received little attf.ntion.

\section{Directions for Airfoil Research}

With the advent of automatic computation, it became possible to conduct theoretical explorations of airfoil characteristics which previously had been too burderisome to undertake. The cirrant analytical programs for single- and mult: : 3nt airfoil shaping are an example..$^{3,4}$

1 : d seem useful to apply such prograrr. the problem of developing airruil and flap systems together rather than separately. with specific application to climb performance.

While theive programs have merit, the following should be pointed out:

First, far cruder analyses, applied sensibly, have provided important indications of what should be done to $\mathrm{m}^{-k}$ ke given modifications in airfoil characısistics.

- Federal Aviation Tegulations. Part 23, Par 2365 of seQ

'Hicks. Raymond M, ot al. An Assessment of Airtoll Design by Numerical Optimization." NASA TM X-3092 July. 1974

- Barger Raymond $L$ and Brooks, Cujler W Jr "A Gtreamine Curvature Method for Design of Supercritical and Subcritical Aitfoils." NASA TN D.7770 September. 1974

- Bingham Gene J Low-speed Aerodyriamic Charac. teristics of NACA 6716 and NACA 4416 Airtolls with 35-percent Cherd Single Slotted Flaps." NASA TM $\times$-2623. May 1974

- McGhee. Robert J, ar d Beasley. Wi!iam D "Low-Speed i-rodynamic Characteristics of a 17.Percent Thick Airfoll Section Designed for General Aviation Applications. NASA TN-D7428. December. 1973
Second, in one or two cases of note, sopnisticated technique.s have produced solutions for airfoil shapes which obviously were no good, but were carried through wind tunnel tests despite the clarity with which the low merits of the selections could be deduced from visual inspection of the airfoil contours.

Third, the ornissions in the experimental data provided for families of existing NACA airfoils have been known to the industry for years. In some cases, filling in the data gaps and extending the ranges of parameters in directions whose utility could easily be perceived, would have provided section geometries wh.ch are only now being explored (an instance is the general correspondence between the characteristics of the NACA 6716 section, only recently tesied, ${ }^{5}$ and thcse of the GA(W)-1 section $^{6}$ ). In one notable case, that of the NACA $230 \times X$ airtoils, a family $c^{:}$. sections with obviously superior high lift characteristics sat around for years, figuratively screaming for more inquiry into just why they were so good.

To many people there were good and suffi.cient reasons for th:a lack of attention to the data gaps - World VJar II, the postwar funding crunch, the advent of diverting work (supersonic flight, missiles. space programs). During thisse periods, understandably, relatively little work was done by NASA; general aviation manufacturers took occasion to point out the lack; the larger airplane companies such as Douglas ar,d Boeing undertook to remedy the situation for their own benefit in their own facilities, and very little appeared in the public domain.

It is suggested that benefit to general aviation would result from a continuing, long-range program of subsonic aerodynamic research which would include:

(1) increased financial support for NASA aeronautics research, to the exient that not only could NAS.A's cwn in-house and :ontractual research be augmented, but also close and cortinual technical monitoring could be maintained over the manner in which government funds in general use are spent for aeronautical research.

(2) cointinuous liaison with universities and with general aviation manufacturers, using circuit. riders if necessary, to determine in what ways NASA or cther government agencier can be 
responsive to their research needs. Coverage should not be limited to those of the public who have government contracts. A mechanism to ensure the responsivness of the government agencies should be devised.

(3) "gap-filling" experimental work. The everyday problems of the small or medium-sized airplane company are not those of pushing out the forefront of knowledge, but rather are those of obtaining detailed information on items basically already well within the state of present artsuch items as airfoil characteristics, aerodynamics of fuselage irregularities, interference drag. engine cooling drag, propeller performance, excrescence drag, etc.

(4) continued publication of compendia of data, of a high order of completeriess, with periodic revisions and reissues.

(5) revival of the pre-1958 NACA inrex system. The current STAR indexes are comprehensive, but need supplementing to increase the visibility of important NASA work. The old NACA index format was excellent in this ragard. and far more usable than the STAR indexes.

Elements of this program exist: some have existed for a long time. The intent of the above suggestions is to express general concurrence with the decisions which have produced the present NASA general aviation aerodynamics programs, while citing areas in which add1ticnal funding seems desirable.

\section{Structures and Materials}

Structural development has beerı paced historically by materials availability. The best utilizable weight/strength ratios in the preWorld War I period were possessed by various wucds (the use of weight/strength ratio is a vast oversimplification. which is why the word "utilizable" has been inserted). Wrought aluminum alloys were not available ir. temper states that allowed use in primary structure. though secondary structure could use it, and did during the war.

The necessity for building stiff structures with low weights and low-strength materials dictated the use of wire-braced, thin-membered trusses: the bridge-type fuselage framework and the biplane wing cellule, which was essentially a repetition of the fuselage truss, disposed laterally and with its horizontal panels covered by secondary structure, the ribs and fabric envelopes. Some all-wood airplanes, their surfaces made of spruce plywood bonded with casein glues, appeared during the war and throughout the 1920's, but they did not account for a major market share. Wooden airliners were killed abruptly following the Knute Rockne crash; the Fokker transport in which he was killed was wooden-winged, and the crash was felt possibly due to the deterioration of the wing structure.

Subsequently, wood for airliners was, in effect, regulated out of ust, and the development of light-metal technoingy was thereby forced. Though unbraced-w'ooden-winged airplanes were built (Lockheed V'ega, Fairchild PT-19), the development of light-metal technology probably was a major factor in promoting aerodynamic improvements st.arting with the unbraced (internally braced iving. One might almust say it forced the aerodynamic refinement, since duplicating woooen structural configurations typically leads to some weight increase, which must be offset by drag decrease if installed engine power is not to ri.e.

The 1930 's were a period, then, of refinement in all-metal design, culminating in the great combat air fleets of World War li.

Immediate postwar developments included the introduction of "sandwich" materials (a double skin of very thir layers prevented from buckling due to in-plane compressive loads by a lightweight core of wood or metal honeycomb). but the impact of this technology on general aviation has not been felt until recently. The delay was dus in part to the difficulty of inspectıng sandwich structure bonding using nondestructive techniques, a difficulty not surmounted until a very few years ago.

The war production programs enabled scme general aviation manufacturers to develop their all-metal technology at public expense. The result was that production of wooden, fabric-coverec. general aviation airplanes rapidly subsidea after the war until at present only a few mir ar types are being produced.

Sheet-me a' tech. logy of World War II level still dc.rinates the civil aliplane field. Early atteminte to us.? plastics technology for 
secondary structures resulted in saving neither weight nor cost. More recently a second cycle of attempts to use plastics technology was begun. One certificated civil airplane, the Windecker Eagle, uses plastics almost altogether for skin, but the extent of plastics use in its primary structure is apparently lower. Other manufacturers have acquired or are acquiring the capability to work major structural components in plastics.

Military structural research has concentrated most recently on the development of composite structure with mono-filament loadbearing memhers. This development has not yet reached the civil field.

Sail plane structure has reached a new plateau with the replacement of composite wood-and-fabric construction by conventional fiberglass/epoxy layups with foam filling. This enables glassy-smooth exterior skin-surfacss to be built fairly easily.

Perhaps the most active area of structures research-at least the most visible at the moment-is the analytica!. The fairly simple sheetmetal structure of 'No, Id War II could be stressanalyzed using closed-form methods. Very thick-walled structures such as landing gear forgings could not be well dealt with using such simple methods, however. The availability of digital computer time has resulted in an explosion of finite-eiement methods for the analysis of thick-walled structures of complex shape.

At the tıme of the disappearance of the wooden airliner, the technology of wooden airplane construction was fairly advanced. Throughout the years between then and $194 i$. wooden airplane development struggled along. and it is row the property of sport aviation and one commercial manufacturer. The state of the technology is practically the same as at the end of the last major wooden airplane production. the PT-19, left it.

It would appear that there is now reason for taking it up again. While the state of availability of the major civil aircraft structural materials of the present day-aluminum, magnesiu'm, and titanium-is better than that of petroleum fuels. still the eininement of these materiais to aircraft standaris is energy intensive. In this regard wood is attractive - a renewable resource, potentially available in adequate supply to suppoit: small airframe production, and with small energy requirements to prepare it for aircraft use.

Larger airplanes will undoubtedly continue to be built of more exotic materials because of the requirements for structural strength, efficiency, and low maintenenace. Wood, however, continues to be an acceptable material for the construction of small airplanes. Fabric is a sort of natural companion of wood for this application, so along with th $\&$ program of resumed development of wood construction technology which is suggested here, might well go one of fabric application development.

The bugbears of the past have been: (1) insidious, invisible deterioration of the mechanical properties of wood structures; (2) nondestructive inspection of woods; (3) rot and infestation; (4) deterioration of fabrics with exposure to sun (hence pigmented dopes replacing the clear dopes of the first two decades of aviation): (5) palatability to field creatures of cordage used in stitching; (6) resistance to action of aviation fuels and lubricants; and. (7) bonding materials and techriques.

Recent years have seen the introduction of synthetic aircraft cloths and long-life dopes. which it is hoped will give finished fabric airplane coverings lifetime durability. However. work toward improving the characteristics of aircraft covering using renewable resources may yet be in order. This same constraint should be considered for application to rese.arch in any of the other areas.

\section{Propulaion}

Propeller airplanes represent an overwhelming percentage of the general aviation fleet, so perhaps starting with the propeller itself is appropriate.

Someone has said that only a real genius could design a poor propeller. Operating at its design point a typical wooden fixed-pitch propeller of World War I vir age would show efficiencies in excess of is percent, and modern technology metal propellers can exceed 90 percent. Thus, aerodynamic refinements for design-condition operation yielded relatively small gains, the largest being experienced when aluminum technology permitted development of metal blades in the late 1920's.

The only major avenue of improvement. then, was in the urea of off-design performance. and this problem was addressed in the early 1920 's. with controllable-pitch and constantengine-speed propellers finally achieving wide 'use by the mid 1930 's. The propeller technology of general aviation tnday is largely the technology of that era, with detail refinements.

Practical piston engine development was along two lines-aircuoled and liquid-cooled. Lıquid-cooled engines are no longer used ex- 
cept for the World War II leftovers, and are not produced at all. Aircooled engines got a rather strange start with the "rotary" engine. whose crankshaft was rigidly fixed to the airframe, the pistons. cylinders, crankcase, and propeller all whirling around at prop speed, which was then (World War I) rather low. The rotary died a welldeserved sudden death after the war, its place taken by the aircooled radial.

The present horizontally-opposed configuration found in most general aviation airplanes dates back to the late 1920 's; it and the prevalent "lightplane" highwing configuration started together at that time. and the family resemblance remains until now. Improvements since the 1920 's have been in materials and detail refinements, such as the introduction of fuel injection and turbo supercharging, both spinotfs from military aviation. Minor types arid freaks have appeared now and then, such as the Guiberson diesel radial, the six-cylinder Curtiss radial (single-row radials have odd numbers of cylinders, so the Curtiss engine was in essence two three-cylinder radials with a common crankcase), and the Hermann cam engine.

Propulsion research has produced many exotic configurations during the last twenty years - lift fans, tilting rotors, tilt-props, tiltprop-tilt wings, tilting ducted fans. and so on. The main thrust has been toward development of VTOL types other than the helicopter. With a

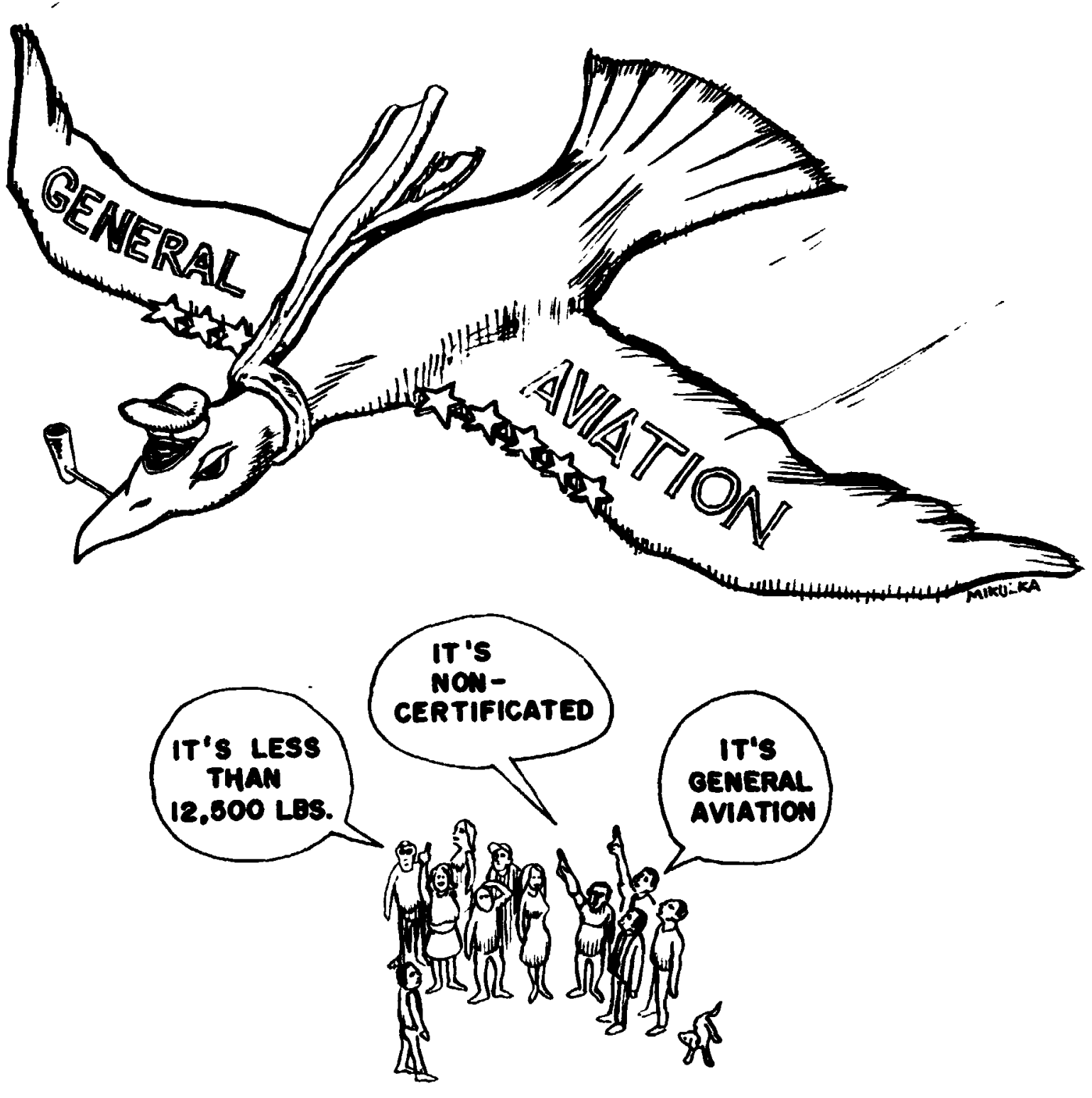


single military exception, these devices have not been undertaken by any firm for production, although the present state of documentation seems fairly good. Much of the information has been condensed into a reference work by Ü. Barnes W. McCormick of Pennsylvania State University. ' Dr. McCormick has broadened the scope of his work to include powered boundary layer control, essentially a part of STOL technology which also has found, to date, only military applications.

Piston engine development has simply incorporated old military engine technology into civil engines, with one notable exception: Teledyne Continental has produced an engine with an altered internal power train and fairly sophisticated dynamic damping devices.

Dowty-Rotol has displayed a controllablepitch piston engine/shrouded propeller combination in mockup form.

Turbine engine development in small sizes has utilized essentially military-funded technology for civil engines of fairly conventional form. Short-life turbine engines, based on drone-engine technology, have been proposed at various times as lift engines (axis vertical) for STOL or VSTOL airplanes, but none has been adopted for production. Turbine engine technology is very expensive to acquire, hence the lack of civil funding for advanced research.

No engine produced to date for aviation. except the diesel, has outshone the conventional gasoline piston engine from the standpoint of fuel economy. The shaft-gas-turbine engin: is lighter and its overhaul times typically longer; :hrough intensive development its fuel consumption has been hammered down to about the leve! of the wartime piston engine. Nevertheless, with little development since 1945 except what the civil engine manufacturers could afford, the fuel consumption of the gasoline piston engine is now, after thiriy years. about as far superior to that of the turbine as it was when gas turbine development started, on a percentage basis.

As long as flight speeds are below about 325 knots, the propeller engine is superior to the only other two types in use. the turbofan and the turbojet. This superiority exists because of propeller, rather than engine, characteristics. The implication of this and the superior fuel economy of the basic piston engine is clear.

Nolse

The general aviation airplane, taken by and

'McCormick. Barnes W Aerodyn imicsof V/STOL Flight (New Vork Academic Press. 1967) large, is a far less noisy device at the distances at which it is typically encountered than is a power lawnmover, a motorcycle or a "performance" car. Experience has shown, however, that the airpiane's high visibility makes it vulnerable, and that noise levels at major airports generate an awareness of aircraft noise that "wipes off" on all airplanes. Also, an objectionable noise need not be "loud," or have any specific frequency content, to generate complaints. There is experience to indicate that many complaints about "noise" are generated simply by newness and unusualness. It all amounts to the fact that silencing airplanes is a response to a political fact of life, however artificially generated, which did not exist as such years ago, but which we now ignore at our peril.

Small piston engines are muffled, but not as effectively as automobile engines. There are two probable reasons: (1) a very significant proportion of the noise of an aircraft power plant is propeller noise_perhaps as much as 40 to 60 percent. The propeller noise therefore masks the exhaust noise at high prop speeds; and (2) weight is always critical, and the tendency is therefore to minimize the weight, as a percentage of the total, of items that do not contribute to safety of flight or to sales potential.

Propeller noise is predominantly due to air compressibility effects at the blade tips. To get rid of the noise, then, demands that either the propeller be slowed to a tip speed where these effects will disappear (usually below $M \cong 0.6$ ) or that blade profiles be reshaped. The "highspeed supercritical" airfoils proposed by Dr. Richard $T$. Whitcomb are designed for the specific purpose of delaying the onset of compressibility effects by approximately $.05-0.10$ Mach. Along with this benefit go increases in the loadings at which it is acceptable to drive the blades, from a power-required standpoint.

Low tip speeds dictate increases in propeller "solidity" (number and width of blades) to realize acceptable thrust power levels. Since thrust not only varies almost directly with solidity, but also with the square of propeller speed. ground and low-speed engine cooling becomes a problem with slow turning propellers, as was again demonstrated with the "spook" airplanes used in Vietnam.

Some persons have proposed lise of shrouded propellers to diminish noise output. There is no present evidence to indicate that the complicated tradeoffs involved in shrouded propeller design will favor low-noise configurations of acceptable weight and efficiency. Indeed, the basic configuration generates noise 
problems all its own at the low-loading end of the range of applicability. At the high end, the shrouded propeller becomes the secondary stage of the ducted fan engine. Here the tradeoffs are considered vis-à-vis the turbojet engine, and are favorable to the fan because of its long shroud (not feasible at low loadings), which can be acoustically treated.

It is surprisingly little understood that small propeller airplanes can now be silenced almost to the level of the automobile at high speed cruise. Detail changes of configuration which must be made to do so include: (1) more effective exhaust muffling; (2) overwing routing of exhaust stacks: (3) slow turning, wind bladed propellers; and, (4) improvements in gro'snd and low-speed cooling, perhaps with auxiliany blowers or a reversion to liquid cooling. But the job can be done within the limits of present technology. An inspection of the circumstances surrounding the addition of noise certification requirements to the Federal Aviation Regulations would seem to be in order, to determine whether. for any small airplane other than the business jets, a real need exists for the regulations.

The changes listed above do not come free. Each has its cost in weight or efficiency, small though it may be. Whether this cost wi!! be tolerable as fuel supplies grow scarcer cannot be predicted, but it is worth considering whether significant amounts of funds should be spent on developing improvements which may in a very few years have to be discarded as the last few percentage points of efficiency are sought.

\section{Basic Configuration}

As pointed out previously, no definitive changes in airplane configuration have taken place since about World War I. That war also generated the basic conventional twin. with wing-mounted tractor-type powerplants, a type which survives and is popular today.

The conventional light twin represents the first step up in performance from the heavy single, largely due to the fact that there are no engines on the market today in the 600 horsepower class except the Pratt and Whitney PT-6 turbine and the R-1340. Neither of these engines is suitable for other than specialized single-engine applications, the turbine because of its cost, the R.1340 because of its limited avallability. The twins, with their modern opposed engines, fill the gap.

The conventional twin as a type, unfortunately, has one bad characteristic, which renders it among the most potentially dangerous machines in the air. This characteristic is the difficulty of "cleaning it up" after a single engine failure. The pilot must sort out which engine failed, shut it down, at the same time conteracting the roll and yaw occasioned by the shutdown, then rapidly retract the gear and raise the flaps if they are extended. The difficulty of doing this is emphasized by the fact that a large proportion of fatal accidents to twin-engined airplanes in which engine stoppage played a part is sustained in training for engine failure emergencies.

Attempts have been made to circumvent the trouble by designing airplanes with "centerline thrust," e.g., the "push-pull" Cessna 337. Such airplanes have their own problems, notably those of detecting when an aft engine failure has occurred, and of providing adequate ground cooling for the aft engine. The concept remains attractive, however, as a remedy for the basic problem, and if the conventional iwin cannot be rendered more tractable by the application of advanced technology, the centerline thrust twin should be taken in hand and developed to the extent that it possesses less serious problems of its own than are possessed by the conventional type.

The Advanced Technology Light Twin (ATLIT). For several years a group under Dr. David Kohlman and Dr. Jan Roskam has been working at the University of Kansas in the area of the improvement of cruise and low speed performance of small airplanes. The general approach is to adopt high-lift airfoil technology to maintain low stalling speeds while improving cruise performance (range) and gust response by reducing wing area about 30 percent to cut skin-friction-type parasite drag. Spoiler ailerons are adopted to maintain good roll performance at low speed.

At present this NASA-contracted program has modified a Piper airplane, an "ATLIT," for further experimental work. Their first airplane was a single-engined Cessna.

Robertson Aircraft. While the aerodynamic gains sought by the ATLIT project are worth achieving, quite a bit can be done toward improvement of low-speed performance alone by adopting less drastic measures. For many years the Robertson Aircraft Company has specialized in modifying conventional production airplanes for this purpose. The modifications consist of sophisticated flap systems. drooped-wing leading edges, vortex generators, and lately full-span flaps and spoilers. Robertson's emphasis has been on keeping modification costs low and doing as little as 


\section{N76 11996}

possible that will affect the structural integrity of the basic airplane.

\section{Short Field Aircraft}

"Short-field Aircraft" is a catchall term under which can be lumped all aircraft which use advanced technology to achieve shorter than ordinary takeoff and landing distances. The term embraces short takeoff (STOL), reduced takeoff (RTOL), and vertical-or-short takeoff (V/STOL) types of machines.

\section{RTOL and STOL}

There have been two definitions associated with each of the names Reduced Takeoff and Landing (RTOI,) and Short Takeoff and Landing (STOL), and much confusion has existed because this fact was not appreciated. The confusion existed because, while Conventional Takeoff and Landing (CTOL) airplane technology and its associated performance were represented by existing types of airplanes, as was Vertical/Short Takeoff and Landing (V/STOL) by the performance of the helicopter. no hardware and no steady performance targets existed for STOL. During the early years in the deveiopment of STOL technology, the typical argument was over what single fixed takeoff and landing distances should be striven for through the application of the technology. One of the early "definitions" of STOL was "500 feet over a 50 foot obstacle." It was surprisingly long in coming out that there were actually two entities to define separately.

The first was STOL technology, the aggregation of technical developments that would enable the design of an airplane with field length requirements substantially less than those of a CTOL airplane, of the same payload, range, and speed.

The second was STOL airplane, and to its definition no fixed field performance requirement could be attached except arbitrarily. ine field performance of successful airplanes designed to a given state of the art is size dependent as shown in Figure 1-3. A STOL airplane, then, is an airplane which utilized STOL technology effectively to produce some percentage improvement in performance, no matter how short or long its field requirement is.

Potential users, however, insist on thinking in dimensional terms so here is a sample run-

- Stalter J $\mathrm{L}$, and Wattson, Robert $K$, Jr. "Experimental In vestigation of a Means of Obtaining independent Control of Lift and Drag in Landing Approach." University of Wichita Engineering ReDrag in Landing Approach. "University of Wichita Engineering Retation Research Command. April, 1959 down of the various field length performance targets advocated throughout the years, with a little information on each:

(1) 1952: 500 feet; this was the point of departure for many discussions among commercial manufacturers, the Army, and the Office of Naval Research. In 1953, the Cessria Aircraft Company actually produced an airplane capable of taking off and landing over a 50-foot obstacle in $\mathbf{4 5 0}$ feet. The airplane was a heavily-modified L-19A. The "improvement" over CTOL was approximately 25 percent.

(2) 1959: 1,200-2,000 feet, developed in part by technical studies growing from ONR/Army-sponsored research performed at the University of Wichita. The aircraft associated with these field lengths were transports in the $30,000-60,000$ pound class At this same time, Lockheed Aircraft started development of a "BLC-130" with comparable performance.

(3) 1968: 1,000 feet. The FAA marked off 1,000-foot sections of runway at Washington National, Friendship. and LaGuardia airports and designated these as "STOL" strips. An airline using Dornier "Sky Servant" heavy twins $(7,700$ pounds) used these strips. Though this airline operated only for a while, it provided information on the feasibility of introducing STOL airplanes into the mix of traffic at a heavily-used airport.

(4) 1970: 2,000 feet. This was a relaxation of the 1,000-foot "requirement" above. Surveys of the larger commuter operators at that time indicated that they would have been content with about 3,500-foot field performance.

(5) 1975: 3,000-4,000 feet. This length is associated with medium weight transport category airplanes (146.000-206,000 pounds) in a NASA-funded set of short-haul systems studies by Douglas. Lockheed, Boeing, and others. Advanced hi-lift technology and materials were necessary at these 


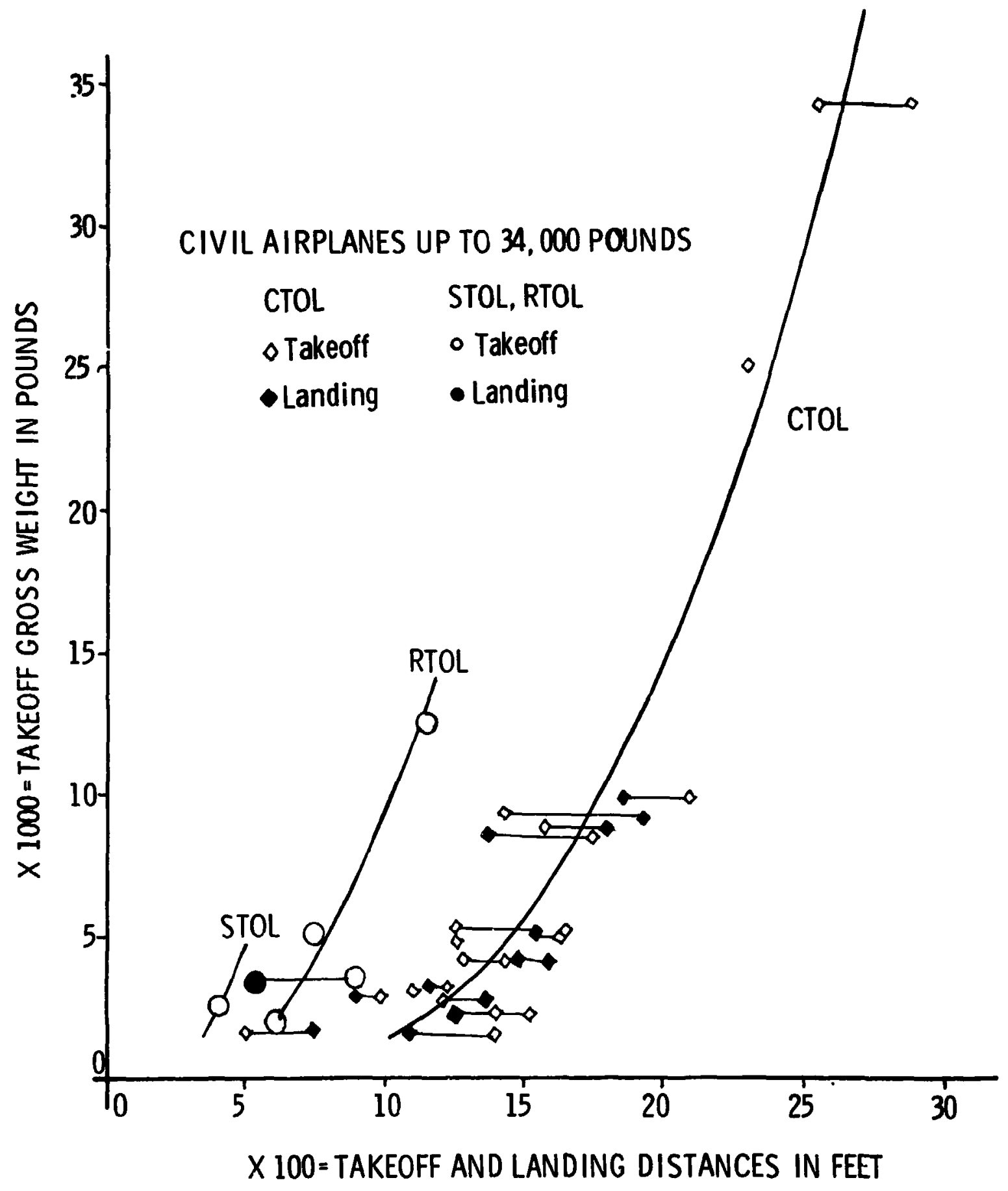


weights. Environmental considerations were invoked. ?

From these cases it can be seen that the field length requirements, and the aircraft missions and sizes of principal interest at the moment, were all mixed up together, which trequently happens when most of the application effort over a considerable period is devoted to studies rather than to the production and marketing of actual equipment.

To try to make some sense of the above, a discussion of STOL aircraft is presented using a historical/technical approach. The initial question, of course, is "what is 'short'?" or "short with respect to what?" As has been seen, there is no way to answer using field lengths; thus, a defin, cion based rather on the state of the technical art must be adopted. This definition requires that a technology associated with "conventional" is adopted first, and that "short" (plus recently "reduced") be related to it through inspection of the technological 'evels habitually associated with them.

Conventional Technology. Perhaps the best period to use to describe "conventional" is the period between 1946 and 1950. By 1946 the biplane and the wooden airplane no longer represented the highest level of tectinology. The technical product of the war years which appeared first on the civil market was characierized by conventional-airfoil straight wings, single or double-slotted part-span flaps, and propeller engines. The turbojet engine technology of wartime was working its way through the military inventory, and would appear on the civil market in the 1956-59 period ir. the forms of the Boeing 707, the Douglas DC-8, and the Convair 880. These three airplanes were "CTOL's" in the sense that, though they employed complicated flaps and leading edge devices, the effectiveness of their wings in producing high lift was; no better than that of the propeller airplanes that preceded them. Their field length requiremenis were very long, $9,000-10,000$ feet, so from either the performance or the technology standpoint they would have to be considered simply as defining a jetairplane CTOL developmental level.

STOL Technology. The initial impetils for the development of a STOL technology was provided by the military. Civil propeller airplanes of the 1946-1950 era had no great trouble operating from the airports of the day. The military, however, concerned over opera-

\footnotetext{
- Savin. Raymond C ot al, "Summary of Short-haul Systems
} Studies." NASA TM X-3010, January, 1975 tions from short fields or aircraft carriers, thought in terms of better field performance than could be displayed even by the propeller airplanes of the period. They were diverted from the helicopter by its slowness and fearsome maintenance costs, and thought instead of short-field fixed-wing airplanes which, while somewhat heavier and more complicated than conventional airplanes, would offer acceptable logistics and some of the desired performance gains.

Conventional high-lift technology seemed to have reached a plateau, so attention was directed towards "powered lift." The means were to be propellers which bathed most of the wing in their slipstreams and could be used in conjunction with very sophisticated wing flaps and drooped airlerons which deflected the slipstreams downward to obtain additional lift. Further, an old concept called "boundary layer control" (BLC) or "circulation control" was invoked to increase the maximum lift of the flapped wings. The application of BLC delays the breakaway of the airstream over a wing by removing (suction) or re-energizing (blowing) the slow-moving layer of air-the bolindary layer-close to the wing surface, the decay of which causes the wing to stall.

Under Army. Navy, and Air Force sponsorship, exploratory programs on prototype versions of liaison airplanes, fighters and transports using BLC with or without propellers went on throughout the 1950's. In France, thie Breguet company developed a deflected slipstream, four-propellered airplane with flap and control-surface refinements, the Model 940 transport. In 1967 its successor, the Model 941. was demonstrated in a series of simulated scheduled airline trips, but nothing resulted.

The state of the STOL art by 1960 , then. was portrayed by: (1) extremely complex wing flaps and slats with or without BLC; (2) large propellers, with or without interconnects to prevent rolling and yawing in event of engine failure on multi-engined airplanes; (3) roll control refinements (spoilers or drooping ailerons); and (4) large tail surfaces, perhaps with BLC applied.

Airplanes with lifting jet engines or lift fans were studied for their STOL-mode characteristics, but were really overloaded V/STOL airplanes.

Civil jet airplane manufacturers meanwhile had been working. Though there was one test of a large jet airplane with BLC in the mıd-1960's, the most notable achievement was 
the Boeing 727, not usually thought of as a STOL machine. Through careful tailoring of the wing shape and flap and slat configuration, Boeing engineers produced a high-speed, swept wing whose high-lift performance was almost the equal of the powered-lift straight wings of the experimental STOL airplanes. Using this wing and the higher thrust/weight ratios available from turbofan engines, they achieved a 7,250-foot requirement of the 707-120. Almost at the same time Douglas achieved similar performance gains using early-generation "supercritical" (not Whitcomb) wings with long double-slotted flaps, and fan engines. The second gencration jet airliners could thus be called true STOL machines, in terms both of thair high-lift technology and of the percentag: improvement in field length achieved.

The technological improvements over the first generation jets were low-speed engine thrust/weight ratios up about 3.0 percent and maximum lift capability up about 60 percent.

Later (1965-1975) efforts have been concentrated in the following areas: (1) "externally-blown flaps" (EBF), an adaptation of the old deflected slipstream concept to the fan engine; and, (2) "Augmentor wings," the addition of auxiliary surfaces using a jet-pump principle to augment the effect of blowing-type BLC. An augmentor-wing prototype airplane exists.

The present situation illustrates a rather curious fact: developments in the powered-lift area did enable wing lift capacity to be raised, but close behind came developments in nonpowered lift-carefully tailured wings, flaps and leading-edge devices-which nullified the gains from powered lift. It alsc appeared that the weight gained by powerec. lift airplanes of any sort was not tolerable c'ommercially. The little Cessna 319A of 1953 grossed 10 percent more weight than the standard L-19A. The weight penalty diminishes with increasing airplane size until for an airplane the size of the Boeing 367-80 (prototype 707) which was flown with BLC, it is only about two percent. When one considers, however, that two percent of design gross weigint is about four percent of useful load and perhaps eight percent of payload, the reason for the unattractiveness of powered lift becomes apparent: with average load factors of 40-60 percent and breakeven load factors in the 40-percent-or-so range, an eight percent penalty in seats available at max-

10 lbid. imum gross weight is completely unacceptable, even though it may be suffered only part of the time.

The fate of the propeller STOL's was similar except for the Twin Otter DHC-6. The Twin Otter is in regular service as a commuter airliner, but its success is due in part to its simplicity and ruggedness; few of the nation's airports from which it operates tax its capability. The Twin Otter is on the upper end of the present general aviation size spectrum. so it is probable that unless needs for serving progressively shorter fields appear, STOL technology of greater sophistication than the Twin Otter's (double-slotted flaps and droopy, double-slotted ailerons) will be unnecessary at 12,500 pound gross weights and below.

In the large commercial airplane area, which commuter airlines can now enter, the situation is somewhat different. Increases in design gross weight are accompanied by increases in wing loading, from which follow the increases in field lengtr, zquirement shown in Figure 1-3. Therefore, "to fit" into a given field, progressively heavier airplanes require progressively more sophisticated high-lift devices to increase the supporting capacity of their heavily loaded wings. Conceivably, this requirement would be encountered occasionally by a comm'ter serving relatively highvolume traffic, but since the relationship between demand and available runway length is generally direct rather than inverse, the occasions calling for large STOL airplanes will probably be exceptional. There exists at this time. however, a large commercial STOL airplane, the DeHavilland DHC-7, which is entering experimental service on a Canadian two-sector route, the airports on which are "close-in" STOL strips. The airplane is at the top of the size range for United States commuters operating under present $C A B$ regulations, but this limitation is not necessarily permanent.

Recently there has been the appearance of the idea of the "Reduced Takeoff and Landing" airplane, a concept sitting somewhere between the present CTOL's anu' the non-existent "powered-lift" STOL category.

The technical features of RTOL are very low wing loading and/or "a little" powered lift. As explained previously, field-length requirement must be associated with aircraft size as well as with technology. The study by Savin, et al., was built around a range of sizes for 40 to 300 passerigers, narrowed finally to 150 passengers. ${ }^{10}$ Gross weights of 146,000 to 206,000 
pounds are developed, depending on the field length requirement and the technology used. It is shown in the study that field lengths of 3,500 and 4,000 feet, at standard sea level conditions, can be realized by airplanes of this size using mechanical flaps or upper-surface-blown flaps, with wing loadings from 72 to 100 pounds per square foot. The increase in direct operating cost of such airplanes over CTOL airplanes of like capacity would be on the order of two percent or so. Interpreted as a fare increase (fixed IOC/DOC ratio) this is probably tolerable in the very special locations for which the aircraft were devised.

Technologies discussed by Savin, et aí., applied to airplanes of general aviation size, would produce far shorter field length capabilities. For example, the well known DHC-6 Twin Otter can in fact be considered technically an RTOL rather than an STOL airplane; its advertised minimum field length is just under 2,000 feet. The nearest counterpart CTOL, the Swearingen Metro, requires 3,550 feet at the same gross weight.

Ideally, aircraft should cruise at maximum weight/thrust or weight/ power speeds. Practically, CTOL airplanes cruise at or near minimum trip-cost speeds, which can usually be shown to be higher than are maximum weight/thrust speeds. The idea that CTOL aircraft might be reoptimized for cruise using STOL technology is attractive from this viewpoint. Using an example from long ago, the Cessna 319A STOL airplane would have had the same field length requirement as its parent. the L-19A, at a gross weight exceeding 3,300 pounds, or about 50 percent more than that of the L-19A. Reoptimizing for high speed cruise instead of short-field performance would have dropped wing area an approximately corresponding amount, and while the gross weight of the airplane would end up little less than the 319A's 2,300 pound weight, the airplane would be more nearly in match-that is, the minimumcust cruise would be closer to its maximum weight/thrust speed. No present day small airplanes are so matched, for various reasons (the 61 knot stalling speed, for one), but some studies have indicated that energy conservation may be possible. The above oxample is vastly oversimplified (optimization analyses for jet airplanes, for example, must include wingfuel volume requirements and their load-relieving effects on structure weight) but the concept is worthy of attention.

From the standpoint of technical feasibility alone, one can design an airplane to any field length requirement at all. There are other constraints, however; here are some:

(1) A short-field airport must accommodate aircra't on ramps and taxiways and terminal facilities, as well as the runway itself. Even if terrinal facilities (except runways) were suppressed, the ramp area required to accommodate any reasonble number of aircraft is surprisingly large. It could conceivably be large enough so that, with parking areas laid end to end, it would be longer than the runway required. This would have the effect of relieving the short-field requirement itself!

(2) Short-field aircraft are typically considered as applied to sectors with at least one end in or near a Central Business District. Unless t he presence of special features of the area-rivers or lakes, for instance-renders land acquisition cost negligible and noise and obstruction problems tolerable, the city-center "STOLport" is of questionable feasibility from the financial and public acceptance viewpoints.

(3) Short-field aircraft consume more fuel per mile than CTOL aircraft. and have greater hardware weights and greater complexity. They are therefore wasteful of energy compared to their CTOL counterparts. in the past it has been acceptable simply to assign marginal costs and to ask whether the resulting fare increases would be acceptable (the answer has usually been "yes" but nobody really knows). The rising importance of eners: conservation now suggests that short-field afplications should be inspected on an energy-level basis, using a concept which includes the entire supporting system along with the aircraft, and compares it with alternative sysiems.

\section{V/STOL Technology}

The Airship. The oldest V/STOL aircraft was of course the balloon. Unsatisfactory as a transportation device for use other than sport, the balloon quickly gave place to the airship. 
Three classes of airship existed by the end of World War I:

(1) Rigid (envelope fully framed, gas carried in internal ballonets)

(2) Semi-rigid (envelope possessed a "keel" structure running its entire length and part way up the sides)

(3) Non-rigid (unframed envelope, the nickname "blimp" coming from the sound an early non-rigid made when its envelop was whacked sharply with a finger).

Rigid airships were constructed in Germany before and during World War I. The United States had one such machine completed for the Navy as a contribution toward war reparations ("Los Angeles," Serman number $L Z$ 126), and built three ("Sr. 'IIndoah" ZR-1; "Akron," ZRS-4; and, "Mace. ZRS-5) all of which were lost. The British bul . a series, the " $R$ " airships, the last two of which, R-100 and R-101, were constructed concurrently. R-101 was lost The "Hindenburg" had a gas capacity of about 7 million cubic feet. a typical payload of about 30,000 pounds, an all-up weight of abcut 260,000 pounds, a 159,000 pound useful load and a maximun speed of $88 \mathrm{mph}$. By the end of the rigid airship era a total of 160 rigids has been built."

Italy croduced an early series of semirigid airships, arid in the mid-1920's built two large ones, "Norge" and "Italia." "Italia" was lost on a polar exploration flight.

In the years from 1931 to 1972 the Goody ... Jorporation built 334 non-rigids, all but 10 of them for the Navy. This represented about 75 percent of the nation's total production. The surviving non-rigids are all used by Goodyear for advertising. The company rebuilds these airships periodically using substantially the technology of the time of their design, thus keeping their Airworthiness Certificates active and current, and avoiding the rieed to type-certificate an advanced airship.

The airship's total lift is secured by a com. bination of displacement lift and aerodynamic lift. The displacement lift is of course due to the difference in weight between equal volumes of helium or hydrogen and air: the aercdynamic lift comes from the force oi the passing air on the envelope; this is increased or decreased by increasing or decreasing the angle of attack, as on an airplane wing. An airship does not nor-

Vittek Joseph A Jr. (ed ). Proceedings of the Interagen cy Workshop on Lighter Than Air Vehicles." MIT Flight Transportation L_aboratory Report R75-2 January, 1975 mally valve helium, but maintains its altitude by making the trades between displace.ment and aerodynamic lift that are necessary as the day progresses and the envelope warms up, expanding the helium gas within (the envelope shape and size in non-rigid airships are maintined by slipstream-air-filled internal balloneis). The larger airships could store ballast in flight by using engine exhaust concensation to replace the old sand bag ballast.

The top speed of the existing non-rigids is about $35 \mathrm{mph}$, and their usual operatıng altitudes are very low. A typicai Goodyear nonrigid has a six-passenger (about 1,020 pounds) payload, and requires a flight crew of one and a small ground crew of perhaps six. Giound support equipment in the field consists of one large equipment van, a portable mast, and crew transportation.

in the recent material on airships, two major techrilogical development possibilities appear.

The first is due to the release from the limitations of the properties of meterials used in the past for hull iraming, envelope, and ballonets. The airships of the early 1930's were framec with what amounted to 17ST aluminum alloy. An all-metal airship, the Navy's ZMC-2, helped stimulate the development of Alclad. which is aluminum-alloy coated with fure aluminum. Since then, nigher strength aluminum alloys have become available, and synthetic fabrics have replaced the fabrics used in the old airships.

The second is an evolutionary development in hull shaping. This development has gone in several directions at once, helped by various advocates, but essentially the technical basis is the following: The cigar-shaped hull of the conventional airship is not an efficient producer of aerodynamic lift. The lift force is very weak, and is accompanied by a penalty known as induced drag (induced by lift, that is). Also this hull is unstable and tends to nose in the direction of the lit: force being developed, so it must be fin-stabilized li.ce a missle or bomb. It has thus been ciear that while the cigar shape was desirable from the standpoint of minimizing drag from hoad-on winds, it was addressed to only a small part of the total aerodynamic problem, since an airship is seldom exposed to direct head-on w'

On the other hand, the airplane deals with "induced" drag and stability problems relatively successfully There should, then, Le some benefit to be gained from shaping an airship r.ull somewhat like an airolane, enabling it 


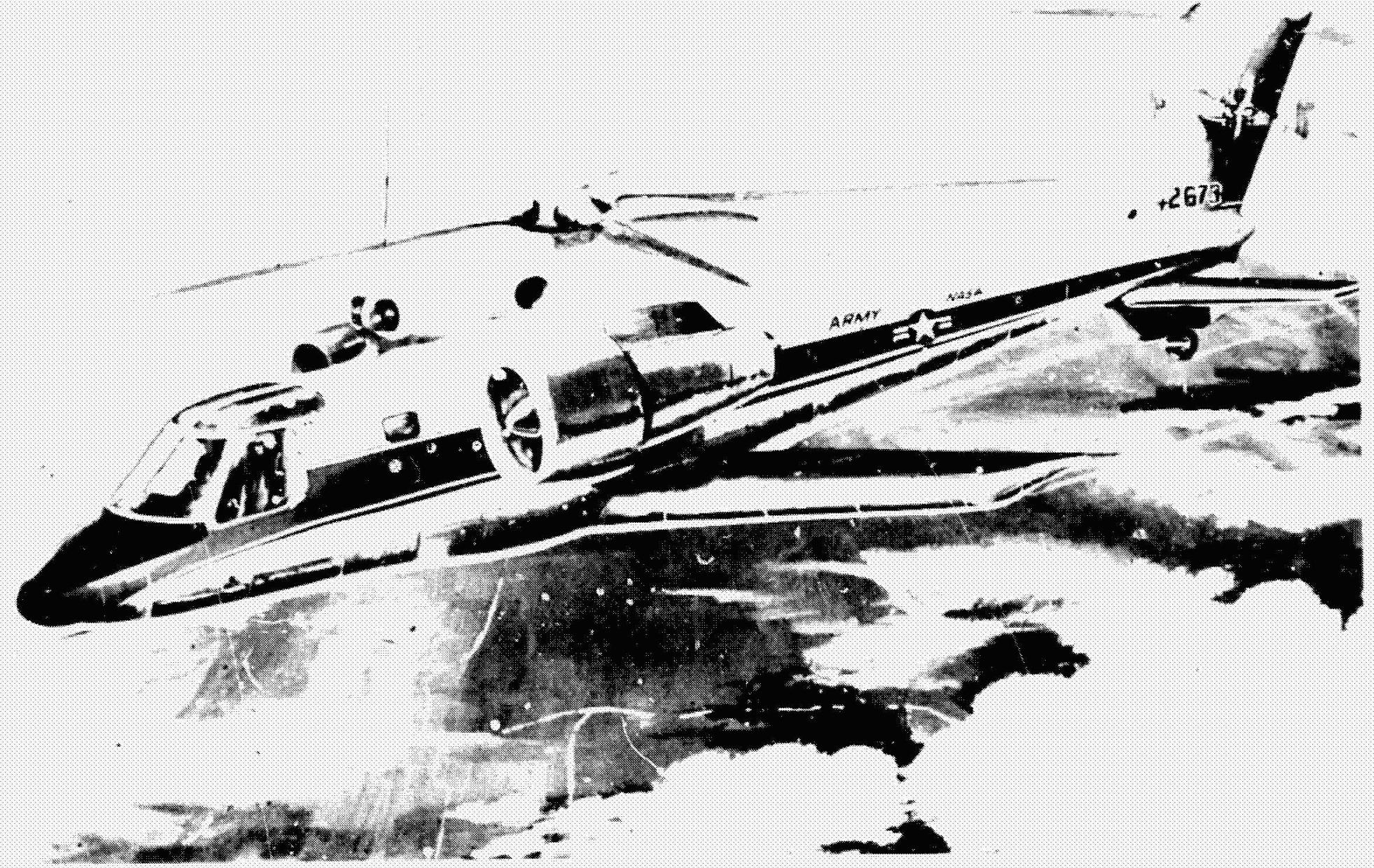

ARMY-NASA EXPERIMENTAL RESEARCH HELICOPTER

(UNLOADED ROTOR WITH WINGS)

FIGURE $1-4$ 
to take more advantage of aerodynamic Itt, and alleviating somewhat the stability and control problems. The recent proposals of methods for doing this have ranged from slightly modified conventional rulis to what in the end arrount to lat, light, and slow airplanes.

The results of "rational" analysis available on conventional and "hybrid" machines indicate so tar that from a cost per avallable tonmile standpoint: whener conventional or hy brid, (1) the airship should be large. (2) Either type should be slow. "Slow" is un the order of $50-120$ knots. As (t. in speed increases the proportion of total lin, which should be aerodynamic lift also increases. (3) Either type should fly low. The cost per ton-mila for either conventional or hybric machines becomes forbidding at altitudes above $10-15,000$ teat."

If the analyses are valid and result: sufficiently accurate for predicting purposis, the best field of application for a commercial ait. ship of almost any sont should be low-urgency cargo-hauling on over-water routes, in large cargo weights. Except tor such special purpose duties in pertorming which the airship could compete with the helicopter, this would seem to eliminate the airship from the general aviation field.

The Helicopter. Almost as soon as powered flight was achieved, the cesire to lly. period, was supplemented by the dasire to be able to fly straight up and to hover, in a heavierthan-air machine (see Figure 1-4)

Experiments with helicopters date back to before World War I, but the first technically practical machine was buitt by Sikorsky in 939. Helicspter development since then has been evolutione y rather than revolutionary. Only three ${ }_{2 \mathrm{~s}}-$ configurations now exist as hardware: tursine engines have replaced piston engines in the larget size machines. A helicopter-like machine, the autogyro, with un. powered rotor, has almost disappeared as a type.

Vibration problems plagued the early hellcopters, but have been alleviated by replace. ment of the piston engine and by relinements in drive train and rotor design. particularly in large-size machines. The lype, lowever, stll suffers from relatively high initial and maintenance costs. Possibly due also in part to the paradox that its most usetul flight condition. hovering fairly near the ground is also its most inefficient ard dangerous one. The helicopter in civil use is still pi ncipally a special purpose machine.

A recent configuration refinement, the compound helicopter. is being explored for the military as part of an attempt to relieve the per. formance limitations of Icw cruising speed and short range (the fastest civil helicopter can cruise at 144 knots and has a range of only 380 nautical miles with maximum cabin load)

The configuration called the hellenpter is definitive, though with a little more variety than hat of the airplane. During the vear of greatest V/STOL research activity several other configurations were proposed titing rotor (which actually flew), unloaded rotor, stopped rotor. and stowable rotor compounds. Thest maclines were attempts to break the speed limitations of the basic helicopter and some were seriously put forward for civil use. Other than the unloaded rotor compound helicopter with wings, none of these machines is now fly. ing since their high development costs suggest that they will not be available commercially until they work their way through the military

Non-helicopter VISTOL. There are no nonhelicopter VISTOL heavier-than-air machines in production except for one subsonic attack airplane but ideas have pioliferated to a greater extent in this technological area than in any other

A great upsurge of interest in non-helicop. ter VISTOL technology commenced at almost the same time as the interest in STOL technology started to be productive of hardw te The impetus was the desire to be relieved of the ilying field requirement of the fixed-wing airplane along with the low top speed and poor economy of the helichter The military again headed the drive lor development work

By he md-littes several conliguration and propuls ve concepts were being explored (see Figure 1.51 and by the early 1960 s a series of small exploratory airplanes, and three large ones, had flown briefly, all under various com. binations of military support Most exhibited marginal thrust-weight ratios and poor handina characieristics. and by now have either crashed or become museum pleces. Two airplanes had longer Ives-the XC. 142 In. service tranesort. "on which development started late in 1960, the single prototype being turned over to NASA tor research, and the Bri. tish Hawker P.1127, nicknamed 'Harrier' in the Untes States Marine lighter aviation invertory The $\mathrm{XC}-142$ was a tour-propeller tilting wing type with interconnected powerplants and special propellers a litlle like helicopter rotors 

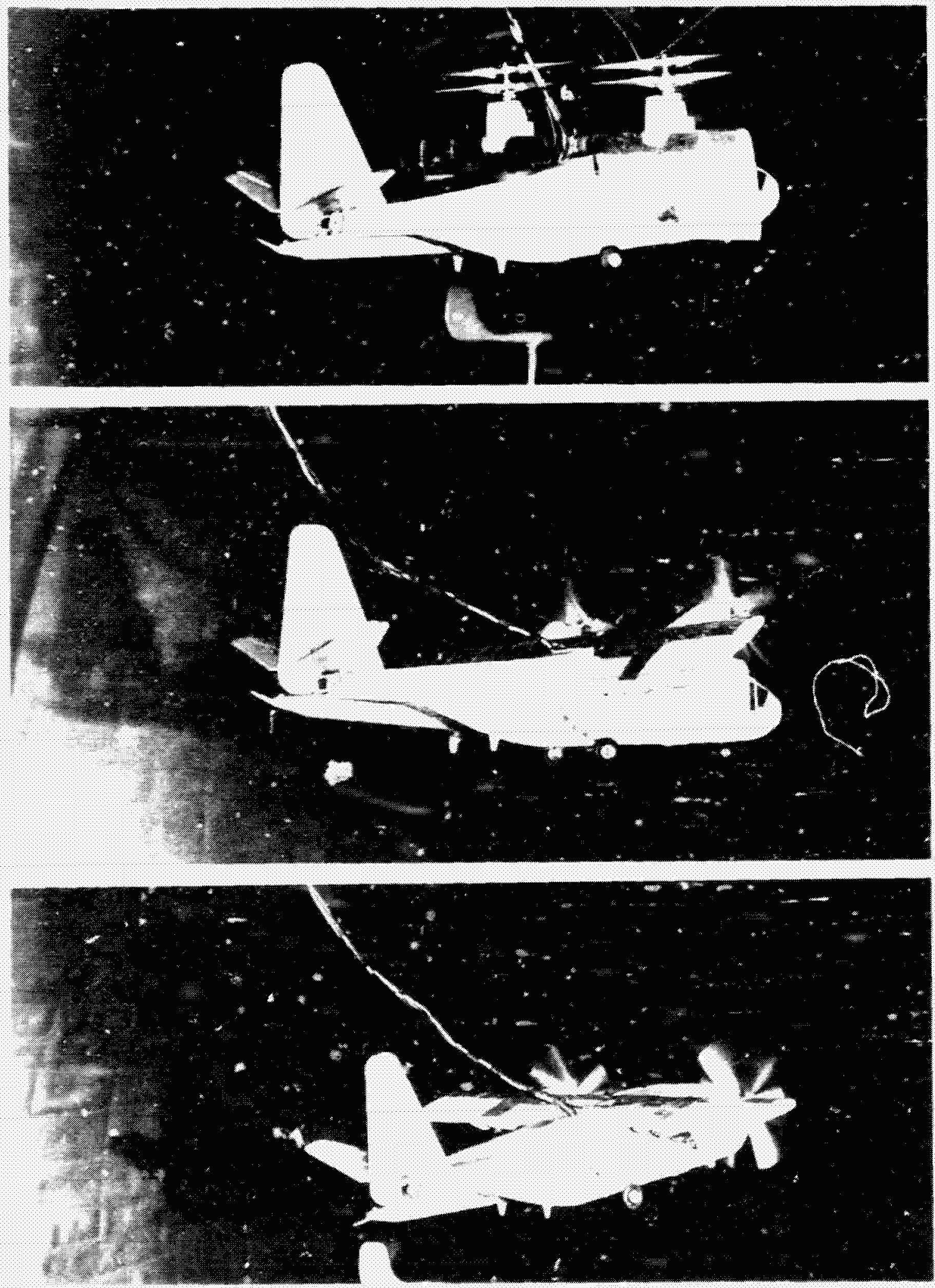

$\checkmark$ STOL WIND TUNNEL TEST MODEL

FIGURE 1.5 
The "Harrier" is a single-engine monoplane, its turbofan engine incorporating four exhaust stacks which can swivel downward over 90 degrees for hover.

\section{Exotic Aircraft}

There is a small group of aircraft which fits into no single category such as those used above. Their performance and technology is mixed, and they are included in this section as indications of the variety of concepts that have been conc: dered in attempts to solve aviation's problems or to increase its versatility.

\section{Flying Jeep}

The Flying Jeep was a military development intended to provide one to four soldiers with airborne battlefield transportation of the same nature as was provided on the ground by the quarter-ton truck. A V STOL aircraft was ex. ecuted: it had two shrouded propellers in tandem (or in orie version four free propellers) with axes vertical, between which sat the pilot and his passengers. No version of the mar.hine proved tractable in the air or maneuverable on the ground. and the concept was shelved.

\section{Airplane/Car}

In one form or another the hybrid airplane/car has been around for a long time. for an obvious reason-again it offers the hope of traveling in either of two transportation systems using only one vehicle. A small car has added to it a power-takeoff drive and extra components of its control system. To the car are attached. when desired. a tail containing an extension shaft for the propeller and mountıng tail surfaces. and the wing. The arplane part of the assamblage car. be towed home to the garage in one concept. or left at the alrport in another

The difficulties with this attractive idea seem to be the following:

(1) as an automobile the vehicle is cramped imore at least than the "family car") and laden with extra machınery;

(2) as an airplane it suffers from having to drag the car around. dimınishing its efficiency as a flyıng machine:

(3) It has an interface problem Either it must be hauled through the streets. vulriorable to minor tiafic accidents any of which can render it immediately useless as an arplane, or the airplane part must be left at the airport to accrue the usual tie-down tees or hangar rent;

(4) in flight it must be operated by a pilot; in the present state of requirements for airman training and certification the vehicle is not the answer to every householder's dream; and

(5) for airworthiness certificaticn purposes it is an airplane. with the costs that this implies.

Considerable engineering genius nevertheless has been brought to bear on the concept, and one type is flying today. though not in commercial quantity production.

\section{Everyman's Helicopter}

The Idea here is that of the absolute minımum one-man machine. consisting of a seat, a rudinentary undercarriage, a smal! engine. a rotor, and a handle by which to steer Such machines surface occasionally. and enjoy brief notoriety before unaccountably disappearing.

This history of appearances and vanishings seems to be the outgrowth of the fact that each such machine is a true helicopter. with the teething troubles and unstable behavior in the air that are characteristic of such craft. By the time these are ironed out. the device has grown to perhaps $400-500$ pounds empty weight. no longer a playthıng but a rea! aircraft. which must thereupon be certıficated. maintained as an aircraft, and so forth.

\section{Flying Saucers}

The term "flying saucer" is not technically definable As a name for "something" the saucer seems to be on its way into the national folklore As a device or class of devices. the saucer possesses an attraction based partly on the inherent diffıculty of making it fly at all: it presents a challenge.

Considered as an aircraft. the saucershaped vehicle can be viewed as airplane and as hovering device

As an airplane. the saucer-shaped vehicle is simply a round-winged varient of the fixedwing aircraft The round wing is under a con. siderable aerodynamic disadvantage (that of excessive induced drag) compared with the slender wings with which ail viable subsonic airplane types are equipped Round-winged airplanes have. however, been built and flown. most notably one conceived during World War II for the Navy as the minımal "contaıner" for two of the heaviest piston engincs. A reducedscale prototype was flown. but the full-scale machine was rendered obsolete by the advent of the jet engine The round-winged fighter's entire wing was bathed in the slipstreams from 


\section{N76 11997}

its large propellers, and though not a V/STOL, the fighter did signal the resurgence of the idea of the wing-deflected slipstream and its application to V/STOL.

To hover, a vertical flow of air must be established to provide the sustaining force on the aircraft. To hover efficiently-that is, without the expenditure of much energy-the diameter of the vertical airstream must be as large as practicable and its velocity very iow. This the helicopter provides admirably with its large diameter rotor. Attempts to produce a sustaining force equal to that of a helicopter, but using a device that accelerates a smaller diameter airstream faster, use more energy than the helicopter uses.

It follows that unless space limitations are critical, the helicopter is the way to go. If rotor diameter is limited (the slipstream small and fast) a ring-shaped shroud can be put around the rotor and will help some (this is the "shrouded propeller" of the flying jeep). The ring can even be configured to look like a "saucer" but there is no aerodynamic advantage in doing so. though some needed stiffness of the shroud may be gained.

There are classes of V/STOL aircraft concepts which use shrouded propellers because of diameter limitations, but they do not resemble saucers because of the inefficiency of the round wing in forward flight.

As matters stand. none of the exotic aircraft in this group has found a commercial application. Although there is always room to say "but they might in the future" and always danger in saying "they never will," there is no present reason for thinking that the compromises and inefficiencies that have characterized them in the past will be overcome to an extent that will give them a place, relative to the successful types of aircraft, more important than they now occupy.

\section{AIR SUPPORT FACILITIES Introduction}

The interface between ground and air is a landing facility which links the air and the surface transportation systems. This facility is commonly identified as an "airport" since most of the landing facilities fall into the category of serving primarily land airplanes as opposed to

\footnotetext{
1) Froesch Charles and Prokosch Walter Airport Planning. ist ed. (John Wiley ind Sons 1946). p 165

- Ibid. p 74

'S Federal Aviation Administration January 1. 1975 Statistics released in news release 75-83. May 27. 1975

- John F Kennedy International Aurport. New York
}

seaplanes, helicopters, airships, or balloons.

More than 50 years ago it was recommended that "flight stops" be piaced along the highway. Such stops would be nothing more than a landing and take-off strip adjacent to a gasoline senice station. This would combine motor car and airplane service to assure maximum and dependable service. Flight stops were to be a part of the national highway system. ${ }^{13}$ A recommendation was made that

No arterial motor highway should be built in the future without including adjacent flight stops every 30 to 50 miles for the personal flyer. Flight stops will mean a landing area for practically every town and hamlet located on such superhighways. thus providing those small communities with an additional means of transportation. ' 4

This scheme, started in the late 1920 's by the Richfield Oil Corporation, failed largely due to the fact that personal aircraft were still too expensive in both initial and maintenance costs. The depression of the 1930 's also played its part in pre senting the commercial success of the venture.

This section will discuss various types of landing facilities with particular emphasis on general aviation airports. The discussion wilt include airport classification. airport design and layout, airport administration and operation. and general aviation support facilities on the airport.

\section{Airport Classification}

\section{Classification by Aircraft Type}

The ground-air interface in the United States consists of a national network of landing facilities which can be categorized by the types of vehıcles served as follows: ${ }^{15}$

$$
\begin{array}{lr}
\text { Airports serving } & \\
\quad \text { land airplanes } & 11.160 \\
\text { Seaplane bases } & \\
\quad \text { serving seaplanes } & 472 \\
\text { Heliports } & 1.430 \\
\text { Total } & 13,067
\end{array}
$$

Airports are designed around one or more landing areas called runways which may range from 50 feet wide and 1,500 feet long to 500 feet wide and 14.572 feet long. ${ }^{16}$ Seaplane bases are primarily docking facilities adjacent to natural lakes. rivers, and ocean or bay areas which support seaplanes (land airplanes with pontoons) and flying boats (airplanes designed 
to land on the fuselage on water surfaces) Heliports are designated facilities for rotarywing aircraft (helicopters) and many separate facilities are located adjacent to an airport. An area (such as those on top of buildings in metropolitan areas) designed to accommodare one, or a few vehicles, is identified as a helipad. A helistop is similar to a bus stop, allowing a helicopter to pick up and discharge passenge:s along pre-arranged routes, but without other support facilities.

\section{Airport Ownership}

Airports in the United States are also classified in terms of ownership as public or private-a classification scheme which determines eligibility for federal aid for development. Public airports are those whose ownership is by a public body such as a city, county. or state. Private airports are owned by individuals or companies and are ineligible for federal funds and, in most cases. state or local aid.

All public airports which have received federal aid are open to public (government), commercial, and private aircraft, within the operational limitations of both the aircraft and the airport. Access to private airports is determined by the owners and generally falls into one of three categories: (1) unrestricted (open to all aircraft). (2) restricted to airport owners and those with prior permission, and (3) restricted to airport owners.

A breakdown of arports in the United States by ownership is as follows:

$\begin{array}{ll}\text { Public } & 4.575 \\ \text { Private } & \mathbf{8 , 4 8 7} \\ & \left(5,599{\text { closid to public })^{17}}^{7}\right.\end{array}$

\section{National Airport System}

The Federal Aviation Administration (FAA) has developed a breakdown of the 3,040 airports in the National Airport System Plan (NASP) shown in Table I-IV. ${ }^{18}$ This classification recognizes that all civil airports in the United States serve general aviation to some degree and measures any airport's functional role by two operational criteria: (1) number of enplaned passengers by certificated air carriers. and (2)

\footnotetext{
op cit, FAA, January 1,1975

- ibid

- An operation is defined by the FAA as a takeoff or a land

ing

20 1972 National Airport Systom Plan, Volume AEA Eastern Region. Federal Aviation Administration 1972

2. Air Transport Association of America, Alr Transport 1974. Washington DC 1974. D 3

" op ctt. 1972. National Airport System Plan updated by Computer Printout to February 1975

"Sources BU and GU from FAA AC 150-5300-4A, 11-68. BT and GT from FAA AC 150-5300-6. 7-69
}

number of annual operations. ${ }^{\prime 9}$ As indicated in Table I-IV the number of passengers determine whether the airport falls into the primary, secondary, or feeder classification; and, the num. ber of annual operations determines the density grouping within these three classifications.

Communities, as distinguished from airports, are also classified in the National Airport System. The cities, or Standard Metropolitan Statistical Areas(SMSAs), fall into one of four thpes determined by the area's share of the national total number of passengers enplaned on domestic certificated carriers. The four types are as fo!lows:

$\begin{array}{ll}\text { Hub Type } & \begin{array}{l}\text { Percent of Total } \\ \text { Enplaned Passengers }\end{array} \\ \text { Large Hub } & 1 \% \text { or more } \\ \text { Medium Hub } & .25 \text { to } .99 \% \\ \text { Small Hub } & .05 \text { to } .24 \% \\ \text { Non-hub } & \text { Less than } .05 \% 20\end{array}$

There are approximately 150 communities in the United States classified as hub. based upon the .05 percent or more of the annual 202 million total passengers or 101,000 enplanements. ${ }^{21}$ Richmond, as an example. with 503,000 passengers and 190,000 operations annually. would be classified as a small hub community, and the airport, Byrd Field, would be classified as a secondary, medium dersity class airport in the National Airport System. ${ }^{22}$ Airports with only general aviation activity usually fall into the Non-hub category, even if a large number of passengers are transported in general aviation aircraft.

\section{Airport Operational Role}

Airport system planners use another classification systen based primarily on the maximum size of the aircraft served by the airport. This scheme divides airports into four categories: ${ }^{23}$

(1) BASIC UTILITY (BU): (Previous distinctıons between Stages 1 and 2 have been eliminated.) This type of development theoretically accommodates about 95 percent of the general aviation propeller fleet under 12.500 pounds (maxium gross weight). There is no special actIvit;' criterion required for this type of airport.

(2) GENERAL UTILITY (GU): This type of airport accommodates substantially all general aviation propeller alrcraft under 12.500 po'unas. At least 500 annual itinerant operations of aircraft between $8.000-12.000$ pounds are required.

(3) BASIC TRANSPORT (BT): These airports accommodate all general aviation aircraft 


\begin{tabular}{|c|c|c|}
\hline \multicolumn{3}{|c|}{ TABLE I-N } \\
\hline \multicolumn{3}{|c|}{ NATIONAL AIRPORT CLASSIFICATION SYSTEM } \\
\hline Airport Category & $\begin{array}{l}\text { Annual Passenger } \\
\text { Enplanements }\end{array}$ & Annual Operations \\
\hline Primary System & More than $1,000,000$ & \\
\hline $\begin{array}{l}\text { High Density } \\
\text { Medium Density } \\
\text { Low Density }\end{array}$ & & $\begin{array}{l}\text { More than } 350,000 \\
250,000 \text { to } 350,000 \\
\text { Less than } 250,000\end{array}$ \\
\hline Secondary System & 50,000 to $1,000,000$ & \\
\hline $\begin{array}{l}\text { High Density } \\
\text { Medium Density } \\
\text { Low Density }\end{array}$ & & $\begin{array}{l}\text { More than } 250,000 \\
100,000 \text { to } 250,000 \\
\text { Less than } 100,000\end{array}$ \\
\hline Feeder System & Less than 50,000 & \\
\hline $\begin{array}{l}\text { High Density } \\
\text { Medium Density } \\
\text { Low Density }\end{array}$ & & $\begin{array}{l}\text { More than } 100,000 \\
20,000 \text { is } 100,000 \\
\text { Less than } 20,000\end{array}$ \\
\hline \multicolumn{3}{|l|}{ Note: } \\
\hline \multicolumn{3}{|c|}{$\begin{array}{l}\text { Airports classified as above are those within FAA's "National System of Airports." The United States } \\
\text { airport network also includes those classified as "local interest airports" and "miitary airports." "The } \\
\text { latter two groups are those pubiic, private, and military facilities not deemed necessary by FAA for } \\
\text { the country's "National System of Airports." }\end{array}$} \\
\hline
\end{tabular}

Source: FAA AC 150-5090-2, June 25, 1971.

up to 60,000 pounds MGW Including propeller transports and business or executive jets. A BT airport must indicate at least 500 (existing or forecast) annual itinerant operations by airsraft between 12.500 and 60.000 pounds MGW.

(4) GENERAL TRANSPORT (GT): These airports generally accommodate transport category aircraft up to 175,000 pounds MGW The minimum requirement for this type of airport is at least 10 existing or forecast itinerant DEPARTURES per week (or 1.040 itinerant operations per year or season) by either the critical type aircraft or ONE of the appropriate families of aircraft. This classification level is sometimes referred to as Scheduled Transports (ST) or Air Carrier (AC).

The system described above relates runway ler.gth and bearing capacity to aircraft size in term.s of maximum take off weight and annual operations. Sume planners may develop finer breakdowns based upon reduced loads, e.g., BT $100 / 60$, a basic transport runway which accommodates 100 percent of the transport fleet at 60 percent of maximum load. This classification system excludes or mandates the upgrad. ing of general aviation airports below the BU level, i.e.. those unable to accommodate 95 percent of general aviation propeller aircraft.

\section{Airport Functions}

Identification of an airport on the basis of a major or specialized function that it performs is often convenient. The most common such designations are as follows:
(1) Air carrier
(5) Reliever
(2) Joint use
(6) Industrial
(3) General aviation (7) Recreational
(4) Local interest

Air carrier airports are those with certificated scheduled air carrier service. Joint use airports are jointly used and/or owned by military and civil users. The general aviation airports are those which serve general aviation exclusively, i.e., the airports without either certificated air carrier service or military operations.

Local interest airports usually are those which are not part of the federal or state system of airports. These can be either privately or publicly owned fields with limited capacity for operations and future development. Limitations may be due to nearby obstructions, unfavorable 
terrain, remote access, or other factors such as population trends which would restrict either the size or number of aircraft using the facility.

The reliever airport is one designated by FAA to serve as a reliever for an air carrier airport in a metropolitan area. In effect, reliever airports are intended to reduce traffic and congestion at the air carrier airport by diverting general aviation activity.

The industrial aurport is as. airport designed around an industrial park enablıng companies with their own airplanes, and/or doing business with companies or clients with aircraft to have convenient air access. This concept is valid from a land use standpoint in that much of the land required around an airport to protect clear zones and approaches can be utilized by industry which is less bothered by noise than residential users.

The recreational airport is one serving a resort or other recreational area by providing a convenient air access facility allowing pilots who fly in to park and walk or be transported to the recreational facilities. Some resort owners view aircraft owners as a legitimate higher income market best served with an airport designed and located as an integral part of the resort facility.

\section{Airport Design and Layout}

\section{Airport Design}

There are at least 10 factors which should be considered in analyzing new sites and in planning and designing new airports. They are:

(1) Convenience to users

(2) Avallability to land and land costs

(3) Desıgn and layout of the airport

(4) A'rspace obstructions

(5) Engineering factors

(6) Social Factors

(7) Avaılability of utilities

( 8) Atmospheric conditions

( 9) Hazards due to birds

(10) Coordination with other airports. ${ }^{24}$ High priority should be given to the first

"Paquette Radnor Astiford Norman and Wright Paut Transportation Engineering Planning and Design. (New York The Ronald Press Co 1. 1972 o 732

19 Abstracted from Airport Master Plans AC $1505070-6$, Federal Aviation Administration February, 1971 o 41

“Utilty Airports AC 150 5300-4A. Federal Aviation Admınistration. November. 1968 pp $89-93$

- STOL - Short Takeoff and Landing VTOL - Vertical Takeott and Landing factor, covenience to users. If the airport is not convenient to those who wish to use it, the project is unlikely to be successful.

\section{Runways}

Although most general aviation airports do not have two runways, or runways over 5,000 feet in length, layout of a general aviation airport recommended by the FAA is shown in Figure 1-6. ${ }^{25}$ The layout is a plan of an airport with a summary of the basic data required for planning and development.

Included in the plan is a Basic Data Table which provides airport information such as its elevation in feet above sea level, its geographic coordinates (a point near the center of the airport is used as a geographic reference point), its navigational ards, and its mean temperature of the hottest month.

Basic runway data include the slope of the runway (effective runway gradient), the wind coverage. the navigation and lighting aids serv. ing the runway, and the runway load bearing capacity for various aircraft.

The airport is designed around one or more runways. The single runway's design is very common for general aviation since it requires a mınimum amount of land. Each airport layout is planned around the direction and velocity of the prevailing winds for the geographic area. The wind rose in Figure 1-6, developed from official weather data shows the percent of coverage of each runway under crosswind conditions. Such a table would indicate the requirement for an additional runway if one runway cannot provide 95 percent coverage under velocities of 15 mph. Most general aviation aircraft can be operated with up to a $15 \mathrm{knot}(18 \mathrm{mph})$ crosswind component (a wind equivalent to 18 mph at $90^{\circ}$ to the runway.) ${ }^{26}$

When a second crosswind runway is utilized, it can be arranged with the first runway as a crossing runway as in Figure 1-6, or as a separate or connecting runway with the arrangement determined by such factors as number of runways. surface (hard surface or grass). length. land available. obstructions, and extent and location of facilities.

The use of parallel or non-intersecting angled runways serves to alleviate traffic for airports with high density of operations or to separate traffıc or incompatible mix such as air carrier and general aviatıon or conventional general aviation and STOL or VTOL. ${ }^{23}$

The runway surfaces may be hard surface. biacktop (bituminous). concrete, or grass/turf. While most general aviation aircraft can be 


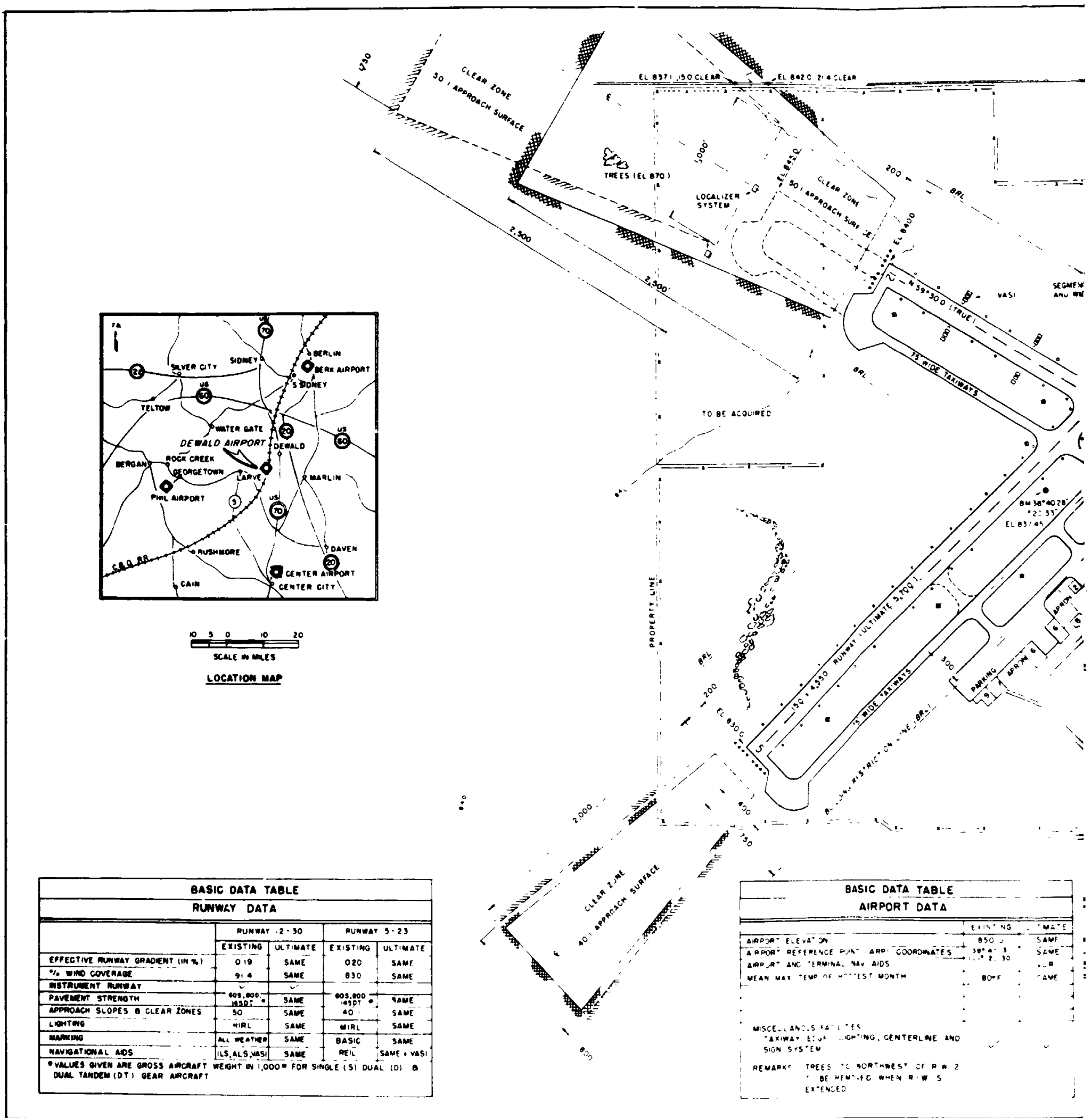




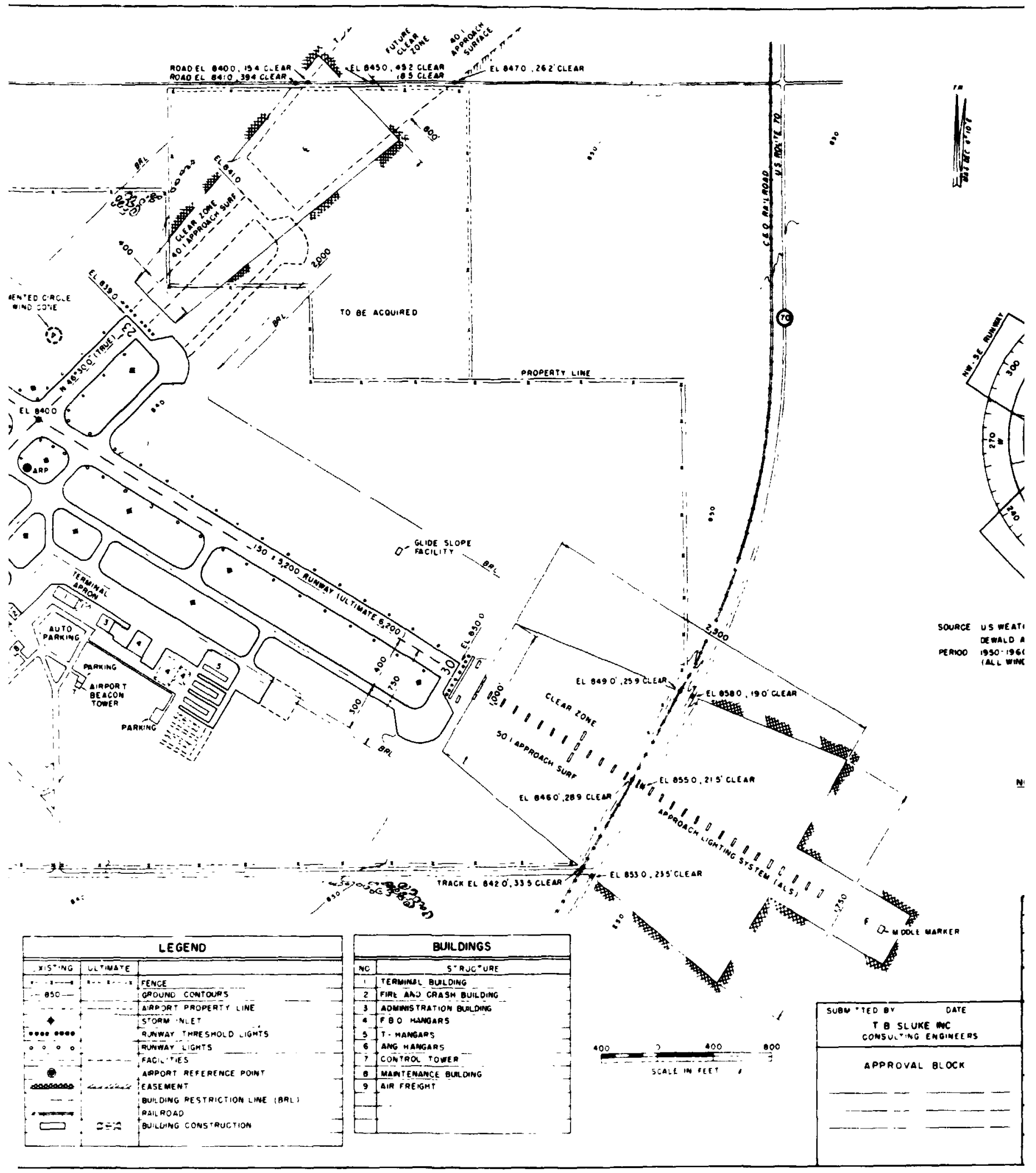




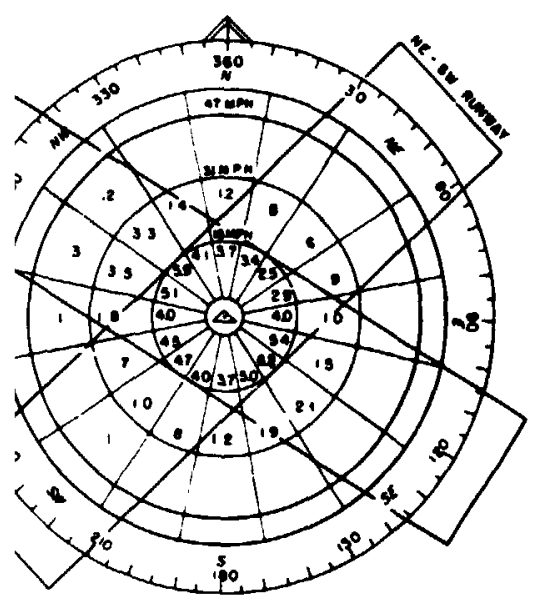

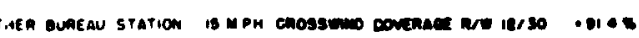
Alpront

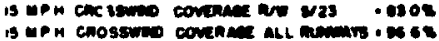

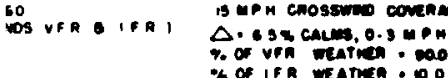

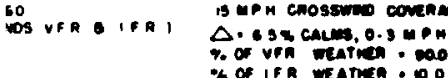

wino nose

yers TMESE PLAMS SMOULD MOT OE USED AS
STANDARDS FOR PLAMHING OR DESIGM

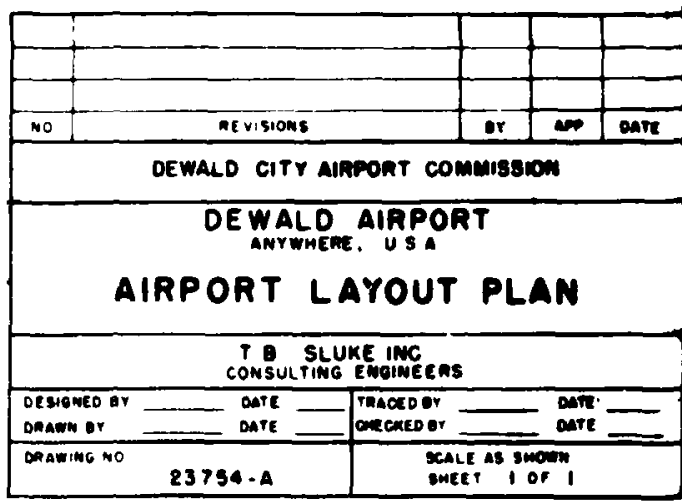


operated from grass surfaces, hard surfaces are desirabic due to reduced friction, smoother ride, and lower probability of aircraft damage by stones and foreign objects.

\section{Taxiways}

Supporting the runway system are access routes called taxiways which connect the runways with the ramp and parking areas. Taxiways separate ground traific from the active runway, thereby increasing the capacity of the airport. Taxiways may be limited to one prımary runway or may encompass all runways with connectors or turnoffs to facilitate exit and entrance at various points.

\section{Airport Airspace}

Airspace around the airport is protected from sbstructions by the legal desigriation of clear zones or corridors. The lower boundary of the clear zone is sloped upwards and away from the end of the runway on a required slope criterion which is determıned by runway use and the operational role of an airport. The slope varies from 20 to 1 for a basic utility (BU) airport to a 50 to 1 slope for a runway with a precision instrument approach system at a general transport (GT) airport. ${ }^{28}$

The airsoace to the side of the runway is also legally protected by buffer zones from any buildings or structures (see Builcing Restriction Line in Figure 1-6), and terrain or other obstructions through side clear zones with generally a 7 to 1 slope.

\section{Airport Facilities}

Connecting the taxiways with the aircraft storage and parking facilities are connectors and aprons which may also serve as temporary parking for aircraft. Long-term parking is accommodated by tie-down areas for aircraft stored outside.

Ground access to the airport is through one or more roads which connect with perimeter roads and driveways leading to administration buildings, facilities, hangars, and aircraft parking areas.

Other facilities on the airport fall into four broad categories:

(1) Administrative and support facilities are those utilized by the airport owners or authorities for offices and the storage and maintenance of vehicles and ground support equipment. Depending upon the airport, the facility may range from a small, steel-type

"Utillty Airports, op cit. p 20

- Alrman's information Manusi Part 1. Federai Aviation Ad ministration. Washington, D C. May 1975, pp 10, 18. 19 structure combining office and storage space to a larger office building and separate storage/maintenance structures. Airports with fire and crash equipment will locate such facilities centrally so as to be close to the runways and taxiways as in Figure 1-6.

(2) Approximately 25 to 33 percent of the resident aircraft owners desire inside storage to protect aircraft from the elements and provide security. Storage is accomplished $\epsilon$ ither by a single unit type hangar containing $5:$, 20 aircraft, or individual stalls commonly called " $T$ hangars." The latter are usually connected in a series and located in rows adjacent to taxiways as shown in Figure 1-6

(3) Air traffic control tower facilities are likely' to be found on top of the administration or termınal buildıng in the case of older facilities. In new facilities these are contained in a separ. ate high-rise structure, located to provide an unobstructed view of all aircraft operating areas on the airport Some navigational aids are contaıned in a small frame building adjacent to the runways that they serve. Airports with an instrument landing system require approach lights near the end of the runway, and off airport aids such as lights and radio beacons called markers.

Figure 1-6 shows navigational aids serving runway 30/12 which consist of the following:

1. VASI. A visual approach slope in. dicator to provide optical/visual descent gu:dance to Runway 12

2 LOC. A localizer system to provide directional guidance for Runways 30 and 10.

3. Glıde slope for electronıc vertical descent guidance to Runway 30.

4. Approach lighting system for visual reference transition on Runway 30.

5. Markers to identity position on the Runway 30 approach An outer marker. not shown in Figure 1-6, is located 5-7 miles from the airport on the center-line of Runway 30. ${ }^{29}$

(4) General aviation services are provided utilizing a variety of termınal and operational facilities which support the particular operation. The terminal building is a facility designed to service air carrier passengers and is not normally found on a general aviation airport unless left over from earlier use of the facility for air carrier operatıons

Most operations are conducted in facilities erected or leased by the general aviation fixed 
base operators commonly called FBOs. FBO facilities range from a small hangar/office/lounge combination facility to an extensive layout with several hangars, mainienance shops, and a large office/lounge classroom building. In addition to the FBO faci":ies there may be several specialized facilities which provide specific general aviation services, operating c'st of hangars, hangar/office facilities or even mobile structures.

\section{Administration and Operation}

\section{Amininistre^jve Organization}

To a certain extent administrative procedures of a general aviation airport are a function of ownership. Most of the privately owned fields in the United States are landing strips on the owner's land which accommodate only a few private aircrafi. Privately owned airports are administered as the owners chocse.

Public airports are administered by the public body (commission or authority) which represents the units owning the facility. There are several types of aaministrative structures with the particular type primarily dependent on the size and activity of the airport. For example. airports may be administered by the mayor of the city as just another unit within his jurisdiction. This method is appropriate for small, low act.vity airports where the administrat:... de. mand does not require the expertise and/or time of a full-time airport manager. Another frequently used method is to lease the entire airport to a general aviation base operator with responsıbility for airport mainter:ance and operations assumed by the operator. Other airports may have a full-time or part-time airport manager designated with one or more additional staff.

\section{Administrative Functions}

in considering the actual administratıon of an airport one must distinguish between the airport and general aviation operations on the airport. The airport owner is responsibie for the design, construction, and maintenance of the physical facilities used by the public and by tenants of the airport. Operations on the airport relate to the operation of aircraft and general aviation services provided for sisch operation. Flight oparation on the airport is the responsibility of the owners or operators of the particular aircraft. Services are the responsibility of those finviding them. In some cases, the airport owner provides one or more services such as aircraft fueling, aircraft storage, and parking.
The major administrative responsibilities of the general aviation airport manager are planning, deve'opment, maintenance, and operations. An airport master plan presents the planner's conception of the ultimate development of a specific airport. Master plans are applied to the modernization and expansion of existing airports and to the construction of new airports, regardless of their size or functional role. Master plans disclose anticipated amounts and tyues of air and ground traffic for proposed or existing landing facilities. Theoretically a master plan program will (1) cause the persons responsible for organizing the local endeavor to come to agreement as to just what should be planned and built and. (2) become an instrument whicn permits those charged with the actual planning and construction of the builaing to proceed with their work in a progressive and orderly fashion.

The FAA emphasizes and encourages long range planning for airports and administers the Planning Grant Program (PGP) which provides funds for up to 66 percent of the cost of developing a 20-year master plan for a public airport. A plan is developed using the cor.:bined efforts of a consultant. the FAA, and the sponsor (the arrport authority or commission).

The master plan as prescribed by the FAA is usually divided into four phases:

\section{(1) Airport Requirements}

This includes an inventory of existing facilities, airspace, airports, land use laws and ordinances, $f-$ nancial resources, and socio-economic factors.

The demand for aviation services for 5,10, and 20 year time-frames is forecast.

A demand/capacity analysis is made to include cost versus benefits, and facility requirements are developed from this analysis.

(2) Site Selection

For new airports or tre relocation of existing airports, a site selection or evaluation is conducted of all possible sites within a 30 minute drive of the community population center.

(3) Airport Plans

The airport layout (Figure 1-6), land use. terminal area, and airport access are shown as planning drawings. 


\section{(4) Financial Plan}

The schedules, cost estimate, economic feasibility, and proposed plan for financing are considered for all proposed development. ${ }^{30}$

Airport development is the process of execution of the master plan. The FAA also particlpates in this phase through the Airport Development Aid Program (ADAP). The FAA will participate in most non-revenue producing development projects such as land acquisition, runways, taxiways, and aprons. The FAA share ranges from 50 to 100 percent depending upon the particuiar project. As the need for a project is identified, the airport authority prepares a project plan and applies to the FAA for approval and funding. Once granted, the airport authority proceeds with the project, which is usually contracted through competitive bids. As the community requirements for aviation services and facilities change so does the aynamic airport planning and development process. The FAA recommends updating of the master plan at one-year intervals if indicated by changes in aeronautical demand.

Maintenance and upkeep of the airport involves many functions common to industrial, highway, and agricultural facilities. The unique characteristic of an airport is the requirement for close survellance and action on items which may affect safety in flight operations; approach paths, runways, and taxiways must be kept free of all obstructions and foreign objects wnich may be a hazard to approaching and landing aircraft cr cause costly damage to propellers and/or engınes. An object ingested by a jet engine from a ramp may result in thousands of dollars in damage.

Small tirs size in relation to weıght of aircraft dictates runway' and taxiway bearing capacities in excess of comparable paved highway surfaces for many general aviation airports. The need is dictated for a smooth, wellmaintaıned surface for all aircraft operating areas Grass areas of the airport which are used by aircraft for runivays, taxiways, and parking must be kept mowed to a low height in order !o reduce friction and eliminate unseen hazards. Some airports have turned unused areas between and adjacent to runways into crops

10 Airport Master Plan. Federal Aviation Administration, AC 150'5070-6. United States Government Printing Office. February. 1971

"Federal Aviation Regulations Part 139. Certification and Operations Land Airports Serving CAB Certificated Scheduled Carriers Operating Large Aircraft Federal Aviaticn Administration. US G P O. Cecember 1974 which provide limited revenue on unused land. A common practice is a contract with a local farmer to mow all the grass areas in exchange for use of certain areas for farming.

Maintenance of lights and navigational dids may be shared with FAA personnel for those facilities which are installed by the FAA and/or used as approach navigaiional aids. The maintenance of leased facilities is determined by the terms of the lease. Snow renioval is a major effort for airports in the northern climates. Since salt cannot be used on runways and taxiways due to its corrosive effect on aluminum, surfaces must be kept free of snow to avoid accumulation and packing. Because snow and ice account for more closed ailports in certain regions than fog, the airport must be equipped to ceal with therr.

The exteni of an airport authority's involvement in operations varies from nil to full responsibility as both airport owner and operator. Most airports restrict their involvement in fuel roles on the premise that it is more practical to consolidate fuel sales through one agency than for each operator on the airport to attempt to negotiate a fuel contract on a lower volume potential.

Airports with certificated air carrier service must be certificated as airports under FAR Part 139. " This reyulation spells out requirements for such airports in the area of safety and operatıons as related to air carriers. While not applicable to general aviation airports, certain provisıons of this regulation may be adopted on a voluntary basis. An example would be the provision for fire/crash rescue capability on the arrport.

\section{General Aviation Operators}

General Aviation Services on an airport are generally provided by one or more FBOs. The FBO operates under a lease agreement with the airport authority under which the airport provides facilities and/or land with the authority to provide services to general aviation users. These services may include any one or a combination of the following, listed in general order of importance and/or frequency:

(1) Aircraft sturage and parking.

(2) Fuel sales to locally based and itinerant general aviation aircraft.

(3) A.ircraft, engine, and accrssory maintenance and repair.

(4) Flight and ground instruction

(5) Aircraft rental 
(6) Air taxi, charter service.

(7) Aircraft sales-new and/or used.

(8) Aircraft parts and accessory sales.

(9) Other specialized services such as air ambulance, aerial photography, banner towing, aerial application (crop dusting).

The extent and quality of services provided is determined by the size and activity level of the airport. the type of users and aircraft, the number of operators, and the airport's compliance standards and lease terms.

Small airports with a low level of activity and few based aircraft (12 or less) might offer only aircraft storage and parking since this service requires no persoinel on duty. Twelve to 25 basec aircraft is generally considered a minimum number to support an FBO offering the first three services listed above. As the number of based aircraft and related aviation activity increases, additional services can be justified. As a general rule, only the medium to large activity airports offer the full range c! general aviation services

An important decision for the airport manager is one of determining if, and when, a second or additional general aviation operator is justified. The Federal Aviation Act of 1958 prohibits the granting of exclusive rights on a federally funded airport. As a result. the airport authority cannot arbitrarily limit the number of operators on an airport. The airport authority can establish reasonable compliance standards for any new operation.

The development of the compliance standards must be done in recognition of the nonexclusive rights provision of the Federal Aviation Acl; of the need to maintain a level of quality and safety ir, new operations equal to or better than existing operations: and, the need to provide reasonable protection tor the investment of an es. sting operator or operators. The latter can only be accomplished by the development of minimum levels of activity necessary to justify additional services or operations. When these levels have been passed, a new operation zan be established on the airport provided that operation meets the compliance standards.

The compliance standards identity the minimum standards for facilities and services to be provided and serve as the framework linder which the lease is developed. The compliance standards and lease terıns vary widely from airport to airport. but a few prov!sions generally are recognized as desirable:

(1) A lease term of at least 10 years and

\section{N76 11998}

preferably $\mathbf{2 0}$ years or longer with renewal options.

(2) The -right to provide desired services and conduct operations in accordance with reasonable standards.

(3) The right to construct facilities for such operations.

(4) Reasonabie rental charges based upon the land and facilities provided by the airport or the gross sales volume or a combination thereof. A typical schedule of lease charges by the airport might be as follows:

2 percent of gross sales excluding fuel and aircraft sales

2 cents- 4 cents per gallon of fuel sold

6 cents-12 cents per square foot of unimproved land

15 cents-20 cents per square toot of improved land (paved aprons, ramps, etc.)

$\$ 3.00-\$ 7.00$ per square foot of hangar and office space (if such facilities are provifed by airports)

Tha lease is a compromise between the interests of the airport authority which desires to obtain maximum revenue in exchange for the land and facilities used. and the FBO who desires the lowest cost lease in order to maximize his profit and return on investment. Since a major portion of many lease charges is fixed and unrelated to business volume, the operator often blames the lease as the cause of his financial failure.

There are frequent instances. unfortunately. of lease agreements developed by an airport without consideration to the limited profit potential and low return on investment. characteristic of most general aviation operations. There are cases on record of airports which have experienced numerous failures of general aviation operators where sufficient activity existed to support an operator. The fundamental cause was ofi . 1 found to be the lease which. if modified to terms more favorable to the operator would make possible a sound, $f$ nancially healthy operation and more revenue for the airport in the long run.

\section{AIRWAYS AND AVIONICS}

\section{Introduction}

This section will deal primarıly with both 
aınvays and avionics as components of the general aviation system. The airways system will be defined to include the en route traffic ianes in the airspace, the airport terminal area. i. - ins equipment installed in the vehicle enabling it tu make maximum safe use of those airways. This discu, on will be concerned with the foliowing ge: eral topic: ar traffic control, navigational aids, and itie operation of these components within the national airways system.

Use of the national airways system has in. creased to the point where the systeri is badly congested at tre hub airports. Increasing congestion along the airways results in an increas. ing probability of midair collisions. The capacity of the airways system must be expanded to accommojate growth in aviation fleets. Vory littie land is avallable near the major propulation centers for the construction of new airports or for the addition of capacity to existing facilities Airspace around these population centers is used to capacity during much of the tıme: a situation presenting safety hazards and unacceptable delays in both the landing arid departure of aircraft. The avaltable navigation ards use most of the available time and spectrum allocated to them. Any improvement in system performance wil! have to be mainly in the capability and sophistication of these aids rather than in an increase of their number. This will permit optimum metering and spacing in the airways system.

General aviation has a problem related to. yet independent from. the air carriers which cause most of the congestion in airways near the major population centers The problem results from high costs involved in equipping ger.eral aviation aircraft with the required navigation and communication equipment necessary for using the airways Many general operations of sucn lighter aircraft are in the vicinity of relatively lightly loaded general aviatıon airports: however. a certain percentage of general aviation activity takes place in the vicinity of the hub airports

Safe and reliable operation requ'res that a flight can be initiated with a reasonable probability of completion. between any two points desired barring poor weather and/or mechanıcal or electrical malfunction

One severe handicap imposed on most general aviation aircraft is their low speed Most air carrier and military activities involve high speed jet aircraft. whille non-jet general aviation aircraft necessarily operate at much lower speeds. Both exist in the immediate air- port environment and in the en route phase of the flight. The great disparity of speed between most general aviation aircraft and the other two segments of aviation activitu will always pose a hazardous condition withir, the airways system. As a result, there will always be pressure on the general aviation community to vacate the airways system, particularly in congested areas The problem then becomes that of upgrading the ability of general aviation vehicles to oparate in the national aırways system with safety and reliabılity. Since only small breakthroughs seem possible in low speed aerodynamics, most of this upgrading musi be realized through beiter electronic systems and improved pilot ability. Possible future directions in this area will be discussed. following descripilons of the Air Traffic Control System and the navigational aids presently in use.

\section{Air Traffic Control}

Air traffic control consists of both ground. based electronic navigational and communicatıons facilities. Grcurid-based facitities consist mainly of high precision radar and visual dispiays. while communications facilities provide for both automatic transmission of information and oral communication among air traffic controllers and between them and operators of the aircraft. Much of the automatic transmission of information is provided by the transponder and the encoding altimeteis located on the aircraft.

The air traffic control system is the most critical component of the entire natıonal airways system and it is approaching saturation This is probably the principal factor which will determıne design and location of major airports in the future. General aviation is affected by this saturation because unless there is alleviation of traific. general aviatıon may be excluded from the major air rarrier airports

\section{En Route System}

The air traffic control problem is divided into two major areas. The first is the en route system. comprising the airways between the major airports. The second is the area surroundıng the major (sınplified in this case to air carrier airports) terminals. The en route system is governed by two sets of flight rules. VFR (visual flight rules) and IFR (Instrument flight rules) In general. VFR means that weather conditioi's are good enough for the pilot to operate the aircraft in a safe and efficient manner by visual reference to the ground. Under VFR conditions. there is essentially no en route air traffic control except where speciílcally prescribed; aurcraft fly according to "rules of the road" usıng designated alitudes for certain 
headings and are responsible for maintaining their own separation.

Positive traffic control is always exercised In IFR conditions and in designated cuntrol areas. Essentially, these rules require the sontrolled assignment of specific altitudes and routes and minimum separation of aircraft flying in the same direction as shown in Figure 1-7. Controlled airspace extends upwaro fiom 700 feet Above Ground Level (AGL) in almost all contıguous areas immediately surrounding an airport. In order to achieve greater airspace utilization and safety the area above 14.500 feet Mean Sea Level (MSL) has been designated as a Continental Control Area. Aircraft flying above this altitude are hich performance aircraft. In positive control areas above 18.000 fee: MSL. all aircraft are controlled by continuous surveillance and are required to be equipped with transponders and communication equipment. Termınal Control Areas, such as the one shown in Figure 1-8. are being designated arour.d major hub areas to impose special operating requirements on al. flights in this aırspace. Additionally. special purpose areas are designáted as areas in which flight operation is elther orohibited or restricted Examples of such rest.ıctions are in weapons ranges. identification zones and student pilot trainıng areas.

The present en route system of arrways is governed by the location of VORTAC (very high frequency omni-range radio transmitter with distance measuring equipment) navigation transmitters, and comprises a system of aırways called Victor Airways. These are designated with even numbers when they run in east and west directions. and with odd numbers when they run north and south. In addition to the radio navigational aıds in the aırcraft, there exists an air surveillance radar This is a radar with a range of 200 miles which is installed in certain control centers around the country and used for trackıng aircraft along an airway

The United States is divided into control areas covering all the en route airways, so that each control center can know the position of all en route aircraft with:ın its area These longrange center radars give the controllers accurate information on azımuth and distance position of each aircraft along the airway and thus reduce the need for communication between pilot and controller. They also reduce considerably the required distance between

"Compiled trom National Aviation Systoms pian. Ten Yea Plan 1973-1982. Department of Transportation rederal Aviation Ad ministration. March 1973 aircraft, thus increasing the capacity of existing airways. There are presently 27 Air Route Traffic Control Centers (ARTCCs) which include 91 different radar installations. The following 20 centers cover the airspace of the contiguous 48 states: Albuquerque, Atlanta, Boston, Chicago, Cleveland, Denver. Fort Worth, Houston, Indianapolis, Jacksonville, Kansas City, Los Angeles, Memphis, Miami, Minneapolis, New York, Oakland, Salt Lake City, Seattle, and Washington.

The capability of the entire ATC system will be upgraded further by requiring all aircraft using the system to be equipped with a Discrete Address Beacon System (DASS). In 1975. all aircraft but not all of the ground-based ATC system were required to be so equipped. When implementation is complete. all aircraft using the ATC system will be equippeci with transponders which will furnish identification. as well as altitude information. This automatic information transfer will facilitate the ATC mission, and substantially reduce the amount of communication required between ground controllers and pilots.

\section{Terminal Area Control}

The next component in the control system is the airport traffic control tower. There are presently 327 control towers in the Untied States located mostly at air carrier terminals. These control towers provide traffic control for aircraft located within a 15 -mile radius of the airport. A zone of control involving tw'o airports is shown in Figure 1-8. Most major control towers have approach control facilities and have air surveillance radar (ASR) which guide ai $\sim$ :aft to the airport from a number of specific pusitions called fixes. Those are approximately 25 miles away from the airport and denote the point at which the aircraft is transferred to the control tower from the AR, $C \mathrm{C}$. At these fixes the aircraft are usually "sta.ked" in a holding pattern. The airport controller is responsible for orderly regulation of aircraft landing and takeoff operations on the airport itself, and for positioning aircraft within its control radius.

\section{Navigational Aids (NAVAIDS)}

Navagational aids may be classified according to several criteria. such as sensing method. frequency. function, location, method of use and others. Since none of these categories is defınitive. the various Items will be discussed separately. Table I-V summarizes the radio aids. ${ }^{32}$

\section{Direction Finders}

The first three items of Table I-V are basically radio direction finders. The Automatic 
VFR ALTITUDES/FLIGHT LEVELS-CONTROLLED AND UNCONTROLLED AIRSPACE

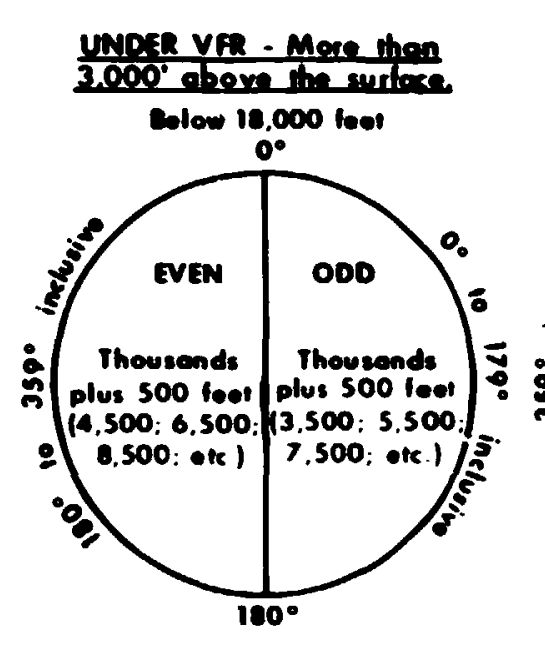

\section{COURSES ARE maGNenC}

Above 18,000 loet MSt to

flight Level 290 linclusive)
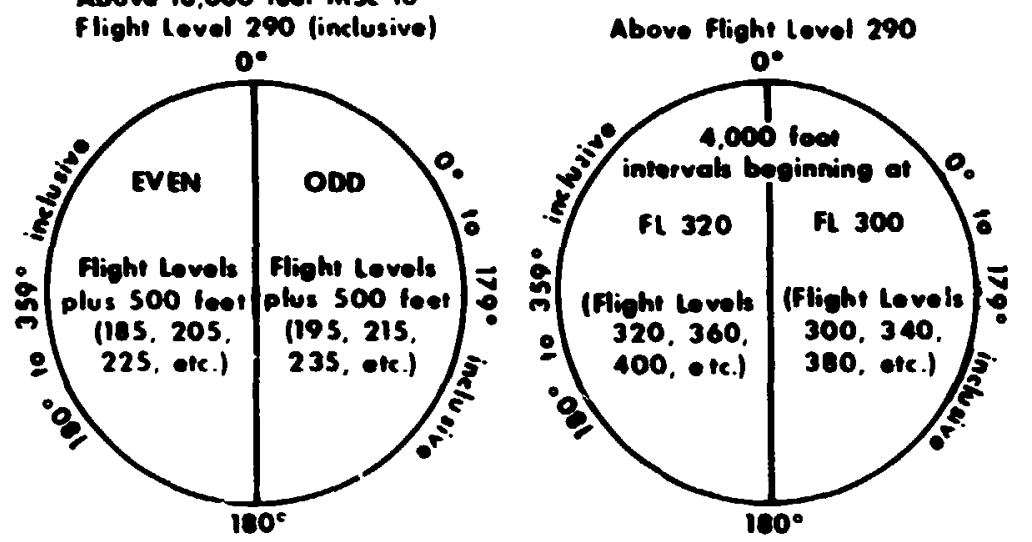

IFR ALTITUDES/FLIGHT LEVELS-UNCONTROLLED AIRSPACE

Ourside Controlled Airspoce
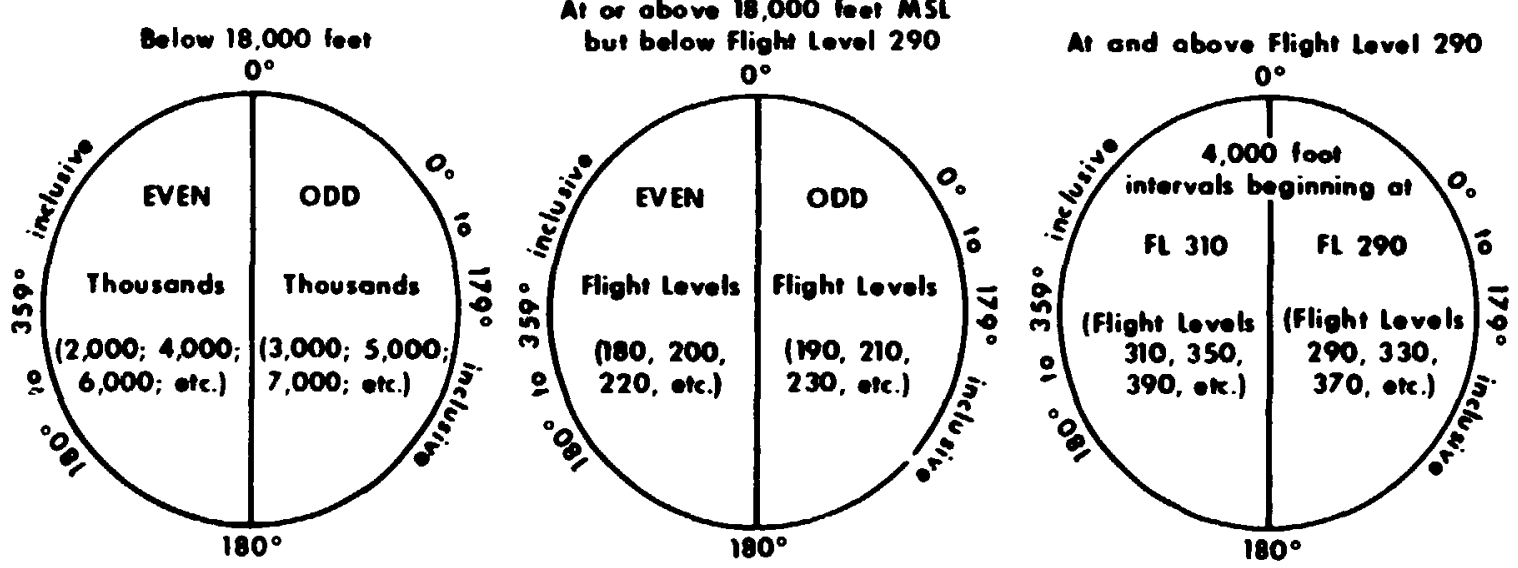

Sou rce: Airman's Information Manual, Part 1, May 1975, pp.1-23, 1-25. 


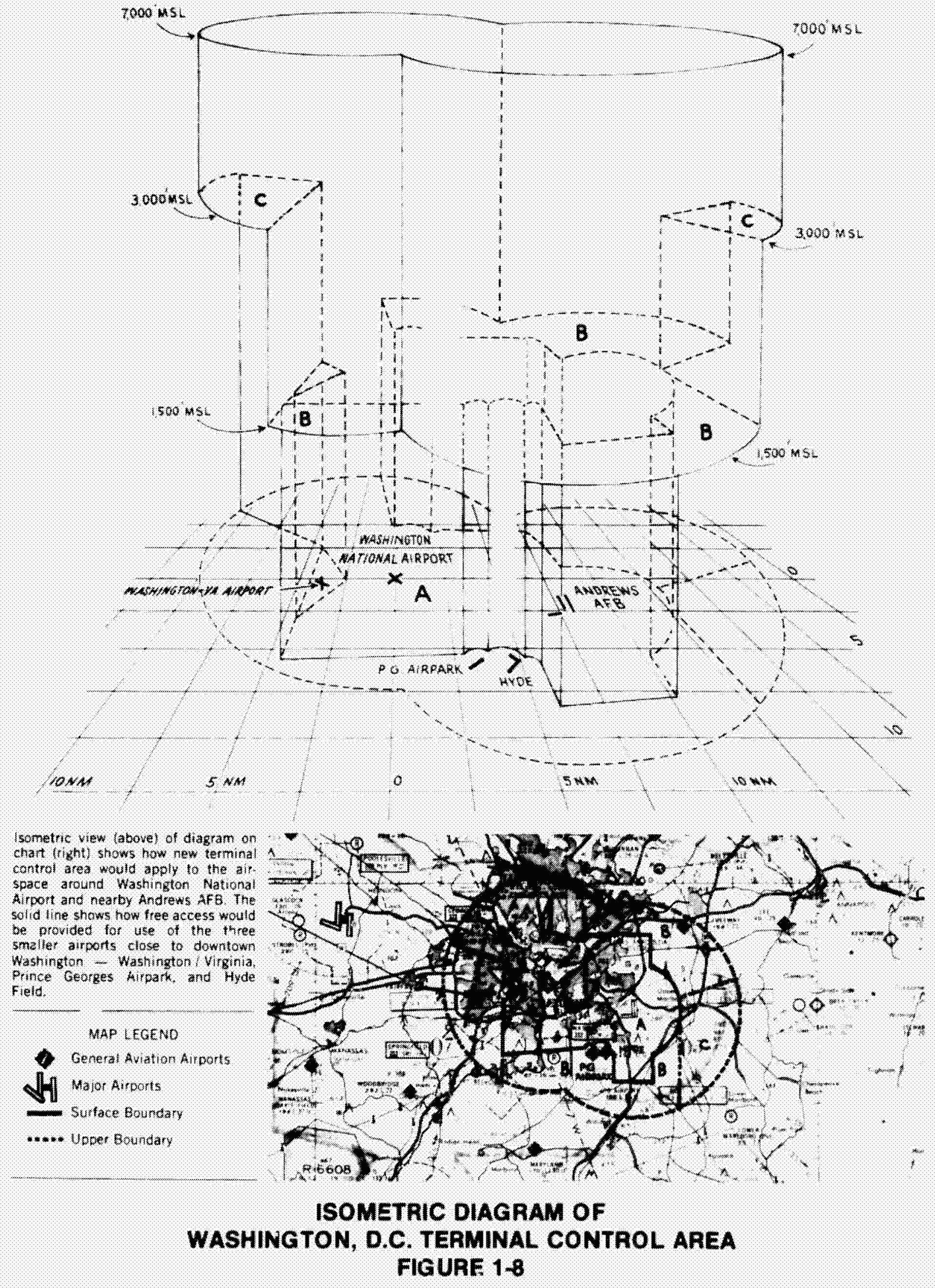




\begin{tabular}{|c|c|c|c|c|c|}
\hline \multicolumn{6}{|c|}{ TABLE I-V } \\
\hline \multicolumn{6}{|c|}{ SUMMAFY OF RADIO NAVIGATIONAL AIDS } \\
\hline \multicolumn{2}{|c|}{ Navigational Aid } & Function & Unit Cost s & System Accuracy & Rango \\
\hline \multicolumn{2}{|c|}{$\begin{array}{l}\text { Automatic Di- } \\
\text { rection Finder (ADF) }\end{array}$} & $\begin{array}{l}\text { Determines beaning to } \\
\text { LF beacon stations } \\
\text { and LF radio stations }\end{array}$ & $\$, 000$ & $\pm 2(20)$ & $50-200 \mathrm{~nm}$ \\
\hline \multicolumn{2}{|c|}{ VHF Omnurange (VOR) } & $\begin{array}{l}\text { Determines magnetic } \\
\text { bearng to VoR facility }\end{array}$ & 4.000 & $\pm 3^{\circ}(20)$ & Line of sight \\
\hline \multicolumn{2}{|c|}{$\begin{array}{l}\text { Dis nce Measurng } \\
\text { Equiprent (DME) }\end{array}$} & $\begin{array}{l}\text { Measures stant range } \\
\text { to DME facility }\end{array}$ & 2.500 & $\begin{array}{l}\text { t } 0.2 \mathrm{~nm} \text { or } 1 \% \\
\text { of range }\end{array}$ & $0.192 \mathrm{~nm}$ \\
\hline \multicolumn{2}{|l|}{ Loran-c: } & $\begin{array}{l}\text { Determnes aircraft } \\
\text { position (hyperbolic) }\end{array}$ & 30,000 & +1500 f1 (20) & Night $1,000 \mathrm{~nm}$ \\
\hline \multicolumn{2}{|l|}{ Onega } & $\begin{array}{l}\text { Determines aircraft } \\
\text { position (nyperbolic) }\end{array}$ & 50.000 & $\begin{array}{l} \pm 2 \mathrm{~nm}(2 \sigma) \text { night } \\
\pm 1 \mathrm{~nm}(2 \sigma) \text { day }\end{array}$ & $6.000 \mathrm{~nm}$ \\
\hline \multicolumn{2}{|c|}{ Doppler Navigator } & $\begin{array}{l}\text { Deternines vector } \\
\text { distance traveled }\end{array}$ & 40.000 & $\begin{array}{l} \pm 0.5 \%(20) \text { of dis: } \\
\text { tance traveled or } 1 \mathrm{~nm}\end{array}$ & global \\
\hline \multicolumn{2}{|c|}{ ATC transponder } & $\begin{array}{l}\text { Provides identification } \\
\text { and altude reporting } \\
\text { to ATC controllers }\end{array}$ & 2.200 & & $200 \mathrm{~nm}$ \\
\hline \multicolumn{2}{|c|}{$\begin{array}{l}\text { Instrument landing } \\
\text { system (glidestope } \\
\text { and locaizer) (ILS) }\end{array}$} & $\begin{array}{l}\text { Provides directional } \\
\text { information for poor } \\
\text { weather landing }\end{array}$ & 6.000 & $\begin{array}{l}\text { Not defined, pilot } \\
\text { llies oown beam } \\
\text { center to runway }\end{array}$ & $20 \mathrm{~nm}$ \\
\hline \multicolumn{2}{|c|}{ Marker Beacon } & $\begin{array}{l}\text { Indicates distance to } \\
\text { end of runway }\end{array}$ & +700 & & \\
\hline \multicolumn{2}{|c|}{$\begin{array}{l}\text { Advanced Instrument } \\
\text { Landing System (AILS) } \\
\text { (MLS) }\end{array}$} & $\begin{array}{l}\text { Provides directional and } \\
\text { distance information lor } \\
\text { all-weather landing }\end{array}$ & N/A & $\begin{array}{l}A Z= \pm 0.05^{\circ} \\
E L= \pm 0.03^{\circ} \\
D M E= \pm 100 \text { or } 1 \%\end{array}$ & $20 \mathrm{~nm}$ \\
\hline \multicolumn{2}{|l|}{ inertial } & $\begin{array}{l}\text { Determines vector } \\
\text { distance traveled }\end{array}$ & 90000 & $\begin{array}{l} \pm 0.05 \%(20) \text { of dis- } \\
\text { tance traveled or } 1 \mathrm{~nm}\end{array}$ & global \\
\hline \multicolumn{2}{|c|}{$\begin{array}{l}\text { Global Positioning } \\
\text { System }\end{array}$} & Satellite-based system & 16,000 & 10 's of feet & global \\
\hline \multicolumn{6}{|c|}{$\begin{array}{l}\text { Sources Aviation Advisory Commission. The Long Range Needs of Aviation: Technical Annex to the Report of the Aviation Advisory } \\
\text { Commission. Volume II. Washington, D.C, Aviation Advisory Commission. January 1973; Business and Commercial Aviation. } \\
\text { Zitt-Davis Publishing Company, April 1975, pp 79-150, and Shriever, B.A, and William W. Seitert, Air Transportation } 1975 \text { and } \\
\text { Beyond: A Systems Approach. Cambridge: MIT Press, } 1968 \text {. }\end{array}$} \\
\hline
\end{tabular}


Direction Finder (ADF) operates at low frequency in the broadcast band of AM radio It is used in conjunction with either a radio beacon at the airport, or a standard broadcasting station. In general, the pilot must have a certain amount of skill to use the device, but no computation is required. The VOR is the mainstay of the national en route airways system. It operates at the VHF portion of the spectrum. which is in the FMtelevision range. As a result, its range is limited to line-ot-sight, just as FM radio and television are Position determination is made by taking bearing on two stations, with the intersection of the lines giving the position. Distance Measuring Equipment (DME) also operates in the VHF range. It is much more accurate than VOR, and gives a much closer determination of position than two VOR stations Sometimes VOR and DME signals are found at the same site thus allowing simultaneous bearing sad distance measurment. Such a system is called VORTAC. which is an abbreviation of VOROME combined with TACAN, the military VORIOME system.

Note that this differs from the previously described AOF because Usually two or more VORTAC stations are combined to find posion. ADF however. is primarily used not to determine a position, but $10 \mathrm{fl}$, towards a point only. It should also be noted that the determination of position from either two angular bearings, two rrtersecting distances, or the dislance and ange tom a station is fairly simple mathematically. This is the primary reason that the VORTAC system is the primary element in the national airways system.

An uncreasing number of arcratt in the general aviation category are able and need to engage in overwater operations. The Loran-C and Omega systems operate in VLF frequency range producing a wave of around 100 . kllohertz which primarily propagates as an earth wave. thus giving a tremendous range. Navigation is accomplished by solving for the intersections of the tamiles of circles surrounding the transmiting stations. These intersections are defined by hyperbolas, hence low Irequency systems are lrequently termed hyper bolic Since there are a great number of hype. bolas to be solved difficult computations are usually needed. This is reflected by the relatvely high prices shown for these systems in Table I-V Loran-C is the primary method of navigation in the North Atlantic corridor, and Omega provides coverage for much of the rest of the world through a system of 8 Omega sta tions. This system is mantained and operated by the miltary, although it can be used by civl aircratt Due to the strategic vulnerability of the transmitters of the Omega system. other systems have beer designed which are either satellite-based or sell-contained, as in the airborne doppler and inertial systems.

Because of the costs involved, neither doppler nor inertial systems are likely to be used on a large scale in the immediate future for general aviation aircraft. However. systems being developed will render inertial systems well within the range of the more sophisticated business and corporate aircraft within a few years. The doppler navigator utilizes a doppler radar, which measures the relative velocity between the aircraft and the ground. Inertial systems provide a gyroscopically or electronically stabilized platform, which is always oriented in a known direction Accelerometers, to measure the acceleration of the vehicle along the roll. pitch and yaw axes of the aircraft are mounted on this plattorm.

\section{Satellite System}

A system which holds future promise for general aviation aircraft is the global positioning system. This is a satellite-based system which would place a sufficient nunber of satellites in the aif 10 provide at least three bearings at any one time. The equipment required on the atcraft would be a receiver (UHF) decoder and clock. This would enable the using aircraft to determine position very closely. At present, the Navy has such satellites in use for submarine navigation systems. The tremendous imvestment required to place the required number of satellites in orbit can be expected to delay implementation of the sustem.

\section{Other Navigational Aids}

The ATC transponder, which provites coded intormation to the ATC controller in the hub airports. will be required on all aicratt using these airports in 1975 in conjunction with these transponders, will be required the encoding altimeters, which will automatically transmit altitude intormation to the ATC control center With these devices, each equipped aircratt will be automatically identified, its position shown on the radat screen, and its altitude displayed

Also considered a navigational aid would be the communications transceiver and the ILS system Obviously the airport the lower and the flight service stations all must be contacted by radio Generally, this recever will operale in the VHF navigation systems An ILS system wil be required in order to land at an air cartier ter. minal This system consists of wo radio transmitters located at the alpont the localiet. 


\section{TABLE L-VI \\ SUMMARY OF VISUAL NAVIGATION AIDS}

\section{Navigational Aid \\ Visual Approach}

Slope Indicator (VASI)

Runway End Identification Lights (REL)

Approach Lighting System

Runway Lights
Function

Provide directional and glide slope information visually for landing.

Provide positive identification of runway threshold under all weather conditions

Used with ILS to aid in locating runway

Lighting for runway proper
Range

$5 \mathrm{~nm}$ located at the end of the runway. and the glide slope transmitter, located at its side. The receiver for these signals is usually displayed in conjunction with the VOR information. This enables the pilot flyng IFR to find the airport and subsequently to bring the aircraft down close enough to the runway to complete a successful landing visually

\section{Visual Navigational Aids}

Under any llight conditions, VFR or IFR certain visual navigation aids are often provided. These are as summarized in Table I-VI. The visual approach stope indicator (VASI) is primanly used to provide the same basic visual intormation as that provided electronically by the ILS system It is primarily useful for approaches over water and those requiring precise control over glide slope for purposes of noise abatement.

Since the cost of all of the navigational aids discussed above is high. it is instructive to consider what constitutes the system needed to fly the national airways system and to land at the air carrier airports. If reference is made to Table I.V an ADF would be desirable, a VOR, a trans. ponder, possibly an encoding altimeter, an ILS receiver, together with the necessary display. and a communications transcelver. The total cost of such a minimal system would be approximately $\$ 16,400$. This would provide the blot full capability of IFR flights on the national airways system, and enable the arroraft to inter. lace with all airports in the continental United States.

If a corporate or business airoraft is con- sidered additional equipment would be desirable, enabling the pilot of the aircraft to navigaie with greater precision, to decrease the workload under IFR conditions, and to fly a less constrained route than the vector headings of the national airways system.

Two items of equipment which greatly increase the safet; and reliability of aircraft are (1) autopilots and (2) area navigavion An autopilot, which may of may not include a sophisticated flight director, accepts commands on flight attitude and direction. and pro. vides signals to the control surtaces of the aircraft Such control can be obteined in response either to a simple setting of altitude and direction by the plot. or to a preplanned flight which is set into the flight director or furnished from external sources. The autopilotflight director greatly relieves the routine tasks required of the pllot, enabling him to concentrate on non-routne decisions

\section{Computerized Area Navigation}

One method for feeding external control to the flight director might be through an area navigation system. An area navigation system. in its simplest version. consists of a simple computer which takes the VOR bearings, and creates a computer VOR station, toward which the plane is commanded to Ily Thus, in accordance with certain preplanned flight plans, the atrcraft is enabled to fly any selected route, including, for iristance, the great circle route. It is planned that at a future date, these routes. known as area navigation (RNAV) routes. will be standard in the national airways system. 
Since this ability to fly more complex routes is inherent in the less sophisticated one-way point system, additional memory in the computer can fumish a great deal of additional capability.

The average RNAV system presently applicable for general aviation aircraft has the capability of storing about 10 way points la geographical location along the flight route usually designated with respect to VORTAC). This means that up to eight course changes may ve made automatically. These systems provide automatic procedures for standard turns, holiting patterns, and climbs. The next step in sophistication is the expansion of the system to include standard instrument departures (SID) and standard termina! arrival (STAP) routines. These routines will include all information required for the pilot to land successfully at the airport, including location. traffic pattern, holding patterns, and obstructions.

Area navigation systems can be made avallable to a general aviation atroraft for as lit tle as $\$ 10,000$. An autopilot-flight director might cost an additional $\$ 20,000$ With this equip. ment. the general aviation aircraft is truly able 10 adapt to a wide variety of expected environments. Safety is foremost among the benefits of these two pieces of equipment. The autopilot relieves the pilot of much of the routine duties of flying the aircraft Area navigation will become the primary method of collision avoid- ance. The ability of the individual aircratt to know its own position, and to be able to communicate that position to the ATC system quickly and accurately, relieves the controller of some of his responsibility as well. As routine flying and station keeping are minimized, the pilots and controllers are able to deal with emergencies much more effectively. Ex. perience with collision avoidance systems has led to the conclusion that the problem can be solved only by installing sophisticated equip. ment in eact, aircraft using the national airspace.

One additional item of useful equipment which is being installed on general aviation aircraft is weather radar It consists of a transmitter and recelver, an antenna and a radar scope. In its simplest version it merely presents information on weather ahead of the aircratt to enable the pilot to avoid threatening storm systems. This is an excellent safety feature, and can be acquired presently for less than $\$ 15.000$. Furthermore, the screen can also be used for display of other material, such as numerical data, map data, and waypoint listings In lact, some of the area navigation systems in addition to cigital display of data. provide such cathode ray tube outputs for plot use.

In discussing such navigational ards one must bear in mind that the profusion of instruments facing the pilot makes the task of learn.

\section{TABLE I-VII \\ COMMISSIONED FAA FACILITIES}

Air route traffic control centers

Air route survellance radar

Airport towers

Combined station/towers

Airport surveillance rada*

Precision approach radar

Flight service stations

Flight service stations, unmanned

International flight service stations

Low medium frequency (LMFI ranges

VORNORTAC

Instrument Landing systems (LS, MLS)

Non-directional beacon (NDB)

Airports

source
1972

27

91

308

42

126

0

324

15

7

24

919

395

289

12.230
1982

25

121

447

0

221

0

107

2.230

7

0

1.016

1.052

311 12.700

ministration. March 1973 p 37 
Ing to operate the aircraft under IFR conditions extremely complex. Certainly, il such improvements are to be added to great numbers of the atrcraft fleet, they must be simplified, the cost brought down, and the training time for pilots decreased

\section{The Future}

Future developments in the airways system may be divided into two categories. The first is the programmed improvements which are scheduled to take place during the next 10-year period. Since the presert airways system is operating at near capacity levels, implementation of the proposed changes is not dependent upon a high rate of future growth in airways usage. The second category consists of probable future trends The airways systems, ndviga. tional aids and communications, and opera tional methods will depend upon future economic and demographic trends, as well as on technological developments

In order to accommodate the expected growth the following FAA facilties have been commissioned for operation by 1982 . These are shown in Table I. VII

The provision for the en route contro system cals for completion of the sem: automation of en route air traffic control faclities, including conflict prediction and resolution (antlcollision system), electronic volce switching, fallsafe features improved man-machine intertace, and revised ATC procedures to take asvantage of the upgraded capablities of the vehicles using the arways $A$ central flow control tacility will be completed to prepare forecasts of air traffic volume and potential congestion powts. When such points are detected the bottlenecks will be eliminated by rerouting andor regulating atr traffic flow Long range radar systems will be expanded to provide closer en route control To be developed and installed is the discrete address beacon system (DABS) to improve ATC sur. veillance and to provide an automatic air-to ground data link for use in the future ATC system. During this time period, improvements are anticipated in reliability, accuracy, and capacity of the existing radar and radar beacon data acquistion systems.

Terminal control wil be improved by pro viding basic automated equpnent for all radar equipped terminal factities, and automatic metering and spacing of approaches in medum and high density terminals. Radar service wil be provided by additional towers, and airport lower control services will be extended to addi- tional air carrier and general aviation airports. Airport surface quidance and traftic detection and control aids will be improved to increase the ground handling capabilities of airports. Flight service stations will be reconfigured, modernized, and automated.

Navigation changes will be made by upgrading the coverage and accuracy of VHF omnirange TACAN (VORTAC) en route navigation system components. The use of long-range navigation systems, such as Omega, will be im plemented. The airways themselves wil! change from the present system of straight-line "Victor" routes to area navigation routes, shortening distances both en route and terminal The precise knowledge of position permits the operator of the vehicle to modity his llight plan permitting the most efficient use of fuel both by the selection or flight protile and of optimum ar: rival time at the terminal, thus elminating some of the holding required at present.

The number of landing aids will be greatly increased by installation of conventional land. ing aids on a great number of additional runways in the lower and medium density airports. and installing mproved ILS at high density air. ports thus raising their capacity This improved ILS will probably be the microwave landing system (MLS) which is less susceptible than the conventional system to interterence, siting problems and approach path limitations. These advantages mean that very litle interterence from artifacts located on or near the airport will be encountered because of multipath propagation Also, approaches other than straight line will be possible yiolding signiticant increases in airways capacily

While the number of airports is expected to remain approximately constant during the time period under consideration, facilities are to be increased. In particular. the number of automatic and non-automatic flight service stations will rise, faciltating formulation of llight plans by users of the airways system here will also be an increase in the number of lLS systems installed dunng this ime period Present high density airports will be upgraded. probably with microwave landing systems some additional runways at major and air car. ner airports will be equipped with instrument anding capablities, and many other aiports will be eoulpped with instrument landing systems. This means that many more airports perhaps as many as wice the present number will be equipped lor fuII IFR operation This should prove to be a substantia beneflt to general awation operations 
General aviation aircratt will be required to contorm to the requirements of the upgraded national airways system, particularty in the more cungested airspace surrounding airports. The changes described above represent only the systems installed, operated, and sited by the FAA. These will be located on the ground All navigation and communications systems required of the aircratt to fly the national airways system will be an expense borne by owners and operators of the aircraft

The projections above can certainly change within the near luture, and may be altered significantly by energy requirements. national priorities, and other foreseeable factors. While upgrading of the airways system and the systems contained in the aircraft themselves will probably proceed on schedule, there are two constraints on development of the airways system which preclude most radical departures from present plans. First. there is limited airspace which cannot be changed at this time. Second, no system for siting airports has ever been followed. They have been sited primarily as a result of economic and poifical factors, rather than in an optimum manner as considered from the system point of view There is only limited space in which to make a more reasonable distribution of hub carrier airports. Furthermore, there is a limited spectrum in wituch to provide the bandwidth necessary for upgrading the communications system. To improve communications over the present state. of the-art requires the tradeoff between band. width of the communications channel and the reliability of the message transmission. Communications channels allocated to these airways activities are unlikely to increase radically in either numbers or quality in the foreseeable future Improvements will primarily occur in the area of hardware and in the automation of the system, such as automatic tuning transmission, etc Advanced modulation technques furnish some possibilities 1 . .9. digital transmis. sion

Within the same framework of navigational aids and communications equipment, the more sophisticated aircratt will be provided facilities enabling them to meter their arrval and depar. ture times to reduce lost time and energy assoclated with the oresent practice of establishing holding patterns near the major aurports

\section{Significant changes can be foreseen in ap-}

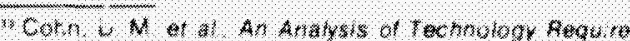

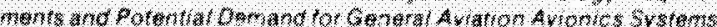

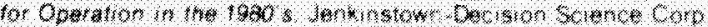
une 1974 plications of microeletronic techniques to in. strumentation, radio recelver controls, and digital computer design. The present cockpit of an aircraft lully equipped to utlize the airways system is complex and confusing, even to a skilled pilot. The problems of monitoring arrcraft status. determining airport location, and tuning communications equipment to proper frequencies places a burdensome load on the pilot reducing his ability to respond to emergencies. One key remedy to this is the digital computer and another the microwave landing system currently under development. White the available microelectronic technology (intergrated circuits) permits inexpensive compact and capable computation facilities to be placed within the atrcraft, cost of a complete MLS may be prcsibitive for general aviation aircraft.

Nevertheless, such equipment might th: clude the flight director/autoplot, automatic turing of the communication equipment, posi. tional computation Sor VORTAC, area naviga tion, and computation for use of VLF navigation aids, with provisio: or use of satellite data from the future global positioning system $*$

Future use of such computational avionics in volume could radically lower their unit price What is required is an analysis of requirements for such an integrated avionics system lot general aviation aircralt, and a design philosophy which will permit efficient use of such a system by the avereze pilot Figure 1.9 gives a possible configuration for such a system, some form of which probably can be implemented at a reasonable cost Although the navigation and communications equipment would be similar to that now existing in many general aviation aircraft. the average private aircraft owner nrobably could not aftord such expensive equipment, however, private flying would continue to exist much as it does today with minimal impact on the primary ainways system congestion. Also shown in Figure 1.9 are op. tional items.

All displays would be integrated into a simplified display array thus easing the task of interpreting the data $A$ reasonable assumption is that an integrated approach to avionics system design and its interface with the pilot would promote both satety and more efficient usage of the aircratt

In summary. general aviation aircratt of the future probably will remain similar aero. dynamically to those presently in use and WII possess an increased capablity to lly the total national arways system Ground based 
NAVIGATION SYSTEM DIAGRANI

CENT KAL PROCESSOR

Area Navigation

Store Flight Plan Data

rune Communications Receivers

Air data

System Monitoring

INPUTS

Air data

Monitoring instruments

VOR/DME

ADF

VLF Systems

Flight Data

ILS/LOC

Radar

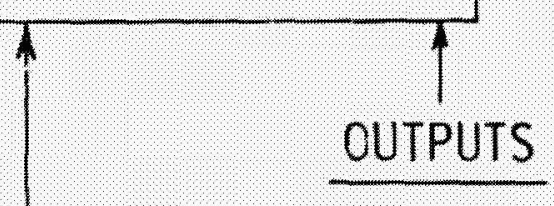

Flight Director /Autopilot

Flight Data Displays

Monitor Displays

ILS Displays

Warning

Position

Radar Display

\section{AUIXILIARY NENCRY \\ Route Date \\ SID. STAR'S \\ Maintenance Programs}

Etc. 


\section{N76 11999}

navigational aids will be upgraded and standardized at more airports.

\section{HUMAN EACTORS IN GENERAL. AVIATION \\ Introduction}

For tens of thousands of years man was a pedestriar on earth, slowly moving and slowly developing his skills and abilities. Yet winin the shont span of one lifetime he has taken to flying. left his teet and developed the ability to fly in the history of aviation, there have been two major challenges:

(1) the design and construction $c$ ? aircraft and

(2) the training of men to operate them sately

The response to the first challenge was and is one of mankind's great accomplishments aeronautical engineering was born and prospered and technological breakthroughs were achieved as airplanes became bigger and flew laster, higher, and longer

In response to the second challenge the relatively lew men sufficienty skilled and qualltied to become operators were selected During World War 11 as arplanes became more complex, there was increasing emphasis on training and training processes By ihe end of the war the capacity to build complex weapons systems and vehicles, particularly aircraht had considerably exceeded the ablity of the average man to operate them $A$ movement to "humanze" these systems developed Instead of searching or the right man for the right job. " the job was bullt around the man An in. terdisciplinary area emerged, variously called human factors engineering psychology or human engineering its goal to examine man's unquely human skills and lmitaticis his sensory, cognitive, and perceotual-motor capacites, and to apply this information 10 the design of equipment. vehicles and artificialen. vironments ${ }^{4}$

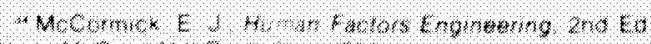

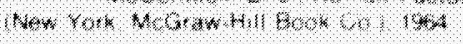

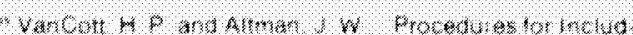

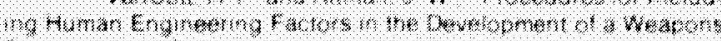

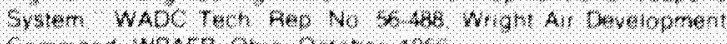

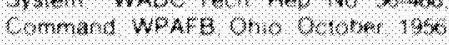

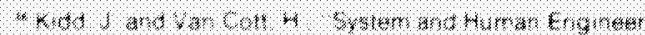

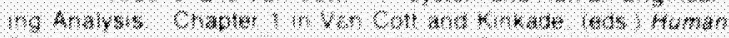

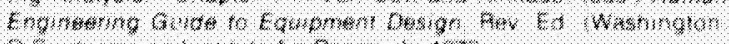

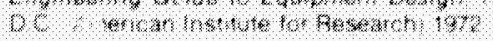

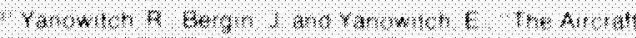

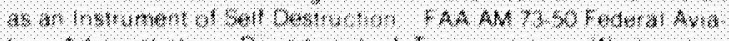

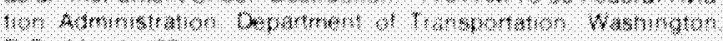
Whan 30 ,
VanCott and Altman viewed the emergence and development of human factors as a process occurring in three historical stages:

(1) Primary emphasis on the machine with the human "adapted" to it by means of selection and training.

(2) Primary emphasis cn man where the machine is adapted or designed for the man; and.

(3) The newly emerging emphasis on the overall system design in which man and machine components are optimally integrated to achieve system objectives. $3 s$

A complex matımachine system in general avlation has been brought forth involving man as operator with aircraft, navigation. communications, and air traffic control systems. A concept of growing prominence is that manmachine systems lincluding men and machines) should be designed to capitalize on those human talents and characteristics that are of optimal use in the system as a whole. 18 . to design the environment and the man. machine intertace so as to make optimal hunan periarmance not only possible but predicta. ble 1

As general aviation operations have ex. panded, human varlables have become in reasingly more importent Technological advances have teen achieved but flight places demands on man which would have been unthinkable a life-time ago behaviors such as paying no attention to his senses, moving in three-dimensional space without a visual horizon for reference and monitoring dozers of instruments simultaneously

\section{The Human Component: The Individual}

Flyng holds a unique place in the lives of most pilots. Otten a plot during llight sees the eircratt as an extension of himsell Yet accord. ing to Yanowich et al if a plot accumulates stress in his lite with which he can no longer cope. that aircratt may become an instrument of sell-destuction in the contex of flyng the plot may engage in subintentional selt. destructwe acts These include such behaviors as neglecting impottant tems on the pre-flght check, taking-oft with barely enounh luel of llying an aircratt which has been poorly main lained?

Based on intormation presented 1. NGAA Business Flyng (1974) a vpical pilot prolle shows that he is most oten male welledu 
cated, earns a good income, has probably seen c. ' ive duty with the military (but not necessarily as a pilot), is most frequently married and has never been alvorced, and is, on the average. 36 years old ${ }^{3}$ General aviation plots appear to be exemplary American citizens.

While fewer than five percent of all pilots are women (36.000 out of a total of 756.000 ), the average temale pilot is stightly younget than her male counterpart As a group. general avialion pilots appear to better educated than the average American citizen with about 80 percent haing had at least some college education. More than 60 percent of general aviation pilots earned income in excess of $\$ 15.000$ in 1973. Their martal status appears similar to that of the general population.

While there has been an invrease of about 250 peicent in the number of certifed airmen over the past 23 years, the average general aviation pilot is getting older. For example, in $19^{-7}$ about 70 percent of the pllots were under $3^{2}$, ars of age while less than 50 percent are today Fortunately, many of the complex psychological functions required of pllots depend upon judgment, reasoning and experience and these have been found to be very resistant to deternoration with age. MacFarland pointed out that I native mental ability, motivation, and interes remain high, no signt sant adverse trends in mental performance by plots need to be expected up to the ane of 55 or $60 . \%$

There are some hume? ablities, however, that have been found to deteriorate substantially with age in the general population. These include vision heiring, menory for recent events, and reaction time Uniess the design of general aviation aircratt accommodates this age trend many pilots wil have tc conclude as did Ralph DeBruler in an article entitled "Age 60 On Final?:

So my lime of reckoning is at hand I will take another check ride This lime I will do it on an airport where l am a stranger. where l do not know the instructor and where / an not familiar with the airplane. If I do well in the checkride. I will fly a while longer. 'n any case. there is a

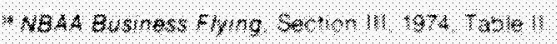

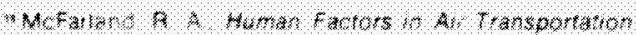

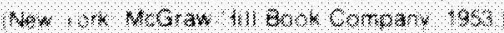
$1,1,4$

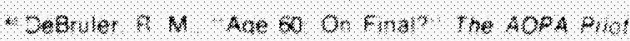

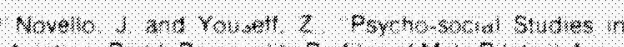

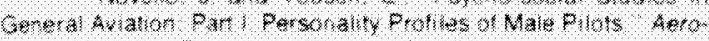

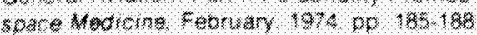

sow decision point some time in the future. I hope I can recognize it when it comes and accept it with grace *0

Pilots sometimes see themselves as a breed apart and tend to think of themselves as somewhat different fom other men in their approach to life in an attempt to deternine how the personalities of general aviation pilots compared with average adult males. Novello and Youseff administered a battery of psychological tests, including the Edwards Personal Preference Scale, to 170 male general aviation pllots. *

In comparing the average general avation pllot with the mean of males in the general United States population, the pliots were lound to score significantly higher on five factors: (1) achiever.ant (to accomplish tasks), (2) exhibition (tc ralk about personal adventures). (3) dominance (to argue for one's point of view). (4) change (10 do new thirgsl and (5) heteiosexuality (to be interested in members of Whe opposite sex

General aviation pllots were found to score signiticantly lower than the average United States male on seven factors: 11 deference (to do what is expected). 2 ) order (to have things organ:zed). (3) affiliation (to participate in groups). (4) succorance (to have others orowioe help). (5) abasement (to acceot blarte), (6) nurturance (to assist o hers) $2 \pi, 417$ ) endurance (to work hard at a task.

Novello and Youseff concluded that there is indeed, a core of personality traits common to pllots. They termed this core an "aviation proflle" because it was also mantfested by Navy plots. The authors went on to describe the personality of genetal aviatior pilots

This aviation profile fits well with the popular description of pllots in song. movie and verse as courageous, romantic "he-men

From a psycho-analytical point of view, this profile appears to describe an active-mascullie or "phallic" male, that is, a man who is oriented toward demonstrating his strength end competency, who thrives on ad. venture. who finds pleasure in mastering complex tasks, and whose manifest sexual orientation is decidely heterosexual. ${ }^{* 2}$

\section{Training}

In addition to the airplanes themselves. equipment used in general avition traming ranges from relatively simple procedureal tramers to full-scale simulation systems. Prs. 
cedure and familiarization trainers are used to teach nomenclature and procedures, to provide the student pilot with an opportunity lo practice techniques, and to deve'op concepts during exosure to different situations. Skill trainers and simulators are used to allow the pilot to practice responses to a wide variety of situa tions, *2, *

Fidelity of simulation refers *o now realistically the llight situation is represented in the trainer or simulator. A rule of thumb has been that as fidelity increases. so do the costs of construction and mantenance of a simulator. Although high fidelity in simulation has been thought essential to good practice situations and to gain acceptance and motivation on the part of the student. recent research reveals that practice on inexpensive. Iow fidelity flight trainers can produce savings in terms of flight hours up to 50 percent. *"

According to Bryan *6 and Bowen, ot al., * some tasks which can be simulated in a flight trainer and for which the student pilot is scored in terms of his perormance are: checklists (ground and airborne), communications (ground and airborne), fight matieuvers, instrument navigation, and maltunctions

In addition to providing indwidualized llight training. task trainers have been developed to provide simultaneous experience to a group of student pllots. each of whom is seated at an individual station while the instructor operates the training system from a console. Radio voice procedure represents an example of an appropriate task for such a training setup. ${ }^{48}$

- Whler 9 Psychologonl Consideratons n the cesign s

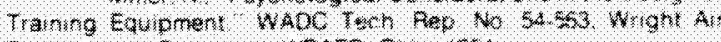
besctopnent Command Wpars otio $\quad 954$

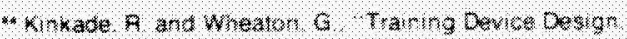

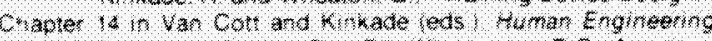

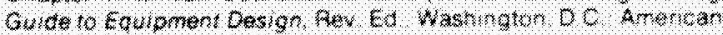
Instute for Reseatch 1972

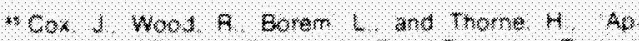

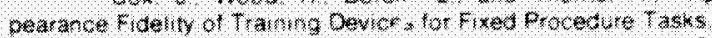
Tern Not $\$ 44$, Alexanona Va Human Fesources Fesearch of 160,1065

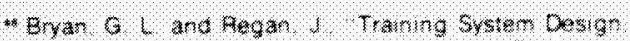

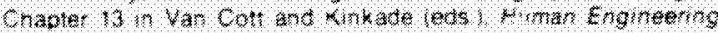
Gude to Equoment Design Wash ton DC Amercan Trotut tor Resatarth 1972

- Dowen 4 bismoo I promisel 0 and Mothrs , Hssessment of Plo Proticithry NATRADEVCEN Tech Rab tho

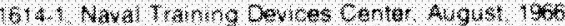

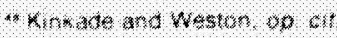

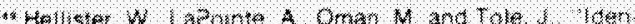

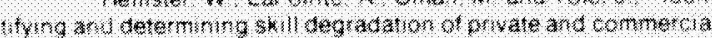

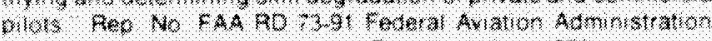

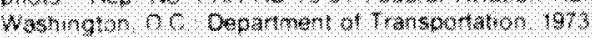

Wh h susmess Frims on th
Until check rides were recently required. active pilots by definition were those who held current medical certificates. Maintenance of active status, however, did not imply that the pilot actually flew since they updated their cer. tificates merely by undergoing periodic physi. cal examinations.

Following the old rubric of "use it or lose it. Ilying skills degrade rapidly when hey are not used, but return rapidly with practice. Thus. simulators can be beneficial in maintaining and in upgrading llight skills. Hellister found that a group of experiential flight tactors accounted for 25 percent of the variance between in. dividual general aviation pilots ( 30 percent of the variance was due to individual differences and 45 percent was due to random variation. interaction effects, and no se in the measurement process). The importance of the variance attributed to experiential factors is that it can be reduced by practice. To bring a pilot with degraded skill back up to standard in one learming session. 0.6 hours of flight for each year spent with no flying was required"

\section{Employment}

Predictions have been made that the emplovment level of active airmen will be driven up steadily over the next decade in 1974. NBAA Business Flying reportsd that there were approximately 53,500 pilots employed in civil aviation in 1972 of whom rougnly 22,000 New general aviation aircraft. Considering the total number of certified armen in the United States a relatively small proportion earn theit livelihoods by Ilying. Tentative Bureau of Labor Statistics figures reported in the same issue of NBAA Business Flying estimated that approximately 68000 pllots were employed in civil aviation in $1973^{\circ}$.

\section{Accidents and Safety}

The final analysis and identification of the causes of all accidents, whether in air transportation or in generai aviation, are the legal responsibility of the National Transportation Safety Board (NTSB). Generaliy, airline crashes and fatal general aviation accidents are in. vestizated completely by the Board itself. Some accident fact-tinding lobs. however, are assigned to the Federal Aviation Administra. tion Among these are the prelimmary investigation of non-fatal general aviation accldents. Though thorough and painstaking. most general aviation accident inquiries give the $m$ pression that a unique occurrence has been in. vestigated, one that has not happened in the past and which could not happen again No lote of general aviation aircratt accidents has been 


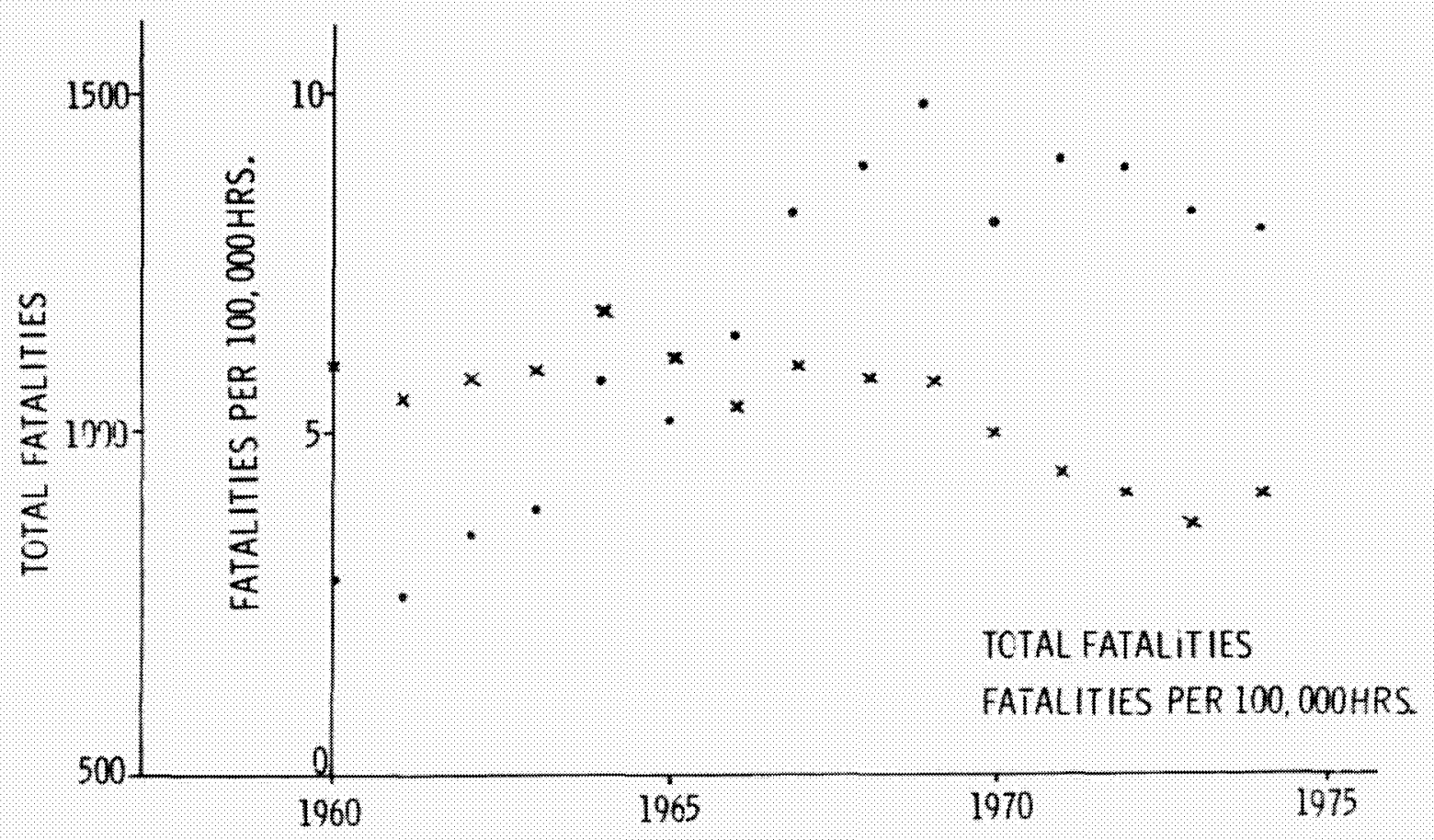

Source: National Transportation Safety Board, 1974 Data

\section{GENERAL AVIATION FATALITIES 1960-1973 FIGURE 1-10}

built up for there is little transter of design implications from one accident to another. ${ }^{31}$

Introducing a discussion of accidents. Hoekstra and Huang stated unequivocably that "the safety record of general aviation in the United States over the period 1359 - 1969 reveals that flying was much safer at the end of the period than at the beginning." 52 Figure 1-10 reveals that the record is not quite as good as those brave words imply. The number of total fatalities has increased markedly over the period 1960 - 1973, but then, so have general aviation activities. The rate of fatalities per 100.000 hours flown, a more comparative index because it is free of activity level, is indeed lower in 1973 than it was at the beginning of the period, and considerably better than the worst year. 1964. To conclude that there has been any marked gain in safety over this particular period would be imprecis because of the up and down fluctuation of the curve By regarding a much longer period of time. such as a span of 50 years, one can truly say that flying has

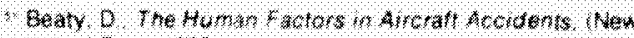

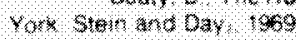

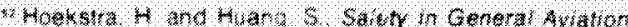

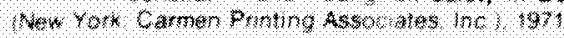

beaty, op
}

become much sater since today's aircraft are much more reliable than they were in the days of World War I when two-thirds of all air casualties were caused by accidents, not enemy action. . $^{3}$

Since general aviation encompasses many types of flying activities, one can determine which activities have better or worse safety records. In 1968. in terms of the rate of accidents per 100.000 flying hours, business. transport, commercial flying, and air taxis had the best records while experimental flying personal flying and other non-commercial flying had the worst as shown in Table I-VIII. From these data one can make the observation, for example, that Instructional Flying. while contributing a high number of total accidents (Rank $=2$ ) was, nonetheless, safer than several other forms of general aviation flying.

The phases of operation of an aircratt at the time an accident occurs are presented in Table I-1X with the percent of total accidents which occurrec in each phase averaged for the years 1968 and 1969 . Approach and landing operations, accountirg for about 50 percent of the total accidents. appear to be the most dangerous phases of flying $\ln$-flight accidents 


\begin{tabular}{|c|c|c|}
\hline \multicolumn{3}{|c|}{ TABLE I-VIII } \\
\hline \multicolumn{3}{|c|}{$\begin{array}{l}\text { RATE AND RANK OF TOTAL ACCIDENTS } \\
\text { PER GENERAL AVIATION ACTIVITY, } 1968\end{array}$} \\
\hline Type of Flying & $\begin{array}{l}\text { Rate per } \\
100,000 \text { Ibying hours }\end{array}$ & $\begin{array}{l}\text { Rank by Number } \\
\text { of accidents }\end{array}$ \\
\hline Experimental. Test. Demonstration. & 100.00 & (2) \\
\hline Other Non-Commercial Flying & 32.88 & 7 \\
\hline Personal Flying & 30.93 & 1 \\
\hline Aerial Application & 28.63 & 4 \\
\hline Instructional Flying & 15.16 & 2 \\
\hline Business Transport & 13.18 & 3 \\
\hline Other Commercial Flying & 11.05 & 8. \\
\hline Air Taxi & 8.80 & 6 \\
\hline
\end{tabular}

Source: Derived from Hockstra and Huang. Safety in General Aviation. Carmen Printing. New York, 1971.

\begin{tabular}{lc}
\hline & TABLE I-IX \\
& GENERAL AVIATION \\
PERCENT OF ACCIDENTS WHICH OCCUR DURING DIFFERENT OPERATIONS \\
Flight Operation \\
Percent Occurrence \\
Static & 0.6 \\
Taxi & 4.0 \\
Take-otf/Initial Climb & 18.2 \\
In-Flight & 26.3 \\
Approachlanding & 49.7 \\
Undetermined & 1.3
\end{tabular}

Source Derived Irom date reported by Hockstra and Huang Safety in General t viation. Nev York: Carmen Printing, 1971

account for slightly more than 25 percent while takeoff and initial climb is the third most dangerous maneuver with slightly less than 20 percent of the accidents occurring during this phase. Because pilot error causes the preponderance of accidents on approach and landing. a concentrated elfort to impr ve satety pertormance in this particular area would yield the greatest payofi.

Accidents otten involve a series cl events. the occurrence of each being cruclal for the accident to happen; however, statisicians treating NTSB investigative data establish single causes whenever possible. In 1968-1969 two causes were established in more than half of the cases (vielding a combined total in excrss

thoekstra and twhos op ot

wasty oo set of 100 percent). The pllot was cited over wheimingly in 83 percent of the cases. as the cause of most general aviation accidents. Weather (21 percent) ran a poor second to pilct error, followed closely by mechanical failure (17 percent), Terrain, personnel, eiroortainway tacilities, and miscellaneous causes followed in that order $*$

In recent decades human error consistently has been the highest causal category for accidents in both general aviation and in ait transportation. The NTSB assigned pilot factors as causal in 58 percent of the latal air carrier acoidents for the years 1964-1969. Though better than pilots in general aviation, the fiqure is still too high for acceptance

Throughout the world the idea is supported th human fars-rs on the part of the pilot are responsible ! ' of the fatal accicents. yet. 
the general opinion seerrs to be that the problem is so complex that little or nothing can be done about it "s, "Pilot error" is a "basket" expression covering a number of difterent sorts of errors. It is easy to say that a pilot falled to use proper judgment, but hard to show how the relationship of major stiuational constraints, design, equipment or system influences contributed to a given failure in judg. ment. Knowing that a pilot committed an error is of little preventative value without knowing the cause. and only recently has there been increased discussion about pllot errors which are "design induced" $"$ s?

Beaty noted that the term "pilot error does not even begin to separate professional skill errors from more typical huma. orrors To him. protessional skill errors occur when the pllot lacks , he experience or skill to do any better He defined human errors as those connected specifically with the fact that the person involved is a tallible human beng s\%

In March. 1971, the Secretary of Transpor. tation ordered a study to analyze the factors contributing to general aviation safety in order to reduce the accident rate ${ }^{5 *}$ The resuting recormmendations included biemnal flight reviews of pllot competency, a general aviation accident prevention program. increasing the tequirements for flight instructors. and establishing a stanoard taffic pattern rule at uncontrolled airports. among others. The recommendations appear to be a step in the rigit diection.

From a human lactors perspective an accldent represents a total falure of the manmachine system in aviation. If pilot error is truly the major cause of aviation accidents one can reach either of two conclusions: (1) remove this

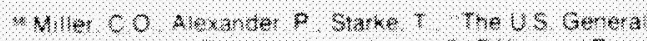

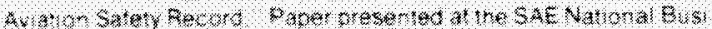

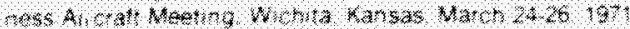

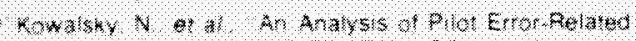

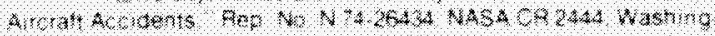

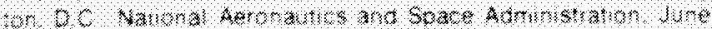
19/4

* Beatr op cot

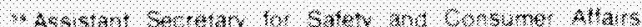

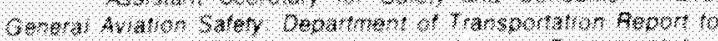

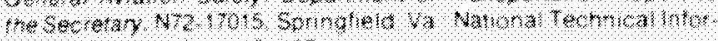

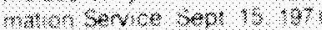

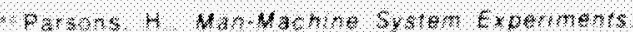

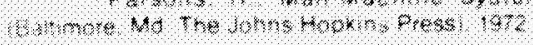

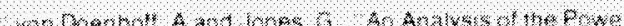

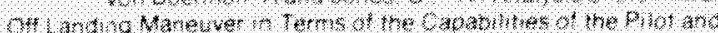

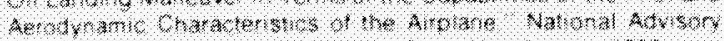

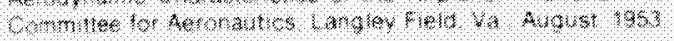

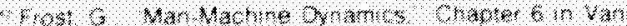

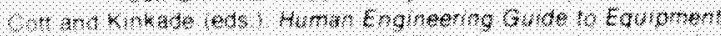

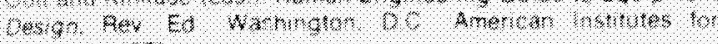

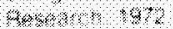

low reliability component (ie. the oilot) from the system, or (2) redesign the system so pilot pertormance is optimized

\section{Man-Machine Dynamics}

The discipline of human factors has focused especially upon man-machine relatronships Some deal with the psychomotor responses of the human controling the device or vehicle he uses, others with perceptual and cognitive human functions such as intormation-seeking and decision-making based on in strument displays. There have been literally thousands of pilot-airplane research studies sponsored primarily by defense agencies over the past 25 years Many of these studies have been relevant to general aviation but untor. tunately, there has not been a compilation to date. The present discussion will be limited to a brief exammation of the field with a few studies cited for llustrative purposes

In a theoretical sense, human pertormance must be considered in terms of various sensory. mental and motor activities: but. in a specific task situation, human performance is inextrica. bly interwined with the performance characteristics of the physical equipment in the 1940 's, for example. to measure the impact of aiframe dynamics on a plot aeronautical design engineers at the Comell Aeronautical Laboratory buil the first airplane whose stablilty could be varied systematically. The arplane was "black-boxed" in such a way that by mpressing control surface motions on those made by the pilot the pitch roll and yas responses of the airplane could rellect those o: a variey of conventional alrcraft Pilot perfor. mance opmion, and acceptance of various tre. quency and damping modes were thus tested and empirical research directed toward im. provement in airplane control design was initlated

Most everyone is aware the vehicular control systems having widely different dynamics may fee' "good" or "bad to the operator Studies such as the ore by von Doenhott and Jones have led to the use of experimental plots as vocal adaptive controllers General avia. tion aroratt designers have made extensive ust of opinon ratngs by sest pllots n the construc. tion of arcratt for good handling charac. tenstics "t?

Over the years general aviation atcrat have become progressively more rellable aid stable This has not been acchental but has grown out of continuing research and extensive trial and errot Basically a pllot's control ac. twity in lyurg an arplans can be broken lnto 
three general categories: (1) stabilization, (2) crmmand maneuver, and ( 3 ) event responses.

Stabilization is essentially a task of error reduction. Studies based on servo-mechanism theory. such as Westbrook's in 1959 have analyzed both the controlled element (some aspect of an airplane's control system/ and the pilot's workload : The performanue of command maneuvers utilizes the same airplane control system as stabilization, but here the er. ror component is nether directly displayed nor easily detected Some command maneuvers. such as takeofl rotation in a helicopter. may even use non-visual signals, others such as airplane roll have no detectable error signal at all. Because all tracking maneuvers are a mix of command maneuvers and stabilization tasks. human lactors was timately involved in tracking studies for many years. The studies of Levine" and Rockway and Franks" reflect this concentration. Event responses nclude single discrete actions such as turning a dial or throwing a switch A study such as Hunt's (in 1957 ) which recommended 15 shape-coded knobs to be used in aircraft controls is an example of research related eventresponses 68 The goa of all such research has been the improvement of pilot performance through simulator training or the improvement of system performance through airplane control systems and cockpit displays designed more optimally

A display is considered to be any method of presenting information indirectly in some coded form Elements of cockpits, such as some instruments and controls, have been im.

m, wow

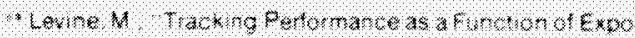

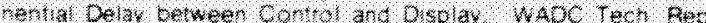

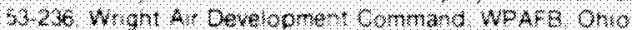

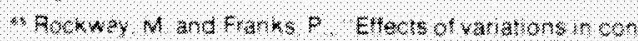
tol bakkast and gan on takk wh pentmance WADC Tew

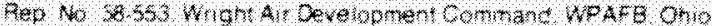
antukn 1369

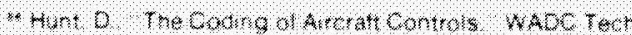

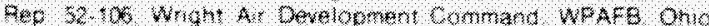
Mroh 19s?

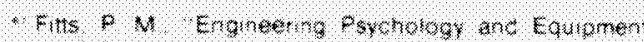

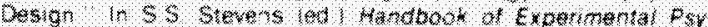

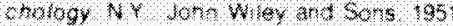

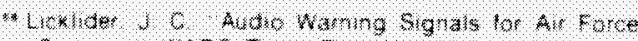

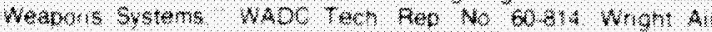

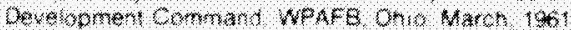

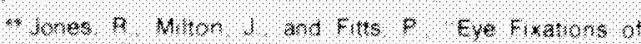

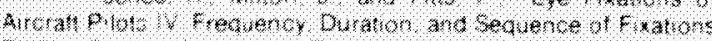

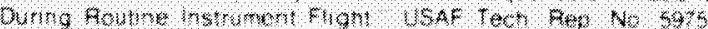

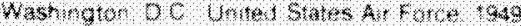

beats $10 \%$

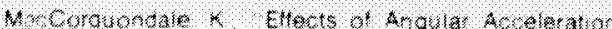

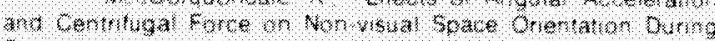

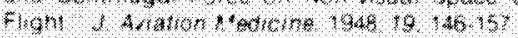

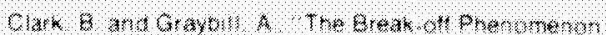

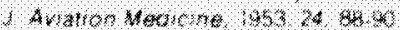

proved in design. Nevertheless. the whole operating environment in most civil aircraft leaves much to be desired. The pllot has to fit himself in among a myriad of switches, controls. levers and dials, and adjust himsell the best way he can. instead of the other way around: :

Not all displayed information is visual, the sense of hearing also has been utilized in the cockpit, particularly for emergency situations Audio warning systems-such as the stall warning horn. the gear-up horn. and the radio bleeper system on ILS approach have been derived :

A now classic Air Force study by Jones Milton. and Fitts in 1949 led to recommenda. tions for display panel layouts based on pilots eye-movements during a climbing maneuver ${ }^{58}$ The applicability to general aviation of this and other layout studies became apparent in the late 1950's when the FAA modified Part 23 of the Federal Aviation Regulations (Airworthiness Standards of General Aviation Planes) to specify a " $T$ " arrangement directly in front of the pilot of airspeed. attitude altitude and direction indicators. To date. however the location of only these lour instruments has been standardized. A confusing clutter is reported by many gentiol aviation pllots who switch from one airplane to another Other airplane displays and controls, not to mention optional navigation and communications equipment, often appear to be placed accord. ing to the manutacturer's or the first owner's whim rather than by their frequency of use or importance. Further. Beaty reported that in analyzing reactions to their own instruments. many pllots inought a number of them were confusine particularly the airspeed indicator altimeter, visual talure warnings on let-down altitude instruments, and radios. There was also criticism of the general layout and design of instruments and switches:

In a plane travelino at both a constan speed and altitude, orientalion is no problem But in var us aircraft mareuvers including changes in speed (acceleratron) banking and pushovers the sensory cues recelved by a pllot are misleading and can que rise to dis. orientation Judgments of the amount of bank have been tound to be grossly underesumated while a tendency to perceve acceleration as a slight climb and deceleration as a slight dive has also been reported " 4 Pllots when decelerating for a landing under conditions of poor visibility may overshoot the runway by cor recting for an illusion of descending too 
rapidly. This may partly account for the fact that there are twice as many overshoot accinents as undershoots.

Disorientation, as well as visual illusions, is enhanced inder conditiom- of fog, darkness. or clouds when the pitot ha: o vis lal trame of reference. The effect of rotary motion and angular acceleration, particularly with refe ence to visual illusions, is a subject of very ecent investigation * * Ar explanation is being sought for a phenomenon reported by pllots in the past of attempting to join un in formation with stars, buoys, and even street lights that appear to be moving.

\section{The Man-Environment Interface}

While many instruments on a pilot's dis. play panel relate to the state of subsystems within the airplane. often the most critical ir. struments are those which give the pilot information about the relation of his plane to the external environment Because of the high incldence of accidents during the landing pnase of flight operations, considerable effort has been expended to develop flight displays which pro*

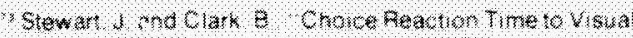

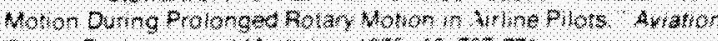

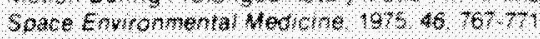

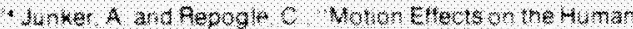

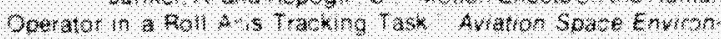
nembl weakne $16,54019,22$

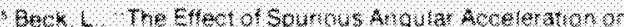

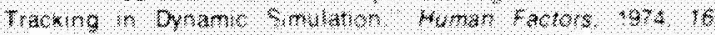
128431

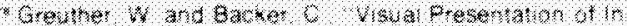

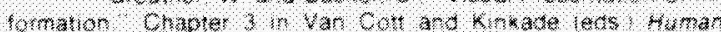

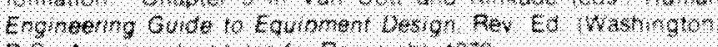

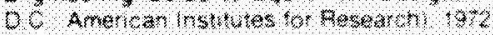

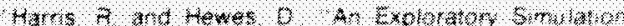

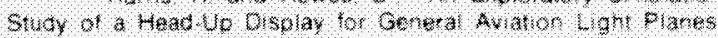

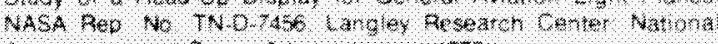

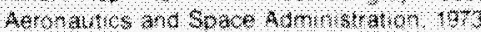

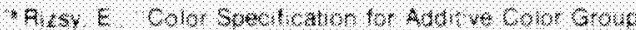

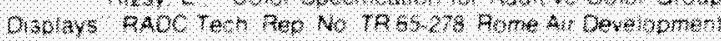
Carter 1065

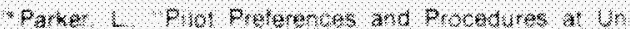

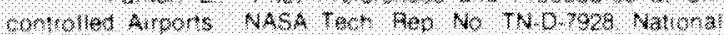

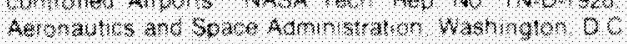

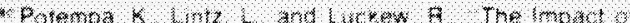

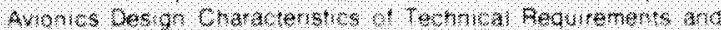
wot Partomance twman factors 197517,32 vide information the pilot could acquire otherwise by direct viewing of the outside world, but with signals added to indicate the correct flight path. A display oresenting a pictorial analog of the real worlo has been developed by Greuther "A "heads-up display which indicates the landing site for general aviation airplanes is being investigated by NASA. Langley 3

Instrumentation of a plane's attiude. airspeed, velocity, flight path and relative bearing to reference points is distributed in various locations on a pilot's display panel. During critical flight maneuvers, the pilot has difficulty integrating these sources of information. A display aid which would superimpose attitude. airspeed heading. and position intormation directly on the windshield, thus removing the necessity for the pilot to search among his instruments, is presently under study by NASA. Such information could be color-coded and avalable to the plot on demano."

The general aviation traftic environment at uncontrolled airports has also come under NAS-'s scrutiny. After radar tracking at three arports and a survey of pilot preferences about landing procedures a standardized landing patern is being recommended to yield sater ap. proach and landing pertormance at atports without towers.

The last several years in general aviation have seen a marked improvement in avionics equipment Plots get lost less trequently the national arspace is utilized more fully, the possibility of mid ar collisions is reduced and existing airports can handle increased trattic loads more sately as a result of this "avionics explosion Despite increased satety an untor. tunate consequeree is that plots workload has incleased The workload is so demanding that the Learjet, for instance, requires two pilots In many situations the pilot's tasks border on overload :o the point where the pllot may not be able to handle emergencles. The use of computer technology and programming to take over at least routine monitoring functions of the pilot is seen as a possble splution to the trend of in creasing complexity of the pilot's task 


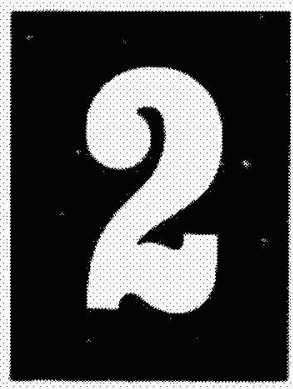

\section{GENERAL}

AVIATION

ENVIRONMENT

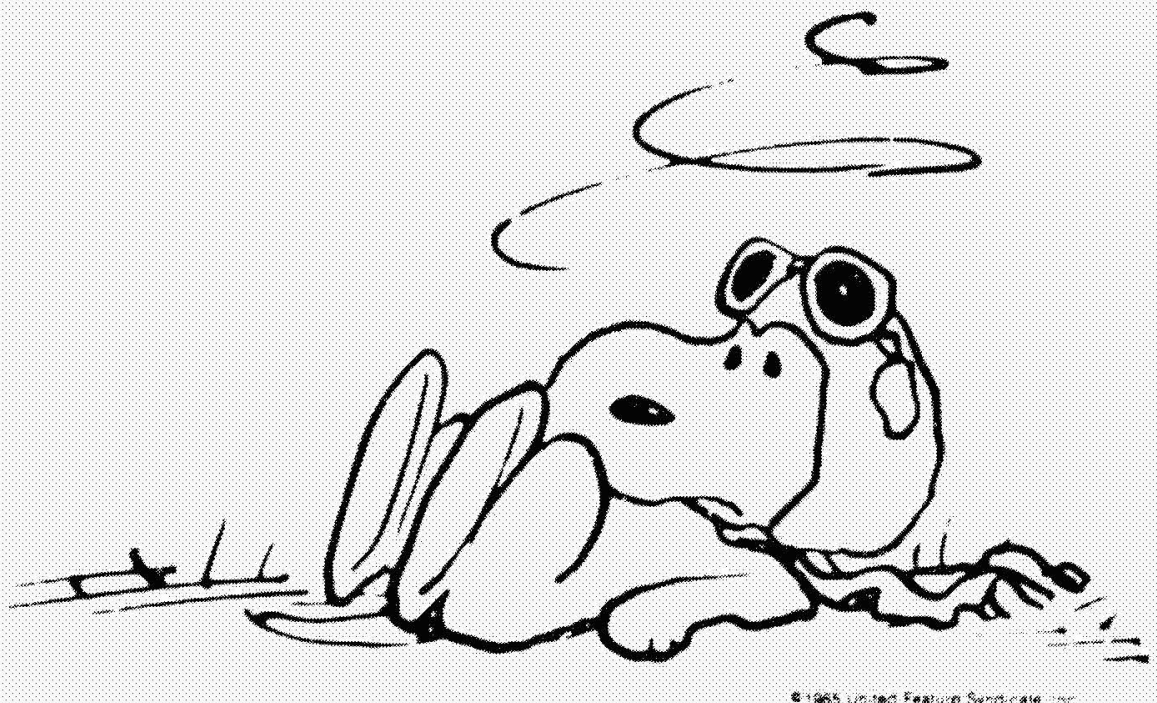

PRECEDING PAGE BLANK NOT ELMER 


\section{N76 12000}

\section{Chapter II GENERAL AVIATION ENVIRONMENT INTRODUCTION}

General aviation does not exist in a vacuum independent of other influences. It is controlled by Congressional action and extensive mandatory regulation. The system components interface in compliance with statutory provisions and operating rules.

Economic factors influence airport administration and finance. Vehicle ainworthiness certification costs are becoming increasingly burdensome. Rising costs of nearly all goods and services necessitate close scrutiny of expenditures. General aviation is no exception. Certain groups are taking hard looks at competitive modes and travel substitutions, especially for intercity and business trips.

Substitution-a change in mobility patterns and communicative behaviors - may lead to profound changes in our interaction patterns.

Protection of the environment. such as lowering of noise levels, natural resource depletion prevention, and the preservation of clean and fresh water are all concerns of general aviation.

The following discussion examines some of the background, development, and relationships between and among these issues.

\section{THE REGULATORY ENVIRONMENT Regulatory Scope}

The four major areas of concern pertaınıng to the role of government regulation in general aviation are: (1) airports, (2) air agencies, (3) aircraft, and (4) airmen. Some regulation of general aviation as weli ds other transportation and public services is undertaken at every level of government.

The Federal Government under its authority to regulate interstate commerce, has played an almost exclusively predominant role in the regulatory control of aurcraft and air agencies. Airport regulation, however, has been predominantly under local control. This situation is rapidly changing as Federal assistance to local arrports increases. States still play an imporiant role in approving the allocation of Federal airport improvement funds. Local governments exercilie their authority PHECLUDNG PAGE BLANK NOT FILMED through the final approval or disapproval of the required matching funds to meet the Federal grants for airport improvement. Physical control of the airport environment also remains in local hands through their zoning jurisdiction, constraining ordinances, and through local court decisions. Different areas of regulatory concern are cross-classified in Figure 2-1, by both the level of government and the area of regulatory concern.

\section{Legislative and Regulatory History}

The people of the United States gave Congress the right to regulate interstate commerce fer the good of the nation. It was natural. therefore, that the first direct implementation of aviation control came through the Air Commerce Act of 1926.

\section{The Air Commerce Act of 1926}

This act undertook regulation by licensing pilots, aircraft, and agencies, and by introducing conditions pertaining to the issuance and renewal of appropriate licenses and certificates. These conditions included demonstration of knowledge and proficiency by pilots and agencies and minimum safety requirements relating to aircraft. Compliance with these rules was made mandatory by the Act. which also mandated the promotion of air commerce and the creation and operation of an airways system. The Bureau of Air Commerce, which was created by the Act, was charged with this responsibility and thus became the forerunner of the former Civil Aeronautics Agency (CAA) and the Civil Aeronautics Board (CAB) and the Federal Aviation Administration (FAA) as we know them today today.

\section{The Civil Aoronautics Act of 1938}

The Civil Aeronautics Act of 1938 created the Civil Aeronautics Authority (CAA) to regulate aviation with respect to both safety and economics. The 1940 amendment gave the Civil Aeronautics Board ( $C A B)$ the authority for both economic and safety regulation and for determination of "probable cause" in aircraft accidents. The siafety regulation was to be implemented by the $C A B$ which was created by the 1940 amendment to the Act.

The 1940 amendment not only gave the $C A B$ the authority to regulate air carriers by es. tablishing fares and authorizing routes, but clearly entrusted the CAA with the responsibılity of promotıng air commerce by developing the federal airways system. This responsibility led to the Federal Airport Act of 1946 and the subsequent Federal Airport and Airway 


\begin{tabular}{|c|c|c|c|}
\hline \multirow[b]{2}{*}{ 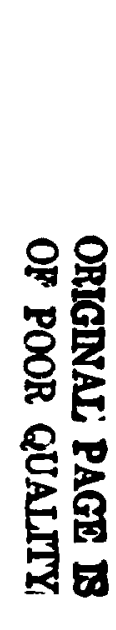 } & minguth & Air Monoudes & Mresent \\
\hline & 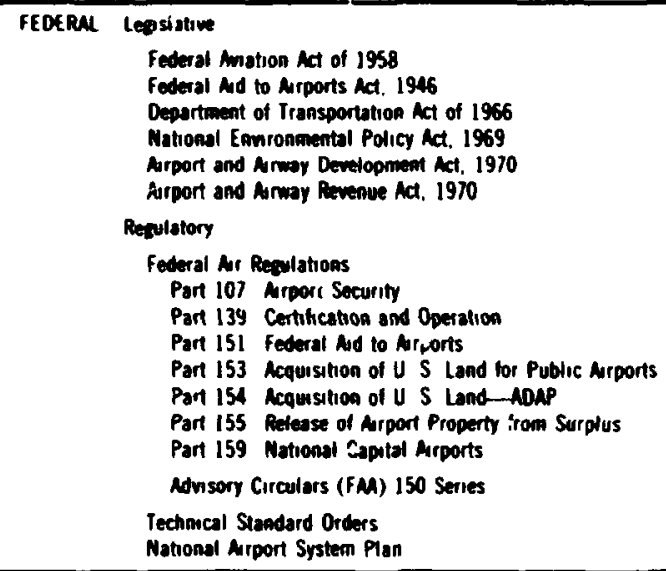 & 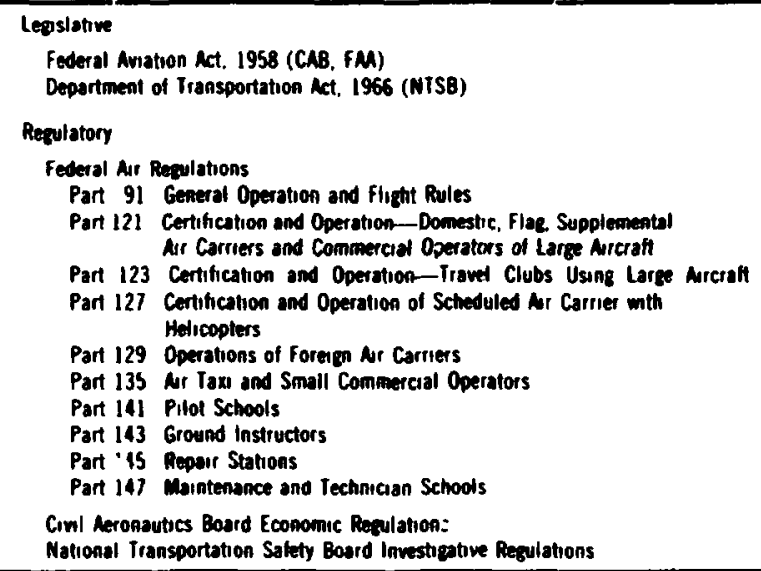 & 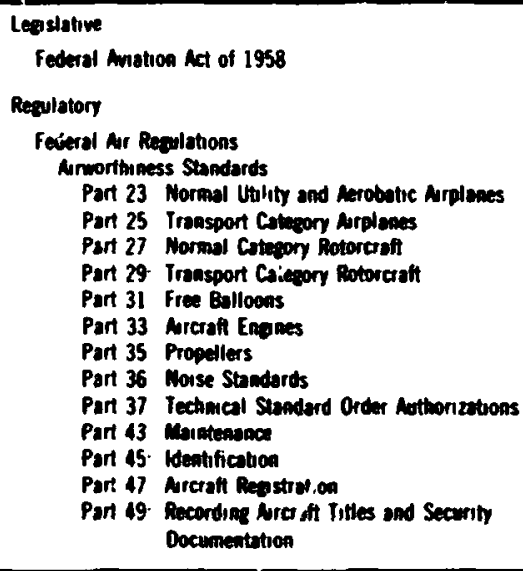 \\
\hline \multirow[t]{3}{*}{8} & 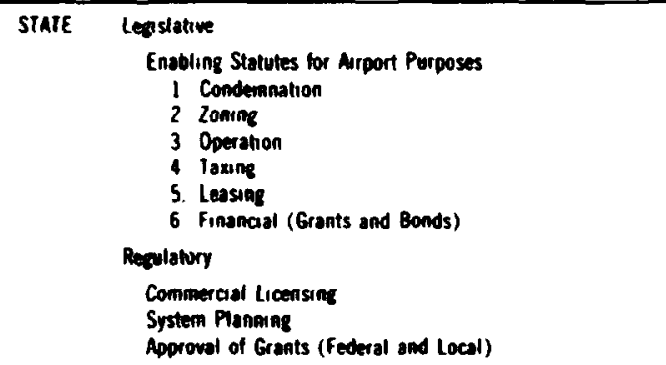 & 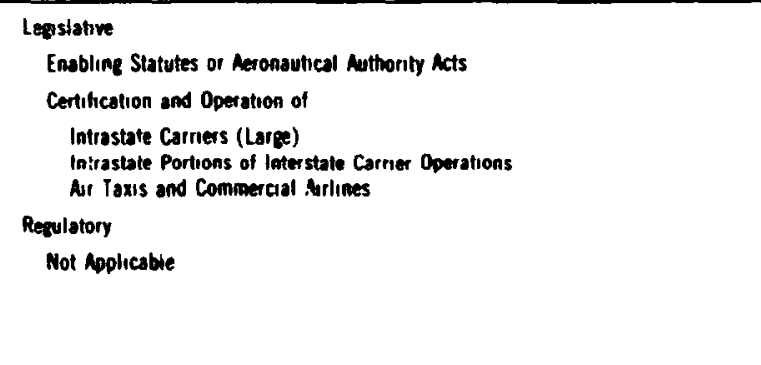 & 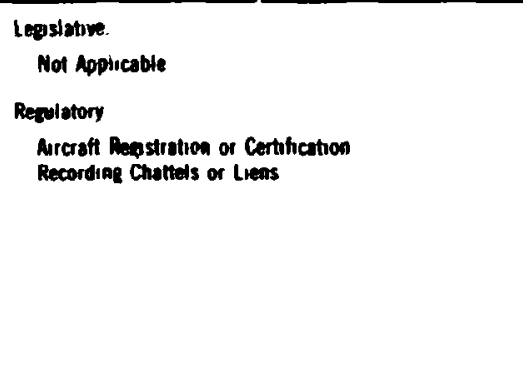 \\
\hline & 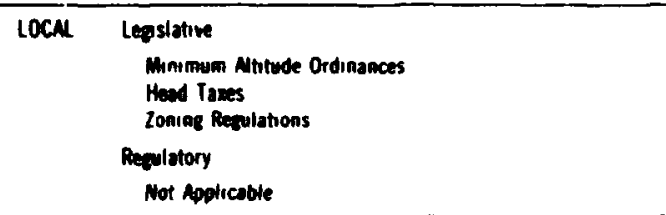 & 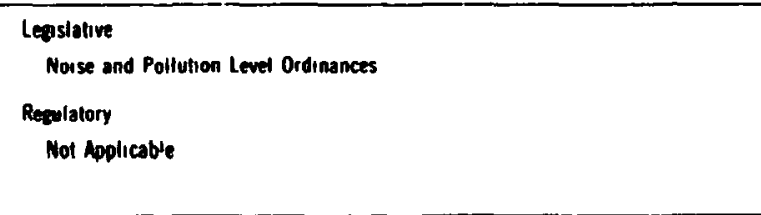 & 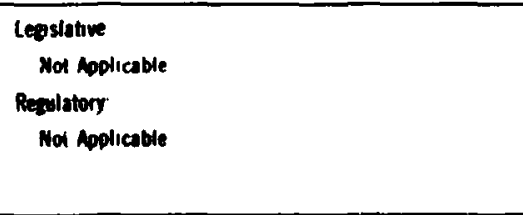 \\
\hline & 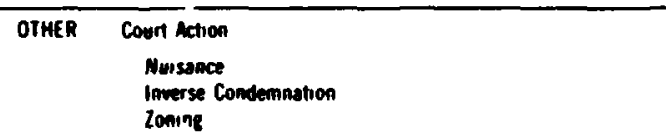 & $\begin{array}{c}\text { Court Action } \\
\text { Nussancer }\end{array}$ & $\begin{array}{l}\text { Court Action } \\
\text { Not Appliceble }\end{array}$ \\
\hline
\end{tabular}

\section{MANOR AVIATION CONTROLS LEGISLATIVE AND REGULATORY FIGURE 2-1}


Development Act of 1970 and the concurrent Airport and Airway Revenue Act. The latter provided funds for the support of programs initiated under the former. The main sources of these funds are airline ticket and aviation fuel taxes.

\section{Thu Federal Aviation Act of 1958}

Following several mid-air collisions in the 1950 's, Congress passed the Federal Aviation Act in order to better define and to isolate air safety responsibility. Under the Act. CAB retained economic jurisdiction and the responsibility for determining probable "cause of accidents," while FAA acquired the responsibility and authority to promulgate safety regulations. Although this system seemed to be functioning successfully (the domestic air carriers hit a zero fatality year in 1970), Congress placed the control of air transportation un Jer the jurisdiction of a newly cieated Departrinent of Transportation in that year.

The Department of Transportation Act of 1870

This act transferred the responsibility for the promulgation of safety rules to the Secretary of Transportation and established the National Transportation Safety Board which now determines probable cause of accidents. It also directed that safety rul zs be placed under the jurisdiction of the FAA, leaving the $C A B$ with the responsibility for economic regulation of air transportation.

Thus, the CAB presently regulates all common carriage by air including route authoriza. tion, fares, and preservation of the financial well-being of the zarriers to assi:e continued existence and service to the public. FAA regulates aircraft, pilot, and air agency certification and operation as well as airway and airport development and funding.

\section{Airports}

Several states have stepped in to fill the voids in aviation regulation or control in the area least affected by Federal legislation-the airport.

Many states license airporis for commercial reasons, including tax regulation and control of fees and charges. The Federal government has recently undertaken to license all air carrier airports for safety requirements (FAR Part 139), and continues to establish minimums for safety specifications at all airports acceptins Federal funds for improvement.

Subdivisions of the states have passed ordinances restricting the use of airports, some of which have been upheld by the courts, while others were declared "an undue burden on in- terstate commerce." Zoning, however, remains the chief regulatory aren cpen to the states and many have passed en ' Jing legislation for local zoning laws and al'.norized condemnation for airport purposes.

The FAA is charged with the responsibility of developing an airport system for the United States. It does so through a National Airport Systems Plan (NASP). Of the approximately 13,000 landing strips in the country, auout 3,040 are in the NASP. Inclusion of an airport in the plan provides it with basic eligibility for development funding, given that all other qualifications are met. Development funds are derived from the Airport and Airways Trust Fund created under the 1970 act. The FAA reviews the following main requirements as conditions to application for development funding: (1) submission of an airport master plan, (2) submission of cost estimates, (3) information regarding the environmental impact of proposed improvements, and (4) a clear indication cf the source and availability of matching funds.

Funds are then allocated on a priority basis according to the then existing policy of the administration. Upon acceptance of funds, the airport must enter into an agreement to construct and operate the airport according to the pertinent Technical Standard Orders (TSOs), Adviscry Circulars (ACs), and Federal Aviation Regulations FARs) issued by the FAA. The agreement also required public operation of the airport and prohibits discrimination.

Regardless of whether or not federal funds are involved, airports serving certificated carilers must comply with FAR_Part 139. This regulation controls the safety characteristics of the airport and facilities, as well as their day-today operation.

Most states have passed enabling legislation permitting their pulitical subdivisions to promulgate zoning ordinances and to institute condemnation proceedings for development or control purposes. Some states also undertake to license airports not controlled by the Federal government while others merely license them for commercial or taxing purposes, thereby avoiding conflict with federal regulations.

States usually exert some control on airport development, through thie provision of matching funds. In some states. such as Connecticut, the entire state airport system is oderated by the state. In others, the State Aviai on Department exercises varying degrees of control over the approval of requests for federal funds. 


\section{Legal Implications of Airport Planning and Land Use}

Few types of transportation facilities generate more controversy regarding their compatibility with neighboring land uses than do airports. General aviation airports, particularly those accommodating corporate aircraft, are no exception. As a community's demand for general aviation services increases in response to its population. growth and economic develonment, the availability of open space in which to construct or operate an airpor: shrinks at an squally rapid rate in response to similar pressures. As a result, horneown.grs living uncomfortably close to an existing or planned facility frequently resort to the courts for protection from any actual or anticipaied encroachments on their right to use and enjoy their property, regardless of who was there first-the airport or the property owner. At the same tıme, local officials typically attempt to devise whatever constitutionally permissible regulatıons are available to minimize this friction between the airport and its neighbors. It is ther sfore from these two perspectives-that of the neighboring homeowners and that of the municipality as a whole-that the airport planner should evaluate the legal implications of any land use plan he formulates for a general aviation airport

Ideally, a community planning a new airport should acquire sufficient acreage of land surrounding the facility so as to insure that the airport could in no way interfere with its neighboring property owners. By leasing back mosi of this butfer area to various industries (with the necessary restrictions on use) it could then reduce some of the acquisition costs and provide for future expansion of the airport as well. However, the initial investment cost alone would still make this approach impractical for many communities. Moreover, any such attempt becomes even more difficult if, as in most cases. the airport is already there when the city or county finally recognizes the need for regulatıng adjacent land use. If the airport is privately ow, ied, the local governing board will alsc lack any authority to initıate such a plan. Consequently, many airports todav-both publicly and privately owned-find themselves in the midst of time consuming and expensive legal tangles with their neighbors.

Thrasherv Allanta $178 \mathrm{Ga} 862$ But See Swetlandv Cur IIss Airports Corp $55 \mathrm{~F} 20201$

Anderson v Souza $38 \mathrm{Ca}$ : $: 825$

Reaber v Martin Theatres of Florida Inc, 52 So 20682

- Vanderslicer Shawn. 26 Del Ch 225
Although actions in common law nuisance and trespass seldom succeed, they can become potent weapons against airports that fial to observe proper operating procedures. In general, it has been held that, if properly located, constructed, and operated, airports are not a nuisance unless it can be shown that they in some significant way endanger the health and safety of neighboring citizens.' Contiguous proderty owners must yield their privacy to a reasonable degree, so that legitimate businesses such as airports, which presumably contribute to the general welfare, may ope ate for the benefit of all. ${ }^{2}$ Similarly, the operator of an airplane has been held privileged to enter the airspace above land in the possession of another as long as he does so in a "reasonable" manner, at such a height as is in conformity with legislative requirements, and without interfering unreasonably with the possessor's enjoyment of the surface and the airspace above it. ${ }^{3}$ Only when the flights are so low and frequent as to be dangerous to the safety of landowners or as to substantially interfere with their enjoyment of their property will an injunction issue in a nuisar.ce or trespass action.

A more serious problem arises, however. where localities have failed to acquire through eminent domain the necessary easements for approach lanes over property surrounding public airports. Although the ancient doctrine of Cujus est solum, est usque ad coelum ("the owner of the soil owns to the heavens") is no longer relevant in this moderr : $\cdots 3$ of air traver, and even though the federal rovernment has declared itself to be possessed of complete and exclusive national sovereıgnty over airspace needed for takecffs and landings (49 USC Sec 1508), courts have nevertheless consistently helci that property owners are entitled to compensation should overflights interfere substantıally with the use and enjoyment of their property. Of course, no artificial line may be drawn to determine at which altitude an overflight becomes a "taking." since each case depends upon the nature of the interference and the kind of use to which the property is being put.

In the lancmark case of United States $v$. Causity, 328 U.S. 256 (1946). the Sup:eme Court held that inverse condemnation or taking had occurred where low and frequent flights by military aırcraft over plaıntiff's property had diminished its value a o severely limited its utility. The court reached a similar decision in Griggs v. Alegheny County, 369 U.S. 84 (1962). noting in particular that. in accepting federal funds for the airport. the county had also 
agreed to acquire all necessary easements therefor.

However, an important distinction has arisen, in the federal courts at least, as to those cases where an actual physical invasion of the airspace over the property in question has occurred and those where the interference did not involve a direct overflight. Although the former may be compensable as an unconstitutional taking. the latter is frequently consijered merely "consequential" damage for which the U.S. Constitution provides no remedy Thus, in Batten \%. U.S., 306 F. 2d 580 ! '962), the circuit court of appeals denied compensation when the noise, vibration, and smoke that harassed residents was not accompanied by physical invasion by the Air Force jets of the airspace directly above "State courts are split on the issue of whether an overflight is necessary for compensation, but many have now rejected the taking.'damages distinction and consiver instead whether the flights are an "unreasonable burden" on the complaining property owners. "

There are also a number of other limitatıcns to recoveny for a taking. By definition, of course, a taking requires public ownership oi control of the airport. Even then. if the market value of the property has actually increas $c d$ because of the airport's proximity, no compen sation is permissible regardless of the noise or other annoyances. ${ }^{\top}$ Depending on the relevant statute of limitations. failure to contest an encroachment can cause the easement to riper, into a prescriptive right. In some instances. subsequent buyers wiin purchase with notice of the adjoining alrport and its flight patterns may be held to have asuumed the risk of noire and other damage when they purchased their land. Finally, courts are reluctant to grant comperisátion without a showing of substantial interference witt, tite use and enjoyment of the property. Flights at altitudes of severa' thcusand feet are not likely to involve an unconstitutional iaking of property without just cur.jpensation.

While private actions such as rilisance and

See al., Bennett $v$ United States $266=$ Supp 627 and Unife. S.ates $v$ DeQueen and Easiern Railioso co $167 \mathrm{~F}$ Supp 545 One alternative 's to "ue under the " teral Tort Cla,ns ict for phvs 3 danage to property as in IVe siem v MgGehee $202 \mathrm{~F}$ Supm 287

- Thomburgr Port of Ponland 376P 2A , walso Mar tir. in int of Seattle $391 \mathrm{P} 2 \mathrm{~d} 540$

Dick v Unitac States '69 F Supp 49

- inill Labulity for Aircraft Noise the Attermath of Causoy and Griggs $190 \mathrm{U}$ Miami L Rev 127.30

- Rathkopt the Law of Zoning and Planning jrd ed New rok Slath Boardman So Lid I 197

Kozesnick: Mo Iownship $24 \mathrm{NJ} 150$ inverse condemnation suggest one kind of approach to resolving land use conflicts around airports, local planning boards are likely to resort to another-zoning. Conceptually, zoning seeks to segregate incompatible uses into their own largely homogenous districts, thereby eliminating the friction between certain users of land. protecting the health and safety of the general public, and insuring orderly growth and development of the community. Yet the effectiveness of zoning depends entirely on the forethought of the original planners and the willingness of administrative officials to strictly enforce the provisions of the ordinance. The checkered histor:' of zoning in most states indicates that it has been. in many instances, a less than successful method $c i$ land use control. However, zoning still rer,ains one of the best tools available today for balancing the rights of individual property owners with the interests of the community in orderly land development.

One of the initial steps both in locating the arrport and zonıng the area around it is determinıng the types of use thiat would be compatible with its operatiun. Schools. hospitals, and residences appear the least desirable, whereas open space, agriculture, recreation. and commercial and industrial development represent the most likely possibilities. Once having identified the proper uses. the task then becomes to devise a large enough buffer zone. particularly under the approasn lanes. so as to exclude ali but these enumerated uses. This kinf of exclusive district zoning has generally been upheld where authorized by the state enabling statute and where enacted uncer a proper exe:cise of the police power. Triat is, it must be shown (as with zoning in general) that the ordinance bears a substant:al relationship to the hea!th. safety. morals. or welfare of the general public and does nor unduly burden a few citizens for the benefit of all. ${ }^{9}$

Several other statutory or constitutional restrictions also must be considered. however Most enabling acts require that the zoning ordinance arid all amendments thereto be drawn "In acc -idance with a comprehensive plan This requirement has been interpreted as $1 \mathrm{~m}$ posing a burden upon the municipality to study ar 1 consider all olom :n:s : nvolved in the zoning scheme. including prior existing uses. topographica! features. and so fortn. such that the final ordinance represents ai integrated , sduct of a rational process " "This. the es tablishment or the butfer district ard indeed of the eirport itself cannot appear hachazard or r ecemeá in relat. in to the rest of the plan "or 
the development of the entire community. "

The concept of a comprehensive plan becomes especially important if a locality needs to amend an older ordinance in order to provide the necessary use districts for an airport facility. The amendment must be consistent with either the previously existing scheme or with one which could be rationalized as a logical extension theresf, or it must be part of an entirely new plan. ${ }^{2}$ Moreover, persons in a previous classification may rightfully rely upon the rule of law that the classification made in the general ordinance will not be changed unless the change is required for the public good. ${ }^{13}$ Some jurisdictions (though a minority) even place the burden of proof on the proponents of the amendment to show that there was some mistake in the original zoning or that the character of the neighborhood had changed to such an extent that reclassification ought to be made. ${ }^{14}$

One option permitted by some enabling acts is interim or stop-gap zoning. An interim ordinance rec! assifies land so as either to discourage temporarily its utilization or to permit only such uses as would not interfere with a contemplated plan. The intention is thus to restrict development until such time as a new comprehensive plan: (which would then include the airport and buffer zone) can be instituted. The number of non-conforming and vested uses can thus be minimized in the critical zones. Hcwe'er, there is a division of authority as to the constitutionality of such an ordinance. "s and most courts approving the measure emphasize the "reasonableness" of the short time lapse involved. 16

Hayeman v. Board of Trustees, 20 Ohwo App 2d 12 (zoning that modified existing comprehensive plan for airport development held to be a taking)

12 Rathkopf op clt

: Kennedy v Cl.y of Evanston. 384111426

14 Wakeheld v Kraft. 96 A.2d 27

"Compare Rubin v McAlevy. 282 NYS 2D 564 with

Peacock v County of Sacramento. $\pi$ Cal Pptr 391

- See. $\bullet 9$. Deal Gardens. Inc $\vee$ Board of Tristees of Loch Arbour. $48 \mathrm{NY} 500$ tordinance in effect for 1.12 years held unreasonable

" Iara El", neering Corp v Newark. $32 \mathrm{~N} \mathrm{JL} 370$ 20439

- Sarasota-Mbnatee A A $\checkmark$ Marrol'; Candy k:i i ien. III So

- Peacick v County of Sacramentc. supra

"Stete es rel H:' $\%$, v Boarce of $C r$ sioners. 37 Onıo Ops 58

" Hathkopt OP cIt

"Frink v Orleans Corp, 159 Fla 646. S.engelv Sranden. 156 Fla 592 . 9
Another type of zoning regulation has also received a mixed reaction in the courts. Although localities universally are permitted (in principle) to impose restrictions upon the height of buildings, height restrictions around airports solely to facilitate the use or operation thereof have more often than not been held to be an unconstitutional "taking." " But a minority of jurisdictions, most notably Florida, have upheld such ordinancos where the public benefit of the height restrictions were diemed to have outweighed the individual haroships imposed. "Moreover, most ordinances that were ruled invalid invo, $3 d$ rather servere restriction on use and considerable diminution in value due to the zoning. ${ }^{19}$ The safest method for a community, of course, would be actually to arquire the easements under the power of eminent domain should the courts there disapprove of airport height zoning.

Municipalities may also encounter difficulties if they attempt to tota!ly exciude airports through prohibitive zoning. Other communities, for example, may have statutory authority to condemn land within the 1 r neighbor's boundaries for use as an airport regardless of any prohibition in the latter's zoning ordinance. ${ }^{20}$ In regard to excluding private airports. the test of validity developed by the courts is simply whether the prohibition has a reasonable relation to the health, morals, and general vielfare of the community in light of the existing uses and characteristics of land in the various districts into wihich it has been zoned, with reasonable forethought for its future development. "' Using this standard, a number of courts have found insufficient justification for the exclusion in some ordinances of privately owned airports. ${ }^{22}$ Moratoria on development in general have encountered similar problems, although temporary restrictions necassary to give the muncipality time to provide sewer and other facilities have been upheld in some circumstances. ${ }^{23}$

Although obviously no panacea for the many land use problems involved with airport development. zoning can nevertheless be an effective regulatory tooi once its areas of usefulness are recognized and its constitutıonal and practical limitations carefully delineated Moreover, although not determinative of the issue, zoning classifications do influence courts in resolving nuisance and other private actions by landowners against airport operators. Of course. previously existing nonconformil.g uses and the necessity of variances will always cisrupt the uniformity zoning seeks to promote. but they need not undermine the over- 
all scheme. For it is only through comprehensive planning that a general aviation airport and its neighbors can peacefully coexist.

\section{Air Agencies}

Air agencies are subject to federal economic control through the $C A B$ and safety and operation control through the FAA. Air carriers engaged in interstate commerce as common carriers usually require a Certificate of Convenience and Necessity which is issued by the CAB. In addition, all carriers are required to obtain operating certificates from the FAA. The names of those certificates vary according to the function authorized. Some common carriers are exempt from CAB certification, and would thus fall in the general aviation category.

Some air agency certificates relate to ground operations only. Examples are ground schools, aircraft maintenance stations, service and repair stations, and others. Each must meet certain minimum requirements in equipment, personnel, and general facilities.

Most prominent are the air-agencies involved in transporting "persons or property... for compensation or hire," and further, those designated as air carriers which meet the further distinction "as a common carrier." all defined in the Federal Aviation Act of 1958

The classifications are somewhat complex and in some ins.ances overlapping. but are also exacting for the purpose of regulatory jurisdiction. Figure 2-2 summarizes the characteristics of the different types of aviation activities discussed below.

International, domestic Irunk, and local eervice air carriers are similar and overlapping in regulatory characteristics. The main distinction is in their area of service. International carriers obviously function across international boundaries; domestic trunk carriers serve route, general!y within the U.S. with average stage lengths of between 700 and 900 miles (797 miles in 1973). Most domestic trunk carriers also coriduct international operations. Local service carriers operate over routes of average stage length of between 250 and 350 miles (303 miles in 1973). ${ }^{24}$ These three types of air carriers are regulated by the $C A B$ which: (1) issues certificates of public convenience and neces'sity; (2) designates routes to be served; (3) designates type of service authorized; (4) sets rates and fares to be charged; (5) :equires extensive statistical and financial repc-ris; and (6) looks after the financial well-being of

1" Air Transport :974, Facts and Figures (Air Transp in Assoriaticn of America. Weshington, C C ) p 21 airlines to assure their ability to continue rendering the service to the public.

These carriers must also obtain an FAA operating certificate before they can commence exercising the authority granted to them by the CAB. The FAA regulates every phase of air carrier operation through the use of approved manuals and extensive operating regulations. Regulations, manuals, and operation specifications prescribe departmental organizations; allocation of responsibility; aircraft and equipment: maintenance organization and procedures; flight operations, training and proficiency check procedures; as well as many other details relating directly or indirectly to safety.

Supplemental air carriers provide supplemental seats during peak demand periods. They are limited, in that they may solicit affinity groups or tour charters only, and may not operate on a scheduled basis between points.

All Cargo carriers may operate as scheduled or non-scheduled and may "hold out to the public" for cargo carrying purpcses only. Thev iray. with special authorization, carry lim: $1^{\cdot}$. . isengers on a charter basis. In contrast. commercial Operators of Large nircraft may not hold out to the public at all. They operate by contract only and with a limited number of different users. If the number of users becomes sufficiently high (9 or 10). they are deemed to be holding out to the public and required to obtain a supplemental carrier's certificate.

Scheduler carriers, supplementals, all cargo and commercial operators operate under the appropriate sections of Part 121 of the FARs. They all operate, or are authorized to operate, aırcraft having certificated gross takeoff weight in excess of 12.500 pounds.

Air Taxi and Commercial Operators of Small Aircraft (ATCO) are considered to be carriers engaged in air transportation when pertorming air taxi services, but are deemed to be merely engaged in air commerce when acting as a small commercial operator involved in contrac flying. The two types of service were combined in one cartificate for convenience. since they are both exempt from certification by the CAB under section 298 of the Board's economic regulations. The exemption is predicated on their use of small aircraft. on the theory that their possible impact on interstate commerce is limited. and thus does nut. at this time, require regulation in the public interest.

For comparison purposes unscheduled air taxis can best be compared to supplementa! 


\begin{tabular}{|c|c|c|c|c|c|c|c|c|c|}
\hline Air Agency & $\begin{array}{c}\text { CAB } \\
\text { Certificated }\end{array}$ & $\begin{array}{c}\text { FAA } \\
\text { Certificated }\end{array}$ & $\begin{array}{c}\text { Air } \\
\text { Commerce }\end{array}$ & $\underset{\text { Transportation }}{\text { Air }}$ & Scheduled & Charter & $\begin{array}{l}\text { Large } \\
\text { Aircraft }\end{array}$ & $\begin{array}{l}\text { General } \\
\text { Aviation }\end{array}$ & $\begin{array}{c}\text { Passenger } \\
\text { carrier }\end{array}$ \\
\hline $\begin{array}{l}\text { International } \\
\text { Air Carriers }\end{array}$ & $x$ & $x$ & $x$ & $x$ & $x$ & $x$ & $x$ & & $x$ \\
\hline $\begin{array}{l}\text { Domestic } \\
\text { Air Carriers }\end{array}$ & $x$ & $x$ & $x$ & $x$ & $x$ & $x$ & $x$ & & $x$ \\
\hline $\begin{array}{l}\text { Local Service } \\
\text { Air Carriers }\end{array}$ & $x$ & $x$ & $x$ & $x$ & $x$ & $x$ & $x$ & & $x$ \\
\hline Supplemental & $x$ & $x$ & $x$ & $x$ & & $x$ & $x$ & & $x$ \\
\hline Cargo Only & $x$ & $x$ & $x$ & $x$ & 0 & $x$ & $x$ & & 0 \\
\hline $\begin{array}{l}\text { Commercial } \\
\text { Operators }\end{array}$ & & $x$ & $x$ & & & & $x$ & $x$ & $x$ \\
\hline $\begin{array}{l}\text { Commercial } \\
\text { Operators }\end{array}$ & & $x$ & $x$ & & & & & & \\
\hline Air Taxi & & $x$ & $x$ & $x$ & & $x$ & ${ }^{\circ}$ & $x$ & $x$ \\
\hline Commuter & & $x$ & $x$ & $x$ & $x$ & $x$ & 0 & $x$ & $x$ \\
\hline Helicopter & 0 & $x$ & $x$ & 0 & $x$ & $x$ & 0 & 0 & 0 \\
\hline Intrastate & & $x$ & $x$ & $x$ & $x$ & $x$ & $x$ & $x$ & $x$ \\
\hline
\end{tabular}

$X$ - Applicable

0 - May be applicable, bu؛ rot necessarily

SUMMARY OF CHARACTERISTICS

OF AIR AGENCIES

FIGUAE 2-2 
carriers, while icheduled air taxi operators known as "commuters" are similar to the scheduled air carriers. The distinction lies in the size of the aircraft operated. Exemptions b-asently cover all operators using aircraft with a maximum certificated gross weight of 12,500 pounds or a carrying capacity of 30 passengers or less with a gross payload not exceeding 7.500 pounds. The Board has indicated a limited inclination to grant waivers to permit AT 20 s to operate aircraft in excess of these limitations upon the presentation of proper evidence showing public need and convenience; ATCOs operate under the regulations contained in Part 135 of the FARs, under close supervision of FAA inspectors, as do the large carriers under Part 121.

Helicopter Operators have been involved in all phases of the above air agency descriptions with the exception of trunk line operations. Their certificates and regulations (Part 127) differ with respect only to giving proper acknowledgement of the unique chariacteristics of rotary-wing aircraft.

Intrastate Air Carriers do not fall within the jurisdiclion of the CAB since they are not, by definition, engaged directly in interstate ait transportation. They are, however, indirectly engaged in interstate air transportation by carrying goods and persons who are in the course of interstate commerce, in presumably sufficient volume to justify $C A B$ regulation, if the Board chooses to do so. These carriers operate large aircraft as the certificated carriers do. For the most part, the states have attempted to fill this regulatory void through the regulation of intrastate carriers by state public utilities commission or other equivalent agencies. Some states are alsu attempting to regulate scheduled air taxi jperators on the grounds that a regulatory void has been created by the CAB.

Whether or not the courts will decree the exemption process implemented by the $C A B$ to be a sufficient abdication of its regulatory responsibility to leave a void justifying state intervention is still to be seen. Preliminary court decisions sciem to indicate a tendency to preserve federal control. The fact that the federal government elected to grant exemptions is construed to be an affirmative assertion of its control ir, that area of interstate air transportation. The courts are likely to recognize this posture in view of its long-standing unchallenged acceptance.

There are currently no attempts or, the part of local governments to regulate interstate or intrastate air transportation.

\section{Airworthiness}

Responsibility for assuring the ainworthiness of aircraft and their components is assumed by the federal government on the theory that aircraft are instruments of interstate commerce. As with airmen and agencies, the responsibility is discharged by writing regulations setting minimum safety standards for the characteristics of the product, prescribing certification requirements and procedures, and setting limits on operations.

In figure 2-1 the Federal Aviation Regulations bearing directly on the characteristics of the product are Parts 23 through 35, known collectively as the Airworthıness Regulations; Part 36. concerning noise; Part 37, concerning certain components; and, Part 39, concerning mandatory actions to increase specific product ainworthiness. Parts 91 through 135 cover certification and/or operations, and Part 21 sets forth the procedures for certification. Parts 91 , 121, and 135 influence the design characteristics of aircraft, as well as operations.

\section{Philosophy}

The Federal Aviation Administration is charged with promoting the safety of aviation. The following are the ger aral concepts observed explicitly or implicitly in writing regulations which help discharge their responsibility in regard to airworthiness:

(1) The FAA takes no view of "mission performance." The top speed, range, and carrying capacity can be anything the airframe manufacturer chooses, the takeoff and landing field length requirements can be selected by the m.anuiacturer, and so on.

(2) Certain items of performance. however. do impinge directly on the safety of flight. For these items the Administrator will set what are considered to be minimum safe values, writing these into the regulations, either as definite ni'mbers or as algebraic expressions utilizing parameters which are themselves set by the manufacturer, are prescribed. or are representative of an observable or idealized environment.

(3) As far as is practicable, the FAA sets standaras on what an airplane must do, rather than on what it is. An airplane when stalled must pitch down, for example, and within certain limits it is known how to configure it so that it will do so. The FAA will not prescribe the configuration, but contents itseif by implying that a full stall is characterized by uncontrollable pitch down. 
(4) On the other hand, prior art is recognized as having given the airplane certain definitive configuration and pertormance characteristics-it has wings, a tail, one of a small number of engine types, and so on; the cockpit controls and instrumentation are all of familiar sorts. When in order to set a standard of safety it is necessary to refer to such items, the FAA does not hesitate to do so. It prescribes the location of the primary flight instruments on the panel, the shapes of some of the control knobs. the positions, angles of visibility, and color and brightness of the red, green, and white position lights, and so on.

(5) Maintenance of an acceptable level of safety demands that the entire process of fabrication be monitored and controlled. The regulations, therefore, cover every aspect from the properties of materials chosen through to the manufacturer's production certificate and the certificates held by the operator and his individual employees

(6) The regulations are the product of many years of experiences which have served to indicate what an airplane should (and should not) do and be to be safe. To assure that these experiences are utilized, the regulations are updated continually.

(7) The regulat ons are intended to be as explicit $\varepsilon=$ possible. The words "each" and "must" appear time after time to insure that the manufaciurer has no doubt about t ie extent and degree of his responsibility.

(8) There is an implicit recognition. however, cf the fact that there are limits to what can be done and still keep the airplane a viable transportation device. The regulations surrounding the structural design for example, do not prescribe the high safety factors often seen in the design of ground structures. Instead, the loads to pe applied to the structure in the course of normal flying are estimated as accurately as can be done, and the structural components are designed to resist these loads while developing almost the highest stresses they can without failing, thus producing an airframe of minimum weight.

(9) There is also an implicit assumption that knowledge of the degree of risk somehow permits that degree to be higher. The argument goes that passengers on an air-carrier airplane deserve greater protection than do those of a general aviation airplane. since the transport passengers presumably are unable to assess the risk they are assuming when they board, while the general aviation passengers somehuw are able to do so. The logic of this is elusive and there may be other "public interest" type points in support to be made instead, but the fact remains that the provisions of Part 25 are more dotailed than those of $\mathrm{Par}^{\text {rt }} 23$.

\section{Content}

The Federal Airworthiness Regulations place definite technological constraints on what the manufacturers do. Below, for illustration, is a condensed outline of the contents of Part 25; other airworthiness regulations are similar:

$$
\begin{gathered}
\text { Subpart A - General } \\
\text { Subpart B - Flight } \\
\text { Performance } \\
\text { Stability, Control, Trim and } \\
\text { Stalls } \\
\text { Ground anc Water Handling } \\
\text { Characteristics }
\end{gathered}
$$

Subpart C - Structure

Flight, Ground and Water Loads

Fatigue Evaluation:

Lightning Protection

Subpart D - Design and Construction

Systems, Control Surfaces, Landing Gear

Accommodations

Environmental

Emergency, Fire Protection

Subpart E - Powerplant

Fuel, Oil, Cooling, Reduction and Exhaust Systems

Controls and Accessories

Fire Protection

Subpart F - Equipment

Instruments

Lights

Sa'ety

Miscellaneous

Subpart G - Operating Limitations and Information

Limitations

Marking and Placards

Airplane Flight Manual

Appendices

\section{Certification of Aircraft and Components}

The following means of obtaining ap.proval for aeronautical equipment exist:

(1) Type Certificate: airframe, its engine, and its propeller are Type Certificated.

(2) Technical Standard Order: A component which has been "TSO $d$ " may be installed on any airplane for which it is suited, without separate approval.

(3) Approval: A new component may be 
tested and approved for instaliation on a new airplane receiving its Type Certificate. This meets the regulatory requirement for the aircraft that certain items of its equipment be "approved." However, unless the component is subsequently "TSO'd" it is not in general eligible for use on another airplane, since in theory it is part of the airplane that was Type Certificated.

\section{C'nanging Airworthiness Regulations}

There are three means by which Airworthiness regulations may be augmiented, altered, or adapted to specific occasions:

(1) Amendments are actual changes in the body of the regulations. They are typically promulgated by the FAA itself in response to what appears to be a need being experienced by the entire manufacturing industry. The FAA follows the standard procedure in which Notices of Proposed Rule Making ("NPRM's") are published in the Federal Register (somatimes "Advance NPRM's" are circulated), co:respondence invited, and a date and place for public hearings set. Anyone interested can respond, but 1i: practice those who do so are mostly the manufacturers who will be affected by the proposed :hange. At the close of the hearings the FAA sets forth, again in the Federal Register, a summary of the comments received. FAA's conclusions with regard to them, and the exact wording of th,e regulatory change. The subscribers to the applicable regulation receive Notices of Amenument, with publication and effectiveness dates, plus revised pages for the regulation itse:.: The Notıce of Amendment again summarizes the reasons "ar it and tue industry response, for background reference.

(2) Special Regulations are similar to Amendments in general handling, but do not affect the basic Airworthiness regulations since their applicability is limited. For example. CAR 4 (the predecessor of FAR Part 25) was iound to be inadequate in dealing with the determination of the takeoff field length requirements of turbine airplanes. Special regulations were therefore written.

(3) Special Conditions are a concessıon to the f tct that manufacturers will (contrary to some f sople's opinions) push the frontiers of the design art forward. and will produce desıgns of tipes with which the existing regulations simply cannot deal. Nevertheless the FAA must in some way approve the safety of a new product by amending the basic regulation for that product only.

Special conditions are established through a series of arguments between the manufacturer's representatives and those of tile responsible FAA Regional office, and frequently those of the FAA in Washington. Proposals are made by both sides and discussed in committees. The result is usually a compromise of some sort, because in the last analysis the FAA will not regulate the new type out of existence since the manufacturer has legal recourse.

The basic regulations can also be "clarified" by the issuance of Advisory Circulars. The Advisory Circulars can be commentaries on anything at all, but when used for this purpose they will specify what tests or criteria can be applied to meet the provisions of the basic regulation. The typical language is:

"This circu!ar sets forth a means, but

not the only means, whereby compliance with FAR 25 Par. 25.xxx may be demonstrated."

Since the manufacturer desires clarity in the regulations with which he must comply, he is very likely to standardize on what is set forth in the Circular, thereby in effect (though not in law) making it a part of the regulation.

\section{Demonstrating Compliance}

Unlike criminal law. wherein the burden of proct is on the accuser, in many regulatory areas the burden is on the manufacturer actively to demonstrate his compliance with the provisions of the regulations. This applies to the Federal Aviation Regulations, and in airworthiness work it is reasonable and economical of time and effort. The manufacturer developing a new type airplane is assumed normally to have the facilities and equipment for demonstrating the airworthiness of his product. The FAA in tuin is relieved of the necessity of spending public money for large amounts of complex equipment, aithisugh it does have some-smali items such as phototheodolites and trailing airspeed bombs - which it will lend or bail to the manufacturer.

The process of demonstrating compliance is contilual throughout the development program. The evidence that the demonstrations have been made takes the forms of:

(1) Drawings of the aircraft and its parts, a complete set of which must be submitted to the FAA Regional Office. The demonstration airplanes, or components therecf which aie used to demonstrate compliance. must be certificated by the manufacturer to be "in comformity with the type design" of which the drawings are representations.

(2) Reports of analyses and tests. An ex- 
ample of analytical reports is the "Basic Loads" report, which sets forth the computations of the external aerodynamic, ground and water loads generated on the aircraft in operation. A typical test report is that of a structural test of a component. Conformity statements must be written for each tested component, and all analyses and tests must be witnessed and signed by a representative of the FAA.

In most cases the means of demonstrating compliance are well knowri and used countrywide. lin cases where they are not, they must be decided by negotiation, which the manufacturer initiates by writing proposals for the demonstration methods.

\section{Ainworthiness Directives}

The FAA keeps watch over the condition of individual aircraft of every type. It can extract portions of aircraft log books to show where additional inspections, modifications or parts replacements need to be made because of inadequacies in design which can be shown only when the type aircraft has been in operation and developed "bugs"-cracks in structure, possibilities for faulty system operation. frequent system fallures. The manufacturer keeps watch too. through his Customer Service Department, and whenever such a defect appears. an evaluation is made of the various means of eliminating it. This results in the issuance of Service Bulletins inviting the owners to take action, sometimes accompanied by ratrofit kits to help with the job.

As long as the manufacturer keeps ahead of the situation the FA.A will take no action. If he does not in any particular case, the FAA will issue an Airworthiness Directive (AD) which prescribes the action to be taken, gives the constructor numbers of the affected aircraft. and sets the deadline for accomplishment if applicable. An $A D$ can prescribe anything írom more frequent inspections to grounding the type until the provisions of the $A D$ are complied with. Manufacturers are typically alert to and anxious ahout defects which may lead to AD's. especially on airplanes in current or recent production. and are usually reasonably quick to forestall an issuance by publishing service bulletins. sending out retrofit kits. and issuing engıneering changes for production. The FAA knows this, anc' in any case which can result in an $A D$. it informs the manufacturer ahead of tinie in order to allow him to take action on his own. This system ma' sound too permissive. but ir. practice it work:s well, though of course. not perfectly The rarity o, aircraft accidents due to hardware fallure attests to this.

\section{Legal Status of Regulations}

Until a very few years ago, the issuance of the aircraft type certificate, manufacturer's production certificate, and airworthiness certificates for individual airplanes was sufficient to lay to rest any questions of airworthiness arising from incidents or accidents. However, recent product liability cases are destroying the protection afforded by the regulative structure, in a few cases revealing unsuspected flaws. Contributory negligence of the operator is no longer a defense for the manufacturer, nor is the existence of type certificate, current airworthiness certificate, or any other documentary evidence. "Reasonable care" in design or manufacture is collapsing, and the "implied guarantee" of the manufacturer in marketing the aircraft is interpreted quite all-inclusively.

An illustrative case (rather an extreme one) is that in which a twin-engined airplane suffered an engine stoppage on takeoff, after having made a high-speed taxiing turn onto the active runway. It was shown by tests that if the speed were high enough and the turn short enough the fuel line from a tank would unport. causing a loss of fuel supply and subsequent engine stoppage. High speed turns onto the runway just prior to takeoff are considered foolhardy by the aviation community and are not generally practiced; the certification pro. cedures normally do not contain tests of this nature, and the manufacturer had performed none. This did not protect the manufacturer. however

The tiend of such cases is to put on the manufacturer the burden of making his product both airworthy and foulproof. Since there is a large. if not limitless, number of ways to get in trouble with an airplane, as well as to attack the credibility of the manufacturer in court. these product liabılity suits are becoming a burden to manufacturers, and the eventuai $\epsilon^{\prime}$ cts will be to make the process of aircraft development slow and overexpensive, and the price of the product ever, higher than it is now.

\section{Operation}

United States civil alrcraft operated within the borders of the country, and air carriers operated Jotn within the Linited States and in international commerce. co so under the provisions of the General Operating and Flight Rules (FAR Part 91) or the Certification and Operations regulations for air carriers and commercial operators of large aircraft (FAR Part 121) Air Taxi operators are under a separate regulation (FAR Part 135). 
Part 91 has no material pertaining to certification. The sections dealing with operations, however, have much in common. To display both the certification and the operation content, the topics dealt with in FAR 121 are presented below in condensed form:

Subpart A - General

Subparts B, C, D - Certification Rules for Air Carriers

Subparts E, F - Approval of Routes

Subpart G - Manual Requirements

Subpart H - Aircraft Requirements

Subpart 1 - Airplane Performance Operating Limitations

Takeoff

Weight

En route

Destination

Subparts J, K - Special Airworthiness, Instrument and Equipment Requirements

Subpart L - Maintenance

Subparts M, N, O, P - Airman, Crewmember, and Dispatcher Qualifications and Training Requirements

Subparts Q, R, S - Flight Time Limitations (Personnel)

Sibpart T - Flight Operations

Subpart U - Dispatching and Flight Release Rules

Subpart V - Records and Reports

Subpart W - Crewmember Certificate, International

There are several Appendices.

\section{Interaction of Airworthiness and Operating Regulations}

As mentioned earlier, the FAA takes no position on performance except as it relate. to safety. The Airworthiness regulations are the device by which tha FAA seeks to insure safety in design and constructicn. However, the FAA also seeks to insure safety in cperations, and to this end they write the Certification and Operating Regulations. These have their impact on aircraft design (particularly on the design of large commercial aircraft) in the following ways:

(1) A certificated air carrier cannot operate his aircraft unless he carri is on board certain items which are not iterns of required equipment in the airworthiness regulations. For example, a manufacturer can certificate an airplane without supplemental oxygen equipment under Part 25, and that Part will tell him what the tecnnical requirements for a supplemental oxygen system are. But the actual requirement for such a system is spelled out under Part 121.

(2) The Airworthiness Regulations are not concerned with the range of the aircraft, so they make no statement about total fuel capacity. But the operating rules are concerned with it, and the concern is expressed as a fuel requirement in this typical form (91.23): No person may operate a civil aircraft in IFR conditions unless it carries enough fuel...to:

(a) complete the flight to the first airport of intended landing;

(b) fly from that airport to the alternate airport; and,

(c) fly thereafter for $\mathbf{4 5}$ minutes at normal cruising speed.

(Some qualifying statements follow the statement above.)

(3) Part 91, in a section for large airplanes, and Part 121, prescribe the composition of the flight crew.

(4) Part 121 makes provisions for limiting the weight of an aircraft at takeoff and landing. The provision for landing states that no person shall take off an airplane, if its weight on arrival at its destination will be more than the weight allowing it to stop within the first 60 percent of the runway. The takeoff weight provisions are more complicated.

The effect of these rules is simply that the manufacturer looks in both directions when generating a new design. : When the provisions of both regulations impact in the same area, such as those for takeoff, the manufacturer includes in the Airplane Flight Manual-an airworthiness document-such operating informatirn as will enable the pilot to comply with both regulations simultaneously. The so-called FAR takeoff field length, charts (which are actually weight-limit determination means) are examples of the technique.

The fuel reserve provision and the equipment provision are met by establishing the airplane weight and fuel capacity at which the desired range may be imet, considering the reserves and extra equipment as dead weight. The same is done with the flight crew requirements: the additicn of a flight attendant requirement simply increases the weight and seating capacity of the airplane. 


\section{Comment}

Some persons have been critical of the Airworthiness regulations from the viewpoint that they stifle the design process. They cite the 61 knot stalling speed of Part 23 as a prime itlustration, and perhaps go on to other things, such as the requirement that an airplane pitch down when it stalls, and so forth.

It should be pointed out in this record that there are two means of "bending" the regulations to accommodate ad!anced designs: (1) Special Conditions and (2) Demonstrations of "Equivalent Safety." When a manufacturer feels that his product cannot meet a provision of the regulations as written, he may demonstrate that the airplane is just as safe with what it can do. Equivalent safety demonstrations can be expensive and long-drawn out, because safety levels are hard to rank-order.

It should be remembered that regulations are the equivalent of case law-they reflect what has been done wrong in the past. Since the future pres.smably will be different and the mistakes different, the regulations can apply only to present art-not to future art. If airplanes are always built within the regulations, they will always be built within the present art or very minor extensions of it. But the art as actually practiced will progress in some direction, and the future will generate its own regulations responding to what is done wrong then. Meanwhile the present regulations prevent us from repeating our past mistakes, and the means of bending them to the demands of the future are thiere.

\section{Pilot Qualifications and Certification}

The Federal Aviation Act of 1958 placed the responsibility of certifying pilots, airplanes, flight schools, ground personnel, etc. . with the Federal Aviation Administration. The FAA meets this responsibility by establishing and publishing the requirements for certification in a series of directives or mandates called Federal Aviation Regulations (FARs) which are revised and updated from time to time. The FAA also issues licenses to individuals, the basic authorizations to fly an airplane.

Two sections of the Federal Aviation Regulations (Part 61 and Part 141) deal with the requirements for certification of pilots. A person s:einpting to qualify for a private pilot's certification may do so by satisfying either set of requirements. Part 141 deals with the kind of training received when a student is enrolled in a certified flight school while Part 61 deals with the kind of training received when a student is placed in the hands of an individual certified flight instructor.

Flight certifications are issued at i levels: (1) student, (2) private, (3) commercial !required of any pilot who receives compensation for flying). (4) airline transport, and (5) flight instructor.

Since the bulk of the nation's general aviaiion fliers are either students, or hold private or commercial licenses, this discussion will be limited to those certificate levels.

Within vach certificate level there are three differeni kinds of ratings which an individual must receive in order to fly. For a student. ratings are added by his flight instructor, while holders of Private and Commercial certificates have ratings added by the FAA or by the FAA's designated examiner. The three kinds of ratings are: (a) category ratings, (b) class ratings, and (c) type ratings.

A category rating deals with the kind of aircraft and is for either: (1) lighter than air (balloons), (2) gliders, (3) airplanes, or (4) rotorcratt (helicopters).

Within the category rating "Airplanes" (above) there are four class ratings: (1) single engine, land planes: (2) single engine, seaplanes; (3) multi-engine, land planes; and (4) multi-engine, seaplarizs.

Type ratings apply to any turbo-jet powered aircraft and to all airplanes over 12,500 pouncis takeoff weight. An individual wishing to fly a light jet airplane or a plane heavier than 12,500 pounds must have a rating for that particular aircraft; however, a person who wishes to fly any model of light plane may do so with a private pilot's license provided he haye proper class and category ratings described above and that he flies alone. To carry passengers, the regulations become more demanding: he must have made 3 takeofts and landings within the last 90 days.

In addition to the above ratings, there is a special rating which must be ashieved to fly on instruments. Table II-I sets out age, medical. knowledge, skills, and experience requirements for a private pilot's certificate is designated by FARs of October 1, 1974. In prictice. the average student obtaining a private pilot license under FAR 61 receives about 65 total flight hours extended over a period of approximately one year while the student certifying under FAR 141 in a concentrated study at a flight school usually totals about 55 hours flying time in a shorter time. 


\begin{tabular}{|c|c|}
\hline \multicolumn{2}{|c|}{$\begin{array}{l}\text { FEDERAL AYLTION REGULATIONS FOR CERTIFICATION AS A } \\
\text { PRIN ATE PILOT, AIRPLANE CATECORY' }\end{array}$} \\
\hline Minimum Age & 17 years old \\
\hline Medical Examination & minimum: 3rd class medical certificate \\
\hline Knowledge ${ }^{2}$ & $\begin{array}{l}\text { 1. FARs applicable to privale pilots } \\
\text { 2. VFR navigation } \\
\text { 3. Recognition of critical weather conditions } \\
\text { 4. Safe and efficient operation of airplanes }\end{array}$ \\
\hline Proficiency & $\begin{array}{l}\text { 1. Preflight operations } \\
\text { 2. Airport and Traffic Pattern cperations } \\
\text { 3. Flight Maneuvering, Grourd Reference } \\
\text { 4. Slow Speed Fiight } \\
\text { 5. Normai and Crosswind take-offs and landings } \\
\text { 6. Instrument Control and Maneuvering } \\
\text { 7. Cross-country Dead Reckoning and Radio Navigation } \\
\text { 8. Maximum performance take-offs and landir.gs } \\
\text { 9. Night flying. VFR conditions } \\
\text { 10. Emergency operations }\end{array}$ \\
\hline \multicolumn{2}{|l|}{ Experience: } \\
\hline Dual hours & 20 \\
\hline $\begin{array}{l}\text { Soio or Pilot in } \\
\text { Command hours }\end{array}$ & $\begin{array}{l}20 \text { (including } 3 \text { solo take-offs and landings at airports with } \\
\text { a control tower) }\end{array}$ \\
\hline Solo Cross Country hours & $\begin{array}{l}10^{4} \text { (each flight must be more than } 50 \text { nautical miles with } 1 \\
\text { fligth with landings at } 3 \text { points each at least } 100 \text { miles from } \\
\text { others) }\end{array}$ \\
\hline Dual Cross Country hours & 3 \\
\hline Instrument Flight hours & 10 \\
\hline Night Flight hours (local) & 3 (including 10 take-offs and landings) \\
\hline $\begin{array}{l}\text { 'Tabled entries are for FAR Part } \\
\text { 'FAR Part } 141 \text { requires } 8 \text { nours } \\
\text { 'FAR Part } 141 \text { requires } 35 \text { hours } \\
\text { - FAR Part } 141 \text { requires } 5 \text { hours }\end{array}$ & $\begin{array}{l}\text { noted } \\
\text { ground discussions (briefings and de-briefings' } \\
\text { tume } \\
\text { ry solo flight time }\end{array}$ \\
\hline
\end{tabular}

Although certificates never expire, to use them (i.e., to fly), a pilot is required to have a physical examination periodically depending upon the level of his certification. For example. private pilots are required to have physical examinations every 2 years, commercial pilots every year, and airline transport pilots every 6 months.

FAR 91 deals with operating rules. In theo$r y$, a pilot's certificate may be removed for violation of these regulations or with violation of the certifiration rules in Part 61. Because the highest priority of the FAA revolves around commercial flight operations, FAA observers are spread out too thin in practice to monitor the bulk of private pilot behavior. Thus, the FAA is a relatively weak enforcer in general aviation. Most monitoring is done by the pilots themselves and peer pressure is an effective enforcer. When a violation is reported to the FAA that agency usually writ: $s$ to the pilot involved stating that he may have been in violation and asking for his statement. The pilot may support his behavior or he may confess to the violation and surrender his pilot's certification for suspension up to one year. Commercial piluts 
found in violation of FAR regulations are frequently given civil penalities such as fines.

\section{AIRPORT ADMINISTRATION AND FINANCE}

\section{Introduction}

Airport administration and finance are highly interdependent. The governmental level of the sponsor of the airport, e.g., federal, state, or local, bears heavily on both the structure of the admiristration and the financing possibilities of airports. The two subjects will be treatad separately below, but with necessary cross referencing.

Manj airpcrts in the United States grew from grass strips, privately owned, on what was then the edge of town. Population growth brought traffic, revenue, and increased local demand for airport facilities. This derrand was originally based as much on civic pride as on economic feasibility. The airport was considered to be a governmental function, and not expected to break-even and certainly not make a profit. Local citizens in the communities with sufficient wealth voted approval of bond issues to originate and improve small airports.

Some communities, not so well endowed, came intc a windfall when the Surplus Airports Act authorized the transfer of Worid War II military training fields to local communities. Many which would not otherwise have been able to afford an airport suddenly owned cne. Assisted to some extent by the airport, the loss sustained in operations was minimized and the loca' taxes made up the difference.

The depression, although it set all development back to a large extent. provided another windfall to pi:blic airports through the Works Project Administration (WPA). This "make work" program expended millions of dollars on airport improvenient and construction.

The Federal Airport Act of 1946 authorized expenditure of up to $\$ 100$ million anriually over seven years on eligible projects at local aırports. This Act was replaced with the more extensive Airport and Airways Development Act of 1970. providing considerably more funds and easing the financial problems of airports to snme extent.

\section{Administration}

The classification of airports by function was discussed in the previous chapter. The administrative structure of an airport is, however. more dependent on its size than it is on its func- tion. Thus, a small air carrier airport may have a similar administrative structure and the same number of employees as does a large general aviation airport, if they both have approximately the same number of operations. An airport's level of activity seems also to be related to the level of government owning and operating the facility. The higher the level of government, the larger the airport tends to be.

\section{Owners and Sponsors}

Inasmuch as the size of an airport determines the governmental level of sponsorship, the size of the political subdivision may also be a significant factor limiting the size of the airport. This is especially true since capital expenditures for improvements are limited by the total assessed valuation of the taxing authority involved. However, airports are frequently owned by towns located near large metropolitan areas and may draw substantial traffic from the population hub. Such airports may generate sufficient surplus funds to support capital improvements independent of tax support. It is thus difficult to generalize a relationship between the sizes of airports and the political subdivisions they serve.

Many cities own and sponsor airports, which are thus financially supported by public funds raised mainly through property taxes. This may frequently lead to problems of conflict of opinion as to need for airport improvements. In large cities, such as Baltimore or Philadelphia, where the more affluent have moved to the suburbs, the remaining population may see little need for frequent use of an airport. In fact some may never expect to see it. and therefore quite naturally are not interested in approving city bond issues to support airport improvements. In some instances this has led to state ownership of the airpcits. State ownership, as it now exists in Baltimore and has existed in Connecticut for some time. has the advantage of spreading the tax investment over a much larger base. It also enhances the probability of obtaining matching funds to qualify for federal grants for airport impro 'ements.

Aside from the question of desirability. locally owned airports are usually operated by locally oriented political bodies such as town boards, city councils, and boards of supervisors. Frequently the airport serves a much larger community and airport needs are not necessarily consistent with the desires of the citizens of the community in which it is located. In fact, quite frequently the opposite is trueeveryone wants the airport in someore else's backyard. Since the local governing body will 
be dependent on local support, it may be more responsive to the local sympathies than to the needs for airport improvement. If, on the other hand, the airport is owned by the state, the state representatives from the local airport community may oppose or support improvements according to the dictates of the local electorate. This could occur without adequate consideration of whether or not the improvement is needed for the benefit of the larger community or the entire state. The opposite might also hold, and a diversified state legislature may not be responsive to local airport needs. State aeronautics departments usually tend to support airport development and keep the legislature appropriately informed to assure proper attention to the overall state airport system.

Where an airport's community of interest extends over several political subdivisions, each subdivision may have its say in the airport operation through an independent authority as expressed by its representatives who are appointed to the airport board. The authority may own th.e airport or merely operate it. It may also have taxing authority for airport development purposes, sometimes with limited time spans and almost always with a ceiling placed on the percentage of total assessed valuations. The authority may also enjoy political independence, as is the case with state operaced airports. This may result in its becoming insensitive to the desires of the local community.

This code of sponsorship is frequently desirable from the tenants' point of view. especially since the total revenue is retained by the authority and generally expended for airport purposes oniy. While some of these revenues may be spent on such facilities as roads. bridges, subways, or even office buildings, this is often preferred to the possible loss of revenue to the general funds of a city's. town's. county's, or state's. At most airports operated by municipal or county governments all airport revenues must by law be paid to the general government fund, and thus made available for appropriation for non-airport functions by the local governing body. This often tends to frustrate efforts at airport improvements.

The determination of who will operate an airport is dependent on both its size 'function. Generally there are four najor possibilities:

(1) At very small airports there is frequently insufficier:l revenue to generate funds to cover an airport manager's salary and an income for a fixed base operator (FBO). Some communities have overcome this problem by appointing a combined manager and FBO, thus providing a salary or partial salary only, yet permitting the manager to receive the proceeds of the normal FBO functions. At a new very small airport, the revenue is seldom sufficient to support a fixed base operator so this model might be the only alternative to sponsoring an unattended airport.

It is usually necessary for the small municipally operated airport to depend on various municipal departments for support functions such as runway maintenance., lawn mowing. snow removal, and legal aid. These airports might also have to depend on air traffic control facilities at nearby airports, because they usually have either unmanned towers or no towers at all.

(2) Many medium-to-large size general aviation airports generate sufficient rever.ue to make the employment of an airport manayer feasible and still leave adequate revenue for an FBO. Such airports often have lımited local air carrier service, and are thus able to afford a limited staff.

(3) Large airports, both air carrier and general aviation, have professional airport managers with staffs of specialists in such areas as operations. administration, and mainteriance. The tenants of such airports usually include FBOs who bid for rental rights and for the right to serve aviation needs at the fields. Many FBOs at that level are highly specialized and provide a single service such as fuel, flight instruction, or avionics maintenance.

(4) The airport authority approach usually involves an administrative struct" 're similar to that of a municipally operated $f_{\text {, sility, with an }}$ in-house staff for handling specialized functions.

\section{Finance}

Because airports are commonly operated by public bodies they are often not conceived of as monopolies. This, however, is true since the user has little choice in selecting an airport once he has chosen his ultimate destination. General aviation and scheduled air carrier pilots are usually captive clients. who do not have the choice to taxi down the street to another gas station where the fuel might be cheaper, except in some instances of preferential refueling.

Monopolies are normaily regulated to pre. vent abuses in the levels of rates and services. While the market has historically been in the buyers' favor, many airports are presently sers. 
ing more than or close to the volume of traffic necessary for an economically feasible operation. With this financial maturity come both the opportunity for innovations in airport finance. and the necessity for governmental regulation, as witnessed by the introduction of airport certification through FAR Part 139. Although restricted in its applicability to airports served by certificated air carriers, it was the first exercise of major governmental control bevond prescribing prerequisites to obtaining federal funds and grants for airport development. In addition, regulation necessitated by essential security measures added to the momentum toward the federal i gulation of airports. Will the authority to approve rates and charges for rentals and landing fees be among the future areas of control as a result of this momentum? It appears that the authority is indeed present and rer ognized by the FAA as is clear from its requirement that airports charge only reasonable and non-discriminating fees

\section{Models of Airport Finance}

There are four common models on which airport financial policy can be based. These are: (1) the general benefit model, (2) the breakeven model, (3) the public utility model, and (4) the industrial model.

The general benefit model applies to small airpo'ts and is thus perhaps the most common. These airports do not generate sufficient revenue to cover their operating costs and the debt service on improvements (or depreciation if the improvements are already paid for). This situation requires partial funding from the political subdivision suonsoring the airport The subsidy is justified on the basis of the need for supporting public facilities from which all citizens derive either a direct or indirect benefit. The social and economic benefit of airports to communities by way of creating employment and promoting commerce and tourism have been suggested in a number of studies and will be the subject of other parts of this report.

The break-even model is the most widely accepted by both airport operators, users, and gcivernmental bodies. In this model the airport is expected to generate sufficient revenues to cover the costs if sperations and amortization and/or depreciat on, as appropriate.

At this point the "single cash register" airport or the airport with an independent financial structure, warrants some discussion. Under this concept all revenue is retained in a fund separate from other governmental accounts. and all revenue is applied to the cost of operations, amortization of debt, or other airport costs. None of the funds are diverted to other governmental use. Surplus revenue (profit), although inconsistent with the true break-even model, if invested in airport capital improvements does not disqualify the airport from this classification. The reinvestment of surplus revenue in capital improvements, tends to be treated as prepayment of, or payments in lieu of, future amortization.

It seer s that tenants and users are not disturbed by ieasonable surplus generated by the fees they pay, so long as they are comforter with the knowledga that the surplus will be "plowed back" into the airport.

Dulles International Airport, operated by the FAA, is a good example of the break-even concept. Airline "use agreements" or leases break down the original payoff period into three 10-year spans. The first is an operating loss period, the second a break-even, and the third is a profit period where the initial losses are recovered.

This approach is extremely well adapted to the ability of users to pay the required fees. Traffic builds up with time and the base over which the charges must be spread is constantly increasing. It is therefore possible to have increasing gross revenues without appreciable rate increases. Rate increases would only be necessary in order to accommodate rises in costs associated with the provision of services which cannot be covered by increased revenues.

The public utility model is most frequently proposed by those communities which ow'n successful airports in highly popuiaied areas drawing their revenue from diversely originating passengers. The profit is therefore at least rartially from residents of other communities. Under this model the airport sponsor is assured of generating sufficient revenues to meet the airport's operating costs, debt service. and/or depreciation, and to generate an acceptable fair rate of return on his investment, similar to the situation in other public utilities. It must be observed, however, that other public utilities are both recognized and regulated as monopolies. As such their rates, efficiency, performance, and accounting procedures are subject to scrutiny and review. This is presently not the case with airports, bu. the possibility for taking such action in the future exists.

The industrial model which allows airports to generate profits in the same sense that industry does, has not riceived wide acceptance It is not appealing to most airport operators because they recognize the public role of air- 
port service; they prefer the assured income approach that avoids the highly fluctuating industrial return. and do not care to undertake the more complicated financing procedures necessary to accommodate wide fluctuation in profit and loss. Most do not want to give up the comfort of assured income not available to the purely market-oriented operation.

Airport Bonding and Sources of Capital

Airport bonds are usually municipal bonds and take the same familiar forms: general obligation bonds or full faith and credit bonds; and revenue bonds. The latter fall in two ger.eral categories: bonds supported by the revenue of the airport only, and special purpose bonds issued against a single segment or function of the airport's revenue.

General obligation bonds are bonds issued against the general obligation of the community issuing the bond. In other words they pledge the full faith and credit of the city, town, or state issuing them. Since the isr.'ing body has authority to levy taxes on local \& - perty to provide amortization funds, the bonds are generally considered a good risk by financial institutions. The tax free interest also acts as an additional incentive to those wishing to invest in them.

Most political jurisdictions are, however. limited in the total amount of bonr., they can issue, relative to the total assessed valuation of real property in the community. Because many citizens, towns, and counties have already reached the limits of their authority to tax, and since many are in poor financial condition because of the exoous to the suburbs, some city-owned airport bonds no longer enjoy their previous appeal.

Because general obligation bonds usually require the voters' consent as expressed in a referendum, airport operators and sponsors often turn to revenue bonds in order to avoid a defeat at the polls. Revenue bonds pledge the revenue of the airport against their amortization. Naturally the rates are higher on revenue bonds, but they still enjoy tive tax-free benefit of municipal bonds and enjoy considerable popularity with financial institutions.

Special purpose bonds are frequently issued by airport sponsors to construct specific projects such as cargo facilities, fuel facilities, or hangars. The special bonds may in that case be issued against the revenue from that suecific project only. The popularity of these bonds is somewhat less than that of the other types for obvious reasons. The success of such a bond issue is more dependent on the probable suc- cess of the particular project and on the credit of the parties obligating rental or royalty revenue by lease or contract.

Build and lease back agreoments may be used either as pledge revenue to support revenue bond issues or against mortgages on facilities constructed for a particular tenant. For example, an FBO may want hangar space at an airport and may be willing to sign a twenty-year lease. The airport may borrow the money, pledging the lease proceeds as a security, and granting conditional possession to the lending institution if the proposed tenant defaults. The institution may then sublease the facility to another tenant, thus continuing the revense flow till the expiration of the debt.

Eanks and other lending institutions have historically avoided financing tenant construction at airports because the title to the land is vested in the airport sponsor. The tenant merely has a leasehold. In the event of default and subsequent foreclosure, the bank has only the leasehold as security, most leaseholds being of the non-assignable or extremely restricted type. They do not present a readily marketable privilege and are therefore not the most desirable security.

Increasing sophistication of many of the medium and large airport sponsors has led to the design of lease clauses containing clearly defined limitations on the assignment or attachment of the leasehold, while simultaneously leaving sufficient flexibility to permit a lending institution to replace the tenant with an equivalent tenant for the remainder of the term.

Because of the financial distress of many cities today and the reluctance of others to devote scarce capital to projects with restricted benefit, many projects such as hangar construction, cargo facility construction, and fuel distribution facilities are being financed in this manner.

\section{Government Assistance}

Most people are oi the impression that the federal aid programs provide the bulk of the funds necessary for airport development. They are also of the impression that the general taxpayers' money goes into the fund. Neither concept is accurate.

Under the previous Federal Airport Act of 1946. funding for airport improvements was derived from airline tax and other aviation sources. These taxes were, however, paid into the general fund and were not actually earmarked for airport or airways improvements.

The Airport and Airways Development Act 


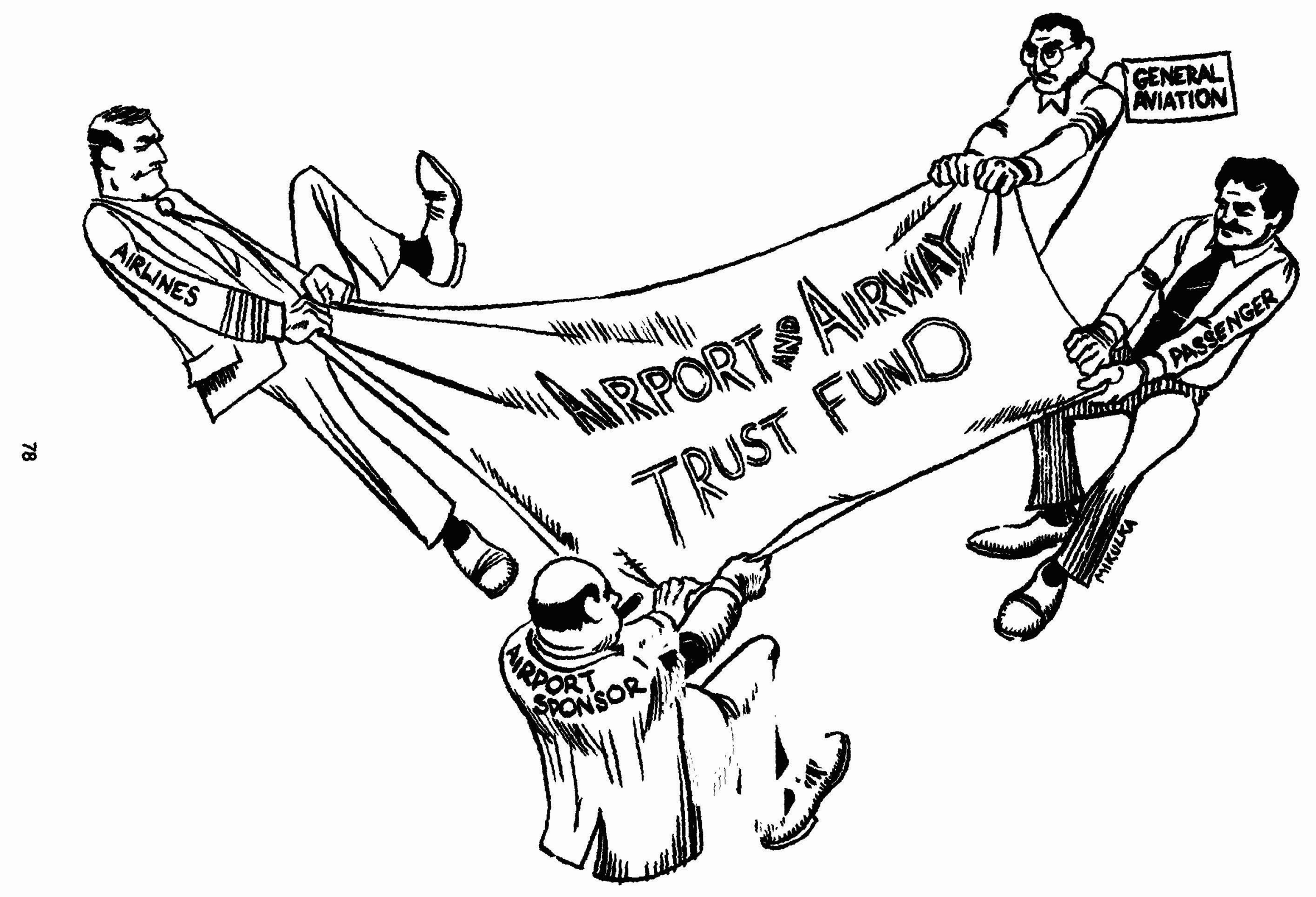


of 1970 incorporated many of the features of the previous act but also introduced many innovetions. The concurrent legislation, the Airport and Ainway Development Act of 1970 provided the funds to carny out the proposed development. Taxes were imposed on airline passenger tares, airline freight or cargo waybills, aviation fuel and related products, aircraft registration, etc. Thus the cost of development was brought home to the user as directed in the act. As protection for the user against the diversion of funds extracted from his contribution, the trust fund concept was imposed and the use of the funds restricted.

The development of the airways system, which was previously supported from general government f'unds, became eligible for receiving $\$ 250$ million per year for the five-year duration of the act.

Airport planning is of course essential to the orderly development of the national aviation s;stem. Therefore, $\$ 2$ million were designated for developing a National Airport Systems Plan (NASP) and provision was made for making individual grants to airports for master planning their own development consistent with the role assigned to them by the NASP.

The funds made available for airport development are divided into two main categories: air carrier airports and general aviation airports. The former are to receive $\$ 310$ million per year (by 19.3 amendment) and the latter are allocated $\$ 30$ million per year.

One-third of the funds is allocated on a statewide basis considering both the population and area of the state. Another third is allocated $n$ n the basis of enplaned airline passengers, which represents the main source of the revenue constituting the fund. The rest is left to the discretion of the administration. General aviation has a similar allocation with different percentage distributions.

The restrictions on eligible projects are numerous. The airport must be in the NASP. The project itself must be completed according to FAA specifications. Another significant restriction is that stipulated by section 20 (b) of the act, which prohibits the use of the funds for any building used for other than safety purposes such as crash and fire facilities. This provision prohibits the expenditure on needed hangars, terminal facilities, roads, and other public facilities on the airport. The recognized rule of thumb in the industry states that for every dollar spent on eligible projects an equal amount will eventually be required on the terminal side to accommodate the additional traffic generated by the improvement.

The act was permitted to expire on July 1 , 1975. As this document went to press, Congressional committees were studying the possibility of extending the act and expanding the list of eligible projects to include public areas of terminals such as waiting rooms, lobbies, corridors, concourses and hold rooms, people-movers, baggage claiming devices, and many others logically related to accommodating the pessenger who is the main source of the funds. The percentage of federal participation under the expired act was 50 percent of eligible projects at large hub airports, 75 percent at smaller airports, and 82 percent for certification or security. The percentage limitations are also undergoing review. The case of 90 percent federal participation in interstate highway facilities is frequently cited to support the argument for changing this formula.

\section{Sources of Revenue}

The successful offering of revenue bonds is dependent on demonstrating the availability of sources of revenue with a high degree of certainty in order to assure sufficient cash flow to amortize the debt. Airports look primarily to airlines, concessions, and general aviation fees, in that order, to generate that revenue. As can be seen, strictly general aviation airports are hard-pressed to produce revenue with the certainty necessary for revenue bond funding. Whereas the airline must serve the airport and is somewhat a captive tenant and user, general aviation aircraft may or may not fly, when and where they choose. By their nature, they are not subject to contractual obligations to assure funds.

The airlines negotiate ieases and useagreements with the airports they serve. The leases usually provide for set rates of squarefeet rentals to cover such areas as private offices, ticket counter space, baggage make-up space and many other areas too numerous to mention. Most accept the policy of rentals for exclusive use areas in terminals, but some dispute still rages regarding the extraction of rentals for areas not under the exclusive control of the airlines.

The rates and charges are generally negotiated and $a^{\text {r }}$ thus acceptable to both parties, even if reluctantly so. Nevertheless, as a result of the airport's monopoly, the airlines really have no choice to reject rates and fees required by the airport. The airport has the authority to establish the rates and charges by ordinance without the consent of the airlines.

One must then ask if federal regulation of 
this monopolistic rate-setting capability would not be consistent with the anti-trust philosophy of our government. Some feel such affirmative regulation is necessary while others feel that the carriers' protection is provided for:

(1) in fact that without the signature of the airline on lease agreements the airport's ability to issue revenue bonds is greatly reduced;

(2) in the fact that upon acceptance of federal funds for improvement, the airport must enter a "grant agreement" with the FAA which prohibits charging unreasonable or discriminating fees; and,

(3) in the fact that generally the airline agreements to a break-even philosophy obligate the airlines senving the airport to review and adjust their landing fees annually so as to assure a loss-free operation of the airport.

The greatest area of dispute centers around proposed improvements to be amortize $J$ as part of the costs underwritten by the carriers. The carriers frequently believe that the improvements may be unnecessary, excessive or, too extravagant. Several airports are presently in court with the airlines over disputes concerning the reasonableness of the rates and fees. Recent economic conditions have made the airlines more cost conscious and less likely to accept unnecessary improvements or expansion.

The landing fees charged to both airlines and general aviation are usualiy based on the maximum gross certificated landing weight of the aircraft, regardless of the actual weight on landing. They range from a few cents per thousand at smaller airports to over $\$ 1$ per thousand ai some large hubs. The airlines and general aviation frequently pay fuel flow charges of set rates per gallon of enplaned fuel. Airports have also generally imposed security charges on the airlines to help cover the cost of additional improvements and operating costs occasioned by federal requirements relating to security measures on airports. The CAB allowed the airlines temporary fare surcharges to meet this contingency, so thie cost has been passed on to the user.

Two categories of concessions usually cover the concession revenues at an airport; aeronautically related and public supported concessions. Aeronautical concessions include a percentage of gross FBO contracts: fuel flow charges; aircraft parking fees; maintenance fees; clearing or turn-around fees, etc Public support concessions include restaurants at 10 percent to 25 percent of gross; auto parking at 25 percent to 95 percent; and many others such as barbers, drug stores, gift shops, and taxi and bus stands.

The general rule of thumb is to estimate future income from concessions on the basis of a per passenger average income of $\$ 1$ to $\$ 2$. This source, at large hub airports, frequently accounts for over 50 percent of the gross revenue and at others is the most significant single factor. Unfortunately at the small general aviation airport there is insufficient passenger flow to generate adequate returns.

In addition to landing fees, fuel flow charges, and percentage of gross on aviation service, such as repairs and maintenance, some general aviation elements pay squarefoot rentals. Corporate based aircraft usually generate demand for office space and frequently lounge space as well. Many airports are solely general aviation and yet are profitable. The volume of revenue may well be there, but because of its relative uncertainty, it is difficult to rely on it as a basis for long-term financing.

Additional financial benefits for the airport may be reaped if the sponsor retains the land surrounding the airport and promotes the development of an industrial park in the area. The "build and lease back" arrangements can be profitable here, and the airport can benefit by an appreciation in the land value.

It is frequently difficult to tell whether an airport is or is not generating surplus revenue. or to make meaningful comparisons of airport fiscal policies. This is due to the lack of standardization in airport accounting systems. All efforts by the federal government, the Air Transport Association (ATA), and others have failed to establish an acceptable standard accounting procedure for airports. The reasons do not necessarily stem from the desire of the airport to hide its financial status, nor from a refusal to cooperate. The problem is a derivative from the more general problem resulting from the fact that each town, city, council, or independently created authority, has by law, certain prescribed accounting procedures to which it must conform. These vary by state and by locality within the state. This is compounded by the demands made by bond indenture agreements and other special situations.

\section{Conclusion}

The large hub airport is generally capable of supporting its own improvements and of functioning on a break-even basis. Airport sponsors proposing the public utility model for airport financing usually meet with formidable opposition from airlines and the federal government. The break-even model therefore seems 


\section{N76 12001}

likely to prevail and the trend toward independent authorities will most likely continue.

Medium and small hub airports will continue their struggle uphill to fiscal independence. More realistic federal airport support policies should help these airports become more independent of the local tax base.

The small general aviation airport appears to be most vulnerable in the temporary economic set back and is likely to suffer most in the cost conscious era to follow. Unless it is located in a hub area which is served by air carrier (not necessarily at the same airport), the airport has little chance of becoming self-supporting and must depend upon continued local tax subsidy. Such airports are becoming less likely candidates for public support as the population perceives a diminished opportunity to use them. Since their revenues are minimal, the possibilities for successful bonding are low. Their continued success will depend on a realistic evaluation of community need and on the use of cost conscious approaches in both capital planning and daily operational policies.

\section{PHYSICAL ENVIRONMENT \\ Introduction}

Noise pollution, air quality, water quality, and land use around jeneral aviation airports are important parts of the physical environment. The planning and construction of public facilities such as general aviation airports should be guided by a desire to achieve the highest possible level of social benefits, with a minimum expenditure of human, physical, economic, and environmental resources. Large scale physical facilities are usually accompanied by undersirable environmental sideeffects.

In an attempt to minimize possible environmental damage resulting from major public undertakings, the National Erivironmental Policy Act of 1969 (Public Law 91 - 190) was enacted to require that for any project which involves major Federal funding, and which significantly affects the quality of the human environment, an environmental impact statement must be filed with the Council on Environmental Quality

\footnotetext{
23 P. L. 191 - 190 Title I, Sec 101, pt C.

n Howard. George P. (Ed) Airport Economic Planning (Cambridge The MIT Press, 1974), p. 425

"I ibid., p. 606

" Stagg v Municipal Ct. of Santa Monica, B2 Cal. Rptr 578
}

(CEQ). This statement must include the following:

(1) The environmental impact of the proposed action;

(2) Any adverse environmentai effects which cannot be avoided should the proposal be implemented;

(3) Alternatives to the proposed action;

(4) The relationship between local short-term uses of man's environment and the maintenance and enhancement, of long-term productivity; and,

(5) Any irreversible and irretrievable commitments of resources which would be involved in the proposed action should it be implemented. ${ }^{25}$

The environmental impact statement should consider ecological factors including (1) noise poilution; (2) air quality; (3) water quality; (4) fish and wildlife; (5) solid waste; (6) energy supply and natural resources development; and, (7) protection of environmentally critical areas such as floodplains, wetlands, beaches, dunes, unstable soils, steep slopes, and aquifer recharge areas.

This section will discuss environmental legislation affecting airports and the more common environmental effects resulting from airport construction, with special emphasis on general aviation airports. The discussion will focus on the regulation of noise, pollution, and water quality.

\section{Environmental Legislation}

Erivironmental legislation which has emerged within the last five or six years may eventually influence the utilization of general aviation airports. One of the primary objectives of the Noise Control Act of 1972 (Public Law 92-574) is to control noise from aircraft and aircraft operations. The FAA is authorized to develop regulations to control aircraft noise emissions, as well as to impose curfews, flight path modifications, or other procedures deemed necessary to protect the public. Among the states with environmental regulations, the State of California has established state-wide controls for noise around airports. ${ }^{26}$ Airport authorities may also control noise: the Port of New York Authority imposes noise standards on the airlines and operators who use its airports. ${ }^{27}$ The right of the operator to control noise through the imposition of a curfew has been upheld in the California courts. ${ }^{28}$ But at least one decision severely limited the power of 
a local government to control noise, in cases where it does own or operate the airport. ${ }^{20}$ This may be an example of the limited control that a community would have over a private airport or possibly an airport just beyond its political boundary.

The 1970 Amendments to the Clean A,r Act (Public Law 91-604) include provision for regional transportation controls. Under the supervision of the Environmental Protection Agency, states are to develop a comprehensive air quality policy which includes land use planning and air and surface transportation controls. ${ }^{30}$ The regional controls will undoubtedly work to reduce automotive traffic-the major source of air pollution-and as such increase the demand for general aviation.

The Federal Aviation Administration affects communities which seek federal funds in acquiring a general aviation airport. Federal airport safety regulations can be fairly costly to the community. If an airport seeks federal funds for expansion under the Airport and Airway Development Act of 1970, it must submit an Environmental Impact Statement. ${ }^{31}$ No project has an adverse effect upon the environment will be authorized if there is a feasible alternative. ${ }^{32}$ On the other hand, the FAA does not tax general aviation for the total cost of its use of the airway system, and thus cost savings may be passed on to the community using the general aviation services. ${ }^{33}$

\section{Aviation Noise}

Noise can be defined subjectively as any unwanted or undesirable sound, or a sound which conveys no information or which interferes with information transmission. Response to aircraft noise is dependent upon a number of factors including sound level, weather, time of day, and numerous human factors. The purpose of this section is to fvaluate the noise effects of general aviation. To do this, noise and noise response measuring scales and forecasting methods are described and attempts to regulate

" Lockheed Air Terminal v. City of Burbank. 411 U S 62412 Avi 17.889 (May 14, 1973)

* Staff of the House Committee on Interstate and Foreign Commerce. 93rd Cong . 1st Sess . Transportation Controls Under the Clean Air Act (Comm Print No 10. 1973). p 52

"Little. Arthur D.. Inc ef al.. Civil Aviation Development: A Policy and Operations Analusis (New York. Praeger Publishers. 1972). p 188

"Ibud., p 188

"Wartord. Jeremy J. Public Policy Toward General Aviation (Washington. D.C. Brookıngs Institute, 1971). p 66

"Dickerson. D. O., of al., eds , Transportation Noise Pollution: $C c$ trol and Abatement NASA-ASEE Summer Faculty Fellowship Program in Engineering Systems Design, 1970. p. 14. noise by different federal ag micies are described.

\section{Noles Scales}

The basic measure of sound level is the decibel (dB) which is defined as a sound-pressure level equal to $20 \log _{10}(P / P$ ) where $P$ is the level of a given sound and $P_{0}$ is an arbitrary sound-pressure level usually taken to be 0.0002 dynes/cm. ${ }^{34}$ The decibel is generally considered to be a poor measure of annoyance and reaction to noise because the human ear perceives higher fir quency sounds as being louder than lower frequency. For this reason, three other scales have been developed. These can be summarized as follows:

(1) Measurement by moter: utilizing the A-Scale sound level, [ $d B(A)$ ], (a measurement that reflects loudness by filtering lower frequencies and weighting higher ones), more closely approximates the response of the human ear, or "loudness." The dB(a) scale has the advantage of being objective, but does not take into accouni the duration of the sound as some of the other scales described below. The dB(A) scale is used in FAR Part 36F which regulates the noise level of small propellerdriven aircraft.

(2) Computation of reaponse to a single exposure: Scales in this category are among the most important because they are the ones used to measure and compute noise levels generated by jet aircraft for the purpose of regulation and certification. They include the Perceived Noise Level (PNdB), which is a measurement of the noise level of maximum itensity during a flyover of an aircraft at specified altitude and engine power, and accounts for the amplitude, frequency, and direction of the sound. Another measure in the category is the Effective Perceived Noise Level (EPNdB), which is subjectively adjusted for perceived noise. It accounts for absolute noise level, noise spectrum, maximum tone, and noise duration. Basically it is intended to reflect perceived noise as determined by human reaction, and is used in FAR Part 36 which regulates the noise level of jet aircraft.

(3) Computation of response to multiple exposure: The measurement and prediction of public response to aircraft noise involves more complex factors than those considered in the scales discussed. Operational procedures, aircraft types, environmental conditions, and people are highly variable. This makes the prediction of annoyance and complaint levels a complex matter. The following facets of an- 


\section{TABLE \|I-\|}

\section{CHART FOR ESTIMATING RESPONSE OF RESIDENTIAL COMMUNITIES FROM COMPOSITE NOISE RATING}

\section{Compoeito Noise \\ Rating (CNR): \\ Takeoffs and \\ Landinge}

Less than 100

100 to 115

Greater than 115
Zone

1

2

3

\section{Description of Expected Reaponse}

Essentially no complaints would be expected. The noise may, however, interfere occasionally with certain activities of the residents.

Individuals may complain, perhaps vigorously. Concerted group action is possible.

Individual reactions would likely include repeated, vigorous complaints Concerned group action might be expected.

Source: CLM/Systems, Inc., Airports and Their Environment: A Guide to Environmental Planning. (U.S. Dept. of Transportation, Washington, D.C., 1972), p.97.

noyance and complaint have been determined:

(1) Estimation of annoyance using noise exrosure as the sole predictor is rather poor.

(2) The inclusion with noise exposure of certain attitudinal or psychological variables affords good prediction of individual annoyance.

(3) An equation can be written for predicting individual annoyance with good accuracy.

(4) Within certain limits the number of highly annoyed households in a community may be estimated from the number of complaints.

(5) An equation for predicting complaints among a random sample. similar to the predictive equation for annoyance, can be written, but its accuracy is questionable.

(6) There is a substantial difference between predictors of annoyance and predictors of zomplaint: predictors of annoyance are primarily physical/attitudinal; predictors of

"Tracor, Inc Community Reaction to Airport Nolse. Vol. II (NASA CR-1761. Washington, 1971). p 223

"Bolt. Beranck, and Newman, Inc. Noise Exposure Forecasts: Evaluation. Extensions ano Land Use Interpretations (FAA, Washington. 1970). complaint are primarily physical/sociological. ${ }^{35}$

Techniques in common use for predicting public response to the impact of noise exposure and for use in land-planning are the Composite Noise Rating (CNR) and Noise Exposure Forecast (NEF). Recently, the F rderal Aviation Administration has developed the Aircraft Sound Description System (ASDS).

The CNR method, which was developed in 1952, is based on PNdB or EPNdB and the following factors:

(1) The average noise level spectrum;

(2) Discrete frequency componentspresence or absence;

(3) Nature of sounds-impulse or nonimpulse;

(4) Sound repetition;

(5) Ambient noise level;

(6) Time of day of the noise; and.

(7) Adjustment for previous exposure of the community to the noise. ${ }^{36}$

Expected response zones have been suggested as shown in Table II-II.

The NEF method involves the use of EPNdB, and attempts to forecast community response by incorporating such factors as absolute noise levels, noise spectrum, noise duration, maximum tone, aircraft type, mix of aircraft, number of operations, runway utilization, flight pattern, operating procedures, and 
TABLE II-III

COMPARISON BETWEEN CNR AND NEF VALUES

CNR

NEF

Takeofis and

Landings

Runups

Less than 100

$100-115$

Less than 80

Less than 30

More than 115

$80-95$

$30-40$

More than 95

More than 40

Source: CLM/Systems, Inc., Airpnrts and Their Environment: A Guide to Environmental Planning. (U.S.Dept. of Transportation, Washington, 1972), p. 99.

\begin{tabular}{|c|c|c|c|}
\hline & TABLE II-I & & \\
\hline ASDS & R TABLES F & ELECTED & RAFT* \\
\hline $\begin{array}{l}\text { Airplane } \\
\text { Model }\end{array}$ & $\begin{array}{l}\text { Down Range } \\
\text { Distance } \\
\text { (Feet) }\end{array}$ & $\begin{array}{l}\text { Aircraft } \\
\text { Altitude } \\
\text { (Feet) }\end{array}$ & $\begin{array}{l}\text { Cumulative } \\
\text { Contour Area } \\
\text { (Acres) }\end{array}$ \\
\hline $\begin{array}{l}C-340 \\
C-340 \\
C-340\end{array}$ & $\begin{array}{l}2400 \\
4418 \\
7899\end{array}$ & $\begin{array}{r}0 \\
426 \\
434\end{array}$ & $\begin{array}{r}34 \\
70 \\
134\end{array}$ \\
\hline $\begin{array}{l}\text { B-707 } \\
\text { B-707 } \\
\text { B-707 }\end{array}$ & $\begin{array}{l}7497 \\
8702 \\
6473\end{array}$ & $\begin{array}{r}0 \\
134 \\
134\end{array}$ & $\begin{array}{l}420 \\
495 \\
369\end{array}$ \\
\hline $\begin{array}{l}\text { B-747 } \\
\text { B-747 }\end{array}$ & $\begin{array}{l}4733 \\
5598\end{array}$ & $\begin{array}{r}0 \\
134\end{array}$ & $\begin{array}{l}256 \\
309\end{array}$ \\
\hline $\begin{array}{l}\text { Learjet } \\
\text { Learjet }\end{array}$ & $\begin{array}{l}5000 \\
6146\end{array}$ & $\begin{array}{r}0 \\
188\end{array}$ & $\begin{array}{l}209 \\
265\end{array}$ \\
\hline $\begin{array}{l}\text { Jet Commander } \\
\text { Jet Commander } \\
\text { Jet Commander }\end{array}$ & $\begin{array}{l}4500 \\
5217 \\
5585\end{array}$ & $\begin{array}{r}0 \\
116 \\
176\end{array}$ & $\begin{array}{l}176 \\
207 \\
224\end{array}$ \\
\hline $\begin{array}{l}\text { Gulf Stream II } \\
\text { Gulf Stream II } \\
\text { Gulf Stream II } \\
\text { Gulf Stream II }\end{array}$ & $\begin{array}{l}5500 \\
5665 \\
6217 \\
6585\end{array}$ & $\begin{array}{r}0 \\
26 \\
116 \\
176\end{array}$ & $\begin{array}{l}278 \\
286 \\
318 \\
340\end{array}$ \\
\hline $\begin{array}{l}\text { Jet Star } \\
\text { Jet Star } \\
\text { Jet Star }\end{array}$ & $\begin{array}{l}5500 \\
5665 \\
6585\end{array}$ & $\begin{array}{r}0 \\
26 \\
176\end{array}$ & $\begin{array}{l}215 \\
221 \\
263\end{array}$ \\
\hline
\end{tabular}

-Data from: Donald Goldman and Francis X. Maginnis, Aircraft Sound Description System (ASDS) Application Procedures, Vol. III, Data Tables (Department of Transportation, FAAEA-74-2, III, Washington, D.C. 1972). 
time of day. Table II-III provides a comparison between the CNR and NEF Scales.

The Aircraft Sound Description System (ASDS) is based on the amount of time that noise levels exceed 85dB(A). It has the advantage of having no subjective correction factors which reflect community response to aircraft noise. ${ }^{37}$ This method is applied by using one or more scenarios which reflect variation in runway length, air traffic, time of day, or operational procedures. ${ }^{38}$ ASDS values are easier to calculate than those of the previous two methods.

\section{General Aviation Noise}

There are ample data available on the noise effects of air carrier aircraft at airports, but much less information is available on general aviation vehicles and facilities. There are seviral reports which give the noise levels of general aviation aircraft, but no studies have been completed which illustrate CNR, NEF, or ASDS contours for a general aviation airport.

Noise levels of propeller driven and jet propelled general aviation aircraft are presented in Figure 2-3. This figure shows a line designating noise levels allowable in accordance with FAR Part 36. As can be seen, a number of presently available aircaraft are not in compliance with these regulations. Not enough data are available to compile such a figure for business jets. Although business jets are generally noisier, the FAR Part 36 allows them a higher noise level.

Table II-IV shows the area contained within the $85 \mathrm{~dB}(\mathrm{~A})$ contour for several aircraft at various stages of takeoff. Landing figures are not given, because they are smaller than takeoff figures. As one might expect, propeller driven planes do have the least effect, followed by business jets and the commercial carriers, in that order.

Prediction of annoyance and complaint from aviation noise, and specifically general aviation noise, is difficult because of the subjective factors which must be considered. Mathematical models for the prediction of annoyance and complaint levels are available, but their predictive accuracy is questionable.

"Goldman $D$ and $F X$ Marinnis Aircraft Sourid Descriotion System (ASOS) Apolication Procedures, Vol I-IV (FAA. EA-74-2. Wastington. 1974)

"Ibid

- Tracor. Inc Community Reaction: to Airport Noise, Vol I (NASA CR-1761, Washington DC 1970) Chapter 6

- Platt $M$ and $E K$ Bastress The impect of Aurcraft Emis. sions Upon Air Quallty (S A E. New York. 1972). pp 42-55
Several variables have been identified and appear to be correlated with annoyance and complaint. In one study the annoyance variables were: fear of crash, noise susceptability, distance from airport. adaptability, air traffic volume, belief in misfeasance, importance of airport, and CNR. The predictive variables for complaint were: CNR, pollution annoyance, disturbance of weekday hours, discussion of noise, disturbance of weekend hours, mobility, ethnicity, size of household, occupation, organizational involvement, misfeasance, fear of crash, age, visitation, rent/house cost, and distance from the airport. ${ }^{39}$

With the possible exception of business jets, general aviation activity around airports causes few noise problems; especially if such movements are mixed with comm s:cial activity. At an exclusively general aviation airport, there may be noise annoyance, but usually the problem is much less than at air carrier facilities.

\section{Air Quality}

Aircraft air pollution first caused public concern it, the 1950's when the turbine-engine was first introduced. The airplane produced visible exhausts which had a more noticeable smell than that of earlier aircraft. Combined with the greater visibility of the airplane in the public eye, it resulted in an inrieasing amount of public complaint.

Major pollutants caused by aviation are carbon monoxide, nitrogen oxides, nonmethane hydrocarbons, particulate matter, and suliur dioxide. ${ }^{40}$ Section 231 of the Clean Air Amendments of 1970 called for the Environmental Protection Agency to study emissions of air pollutants from aircraft to determine: (1) the extent to which such emissions affect air quality in air quality control regions throughout the United States, and (2) the technical feasibility of controlling such emissions.

Section 231 further required that the Environmental Protection Agency (EPA) establish emission standards for aircraft engines that cause or contribute to air pollution endangering public health or welfare. The EPA was also required to provide a schedule for the imple. mentation of these standards, based on a reasonable cost of compliance and on available technology.

Carbon monoxide $(\mathrm{CO})$ results from the incomplete combustion of hydracarbon fuels. It is colorless, ordorless, and is absorbed in the lungs where it reacts with hemoglobin, thus im. pairing the ability of red boood cells to transport oxygen. 


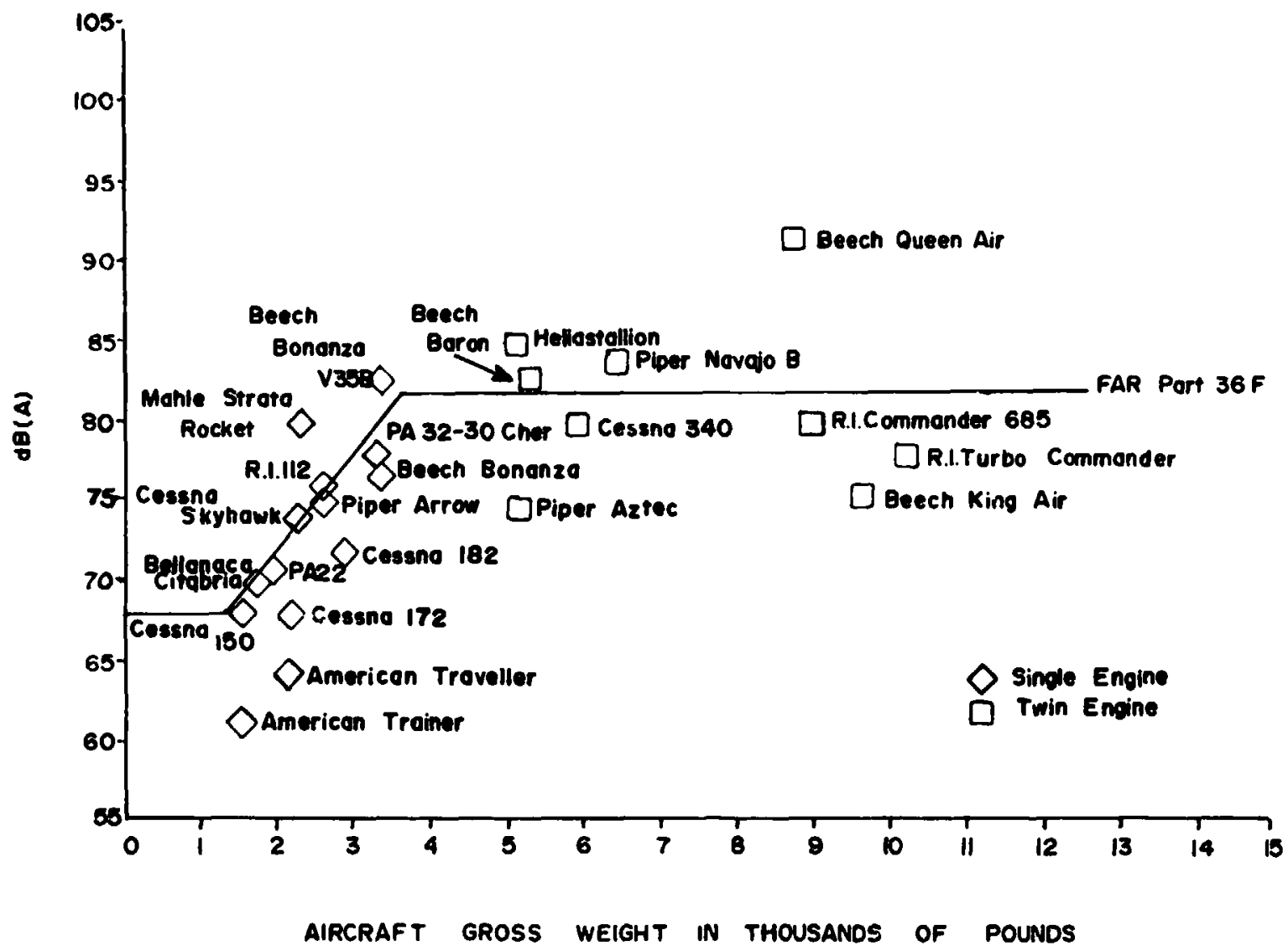

Source: Noise Certification Rule for Propeller Driven Small Airplanes

(U. S. Environmental Protection Agency, Project Report, Washington, D. C. 1974), P 11-1-11-31.

NOISE LEVELS FOR PROPELLER DRIVEN SMALL AIRPLANES AT MAXIMUM CONTINUOUS POWER

FIGURE 2-3 
Nitric Oxide (NO) and nitrogen dioxide $\left(\mathrm{NO}_{2}\right)$ are formed by all combustion processes in the Earth's atmosphere. The effects of NO, if any, are unknown. Even low levels of $\mathrm{NO}_{2}$, however, can cause respiratory problems and chronic lung disease.

Non-methane hydrocarbons are photochemically reactive; non-methane hydrocarbons produced by aircraft engine combustion and unburned fuel components produce several oxidants, primarily ozone, when exposed tc sunlight.

Solid or liquid material (smaller than $\mathbf{5 0 0}$ microns) which is dispersed in the air is called particulate matter. Most of the particulate matter from airplanes is carbon and free sulfur. In high concentrations, particulate matter may injure the surfaces of the respiratory system.

Sulfur dioxide $\left(\mathrm{SO}_{2}\right)$ is produced by combustion of sulfur-bearing hydrocarbons. The concentration of $\mathrm{SO}_{2}$ in aircraft exhaust is less than that for automobiles, because aviation fuel is relatively low in sulfur impurities. $\mathrm{SO}_{2}$ can have a number of adverse effects on health, the most important of which is respiratory damage.

The only major study involving both air carrier and general aviation airports showed that non-methane hydrocarbons and carbin monoxide levels exceeded national ambient air quality standards at some air carrier airports. At general aviation airports, however, these levels did not exceed ambient standards, although the amount of lead approached a potentially harmful level.

General aviation aircraft and airports to not appear to be as significant a ceuss 3 of air pollution as are automobiles. No instances have been found where concentrations of pollutants exceeded the national air quality standards at general aviation airports. ${ }^{42}$

\section{Water Quality}

Water pollution is a potential problem during both the construction and operation of an airport. Anticipation and prevention of prob-

\footnotetext{
" Ibid

"Los Angeles County Air Pollution Control District. Study of Jet Aircratt Emiszions and Air Quality in the Vicinily of Los Angeles International Airport (Los Angeles APCD. April, 1971). p 18

" CLM/Systems inc Airports and Their Environments. A Guide to Environmentel Planning (US Dept of Transportation. Washington. DC, 1972). p 18

“ Schmidi, M E. Environmental Effects of Highways, (Jour. nal of Sanirary Engineering Division. A S C E, Vol 93. No SA5. 1967, pp 17-26

* ClM/Systems. Inc op cit, p 265
}

lems is much more effective than attempting to solve them after the fact. The problem of water with high concentrations of petroleum resulting from servicing airplanes, for example, is solved best by designing the system to separate foul water from other water. Proper airport construction procedures can prevent erosion and sedimentation problems.

The major factors which contribute to water pollution are: physical, construction practices, facility operations, and induced development. ${ }^{* 3}$ Airport construction usually involves paving runways, taxiways, and roads, as "ell as building construction. This construction

- Jlaces the natural surfaces which allow inflitration with impermeable surfaces, with a resulting increase in surface water runoff and a decrease in the amount of time for the runotf. This situation creates large peak flows during short time spans, and increases the potential risks and dangers of flooding.

The ground surface serves as the groundwater recharge area. If the surface is sealed by impermeable surfaces, the effect will be to lower the water table.

Reinoval of natural cover during construction can lead to great increases in erosion and sedimentation if proper construction practices are not foliowed. An increase in sediment volumes of 5,000 percent, for example. has been reported in situations where there was unregulated stripping without any provision for sediment control. "Sediment load increases can lead to ilooding problems due to filling in lakes and streams. They also can cause degradation of the biologic environment because of light filtering and change in substrate type.

This pollution $p$. blem covers water used in any part of the lacility operation such as maintenance, ail conditioning, fire protection, and asociated industrial development. Much of this water picks up waste before it is returned to the system. The approach to dealing with these problems is not unlike that of a municipal waste treatment plant except that the water is more contaminated by oil and fuel in the airport area.

Induced development may cause some important problems in waste control. The three main fartuis to be considered are: (1) water body capacity: (2) water supply and solid waste disposal; and (3) power source and new industry. ${ }^{45}$

General aviation airports, because of their smaller size should cause fewer water problems than air carrier airports. The impact of 


\section{N76 12002}

each airport on water quality degradation has to be evaluated individually. Factors to be considered include: rainfall (amount and frequency), topography, stream proximity, stream size and capecity, aquifer recharge areas, soil and rock types and permeability. plant cover, and surrounding land use.

\section{ALTERNATNE MODSS AND TRAVEL SUBSTITUTES}

\section{Introduction}

Mobility, contemporarily considered as a fifth freedom, has become an accepted, and often demanded, product of the American way. A lifestyle and a value stiucture founded in Westward expansion today holds freedom of movement in exaltation.

One may travel using public or private means. Abourd intercity public modes (bus. rail, passenger aur carrier), travel is regulated as to route followed, fare charged, and quantity of route service provided. To be economical, public modes require the use of large vehicles and scheduled service.

Private modes are those permitting an individual to t:ansport himself or others in his own vehicle. Automobiles and some portions of general aviation fall into this category. Here, one is governed by his personal demand schedule.

Although general aviation constitutes only a small part of the total transportation system, its impacts tend to be very concentrated. Presently, a large portion of the work force in the United States is invoived largely in the manipulation and flow of information. While much of this flow is necessarily personal, faceto face contact at specific locations, significant amounts of data can, and are, transmitted and received by other means.

The era of "information exp'osion"-particularly in business. engineering, scientific. and social/behavioral fields - has led to dramatic advances in technological communications. In solid state electronics, the rapid growth and lowere $J$ costs of computers, communicationis systems, and instrumentation technology. plus iowered costs have enabled great advances in information flow. "In other words, we can transmit the producis of the white collar worker-his ideas and thoughts (information - electronically and relieve him of being transported physically so as to capitalize

" Lathey. Charles E Telecommunications Subsitutability for Travel An Energy Cunservation Potential Department of Commerce January 1975 upon his outputs." 2 Telecommunications appears to have frequent application as a reasonable and cheap substitute for travel.

Modes alternative to general aviation and the substitutability of telocommunications technology in lieu of intercity travel will be reviewed in this section.

\section{Modal Choice}

Transportation modes to be considered in this analysis are those which offer competition with general aviation for both passenger and priority freight. General aviation includes both public and private transportation, the former consisting of air taxis and commuter service; the latter, all other categories.

Highway, railway, and air carrier service are competitive with general aviation service. Highway transportation includes public modes such as intercity buses, priority freight, and common carrier trucking (firms represented by the United Parcel Service or the Railway Express Agency). Private modes using the highway system include the automobile and private trucking. For present purnoses, railway services will be limited to passenger movement since railroad freight is rot competitive with general aviation in the area of priority freight transport.

A transportation system consists of vehicles, ways, and terminals. The vehicle is characterized by its speed, capacity, range, and energy consumption. The way includes both the physical infrastructure and the coritrol systems, the characteristics of which determine its capacity. The terminal is the point at which. access to, and egress from the system occurs. Terminals usuaily represent a constraint on both the capacity and accessibility of the system.

The following paragraphs describe the technological characteristics of these components for general aviation and for each of the other competing modes, and discusses their integration into an operating transportation system.

\section{The Vehicle}

Speed and capacity figures of selected transportation vehicles for both passenger and priority freight are shown in Table II-V. General aviation vehicles are among the fastest. yet they are of limited capacity.

\section{The Way}

Three major classifications of the way that are of concern here: (1) airway, (2) highway, and (3) railway. The type of control system associated with the way often determines its 
capacity. Positive control is exercised over all planes in the national airways system. Minimum separation of 3 miles within $\mathbf{4 0}$ miles of a radar site and 5 miles beyond a radar site is maintained with a resulting airway capacity of 30-120 planes per hour at each designated altitude level.

Highway capacity varies with its functional classification, which is defined in terms of the number of lanes and the type of acress control, and is limited by the speed limit now set at 55 mph.

Railroad capacities are determined by the control system as shown in Table II-VI. Block signals refer to signals set by the passage of a train. Control is by means of train orders, which

\begin{tabular}{|c|c|c|}
\hline \multicolumn{3}{|c|}{ VEHICLE CAPACITIES } \\
\hline A. Passenger & Capacity (passengers) & Speed (mi/hr) \\
\hline $\begin{array}{l}\text { Air Carrier } \\
\text { General Aviation } \\
\text { Highway }\end{array}$ & $\begin{array}{r}31-500 \\
2-\quad 30\end{array}$ & $\begin{array}{l}300-650 \\
100-560\end{array}$ \\
\hline $\begin{array}{l}\text { Auto } \\
\text { Bus }\end{array}$ & $\begin{aligned} 2- & 10 \\
30- & 50\end{aligned}$ & $\begin{array}{l}70-120 \\
50-75\end{array}$ \\
\hline $\begin{array}{l}\text { Car } \\
\text { Train up to } 20 \text { cars }\end{array}$ & $\begin{array}{l}50-70 \\
50 \cdot 1,400\end{array}$ & $\begin{array}{l}60-125 \\
60-125\end{array}$ \\
\hline B. Freight & Capacity (tons) & Speed (mi/hr) \\
\hline $\begin{array}{l}\text { Air Carrier (tons) } \\
\text { General Aviation } \\
\text { Highway }\end{array}$ & $\begin{array}{rr}10- & 100 \\
0.1- & 3\end{array}$ & $\begin{array}{l}300-650 \\
100-560\end{array}$ \\
\hline $\begin{array}{l}\text { Auto } \\
\text { Truak }\end{array}$ & $\begin{array}{rr}0.5- & 1 \\
1- & 30\end{array}$ & $\begin{array}{r}70-100 \\
50-75\end{array}$ \\
\hline
\end{tabular}

\section{TA3LE II-VI}

HIGHWAY AND RAILWAY CAPACITIES

\section{A. Highways}

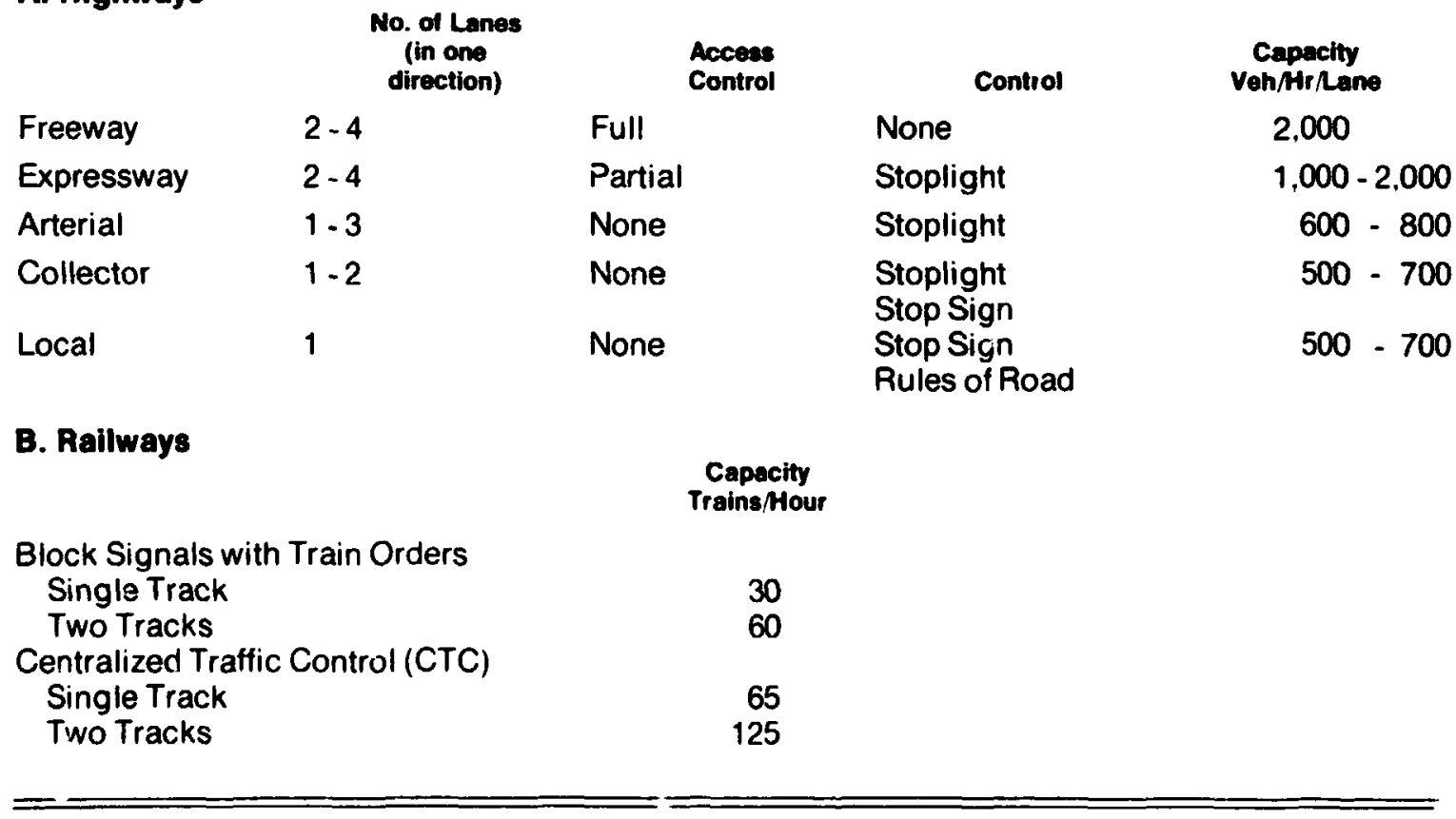


specify the location of meets between trains. and winere each train shall hold, while centralized traffic control (CTC) refers to the control of all - jnals and switches along a given stretch of track (as much as $\mathbf{5 0 0}$ miles) by a dispatcher in a central location.

\section{Terminals}

Airport capacity, usually expressed in terms of operations/hour, is frequently a determir:ang factor of total system capacity. The capacity $\mathrm{c}_{i}^{f}$ an airport is influenced by factors such as the traffic mix, weather, and runway configuration. A "light aircraft" traffic mix includes 10 percent twin engine piston vehicles and 90 percent single engine piston. For exam. ple, a single runway can handle 53 light aircraft operations per iour under IFR conditions, 99 under VFR. With dual runways. capacity is increased to 79 and 198 operations per hour respectively. Bus terminals can have capacities of between 6 and 45 buses/Mour/berths. Intercity bus terminals tend toward the lower figures, particularly where pull-in back-out angle stalls are used. Rail terminal capacity varies from 6 to 40 trains/hours/track depending upon type of service offered. Again, intercity service tends toward the lower figure. The utility of a terminal is a function of its accessibility. Airports are usually iocated at some distance from a town's central business district (CBD). Access may be available by private automobile only, or by taxis, limousines. buses and mass transit facilities as well. depending 0.7 the size of the towr.

Bus terminals tend to be located on the edge of the CBD. with bus service usually operating on a non-stop basis between major terminals. Occasionally major services will stop, briefly, at suburban locations but these usually require time-consuming detours.

Although there may be many rail terminals in a city, there is lisually only one per rail line. located close to the CBD on the intercity portion of the line passing through the city.

\section{System Characteristics}

System characteristics which will be discussed include avallability, reliability, adaptability, routing flexibility. and safety.

The concept of availability is comparable to that of accessibility for public systems. Only private systems will be compared in terms of avaılabılity. The highway system is available to all who have a driver's license and have access to an automobile. This is a sizeable portion of the population. especially as compared to the number of licensed pilots and private aircrart.
This small number tends to limit the availability of the general aviation system.

The air carrier system is reliable because a.r carriers fly IFR, which will get them through mont bad weather situations. Severe snow, rain, and cloud conditions, however, can stii, stop flights. Under severe weather conditions, arrpcrt operations at crowded airports are slowed down, resulting in extended delays. Due to their ability to land at smaller airports, general aviation aircraft can avoid congestion, but their frequent dependence on VFR reduces their reliability in unfavorable weather.

Reliability of the highway system can also be significantly reduced by adverse weather and congestion conditions. The intercity bus system suffers from the same highway system deficiencies, but is usually fairly reliable, and published schedules are usually adhered to and rarely canceied. The rail system has the potential for greatest reliability. because both the railway and rail traffic movements are under the exclusive control of rail management. The system. however. s'uffers from deferred maintenance to both the way and the vehicle, causing slow running-speeds and increased accident rates.

Another transportation system characteristic is adaptability both to load and terrain. as characterized by the important factors of weight and space limitations. In dealing with bulk freight for example. the modes with the greatest limitations are general aviation. bus. and autos as compared to trucks and air carriers having larger cargo space.

Terrain adaptability is dependent upon the ability of a particular mode to function in different environments. Highway modes are limited to the highway system. Railroads face fixed rıght-of-way limitations, and airplanes. although lımited by the placement of an airport. have the capability of bypassing all but the most rugged terrain

Routing flexibility refers to the ability to change a route. or change destinations while en route. Public systems are generally less flexible than private ones. with the most flexible being the intercity bus followed by air carrier (which is limited to certain large airports) and rall (which is limited as to destınation and route) Among private systems, the auto is most flexible.

General aviation has the following characteristics: (1) small (2-30 passengers) vehicle capacity: (2) a greater network of terminals than in air carrier transport. This network of facilities 
is, however, less ubiquitous than other ground transportation modes; (3) more limited availability than other modes; (4) the interface of general aviation with other modes is plagued by the same type of airport accessibility problem as those facir.g many air carrier airports; (5) the reliability of genera! aviation services is highly dependent on both pilot qualifications and weather conditions: (6) limited load adaptability; and, (7) excellent terrain adaptabili, and flexibility depending upon airport availability.

These characteristics suggest several different uses for general aviation, such as (a) high speed point-to-point transportation for small groups or small packages of high value particularly from general aviation airports to other airports; (b) convennient travel where distances are great and weather is dependable; (c) accessibility to remote areas in rugged terrain where landing facilities are available.

\section{Cost Comparisons}

In an analysis of the out-of-pocket costs of intercity public transportation mode, fares for one-way trips of different lengths and travel modes were compared. These modes included intercity bus, coach rail, roomette raii. tourist and first class trunk and local service airlines. and commuter airlines. The last mode represents the public transportation sector of general aviation. Data were obtained by random selections of trips from the schedules and rate charts published by these common carriers. A linear regression line was fitted to the data, to produce an equation of the form:

Fare $=($ Fixed Cost $)+($ Variable Cost $)$ (Trip Length)

where costs are in dollars and trip length is in miles. All regressions had coefficients of determination $\left(R^{2}\right)$ in excess of 0.955 . The following equations were obtained:

(1) Bus Fare $=370+(00423)$ (Trip Lengih) $\mathrm{A}^{\mathrm{z}}=0985$

(2) Coach Rail Fare $=877+(00423)$ (Trip Length) $R^{2}=0990$

(3) Roomette Rail Fare $=1609+(0078)$ (Trip Length) $R^{*}=0986$

(4) Tourist Air Carrier Fare $=2059+(0068)$ (Trip Length) $R^{2}=0970$

(5) First Class Air Carrier- Fare $=2738+0095$ (Trip Length) $R^{2}=0974$

(6) Commuter Airlines Fare $=1153+(0112)$ (Trip Length) $R^{2}=0955$

These regression lines are shown in Figure 2-4.

- "Commuter Arrines Commuter Aurline Assoctation Re. port No 3 July. 1975 p 3
The variable costs per mile for bus and coach rail travel are almost equivalent, but the fixed costs portion of rail travel is about $\$ 5.00$ in excess of that of bus. As expected, both are less costly than any of the air travel modes. For trip lengths of less than 135 miles, commuter airtines are obviously the most economical mode, exclusive of bus and coach rail. For trips of $135-450$ miles, the first class rail is more economical, but the time difference is significant enough to result in these modes accommodating different and separate markets. The traveler who values physical comfort over saving time would probably select first-class rail. The traveler who values his time and who is determined to travel by air, would c.noose the commuter airiine which is the least costly mode for trip lengths of up to 200 miles.

Considering the time differential between rail and air, and assuming that the additional time required for rail or other ground travel is not acceptable to the traveler, then commuter airlines provide the cheapest acceptable mode for trips of up to about $\mathbf{2 0 0}$ miles. It is interesting to compare this with the average trip length of commuter airlines. which was reported to be 102 miles of non-stop travel. ${ }^{47}$ The difference between these two figures can be explained by the fact that the average trip is made up of more than one non-stop hop, and that the traveler expresses a preference for the more comfortable air carrier. Upon considering the tradeoffs between cost and convenience, more travelers will opt for the more costly air carrier mode. as the cost difference decreases and the distance traveled approaches 200 miles.

The private automobile remains the most economical mode of travel, and possibly the most convenient for many trips' purposos. Auto travel costs are less than commuter airlines for distances of up to about 500 miles. This distance is based on a single passenger occupan$c y$, and of course increases as car-occupancy increases. Here again, time presents itself as a significant factor. because many travelers would not be willing to drive for ten hours in order to cover a 500-mile trip which should take less than three nours by air. The automobile. however, remains as a serious competitor with general aviation lor business trips ranging up to 200-300 miles; for longer recreatıonal trips where the relative value of tıme is not significant; and. where a higher average automobile occupancy can be expected.

Because of real tıme expenditures and costs involved in physical transportation, travel substitutes are being st'jdied with a view 


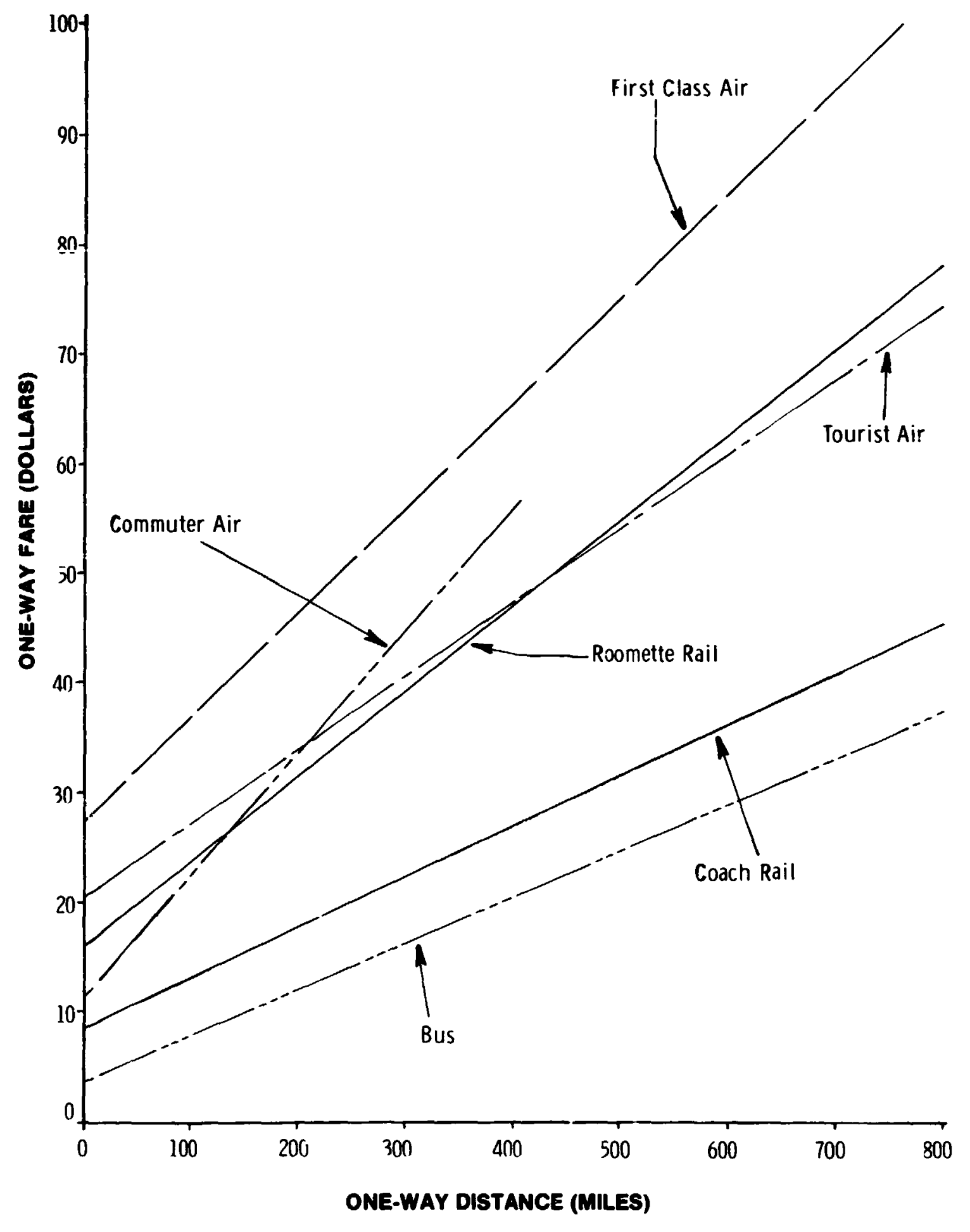

COMPARATIVE FARES OF INTERCITY PUBLIC TRANSPORTATION

FIGURE 2-4 
toward reducing unnecessary intercity movement.

\section{Communication}

Communication is the complex process of generating meaning by transmitting and receiving messages (information) between one person (or group) and another (or group of others). In a business setting interaction between individuals is usually either by oral, written, or nonverbal cues. A logical communicative extension for point-to-point interaction where personal subtleties are not important is telecommunication. Well known to the general public, telecommunication occurs in a contınuous mode-television, $A M$ and $F M$ radio, and the telephone. The impetus of the space age together with integrated, solid state technology has permitted a more diverse, efficient and less known form of communication, discrete or digital in nature, to mature.

\section{Telecommunication Scope}

Today telecommunication is used in such fields as clinical diagnosis, education, public services. cultural and entertainment opportunities, banking, access to computer data banks, and computational facilities. Even offices are being reshaped due to the electronics and digital revolution. Not only is telecommunication becoming a substitute for travel, but it is also becoming an integral part of the postindustrial society.

Though substitution of travel for telecommunication can be discussed on both an intracity and an intercity level, since concern here is with aviation, only the latter case is relevant. Of the 370 billion miles traveled intercity in 1972,315 billion were by car and 43 billion by air. the remaining used other modes. These represented 391 million and 53 million trips respectively. ${ }^{48}$ While general aviation is a small part of the total picture described. Its growth trends have been significant in recent years. The principles to be discussed below are equally app:icable to general aviation as well as other modes of travel.

At the present time. with no disincentives or iricentives either way, the relationship between travel and coinmunications is highly correlated. Those who tr avel more tend to use the communications medic more, while those who travel less tend to use th.em less. This relationship, however, is influencend by considerations of the social. cultural, tect nological, environ-

"Kollen James H Transporfaion-Communication Substitutability A Research Proposal. Bell 'anada February 1973

"Lathey op oit mental, and economic characteristics of the substitution mechanism. Taken collectively, these factors can reduce the utility of travel, and thus might iesult in a substitution of communication for transportation. Technological deve!upments coupled with comfort/convenience and cost savings can be expected to significantly influence modal choice. While truvel might appear to be inelastic with respect to cost. attitude change (a behavioral component) is probably its most effective component.

\section{Telecommunication Technology}

Today a variety of information transfer methods exist which can impact on the substitlitability issue.

Telephone Network. The Bell Telephone System and the independent telephone companies transmit over 155 billion messages annually with a growth rate of 8 percent per year. "While the primary purpose of this transmission system has been the continuous transmission of voice in a narrow range of the audio band, research over the years has adapted it to other uses without changing the transmission characteristics. Thus, for ex.ample, by coupling special units (modems) at each end of the telephone link, digital data can be sent at medium speeds up to 9600 bits/second. By coupling various numbers of telephone lines together, slow scan video or full video can be sent over ordinary telephone linkages. The latter use is of course inefficient but remains to be cheaper than any travel alternative.

Dedicated Digital Transmission Systems. The famous Canterfone Decision by the FC. 5 in 1968, which allowed non Bell Equipment to be connected to the telephone system, ushered in a new era in telecommunications. More recent decisions have had a direct impact by allowing special digital-only tarift carriers to compete with the telephone system. Such companies as MC. and Datran have set up dedicated digitalwideband-links between regional cities around the country. In response, the Bell System introduced the Data Under Voice (DUV) system and is in the process of putting in its own specialized digital lines. All these are wideband lines. equivalent to many telephone circuits in bandwidth; and, being high speed in nature, could handle video signals an Nell.

Computer Networks. As computers become more developed, their impact or, society increases. Aside from scientific computations, they can also manipulate symbuls. thus enabling them to be used as interpreters. string processors, and simulators. They are 
capable of storing miilions of bits of information and accessing millions more in auxiliary storage devices such as magnetic tapes anci discs. With the time-saving software now available, terminals remotely hooked up through a telephone line or a dedicated line. have the full use of the computing system at a central location. Thus, simple information retrieval becomes a reality. If entire libraries can be stored in a data bank, trips to specialized facilities are no longer necessary. Resources savings like these have been developed through the Advanced Research Projects Agency (ARPA) and are being extended to Europe via satellite.

Cable Television. The advent of cable television has caused further consideration of two-way systems like the telephone system. Since cable television is broadband by nature, its extension to a two-way system would be simple. though much development remains to be done on the practicality and economics. The potential of a two-way switched system similar to the telephone system has profound implications for shopping, library services, banking. education, and even home offices. Such a system, however, is expensive and might not be practical in the near future, except for special applications such as those in business or education

Other Visual Media. While two-way cable television might be impractical, there are other useful picture transmissicn applications such as Picturephone" so conference television (closed circuit), alpha numeric terminals (intelligent and passive), graphic terminals, and facsimile. Each of these media has the attribute of providing visual information to the user yet each requires different types of facilities.

Picturephone uses long distance, two-way picture transmission for business applications By its :ery nature video transmission requires large bandwidths. Even at the slow scan speed used, many ordinary telephone channe!s are required: 80 , three-kilocycle channels as opposed to 1500 , three-kilocycle telephone channels for ordinary television. Picturephone has turned out to be expensive and requires special hookups, since it is not operated through the regular telephone switching system. Conference television requires large bandwidths and special facilities. But used in place of travel. ilese approaches can effect significant cost savings

Terminals used with computers, if operated

sn Picturephone is a registered trademark of the Bell System at normal teletype (TTY) speeds (100 characters/second), are very effective but limited. They provide useful output from data banks and are capable of sending messages to other users. Graphic terminals, while also connected to computers, can draw lines in addition to writing text. Some of both types can operate in the intelligent mode-involving user interaction and having its own computational ability-and can also operate at high speeds up to 60 kilobits/second. But the higher the speed, the higher the capital and optrational costs. An advantage of both types is the ability to connect to a hardcopy device for a permanent record (very slow).

Finally, with facsimile, a permanent hardcopy is sent with slow to medium speeds. usually over regular telephone lines. For those cases where a specific document is required, this procedure is cheap and adequate.

Communications Satellites. Such equipment allows any signal. slow or fast. to be transmitted over long distances where cables are not available. Many telephone and television circuits are now avallable through this mejium at less cost than equivalent land pointto-point facilities.

\section{Future Thinking}

In dealing with the overall substitution problem a significant amount of research in several areas is necessary. Attitudes must be studied to discover the reasons why people do what they do, and underlying assumptions about human needs and behavior must be scrutınized. Extensive substitution of electronic communications for travel and face-to-face interaction requires a restructuring of values and both affective and cognitive behavioral change. One must re-evaluate the reasons why, and ways in which, people interact interpersonally within a decentralized industrial facility. Fortunately a beginning has been made in answering some of these questions. Current research in this area is increasing at a rapid pace. It is an opportune time because transportation, a highIv visible network is slowly becoming saturated. while telecommunications is much less visible and its saturation level much higher. Research areas include: innovation towards more efficient use of the present telecommunications network; the effects of disincentives towards travel: and studies of the costs and benefits of substitition. In addition the behavioral aspects must be considered.

The New Rural Society Program (NRSP), a program supported by the Department of Housing and Urban Development (HUD) and oper- 
ated by Goldmark Communications through Fairfield University, has undertaken a longrange program to address a number of issues of this type. ${ }^{31}$ Principal conclusions relevant to the present discussion can be summarized as follows:

(1) For companies which had recently relocated, top management felt that movement was done for space, modern facilities, costs in cities, crime, and transportation. Communications was not a problem, however, those companies which had considered moving but did not, stated communications as a prime reason. This was because of dissatisfaction with future phone service, and a possible reduction of face-to-face relationships.

(2) A major conclusion of audio-only conferencing systems was that they are more acceptable than previcusly thought. Specifically:

(a) multichannel audio was not more acceptable than monaural between two people:

(b) multispeaker lone speaker for each person) audio systems are more advantageous than monaural in a group confereince call: and.

(c) the multispeaker arrangement had the advantage of

(i) separate sound image for each person

(ii) facilitating a more stimulating discussion

(iii) a better quality sound

(iv) warmer contact between conferences.

(3) Given a problem-solving task, acquainted persons peformed better than unacquainted persons using an audio only system. In addition face-to-face contact under the same conditions was less desirable.

(4) If bargaining was involved in the communication. the tendency was

Abstracts, New Rural Society Project Stamford Connecilcut 06904 November 1974

"The Scope for Person-to-Person Telecommunications Systems in Government and Business. Communicative Study Group. University College London September, 1973 in Lathey, op cit.

"Tomey J F "Union Trust installs NRS Sound Imaging Teleconferancing System. Communications News, May 1975 to coinpromise, except in audio, between unacquainted people where the stronger case dominated. The situation of number (3) above was not supported with bargaining involved.

(5) A full test between two facilities using audio, visual, and facsimile transmission indicated that such a method were useful and important.

These results of studies conducted by the New Rural Society are not generalizeable beyond the organizations in which the studies were corducted, nevertheless they demonstrate that attitudes and behaviors toward substitutabılity can be modified.

Telecommunication is not a total substitute because people miss face-to-face contact even when video is provided. This is particularly true in a direct sales environment, in counseling. and in areas where empathic sensitivity is required. The Joint Unit for Planning in England reported that audio conferees found meetings to be more business-like and more tırıng than conventional meetings. nossiblly resulting from concentration fatigue. ${ }^{52}$

\section{Teleconferencing Utility}

Two excellent examples illustrate the utılity of teleconferencing: (1) Union Trust Company from December 1973 to May 1974: the Union Trust Company with offices in Stamford and New Haven, Connecticut, 25 miles apart, conducted a teleconferencing experiment under the auspices of the NRSP. ${ }^{.3}$ Using a special electronic "sound imaging" procedure. which uses ste:eo techniques and isophonic loudspeakers, audio communi: ations were set up between two officers using both Class $A$ audiograde and Class $C$ voice-grade lines (the latter proved acceptable). The system allowed each participant, with a separate microphone. to be identified Documents were sent via the facsimile part of the system for hardcopy. Video was eliminated as being too expensive and not really necessary. The system had: (1) simplıcity arid tamper-proof design; (2) poitability; (3) aesthetic appeal not detracting from the cor.ference rocm; and, (4) a design for up to six participants (more could be handled if necessary).

The project was designed to test users' attitudes and feelings before and after the experiment. the effectiveness of the operation. and the frequency of use as a substitute. The results were significant:

(1) Throughout the extended field trial, 
the use of the teleconference system was high. Nearly all participants in the trial substituted use of the system ior at least $\mathbf{5 0}$ percont of their face-to-face meetings. More than one-third substituted teleconferencing for 80 percent or more of their face-to-face meetings.

(2) Users of the system reported that teleconference meetings were as effective as the face-to-face meetings that teleconferencing replaced. This evaluation was reported in each questionnaire administration during the length of the field trial.

(3) Teleconference meetings were generally 30-35 percent shorter than the prior face-to-face meetings.

(4) In comparrison to previous face-toface meetings, participants were more attentive to what was being said, it was easier to get a point across without a lengthy debate, and discussion of particular items tended to be shorter

(5) Participants reported that the human aspects of meeting were maintained in the teleconferencing environment.

(6) The teleconference system proved to be cost-effective, saving approximately $\$ 500$ per month, considering only system cost in comparison with the value of saved travel costs and executive travel time. Executive time saved by achieving objectives in a briefer time period would add significantly to the cost-effectiveness of the teleconference system.

A particularly significant benefit gained from the system was reported by Thomas Richardson, the bank's chairman and chief executive officer:

Not only does this type of meeting

\section{4/610}

"Polishuk P. "Review of the Impact of Telecommunica tions Substitutes for Travel to appear in the IEEE Transactions on Communications. October 1975

* Sincolf. M Z et al. Urban Transportation Perspectives on Mobility and Choice. NASA No NGT.47-003-028 August 1974

"Fordyce $S$ Evaluation of the Teleconference Pilot Pro ject After Three Months of Operation. NASA ir , mal riemo June. 1975 save energy and travel time, but it requires less executive time during the actual sessions. Participants are more inclined to adhere to the prepared agenda and not get sidetracked into irrelevant discussions. Everyone agrees that most meetings show an actual increase in efficiency. ${ }^{34}$

(2) NASA: In order to expedite the tremendous volume of complex information-technical, planning, and administrative-associated with the Apollo program, NASA in 1968 set up a teleconferencing capability between the manufacturing, testing, and decision-making centers of the program. It included a capability of handling up to 50 people at a conference with high and low speed facsimile. No video has been used. For each dollar spent for teleconferencing, an estimated 3 to 5 dollars has been saved in travel. ${ }^{\text {ss }}$ The present Viking Project, scheduled to soft-land on Mars in July 1976, has been involved in a similar project at considerable savings. ${ }^{56}$

Because of initial successes, NASA has made a total commitment to the teleconferencing arrangement. A modification of the Bell Systems Model 50-A teleconferencıng system with facsimile facilities, became a permanent part of the entire NASA system in January 1975 and an effort has been made to encourage teleconference use between and among the NASA centers.

In the first three months of operation, 395 teleconferences were held with 13,084 people involved. The facsimile network transmitted 84,172 pages. This amounts to an average conference of 37 people using five terminals for about three hours. It is estimated that 2,414 trips have been saved in the three months at a cost savings of $\$ 521,000$. "So-called "saved trips" are difficult to estimate since they are "trips" which may not have been taken or for which other trips were substituted.

NASA is interested in both evaluation of present facilities and research into new undeveloped modes of teleconferencing. Presently a hardware device (modem) is being built to supply both audio and slow scan pictures between Houston. Texas, and Rockwell International in California using Frequency Shift Keying (FSK) techniques. It will take place in real time providing a hardcopy in less than one minute.

Video transmissions have not been neglected. In cooperation with the Canadian Government, NASA is designing a high speed 
digital transmission system in the 12-14 Gigahertz range for the Canadian Television System (CTS) relay satellite. Transmission rates will be about 11 megabits. While probably not cost effective since it is experimental, the system will be available to NASA users on a sharing basis with Canada for the cost of the receiving and transmitting units.

Finally, using the electronic blackboard developed by the Bell Telephone System, NASA hopes to install 12 such units when they become available at each center presently hooked up in the telenet. These have been designed for the 50-A Portable Conference Telephone and will provide the ability for written communications in real time. Other teleconferencing experiments and operational systems are described by Polishuk ${ }^{58}$ and Lathey. ${ }^{59}$ They include: Confravision-British Teleconferencing. Australia CCTV Teleconference, Bell System Video Teleconferencing. Metropolitan Regional Council Television System (MRC-TV), Dow Chemical USA Interactive Television System, Vermont-New Hampshire Medical Interactive Television Network, Massachusetts General Hospital-Veterans Administration Hospital CCTV Network, Arizona Telemedicine Network, New York-Boston Banking Video Teleconferencing System, GSA Teleconferencing System, Forum-A Computer Teleconferencing System.

\section{Conclusions}

Intercity transportation will contınue. albeit modifieci, verhaps in speed, frequency, and cost. The future of telecommunications as a

\section{* Polishuk. op cll}

"Lathey, op CIl, McDowell CB. et al, Remote Blackboards System for the DDD Telephone Network Proc IEEE Electronic Conference Chicago III Oct 1971. "Confravision The New Post OHtice Service lo, Business Meetings Between Two Centers. British PO Telecommunications. London England May 1973. Morico $R$ and Bruggeeman H. "A Discussion of Multi-Location TV Conterence Arrangements Austraira PO Research Report No 6736 May 15. 1975 Horkuess. R. "Telecommunications Substitutes fo Travel Dept of Commerce OT-SP.73-2 DecemDer 1973. "Two-Way Television Conterencing tor Government The 'How Dow Talks to Dow on Closed-Circuit TV' Business Week August 10 1974, Reeves J. et al. "A Description of the Vermont. New Hampshire Medical Interactive Network Proc IEEE National Telecommurications Conference. Aprit 1971 Siebert D J Development and Evaluation of a Modet In System Dartmouth Medical Schoo' December 1972 'Arizona Tele Medicine Network Engineering Master Plan University of Arizona College of Medicine December 1972. Communications News. October 1974 Letter Automated Data and Telecommunicaions Services GSA March 1974 Vallee J and Miller RH. Group Communicattons Through Computers Report No R-32 Institute for the Future. Menlo Park Calıfornı

- Penner. SS and Icerman L, Demands. Resources Impact Tochnology and Policy. vi Addison-Wesley, Reading. Mass 1974 substitute for intercity transportation is bright. Telecommunications technological improvements coincident with continued, demonstrable applications in the practical use of the media in intercity transmission, will secure the place of this travel substitute. Modifications in our attitudes and behaviors will allow electronic communications to substitute where travel in the past has been considered a necessity.

\section{ENERGY RESOURCES AND USE \\ Introduction}

As one of the most industrialized nations in the world, the U.S. requires enormous alnounts of energy to function. It is projected that the U.S. will require a doubling of energy demand in the period 1970-1985. ${ }^{60}$ Based on 1971 estimates, it is anticipated that dependence on coal and the use of imported oil will both increase in the future. About 92 perceint of all our energy is derived from fossil fuels today, while in 1990 it is expected that this proportion will drop to 70 percent, the difference being absorbed mainly by nuclear energy sources.

The increased use of energy in the United States is due to both increased industrialization and population growth. This fact is brought out more clearly in Table II-VII where past trends and future projections have been made for total energy and for transportation energy demand in the United States along with the trend of petroleum consumption.

While the demand for energy' Increases exponentially, transportation is expected to continue to consume the historically stable 25 percent of the total. More serious. however, is the lagging domestic energy production making the nation more dependent on foreign sources for energy supplies.

Our most critical energy source now and in the near future is petrcleum. As shown in Table II-VII transportation is one of the largest users of petroleum and presently derives 96 percent of its energy from it. With its increasıng dependence on a source of energy which is not only dwindling but subject to future political vagaries, the transportation industry - the lifeblood of any nation-is in a very difficult situation.

To further elaborate. Figure $2-5$ shows the total historical use of petroleum by industry in the U.S. along with various transportation demands. Each category has been exponentially increasing and projections are for a 75 percent increase in the six years ending in 1978. Indica. 


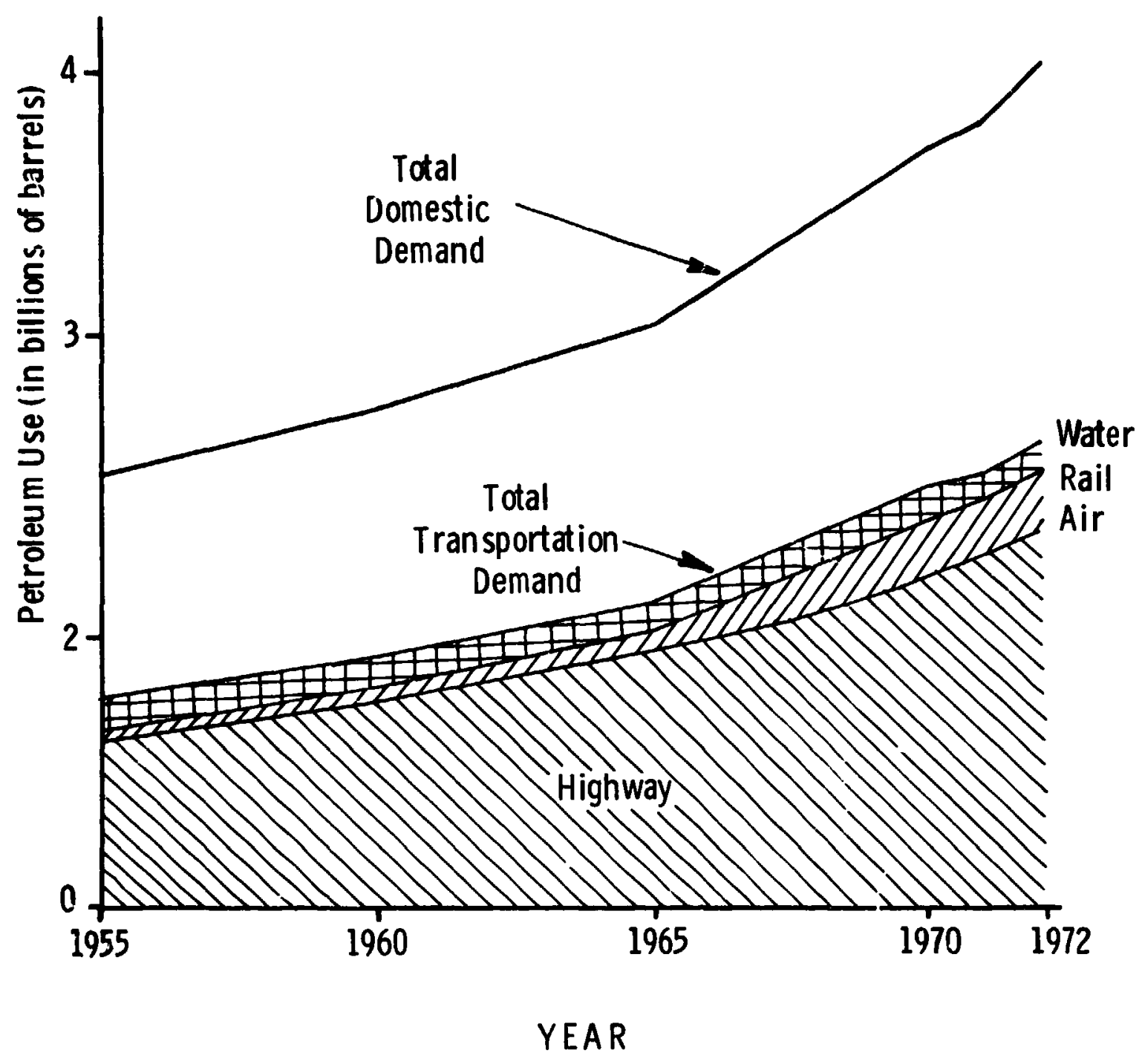

Sou rce: Adapted from "Tran sportation Facts and Trends,"

Transportation Association of America, December 1974. 
TABLE $\|-V\|$

THE USE AND CONSUMPTION OF ENERGY \& PETROLEUM

Total Energy

Veer Toul Uan Toul Produad
(ETU $\left.\times 10^{\prime \prime}\right)$

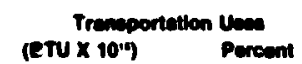

1950

1960

1965

1970

1980

2000

34.2
44.9
53.8
68.8
88.1
168.6

34.5

41.6

49.1

61.9

168.6

(ETU $\left.\times 10^{\prime \prime}\right)$ Percent

8.7
10.9
12.8
16.5
21.6
42.9

25.5

24.2

23.7

24.0

24.5

25.4
Total Petroleum Consumption
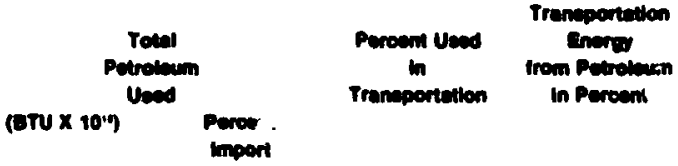

$\begin{array}{rr}13.5 & 10.6 \\ 20.1 & 17.8 \\ 23.2 & 21.4 \\ 29.6 & 22.2 \\ 35.9 & 50.0 \\ 57.6 & ?\end{array}$

77.8

95.3

95.5

95.5

96.1

97.1

Source: Hirst, E., Energy Consumption for Transportation in the i..S. (Oak Ridge National Labs, No. ORNL-NSF-EP-15, 1972).

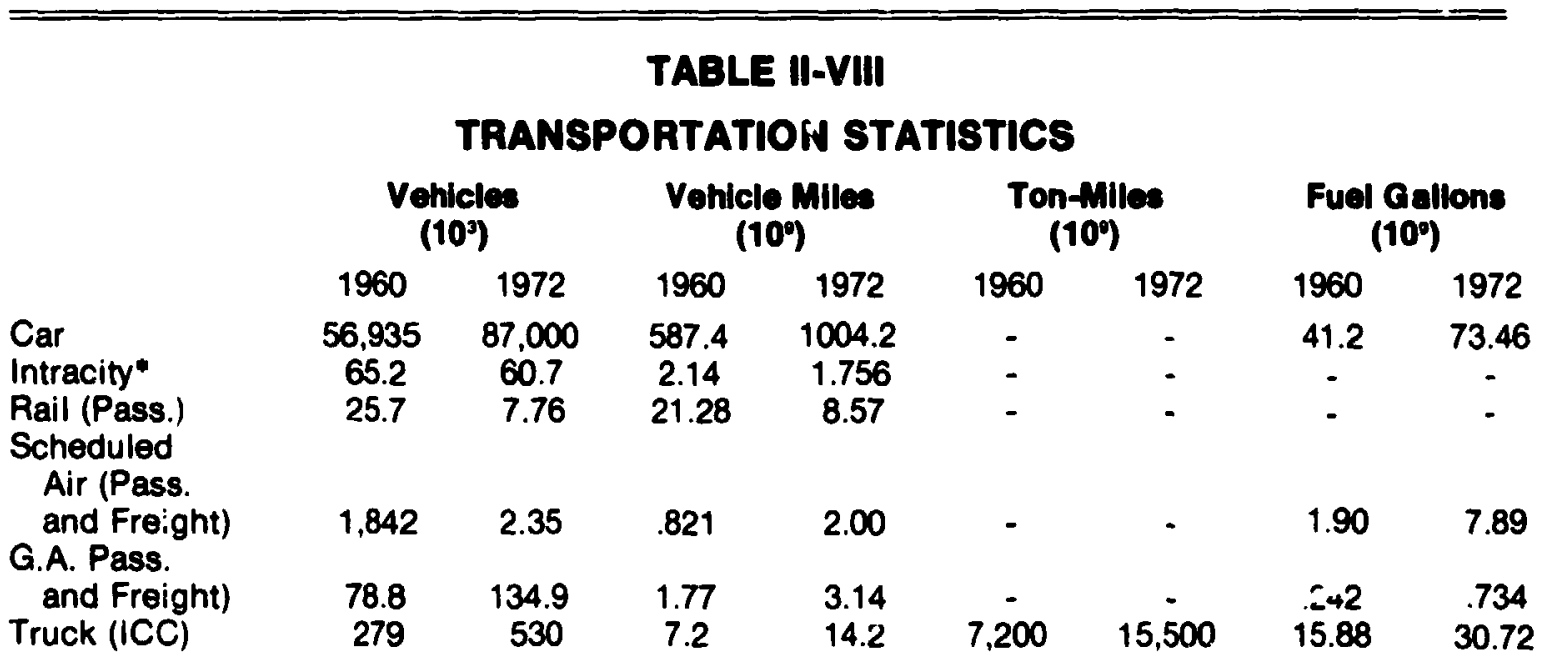

* All Intracity Public Transit Modes

Source: U.S. Dept. of Commerce, Statistical Abstracts of the United States (Washington, D.C., 1974).

tions are that aircraft demand, though only a fraction of the total, is increasing at a faster rate than other modes. Compounding the problem is an expected increase of energy loss (waste) due to conversion processes from about 49 percent in 1970 to 58 percent in $1985^{\circ}$.

- Certain Background Information for Consideration When Evaluating the National Energy Dilemma, Joint Committee on Atomic Energy. U S Government Printing Otfice. Washington, D C 1973

\section{Energy Intensiveness and Efficiency}

Both passenger miles and freight ton-miles for automobiles and aviation have been increasing at a faster rate than the number of vehicles in operation. Table II-VIII summariz6s the situation for the 12-year period 1960-1972.

The use of gasoline is increasing not only because of increased vehicle miles, but also as a result of the decreased efficiency of sutomo- 


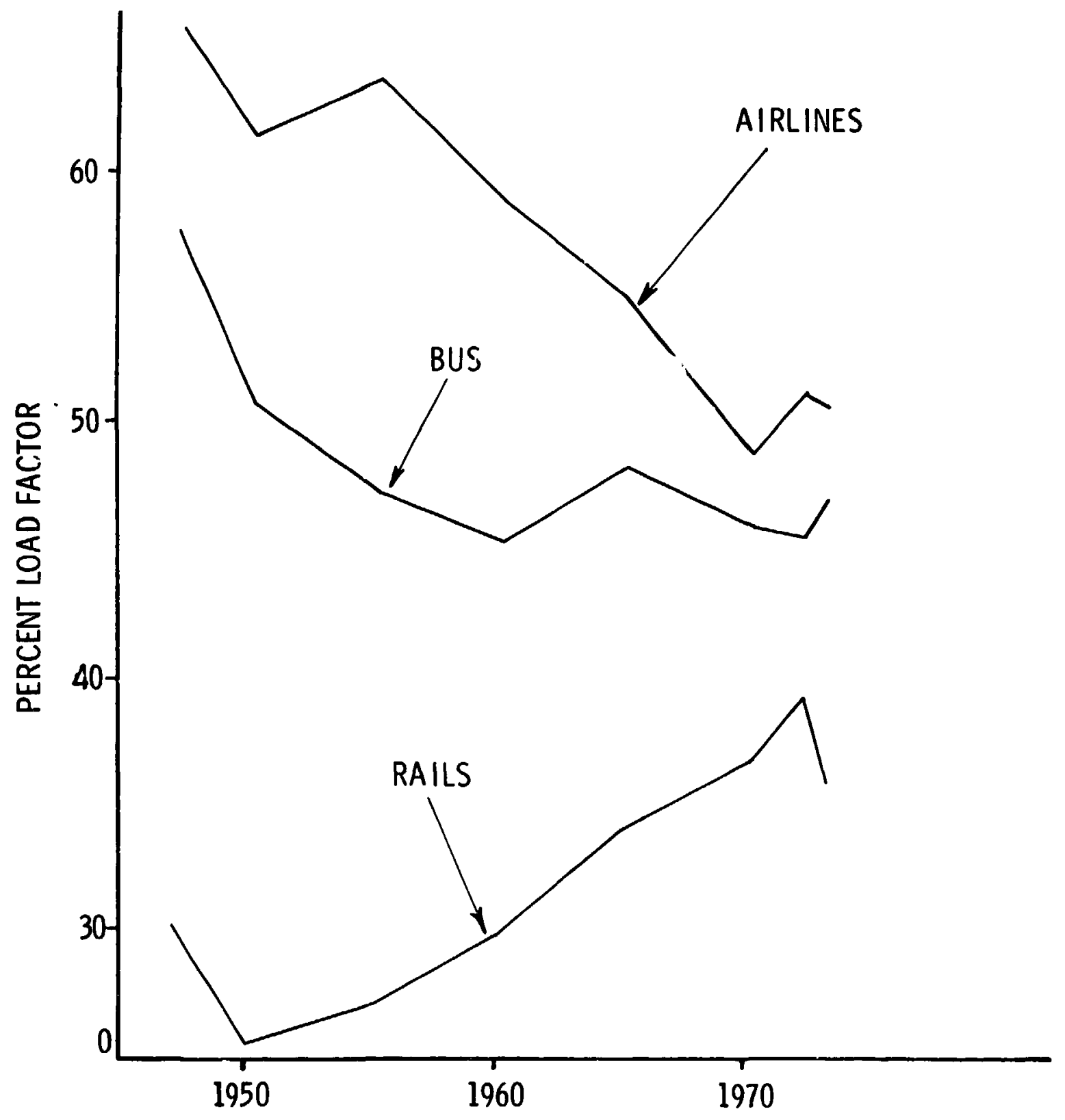

YEAR.

Source: Adapted from "Transportation Facts and Trends",

Transportation Association of America, December, 1974. 
biles as reflected in decreasing aucumobile mileage per galion (m.p.g ). It has been recommended by the Federal Energy Administration that the latter figure be raised to 20 m.p.g. from the present 12.67 m.p.g. as a conservation measure.

Since transportation has many aspects. attempts to classify each ior comparative purposes is difficult. In terms of energy, it has become common practice to measure the efficiency of transportation in Btu's per passengermile or Btu's per ton-mile, i.e., energy intensiveness (EI). This figure of merit is affected by many parameters such as speed, mode. seat capiscity, design, and typical load factor. Table II-IX which is a composite set of average numbers drawn from many sources has been compiled to allow ready comparisons. It is immediately obvious that walking and bicycling are the most efficent in the use of energy while autos and arrilanes are the least efficient, with the business jet being by far the worst. Load factors used for the calculation values given in the table were chosen so as to refiect what seems to be reasonable averages. Actual load factors over the last 23 years appear in Fig'ure 2-6 for airline, rail, and bus carriers. C.learly,

TABLE II-IX

THE ENERGY INTENSIVENESS OF ALTERNATIVE TRANSPORTATION MODES

\section{Urban}

Bicycle

Walk

Auto (Large)

Auto (Compact)

Auto (Electric)

Motorcycle

Bus (Diesel)

Bus (Gas)

Van (Gas)

Subway

Urbar urban

Comi - Zail

Elect

Diesel

Gas Turbine

Helicopter (3-engine)

Intercity

Bus (Diesel)

Rail (feet)

Rail (crnss country)

74 ? jet

707 Jet

STOL

VTCL

G.A. Recreational (Cherokee 180)

G.A. Business (Twin) (Baron B55)

G.A. Business Jet (Learjet 35)

*Energy Intensiveness

- "I.oad Factor

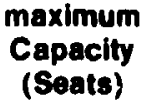

Sperd

(mph)

1. 10

1. 5

5- 20

5- 20

5- 20

10- 25

5. 15

5- 15

15- 20

15- 30

25- 45

25- 45

25- 45

$9 j-150$

40- 60

$50-100$

40- 60

500

500

200

200

141

225

500

1

1
6

125
90
80
78

50

ธิ
El*

at $100 \%$ LF": (BTU/PM)

Average El at Average Load Fertur Load Factor (Perceld) (BTU/PM)

200

300

2060

2000

1360

2260

660

1000

1000

850

100
100
30
30
30
100
58
45
45
35

200

300

6870

6670

4500

2260

1170

2220

3330

2430

570

940

1700

10030

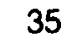

35

35

58

2700

4860

17300

390

540

650

3250

3850

3960

4533

46
35

850

1540

1860

5900

6200

7200

8240

2073

4146

2670

5340

9527

50

19054 


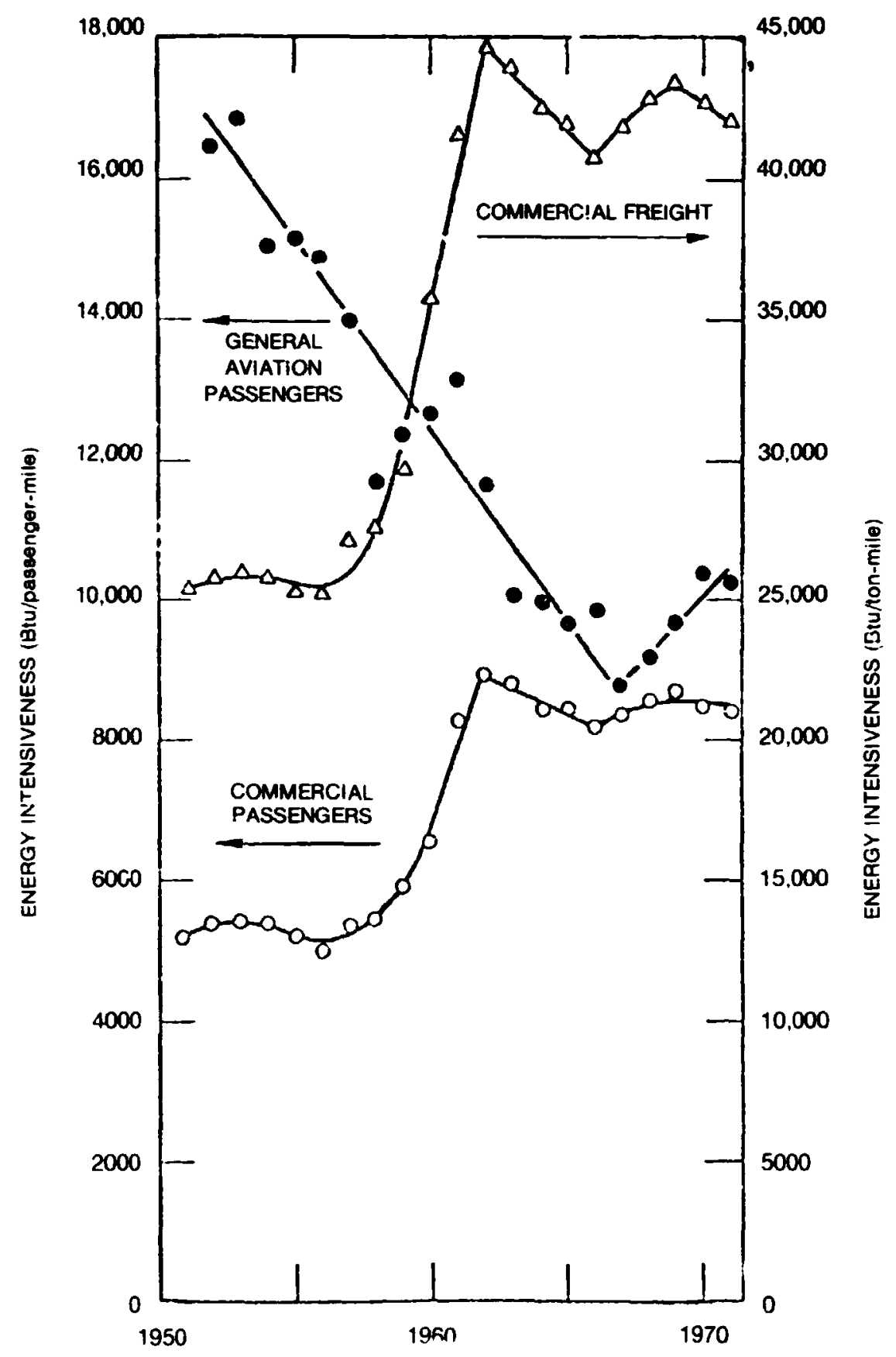

Source: E. Hirst, "Total Energy Use For Commercial Aviation in the United States", ORNL-NSF-EP-68,

April, 1974. 
there is room for improvement and together with increased vehicle efficiency, substantial energy savings can be achieved

To balance the picture a similar efficiency rating can be made for freight movement. One ton-mile of air freight consumes 42, 000 Btu while trucks and railroads have respective ratings of 2,700 and $700 \mathrm{Btu} / \mathrm{T}$ on-mile. ${ }^{62}$

As shown in Figure 2-7, the El for both the airlines and general aviation in the 1950-71 period reveals that the El for commercial freight and passengers has dramatically increased due mainly to declining load factors and the use of turbojets which are more energy intensive. However, in this period the average speed of travel increased by 100 percent from $200 \mathrm{mph}$ to more than $\mathbf{4 0 0} \mathrm{mph}$. General aviation improved in this same period due to an increased load factor. ${ }^{62}$ In fact while passenger traffic in general aviation increased, fuel use grew more slowly, a trend which reversed itself in 1966. It is important to note that general aviation is still more energy intensive than commercial airlines.

In addition ro the direct energy costs of transportation, there are also indirect costs associated with transportation which include the "energy needed to extract, transport, and refine oil; to manufacture, maintain airports; and to carry out other air-travel-related activities. ${ }^{63}$ Fuel use represents a larger portion of direct cost for aircraft than it does for autos. Typical El's in terms of direct and total energy uses of commercial air travel are 8400 and 11200 Btu/passenger mile. Corresponding values for intercity auto travel are 3300 and 5700 Btu/passenger-mile.

\section{Future Research}

In addition to work directed toward the solution of well-identified technical problems, it may be conjectured that there are two ways in which research and development might impact general aviation favorably over a long range:

First, research and development's efforts directed specifically toward moving general aviation out of areas of resource use wherein the longrarige outlook for resource availability is poor

Second, efforts directed toward uther transportation and public utility areas, the results of which will

"Hirst E. Total Er.ergy Use for Commercial Aviation in the U S. Oak Ridge National Labs, No ONRL-NSF-ED-68. April 1974

"loid remove pressure on general aviation and so allow a slower abandonment of present technology. Some of this work would presumably be of both direct ar.d indirect benefit to general aviation.

The dismay of the public over energy availability appears to be directed more toward the increasing custs of fossil fuels than toward their enventual exhaustion. The ultimate problem, however, is truly resource exhaustion rather than cost. The rising prices simply emphasize the diminishing availability of the resources. It is cynical to suggest that a 200 year coal supply affords significant energy relief to a race whose problem of survival presumably extends thousands of years beyond. It is likewise thoughtless to neglect our present technology by stiting that the technological level on which future generations will live simply will have to be lower than the present one. This thinking has never been generally acceptable, and it is reasonable to expect that gains we have so far made will be given up reluctantly. But we must realize that research and development in the direction of long-range relief from the fossil-fuel exhaustion problem must be dcre now, while the short-range outlook still indicates that a few years are left.

The two general deficiencies in the area of energy resource conservation have been that we have not developed the ability to use free and renewable resources within the rate limits that would avoid exhaustion, and that we have not developed the ability to store energy over long periods of time. Our two principal means are the hydroelectric reservoir and the tank farm, as they have bee- for forty years.

It is also worthy . $u$ note the directions of change that have taken place specifically in the aircraft area. Fuels and lubricants have the same source as they did at the start: nonrenewable fossil resources (through castor oil was used during World War I as a lubricant). The choice of materials of construction has swung from renewable to non-renewabie ones-from wnod and fabric to metals, and lately to energy-intensive materials, the plastics.

The hold that general aviation has on the small percentage of our resources that it does use is very insecure. A flel panic such as that of 1973 can cause gerieral aviation fuel supplies to be imperiled in the search for the most visible ways to alleviate the trouble. Continuing increases in resource use can cause repetitions of similar crises and can eventually put general 
aviation quite literally on the ground.

There are no means of stepping completely outside the areas of resource use of non-aeronautical technologies. There are, however, ways in which at least temporary relief can be secured.

The search for alternate aircraft fuels is on already. There has been considerable speculation over the possibie direct use of liquid hydrogen as an aircraft fuel. The manufacturers of large airframes have conducted studies indicating that hydrogen-fuel technology might enable development of airframes weighing substantially less per pound of useful load carried. than do airplanes using hydrocarbon fuels. This advantage apparently does not extend to smaller airplanes. The use of hydrogen also depends upon the development o: a hydrogen economy. which in term waits upon construction of inexpensive hydrogen generating plants in large capacities. Similar remarks can also be made regarding the next runner-up, liquid methane.

It would appear that the small general aviation airplane in roughly its present form and using fuels requiring no more special handling than does avgas. should be the best candidate for survival. If this is granted, the search should now shift to acceptable mears of obtaining replacements for the present fossil source of the fuel. The cremical composition of such fuels must be generally simılar to that of avgas to yield similar performance and handling properties. The desirable elements of the fuel are. to start with at least. only carbon and hydrogen.

The production of liquid hydrogen is no longer a technological problem in the sense of the difficulties it presents, but is rather a problem of cost. In 1974 the cost of liquid hydrogen was stated to be from $\$ 2.50$ to $\$ 8.50$ per Btu (taken by itself as a fuel), the highest cost of any aircraft fuel considered. except boron ( $\left.\mathrm{B}_{5} \mathrm{H}_{9}\right)$. Nevertheless hydrogen is abundantly available. and is returnable to the environment in the form from which it can be extracted in largest quanity. water.

Obtaining carbon. however, is another matter. Coal, which is being talked of popularly as a source of gaseous fuel as well as for direct use in its natural form, will have heavy pressures placed upon it for non-aviation uses as petroleum resources dwindle. Since aviation is

"Nassikas J N National Energy Policy Directions and Developments IEEE Transportation on Industry Applicetions. VIA.9 NO 5 Sept OCt

"Hirst E op cll a small consumer of energy even in the transportation market, it would seem wise from a strategic point of view to attempt to sidestep the blow that is sure to be felt as non-aviation uses impact the supply, and seek other sources of carbon, such as vegetable matter, atmospheric carbon dioxide. and limestone. Of these three. the visible environment will be influenced loast by extraction from atmospheric carbon dioxide, and most by extraction from limestone. Of the three, two methods meet the desirable goal of utilizing renewable energy sources.

Little commercially-usable technology is in hand for any of these extraction methods yet, but it is not too early ic consider acquiring it.

Aviation fuel synthesızing. in the general fashion called for by the exploitation of the above techniques. is being explored by the Air Force. To illustrate how far the development has to go, in 1974 the price of a gallon of one such fuel was $\mathbf{\$ 8 5}$. The fact that the Air Force interest is along the line of tailoring fuels and engines to each other brings up the entertaining possibility of exploring the feasibility of doing the same thing for non-military power plants.

\section{Conclusions}

The overall energy picture for the United States and the world is not very promising. With only 5 percent of the world's population. the United States uses over 30 percent of the worid's energy. This use is predicted to increase even in the face of competition for energy resources by developing nations seeking to raise their standards of living. The result. even considering only the most optimistıc predictions. is that by 1985 the nation will be only 62 to 89 percent self-sufficient. ${ }^{64}$

However some saving in energy used can be effected oy increasing vehicle passenger and cargo ioad factors and changing the present trinsportation mode mixes away from trucks and airlines and toward raılroads. Voluntary conservation to date has not worked. The use of electricity did drop by 1.5 percent in the last quarter of 1973 after contınuing its normal 7 percert growth rate up to that time. By by "1974. a substantial return to normalcy had occurred. Imports were approachıng 40 percent of U.S. petroleum consumption... and the U.S. had become even more dependent on foreıgn supplies that it had been before the crisis of 1973-74 The needed dedication to implement Project Independence was absent." 65 In fact. domestic production of petroleum has declined in the past year and relaxation in conservation 
appears total. We now draw 26 percent of our oil imports from Arab countries as opposed to 16 percent in late $1974 .^{\circ 6}$

The effect of energy shortages will affect automobiles and airplanes the greatest tecause of their energy intensiveness. If fuel

- Time Magarino. July 21, 1975 p 42

- "General Aviation Aurcratt." GAMA Washington. DC. were allocated on the basis of national need, general aviation is bound to be affected the most, although it only uses about .42 percent of total fuel needed by transportation. "7 Furthermore, because of its characteristics, aviation cannot easily switch to alternative modes or even take easy actvantage of those technological acivances persently on the drawing board such as solar, geothermal, or nuclear. 


\section{COMMUNITY PERSPECTIVES}

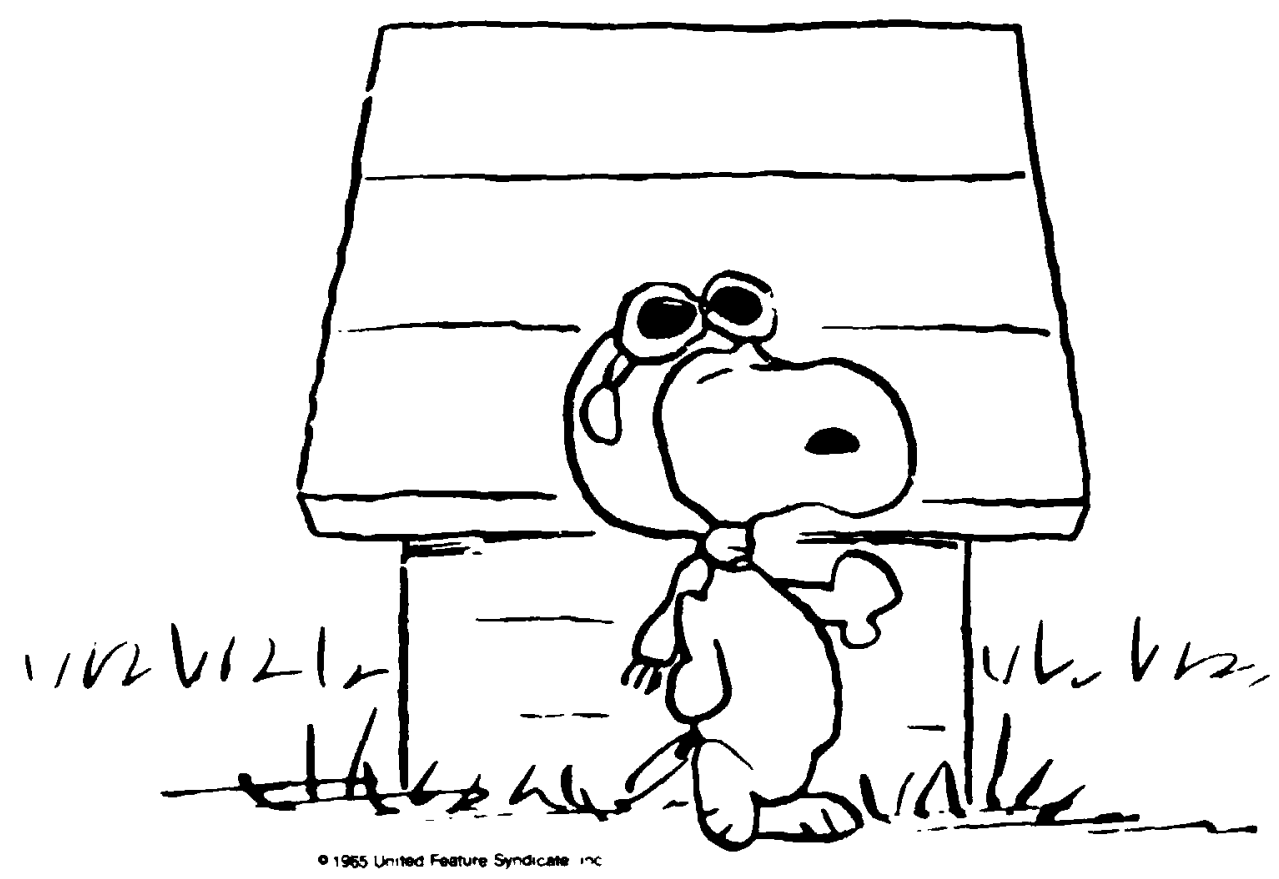

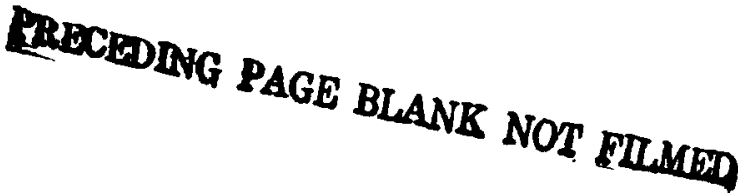




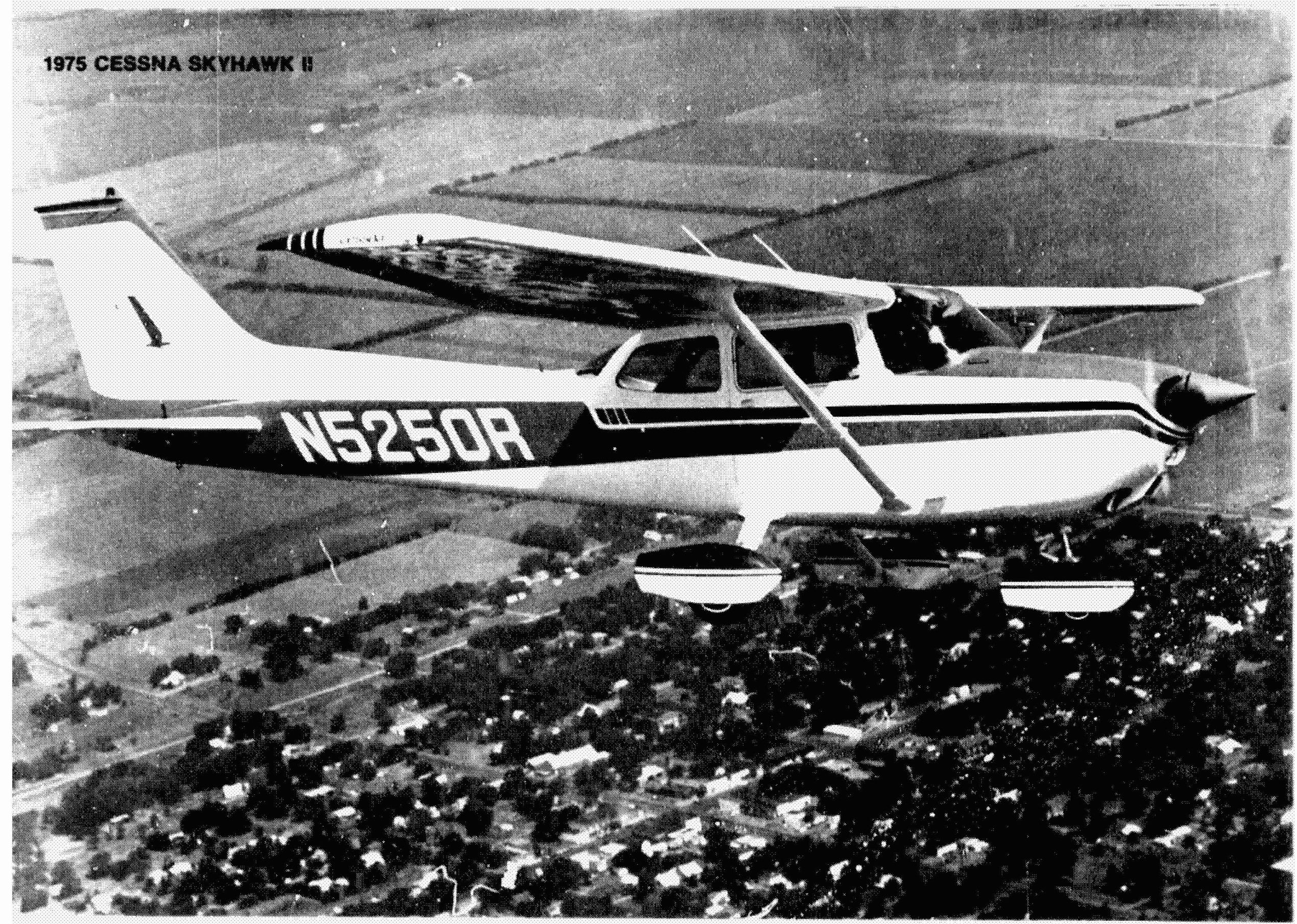




\section{N $\overline{7} \overline{6} \quad 1 \overline{2} 0 \overline{0} 3$ CHAPTER III COMMUNITY PERSPECTIVES INTRODUCTION}

Chapters I and II have presented the technological and human components of general aviation and the regulatory, competitive, and physical environment within which it operates. General aviation is usually of little concern either to those communities which have its service or to those which do not. It becomes a matter of public concern, however, when someone urges local authorities to obtain or improve access to general aviation services. (It also becomes a matter of public concern when general aviation becomes incompatible with other commu.rity values-noise, conflicts with other land use or development, etc.-but that is not a concern of this chapter.) At that point. general aviation becomes a public and political question which may involve such issues as taxation. lifestyle, and land use, as wel! as other community goals and individual aspirations. The objective of this chapter is to put general aviation into the perspective of the local community's decision-making process. The basic questions addressed by this chapter are. How can a community decide whether it needs better access to general aviation services? And. if such improved access is desired. how can it best be acquired? "Access to general aviation services" rather than "a general aviation airport" is discussed because the best policy in some cases may be to utilize or expand the services avallable at an exıstıng aırport not too far away.

The object of this analysıs-the local community-is difficult to define or describe in general ter ns Communities vary enormously in sıze and density of population; in geography. form of government, and styles of life: in economic base. level of incomes, and educatıon; and. in a host of other ways which make it almost impossible to prescribe the best course for each and every community. Even if the best course could be prescribed, the communities would still have to be persuaded Rather than prescribing. this chapter analyzes the factors which any community considering generai aviation ought to take into account and also outlınes a decisıon-making process to be followed. But the facts of the case and the importance accorded each of the factors involved can only be known and decided upon at the local level. To assist local decision-makers, the conclusions of this chapter are presented again in a concise and schematic form in Chapter V.

THE DECISION-MAKING MODEL

While many studies have been done concerning the development of general aviation facilities, a survey seems to indicate that all of them are bascd on estimates of the future requirements for the services offered by the general aviation facility. These requirements are generated by the direct users, the private airplane owners. the pilots (both private and those employed by commercial enterprises), and other individuals and corporations who are direct users (or beneficiaries) of aviation. Another approach to plannıng is to base decisions on the needs of the community with respect to the addition, expansion, or improvement of, a public facility. The purpose of this section is to look at the needs of the community rather than the requirements of the user in order to determine the advisability of alternative actions. In order to determine those needs, an analysis of the community characteristics and the pressures brought on the community, both internally and externally. should be undertaken (See Figure 3-1).

The facilities concerned are those which permit an interface between available ground and air transportation. Considering the present state of the art. these facilities are airports or helıports. but the future may bring other possibilities. Naturally, the type and size of airnort. as well as the services avarlable at the airport, become a funct. nitude of services needed by the community

In the initial evaluation of the need for the services of general aviation. community characteristics such as demographic data. socio-economic characteristics. and institutional structures must be consıdered. In additıon. Internal and external sources exert various pressures on decision-makers External sources are defined as those cutside the control of the cominunity. Internal pressures are those that are generated from withın the community. These three determinants of need are brought together by the decision-maker and affect the initial decision as to whether or not the community needs the services of general aviation and whether or not it should investigate further the desirability of constructing a new facility or implementing changes in an existing facility or service. If the decision-maker finds that no need has been demonstrated, then the process ends; if need is demonstrated. it should take the form of an estimate of economic 


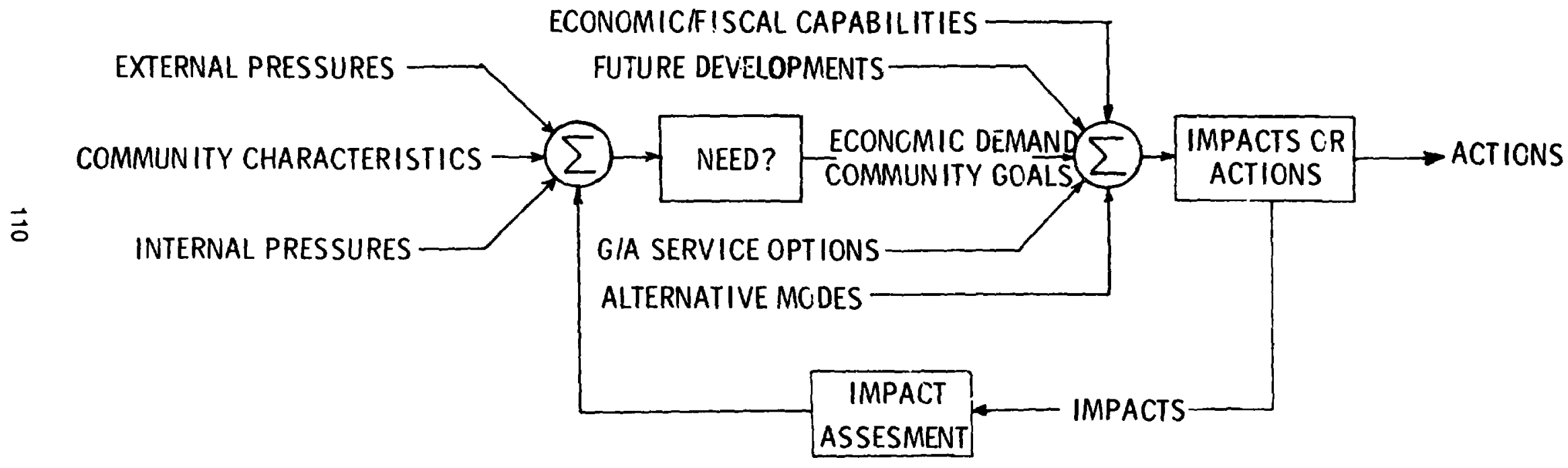

MODEL OF COMMUNITY/GENERAL AVIATION DECISION-MAKING PROCESS

fIGURE 3 -1 
demand for service and of the community's goals to make sure they are in accord with general aviation.

Once the economic demand for general aviation services is established and found consonant with conımunity goals, additional factors must be consıdered prior to taking any action. These factors include the economics and fiscal capabilities of the community; the future possibilities concerning items such as the growth and potential need of the community: general aviation technology, fuel supplies, future lifestyles, etc.: the specific services that general aviation can be expected to offar and which can satisfy the economic der,lands and social and political community goals as specified in the needs ans; , sis; and, finally, an analysis of alternative mode, capable also of satisfying thees future needs.

As this intormation is synthesized by the decision-makers, they will be in a better position to determine whether or not any action needs to be taken. If, the decision is that no action is warranted, the entire project would be dropped. If, however, some action is called for, alternative options must be specified and an assessment of the various impacts of each of these options must be undertaken. The results of these impact assessments are then fed back into the decision-making process to determıne whether the proposed change in the supply of aviation services and the impacts of such a change do in fact satısfy community needs or whether the plans need to be reised. The cycle of option specification. impact assessment. and option respecification continues, until an option has been found which s'it:sfies the needs of the community and which i.s within the constraints and limitations set by different factors in the system's service area. At that point. the decisıon-maker is ready to initiate action which wiil change the existing structure of the avia. tion services avaılable to the community of interest.

\section{THE PRELIMINARY DECISION}

When the question of the acquisition of general aviation services is raised in a community, the decision-maker must be able to make a preliminary determination as to whether it is worthwhile to initiate a detailed investıgation of the options avarlable concerning the building. Improvement. or change in the aviation service system in view of the real needs of the commuinty

The criterion of "need" differs from that of "requirement." "Requirement" for an airport. for example, is determined by the number of aircraft or aircraft engines owned by people within the service area of the proposed airport The simple fact that a number of people in an area own airplanes is, however, no more adequate a reason for constructing a publiclyowned airport. than is the existence of a number of boat owners adequate reason for creating a publicly-owned lake. Other factors must be taken into consideration.

The criterion of "need" provides a way to take other factors into account. Need may be defined as a pressing lack of something essential. Thus. need for general aviation services is not merely the lack of them. A determination that the services are essential and that the lack of the services is pressing also must be made. The terms "pressing" and "essential" must be defined relative to the special character of the community involved A community which regularly faces floods may find that the construction of a dike is essential while the construction of an airport is not. A community with more than adequate public services in other respects may find that .1 airport is the most pressing "lack" it has.

The decision-making process of initıal need-determination is represented by the section of Figure 3-1 reproduced in Figure 3-2. The decision process is usually initiated when someone in the community-perhaps the decision-maker-urges the development of new or better general aviation services. Sometimes internal pressures result from external pressure. as would be the case when a representative of the state aviation agency addresses the local Chamber of Commerce on the subject. External pressure itself, however, sometimes initiates the process, as when a firm promises a community that it will locate there if an airport is constructed which can accommodate its corporate aircraft.

Whatever the pressures. the responsible decision-maker should evaluate them in the light of community characteristics. In this phase of the process, need is determined by estimating economic demand and community goals. The economic demand estımate is a projection of the willingness and ability of people in the area to purchase the service. The estimate of community goals determınes whether the acquisition of the service promotes. hinders, or is indifferent with respect to the objcctives of the community as a whole Sometimes the goals alone may justify the service an island commurity may wish to build an aırport in order to provide access in emergencies. even though the airport would not be used often. 


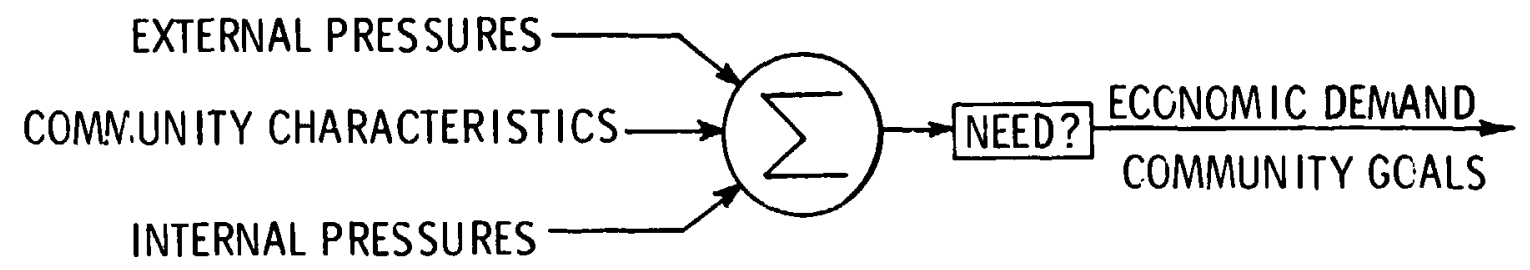

\section{THE PRELIMINARY NEED-DETERMINATION FIGURE 3-2}

If there is no demonstrable need or even likelihood of need, the decisıon process comes to an end and the decision-maker decides not to pursue the matter. If there appears likelihood that a need for general aviation services exists. the decision-maker will proceed to the next step.

The remainder of this chapter deals with the components of the preliminary decisıonmaking process in detail: the three main inputs to the decision (external and internal pressures, and community characteristics) and the decision-making process itself.

\section{External Pressures}

External pressures on the community to alter its policy toward general aviation services influence the local decision-making process. Such pressures arise from government planners, special interest groups, economic factors. and legal restrictions. The community should be aware of the nature of these inputs so that they may be evaluated as to which are unavoidable, which may be modified, and to what degree they should be considered.

Through comprehensive planning, federal. state, and regional aviation plannıng agencies influence local general aviation policy. The Federal Aviation Administration (FAA) is responsible for the development of the airways system Since the FAA measures the need for airport improvement funds by the level of activity. some FAA officials tend to promote aviaion in small communities on the premise that the facilities are required in order to generate the traffic necessary for "expansion." "If the

\footnotetext{
Steven E Rhoads Policy Analysis in the Federal Aviation Administration. (Lexington DC Heath and Company 1974) p 24

'George P Howard Airport Economic Planning.

(Cambridge The MIT Press. 1974), p 425

' Rhoads oo $\mathrm{ctt} .028$

- Talk oy James Gray Division of Aeronautics, Common. wealth of Virginir July 111975

"Lane Council of Governments Airpon Needs Study, (HUD Propect No Oregon P-145, January 19711. D 33

- Ibid. p 108
}

problem facing a community is too much air traffic, the FAA usually recommends acquisition of new facilities rather than improving the efficiency of the existing ones. ${ }^{2}$ The FAA acts in part on the basis of a number of studies of the community impacts of aviation which it has sponsored. Two problems arise in relying solely on these studies: (1) political pressures tend to make the analysis conform to established policy objectives instead of evaluating them. and (2) the studies tend to emphasize quantifiables to the point of discounting qualıtative aspects. ${ }^{3}$

Many state aviation agencies are involved in planning statewise airport systems. Criteria for measuring airport need differ from state to state and sometimes between the states and the FAA. Ohio and Georgia, for example, had a high rate of success in convincing local communities that every county needed its own airport. The airport plan for Virginia uses population, income, and rate of growth of an area as principal measures for determining the need for air facilities

One example of community reaction to state plannıng is the Cottage Grove State Air port. owned by the State of Oregon. Board of Aeronautics. "Although Cottage Grove has one of the better general aviation airpcrts in Oregon. community acceptance of the airport is low Many reasons for the antipathy of the community are given. but the most frequently mentioned reason is that many citizens of Cottage Grove feel that the airport was forced on tive city by the Board of Aeronautics "s

Port Authorities. Airport Commissions, and other regional aviation bodies influence general aviation development in the community One solution to congestion at hub airports has been peak pricing. which tend: to price general aviation aircraft out of the airpor during peak hours The airport commission's answer to this situation is to seek to establish general aviation airports close to urban centers. "Under those conditions, external pres- 
sure for a community to acquire i general aviation airport may come from a nearky congested hub airport that seeks a reliever airport. The Minnesota Airport Commission, which was created in 1943 to develop the airports in the Minneapolis-St. Paul area, built a reliever airport at Ham Lake. The Los Ingeles Department of Airports decided on the basis of demand estimates that if should build a reliever airport at the City of Palmdale.'

National spe:cial interest groups such as aviation interests or environmentalists lobby on all levels in order to affect aviation policy. In an article entitled "The Fine Art of Communication with the Public." Barney Oldfield, an aviation enthusiast, proposed that the desire for acquiring aviation facilities and the acceptance of the consequences must be sold to the public under the banner of progress. ${ }^{\theta}$ The '. . Transport Association of America (represe I the air carriers) and the Aircraft Owners anı Pilots Association. (representing general aviation) are the most effective lobbies on the national level ${ }^{9}$ The General Aviation Manufacturers Association seeks to persuade industry and the community that "business aircraft are an essential component of America's economic machinery and a significant contributor to the nation's economic well-being." ic As the construction of new airport facilities affects the environment. national environmental groups become interested in projects which have the potential for adverse ecological consequences. National conservation groups so aroused the general public that the plans for the new Miami Everglarise etport were hatted General aviation airpor:i, if planned near critical areas of the environment such as wetlands, would also

- Gary H Lanter, Community Opposition to Airpors Development (Cambridge Massachusetts Institute of Technology 1972 pp 185. 108

- Angelo J Cerchione. ot al. Master Planning the Aviation Environment. (Tucson The Universivy of Arizona Press 1970). 138

- Rhoads. OP clt, p 39

"GaMa, Airplanes Are Business Tools. D 3

" Interview with Tom Ferguson of Piedmont Aviation at Nortolk Regional Airport. Nortolk. Virginia, June 26. 1975

"Federal Aviation AJministration Eastern Region Generai Aviation and its Relationship to Indusiry and the Community (Jamaica New York May 1, 1962 Reviser February 28. 1963. April 7. 1964). pp 33. 24-5

"Department of Transportation A, dd Naticnal Aeronautics and Space Administration Civil Aviaticon Research and Develoo ment Policy Study-Supporting Papers. (Washington. DC March. 1971), p 642

1. Va Code Ann $5 \$ 51.46,51.48$ and 51.56 to 51.76

is a Dixon Speas. Tennessee Airport System Plan. December, $1972=23$

14 Howard op cit, p 248 draw criticism from advocates of the environment.

Economic pressures can influence community decision-making witt: respect to general aviation services. Sometimes an industry will offer to locate in a community. on condition that the local government provides adequate general aviatıon íacilities. A candy company located in Clarksville. Virginia, only after the airport it required had been constructed. "The City of Manchester, New Hampshire, negotiated with the Air Force in order to provide the airport location insisted upon by the Marian Electric Company in order to establish its new plant. Two companies purchased private airports for industrial developn ent in neighboring northwestern Virginia towns, and then notıfied the communities that they would require an alrport to ser, 2 their corporate aircraft before they would begin development. ${ }^{12}$

Funaing available from the federal and state governments or the airport commission can make the acquisition of general aviation facilities more attractive to the community. Federal assistance to airports has long been relied on. through a history of federal involvement in aviation. and such subsidy programs as the Federal Aid to Airports Program, the Airport Development Aıd Program, and airport access improvements through highway funding: as well as riaintenance of the air traffic control system and air vehicle and new airport certification. ${ }^{3}$ The Commonwealth of Virginıa is involved in the funding and operation of airports through the Division of Aeronautics of the State Corporation Commission which is the agent for federal and state funds for county arid municipal alrports. and the Virginla Airports Authority. whicn has the power to build and operate arports. ${ }^{4}$

If Virginia believed that a panicular area needed a general aviation airport, it could provide partial or total funding. In Tennessee, funds for airunit construction are available from both the Tennessec Department of Transportation. Bureau of Aers, lautics, and the Appalachian Regional Commission is Airport commissions may be self-supporting and could be in a position to provide for new aviation facilities without community financing. The commission may, for example, issue revenue bonds to provide needed funds, on the condition that income from the airport will be used to retire them.' ${ }^{16}$

Many states have created iegional pla. ning districts. typically consisting of a contiguous group of counties which share 
geog. aphic or economic characteristics. Planning districts can be an important source of external pressiure on a community. This problem is discussed in some detail in Chapter IV with reference to conflicts between state and regional planners and the local communities and citizens involved in arrport planning for Roanoke, Virginia.

Legal restrictions on the aviation environment affect community planning processes concerning general aviation. Regulations, common law suits, and zoning options must be dealt with by every community which decides to build a general aviation airport.

The areas of ragulation which are most likely to influence general aviation airports are energy, environmental, economic, and safety concerns. Comprehensive energy allocation plans are being explured by both Congress and the President. As the program of gasoline allccation in 1973-74 indicates, general aviation fuel supplies may be restricied as crude oil becomes less availabie. The community should consider the fuel situation in estimating demand for new transportation facilities.

In addition to FAR Part 36 explained in Chapter II, the area of common law nuisance affects the operation of airports. Those responsible for airplanes flying low over a person's property are liable to the property owner for any diminution in the value of his property brought about by the airplanes' noise. "The Los Angeles city attorney estimated that potential damage claims based on nuisance caused by the city airport could cost the city $\$ 4.5$ billion These suits prımarily concern jet noise, but it is possible that a substantial amount of general aviatıon traffic could breed nuisance suits for a community-operated general aviation airport.

Through the use of available zoning procedures. the community miay establish an air. port which is in harmony with the local environ-

\footnotetext{
"Richard A Posner Economic Analysis of Law, (Boston Little. Brown and Company 1972). D 26

- The Aviation Advisory Commission the Long Range Needs of Aviation. (Washington DC The Government Fintıng Of. fice. 1975) p 14

- Cerchione. op ctr, p 197

"H Floyd Sherrod. Ji ed Environment Law Reviow1973. (New York Clark Boardman Company 1973) p 387388

"Smirh $v C_{C}$ of Santa Barbara, 243 A C A 126, 52 Cal Rprt 292 Dist Ct App 2nd Dist (1966)

"V O Key Jr Public Opinion and American Democracy. (New York Knopt 1967) p 411

"Frank Muriger Opinions Elections Partils and Policies A Cross.State Inalysis paper delivered at the annual meeting of the American Political Science Asscciation NY 1969

14 Thomas $R$ Dye and Harmon Ziegler The Irony of Democracy. (Belmont Wadsworth. 1970
}

ment. The safety regulations of the FAA establish the minimum approach zones and boundary conditions for the airport itself. '1 Some states control zoning in the airport interface, and others allow the local governments to do so. ${ }^{20}$ One reason for proper zoning is to prevent airport encroachment, which can spawn nuisance suits and prohibit future airport expar.sion. The right of a co'nmunity to use comprehensive rezoning procedures to avoid thic problem was upheld in Santa Barbara. California. "The locality could also buy all of the land needed for careful planning, and then either rent the surrounding plots or sell them with restricted deeds.

\section{Internal Pressures}

The impact of internal pressure on policy decisions must be based on a number of assumptions including: (1) that at least some citizens play a role in both the formation and the content of public policy: (2) that opinions are expressed by a variety of groups (individuals in many different ways with varying degrees of intensity); (3) the belief that local political decision-making leads to an uneven distribution of rewards and disadvantages, depending on such factors as the issue and groups involved in the decision-making prcecss.

An application of these assumptions to the field of policy analysis, including the general aviation field. suggests that citizens often have little positive policy impact. Past studies have demonstrated that the general public has no knowlecige of, or opinicns about. many public policy questions. Even :I.O. Key, who was convinced that mass preferences rave an impact on policy was forced to conclude "that the supposition the: public opinion enjoys weight in public decisions is a myth and nothing more. albeit a myth that strengthens a regıme as long as people believe it." 22 in the same context. Fiank Munger. in an analysis of five policy areas about which people have some opinions. concluded that the chances of a state matcining the policy preferences of its citizens is only a little better than $50-50 .{ }^{23}$

It is apparent that the political system trequently does not act in congruence with the preferences of the general public and that some individuals have influence disproportionate to their numbers. ${ }^{24}$ Policy in this context reflects the preferences of an elite and flows downward from the elite to the masses. This does not imbly that public policy resulting from elite preferences is necessarily anti-mass " not in the public interest. since it is possible that 
values of the elite may be public-regarding and not private-regarding. Thus, the elite may feel responsible for the w'elfare of the masses.

The elite model of decision-making has also been applied to the study of local zommunities. Various researchiers have indicated that communities vary in their degree of elitism depending on such factors as the size of the community and the degree of community integration. ${ }^{25}$ In many communities policy decisions can best be viewed as a product of the interactions of the members of the elite. Depending on the policy are? " en, this product might be ratified by the maser's.

Although none of thes: studies has dealt with general aviation policy, a reasonable assumption is that the elite model would also apply to this area of decision-making. Caution is required, however, in applying thi', mode: to the community's support and the use of general aviation for at least three reasons. First. conimunities vary greatly in their economic and socio-political makeup. Second, general aviation includes a wide range of activities. Third. general aviatıon activity has not developed as a coherent policy field

The variation in comiriunity types and characteristics has been shown in numerous studies which have classified communities by their demographic, social, and economic characteristics. ${ }^{26}$ One would expect. for example. upper-middle class comm' nities with a technically oriented economic base to generate a greater economic demand and political pressure for all types of general aviation including business flying, commercial flyıng, and p!easure flying, than would lower class comunities with a general industrial tax base and large numbers of blue collar workers. Again. many individuals are convinced that general aviation is of importance only to those in the upper socio-economic levels Thus, an attitudinal factor constrainıng the development of general aviation is the widespread conviction that air transport is important to onlv a small

"Nelson Polsby Community Power and Folltical Theory. (New Haven Yale University Press. 1973)

* Robert Lineberry and Ira Sharkansky Urban Politics and Public Polleje. IEnglewood Clitts NJ Prentic 3 Hall. 1974,

"Joint DOT-NASA Study Civil Aviation Research and Development Polley Sludy. March 1971 DP 6.4 and 6.6

- Jeremy I Wartord Public Policy Ioward General Avia. IIon, (Washington DC Brookings Institution 1971)

"Aviation AJvisory Commission General Avialion. (Janu ary 1 1973) $20-x$

"Opinion Research Corporation General Avialiun Today. (Princeton N J June. 1973 segment of the populc ticn. This limited colitical constituency inhibits aviation supporters from translating their desires into market $d \epsilon$ nands. In general, one can safely assume that "the overall attitude of the community toward airports is invariably negative.' 27 Th:s attitudinal problem would not be as great in an upper class community as in a cominuility comprised of working class ind:viduals."

A second difficulty in assessing the demand for general aviation in a given conımunity lies in the nature of general aviatıon itself. General aviation, which encompasses all civilian aviation activity except that associated with the operation of $\mathrm{CAB}$-certified air carriers, has a serious ideriticy problem. George Coker wroie inat "the reie of General Aviation can best be described as 'filling in the gaps' left by the common carrier airline services." He argued that the importance of general aviation is not readily recognized because: (a) the industry is composed of many uncoordinated segments; (b) the magnitude and glamour of the certificated airline industry; and (c) the reluctance of the vast majority of large corporations to publicize their owner' $\supset$ and use of business aircraft. ${ }^{29}$

A study conducted by the Opinion Research Corporation in June, 1973 indicated that a majority of the general public (59 percent) has not heard the term "general aviation" and that most of those who have heard the term equate general aviation with air travel in general. despite the finding that 41 percent of thiem claim to have flown in a private or bus:ness plane or used a commuter service Nevertheless. most members of the public agree that general avition provides many benefits such as: emergency service (95 nercent). jcts ( 95 percent). and industrial growth (76 percent) ${ }^{30}$ Thus, although members of the general public are not kriowledgeable about what comprises general aviation. they ex. pressed positive views about its impact once the polling team defined general avidion to the interviewees. One can conclude that the pressure for gener." aviation is probably created by community leaders or a small group of in. dividuals either from inside or outside the community in sum the development of general aviation is frequently constraired by the lack of bioad. and supportive, cunstituency. It shoisd be kept in mind. however. that the size of a conshituency in a policy area may not te as important as the characteristics of that constituency Frequently a small group. which is well. organized and high in sccio-economic status. 
can exercise authority disproportionate to its numbe, 3. ${ }^{3 i}$

A th ird problem. in assessing the demand for general aviatıon is the lack of a national transportation policy. According to a study commissioned b; the Aviation Advisory Commission, the transportation policy of the United States can best be described as

a patchwork of disorderly transportation policies which are an aggiomeration of explicit siatutory provisıons and implıcit approaches. resulting from usually unstated assumptions. changing social priorities. and scattered responses to random developments over the years. National transportation 'policies' are better revealed in what is done, or not done, than in what is said. ${ }^{32}$

The lack of a transportation policy system. whir, is reflected in the general confusion about the proper role of the various levels of government in general aviation. increases the difficulty of attempting to determıne the demanc for general aviation activity. It is. for example. difficult to measure the impact of mass public opinion on policy when the policy is not clearly known. There is little evidence that mass opinion is an irnportant indeper Jent aeterminant of public policy. particularly in a policy area as vague as general iation.

The lack of national policy has been one factor which has led the federal government to adopt ihe approach thai poiicy decisıons should be decentralızed and made by local units of government The advocates use of special revenue-sharing funds for transportation p!inning does little to solve this lack of direciion The revenue-sharing approach. which is baseo on the principle that local units

3 It shcula be kept in mind however that the size of a constivency in a policy area may nu: be as important as the characteristics '.? that consituency trequen:ly a small group which is well... jentzed and high in socio-conomic status can exerciso authofit dispropertionate with its numbers This corcept is developed bu David B Truman the Governmental Process (Now York Knopt 1951) General aviation poil. y may be the result of elite preferences and not the preferences of the masses Seg for exam. ple Thomas R Dyt and Harmon Ziegler. Ine Irony of Democracy. (Beimont Wadsworth. 1970)

Rictrard I Barber Report on National Transponation Policies-Pan '. Analysis and Trends. il S Department of Com. merce National Techn:cal Information Senice September 19;1)

"Aviation Advisory Sommission. Aviaticn in a Long-Range Public Planning Contexp February 151973 p 44

- Andrew J Wintrey Joseon C Corradino and Charles Schimfeler. 'Developing An Environmental Assessment Report For a Regional Airpon-Industial Complex. Trensportation Research Record. 529 (Washington. DC 1975) of government should have greater discretion in the spending of funds, leads to further confusion since the combination of local transportation policies does not necessarily lead to any type of national policy.

The above discussion has distinguished between the mass public and the various specific publics involved in the development of general aviation activity. Another distinction, based on the propensity to use general aviation aiso should be made. This is the distinction between the consumers of service and the nonconsumers. Rai Okamoto, a member of the Aviation Advisory Commission, has classified the non-consumers into two groups. ${ }^{33}$ First, those who use the system but do not want to be disturbed by it once they are on the ground. This group uses air services but at the same time is very concerned about avoiding its negative impacts. This group can be compared to automobile drivers who drive their cars but do not want expressways located close to their homes The second group of non-consumers is comprised of those who rarely or never use the system. This group could be composed of the community's taxpayers who use other modes of transportation on a daily basis. To them, an airport is something exotic and perha;s not necessary. Transportation probiems are viewed in terms of highways and iscal mass transit. Consequently. they woulc not be in favor of the development of general ar' ation facilities.

Evidence suggests that $g$-neral aviation proponents are usually the only members of the pubıc involved in the initial stages of airport development. Only when specific issues are put in the context of the decision-making process. do other individuals and groups become involved. These groups, which are usually composed of residents near the proposed facility. generally play a negative role-they want to stop something (an airport) from happening. ${ }^{34}$ This negative role of varıous community groups is demonstrated most clearly in the environmental assessment review process in which local citizens become involved only once certain basic decisions about the facility have been made. Clearly, citizens frequently lack the resources to participate effectively against the proponents of the airport who have the money and/or expertise to obtain the facility.

The response of the politıcal system to the demand for specific actions. such as the growth: or establishment of general aviation activities. can only be understood by recognizing that politics involves the distribution of rewards and disadvantages. One must recognize that 
transportation policy. particularly from the vantage of the local community. does not constitute a set of coherent directions. It is most probably no more than the sum of actions taken in response to the expressed demands of various segments of the community at various tımes. Although decision-makers engage in broad activities such as organızing, rankıng priorities. and allocating costs and benefits. they also tend "to respond positively to every demand without worrying about the total costs or total ber fits (consequences) or considering alternatives." ${ }^{35}$ In addition. the political system functions in a way that enables the definer of the problem to set the agenda for action and to play the key role in formulating the solutions to the problem. ${ }^{36}$ Giver, the fact that the meaning of the term "general aviation" is not clearly understood by the general publıc. one would expect the aviation support to be in many cases the only intial ir.fluence on the policy-making process.

In some cases. such as in the development of ine Creswell. Oregon airport. the airport is desired by a narrow group of users. According to a local study. "the original purpose of the Creswell Airport was to meet the general aviation needs for pilots in the Creswell area." The study indicated that aviationısts involve local government to qualify for federal aıd and warns that "local governments must be aware that general aviatıon aırports are expensive. ${ }^{37}$

The desire to fulfill the specific demands of aviationists is not the most frequently expressed basis on which a community's need for air service is justified. A recent workshop on low/medium density air transportation concluded that communities justify their need on four basıc grounds-community pride. economic development. population dispersion. and isolation. ${ }^{38}$

"See William Mitcheli The American Policy. (New York Free Press 1962) for a discussion of decision-making The quote is taken from Norman Wengert. Political and Administrative Realities of Regional Transportation Planning in Joseph De Salvo ed Perspectives on Regional Transportation Dianning ILexington Mass DC Heath 1973) o 381

* V'engert op cit p 382

"Lane Council of Government Airpon Needs Study. Eugene Oregor January 1971 pp 36 and 47

- Joseph Vittek ed Air Service to Small Communities Directions for the Future final Report of the Workshop on Lon Medium Density Air Transportation. Cambridge M/T Fight Transportation Laboratory Februany 1974) pp 39-41

- George P Coker General Aviation in Our Air Transportation System in Airports Challenges of the Future. American Society of Civil Engineers p 133

- Don W Farnsworth The Ohio County Airport Story. 1964.1972 State of Ohio. Department of Commerce. Uivision of Aviation, $p 24$
Community pride is a significant reason for seeking general aviatıon services because many individuals, particularly elected officials. attach a great value to being in a progressive community. George P. Coker, Vice-President of Airport Services for the Southwest Airmotive Company. used this type of rationale whan he suggested that communities without jeneral aviation services "may find themselies outmanuevered by competitive communities." 39 In addition. the airport as a physical entity is a specific thing leaders of the community can point to when discussing their achievements.

Second, some coinmunities seek airports due to their isolation from certain markets or services. These communities do not want an airport for business reasons, or for community prestige. but desire air services because other modes of transportation are either unavallable or impractical

Third. communities want an airport to further their economic developinent. These communities. which are probably governed by city administrations embodying a growth philosophy. desire an airport to provide a service for the industrial business community which is probably located (or to be located) in an ındustrial park area withın the community's boundaries. Assessing the economic impact of a proposed airport is a complicated matter. The arport alone is unlikely to draw new industry into a locality unless many other attractive community characterıstıcs exist as well. The role of airports in economic development is discussed later in this chapter

The supposed economic advantages of airport development are an important part of the arguments used by those who attempt to promote community interest in. and pressure for. general aviation services. Many members of the community have to be sold on general aviation because of its lacii of identity in the public mind or other nagative factors mentioned above. The persuaders may be outsiders or members of the community One prominent proponent of aviation development is Norman Crabtree. Ohıo's Aviatıon Director, who did a "gigantıc selling job to drum up community interest " As a resuit of his effort "community spirit blossomed with the excellent help and footwork performed by service groups, including the Kiwanis. Lions. and Rotary ${ }^{40}$ In a community in another state the demand for a new airport also came from a local service organization. the Jaycees. who were successful in "sweeping the cobwebs away from community inertia and set a record for ambition and ingenuity." Without expen- 
diture of public funds, the community has an airport due to the efforts of several dozen men who took the time and effort to learn that an inexpensive, satisfactory airport development project could be both possible and profitable." "

The involvement of local service organizatıons in developing aviation activity for the economic benefit of the community is indicated in other examples of how communities have started airport plannıng projects. The city manager of La Crosse. Kansas predicted that the small towns "will have to have an airport. just like they needed a railroad in the old days" to survive. ${ }^{42}$ The following examples are taken from an FAA report. 3 Lincoln, Rhode Island developed an airport study because the city's chamber of commerce detected "intense enthusiasm for such a project." In Manchester. New Hampshire the "city did not at first recognize the importance of the new airport to future city development." Later. however. the owner of Marıan Electric Company "felt so strongly about improving the economy of the area that he donated one-half million dollars" to develop an airport. Once agaın, the cornmunity was described as "giving whole-hearted support to the airport development. "Springfield, Vermont also felt a need to provide aviation facilities and responded by obtaining funds from the state legislature and frum industries and individuals withın the town. The FAA commented that "such an expression of faith and confidence on the part of industry and outstanding citizens in Springfield underscores the economic significance which the donors attach to this facility." Similar support by the economic interest of the community was also expressed in Hayward. California; Islip. Long Island, New York; and, South Plainfieid. New Jersey. A different case in point, but one which also shows the significant role of the business coinmunity in airport development is Oneonta. New York, which failed to attract industry because of its lack of aviatıon facılıties. One firm "did not visit Oneonta due to a lack of an airport." Another firm "rejected the area because it felt that too much time would be wasted and high travel expense would result if a new plant were estab-

- Bascom Nelson "An Airport for a Small Town flying (May, 1962) Vol 70 No 5 po 748084 and 86 The aurport was provided without expenditure of public funds

$\because 1010$

"Aviation Advisary Commission, The Long Range Needs cf Aviation ianuary 1973 p 10

“ General Avration and Its Relationship to Industry and ine Community, op cit pp 30.45

"Ibia lished in an area without suitable airport facilitıes." (Oneonta establıshed an airport in 1966. Despite a mild increase in population. however, the work force of the city in manufacturing fell from 800 to 537 between 1960 and 1970.) in a similar situation, the Sunbeam Corporation agreed to locate in Forest. Mississippı, only when the city agreed to build an adequate general aviation airport. *

The cases cited above indicate that the impetus to airport development often comes from the busıness community of a given city. Business leaders are concerned with the economic costs of general aviation activity although the social costs may be of significance equal to the economic ones. At the same time. one must be careful not to attribute benefits to general aviation which the specific aviation activity did not cause. A preliminary analysis of the Quakertown. Pennsylvania and the Mannontown. New Jersey projects indicated that general aviation led to high levels of prosperity; however, a later examination of those communities indicated that both communities would have had high levels of prosperity. regardless of the existence of genoial aviation activities there. ${ }^{45}$

While the initial internal pressure for the acquisition of general aviation facilities generally stems from the local aviationists or the business community. other internal pressures. both for and against suc.- acquisition are likeiy to develop as plans become more concrete and more certain of implementation Such pressures will appear to public authorities to have arısen out of the blue. and the authorities. reaction to the new pressures may well be an important factor in the strength of new oppositıon. Citızens who believe an airport is being forced on them on behalf of a special interest group may show intense hostility to an airport where none existed before. Consequently. authorities must make some effort in the initial planning stages to consider the goals and values of citizens who have not yet voiced an opinion about the airport. This will be done if decision-makers use the criterion of "need" withın the context of relevant community characteristics in their inıtial decision as to whether or not the community needs better access to general aviatıon services.

\section{Community Characteristics}

The decision-maker who must make a prelimınary deterimination as to whether or not there is a community need for improved general aviation services faces that decision because of some pressure, internal or external, for those 
services. The decision to pursue the matter must, however, take into account not only those pressures for public action and the expenditure of public money but also the degree of willingness and ability to purchase general aviation services (economic demand) and the extent to which the acquisition of facilities supports, hinders, or is unrelated to community goals and objectives

The "community" is defined for the purposes of this study as a group of individuals living within a specific spatial unit. These individuals possess a feeling of. or in fact have. common objective economic, social, or political bonds. These objective bonds are. indeed. the characteristics of the community that define its fixed or political boundaries, its sphere of economic influence or its social interaction space. This so-called "community of interest" encompasses a wide range of political. economic. and social activities. The type and breadth of each of these classes of activity delımits the extent of the interaction space called "community."

In the broadest sense. the nation. region. state. SMSAs, cities, towns, or villages are communities. But at the local levels each community is defined. obviously. within the local framework and context of the individual interaction space and community characteristics. In turn. the decision-making process in general, and the decision-making process with regard to general aviation services in particular, is related tc individual community characteristics. Sionificant community characteristics will be discussed in terms of their relevance to the general aviation services decision-making process.

Once the community has been defined from the viewpoint of general aviation services, i.e., the area to be served by a proposed or existing general aviation facility, certain demographic characteristics can be considered. Population size, structures, density. and rate of change appear to be important variables in the determination of the need for general aviation services. For example. there is, perhaps, a threshold population for each service industry below which the service will not be provided. In Virginia, for example, there are presently only eight airport facilities serving areas with populations of less than 50,000 persons. The exact number of persons required before general aviation services can be provided is an elusive figure. Other community

* John A Nammack. "Airports and Their Economic Im pact." Airport Services Management, November 1971 characteristics such as density. income, and age structure should be considered in combination with the community's population size in an attempt to arrive at that threshold figure.

Population density (i.e.. persons per square mile) can also be a determinant of community types. The range is large but there appears (at least regionally) to be a positive correlation between aircraft ownership and lower levels of pooulation density. Lower levels of population density figures imply a degree of rurality or agricultural activity. The degree of rurality versus urbanization can be an important consideration in assessing some types of general aviation services. Agricultural areas may make use of. for example. crop dusting, sprayıng, and seeding services.

Still within the realm of demographic consideration, the age structure and rate of population change, also have direct bearing upon general aviation service demand. Usually. general aviation services tend to be used with greater consistency by younger populations. The community's relative rate of population growth or decline can also be indicative of economic conditions and hence general aviation services need. A stagnant or declining population is less likely to elicit effective demand for general aviation services than a growing or stainle population base (unless one accepts the argument that general aviation is a godsend to end economic debility).

The community s economic characteristics are not unrelated to. and. in fact, determine. some of its demographic and social characteristics. There is, for example. considerable difference in the quality of life and life-style between communities having a balanced or diversified economic base and communities dominated by one economic activity. Regardless of these differences, all communities can be examined within a framework of basic economic factors. Those factors to be examined in assessing a community's economic base relative to general aviation services are income. education levels, employment sectors. unemployment rate. Industrial mix, tax base and tax rate. land values, degree of agricultural activity, and markets. All of these variables appear to be correlated positively to general aviation service need. For example. communities which are marketıng or institutional centers (and therefore possess below average industrial employment) are more likely to generate traffic than are industrial or "balanced" centers. ${ }^{46}$

Many of the factors mentioned are related 
to each other. One of the most important is income. High levels of per capita income, median family income. and disposable income directly impact general aviation service demand and availability. In other words, income levels can provide a valid indication of a community's ability to support general aviaticn services.

All of the community characteristics expressed above are quantifiable. Various United States Bureau of the Census publications (Census of Population. Census of Manufacturing, Census of Business, Census of Agriculture, etc.) provide general, and in some cases detailed, information about the community.

Other community characteristics are of a less tangible nature. Individual community "goals" as perceived by the members of the community are often immeasurable but are nevertheless real. Depending upon the power structure. i.e., those setting. establishing. and carrying out policy, these goals can vary widely from place to place and time to time. At one extreme is the "no-growth" or stability policy. At the other extreme is the more common "bigger is better" approach to community developmen:. in which steady and continual expansion of the economic base is deemed cesirable. Individual goals at both poles and at intermediate positions, should be assessed as they intuitively become a part of the decision-making process concerning general aviation services. One should keep in mind. too. that different elements of the community may harbor or avow contradictory "community goals."

Many of the same factois which indicate the likelihood of demanc' for general aviation service provide clues to community goals. Goals are likely to vary with socio-economic class and education. Age can be an important variable: the goals of a largely-retired community will differ considerably from those, of "young-marrieds." In addition. history and geography may play a role. Long-term resıdents are likely to have the goals of their parents. Communities near metropolitan areas may seek to become growth centers in opposition to the spreading metropolis or they may prefer to serve as "bedroom" communities

Implicit in the above is the realization that all pertinent community characteristics in relation to the general aviation services decisionmaking process are totally relative to each individual community as defined by its decision.

- Nevins Baxter E Philip Howry and Rudolph Penner Public Investment in General Aviation Airports An Application of Cost-Benefit Economics iFederal Aviation Administration. Washington DC. May 11967 makers. No generalizations can of should be drawn at this point.

\section{Making The Preliminary Decision}

The factors involved in making the preliminary decision about general aviation services are presented in schematic form in Chapter $V$. The lists found there are drawn from the analyses presented in the foregoing sections of : ve present chapter. The preliminary decision is whether or not to begin serious planning for the acquisition of general aviation services. If and when such a plan is undertaken, all the relevant factors will be considered more thoroughly than they are in this preliminary stage. As will be evident, there exist some methods for estimating the future economic demand for general aviation services in the community. Much more difficult to assess is the future degree of political support and opposition. Without political discussion or controversy in a community the decision-maker has difficulty in discovering community goals. In the case of general aviation. the community input to the decision-maker is primarily informal in nature and restricted to a relatively small number of individuals favoring general aviation development (i.e.. aviationists and the business community). The major input from the public at large is apathy, rather than either support or opposition.

One can safely predict that this general community apathy will only be awakened and become non-support if controversies arise concerning the social and environmental impacts of the airport facility and/or the financing of the new or expanded facility. The decision-maker should attempt to foresee such possible developments as early as possible. It is difficult. however, to generalize in this area because of a number of recent political events. which have changed. at least to some extent. the interaction patterns of elites and masses. The most significant of these are the growing suspicion about the bureaucracy, the questioning of the supposed benefits of technological advancement, the uncertainty about the type of growth or no-growth policy a community should assume, the demand by citizens for self-determination, and the requirement that citizens be involved in planning decisions. These events clearly impact on the development of general aviation. Citizens have frequently handed together through "politıcal mobilization" to stop the expansion of airport facilities. "In mobilizing. the citizens have challenged the view-generally shared by bureaucrats--that the public bureaucracy involved with airport 
planning and operations is necessarily acting in the public interest. In the mobilization process, certain special publics, not the mass public, demand accountability. The proponents of airport development must show what the costs and benefits involved in the development are. In addition, many members of the public no longer readily accept claims of efficiericy nor do they believe that the expansion of technical facilities, such as airports, is always a means of progress. In brief, the cost/benefit calculus no longer includes only the more readily quantifiable economic costs but also social costs and value orientations. ${ }^{49}$

Rai Y. Okamoto, a member of the Aviation Advisory Commission, noted that "evidence continued to mount that aviation's failures were inextricably bound to those of a non-aviation or institutional nature. ${ }^{\text {so }}$ One must reasonably assume that air transportation is only one means to achieve a goal, although many of the statements made by its proponents do not reflect this. At the same time, the proponents often fail to use a systemic perspective in their evaluation of the need for airports Airport proponents must realize that the public is not a passive element in the system, that technical mystique is no substitute for publi; support. and that the public may also have its own goals which are quite inconsistent with the goals of the airport development proponents. At the same time, the proponents of further development should realize that the negative and positive impacts of aviation activity are unevenly distributed within a given community, and that it is extremely difficult, if not impossible, to develop aviation activities without a willing public.

Consequently, decision-makers must not respond simply to the pressures exerted by interest groups; they must justify proceeding with the planning process in terms of public interest. The section on the impact of general aviation discusses these issues in more detail, but at the preliminary stage one must ask what are the beneficial impacts of general aviation on the community. Some of the intangible, unmeasurable impacts include:

(1) Value of time saved (by passenger plus "domino effect")

(a) Business flying

a Robert Horonjeft, The Planning and Design of Airports. (Now York: McGraw Hill, 1962)

- Dorothy Nalkin, Jetport: The Baston Alrport Controversy. (Now Brunswick. Transaction, Inc, 1974).

- Aviation Advisory Commission, Aviation in a Long-Aange Publlc Planning Context, February 15, 1973, p 2. (b) Pleasure flying

(c) Utility flying

(2) Emergency value (human life and property)

(a) Natural disaster (earthquakes, floods, wind, weather)

(b) Crime control and law enforcement

(c) Riots and civil disturbance

(d) Rescue and life saving

(e) Forest fire fighting

(f) Business decisions

(g) Food drops for animals; other forms of remote resupply

(h) Ambulance service

(i) Industry equipment and repairs

(3) National defense value

(a) Pilot training and availability

(b) Saving in military ai, zraft through joint sharing of aircraft development and production costs

(c) Value to wartim.e combat use

(d) Civil A:r Patro!

(e) Efficient and productive plant operations during war time

(4) Promotion or stimulation of air carrier flying (ticket sales).

(5) Entertainment value

(a) Value to general aviation passengers (in terms of gratification):

(1) Air shows

(2) Radio. TV, movies

(3) Vacation and resort area development

(4) Sightseeing and other transportation modes

(b) Value to entertainment industry

(6) General business industry associated with General Aviation Travel

(a) Hotels

(b) Ground transportation (taxi, limousine, car rental, etc.)

(c) Air carrier helicopter services

(d) Meals

(7) Specific benefits related to General Aviation

(a) Aurial photography and mapping

(b) Fish spotting and fish saving

(c) Forest fire patrol

(d) Power and pipe line patrol

(e) Corporation internal business aircraft management, maintenance and operations, personnel and expenses 


\section{TABLE III-I \\ DEMAND MODELS APPLICATION TO FORECASTING AIRPORT USAGE MODEL \\ Direct Demand \\ COMMENTS}

Economic Demand Model

McLynn Model

Bauman-Quandt ?viodel

Trip Generation

Trip Generation Regression Model

Cross Classification Technique

\section{Trip Distribution}

Growth Factor Distribution Models

- Uniform far.tor

-Average factor

-Detroit

- Fratar

Gravity Model
Good theoretical structure but calibration has not been fully tested and is limited because of the requirements of a large sample size.

Never fully tested in application.

One of the few "abstract" mode models; good formulation, but has calibration problems.

The most widely used trip generation technique. Used mostly by scheduled airlines in route planning.

Computer programs exist. The model cross-classifies people (usually according to income, education, and occupation), and calculates a percentage used to determine usage.

Simple to use. None of the models relate demand to explanatory factors. These models, however, have been widely used only because of their simplicity.

Used widely by scheduled airlines for planning new flights.
(8) Related business development

(a) Development of industry near general aviation airports (factories and plants)

(b) Development of geographically isolated areas (mining, oll, timber)

(9) Incentive to foreign businesses who then emulate, interact with, and stimulate United States business, including their second order effect in generating facilities and services.

(10) National prestige (growing fleets of aircraft in under-developed coun. tries).

(11) Social cohesion and unity through increased avenues of personal contact and communication.

(12) Political henefits derived from the positive influences of relative stability and growth in income and employment, and foreign trade impact. ${ }^{\text {s1 }}$

" $\mathrm{A}$ Dixon Speas Associates. The Magnifude and Economic Impact of General Aviation, 1968-1980, (Manhasset. New York Aero House, 1970). DP 141-142
The benefits of general aviation cited above only become meaningful once they are interpreted in terms of the specific benefits various local community people think are to be derived from this activity. These benefits are dependent upon the goals a community seeks to achieve.

The questions of intangib!es-community goals and community support-have been dealt with first because they are the most difficult to think about. The question of expected usage of general aviation services-economic demand-is more straightforward.

\section{Forecasting Demand}

Economic demand forecasting is essential for the proper planning and evaluation of community alternatives. According to the FAA Advisory Circular AC 150/5070-6 on airport master plans, forecasts of usage are required in four of the five planning phases. Because of their importance, and because they have not been thoroughly analyzed, it is important first to discuss present approaches and techniques for estimating economic demand in a community planning context. 


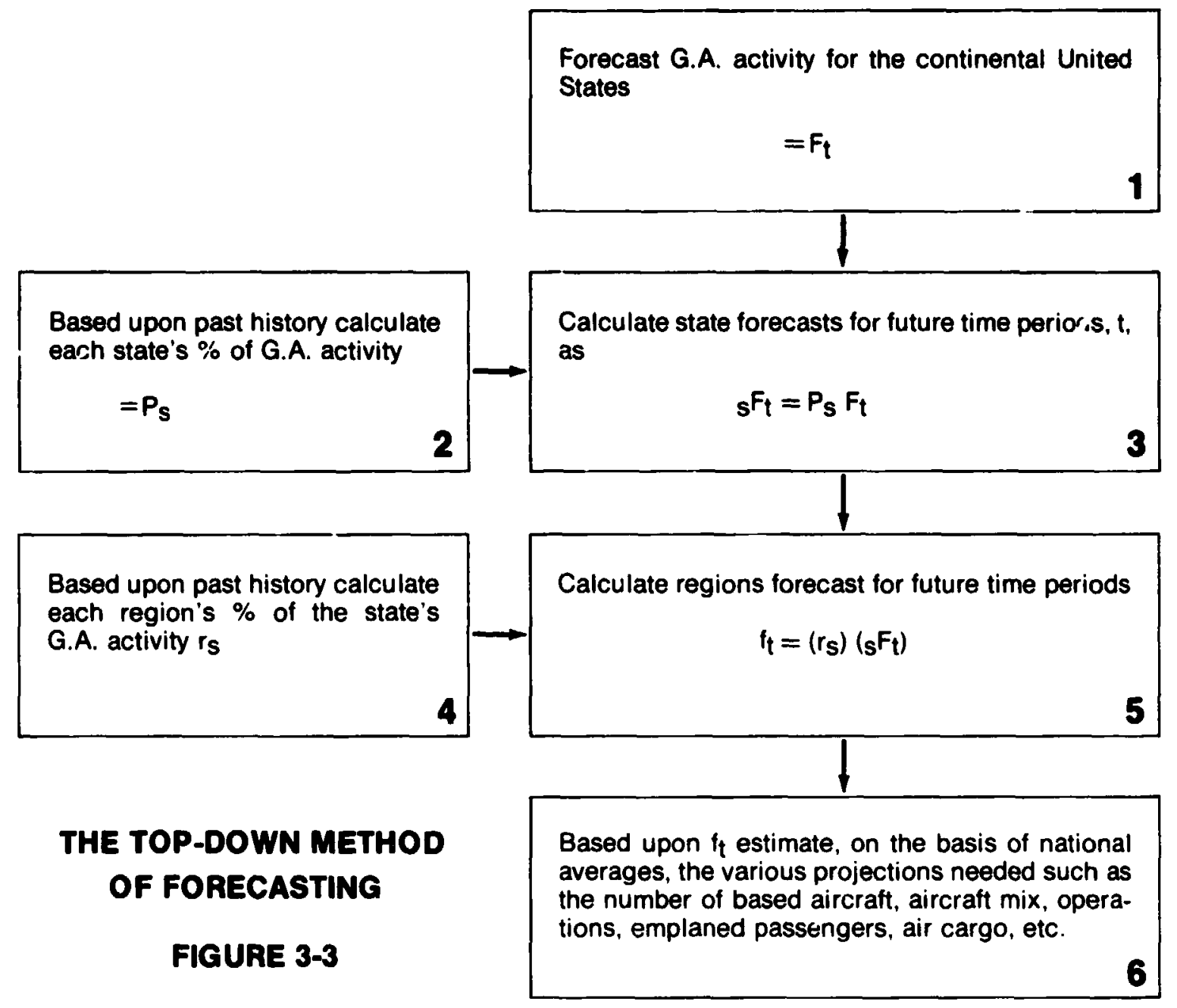

Table III-I presents a general view of existing models applicable to forecasting demand for the services offered at an airport, along with comments on the model itself.

In application the most widely used procedures are the growth factor distribution models in a top-down fashion. Figure 3-3 charts this approach. The first box requires estimating general aviation activity for the United States as a whole. The measure used is usually the number of licensed aircraft or aircraft operations. A forecast of licensed aircraft $\left(F_{t}\right)$ is obtained by regressing the number of aircraft against historical values of such independent variables as time, population, and per capita income, and forecasting the future value of these variables.

The second step is to estimate, on the basis of historical data. the share of a given state of the national general aviation acitvity $\left(P_{S}\right)$. This

Share is then forecast into the future and ad. justed for differences in growth patterns between those of the state in question and the nation as a whole. For example, if a state is expected to grow at a faster rate than the nation. the state will be projected to have a larger future share of the national fleet of licensed aircraft. It then becomes possible to calculate the projected licensed aircraft in the state $\left(s F_{t}\right)$ as the product of the future national forecast and the future expected share for the state.

For each subregion :vithin the state, the same type of calculation can be made. by again adjusting for differential growth rates among regions. This yields the local forecast of licensed aircraft.

On the basis of the total number of licensed local aircraft, the aircraft mix, the number of takeotfs and landing, or the number of 
enplaned passengers, the last step is to estimate breakdowns for each category at some designated future date. Information can be obtained by using national averages for such values as the percentage of single engine aircraft or the number of operations performad by a certain type of licensed aircraft. By multiplying the projection of licensed aircraft by these averaya figures, forecasts of the expected numbers of single engine aircraft or operations to be performed on an airport can be estimated.

The procedure described here (and used in the Virginia AIr Transportation System Study) potentially can lead to inaccurate projections for several reasons. First, since the number of operations is estimated on the basis of forecasts of the number of based aircraft at an airpnrt, an error in forecasting the number of based aircraft would be compounded in the operations subs'squently forecast.

Second, forecasts of operations depend critically on the base-year level of operations assumed for each airport. At non-tower airports the current estimated level of operations could be grossly in error. Some method needs to be used to determine accurately the number of operations at these airports (perhaps through actual counts)

Third, present forecasts are often conducted using data obtained prior to the occurrence of the energy cirsis and the current economic recession. Forecasts made using these data should be adjusted accordingly.

\section{Forecasting for Community Planning}

In its analysis for the need of general aviation services, a community initially must forecast the future use of such services and the returns that it can expect from the provision of these services. In determining needs, the community must review the total list of service options discussed previously, in order to determine those which it might demand. The different categories of services for which a demand assessment will be needed are:
A. Transportation
1. People
a. Business
b. Personal
2. Cargo (mail)
B. Industrial Aid
1. Primary
2. Service
3. Manufacturing

C. Special Community Services

1. Emergency

2. Law enforcement

3. Environmental management

D. Recreational

1. Flying

2. Other

E. Based Aircraft

These categories are discussed in detail in a later section of this chapter. They will be briefly reviewed here. Transportation includes the itinerant carriage of people or cargo by commercial air carrier, air taxi, air freight, or business aircraft. Recreational service is basically local, but includes private flying to another point as well. Aircraft are used as industrial aids and for special community services. The former includes crop dusting and utility inspection, etc., while the latter covers such areas as traffic control, fire-spotting, and air ambulance. The number of based aircraft will provide some estimate of the income to an airport.

Formal forecasts can be done oniy for the transportation, based aircraft, and recreational categories. The need for the services available in the industrial and community services categories is highly dependent on the nature of the community and its goals.

To project the economic demand for the services listed above, it is necessary to develop a profile of the community involved in terms of its socio-economic and environmental characteristics. This profile is composed of the following sets of data:
A. Demographic
1. Population
2. Density
3. Age distribution
4. Rate of change of population
B. Economic
1. Income
a. Average disposable per capita income
b. Family income
c. Distribution

2. Employment
a. Primary
b. Service
c. Manufacturing

3. Assessed valuation

C. Social

1. Educational level

2. Number of pilots and other personnel

3. Availability of emergency service 


\author{
D. Environmental \\ 1. Isolation index \\ 2. Community of interest index
}

It then becomes possible " develop regression models which give the nun. jer of expected passenger trips, tons of cargo, number of recreational and instructional operations, or the number of based aircraft as functions of such variables as community population, average disposable per capita income, percent employed in certain types of industries, and level of educational attainment. It also becomes possi ble to estimate the number of instrument lar,ding, maintenance needs, aircratt operations, and fuel sales, on the basis of the estimates of demand obtained above.

For example, Table III-II provides a way to obtain an approximate number of based aircraft from the average household Income and the size of the population. The table gives a Based Aircraft Factor according to the Average Income of the community. To obtain the expected number of based aircraft, the Based Aircraft Factor must be multiplied by the Conimunity Size Factor which is the population of the com. munity divided by 10.000 and raised to the 0.71 power:

Expected Based Aircraft $=$

Based Aircraft Factor $\left(\frac{\text { Population }}{10,000}\right)^{071}$

This equation will provide a rough estimate for any community. It is however least accurate for communities of less than 15.000 people

Another way of estimating the number of based aircraft uses the number of households in the community which have an annual income exceeding $\$ 15,000$. Figure $3-4$ is a scatter diagram of the relation:hip between the num- ber of such households (which is easily obtainable from 1970 Census information) and the number of based aircraft for communities in Virginia. Each point in Ficjure 3-4 represents a community with an airport. ("Community" includes counties and independent cities.) The data show a positive relationship between the number of families with income in excess of $\$ 15,000$ and the number of based general aviation aircraft.

In addition, the user costs of aircraft are also related positively to the number of families with incomes over $\$ 15,000$, as shown in the scatter diagram. Figure 3-5, also for Virginia. User costs cover the total annual costs of aircraft ownership in the community, and are reflective of the maintenance, repair, and operating costs of these vehicles. These costs are also indicative of the volume of business and the direct economic impact that general aviation can have on communities with different income distribution characteristics. The trends demonstrated in Figures 3-4 and 3-5 have an upper limit, which is probably due to the capacity limitation of the general aviation aırports.

Virginia, however, is no more typical of the nation than many other states. The fifty states were tabulated according to population, area, per capita income, and degree of urbanization. To measure probable economic impact. a unit known as the Equivalent Single-Engine Airplane (ESEA) was used. Tryo-engined piston, turboprop. and turbojet aircraft were assigned ESEA weights according to their relative capital cost. operating costs. hours of operation. and fuel consumption (Table III-III). By using these equivalents, a more accurate estimate of the economic impact of arrcraft on an area can be obtained. The annual cost (taken as the varia-

TABLE III-II

THE BASED AIRCRAFT FACTOR

Average Annual Household Income (\$)

$$
\begin{array}{r}
8,000 \\
10,000 \\
12,000 \\
15,000 \\
17,000 \\
20,000
\end{array}
$$

Based Aircraft Factor

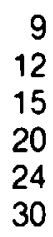

Source: Based on equation obtained from Virginia Air Transportation System Study, Final Draft, June 1975. 
ble cost plus 20 percent of the capital costs) of one ESEA is approximately $\$ 5,300$ (in 1971). Table III-IV shows the relevant figures for the fitty states, grouped by region. None of the variables reflect the degree of aviation activity with any degree of consistency. Rather, it appears that the degree of activity as reflected economically is a complex function of a large number of variables. However, several trends do emerge.

First, aviation activity rises as population and population density decrease. However, population densities are found in less urbanized states which have larger distances be- tween population centers. This places a premium on rapid transportation over long dis. tances. Thus, in genaral the demand for gyiation services increases from east to west.

Second, regions seem to be statistically similar. For instance, the Eastern states are similar to each other but different from the states in the Great Lakes region. The Great Lakes states are, however, similar to each other.

Third, aberrant cases can be spotte: $t$ on a regional basis. For instance, in the relatively low activity rate associated with the Eastern

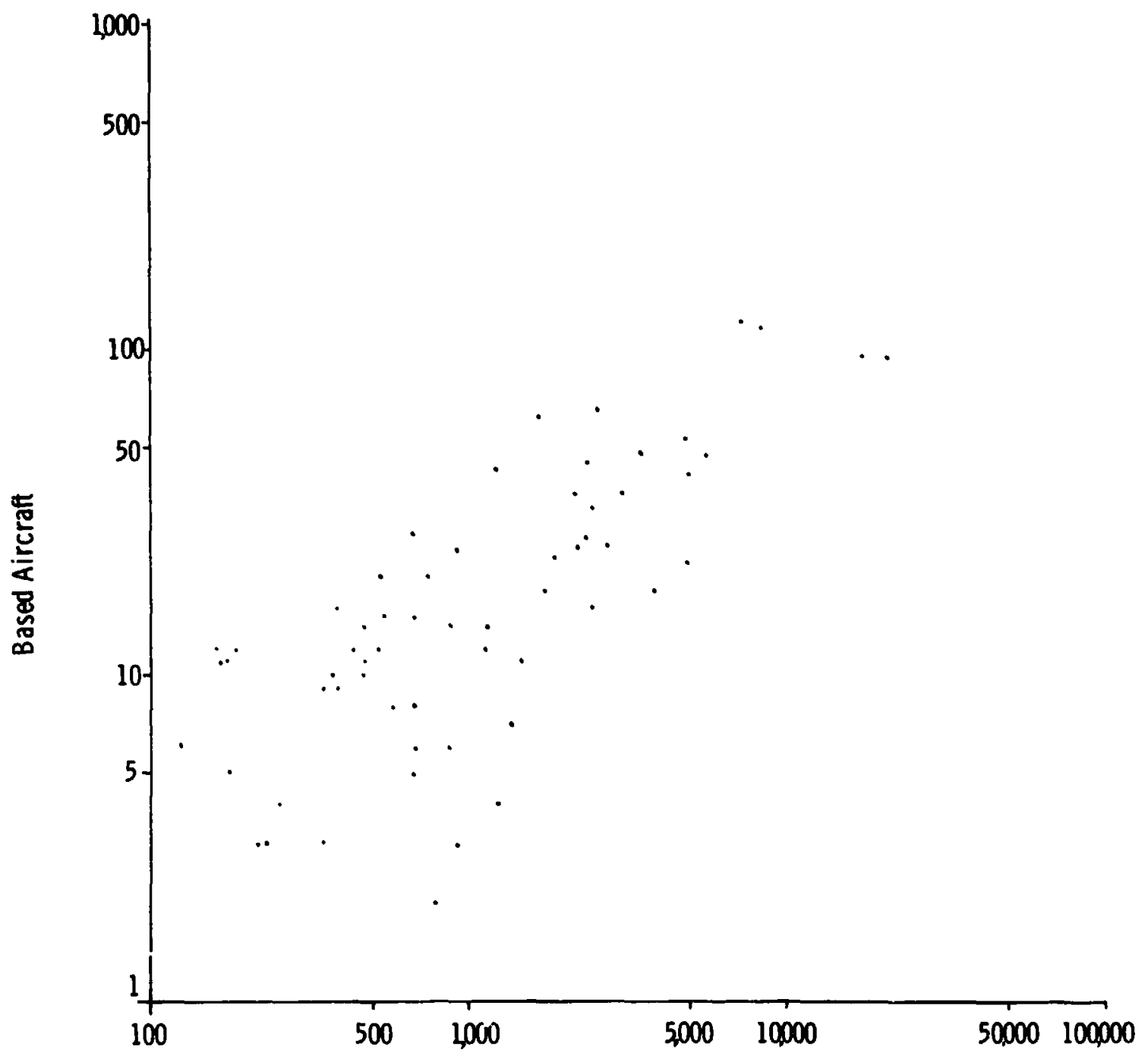

BASED AIRCRAFT VS. NUMBER OF HOUSEHOLDS WITH INCOME OVER \$15,000/YEAR FOR VIRGINIA AIRPORTS

FIGURE $3-4$ 
TABLE III-III

EOUIVALENT SINGLE-ENGINE AIRPLANE WEIGHTS

Type of Aircraft

Single engine piston

Multi-engine piston

Turboprop

Turbojet
ESEA Woights

1

5

25

50

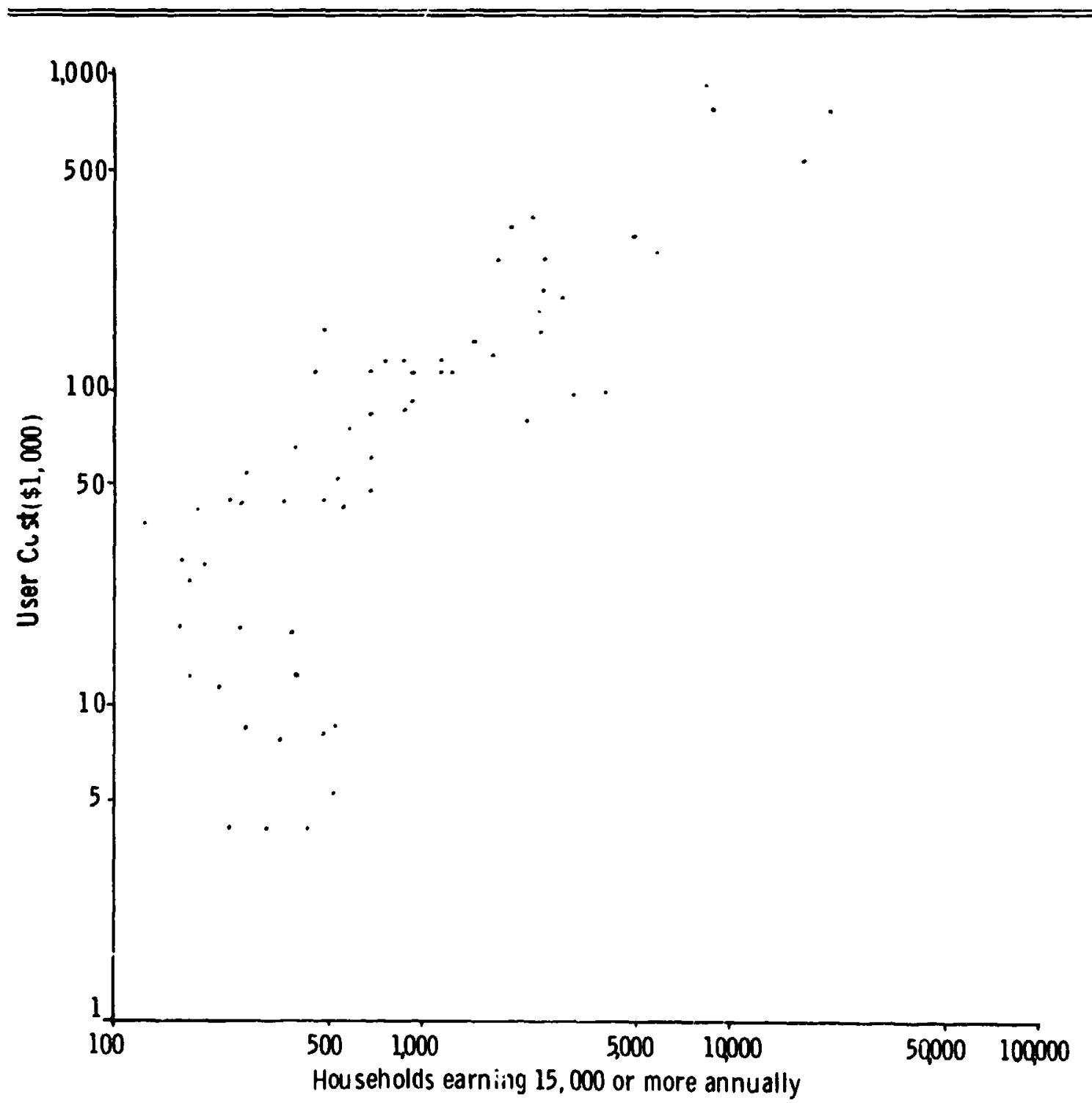

USER COSTS VS. NUMBER OF HOUSEHOLDS WITH INCOME GREATER THAN $\$ 15,000 /$ VEAR

FOR VIRGINIA AIRPORTS

FIGUAE 3-5 


\begin{tabular}{|c|c|c|c|c|c|c|c|c|c|c|}
\hline 억율 & & & & AVIATION & $\begin{array}{l}\text { TAB } \\
\text { ACT }\end{array}$ & $\begin{array}{l}\text { III-IV } \\
\text { TY V }\end{array}$ & MABES & & & \\
\hline 乌s & FAA Rogien & State & $\begin{array}{l}\text { Population } \\
\text { (miltions) }\end{array}$ & 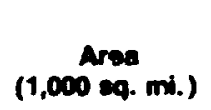 & $\begin{array}{l}\text { Pop. } \\
\text { Density }\end{array}$ & $A / C$ & $\begin{array}{l}\text { Per Cepita } \\
\text { Income }\end{array}$ & Urban & Esen & $\begin{array}{c}\text { ESEA } \\
\text { per 1,000 } \\
\text { Population }\end{array}$ \\
\hline & A.laska & Alaska & 0.3 & 586 & 0.5 & 3,268 & 3,725 & 48.4 & 4,295 & 14.32 \\
\hline$\sum_{\infty}^{\infty}$ & Central & $\begin{array}{l}\text { Io'wa } \\
\text { Kansas } \\
\text { Misscurı } \\
\text { Nebraska }\end{array}$ & $\begin{array}{l}<83 \\
2.95 \\
469 \\
149\end{array}$ & $\begin{array}{l}56.3 \\
82.3 \\
697 \\
77.2\end{array}$ & $\begin{array}{l}50.5 \\
27.5 \\
67.8 \\
19.4\end{array}$ & $\begin{array}{l}2.884 \\
3.070 \\
3.313 \\
1.826\end{array}$ & $\begin{array}{l}2.884 \\
2.929 \\
2.952 \\
2.797\end{array}$ & $\begin{array}{l}572 \\
661 \\
70.1 \\
61.6\end{array}$ & $\begin{array}{l}5,224 \\
6,232 \\
6.036 \\
3,728\end{array}$ & $\begin{array}{l}1.85 \\
2.77 \\
1.39 \\
2.50\end{array}$ \\
\hline$\vec{\infty}$ & Eastern & $\begin{array}{l}\text { Dela'yare } \\
\text { Maryland } \\
\text { New Jersey } \\
\text { New York } \\
\text { Pennsvivania } \\
\text { Virginıa } \\
\text { W. Virginia }\end{array}$ & $\begin{array}{rl}0 & 55 \\
3.94 \\
719 \\
183 \\
118 \\
466 \\
175\end{array}$ & $\begin{array}{c}2.06 \\
106 \\
7.84 \\
49.6 \\
453 \\
40.8 \\
24.2\end{array}$ & $\begin{array}{l}277 \\
397 \\
953 \\
381 \\
262 \\
177 \\
725\end{array}$ & $\begin{array}{r}446 \\
2.163 \\
3,403 \\
5.621 \\
5,045 \\
2.228 \\
846\end{array}$ & $\begin{array}{l}3,265 \\
3,512 \\
3,674 \\
3,608 \\
3,066 \\
2,996 \\
2.333\end{array}$ & $\begin{array}{l}72.2 \\
76.6 \\
889 \\
85.6 \\
715 \\
631 \\
390\end{array}$ & $\begin{array}{r}2,165 \\
4,189 \\
8.417 \\
13.162 \\
12,327 \\
4,871 \\
2,014\end{array}$ & $\begin{array}{l}3.94 \\
1.06 \\
1.17 \\
0.72 \\
1.04 \\
1.05 \\
1.15\end{array}$ \\
\hline & Great Lak:us & $\begin{array}{l}\text { Illinois } \\
\text { Indiana } \\
\text { Michigan } \\
\text { Minresota } \\
\text { Ohio } \\
\text { Wisconsin }\end{array}$ & $\begin{array}{c}111 \\
52 \\
8.89 \\
382 \\
107 \\
443\end{array}$ & $\begin{array}{l}56.4 \\
363 \\
58.2 \\
84.1 \\
412 \\
562\end{array}$ & $\begin{array}{c}144 \\
144 \\
156 \\
\therefore<0 \\
260.0 \\
811\end{array}$ & $\begin{array}{l}6.326 \\
3.677 \\
6,077 \\
3.518 \\
6.586 \\
2.921\end{array}$ & $\begin{array}{l}3.453 \\
3.070 \\
3.357 \\
3.038 \\
3.199 \\
3.032\end{array}$ & $\begin{array}{l}83.0 \\
64.9 \\
73.8 \\
65.4 \\
75.3 \\
65.9\end{array}$ & $\begin{array}{r}13.565 \\
2,163 \\
12.361 \\
6,628 \\
15.976 \\
6.245\end{array}$ & $\begin{array}{l}1.22 \\
1.38 \\
1.39 \\
174 \\
1.49 \\
1.41\end{array}$ \\
\hline & New Erigland & $\begin{array}{l}\text { Connecticut } \\
\text { Maine } \\
\text { Massachusetts } \\
\text { New Hampshire } \\
\text { Rhode Island } \\
\text { Vermoit }\end{array}$ & $\begin{array}{l}3.04 \\
1.00 \\
571 \\
074 \\
096 \\
045\end{array}$ & $\begin{array}{c}5.0 \\
33.2 \\
3.26 \\
9.30 \\
121 \\
961\end{array}$ & $\begin{array}{c}264 \\
32 \\
227 \\
817 \\
903 \\
479\end{array}$ & $\begin{array}{r}1,190 \\
821 \\
2.268 \\
699 \\
240 \\
331\end{array}$ & $\begin{array}{l}3.885 \\
2.548 \\
3.408 \\
2.985 \\
3.121 \\
2.772\end{array}$ & $\begin{array}{l}77.4 \\
50.8 \\
84.6 \\
56.4 \\
87.1 \\
32.2\end{array}$ & $\begin{array}{r}2,490 \\
1,218 \\
3,834 \\
1.239 \\
363 \\
575\end{array}$ & $\begin{array}{l}0.82 \\
1.22 \\
0.67 \\
1.67 \\
0.33 \\
1.28\end{array}$ \\
\hline & Northwest & $\begin{array}{l}\text { Idaho } \\
\text { Oregon } \\
\text { Wastington }\end{array}$ & $\begin{array}{l}072 \\
210 \\
341\end{array}$ & $\begin{array}{l}836 \\
970 \\
68.2\end{array}$ & $\begin{array}{r}86 \\
217 \\
512\end{array}$ & $\begin{array}{l}1.390 \\
2.953 \\
4.005\end{array}$ & $\begin{array}{l}2.644 \\
3.148 \\
3.357\end{array}$ & $\begin{array}{l}54.1 \\
671 \\
22.6\end{array}$ & $\begin{array}{l}2.269 \\
4.870 \\
5.83 y\end{array}$ & $\begin{array}{l}3.15 \\
2.32 \\
1.71\end{array}$ \\
\hline
\end{tabular}


TABLE III-IV (Continued)

\begin{tabular}{|c|c|c|c|c|c|c|c|c|c|c|}
\hline & FMA Region & State & $\begin{array}{l}\text { Population } \\
\text { (millions) }\end{array}$ & $\begin{array}{c}\text { Area } \\
(1,000 \approx q . \mathrm{mi} .)\end{array}$ & $\begin{array}{l}\text { Pop. } \\
\text { Density }\end{array}$ & $A / C$ & $\begin{array}{l}\text { Per Cepila } \\
\text { Income }\end{array}$ & Urban & ESEA & $\begin{array}{c}\text { EsEA } \\
\text { per 1,000 } \\
\text { Popubtion }\end{array}$ \\
\hline & Pacific & Hawaı & $0.7 ?$ & 645 & 1196 & 277 & 3.373 & 83.1 & 552 & 0.72 \\
\hline & Rocky Mountain & $\begin{array}{l}\text { Colorado } \\
\text { Montana } \\
\text { N.Dakota } \\
\text { S.Dakota } \\
\text { Utah } \\
\text { Wyoming }\end{array}$ & $\begin{array}{l}222 \\
0.70 \\
0.62 \\
067 \\
107 \\
033\end{array}$ & $\begin{array}{l}104 \\
147 \\
70.6 \\
770 \\
849 \\
974\end{array}$ & $\begin{array}{r}213 \\
9.8 \\
8.9 \\
88 \\
12.9 \\
34\end{array}$ & $\begin{array}{r}2.682 \\
1,449 \\
1,117 \\
1,009 \\
970 \\
670\end{array}$ & $\begin{array}{l}3.106 \\
2.696 \\
2.469 \\
2.387 \\
2.697 \\
2.895\end{array}$ & $\begin{array}{l}78.5 \\
53.4 \\
44.3 \\
446 \\
80.4 \\
605\end{array}$ & $\begin{array}{l}5,193 \\
2.243 \\
1,420 \\
1.325 \\
1.565 \\
1.373\end{array}$ & $\begin{array}{l}2.34 \\
3.20 \\
2.37 \\
1.98 \\
1.46 \\
4.16\end{array}$ \\
\hline 象总 & Southern & $\begin{array}{l}\text { Alabama } \\
\text { Florida } \\
\text { Georgia } \\
\text { Kentucky } \\
\text { Mississippı } \\
\text { North Carolina } \\
\text { South Carolına } \\
\text { Tennessee }\end{array}$ & $\begin{array}{l}345 \\
685 \\
461 \\
323 \\
222 \\
510 \\
260 \\
394\end{array}$ & $\begin{array}{l}516 \\
586 \\
589 \\
404 \\
427 \\
526 \\
311 \\
4<2\end{array}$ & $\begin{array}{c}679 \\
126 \\
790 \\
812 \\
46.9 \\
104 \\
857 \\
949\end{array}$ & $\begin{array}{l}2.572 \\
2.241 \\
3.256 \\
1.24 i \\
1.691 \\
3.186 \\
1.379 \\
2.185\end{array}$ & $\begin{array}{l}2.317 \\
3,058 \\
2.640 \\
2.425 \\
1.925 \\
2.474 \\
2.303 \\
2.464\end{array}$ & $\begin{array}{l}58.4 \\
805 \\
603 \\
54.6 \\
44.5 \\
45.0 \\
476 \\
58.8\end{array}$ & $\begin{array}{r}5.419 \\
16.596 \\
7.125 \\
2.799 \\
2.968 \\
6.869 \\
3.043 \\
6.474\end{array}$ & $\begin{array}{l}1.57 \\
2.42 \\
1.56 \\
0.87 \\
1.34 \\
1.35 \\
1.17 \\
1.64\end{array}$ \\
\hline 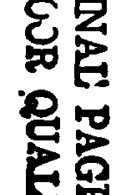 & Southwest & $\begin{array}{l}\text { Arkansas } \\
\text { Louisıana } \\
\text { New Mexico } \\
\text { Okıahoma } \\
\text { Texas }\end{array}$ & $\begin{array}{r}195 \\
365 \\
1.02 \\
257 \\
112\end{array}$ & $\begin{array}{c}531 \\
485 \\
122 \\
699 \\
267\end{array}$ & $\begin{array}{r}370 \\
810 \\
8.4 \\
372 \\
427\end{array}$ & $\begin{array}{r}1.935 \\
2.524 \\
1.376 \\
3.713 \\
11.115\end{array}$ & $\begin{array}{l}2.142 \\
2.330 \\
2.437 \\
2.694 \\
2.742\end{array}$ & $\begin{array}{l}500 \\
66.1 \\
698 \\
680 \\
19.7\end{array}$ & $\begin{array}{r}4,511 \\
4.624 \\
2.360 \\
8.010 \\
28.439\end{array}$ & $\begin{array}{l}2.31 \\
1.28 \\
2.31 \\
3.12 \\
2.54\end{array}$ \\
\hline 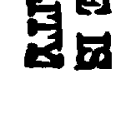 & West & $\begin{array}{l}\text { Arızona } \\
\text { Californıa } \\
\text { Nevada }\end{array}$ & $\begin{array}{c}179 \\
20.0 \\
049\end{array}$ & $\begin{array}{l}114 \\
159 \\
111\end{array}$ & $\begin{array}{c}15.6 \\
128 \\
4.4\end{array}$ & $\begin{array}{r}3.081 \\
19.774 \\
1.138\end{array}$ & $\begin{array}{l}2.937 \\
3.614 \\
3.994\end{array}$ & $\begin{array}{l}79.6 \\
90.0 \\
80.9\end{array}$ & $\begin{array}{r}5,254 \\
32.389 \\
2335\end{array}$ & $\begin{array}{l}294 \\
1.52 \\
477\end{array}$ \\
\hline
\end{tabular}

Sources: Compiled from General Aviation Manufacturers Association, Statistical Data, 1973; McNally Road Atlas (United States, Canada, Mexico). Rand McNally \& Co.. 1974; U.S. Fact Book, 95th Annual Edition, Grosset \& Dunlap. 1975; U.S. Statistical Abstract, Bureau of the Census, 1975. 
region, Delavare shows a high rate of activity. This is probably attributable to the fact that Delaware's corporation laws encourage many corporations to be chartered in that state. thereby increasing the degree of business aviation. Again. Nevada shows a relatively high rate of activity, probably because of the Las Vegas air fleet which ferries in people for entertainment. Even more variation could be expected on the local level, where countervailing factors will be less likely to average out.

While estimates of local general aviation service demand are necessarily inexact, they are needed in order to provide some guidance to the decision-maker. If the community is sufficiently distant from a large hub. it may provide enough traffic tc interest a third-level (commuter) airline or perhaps only an air-taxi. The foregoing tables and figures may help project the number of based aircraft. Local conditions will indicate the demand for industrial aids or special community services.

\section{THE PLANNING PROCESS}

Once it has been determined that the community has a need for better access to general aviation services, the planning process has begun. This, however, does not necessarily indicate a commitment to positive action. The decision that a community has a need for ger.eral aviation services may have to be revised in the light of such factors as cost; economic. social, and envircnmental impacts; or, unexpected projections of use or development. Planners and decision-makers must bear in mind that (1) there are many "needs" which are not "musts," and thet (2) the conclusion that action is unwarranted may in itself be a benefit to the community.

The planning procris takes into account all the factors which went into the initial decision as well as a host of other factors which could ...clude (1) the economic and fiscal capabilities of the community, (2) general aviation service options open to it. (3) alternative modes of satisfying community needs, and (4) future developments affecting the general aviation system, its environment, and the community.

This stage in the decision-making process is illustrated in Figure 3-6. The information on the left-hand side of the figure is collected and fed into the decision box labeled "impacts or actions." This box represents the process of planning to satisfy whatever needs have been established in the preliminary analysis. The plan which is developed can be the basis for either action or a subsequent impact analysis and evaluation study. If the plan is to do nothing or to implement marginal changes in the system, then it is possible that action could be taken without an impact anaiysis. If, on the other hand, an action or project of some significance is proposed, the impact of the project must be analyzed and evaluated to determine if revisions to the plan need to be made.

The following sections describe the four additional factors listed above, as well as the method of incorporating them in the deve!opment of a plan.

\section{Economic/Fiscal Capsbilities}

The ability of a community to finance. maintain, and operate general aviation services depends on its sources of funds, its choice of funds, its choice of service and facility opticns, and the costs and revenues associated with those services and facilities.

\section{Sources of Funds}

Funds for airport construction are available from federal and state sources as discussed in Chapter II. Decision-makers will have to obtain current infoimation about these sources since the Airport and Ainway Development Act expired in June 1975 and has not yet been replaced and since state policies may undergo similar revision. Local financial support through general obligation, revenue, and special purpose bonds was also discussed in Chapter II. Other local support is sometimes available in the form of individual and corporate donations. Ohio's county airport system was developed in several instances through donations. Sometimes land-owners donated a portion of their land to the community in hopes of increasing the value of the remainder. Mining companies donated strip mined acreage which was no longer of value to them. Local unions or corporations contributed labor or the use of construction equipment for the construction of facilities.

If the alternative chosen does not involve the construction or improvement of an airport. other sources may have to be investigated. For example, if a ro- $t$ is built or improved to provide better access to an existing airport. federal or state highway funds may be obtained.

\section{Alternatives}

Communities considering the construction of an airport should investigate the costs of construction under FAA specifications as opposed to other specifications. Building to FAA specifications is often much more expensive since they were written primarily with the heavy 


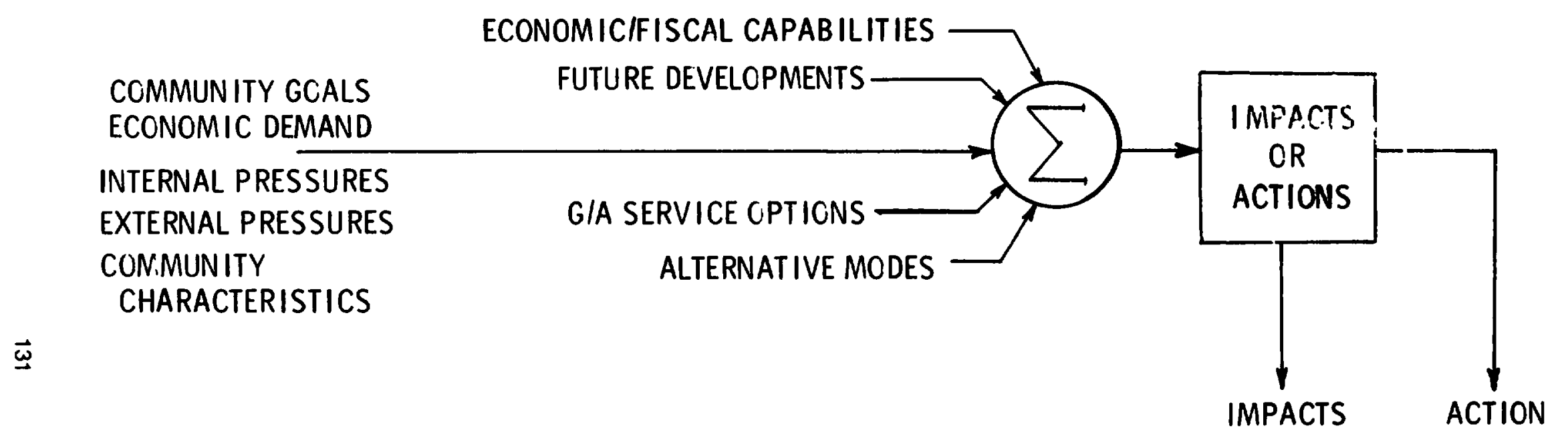

THE PLANNING PROCESS

FIGURE 3-6 
air-carrier aircraft in mind. The State of Ohio avoided federal support for its county airport system and urged local communities to consider an airstrip for general aviation to be a road, 4,000 feet long and 75 feet wide, designed to bear a certain load under certain conditions. In the future it may be possible to secure federal funds without conforming to FAA construction requirements. This will depend on whet!er the final version of the legislation which replaces the Airport and Airway Development Act of 1970
1970 will allow the states more freedom in setting technical standards.

Bettei access to an existing airport may be secured, according to conditions, by the construction or improvement of highways or by the institution of scheduled or demand-activated ground transportation such as bus, limousine, or taxi service. A helicopter service may also be feasible for this purpose.

Alternatives to the use of air service may

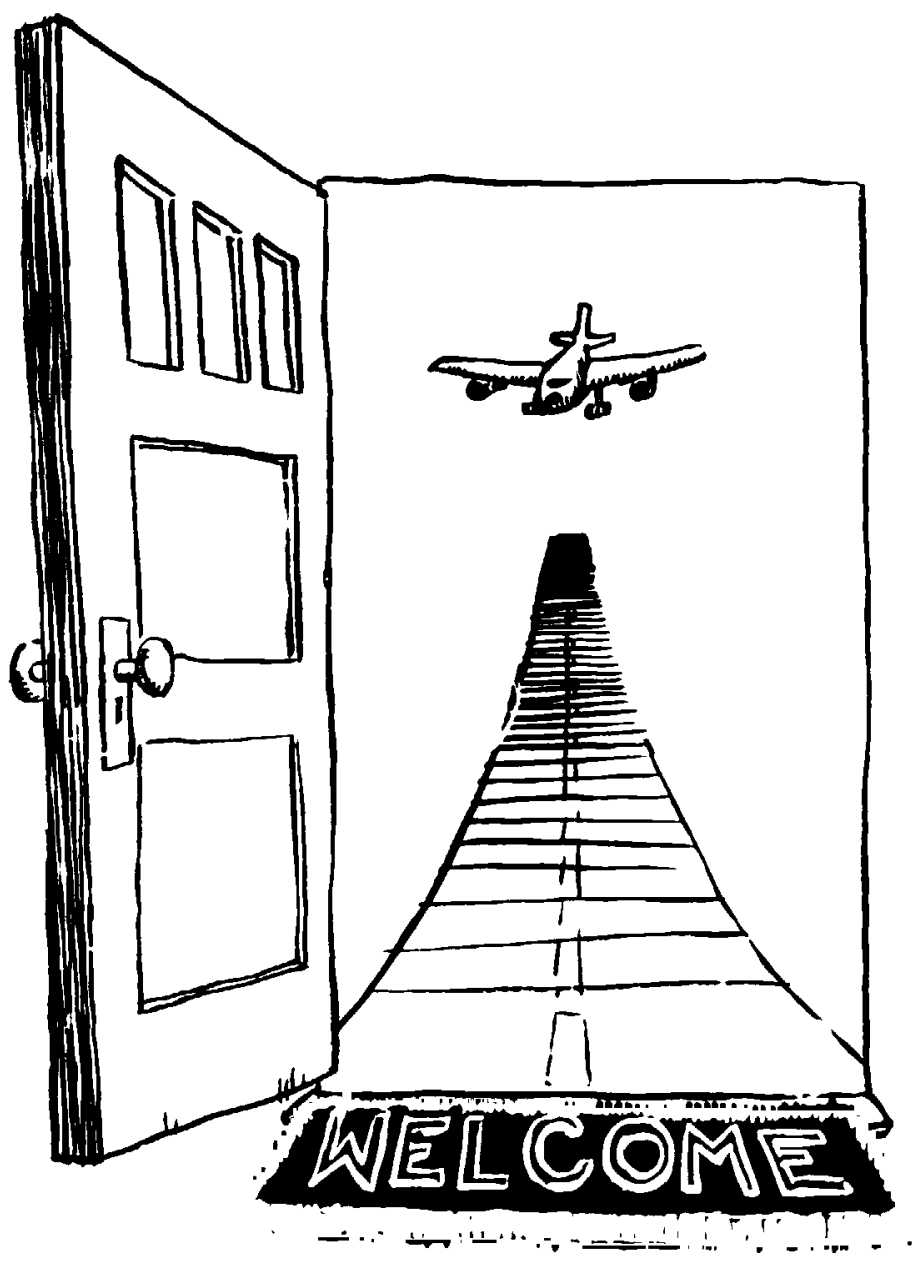

THE FRONT DOOR TO YOUR COMMUNITY IS A HOHWAY 4.000 FEET LONO ANO 78 FEET WIDE 
also be found in alternative modes of transportation and communication as discussed in Chapter II. If, for example, the community's main need is better medical service, it may be more feasible to hire a qualified nurse and establish a closed circuit television connection with an out-of-town doctor than tn construct an airport for the purpose of flying a doctor to town, or the patient to the ooctor.

\section{Costs and Revenues}

Alternative fiscal arrangements for airports are discussed in Chapter II, where it is noted that small general aviation airports usually lose money and require some sont of subsidy. J.A. Neiss stated that as the number of passengers at an airport decreases, the airport can be expected to show less profit; that "generally only those metropolitan general aviation airports with a large commercial/industrial revenue base which generate over 160.000 annual aircraft movements earn sufficient revenues to meet their operating expenses." 52

Discussions with FBOs indicate that the largest. most stable revenue producers at an airport are line service (fuel, oil, and aircraft parking). hangar rental, and office space rental

Operating revenues which an airport can expect to derive can be classified as airfield, hangar and buildings, non-aviation functions, terminal, and concessions. Each of these sources of revenue will be discussed below. In the airfield area, revenues car: be derived from air carrier landing fees. landing fees for other aircraft, fuel and oil sales, airline catering fees. aircraft parking (overnight and long-term), and use fees for military reserves and air guards Obviously. the revenues derived are very closely associated with the size of the airport.

Hangar and building area revenues are derived from hangar rental. office space rental to commercial and industrial concerns. rental of cargo and freight forwarding areas, rental of space to governmental agencies-such as the FAA or the National Weather Service-and the rental of facilities (hangars and offices) to FBOs. Frequently, the airport administration does not provide the buildings directly, but leases the land on a 25- to 30-year basis to an operating organization which will build the facilities; the ownership of the facilities will revert to the administration and will be rented back to the operator at the end of the lease period.

Non-aviation revenues can be derived from

"J A Neiss. Economics of Airport System Planning (Now York American Institute of Aeronautics and Astronautics. Inc. York
1973) the sale or lease of property for industrial or commercial enterprises which desire access to an airport.

Most of the revenue derived from the terminal area comes from the airlines for their ticket counters, waiting rooms, and offices; and, from automobile parking. In addition, many other concessions tend to congregate about the terminal area. Among those are auto rental, restaurants, various shops, flight insurance, hotel or motel facilities, and advertising spaces.

Each of the revenue producing areas also has associated costs. in the airfield area, costs include the maintenance of the runways (resurfacing, regrooving, rubber removal, snow removal, etc.), replacement of runway lights. and mowing the grass. Hangar and building costs consist of the general upkeep of the buildings (roofs, doors-hangar doors can be especially troublesome). Facilities that are rented to FBOs are usually maintained by the FBO. In the termimal area, costs include those of security police (particularly if air carriers are using the facility). utilities, gener $/$ upkeep of halls, corridors, main loibies, rest rooms, and other unassigned spaces; concessions at an airport are usually expected to provide the upkeep of their own facilities with the exception of parking surfaces.

\section{Future Developmen's}

A consideration of future developments is central to any planning effort. These developments could be local, regional, or national in nature. They could also be social, economic. political. or technological. It is, of course. difficult to see very far or very clearly into the future but some projections must be made and considered by local planners. If. for example. there were a high probability that a cheap and efficient VTOL or STOL vehicle would be developed. future runways requirements for general aviation aircraft might well be very short and much less land would have to be acquired. Again, if it be likely that general aviation aircraft wiii become much more expensive to own and operate. projections of demand for facilities and services would have to be revised. On the local level, it may be possible to foresee the development of strong anti-airport sentiments among the citizens which would affect the siting or even the existence of an airport in future plans.

The conclusions reached below are of 2 tentative nature and are indicative only of the type of concerins which must be addressed regarding the future. Communities considering 
the acquisition of generai aviation services would be well advised to check the validity of what appears below, for unexpected developments may change the probabilities of important factors.

\section{Population Dispersion}

There has been considerable discussion of the desirability and feasibility of a national policy of population dispersion. If such a policy were to be adopted, the allocation of federal funds for the establishment of airports in designated regional growth centers or in exurban areas generally might well be increased. ${ }^{53}$ Such an approach could change the present funding criteria for airport development, which is based cn accommodating existing and projected aircraft ownership in an area, rather than guiding the location of aviatıon activity

A policy of population dispersion has been suggested in view of the increasing metropolitan-area problems which are magnified by the rise in urban population on the national level Proposed programs include such options as the encouragement of the location and relocation of jobs in non-metropolitan areas to draw people away from the cities and suburbs: the provision of economic support for the non-metropolitan population in order to stem the tide of migration from rural to urban areas: the creation of new small and mediumsized cities away from heavy concentrations of population; the revitalization of viable small towns: and the development of underdeveloped regions. The development of airports might play a role in many of these proposals in order to overcome the disadvantages of isolation and to make such areas and places more attractive to business.

"This concept is discussed in the sollowing Vary $T$ Coates. Technology Assessment Group Program of Policy Studies in Science and Technology the George Washington University Pevitalization of Small Communities Transportation Options (Washington Department of Transportation. May 1974). Joseph F Vittek Jf (ed ) Air Service to Small Communities Directions for the Fulure, Final Report of the Workshop on Low/Medium Density Air Transportation. (Cambridge MIT Flight Transportation Laboratory. February. 1974). articles by Haren. Hansen. Rosenblatt. Chinitz, and Heady in Larry R Whiting (ed) Rural industrialization Problems Heady in Larry R Whising (ed) Rural Industrialization Problems
and Potentials. (Ames lowa lowa State University Press. 1974), Richard J Barber. Report on National Transportation Policies. (Washington Aviation Advisory Commission September 1971). Louls H Mayo. The Program of Policy Studies in Science and Technology of the George Washington University. Social Inpacts of Civil Aviation and Implications for $R$ and $D$ Policy. (Washington Department of Transportation, 1971), Jerome R Pickard. is Dispersal the Answer to Urban Overgrowth." Urban Land. 29 3-12 (January 1970)

"Niles M Hansen "Factors Determıning the Locatıon of Indu' irial Activity." in Whiting op cil p 42

" loid pp 28 and 35-42 Benjamic Chinitz Public Inter. veintion and Guidance of Market Forces to Achieve Recistribution, in Whiting. Ibid. p 55

* Pickara, op cil, pp 11.12
Among the trends most frequently mentioned in support of such programs is the decentralization tendency of some sectors of the economy. For various reasons, many firms have located or relocated manufacturing plants away from central cities and even away from the suburbs. In larger companies, the tendency is to locate assembly plants in scattered locations while maintaining headquarters in urban centers near transportation, communication, and financial facilities. This trend is presently small, however, involving between 500 and 750 locations each year and is unlikely to accelerate or have much impact without the stimulus of a national policy..$^{\text {st }}$ Industries which relocate are those which can make use of the generally lowskilled labor available in non-urban areas. Such industries are typically those in their later stages of development because they have routinized procedures and automated production. Older industries tend to be slow-growth since ample time has passed for the market to become relatively saturated. Even if more of such industry relocated in the countryside, it will be unlikely to induce growth at rates equal to those found in metropolitan areas. In addition, the proportion of industry devoted to manufacturing has been undergoing a steady decline while service-oriented industry has dramatically increased to 62 percent of the nonagricultural jobs. Service-oriented firms are unlikely to locate away from population centers. since it is to their benefit to be very close to large markets. ss

The creation of new towns and communities has definitely begun, but. agaın, the enterprise is presently of limited size. In 1970. the Department of Housing and Urban Development (HUD) compiled a list of large communities and new developments. While the list was not exhaustive, it was made as complete as possible. HUD located a total of 63 new communities which had been completed or begun between 1947 and 1969. The total projected population of these developments amounted to less than four mi!lion residents ${ }^{36}$ Other trends which are relatively small. but may become more important, are the use of small towns as places for retırement. due to the lower cost of living and slower pace of life; and the growth of leisure activities in the form of tourism and recreation.

The importance of these trends could be modified by a significant national policy aimed at redistributing metropolitan population or at least slowing the migration to metropolitan areas, but at present. population dispersion does noi seem to be a clearly recognized goal. 
In 1970. President Nixon stated it as a goal in his State of the Union address, but as late as 1974 that goal had not been reaffirmed. There are, however, a host of programs to improve the quality of rural life, which may imply a national goal of increasing the relative attractiveness of rural areas, thereby decreasing the trend toward migration to rural areas and making it more possible for people to relocate in the exurban regions. Such programs include the Appalachian Program and the Rural Development Act of 1972.5'

It is not clear, furthermore, whether population redistribution should be a national goal. The United States has a relatively homogeneous culture-metropolitan and nonmetropolitan populations have much the same idea of the good life. Many of their goals relate better to urban living than to rural. At present the majority of the population seems to prefer urban life, but it is unclear how important economic factors are-especially the supply of jobs-in that preference. Various studies offer vastly different estimates of the number of people who would like to live in non-metropolitan areas if jobs were crailable. ${ }^{58}$

Without information about the true desires of the citizenry, one cannot assume that simple redistribution, without regard to the types of people likely to be redistributed, is a good thing; such a policy might simply accelerate the flight of those who are better-off from the centers of cities leaving others behind.

Finally, it is not clear that non-coercive policies could. in fact, reverse present migration trends

In sum, there seems to be a real possibility of a national policy to redistribute jopulation. but such a policy has a low probability of being enacted in the near future. Consequently, planners should assume perhaps, that the federal government will give little support to exurban indistrial relocation and no more support than is presently available to airport development.

\section{Cost of Aircraft Ownership}

There are several reasons to believe that the cost of aircraft ownership and operation will increase significantly in the near future. Such increased costs might tend to drive the private owner of smaller craft out of aviation and thus change the mix of arrcraft in general aviation. This may have significan* sonsequences for decision-makers

\section{"Vittek, op cil, p 31}

so vittek loid, pp 31 and 56 Coates. op cir. pp 8-9. Hansen, op clt. $p 31$
The increased costs will be due primarily to the congestion of the airways and the expense of fuel. As was discussed in Chapter I, general aviation's use of airspace has been increasing steadily. Safety problems are posed by this increase as well as by conflicts which arise beween general aviation on the one hand, and military and air carrier aircraft on the other. especially near air bases and hubs. The result of these problems has been an increase in the amount of avionics equipment required on aircraft and an increasing sophistication and cost of operation of the airways and air traffic control systems. At present, general aviation aircraft are excluded from some congested areas and airports unless they are equipped with certain avionics devices. Increasing demands for improved safety and the growing traffic at hubs are both likely to increase location in which planes are required to have more elaborate electronic capabilities. Inexpensive aircraft will become, therefore, less attractive. while better equipped and more useful aircraft become more costly.

Aircraft operating expenses will also increase as the cost of airways system operation increases. This cost is presently borne by taxes on aviation fuel and parsengers. Such taxes may increase in the future and general aviation may be charged a larger share of the system operating cost.

Fuel costs are likely to increase also as all forms of energy become more expensive. While there are possibilities for the use of liquid hydrogen as an alternative to fossil fuels, at present this technology seems to be applicable only to larger aircraft. In addition, there seems to be little likelihood of a significant increase in fuel efficiency resulting from changes in design of smaller general aviation aircraft, although some increases are probable.

As general aviation becomes more expensive the private flier will find it less and less attractive. Therefore general aviation will be composed of a higher percentage of business aircraft; air taxi, commuter, and cargo services; as well as industrial aid and special community services. In addition, many smaller companies which might have used their own aircraft in the past will find it prohibitively expensive and may turn to commercial air services and to alternative modes of transportation and communication. Decision-makers should therefore be cautious in estimating the future economic demand for general aviation services, especially when their projections are based on the present number of aircraft owners or aircraft engines 
owned in the service area. It may be also true that airports of the future will be viable only if they can accommodate the larger types of aircraft used for business and commuter services.

\section{State and Local Plans}

Many states are presently developing state airport system plans and some are formulating intrastate commuter airline plans. Such plans may have important effects on the future of local communities and may indicate the future allocation of state funds.

Decisions affecting the future of the local community are made by many people and in many sectors. Decision-makers concerned with general aviation would do well to coordinate their plans with other planning efforts in their community and in neighboring areas, and to consider the variety of future options discussed in this chapter and procedures recommended in Chapter $V$ of this report.

\section{Genera! Aviation Service Options}

A community's utilization of general aviation services is derived from its socio-economic, geographic, and functional characteristics. In ocean-front community may require aerial fish spotting; one which grows or manu?dctures perishable goods may find its mos! important need for general aviation service to be air cargo service to remote markets; or, a community with strong ties ic a metropolitan area 200 miles away might seek some form of public air transportation. Each of these communities will probably find that it has needs for services other than the primary ones described previously. While a single-purpose aviation facility might not be justifiable, a multi-purpose facility might be more viable. with decreasing marginal costs for improved utilization and community service.

General aviation services can be classified into itree basic categories: (1) transportation, (2) industrial and community service. and (3) sports and recreational. These are described below.

\section{Transportation}

This category covers the movement of p. Jple and goods by commercial service. Passenger air transportation can be provided by (1) certificated air carriers, (2) commuter airlines. (3) air taxi operators, and (4) privately owned business and corporate aircraft.

"Aviation Advisory Commission. The Long Range Needs of Aviation. op $\mathrm{clt}$

- Listed in the Official Airline Guide of May 1975
The transportation of people and cargo by the certificated air carriers is not a part of general aviation by definition, and will not be discussed here in detail. The interface between the certificated air carriers and the other three means of transportation will be considered, however.

Determination of whether the certificated air carrier, the commuter airline, or the air taxi will be the primary option suited for a community depends largely on the population of the area being served and the area's industrial and service mix. Of all the airports served by certificated air-carriers, 25 handle approximately 70 percent of the total airline passenger traffic. ${ }^{59}$ The certificated airlines primarily serve large hubs with a population of one million or more. An analysis of the commuter ("third level") air carriers shows that they serve both large hubs and smaller communities. They provide passenger and cargo feeder service from the small communities or to the large hubs, and frequently provide connecting flights.

Three hundred and fifty-five (355) towns and cities are served by commuter airlines in the United States. ${ }^{50}$ A preliminary analysis of commuter airline services reached no firm conclusions about factors which would indicate the potential success in establishing such a service, but states having the best commuter service are in order, California, Kansas. Texas, Wastington, and Hawaii, suggesting that commuter airlines provide more service in states where population centers are spread out. Geographic location and tourist attractions seem to be significant factors governing the number of departures per day for population centers of less than 2,500. In that catecory. Hawaii offers the best commuter and intrastate service and is second in the number of departures per day. Nevertheless, the degree of isolation of the population centers seems to be the major determinant of the existence of commuter services.

Alr taxi operators fill a gap in public air travel by providing demand-activated air transportation By necessity, air taxi operations depend on both the population base, and the economic character of the community. Serviceoriented communities tend to require more intercity and interstate travel and are inclined to support air transportation services. Many commuter airlines began as air taxis and have continued to provide both types of service. An air taxi operation is the least expensive of the listed air transportation methods and the easiest to establish under federal regulations 
Although air taxi operations are usually considered to be short-haul air transportation. some operate both nationally and internationally. Executive Jet Aviation which is based in Columbus, Ohio, for example, provides jet air taxi service from any point in the United States, to any airport in the world capable of accommodating its Learjets.

Business and corporate aviation includes trips performed in owned or leased aircraft which are operated by the business or corporation. This category covers 44 percent of all hours flown by general aviation aircraft. ${ }^{61}$ If the business or corporation establishes a particular airport as its primary base of operation, the local community will derive significant revenue from tie-down or hangar fees, fuel and oil costs, and wages paid to mechanics and flight crews.

The potential for air-cargo is usually limited to high priority items and perishable goods which could not reach many of their markets without rapid transportation. "The reasons for the sudden interest in the cargotransport capabilities of general aviation is, of course, the drastic deterioration of the postal services, coupled with the unacceptable increases in rates, and the increasingly frequent mishandling of air freight, which, unless personally brought to and picked up from the aircraft, may end up for days on some out-ofthe-way loading dock, gathering dust."62 Goods transported by air include such items as:

(1) high priority machıne parts or materials which may be needed for full production capabilities;

(2) bank paper delivered to the Federal Reserve Banks in order to obtain maximum interest benefits;

(3) perishable cargoes of fruits. vegetables, flowers, and tropical fish;

(4) remains of deceased persons; and,

(5) mail and newspapers.

Industrial and Community Service

Service related functions performed by aircraft can be divided further into industrial aid services and special community services. Some of the possible industrial aid service re-

- Aviation Advisory Commission. General Aviation (Wash Ington. DC Aviation Advisory Commission, January 1. 1973). D C- 55

"2 Paul Garrison. "Keep on Haulin'." Air Progress Magazıne. July, 1975 n 35

"Aviation Advisory Commission General Aviation, January 1. 197?. p C-56 lated functions performed by aircraft are: agricultural seeding, spraying, and dusting: livestock management; fish stocking and spotting; utilities patrol; advertising, photography. mapping, surveying, and prospecting; construction, such as placement of utility poles by helicopters; and, carrying television cameras for aerial views of sports events.

Special community services aid the genera! community in health, safety, and public welfare. They are functions normally performed by local government organizations such as the police, fire department, or forest service. Among some of the functions performed by aircratt are: shark patrol, medical emergency services (air ambulance), disaster patrol (forest fires, floods), wildlife management, firefightıng. meteorological observations and law enforcement (traffic patrol).

Industrial aids and special community services may not only bring in revenue after they arrive but also serve as justification for some public subsidy of the cost of providing the necessary facilities.

\section{Sport and Recreational Flying}

This category includes those operations which are performed primarily for pleasure, recreation, entertainment, or other ncn-commercial purposes. The majority of spurts and recreational fiying is performed by individuals who own airplanes or periodically rent an airplane from an FBO. It accounts for 28 percent of all general aviation transportation hours flown. ${ }^{63}$ This type of flying contributes to airport financial support in the form of tie-down and hangar fees, fuel and oil sales. and periodic maıntenance. Other types of aviatıon activities which are considered in this category include: sport flying. sailplaning, sky-diving, local area rides. and air shows.

Sport aviation refers to that segment of general aviation which designs and builds its own aircraft and is usually associated with the Experimental Aircraft Associatıon (EAA), an international organization devoted to the purposes of sport aviation. Sailplaning depends largely on the type of airport facilities-primarily the runway landing area. An optımum landing area for sailplanes would be relatively wide so that the sailplane approach can be ad. justed for its lack of power. The airport should not expect to derive tie-down and hangar revenues similar to those of powered craft since sailplanes are easily disassembled. loaded on trailers, and hauled away for storage. The main tie-down or hangar revenue would be derived from the tow-plane. Special considerations 
should be given to try separate airplane and sailplane traffic patterns whenever possible.

Sky-diving, or parachuting, contributes to the direct support of an airport through tiedown or hangar fees paid by airplanes which are used to carry the parachutists to their "jump" aititude. As with sailplaning, one aircraft can handle several participants and therefore is not considered a large potential source of revenue.

Air shows usually are offered at airports at the rate of no more than one per year, if at all. Direct revenues to the airport operator are minimal, but such shows improve the public image of the airport and contribute to community support of airport operating costs.

\section{Ground Service:}

The direct aviation services described above are usually accompanied by secondary services in the form of ground support aircraft operations, including aircraft maintenance, repair, and fueling, and flight instruction and aircraft rental. Each FAA certificated aircraft is reqi.ired by law to have at least one major inspeciion annually, performed by an FAA licensed airframe and powerplant mechanic. The availability of a licensed mechanic at an airport affects the number of airplanes which will be based there permanently. Many aircraft owners will not base their aircraft at an airport lacking maintenance facilities. Conversely, the number of aircraft based at an airport vill be the major determinant of whether or not that airport can support a full-time mechanic.

Estimates from several FBOs in Virginia indicate that costs of these annual inspections start at $\$ 200$ for a small four-place. singleengine airplane and range upward depending on the complexity of the aircraft. About 50 such inspections are required each year in order to support the services of a full-tıme mechanic.

The availability of fuel and oil also contributes to the number of aircraft which will be based at an airport, and will definitely affect its amount of itinerant traffic.

In most cases, unless an aircraft is flown at least 240 hours per year it is more economical to rent an aircraft rather than own one..$^{64}$ Therefore, the rental of aircraft is a vital part of an airport operation. Rentals usually start at approximately $\$ 15$ per flight hour for two-place. trainer-type aircraft and increase from there based on the size and complexity of the aircraft.

" Paul Garrison, $T$ Taylor, V Fagan Inside Private Aviation (Now York H\&C Publishing Co. Inc, 1974), p 37

"Ibid, p 48
Flying clubs are fiequently established in order to reduce the cost of flying, but a person must fly approximately 100 hours per year in a flying club to justity his membership as more economical than renting an airplane.65

Closely associated with aircraft rental is flight instruction which requires the services of a licensed flight instructor and usually the rental of the aircraft in which he is instructing.

Additional revenue-producing services offered at an airport include the sale of parts and study materials, restaurant services, and ground transportation rental.

Because the dollar amount derived from the services discussed above is dependent upon the number of customers available in establishing an airport in a community, cne should expect that a low scale initiation of services will be the most stavle. This means that only limited services may be offered or that the personnel providing these services have a sufficiently broad background allowing them to perform a variety of duties.

\section{Alternative Modes}

Communities contemplating the acquisition of general aviation services should give serious thought to the modes of travel and communication which may be adequate substitutes for air services. Some services such as aerial photography cannot be obtained in any way other than flying; others, such as rapid transportation to a metropolitan area, can. Once the mix of services desired by the community has been determined, consideration should be given to possible substitutes for each service and to the necessity for the nonsubstitutable services. The decision as to whether or not another mode is an adequate sutstitute is dependent to a great degree on the characteristics of the local community

There is no need to repeat the discussion in Chapter II of rail, bus, truck, automobile, and telecommunications. It will be of some interest. however, to review the concepts used to evaluate the various modes and to relate those concepts to the local community.

The first concept is that of availability and accessibility. Aircraft almost always require that some mode of ground transportation be available. An airport must have an access road and a parking lot. Itinerant traffic will often require taxi or limousine service. Without scheduled service, the accessibility of the airways is limited to those having a pilot 's license or to those who can afford to hire a plane and pilot. Highways are accessible to anyone with a 


\section{N76 12004}

driver's license. But for that very reason they may not be accessible to the elderly, the young. the poor, or the handicapped who require some form of puvlic transportation by air, rail, or highway.

A second concept of evaluation is reliability. All forms of transportation are generally mechanically reliable. Aircraft, however, are much more vulnerable to weather than the other modes. Localities with severe weather conditions may find a corresponding lack of reliability in air service. Under some conditions, however, air service may be more reliable than highway modes.

The third concept is adaptability to both load and terrain. General aviation is not as well adapted to bulk loads as are trucks or boxcars. Buses and cars suffer a similar limitation. Terrain, except the most rugged, poses little problem to aircraft, however.

Routing flexibility is the fourth concept. Except for rail (and water) transportation, most modes can reach most areas.

Fifth, the cost of using the various modes is also discussed in Chapter II. The importance of this factor depends on the socio-economic characteristics of the citizens of the community, some of whom could afford to use one mode but not another. Economics must also be considered in the light of the importance of time and comfort. Americans tend to consider the full-size automobile as a standard of comfort.

\section{Introduction}

\section{Developing The Plan}

So far this chapter has discussed the factors involved in deciding whether or not the community needs the services of general aviation and in formulating a plan to meet any such needs. That a plan is to be forinulated implies that a prelimiinary decision has been made by the community that it needs the services being planned.

Such a preliminary decision is little more than an educated guess, especially since it is based on a subjective estimation of community goals which, typically are difficult to determine since they are rarely discussed. They exist more in behavior patterns and in basic assumptions than in words. A decision-maker is more likely to discover the goals which certain individuals or groups advocate for the community than those of the community as a whole.

The difficulty of discovering community goals is compounded by the lack of citizen response to less-than-concrete plans and to invitations to become involved in the early stages of the planning process. As plans become more concrete, citizens are more likely to respond, only to discover that their role is simply to applaud or oppose the developed plans but not to contribute to them. Consequently, community leaders must take steps to involve citizens in the formulation of plans as early as possible in the planning process. If done successfully. citizens will have an opportunity to articulate their goals and to incorporate them into the developing plans.

Such an effort runs contrary to an authoritarian leadership style in which a decision is made and then announced to the community. A democratic approach, seeking community input before the decision is reached is antithetical and seems to be slow, frustrating. and bogged down in endless discussion.

Leadership seeking community involvement enables the community to discover its goals during the process of planning; the "endless discussion" becomes a method of incorporating those goals. If, indeed, the discussion is endless, one could argue that the proposed public project is not - insonant with community goals but stems, instead, from some special interest.

There are several benefits to community involvement. Once a plan is formulated, it is unlikely to be bogged down by unanticipated opposition, lawsuits, and action groups, because all interests have been consulted. The cooperation involved in formulating the plan will promote a sense of community pride and awareness. Furthermore, the goals discovered through such a process will provide guidelines for future planning efforts. One gains thoroughness of decision-making by sacrificing speed.

While the ideal of full citizen participation in planning may be unrealizable presently, it can be approximated by publicizing the planning process, soliciting comments, and holding well-announced public hearings before making decisions at crucial points in the planning process, as well as by conducting surveys to determine local preferences.

In addition to citizen participation, a second principle of planning is comprehensiveness. Satisfying the needs for general aviation services should be part of the overall community development effort.

Chapter I provides a useful outline of the many steps necessary in the planning process. The basic sequence in the planning development process will be discussed here. It consists of (1) describing alternative ways of satisfying estimated needs, (2) evaluating the alternatives 
and selecting one, (3) developing a plan to implement the selected alternative. (4) measuring the physical, economic, social, and political impacts of the selected plan on the corimunity, (5) evaluating the impacts which have been projected, and (6) revising the plan on the basis of the assessed and evaluated impicis. This section will deal with the first three steps in the basic sequence.

\section{Alternatives}

Once the needs have boen identified, planners should devise a variety of ways. if possible. to satisfy those needs. Alternatives will have to be evaluated on the basis of the existing resources of the community. Consequently, the first step is to list the estimated needs and the second is to take an iriventory of those factors in the community which may contribute to need satisfaction

The needs may be satisfied by other means than the acquisition of access to general aviation facilities. Better transportation of people and/or gonds may be obtained by the acquisition of bus. truck, or railway service, or simply by improving the local highway system or access to interstate routes.

Sometimes, however, important needs cannot be met without the acquisition of better access to a general aviation facility. It is possible that a nearby community has an airport which would be suitable. One plan might be to improve access to that airport by instituting taxi or limousine service or by building or improving an access road to such an airport. If such an airport exists nearby hut does not provide the services required, one plan might be to join with the neighboring community to improve their airport, in effect making it a regional airport.

Another alternative is for the community to construct or expand its o' 'n arrport. Then two important sets of alternatives arise. The airport may be the local community's or it may be established through a regional authority or commission. Again, the airport may be constructed to FAA specifications or it may be built using other standards. (The implications of this alternative have been discussed above.)

Each of the various alternatives relevant to the local situation (and outlined in the preceding portions of this chapter) should each be formulated in terms of the needs it satisfies, the costs and revenues, and the community goals it senves.

\section{Evaluation and Selection of Alternatives}

Brief descriptions of methods for com- munity need satisfaction will serve as the basis for involving the community in the decisionmaking process. The fact that a plan is in progress should be publicized and local civic service organizations should be notified about the tentative plan choice. The plans should be made easily available and written comments should be solicited. Finally a public hearing on the alternatives shculd be announced. After the public hearing, the decisıon-makers will have some basis on which to select the most desirable alternative.

\section{Development of Preliminary Plan}

Unless the alternative selected involves building or expanding an airport, it falls outside the scope of this report. If a new airport is chosen, a preliminary plan must be developed. This plan shouid be developed by considering various alternatives in the light of the factors mentioned earlier in this chapter. Planning development is covered more thoroughly in Chapters I, II, IV, and V. Among the factors to be considered are the sponsor, function, form, funding, and site of the airport. Alternatives should be considered for each item.

Once several alternative plans have been drawn up, community input should be solicited again in an effort to provide clues to unexpected impacts of tho various alternatives. After this solicitation the plans should be assessed and evaluated in terms of their impacts as discussed in the next section.

\section{IMPACTS}

This section will deal only with the impacts of airports upon the community. Chapter II identified and discussed many of the physical impacts of general aviation, including noise level, air and water quality, and land use. In this section economic, social, and pol: al effects will be considered. Some economic :mpacts of a proposed airport will have been included in the plans as a projected demand for genicral aviation services and as an examination of the economic and fiscal capabilities of the community. As Chapter II Indicated, general avia. tion airports frequently opierate rit a loss and the subsidy they receive is ofter, justified on the basis of hnped-for sec nndary impact. such as industrial development.

Once probable impacts have been identified. It is necessary to recorsider the question. of community need At that point the public is most likely to become seiciousig interested in the planning since people tend to rejact only to projects which are relatively concrete. 


\section{The Use Of Airports To Attract Industry}

It has been argued that airports and general aviation services are a necessity if a small city or town is to expand or retain its present industrial base. Since many small towns believe that industrialization is the answer to their problems, they may be led to invest their development efforts in aviation facilities rather than in other areas. The arguments in favor of aviation development and the likely consequences of industrialization should be considered by any town seeking revitalization.

The problems of small towns which lead them to seek new industry are generally the result of the trends toward the mechanization of agriculture and the urbanization of the population. Mechanization increases agricultural productivity per worker so that fewer farm workers are needed. Workers not needed either migrate from rural areas or remain to become unemployed or underemployed. ${ }^{66}$ Declining population is bad for business. Local businesses leave, thereby degrading the qualıty of rural life and making the cities more attractive for those who remain. As the population of the countryside declines. local industries may leave if they depend on local markets. ${ }^{67} \mathrm{Com}-$ munities believe that added industry would attract nev jopulation, increase the tax base, and create more disposable income, all of which would improve the social and economic quality of life.

Proponents of general aviation argue that the availability of air transportation will promote economic growth by (1) attracting new industry, (2) helpıng established business and industry expand (thereby employing surplus rarm labor). and $(3)$ retaining present industry. ${ }^{68}$ This view is based on the expanding use of business aircraft and on the trend of industry to avoid the

" Federal Ayiation Administration. Systems Planning Divi. sion Airports Sarvice The Airport Its influence on the Coinmunity Economy (Washingtc7 "ederal Aviation Administration 1967) p v

- Kenneth Holl and Jern Pratt. "Company Otficials and Community Leaders. In Larry $A$ Whiting (ed) North Central Regional Center for Rural Development. Rural industrialization Probiems and Potentials (Ames. lowa lowa State University Press 1974). pp 120-121

- Federal Aviation Administration Systems Planning Divi sion. Airports Service op cit. p III. Louis H Mayo. op cll. pp 12 56

- Nammack op cil., 24

"Aviation Advisory Commission Genaral Avia"ion. p C-60 "Federal Aviation Administration, Eastein Region. op, clt.

p 1

Nammack, op cul.p 25

"Wartord

4 ibio central cities.

The ecoriomic impact of sirport development was suggested in a study by the Indiana Aeronauiics Commission which concluded that Indiana should develop a $\$ 112.5$ million system to handle business aircraft because "any Indiana community without convenient and adequate airport facilities nearby will be at a severe disadvantage in competing nationally for business investment and employment." 69

According to the Aviation Advisory Commission, airports "act as magnets to attract business and industry." The commission also argued that "it has been factually established that few businesses are willing to build plants and other facilities in a community that has no airport."'o The same direct relationship between aviation activity' and economic development has been suggested by the FAA which indicated that (a) the airport is a direct economic asset to the community because firms require aviation services, and that (b) "documented cases" show that the existence of an airport is a controlling factor in the decisions of industries to move in or out of a community." The FAA however, has not presented the "documented cases" that support the suggested critical in fluence of an airport in plant location. In addition, the type of cocumentation that is available is frequently questionable from a methodological point of view An example is a 1965 survey of 500 coinmunities conducted by the Texas Aeronautics Commissiun. The commission reported that it asked communities whether or not industry and business had located there due to the existence of an airport and found that all of the communities in the $50,000-100,000$ population range responded yes. while only 36.3 percent of the communities in the 2,000-5.000 population range responded yes ${ }^{\prime 2}$ One would expect the larger communities to have access to an airport and to rationalize the airport in terms of the needs of the busıness community. This is probably a good example of the bias in aviation studies that Jeremy Warford referred to in his study entitled Public Policy Toward General Aviation. Warford argued that it is usually aircraft-owning businessmen who are polled on the importance of gons:al aviation and they rate it.s importance nighly."

The relationship between industrial development and general aviation services is much more compiex than the FAA and other studies sl.jgest In fact. although many studies show that aviation facilities are an important iactor in industrial lc?ation decisions faw have been able to demonstrate the importance of general aviation in plant location." However. 
as a study by M.I.T. Flight Transportation Laboratory points out "unless there are other factors such as access to materials, an adequate labor supply and the proper tax structure, air servico wi!l not induce new industry to an area." 78

Whether or not an airport alone is a sufficient condition to encourage the development of new industry is certainly open to question. It seems clear, however, that plant location decisions are based on a variety of criteria includ. ing: (1) traditional factors such as the existence and accessibility of markets, raw materials. utilities, transportation, and labor; (2) institutional factors such as the type of government and tax rates; (3) community factors such as amenities (cultural facilities and natural environmental conditions), attitudes and population size; (4) personal preferences such as the desires of management and the residence of the owners; and, (5) site factors such as land and buildings. ${ }^{76}$

There are a number of reasons why nonmetropolitan areas are attractive to industry Employers are not enchanted with big cities where employees' productivity suffers from the frustration of rush hours, and where crime. noise, pollution, and expenses are increasing. The suburbs, which were likely locations for new or fleeing industry, have become less attractive as the metropolitan area and its blight swallows them. They suffer from pollution. haphazard land use, transportation difficulties. high land costs, and labor shortages. Small cities are attractive because they are free of many of these disadvantages. In addition, their labor tends to be non-union. more pruductive and cheaper than urban labor. The national highway system has made most small communities accessible. Utilities, land, seasonal

"Vittek, op cit.p 40

" Henn L Hunder. Industrial Development (Lexington. Mass OC Heath \& Co. 1974). Chapters 5 and 6

"This paragraph is based on Maurice Fulton. "Industry's Viewpoint of Rural Areas." in Whitung op cit. po 69-74 and Niks $M$ Hansen, "Factors Determining the Location of Industrial AC$M$ Hansen, "Factors Determining the
fivity." in Whiting. OD cif, pp 28-29

- This paragraph is based on Hansen op CIt P 29 Fulton. op cif D 74, H A Wadsworth, "Community Planning and Docision-making to Attract Industry." in Whiting. Op clt. $p$ 65, and Ralph Widne", "Regionai Coordination of Communities with In dustrialization Potential." in Whiting OP Cli., D 131

- Fulton, op cit. 59 Hansen. op cit.p 3

- Hansean, co cit po 28 and 30. Benjamin Chiniz. "Public Intervention and Guidance of Market Forces to Achieve Redistribution." in Whiting op cit, $p$ 131, and Widner, op cll, p 129

- Mansen, op ctt, p 35

"Eerl O Heady, "Rural Development and Rural Con. munities of the Future "in Wtiling. Op cil, p 139 . Hansen, op clt. p 42 workers (spouses), and recreatıonal activities are available. Taxes are lower and the towns are generally eagei to accommodate new in dustry."

On the other hand there are many firms which recognize the advantages of metropolitan areas. There is a rich supply of knowledge available in local universities. research institutions, and engineering firms. At hand are advertising agencies, sophisticated financing. utilities, and transportation. In addition metropolitan areas benefit from the external economies of agglomeration and from the cultural amenities which can only be supported by a large population. Small communities often present problems to industry. They may provide low levels of public service and few opportunities for contact with customers, supplier: and other producers. Local labor may not be easily trained due to lower levels of education; management and executive personnel are unlikely to be available. Also, there is likely to be a lack of mechanical and construction workers, of housing, and of other facilities. ${ }^{78}$

It is important to keep in mind that the national economy is becoming more and more service oriented. Thus, while one-third to onehalf of new manufacturing plants open in small or non-metropolitan communities goods-related employment has dropped from one-half of the non-agricultural total to 26 percent. ${ }^{79}$ in the past, many industries located near raw materials, but today only seven percent of the labor force is estimated to be near such resources; consequently, industries tend to locate near consumers and capital. It is often hard to find capital in rural areas with which to finance new industries because local banks are more conservative and less growth minded than branch Dariks and they often find commercial paper more attractive than local inves. ment. ${ }^{\text {Bo }}$ Service industries, are much less likely to locate away from large markets than is manufacturing."

As a result of the drawbacks which many firms see in small communities and of the transformation to a service economy. there are many more communities seeking industry than there are firms seeking non-metropolitan locations. While communities have spawnec approximately 14,000 industrial development organizations, there are only 500 to 750 new plant locations each year ${ }^{82}$ If each organization sought only one new plarit for its community, at preserit rates it would take over $2 \hat{u}$ years to sup. ply them all.

In view of the disparity between the number 
of firms seeking locations and the number of co.nm!nities which believe they would benefit by attracting a new manufacturing facility, it is important to investigate all the factors which contribute to a firm s location 'recision. A community must have advantages which make it attractive to industry before aviation facilities would become a factor. Because of the variety of factors involved in location decisions. it is difficult to generalize about them: nowever. several studies have been conducted which may provide some guidance in this respect.

According to a report writien for the Appalachian Regional Commission by Management and Economic Research Incurporated (MERI), a substantial amount of information has been generated in recent years concerning the airport's influence on plant location decisions. ${ }^{33}$ The information takes two forms: individual airport case studies and industrial surveys.

The case study approach generally suppurts the conclusion that airports are. in fact. an important community attribute for the attraction of industry. Yet. none of these studies measures the relative importance of the airport's attractiveness quantitatively compared to the other community attributes. In addition, many display a pre-airport bias. For examf's a report prepared by the FAA entitled The irport-Its Influence on the Community Economy cited as its purpose to seek ". . . ta: igible evidence of significant community benefit which could be cause"y related to each airport's development." "sa

The MERI repurt also cited the industrial survey as a measure of the i.rport's influence in location decision-makıng. Despite potential analytical and conceptual problems. the results do provide. at kas.. some indication of the role played by airports in locatıo. decisions. Airports were listed as important by 20.30 percent

"Mariagement and Economic Research incorporated Guidelines for an Appalachian Airport System Appalachian Research Report No 3 (Palo Alto 1967) pp 40-48

“ Federa' Avialion Administration Systems Planning Division. Airport Service op cit. p 11

"Managemeit and Economic Resedrch incorpcrated op cit, pp 42-47 121.122

- Fulton. op cit. pp 77.78 Holt and Pratt op clt. pp

- Plant Location 1974 iNew York Siminons-Boardman Publisning Co 197's p 7 G A Hornberger "Corporate and Com. munity Decision Making for Locating industry in Whiting. Op it 85.88

" Holt and Pratt cp $c:$ : pp 121-122

- Farnsworth op cit o a Clair Stebbins Ohios Airpor Bulling Program The AOPA Pllot. December 1974 pp 38-39 Larry Trask "Ohio Shews FAA How to Build Airports. The AOPA 3 Ilot. November 1970. $p$ z9 of those involved in the location decision-making process. ${ }^{\text {ss }}$ It appears, then, that only in some cases is an airport a primary determinant in decision-making.

Robert $W$. Shively studied 330 responses to a survey of Nebraska industrial plants. The most important factors determining industrıal location decisions included qualıty, availability. and cost of labor and the existence of a rightto-work law in the state; highway transportation and proximity of markets; reliability of electrical service and availability of natural gas: availability of sites; and the fact that the people who started the plant lived in the area. (See Table III-V.) A consultant indicated that small communities attractive to industry had good highways with ready access to Interstate rnutes; - strong and intelligent community leadership; a lack of domination by a single industry; a good supply of labor; a big city within 50 miles; and unforbidding terrain. Another consultant mentioned trainable labor, good mighways, and adoquate utilities. ${ }^{86}$ Checklists from two sources emphasized public services and a progressive attitude in addition to those factors aiready mentioned ${ }^{\text {B7 }}$ In sum, the major factors involved in plant location decisions seem to be labor. highways, utilities. availability of sites. community attitude. and proximity to markets.

In cor.trast to these and other factors. aviatıon services do not seem to be rated especially important. In the Shively study. air freight transportation and air passenger transportation were respectively $33 \mathrm{rd}$ and 36 th in importance among 43 factors. (See Table III-V.) According iv one of the consultarits, "a few firms needed or wanted airport facilities nearby for fast shipment of raw materials and finished products." A survey conducted by the Minnescta Department of Aeronautics tends to confirm the secondary importance of aviation in industrial site location. (See rable III-VI.) Unless the above mentioned factors and others are present. it is unlıke:y that aviation facilities will aıd in wooing industry. If all of these factors and others are present. it is unlikely that lack of ger 2 al aviation services would deter an interested company.

The Ohio County Airport System is often credited with aiding in the development of the state." Under the plan low-cost. paved. singlerunway airports were built in almost every county. Yet it is difficult to credit the subsequent industrialization to the airports or even to estimate the degree to which they were necessary, since the state as a whole has many fac- 


\section{TABLE III-V}

\section{RANKING OF LOCATION FACTORS IN NEBRASKA, ALL INDUSTRIES}

Factor

1 L jor quali:"

2 Highway transportation

3 Labor availability

4 Available site

Relıability of electric service

Wage rates

7 Proximity to market

8 People who started plant lived here

c Natural gas availability

10 Right-to-work law

11 Taxes

12 Electric rates

13 Rail transportation

14 Comminnity attitude toward industry

15 Friendliness of people

16 Natural gas rates

17 Attract.viness or community

18 City water at site

19-20 Health facilities and services

19-20 City sewer at site

21 Avallable building

22 Quality of local schools

\section{Rank}

Aroundwater supply

Amount of unionization

Proximity to raw materials

Construction costs

Housing for plant workers

Housing for executives

Calıber of local ID yroup

Local financial institutions

31.32 Recreational opportunities

31-32 Vocational training programs

Air freight transportation

Nearness to colleges and universities

Hotel, motel, and meeting facilities

Air passenger transportation

38 Local investors

39 LDC financing

40 Local subsidies

41 SBA financing

42 Industrial revenue bonds

43 Recummendation of consultant
Points

420

417

416

401
385

372

347

327

298

298

293

288

271

267

230

166

159

126

120

Note A factor was awarded one, two, or three points each tıme it was rated of minor importance, important, or very importarit, respectively. Source: Robert W. Shively, "Decisıon Making for Locatıng industry," in Larry R. Whiting. Rural Industrialization: Problems and Potentials, Ames, lowa: Iowa State University Press, 1974. 


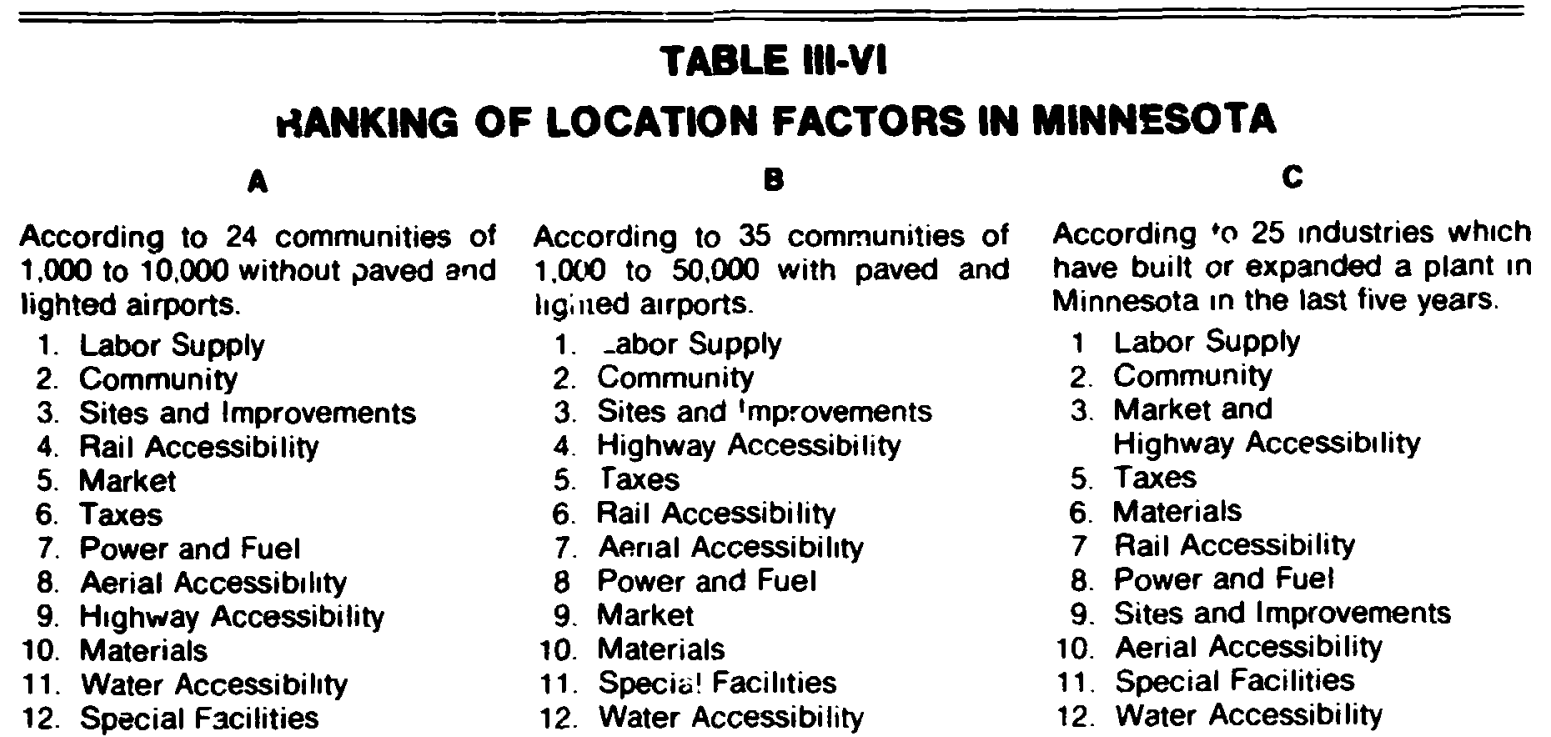

Source: Minnesota Department of Aeronautıcs, A Study of the Socio-Economic Impact of Aviation on Selected Communities, 1 January 1975.

tors which are attractive from a bu', ness point of view. If, as one consultant suggested, a !ocaticn decision is begun with a delimitation of an appropriate region relative to markets. Ohio is geographically favored. ${ }^{90}$ In addition, Ohio has a strong highway system. a favorable tax climate. plentiful labor. and good factory sites. ${ }^{91}$ The same governor who promoted the airport system also initiated an extensive system of regional vocational education centers. The state was heavily industrialized (except in the southeastern section) before the airport system began. Many communities are within fifty miles of the state's large cities (Cleveland. Columbus, Cincinnati, Akron. Toledo. Dayton.) While the airport program made the state more attractive to some industries,.$^{92}$ it is not clear that the lack of the airport system would have prevented substantial development. It can be argued. however, that while the airport system had little influence on the degree of industrialization in Ohio, it may well have determined the distribution of new industry; that is. new plants may have been constructed in smaller communities rather than on the frincos of the larger cities.

Assume that a community has an airpsit. many other factors attractive to industry, ar,d an

- Hornberger op. c1t. pp 85-88

"Stebbins, op cit, p 39

- Trask. op cif. p 29

"John T Scott. Jr and Gene F Summers. Problems in Rural Communities atter Industry Arrives. In Whiting. op chl.p 96. Wadsworth. op ctt, p 63 active and progressive leadership. What then are the impacts of industrialization likely to be? The answer to this question depends on the nature of the community and on the new industry, but there are certain factors which can give a general indication of the probable effects.

First, the favorable economic impacts of the new firm may be less than anticipated. Communities often seek industry in order to bring in more money and improve business with the payroll of the new firm. Thus. each dollar of payroll will generate income for others as it is spent. If the new industry is to be a significant economic benefit this multiplicative effect should be large. Unfortunately. the smaller the community, the smaller the multiplier, because the money flows out of a small community faster than out of a larger one. So while the multiplier for investment dollars is taken to be about seven on a national level, the multiplier shrinks to three or four at the state level. The local sommunity. if smali, can count on very little from this m! iltiplication..$^{93}$

The loss of payroll multiplication is due to ine "leakage" of money oui of the community or the failure of the payroll to represent new mones. A majcr cause of leakage is the portion of the work rorce composed of non-resident commuters who take their paychecks out of the community in which the firm is located and spend it elsewhere. In the case of one steel plant, 83 percent of the work force resides in counties other than that in which the plant is lo- 
cated. Again, the local residents who commute to jobs outside the community. may quit their old jobs to take new ones at the new local plant. Except for the increase in their wages, their take-home pay represents no new money coming into the community. since they were already bringing it in from the jobs to which they previously commuted. Similar considerations apply to those on welfare or unemployment-that portion of the payroll which really $r$. 'esents new money may not be spent locally unless an adequate economic infrastructure has developed locals may travel to larger towns or use mall-order catalogs to shop because of the expense and lack of variety of goods locally. Money saved $\mathrm{r}_{\mathrm{i}}{ }^{\circ}$ 'cal banks may also represent leakage since commercial paper may be more attractive than local investment. ${ }^{\text {ss }}$

Consequently. communities should not accept new plant locations without evaluating the prospective industry ${ }^{96}$ The most important questions in this regard are the kind and source of labor. Will the plant require labo: of a sort available locally or will a large number of the workers commute? One plant locater in Appalachia employed 3.000 workers who commutes to the plant from 27 counties in two states." Some companies prefer their workers to live out of town in order to reduce local public service needs and consequent taxes on the firm. ${ }^{98}$ Will the new industry employ workers who are now unemployed or underemployed. or will it simply increase competition for those already employed? If so. it is unilkely to employ displaced farm workers Even companies which hire locally may not increase employment as much as expected since they may hire the better workers who are then replaced by thcse wh. had been employed or underemployed at marginal, unnecessary. or redundant jobs which cannot subsequently be filled economically."

A second major consideration is whether the company will hire women or men primarily. Scott and Summers pointed out that the sex of the workers has important local economic consequences. ${ }^{100}$ If a plant hires women primarily.

\footnotetext{
* Scott and Summers op cit, p $96 \mathrm{ct}$ Wadsworth op ctt p 63

" Widner op clt pp 129-130 Scott and Summers, op cIt. $p$ 96. Hansen. op cit, $p 30$

- Wadsworth. op clt.p 62

- Wianer op cif p 131

- Scott and Summers op cti po 104-105

"Wadsworth op clt.p 64 Hansen op cll, pp 40-42

+o. This paragraph and the next are based on Scott and Sum mers. op. cit. Pp 102-105
}

it is unlikely to have an effect on the size of the local pcpulation since there is generally a good supply of female labor among the wives and daughters already residing in the area. While the w will be paid low wages. their income will all go to local families already in existence; average family income will increase, as will consumptiorı. It is likely that more cars and more expensive cars will be purchased hy such families. Families with working wives will purchase more convenience foods, household services (e.g., laundry), and women's clothing They are likely to eat out more often and at better restaurants, and upgrade their houses and furniture; however, they will be unlikely to build many new houses.

If. on the other hand. a factory hires men primarily. Scott and Summers argued the consequences will be vastly $0 .$. i. 2 rent. Population will increase as workers move closer to their jobs and bring families with them. Aggregate community income will increase but not per capita income to any great extent. The new families will require housing. furniture. and low-cost automobiles. Low cost food sales will increase, but not restaurant business; however. int re will probably be more activity at taverns, bowling alleys. and other places of entertainment The larger population will increase the number of students who require public schools and put a larger demand on public services in general. In addition there will be an increase in the number of young heads of households.

If Scott and Summers are right. there seems to be a trade-off between growth and increased standard of living. If a community acquires industry which employs men. it might grow and be likely to persist in the future since the number of young families will increase. Per capita income will be low, however If the industry employs women, family income will increase, but the population will not.

Impacts on the community result not only from employment after the plant is built, but also from the workers who construct it. It will make a major difference whether local or imported construction labor is used. If construction labor is brought into town for a relatively short building project, there will be a short-run demand for sleeping quarters for inexpensive eating places, along with the generation of additional business at places of entertainment However, local businesses will not be able to expand to meet the demand comfortably since It will exist for only a relatively short time. If the buliding project is long-term. workers will bring in their fam' vho will put a strain on the 
school system and on other municipal services. One town expanded its schools and services because it expected the new industry to promote new growth. When the town failed to grow, the citizens enjoyed more services as well as a higher tax bill. ${ }^{01}$

New industry can have many other effects on the local community. The potential stress on local public services has been mentioned in passing. Paying for increased services can be a financial strain on a small community, especially if the new industry has been offered tax incentives to locate in that area. This form of inducement should be avoided since "tax policies are seldom a decisive irifluence in selecting a branch location " except in metropolitan areas. ${ }^{102}$ Again, eculogical problems may result from new plants. While polluticn is not a frequent consequence, it should be evaluated in each case. More important is the increased water runoff created by the added roof and parking lot area. Runoff can tax the sewer or storm system, cause erosion, and flood basements. ${ }^{103}$

There ar? social and political consequences to be considered as well. If the new industry will attrac! new population, what are the likely characteristi:s of that population? How big will it be relative to the present community? How will it be integraied into the life of the community? ${ }^{104}$ The plant may become a factor in the local power structure. The town may be put in a subservient position if the plant employs a large portion of the nopulation. ${ }^{105}$ On the other hand. new industry can help provide leadership and brainpower for the community and help it to progress in the future. ${ }^{106}$ In many cases physical and social improvements follow the estab. lishment of a branch plant. ${ }^{107}$

\section{Conclusion}

Communities may make two assumptions in their plans for development. These assumptions are both questionable. The first is that the acquisition of new industry will be of benefit to the community. The second is that an airport will be a major aid in attracting new industry.

The first assumption is questionable because the effects of a new plant on a com-

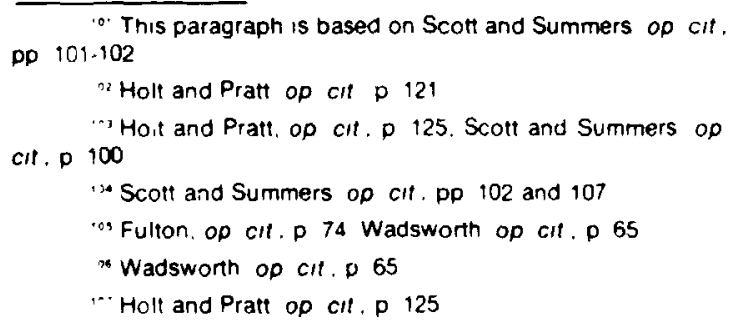

munity vary considerably because of low economic multipliers, payroll leakage, the source and kind of labor, the method and duration of construction. new demands of community services, social problems, changes in the political structure, and ecological considerations.

The second assumption is questionable because of the relatively small market for the many communities seeking industry and the factors which are far more important than air service in the location of new plants.

\section{Social And Political Impacts}

Most of the social impacts of an airport on a community art dependent upon the economic variables. Economics lead to political consequences as well. If a town builds an airport with hopes of industrial development the reputation of the responsible community leaders may rise or fall as industry arrives or fails to appear in addition. the cost of constructing an unwarranted airport will either result in higher taxes or lower levels of local services.

If the airport does help to bring in incustry, the community may find that its life style has changed. for example, from serni-rural to semiindustrial lite. Since new industries could be expected to draw employees from the surround. ing couritryside. the new life style would involve daily commuting. which in turn may lead to rush hours. traffic jams, new road construction, and an increased police force to handle the traffic This will result in some increased stress. as will the change from a farm life to an industrial discipline.

Should significant growth take place the locality would be called upon to provide the higher level of government service typical of a small city. It is likely that local taxes, after an initial decrease in rate to take into account the added base due to new industry. would once agaın begin to clımb

Social and economic impacts will of course vary depending on the nature of the community involved. In a large metropolitan area. the effects of addıng a small general aviation airport would be minimal compared to the area's entire economv and society if the general aviation airport is really' a new metropolian airport suitable for air carrier service. the effects would be larger and are rather well studied in an isnlated urban area. there may be a large economic effect and a smalier social impact since the life style is already in. dustrial and urban

There are also some consequences which seem to be reiatively independent of the eco- 
nomic variables. They are hard to measure and fall primarily into a category which one could call community solidarity or community interaction. Despite the difficulties of measurement. these factors can be extremely important in the quality of life of the community.

In order to build an airport under the Ohio plan, a community had to seek it actively by developing plans and raising money. It therefore became more organized than it had been in order to acquire the airport. Leaders had to promote, persuade. and generate community concensus. ${ }^{108}$ In effect the community united around a project and the project became a symbol of the community. While the airport may not put the community on the map in the eyes of the rest of the world, it makes the community feel that it is on the map: the airport becomes a source of civic pride and identification.

The airport in Vinton County, Ohio. became a more lasting example of this theme. Vinton's aurport became its community center, a place where art exhibits and other cultural and recreatıonal ever's take place. ${ }^{109}$ Again the airport serves as \& way of bringing people together and making them proud of their community.

These characteristics of the local airport do not follow automatically from its mere creation: they are highly dependent on the planning process, becoming possible with full citizen participation. Positive benefits also depend on comprehensive planning and land use. With proper planning and implementation an economically-warranted airport can become something of direct value to many citızens. since others besides businessmen and pilots will be users of the facility. Such direct benefits are more easily perceived than those indirect benefits which flow from the additional industry an airport may generate.

It is important to point out. however, that such benefits as these may be derived from things other than airports-the ccmmunity could unite around building a community center, a water supply system. or a recreational area. If other circumstances do not warrant an airport. the above mentioned social benefits alone do not justify it either.

\section{Re-Evaluation}

Once the various plans have been studied and their probable impacts determıned. the

\footnotetext{
10 Farnsworth, op cil.p 24

$\therefore$ Stebbins. op cIt. P 42
}

community has developed a new awareness of the issues involved in providing general aviation services. !t is likely that groups within the community have become interested in the issise, and that anti-, pro-, and neutral-airport sentiments have developed. It is reasonable to assume that there could be a significant difference between the estimate of community needs made at the time of the initial decision to initiate the planning process, and that which could be made now in the light of concrete facts, plans, and additional community inputs. Decision-makers must take advantage of this opportunity to re-evaluate their original firdings. Consider, for example, the case where the plans cal! for the construction or expansion of an airport. The airport is now more than a dream: It is an actual plan with estimated benefits and costs and projected physical, sou.al, political, and economic impacts. It has attracted the attention of numerous individuals in the community. One of three possible paths might now be pursued: the plan may be dropped, revised, or implemented as is.

The same methods described earlier in this chapter may be used to stimulate the incorporation of citizen infuts into the decision-makıng process - publicizing the plans, soliciting comments, and holding public meetings.

Impacts are not necessarily exclusively good or bad. Even among those undesirable impacts, some will be worse than others. How important is it to the community. for example, that the airport is likely to increase the noise level in certain areas by a given amount? in the case of social and economic impacts, evaluation is even more difficult. If it seems likely that an aırport will attract industry and increase the size of the community, then the community must decide on the desirability of such an impact. What value does the community place on the pride that may go with having an airport? The community will have to determine the possible degree of relationship between general aviation and each of a variety of factors. It mur' also evaluate the relative importance of the se factors in the !ight of community goals. The evaluation of the overall benefit or disbenefit of the impact of a general aviation airport on the community is a complex matter Several evaluative techniques are available, but none of them is completely satisfactory.

One approach is to develop "before-andafter" scenarios describing the community with and without the facility. in terms of such factors as exparided industry, population growth. tax values, and the like. These scenarios could 
then be evaluated subjectively by the community, in the light of its goals and cobjectives This method assumes the gener ai aviation facility to be the only influencing variable in social and economic development and tends to neglect other equally impc $r$ factors in the community's development $\epsilon_{ı}$ Iurt. It also tends to neglect those real values within the sociocultural framework of the community hich are neither economic nor quantifiable. Another method is that of "cost-benefit analysis," which weighs economic and social benefits against economic and social costs. The analysis is conducted after dollar values are assigned to all non-monetary costs and benefits. The artificial quantification of such facturs as the value of human life and the quality of the environment. however, can lead to questionable, or at the least controversial, conclusions.

A reasonable approach to impact evaluation therefore, seems to be one in which both monetary and non-monetary factors can be analyzed withın a framework that maintaıns a viable separation between the two. yet offers insight into the interaction between them. Such a framework is that cf "cost-effectiveness," in which the direct and indirect non-monetary costs or benefits of a given course of action are evaluated relative to the monetary costs. Each alternative plan could thus be ranked in accor- dance with the degree to which it satisfies given community goals. Tradeoffs between the levels of satisfaction of different competing. and sometimes contradictory, community goals must be considered by the planners, decisionmakers, and the community at large. The decision is basically one in which the community has to make a choice between alternative options leading to different ic sntifiable futures, given t've costs associated with these options. Such anaiyses and decisions are usually made in the political arena, in accordance with the processes of social choice prevailing in the community.

The re-evaluation of community needs and goals might show that the facility is not warranted after all. !t may, on the other hand. accentuate the need for the facility. The reevaluation can form the basis for a determination of the types of desirable impacts to be encouraned. As revised and amended plans are developed, impacts must the re-assessed in order to make certain that no new negative impacts are introduced, and that the replanned facility has both mitigated the negative and augmented the positive expected impacts. The iterative process of planning. assessing impacts. and re-evaluating should continue until a satisfactory plan is obtained 


\section{TRANSPORTATION AND GENERAL AVIATION IN VIRGINIA}
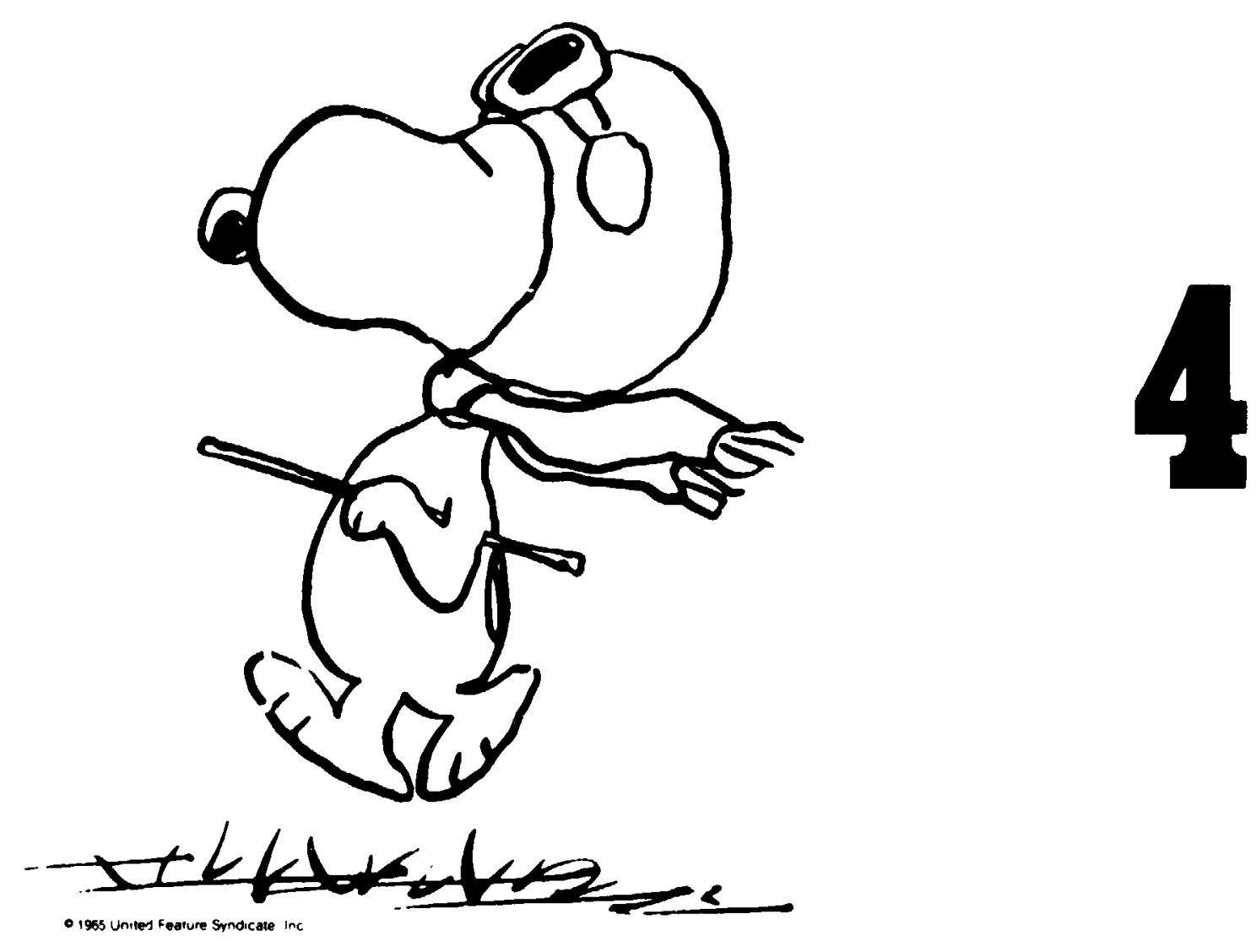

PRECEDING PAGE BLANE NOT ELLMED 


\section{N76 12005}

\section{CHAPTER IV}

\section{TRANSPORTATION AND GENERAL AVIATION IN VIRGINIA \\ INTRODUCTION}

Virginia, the site of the first permanent English settlement in America in 1607, and one of the original 13 colonies, has occupied an important position in the history of the United States.' Richmond, its capital, was the capital of the Contederacy and Virginia and the site of many important battles in the Civil War. Because of its central location along the Atlantic Coast and its excellent harbor at Hampton Roads, Virginia is an important government, port, and shipbuilding center.

Geographically, the Commonwealth may be divided into four regions: (1) The Coastal Plain is divided into peninsulas by the action of the James, York, Rappahannock, and Potomac Rivers-all navigable from the Chesapeake Bay to the fall line extending roughly from Richmond to Washington. (2) Here, the Piedmont Plateau begins, a region of rolling hills divided into farms and woodlands, sloping gradually to the Blue Ridge, which divides it from (3) the Great Valley of Virginia. (4) The very southwestern part of the state is in the Appalachian Plateau region, an area of steep mountains and hollows.

In 1974, the population of Virginia ranked thirteenth in the nation, with an estimated 4.908.000 persons or 2.3 per cent of the United States total. Population increased 17.2 percent in the decade of the 1960's, and since 1970 it has increased an additional 5.6 percent. In 1970,63 percent of the population was urban. The densest portions occur in Virginia's eight Standard Metropolitan Statistical Areas (SMSAs), which account for 66 percent of the population. In order of size these are: (1) and (2) Norfolk and Newport News-Hampton, the two SMSAs located in the Hampton Roads area (with 1,073,000 ; ?or, 1t); (3) Northern Virginia (with 986,000 rar;le), containing many federal goverriment and military Installations; (4) Richmond (with 556,000 people), a manufacturing. commerce, and headquarters city; (5) Roanoke (with 212,000 people), the manufacturing, trade, and transportation center for the western part of the state: (6) Lynchburg (with 140,000 people).

The information in the introduction to Chapter IV is abstracted from Ware. Peggy (ed) Virginia facts and figures1975 Division of Industrial Develo ment, Commonwealth of Virgınıa. Rıchmond. Virgınıa a manufacturing city; (7) Petersburg-Colonial Heights-Hopewell (with 127,000 people), a manufacturing area with some federal activity; and, (8) Bristol, another manufacturing center. The remaining 34 percent of the state's population is in small urban and rural areas. Politically, the state is divided into 95 counties, 38 independent cities, and 192 incorporated towns. The independent cities are politically independent of the counties in which they exist; incorporated towns are not.

Important elements in the economy of the state are manufacturing, federal government employment, commerce, agriculture, tourism. isheries, and natural resources. Manufacturing, employing one-fifth of the state's civilian labor force, is highly diversitied and geographically well dispersed. Principal industries are textiles, apparel, chemicals, food processing, trans,ortation equipment, and electrical equipment. Principal manufacturing centers are in Richmond. Newport News, Norfolk. Lynchburg, Danville, Martinsville, and Roanoke.

Federal government employment is conzentrated in both Northern Virginia and the Hampton Roads area. In addition, many Northern Virginia residents work for the federal government in Washington, D.C. Commerce is important because Virginia's location in the middle of the Atlantic Seaboard causes a great deal of north-south shipping to pass through. In addition, it is the site of Hainpton Roads, one of the world's best deepwater ports. Because of its proxımity to the West Virginia coal fields, it has two coal-hauling railroads. Agriculture is important to South Central Virginia and in the Shenandoah Valley.

Tourism is important to much of the state with many water recreation opportunities on the coast: important Colonial, Revolutionary War. and Civil War sites in the east; and, many hiking and camping possibilities in the west. The Chesapeake Bay provides tourists, as well as the state's commercial fisheries, with some of the best fishing in the country.

Natural resources are important in the Western part of the state. Coal minıng. Important in the Appalachian region, has undergone a resurgence with the rising price of imported oil. Extensive forests cover the western mountains supporting the lumber industry.

In this chapter the diversity of Virginıa will be examined with respect to its transportatıon facilities and services, the Virginia $A_{i}$ Transportation System Plan, regionalism, and 
selected case studies of individual aviation facilities within the Commonwealtli.

\section{TRANSPORTATION FACILITIES AND SERVICES}

In the following sections, the Virginia highway network and the statewide intercity bus, rail, and air carrier services wiii he described. A description of the Virginia airport facilities will follow.

\section{Highways}

The highway network in Virginia is com. posed of several classes of highways ranging from interstate freeways to local roads. Figure 4-1 shows both the Interstate and the Virginia arterial networks. The Interstate system consists of 1-81, through the Shenandoah Valley: 1-64. from Greenbriar, West Virginia through Clifton Forge, Staunton, Charlottesville, Rich mond. Newport News, to Norfolk: 1-95, from Washington to Ricinmond, Petersbury, and toward Rocky Mount, North Carolina; I-85 from Petersburg toward Greensboro, North Carolina; and 1-77, running north-south through the western part of the state.

The Virginia arterial network includes the following roads: U.S. 58 through the southern part of the state from Norfolk to Martinsville: U.S. 29 from Danville through Lynchburg. Charlottesville, Culpeper, and Warrenton to Gainesville; U.S. 360 from South Boston to Richmond and on to Tappahannock and Reedsville: U.S. 17 from Chesapeake to Fredericksburg and Warrenton. U.S 13 on thie Delmarva peninsula; U.S. 460 from Norfolk through Petersburg and Lynchburg to Roanoke: and from Christiansburg to Bluefield. through a part of West Virginia. and then from Bluefield through Tazewell to Grundy: U S 301 from the Toll Bridge over the Potomac at Newburg to Bowling Green and then Virginia 207 from Bowling Green to 1.95 at Carmel Church: U.S. 225 from Martınsville through Roanoke to Clifton Forge; U.S. 58 Alternate. from Abıngdon through Norton to Pennington Gap. U.S. 23 from Pound through Norton to the Tri-City area; Va. 7 from Washington to

\footnotetext{
Rand McNally Golden Anniversary Edition Road Allas Rano McNally Chicago III 1973

Departinent of Highways Virginia 1974-Otficial State Highway Map. Commonwealth ol Virginia Rand McNally Chicaco III 1974

- Russell's Official Nallonal Motor Coach Guide Russell s Guides Inc Volume 47 No 8 Cedar Rapids lowa May 1975

'Amtrak All-America Schedule. Washington May 151975

-..... Otıcial Ralway Guide. The North American Freight Service Edition National Railway Puhlication Company Volume 107 No 5 New York. March April 1975
}

Winchester; U.S. 522 from Winchester to the State Line: U.S. 33 from Ruckersville to Morrisonburg; and, U.S. 211 from Warrenton to New Market. ${ }^{23}$

\section{Intercity Bus}

Figure 4-2 shows the intercity bus routes in Virginia, operated primarily by Greyhound and Trailways. Some small amount of service is also provided by other bus lines: D\&M Bus Company is South Central Virginia, James River Bus Lines around Richmond, and Bristol. Jenkıns Bus Lines in Western Virgınıa.

Most intercity bus services in Virginia are operated as parts of a national network. The greatest amoun: of service is from Richmond to Washingtor, along 1-95 as part of the major East Coast service. Another major route is from the Northeast to Tennessee, operating in Virginıa from Washington, D.C to the Shenandoah Valley and along 1-81. There is, in addition, a north-south service along U.S. 29. A subsidiary part of the East Coast service operates along the Delmarva penınsula to Norfolk There are very few east-west routes, the major ones being Norfolk - Richmond - Charlottesville - Staunton. and Norfolk - Richmond - Lynchburg Ruanoke. The entire state is served by at least one bus per day, and many communities isolated by other intercity modes are served by bus lınes. ${ }^{4}$

\section{Rail Passengers}

There are four main scheduled railroad routes through Virginia, three run by Amtrak and one by Southern Railway as shown in Figure 4-2 The major north-south services operate from Washington. Amtrak operates three trains a day to RIchmond and south. splitting at Petersburg: and. one train a day to Charlottesville. then to Charleston. West Virgınıa. and west Southern Raılway also operates from Washington to Charlottesville. Lynchburg. Danville. arid points south. Three tra'ns run to Lynchburg and two go beyond. Southern has filed application to abandon some of its service

In addition to the north-south routes two run east-west one on the Chesapeake \& Ohio from Newport News through Richmond and Charlottesville. connecting with the Washington section to the west: and. the other on the Norfolk \& Western from Norfolk thioug in Petersburg. Lynchburg, and Roanoke to Cincinnatı. ${ }^{\circ}$

\section{Air Carriers}

The major air carrier airports in the state are located at Roanoke. Richmond. Norfolk. 


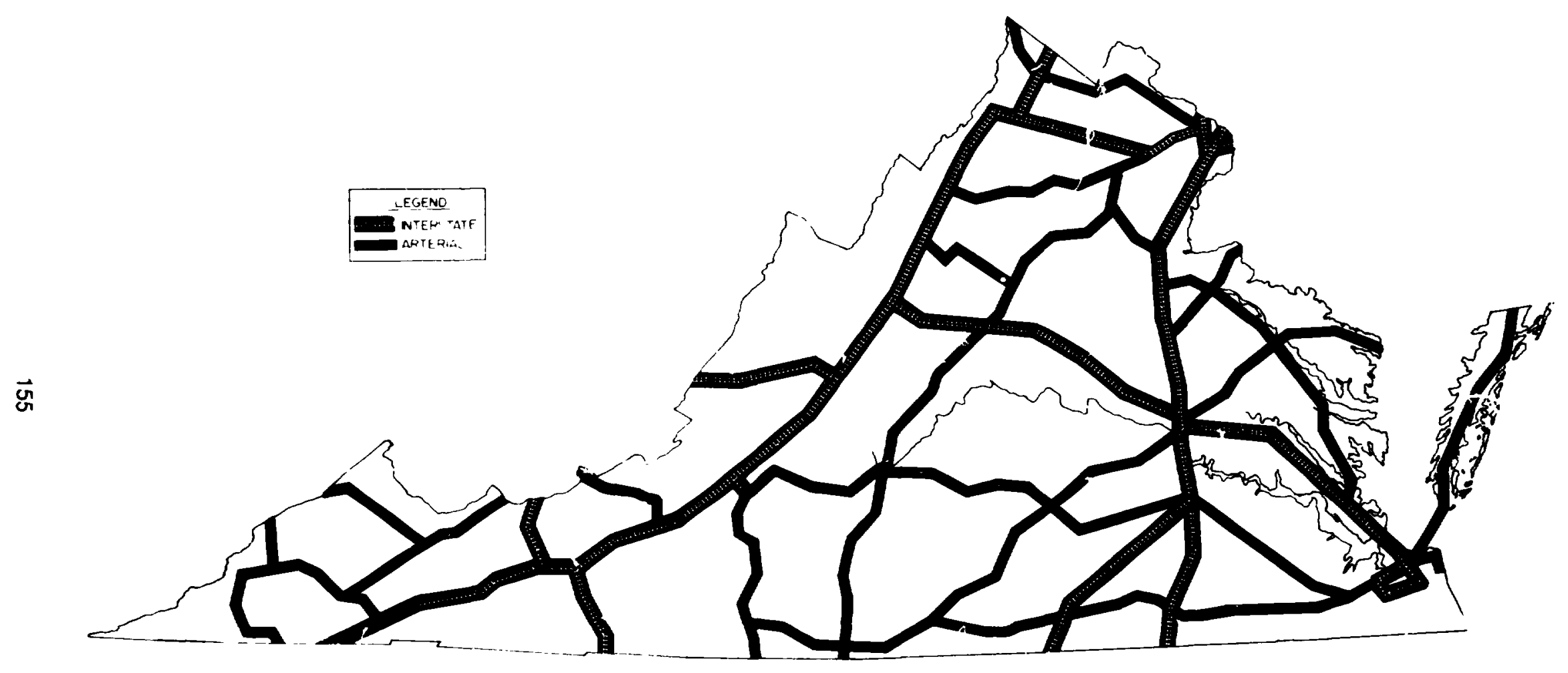

MANOR HIGHWAY SYSTEMS IN VIRGINIA FIGURE 4-1 


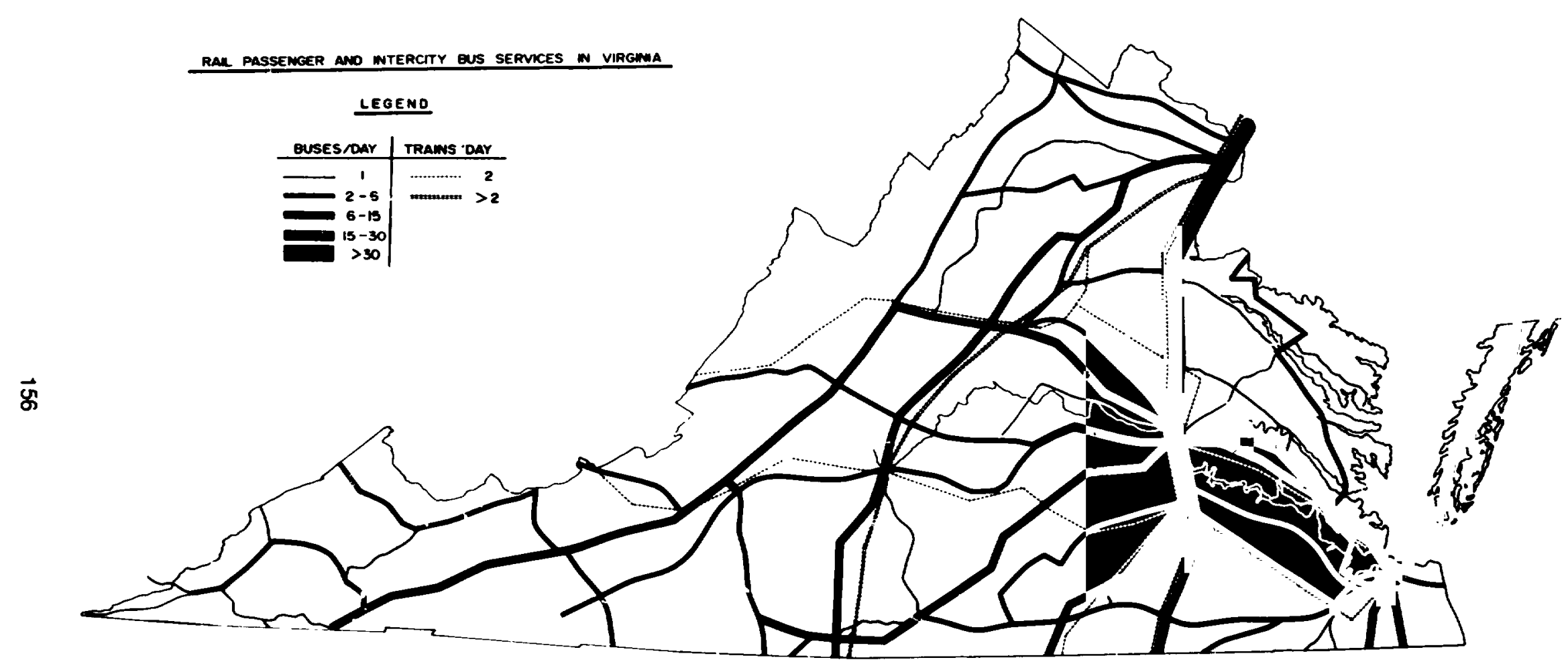

RAIL PASSENGER AND INTERCITY BUS SERVICES IN VIRGINIA FIGURE 4-2 


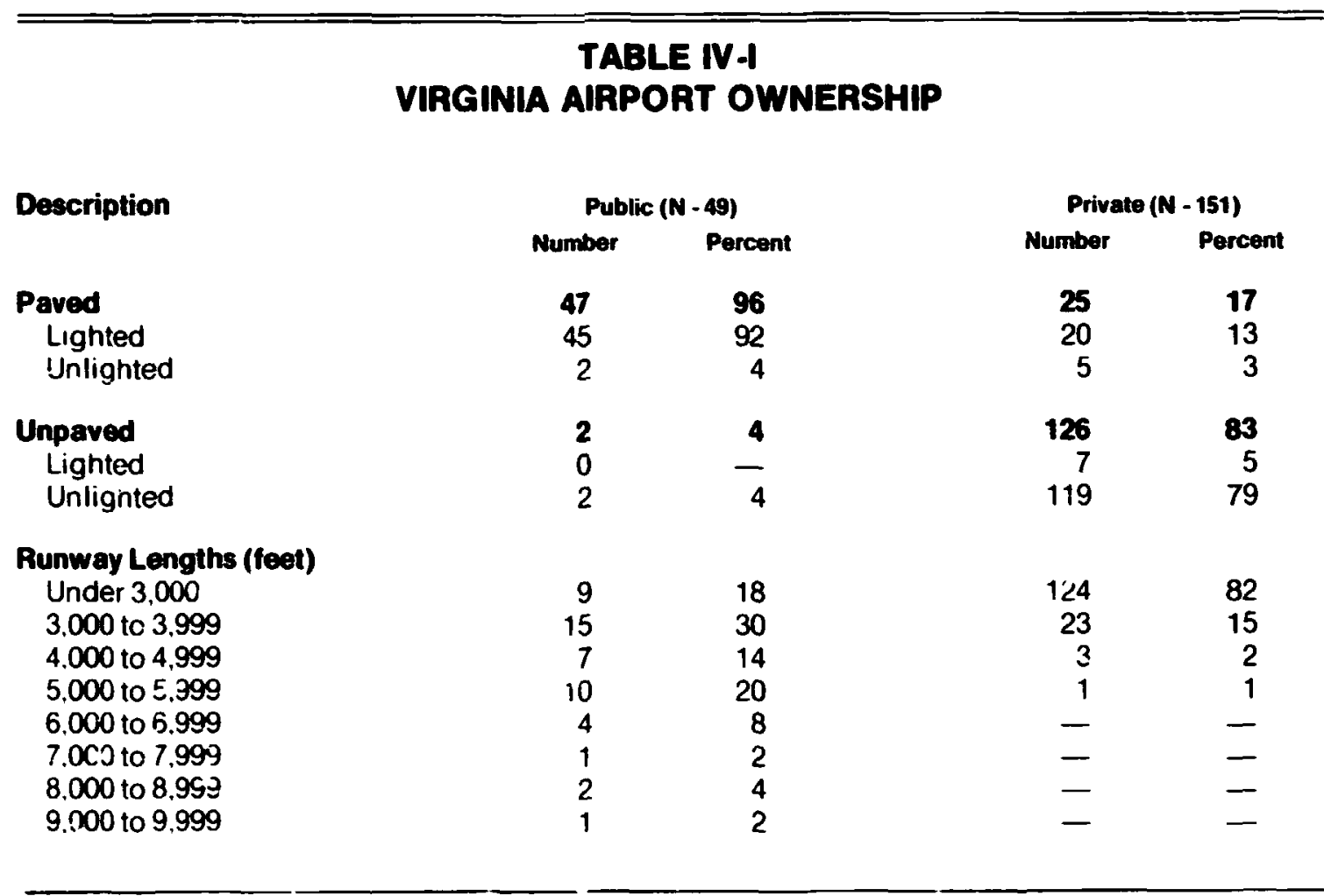

Source: Preliminary Dratt of the Plan for the V.rginia "ir Tra ssportation System, Richmor,d, Virgiria, December 1974

Newport News, and Wasinngton. D.C.. served by Natıonal and Dulles airports - both operated by the federa! go'ern nent. As shown in Figure 4-3. intrastate serv: we is heavily focused on Washington Nattonal Airport, with 8-10 flights a day to and from the major Virgınia airforts. The major intrastate aır carrier is Piedmont Airlines. Other carriors serving the slate inslude Allegheny. United. Eastern. and National Aurlines. The best interstate service is offered at Richmond ar.u Norio!k. with Roan - ! e, Newport News, and Tri-City providing lesser amounts. Several commuter air carriers also serve V'ırginia airports with Philadelphia, Baltimore. and Washington Dulles being principal destinatic. I. Iroin Virginia cities.'

\section{Virginia Airport F winities}

$\therefore$ it present 227 arrcraft landing fo, ; 'ities exist $n$ the Commonwealth $c^{*} V^{\prime} r_{y}, ' a$. both

(Cficlal Airline Guide. (UAG) North American Edition. Reube - H Do,velly Fublishers Oak Brook III. May 151975

- FA.A Bulletin 70-8?. Washirgton DC. May.27 1975

- Division of Aeronautics Prelimirary Draft of the Plar for the Virqi' la Air Transi italion System. Richmond. Macemb' r. 19/4 publicly and privately owned. ${ }^{8}$ Of thesc, three are seaplane bases, and 24 . heliports. The remaining 200 airports vary from mere grass strips offering little or no auxi,iary services to the mammoth Dulles Airport with its 11,500-foot runway capable of handling jumbo jets.

Only 49 airports, or roughly one-quarter of the total in the state. are publicly owned, as shown in Table IV-I. Several municipalities, of course. jointly operate airports through airport authorities such as the Peninsula Airport Commission. which is sponsored collectively by York County. James City County. Newport News, and Hampton. Despite the small number of publiclv owned facilities, 92 airports (46 of them privately owned) are listed by the FAA as open to the public. Interestingly. three publicly cv. ned facilities are $r, t$ included within this category. In ado...... six airports were abandoned in 1974. one of them publicly owned.

Fleven airports in the state ai: served by $\because$, leduled air carriers. with nost of the remainIng 189 airporis possessing only general aviatıon :apability often extremely limitert at best." T-vo-thirds of virrinia airports, for example. 


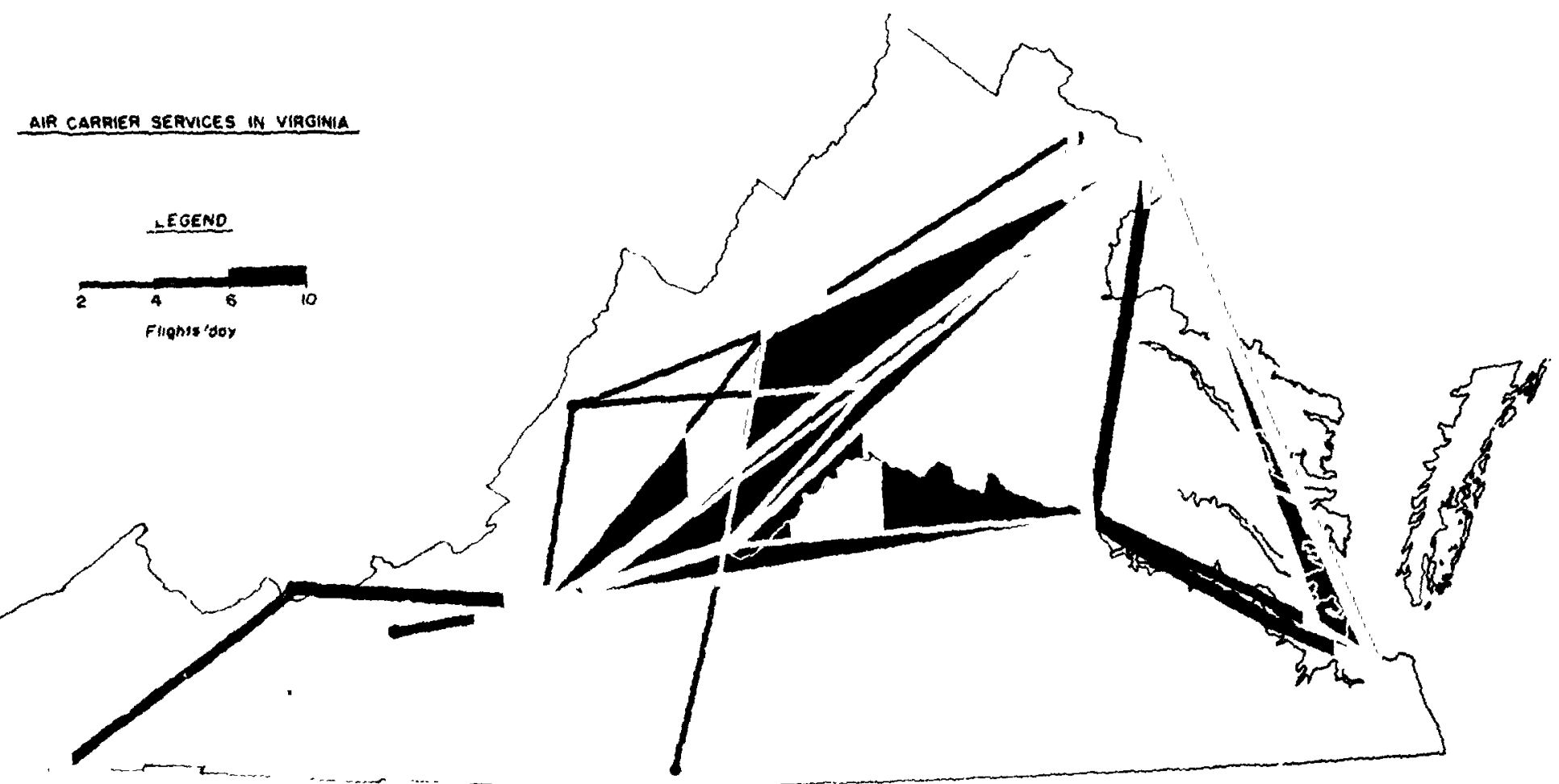

AIR CARRIER SERVICE IN VIRGINIA

FIGURE A-3 
have maximum runway lengths under 3,000 feet and 86 percent have runways shorter than 4.000 feet (see Table IV-I), yet publicly owned airports possess $5 y$ far the better facilities, with $\mathbf{4 5}$ of the 49 offeririg runways both paved and lighted. Forty have maximum runway lengths of at least 3.000 feet and well over one-third of all publicly owned airports hr.ve runways in excess of 5,000 feet By contrast privately owned airports boast only 20 facilities out of a total of 151) with runways both paved and lighted. Most have runways less tnan 3,000 feet and only one airport has a maximum runway length over 5.000 feet Thus. the private airport in Virginia, characteristically, is of very limited capacity. while the publicly owned facility usually maıntaıns a much hıgher capability and can accommodate more numerous and more varied types of aircratt.

\section{THE VATS PLAN}

The Virginia Air Transportation System (VATS) Plan attempts to identify aırports that are expected to be needed in the Commonwealth of Virginia by 1990 .

Financed in part through an Airport System Planning Grant. pursuant to the Airport and Airway Development Act of 1970. the plannıng and research that resulted in the final proposal was the joint effort of a special consulting team and the Virgınıa Divisi on of Aeronautics. Because any arrport expecting federal funding must be included in the state plan as well as in the $\mathrm{Na}$ tıonal Aırport System Plan (NASP). the sıgnificance of the VATS PIan to each locality should not be underestimated. In additıon. as the planners were careful and insistent in pointing out. actualization of the plan depends almost entirely on local initiative and local justification. Federal and state support for each airport wili not be automatic.

Sevf.n goals of the VATS Plan (which was schedulto for put lic release shortly after this document went to press) have been proposed by the planners. These are to:

(1) Provide a system of air orts which effectiveiy complements a balanced total transportation system for the state.

(2) Provide an ali transportation system which is compatible with the recognized developmental policies of the state. regicin. and community
(3) Develop an air transportation system which is both adaptable and flexibie to changes in air transportation demand and to technological innovations in transportation service.

(4) Provide an air transportation system which will be technically, economirally, and politically feasibie for implementation.

(5) Provide a system of airports which will produce social and economic benefits to citizens of the Commonwealth.

(6) Develop an air transportatior. system which provides an effective means to safe. reliable, and convenient intra- and interstate travel.

(7) Minımize loss and inetficient use of natural resources, and avoid degradation of human and natural environments. ${ }^{10}$

The system concept that was selected essentially requires. first. the expansion of existing facilities and. second. the establishment of a limited number of additional facilities where present airports do not exist or cannot be expanced " noet expected demand. The fifteenyear $:$ : 'structured around three stages of developinent-1976, 1980, and 1990. Determinants ior establıshing the facılity requirements of each plan,ing district in the Commonwealth (there are 22 districts in all) are the forecasts of based aircraft and annual operatıons during each of these time frames. For example. In Plannıng District 3. Virginia Hıghlands Airport. with 30.000 annual operations and 24 baser arrcraft in 1974, is expected to have 111.774 annual operations and 39 based aircraft by $1990^{\circ}$ This will then require facility expansion from "Basic Utility" to "General Utility" and an expenditure of $\$ 1.43$ million iri Dublic funds ${ }^{12}$ Similarly. two other existing airports in the planning district are scheduled for exapnsion based upon these same criteria: however. the planners emphasize, and rightly so. that the development of the system depends not so much on forecas!s made in 1975 but ther on events as they actually unfold in the next fifteen years. In short. "the plan is iritended to identify a probable development and the development of options tnat shouid be kept open (emphasis added) ${ }^{\prime \prime}$ ' (Figure 4-4 shows the classification scheme used in the VATS Study to categorize the operatiorial capabilities and the navigatrona: ald (NAVAID) standards of Virgınıa airports )

Overall, the VATS Plan will involve 96 airports in 72 different count'es and will vary from large air carrier facilities to unpaved strips pro- 


\section{FIGURE 4-4 \\ CLASSIFICATION OF GENERAL AVIATION AIRPORTS IN VIRGINIA \\ Operational Roles}

BASIC UTILITY (BU): This type of development accommodates about 95 percent of the general aviation propeller fleet under 12.500 pounds. There is no special activity criterion required for this type of airport.

GENERAL UTILITY (GU): This type of airport accommodates substantially all general aviction propeller aircraft under 12,500 pounds. At least 500 annual itinerant operations of aircraft between 8,000-12,000 pounds are required.

BASIC TRANSPORT (BT): These airports accommodate all general aviation aircraft up to 60,000 pounds MGW, including propeller transports and business or executive jets. A BT airport must indicate at least 500 (existing or forecast) annual itinerant operations by aircraft between $12.500-60.000$ pounds MisW.

AIR CARRIER (AC): These airnorts generally accommodate transport category aircraft between 60.000 pounds and 175,000 pounds MGW. The minimum requirement for this type of airport is at least 10 existıng or forecast itınerant DEPARTURES per week (or 1,040 itinerant operations per year or season) by either the critical type aircraft or ONE of the appropi iate families of aircraft.

LOCAL SERVICE (LO): These airports have known or forecast development limitations or expansion constraints.

Limitations and constraints include:
(a) Environmertal
(b) Airspace
(c) Topography
(d) Proximity of sımilar services
(e) Land use incompatibility
(f) Ownership status
(g) Financial infeasibility
(h) Surrounding development strangulation
(i) Low activity projections

vidıng lımited service. Seventy-seven existing airports are included in the system, 26 of them now privatelv owned. In addition. 15 existing facilities which are presently cpen to the public. have been exc'uded from the system. Although no nev: air carrier airports are planned to supplement the 11 now serving the state, 19 new general aviation facilities will be constructed as shown in Table IV-II Eventually seven airports will be "deleted" or phased out as these newer ones replace them. so that by 1990,89 airports will comprise the entire system. Fifty-four of these airports already have paved and lighted

$$
1 \cdot 1 b i d
$$

iunways and an equal number also have runways in excess of 3.000 feet. The plan proposes that no public funding be expenaed for expansion or improvement of 33 airforts. Seven of these will be deleted entirely from the system. 20 downgraded, in classification, and six will remain unchanged. However, 44 existing airpoits will be funded witı must of them merely maıntc $\bar{c}^{\prime}$ ed at their present levels and the rest upgraded either one or two levels. As indic red in Table IV-II, the largest single car zgory of general avia"ion airports will be "Gene-al Utility." followed by "Local Service." " A map showing these airport locatic.s is shown in Figure 4-5. 


\section{FIGURE $4-4$ (continued) Navaid Standards}

BASIC UTILITY AIRPORT (BU)

VOR Apprcach - if possible from existing facilit; either on or off the arrport; otherwise, SDF* or NDB* if over 10,000 annual total operations.

SAVASI or VAPI*

GENERAL UTILITY AIRPORT (GU)

VOR with straight in approach-if possible from exıstıng facility, either on or off the airport; othervise:

TVOR if over 10,000 annual total operatıons

$\mathrm{SDF}^{*}$ or NDB* if under 10000 a'inual total operations.

VASI-2

REIL at instrument approach enc of runway.

BASIC TRANSPORT AIRPORT (BT)

ILSMALSR if 35.000 total operations or more (MLS after 1980)

VOR with straight in approach and inal approach $f_{1} x \rightarrow-1 f$ possible from existing facility: either on or off the airport: otherwise; TVOR

REIL at approach end of ru iway if no MALS, otherwise opposite end.

VASI-2

\section{GENERAL TRANSPORT AIRPC RT (GT)}

ILS/(S) SALS with RAIL i, 35,000 total operations or more (MLS after 1980)

Straight in VOR approach with FAF and (S) SALS with REIL if less than 35,000 total operations

REiL at opposite end of runway from ILS

VASI-2 at each end of runway (VASI-4 with large turbo-jet operatıons)

\section{SCHEDULED AIR CARRIER AIRPORT}

ILS/ALS (MLS after 1980)

Straight in VOR approach with FAF

REIL at opposite end of run'way from ALS

VASI-4 each end of runway

NOTE: Low cost. low power DME could be programmed with TVCR and ILSMLS facilities.

*Indicates NAVArDS not eligible for $100 \%$ Forde al funding.

Source: Prelimiriary Draft of the Plan for the Virginia Air Trarisportation System. Division of Aercriautics. Richmond. Virginia. December 1974.

\section{REGIONALISM AND AIR TRANSPORTATION}

That a regional approach to air transporta. tion has been adcpted in Virgınia should not be surprisıng. Hegional problem-solving has achieved wide recognition s 'ree at least 1965 when the Water Resources Planning Act addressed the problem of development on a regional basıs. ${ }^{\text {s }}$ Such acts as the Public Works and Economic Development Act (Title V) and

- Wengert Norman Political and Admiristratıve Realities of Regional Transportatior Planning in Joseph De Salvo it Persfoctives on Regional Transportation Pian ing Lexington Books. Toronto 1973 p 387 the Appalachian Regional Development Act have stimulateu bureaucrats and politicians to look at problems on a regional level insteaf cf using a local or state perspective in addi.'on. many treatments oí urban transportation have focused on the need for looking at problems of an entire urban region or metropolitan area. rather than those of a series of adjoinıng cit:es The move toward the formulation of a regional perspective for air transportation pol:cy has received additionai impetus from the following situations.

(1) The ànways are becomıng increasingly congested with traffic No longer do many per- 


\section{TABLE IV-\| CLASSIFICATION OF VATS AIRPORTS}

$\begin{array}{ccccc}\text { Calegories } & \begin{array}{c}1975 \\ \text { Existing }\end{array} & \text { Planned } & \text { To Be Built } & \begin{array}{r}1990 \\ \text { Total }\end{array} \\ \text { LO } & 12 & 25 & 0 & 25 \\ \text { BU } & 41 & 3 & 0 & 3 \\ \text { GU } & 7 & 18 & 16 & 34 \\ \text { BT } & 6 & 13 & 3 & 16 \\ \text { AC } & 11 & 11 & 0 & 11 \\ \text { TOTAL } & 77 & 70 & 19 & 89\end{array}$

Sources: Data compıled from FAA Bulletin No. 75-83. May 27, 1975: The Virgınia 1975-76 Airport Directory; 1974 A O P A Airport Directory; and Preliminary Craft of the Plan for the Virginia Air Transportation System. December 1974.

Sons acquainted with air transportation plannıng feel it sufficient for each airport to have '* own master plan and from there on to "let a hundred flowers bloom." ${ }^{\prime 16}$ Specifically, the regional airport an

. Is a representation of the aviation facilities required to meet the immediate a. - future air "-ansportation needs of the regionalimetropolitan area and is considered a sybsystem of the state airicort system It recommends the extent. type. nature. G. eral locatıon. estımated cost. and tıming of airport development required to meet the aviation needs of the reginal/metropolitan area and provides the framewo' for definitive and detailed individual airport master plannıng."

if General aviation aircraft often impede. or are impeded by, the activities of commercial carriers at hub airports leading to the demand for reliever aırports in the vicınity and the need for sorric type of plan encompassing more than just one airport: though possibly stopping sho.t of being a full statewide plan.

(3) Ideally there should be a transportation plannıng policy which attempts to coordinate air and ground transportation for maximum efficiency: however. by "regional transportation policy" vis-à-vis the airplane, one typicaliy

- Plan ing the State Airpor: System AC $; 5050500-3 A$ Department of Transportation Washirngton DC June 1972. $p$ if

is.d p is

- Wengert op $\mathrm{cr} . \mathrm{P} 387$

, 10, p 389 means a consideration of air policies for a region of a state without too much regard for the existence of alternative transportation modes or the desirability of their development

An additional impetus for dealing with a problem on a regional basis came from the Advisory Commission on Intergovernmental Relations which described in a series of studies the need for treating the metropolitan area in a more coordinated way. Regional cooperation was further encouraged by the Federal Intergovernmental Cooperation Act of 1968. designed to create a national policy of includ. ing for consideration local, regional. and state interests when adinınıstering federal aid programs tor local development. ${ }^{18}$ As Wengert has pointed out, one must add "where" to Harold Lasswell's definition of politics as "who gets what when and how" to stress the importance of the geographical allocation of benefits and costs. ${ }^{19}$

One of the most important decisions. If not the most important. made in any regional analysis is the decision as to where to locate the boundaries of the region. The boundary location decision may alter sinnificantly whatever decisions are to be made on a regional basis. Usually a variety of criteria are used for drawing boundaries. For example, the decision to form one planning district for aviaison development for the combined New River Valley, Fifth. Central, and West Piedmont planning districts of Virginıa was motivated by the perceived existence of close economic ties interrelated multimodal travel patterns, and simi- 


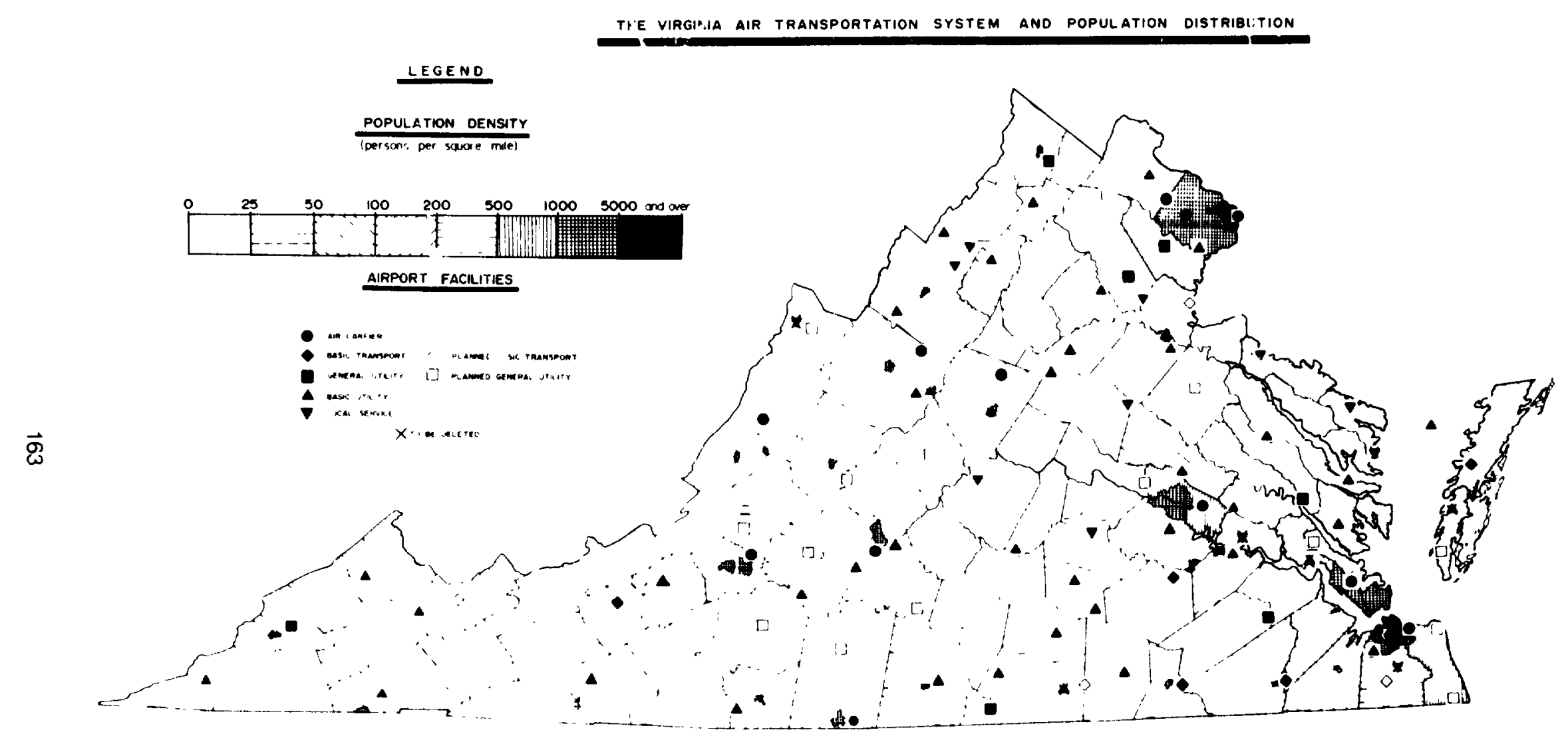

THE VIRGINIA AIR TRANSPORTATION SYSTEM AND POPULATION DISTRIBUTION FIGURE 4-5 
lar urban versus rural environments of these four regional areas. ${ }^{20}$ The National Resources Planning Board in 1935 concluded that there were no general criterıa for regıonal admınistrative boundaries, and that generalized regions could probably not be determıned "

Regionalısm often benefits some at the expense of others. An illustration of this can be seer, from a study of the proposal to expand the Roanoke Virgınia aırport versus a decision to construct a new regional facility to serve three communities. ıncluding Roanoke.

Theoretically, local, regional, and statewide planners each function with the welfare of the public as a paramount goal: however. what seems to be in the best interest of a local community may be seen as obstructive and counter-productive to the interests of a whole state or even of a substate region. The Roanoke airport controversy is illustrat!ve of one of the most difficult areas of conflict resolutıon. namely the problem which arises when a single regional airport is proposed to serve iwo or three urban centers. In order to understand the conflict which arose in the Roanoke area. one must examine in some detall that city's position related to its airport facilities

In March 1974 a steering committee from four Virginia planning districts (New River Valley. Fifth. Central, and West Piedmont) approved a study design for an air transportation system study of the area. The study was funded by a $\$ 100.000$ grant from state and federal agencies: its purpose was "to develop a realistic plan which will furnish information and guidance for the governing bodies of the counties. rities and towns to be concerned prir.cipally with the provision of adequate air transportation facilities..." "22 Even as this regional airport study commenced, some were concerned that its recommendation would be the construction of a regional airport. somethıng many Roanoke city officials opposed.

The cities of Lynchburg and Martinsville had expressed an interest in having a regionaı airport wrisch would serve those two cities plus Roanoke (see Figure 4-6) Roanoke officials felt that the sity of Roanoke could not benefit from such an airport since it would mean downgrad-

\footnotetext{
Blue Ricse Air Transporation System Study Program Narrative p 2

Ing Woodrum Airport. the Roanoke facility located just a few minutes away via Interstate 581 Roanoke clity officials pointed out that Woodrum contributed over $\$ 300.000$ annually to the city and this figure would stabilize or even decreas 3 if a regional airport were to attract passengers who would normally fly out of Woodrum. Figure 4-7 shows the facilities presently existıng at Woodrum

Meanwhile, the Director of the Virginia Division of Aeronautics. said he saw no obstacle preventing the four-district study by the summer of 1974 . He observed that an "unlımited" opportunity existed. The four-district area could have a plan that would look ahead 40-50 years and serve the 30 cities. counties. and towns represented in the four planning districts. ${ }^{23}$

Several months later the Virgınia Aır Transportation System planners who were charged with planning air transportation facilities for the whole state through 1990, made a preliminary recommendation that iuture transportation needs in the state could be met principally by expanding facilities to handle future growth. ${ }^{24}$

With respect to the Roanoke case, this meant that state planners favored the expansion of Woodrum to meet projected 1990 aviatıon needs Statewide planners were careful to say that this did not necessarily mean that a regional airport serving Roanoke. and other cities. was nut feasible. Specifically, for the four flanning districts which had decided to plan their air iransportation facilities together. the state plaıners had scheduled the construction of a reliever airport to be built in Botetourt County to handle excessive general aviation traffic The program manager for the VATS Study emphasized that the individual locality must approve any airport construction pians before they are carried out.

In October 1973. the City of Roanoke submitted a priority list of airport projects to the FAA included in this list was a proposed 900 foot extension of the east-west runway of Woodrum Land not currently part of the airport would have to be acquired and federal funds .vere sought for this purpose $A$ formal request for iunds ivas, not submitted pending the resuits of an engineering study and the completion of the environ.riental impact statement

Presently. under certain weather conditicns. jets with full loads are not able to leave Woodrum using its 5.900-foot runway Woodrum, is one of the faslest growing airports in the state In terms of takecffs and landings it 

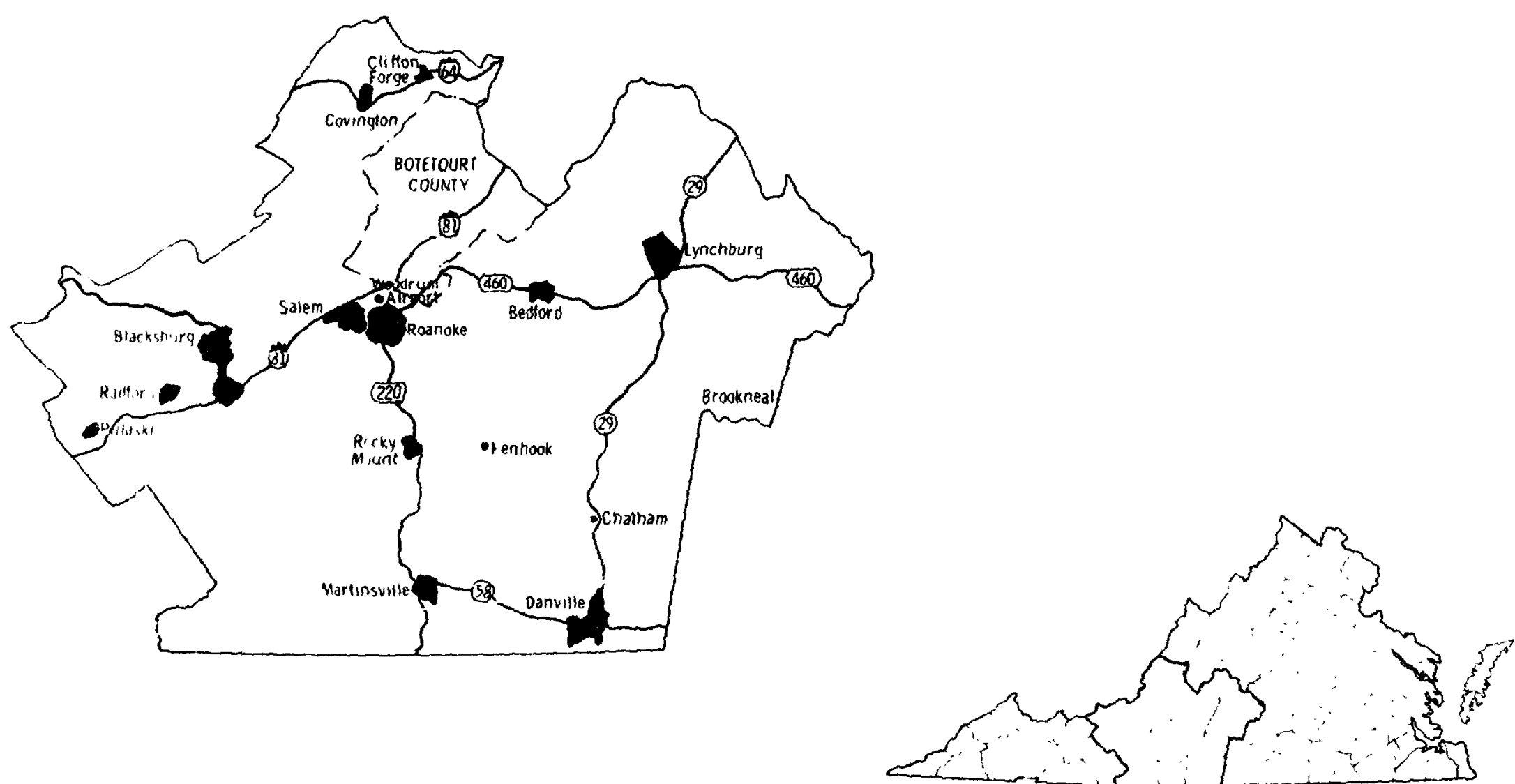

BLUE RIDGE AIR TRANSPORTATION SYSTEM FIGURE 4-6 


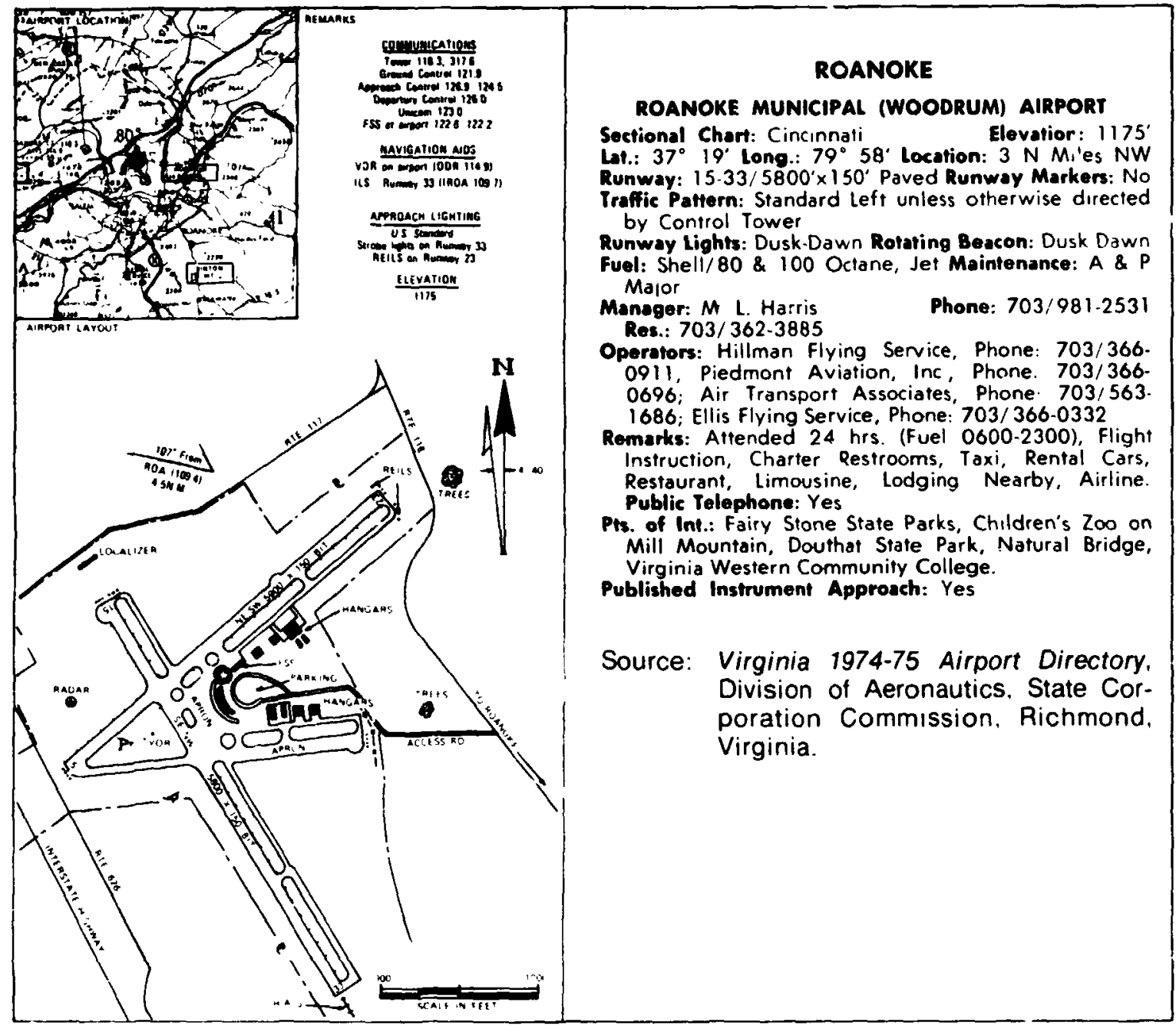

ROANOKE MUNICIPAL (WOODRUM) AIRPORT FIGURE 4-7

could support the additional air traffic which a lengthened east-west runway would provide. Increased air traffic at Woodrum would mean a crowding of the general aviation facilities there: however, the tentative state plan calls for a reliever airport at Botetount County to accommodate generai aviation traffic. leaving Woodrum (expanded) freer for the larger jet carriers

Early in 1975. FAA officials wrote to the City of Roanoke that isnds for extending the runway would not be forthcoming pending the results of the regional study which was consideri 3 buildirig a new regional dirport to serve the Roanoke-Lynchburg-Martinsville area Any major airport expansicns would have$$
\text { "Airport Runwa, Plan Called Premature Foanoke }
$$
Times January $8 \quad 1975$ to wait until the results of that regional study were completed. On the other hand. the Assistant Director of the Divisıon of Aeronautics said that he "couldn't endorse Virginia airport projects lyıng dormant until 1990. "25 $\mathrm{He}$ said the Virginia Air Transportation System Study. although not yet public. would not depart from its basic concept that airports in the 4th. 5 th. 11 th, and 12 th planning districts (which comprise the South Urban planning cistrict of Virginia) should expand existing acilifies rather than building new regional airpoi's.

In February 1975, the project manager for the Blue Ridge Air Transportation System Study of the four Virginıa plannıng districts saıd that there had been a misunderstanding and that the extension of the runway at Woodrum should not be held up pending the results oi the regional 
air transportation study. Echoing the arguments of Roanoke city officials, the argument was made that Woodrum is already a regional airport, the fastest growing one in the state. Roanoke city officials were urged to apply formally for federal funds to extend the Woodrum runway without delay. ${ }^{26}$

Additional reasons for withholding funds for acquisition of the land to allow a 900-foot extension of the east-west Woodrum runway (estimated to cost over $\$ 4$ million) included a general shortage of federal funds for eligible capital projects throughout the country, and a series of letters to the FAA from residents near tr. 3 proposed runway expansion site protesting that expansion.

Meanwhile, within the environs of Roanoke itsel!. npinion became divided as to whether or not the Woodrum runway extension was advisable In March 1375, the Roanoke County's supervisors went ol ecord opposing the extension on the grounds that (1) there had been citizen protests and (2) regional planners should have an opportunity to study the whole regional situation.

The chairman of Roanoke City's airport commission claimed that the county supervisors should have checked with the airport comimission before issuing a negative statement about the proposed runway extension. He also pointed out that if the city waited for the results of the regional planning study before extending the runway at Woodrum-a wait of approximately a year-the expansion would cost an extra $\$ 500,000$ due to rising construction costs and inflation: thus. It would be priced out of existence. Those who argued in favor of a new regional air facility maintained that such an airport would help attract more alr service to the Roanoke area as well as serve passengers from Lynchburg and Martinsville. Besides. expansion of Voodrum is somewhat limited in the iong run by geographic considerations since Roanoke is surrc.'nded by mountains. A new regional facility could be !ocated so as to insure continued expansion without interfering with already existıng residentıal or commercial land uses

Toward the end of May 1975, the controversy over a proposed regional air facility versus extending the runway at Woodrum intensified At a rr.eeting held to get citizen input on the goals and objectives of a regional air transpor-

\footnotetext{
Planner Sa; s Study Needn I Stall Runway Ald Roanoke Iimes February 21,975 241975
}

tation study, opponents of the Woodrum extension proposed a regional airport to be located in the Penhook section of Franklin County (see Figure 4-6) to be used by Roanoke, Lynchburg, and Martınsville. A county supervisor said that Woodrum was beginning to have a blighting effect on the surrounding community and he questioned the advisability of further expanding that facility. Further, the argument that a 900 -foot extension of the east-west runway would result in bringing in larger aircraft such as the Boeing 727 on a regular basis was questioned. ${ }^{27}$

A new regional airport might result in nonstop service to Florida and the West Coast. Such flights from the region's three airports which service commercial airlines currently have layovers in Washıngton, D.C., Chicago, or Atlanta.

The Blue Ridge Air Transportation System (the name the four planning cistricts chose) Study in June 1975 contınued a series of open meetings desıgned to elicit public opınion about the future of air transportation in the South Urban region of the state. Planners carefully listed two regional development alternatives, pointıng out that nothing definite had yet been decided about building a new regional airport versus expanding Woodrum

(1) Upgradıng existing facilities within physical limits, providing a "reliever" airport for Roanoke.

(2) Upgradıng existing facilitıes withın physical limits only.

(3) Consolidating services now prov!ded at Roanoke. Lynchburg, and Danville at a new regional aırport site.

(4) Developing a regional aırport at the existing Roanoke site.

(5) Developing a regional airpoit at the current Lynchburg site

In late June 1975. the Blue Ridge Air Transportation System planners scheduled public meetıngs in each of the four regional planning districts With the promise of evenhandedness and fairrisss. the Blue Ridge Air Transportation System planners will attempt to walk the narrow line between aeronautical requirements and political ramifications

The Woodrum airport controversy is not simpiy a case of the city planners versus the aroused local citizenry who uppose expansion Except for those persons living right around the airport. most people who are aware of the issue 
seem to wani the east-west runway extended. This will mean the Woodrum will continue to bring in revenue for the city and continue to be the central air tacility in the vicinity. Opposition to this course of action comes largely from residents in the immediate vicinity of the airport and persons living in the Lynchburg and Martinsville areas who favor the construction of a regional air facility, but for two different reasons. The people who live around Woodrum want the regional facility in the hopes that Wocdrum will not be expanded and they will not be disturbed by the noise and pollution of jet traffic. People who live in the other two cities favor a regional airport because it wculd offer better air service than they now have, in a fairly accessible place (presumably somewhere equidistant from the three cities) but far enough away from them that their own residences would not be affected. The forces favoring extension of Woodrum's runway cite the initial recommendations of the prelimir.ainy VATS study which favors expansion of existing facilities rather than the building of completely new regional airports. Those favoring a new regional airport approve of the stand taken by the Blue Ridge Air Transportation System planners who say that Roanoke and Woodrum will receive due consideration, but that there are 16 counties and many cities in the area being studied and all will get just consideration.

Attitudes about the expansion of Woodrum airport versus the building of a new regional facility are very much a function of one's geographical location. Moving major air transportation facilities away from Roanoke will please some and will disappoint others. One might be tempted to dismiss the problem with a superficial "let some objective person living in Richmond or Washington, D.C. decide what is best for the region." On the other hand, what of the doctrine of local control? Should the persons living in a region have the right to decide about the future of air transportation in their area? If so, should it be majority rule in tha: area? Such considerations are known for their complexity. and in the end. some type of compromise must be made. In this particular case a lack of federal funds for brand new airport construction may :orce a decision in favor of expanding Woodrum and possibly building a reliever airport in Botetourt County

\section{SELECTED CASE STUDIES Rationale}

Communities and their airports, like people, have individual personalities reflecting the historical, geographical, cultural, and socioeconomic characteristics of the area. 4 study of general aviation's role in community development must address itself to this fact and to the dissimilarity that often exists between communities with comparable general aviation facilities and between airports serving comparable communities. The study of unique characteristics of each community is a necessary supplement to statistical analyses which are based on state and national date.

For this reason a determination was made that several communities with general aviation services should be studied in depth. The communities and/or aviation facilities selected for study and the general criteria used for selection are given in Table IV-III. An attempt was made to obtain a broad cross-section of community types and associated general aviation facılities.

Richmond is a large urban community with a publicly owned air carrier/general aviation airport providıng most of the general aviation services in the area. The interaction between air carrier and general aviation along with recent financial failures of tNo general aviation operators on the airport provided good factors for a study dealıng with airport financing and FBOs.

Williamsburg presently has a privately owned airport which serves the small urban community whose primary activities are tourism and the College of William and Mary. The Peninsula Airport Commission has sponsored a study of the need for additional general aviation facilities to serve the Williamsburg area and act as a reliever for the Patrick Henry Airport in Newport News.

Some question exists concerning the merits of developing a new airport as compared to expanding the existing private ield. The study dealt with the question as well as with is: related question of the development limitations of privately owned airports.

Virginia Beach represents a fast growing tourist and recreational community. State planners have selected the community for two new proposed airports to he developtd during the riext 15 years. Since the community does not have a general aviation aurport at the present time. the community served as an interesting case for the study of the initial phases of planning.

Chesapeake is a suburban/rural com. munity presently served by two general aviation private airports and one air carrier facility. A new airport is proposed by Chesapeake City Flanners to provide expanded general aviation services as an inducement for new industry. 


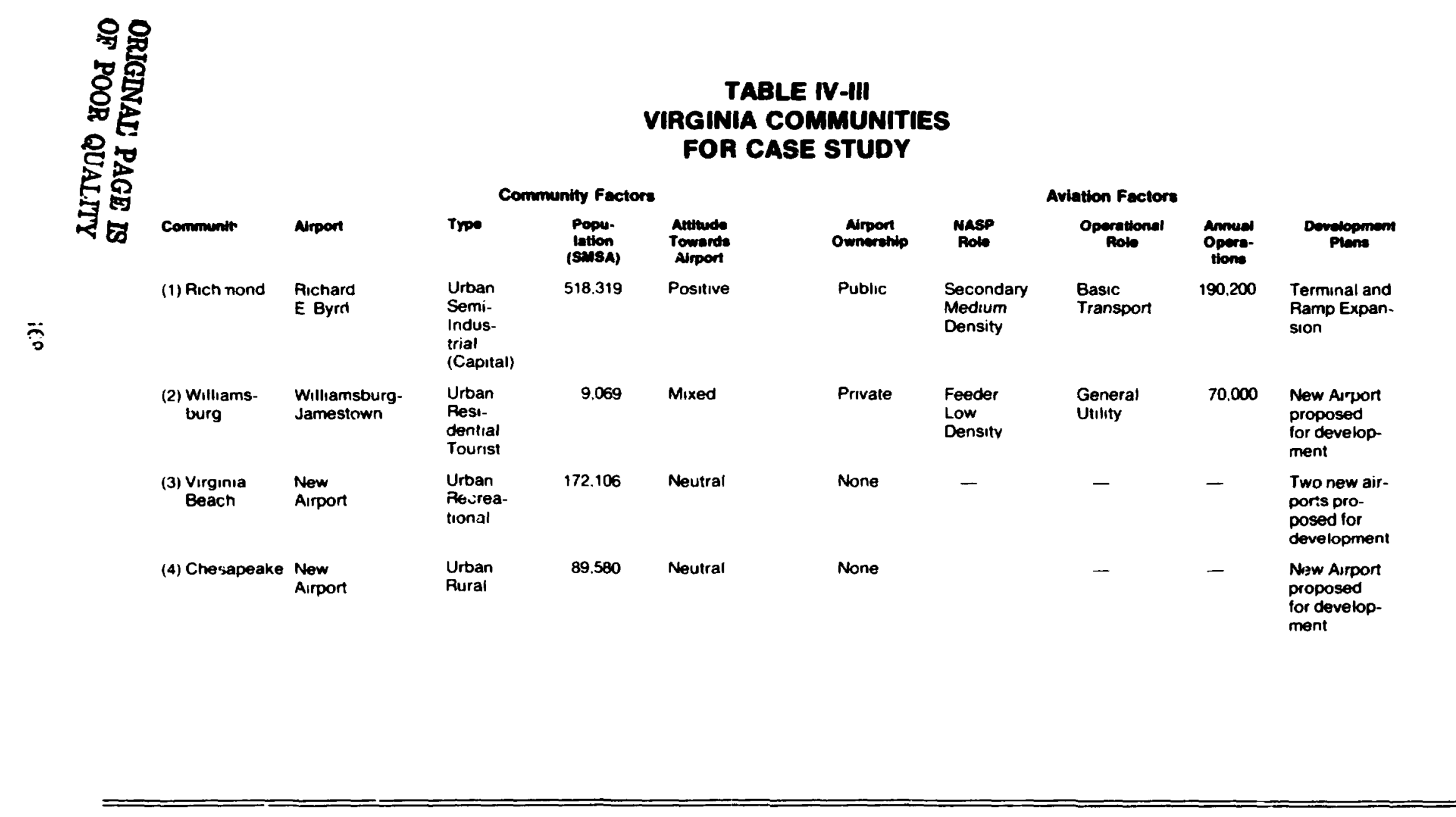


Unlike other communities studied in this section. Chesapeake involved few major issues or planning problems but did highlight the fact that some facilities can be planned and developed routinely.

\section{Introduction}

\section{Richmond}

Richard E. Byrd International Airport was selected as a case study for two reasons:

(1) Its community of interest spans many political boundaries. Yet, the airport losses were being borne by its sponsor alone. The pending solution niay be of interest to other airport communities with the same problem.

(2) Although Richmond has sufficient activity to support financially healthy fixed based operators (FBOs), two have failed recently while others have indicated a less than desirable financial status.

Both of the above probiems are discussed in the following sections.

\section{Community Characteristics}

Byrd airport serves Richınond, the capital of Virginia: Henrico County. in which it is tocated: Chesterfield County. which has its own general aviation airport; and, other communities composing the Richmond Standard Me:ropolitan Statistical Area. The populations of these areas are:28

\begin{tabular}{lcc} 
Pichmond & Population & $\begin{array}{c}\text { \% of } \\
\text { SMSA }\end{array}$ \\
Henrico County & 249.621 & 48 \\
Chesterfield County & 154.364 & 30 \\
Other & 76.855 & 15 \\
Richmond (SMSA) & 37479 & 7 \\
\hline
\end{tabular}

The City of Richmond rias a mixed industrial base. which includes some of the largest corporations in the chemical. metal. tobacco. paper, and other manufacturing industries. The city has experienced the common outflow of affluent residents from the central city to the suburbs. and the resulting financial difficulties resulting from this exodus The delınquent tax rate has risen. welfare roles have swollen. and the city population has decreased

Presently ine black population comprises about one-halt of the total population in spite of the annexation of a portion of the predominately white Chesterfield County.

\footnotetext{
- 1970 Cersus

- National Airpoll System Pian Untred States Department of Transportation Washington DC Iupda.ed 1974$$
\text { " FAA Air Traflic Activity Calendar 1974 US Dept if }
$$

Transportation Washinoton DC 1975
}

Blacks in the community do not see the arrport to be of either a direct or indirect benefit to them. They disapprove of the burden it creates on the city budget, although the airport has never become a major political issue. The black leaders in the community would be satısfied if the losses issulting from airport sponsorship were borne equitably by all of the communities benefiting from the airport. They estimate that only $\mathbf{4 0}$ Dercent of the airport use originates in the City of Richmond.

\section{Airport History and Development}

Byrd Field was constructed in 1928 by the City of Richmond for use as a general aviation airport (Figure 4-8). During World War II it was used by the Army, deve!oped extensively, and returned to the city in 1947. Over the years it has developed into a basic transport (BT) category airport served by three certıficated carriers (formerly four) and one commuter air!ıne. The airport enplanes approximately 503.000 air carrier passengers per year. ${ }^{29}$ Military air carrier and general aviation contributed to the 178.525 operations per year, of which the air carriers accounted for 25.174: the scheduled air taxis for 10.568 and general aviation for $98.543 .^{30}$

Nearby air carrier airports are Dulles and Washington National, one hundred miles to the north; Roanoke. 100 miles to the southwest: Charlottesville. 60 miles to the west: Patrick Henry and Norfolk about 55 and 80 miles to the southeast. respectively.

Byrd is surrounded by general aviation airports of varying sophistication: Chesterfield County Airport 13 miles southwest; Hiriover County Municipal Airport 20 miles nutiti. Ne' Kent County about 10 miles east; and. Hopewell 17 miles southeast. All of these have some impac s on the general aviatıon market in the Rich. mond SMSA.

The isty of Richmond. as previously stated. sponsors and ope $7^{\text {tas }}$ the airport. It is therefore responsible for iunding improvement or expansion programs at the airport it has recently undertaken such a program. with an esilmated value of $\$ 10$ million dollars. $\$ 7$ million of which had been invested by 1971 These Improvements included the reconstruction of the terminal and an increase in the number of gates from four to five Three more cyates could be added at an additional cosi of approximately $\$ 7$ million This purtion of the improvement program. along with $\$ 2.7$ million in other improvements, has been postpored for fiscal reasons The ramp was also expanded extensively to accommodate additional aırcraft parking posıtıons. 


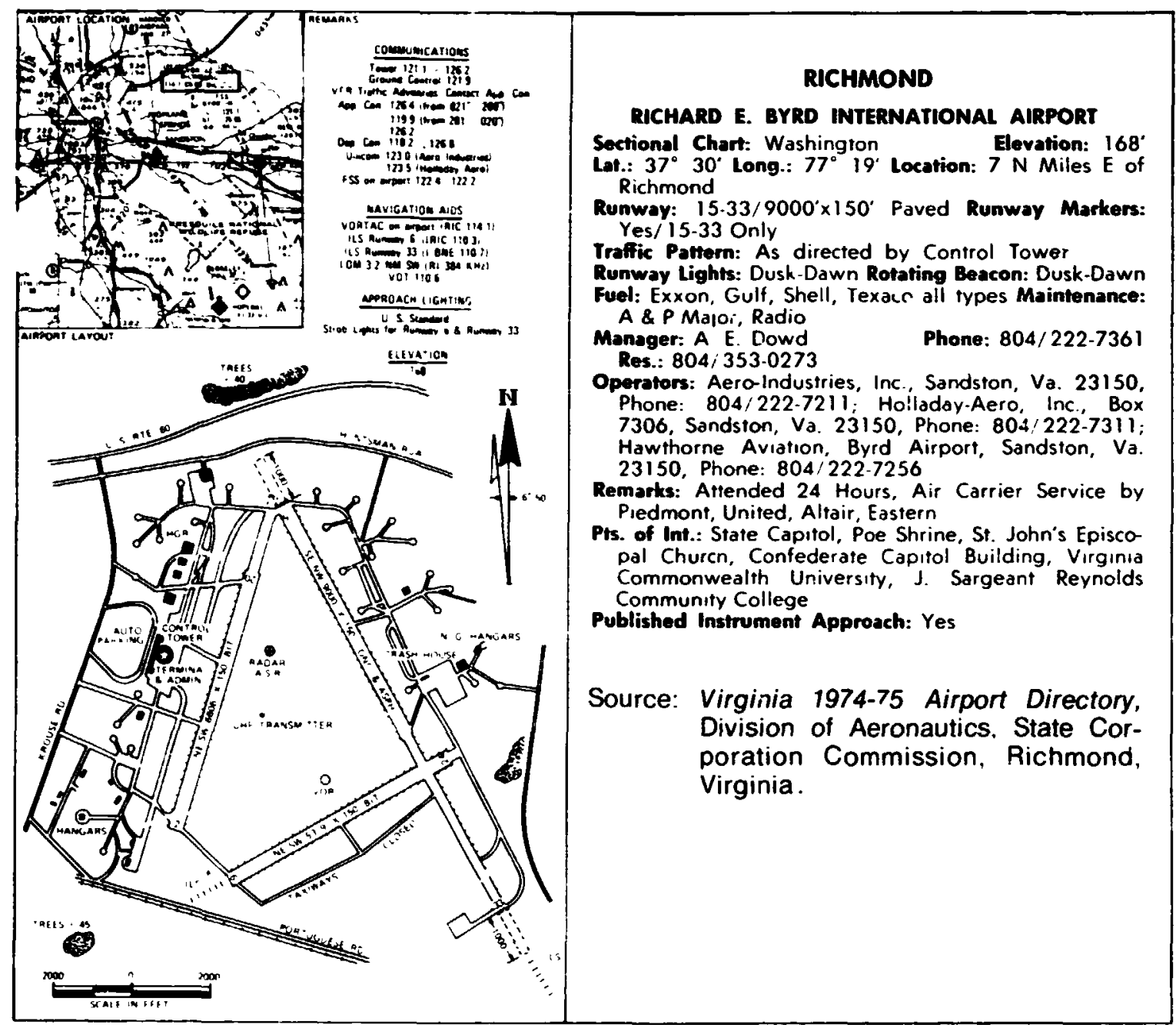

RICHARD E. BYRD INTERNATIONAL AIRPORT FIGURE $4-8$

Airport officials were somewhat optimıstic about the extent of the need for expansion and thus provided capacity in excess of the projected airline requirements. Prior to the expansion, the airport charged landing fees of $10.5 \$$ per thousand pounds of landed weight and was breaking even. At that time Byrd was served by Eastern, Piedmont, United, and National Airlines in the order of their number of enplaned passengers. During the expansion program, National applied for and was given consent by the CAB to withdraw service, leaving only three carriers to support the expansion program. Altair, a commuter airline, introduced service to Richmond in 1968.

The expansion program left an annual revenue which was about $\$ 350,000-\$ 500,000$

"Revenue Expenditure Projections." Richard E Byrd Airport." June 25, 1974 (City Staff Study) short of covering operating expenses, in addition to the new debt service. This resulted in a drain on the city taxes and the city looked to the airlines to cover the deficit through an increase in landing fees. The city demanded an additional $36 \$$ per 1,000 pounds in landing fees, and the carriers offered only 134. After a somewhat bitter struggle, a compromise of $18 ₫$ was agreed to. Reduced airline schedules and a decline in the general economy, however, have still left the city with an annual deficit in the airport budget.

The sources of airport revenue break down approximately as follows: ${ }^{31}$

Direct (in ticket charge)

Boarding fees (security) 


$\begin{array}{lrr}\text { Landing fees } & 184 & \\ \text { Terminal rental } & 167 & \\ & 645 & 44.2 \\ \text { Indirect } & & \\ \text { Ground transportation } & 176 & \\ \text { Restaurant } & 69 & \\ \text { Miscellaneous concessions } & 82 & \\ \text { Parkıng.i. } & 372 & \\ & 701 & 48.0 \\ \text { All Otr rrs } & & \\ \text { Utilities } & 9 & \\ \text { Ground rentals } & 51 & \\ \text { Building and } & & \\ \text { hangar rentals } & 53 & 7.8 \\ & 113 & \\ & 1,459 & 100.0\end{array}$

The airport has the capacity to provide the community with automobile parking. terminal, gates, and ramp facilities which are adequate to meet air carrier passenger demands for some years to come. Available aviation services include scheduled airline service connecting to most parts of the world; commuter airline service; air cargo service; express cargo service; air charter in fixed-wing or helicopter; aircraft maintenance including major epairs and alteration; aircraft interior design, installatior. and upholstering; aircraft painting; parts sales for most aircraft; avion:cs sales and repairs; fueling and line or ramp service; aircraft parking and storage: hangar and office rental; aircraft sales; and, a unique large commercial operator service devotec exclusively to flying live eels to the Netherlands to satisfy a somewhat unique culinary demand.

Gerieral aviation sperations account for 100,000 to 120,000 of the 178.000 total operations at Byrd Field. The mix of this traffic includes 68 percent itinerant and 32 percent locally based.

To serve approximately 130 based aircraft, the airport has provided faciliteis to house three full-service FBCs. ${ }^{32}$ These facilities have usually been constructed by the FBOs, on land leased from the airport. The FBO owns the facility until the expiration of the lease, at which time ownership reverts to the airport. Of the three current operations, one has been in business for over 30 years and the second for over 16 years. The third has been in business for over 13 years and is presently involved in bankruptcy proceedings. A portion of his business, in the form of a flight school and a charter operation seems to have survived the bankruptcy and contınues to exist as a fourth FBO. Only one of the existing FBOs is a full-

"A full service FBO is one providing all of the first 8 services listed in the General Operations Sect'on of Chapter I service FBO. The other two are complementary; i.e., they do not compete in the services they provide. For all practical purposes then, there are two full-service FBOs.

The FBO leases generally provide for an annual ground rental of $10 \$$ to $12 \downarrow$ per square foot for the use of the land on which their own buildings are constructed; a similar but higher rate for ramp area; a varying rate for building rental or buildings owned by the airport; a fuel flow charge of $1.5 \$$ per gallon on fuel used or sold; a.tu, a requirement that the FBO maintain the premises (including ramp) in satisfactory condition at his own cost and expense. Other terms are similar to typical leases at other comparable airports.

\section{Airport Role and Support}

Although the airport has had some disputes with the airlines, and has experienced some mild opposition to expenditures from councilmen, it appears to enjoy a rather comfortable position in the cornmunity.

Some of the largest corporations in the country, with based aircraft in the Richmond SMSA, are: Allied Chemical, DuPont, Phillip Morris, Universal Leaf Tobacco, Ethyl, Reynolds Metal, Robins Chemical, Thalheimers, and Chesapeake Co. It has been assumed by the city council members and the city administrators that these industries benefit from the existence of the airport and that the city benefits from the existence of the industries. Neither group felt the airport was dispensable, and all favored reasonable development if the costs were equitably distributed.

All city council members interviewed showed enthusiasm for future industrial or commercial development for Richmond. They all recognized, however, that with 75 percent of its land already developed, the city itself has li:tle or no land left for such development. Thus, they are willing to accept regional expansion as a substitute for city expansion. Although the benefits to the city may not be direct, these benefits are nevertheless sufficient to warrant the support of city council members for the concept of regional expansion.

Presently the airport itself makes the following contribution to the community payroll:

\begin{tabular}{|c|c|c|}
\hline & $\begin{array}{l}\text { Number of } \\
\text { Employees }\end{array}$ & $\begin{array}{l}\text { Payroll } \\
(000)\end{array}$ \\
\hline $\begin{array}{l}\text { Alrport Department } \\
\text { Employed on Airport } \\
\text { (Full Time) }\end{array}$ & $\begin{array}{r}78 \\
1.400\end{array}$ & $\begin{array}{l}\$ 704 \\
11,000\end{array}$ \\
\hline Military (Part Time) & 900 & $\begin{array}{r}\text { (not available) } \\
\$ 11,704\end{array}$ \\
\hline
\end{tabular}


Applying the generally accepted 2.7 multiplier discussed in Chapter III, th : total impact on the community could approach $\$ 31.5$ million.

\section{Commiseion or Authority}

The only significant community dispute involving the airport involves several surrounding communities benefiting from its existence. Henrico County, which provides an estimated 30 to $\mathbf{3 5}$ percent of the enplaned passengers using the airport, has imposed ad-valorum taxes (personal property, sales, etc.) on both property and transactions at the airport. Depending on the estimator, it is reported that these taxes range from $\$ 150,000$ to $\$ 250,000$ annually. Henrico County dces not make this information availazle to the public. The city taxpayers insist that they are mostly in the lower income brackets and that they derive little use from the airport, while those in the surrounding counties who are gaining the most in convenienre, are not sharing the fiscai burden. They believe that the burden should be shared by the creation of an authority or commission composed of all users and that the debt service should be spread equitably among those users.

This loss of revenue from the airport by a political jurisdiction which does not contribute to the support of the debt service, encouraged Richmond to seek lega: means for capturing this taxing authority by extra-territorial powers.

On three occasions the airport staff has examined the license plates on autos in the longand short-term parking lots to determine the mix of autos from surrounding counties. Although this may not be an exact indicator of the origins of enplaned passengers, it appears to have sufficient correlation to make it worthy of examination. The results were as follows:

Location

Richmond

Henrico (Co.)

Chesterfield (Co)

Other

$\begin{array}{ccc}1800 & 1971 & 1974 \\ \% & \% & \% \\ 30 & 17 & 30 \\ 29 & 27 & 32 \\ 11 & 23 & 10 \\ 30 & 33 & 28 \\ 100 & 100 & 100\end{array}$

Although the state legislature did not take affirmative action on approving the extra-territorial power of Richmond, as requested, it did imply unofficially that unless the dispute was settled locally between the city and the county, it would intervene and settle it for them. The legislature also passed legislation enabling the creation of a joint commission.

Henrico County and Goochland County have indicated a willingness to join in the for- mation of such a commission to operate the airport and to share in some as yet undetermined pro-rating of the losses.

Goochland County, adjacent to Henrico on the northwest. has no airport and by joining such a commission could gain some say in the future of the airport with a presumably low snare of the deficits.

Henrico, on the other hand, is already enjoying the benefits of the airport without sharing the debt and is further collecting revenue from its operation without renewing future obligations. Its motives in agreeing to the commission may be somewhat more subtle. Opinions of those interviewed included the following:

(1) Realization that if they did not agree, the legislature would prooably revoke their taxing authority on the airport and extend it tc Richmond by extra-territorial powers. The loss of tax, and the possible threat of granting the extra-territorial powers to the city in recognition of the regional character of the airport, could be extended to other areas and might eventually lead to annexation on a "community of interest" basis.

(2) Recognition of the fact that the increase in traffic and the resulting increase in revenues at the airport within the next few years should result in a break-even operation and the county could therefore "buy in" with a gradually diminishing exposure for future obligation.

(3) Recognition by the courts of the benefits derived by the county from the airport and its consequent responsibility for contributing to its support.

Chesterfielc County apparently has rejected participation in such a commission. It has been suggested that this attitude may have developed from previous attempts on the part of the city to take land and population from Chesterfield by annexation, without their concurrence.

Chesterfield County has established its own general aviation airport and acquired sufficient buffer zone land in the immediate airport vicinity to promote industrial development. It is possible, therelore, that Chesterfield rould operate the airport $a^{*} \ldots$ ioss in competitio, 1 with Richmond, and derive its benefit from development of the surrounding industrial land and the subsequent land or building rentals which could conceivably support the airport in the future.

The other major problem confronting the airport concerns the FBOs and the future level 
of general aviation services at Byrd Field.

The number of based aircraft, annual operations and, the relatively large number of corpcrate jets would seem to support several FBOs. Recent developments, however, have yielded the conclusion that three or more operators will dilute the existing business such that the financial health of all operators will be in jeopardy. As previously mentioned, one firm which has been in operation for 13 years is presently in bankruptcy. This failure was preceded by that of another firm which had been in busir.ess for a shorter period. In addition to these two failures, one of the other operators is prepared to sell if business conditions fail to improve.

Key airport officials and existing operators are of the copinion that Richmond can support no more than two FBOs. The airport has taken the position that at this time it is not seeking a tenant for the facilities to be vacated by the failing FBO. The FAA, however, informed the airport staff that since they had accepted federal funds for airport development, they were obligated to entertain all applications and to permit anyone who is reasonably responsible to locate on the airport regardless of the total business available. This obligation stems from the "open to public" clause of the Airport and Airway Development Act of 1970.

Airport officials are presently preparıng compliance standards to assure a level of activity and investment on the part of the new FBO that will not discriminate against the present FBOs who have extensive investments in the airport.

All of the FBOs agreed that fuel sales. line services, and tenant facility leases (hangar rental and offices) were the most profitable activities and required the least investment. Following in order of profitability are avionics repair, aircraft repair, and flight school and charter. It seems obvious that minimum standards are necessary to prevent a third operator from coming in with a minimal investment and skımming the top off the fuel and line service revenue.

The outlook for Byrd Field, compared to other airports today, seems to be satısfactory. It appears that air carrier traffic will continue to grow at this field. An economic recovery will help such growth. Many persuns interviewed believed that increases in schedules by the arrlines would be in order-but all seemed to

"Virginia Air Transportation System Study. Final Draft. Rıchmond. Virginia July 1975 recognize the need to generate additional passengers to warrant compliance with that request. Presumably, the resulting increase in revenue will offset the amortization deficit within the next ten years. The establishment of a commission will eventually spread the burden of the deficit over a more equitable base.

The future of healthy FBO operations seems to depend heavily on preventing the forced introduction of unnecessary competition. This may be accomplished by the development of minim,um FBO standards by the airport staff.

The shift to commission or authority control is consistent with the trend toward recognizing the regional nature of small-to-medium hub airports. It could shift the temporary tax burden to a broader base. thereby dispelling the only severe political opposition to the continued healthy growth of Byrd Field.

\section{Williamsburg}

\section{Introduction}

There appears to be some interest in determining whether present airport facilities in the northern peninsula area of Tidewater should be expanded, or whether a new airport should be built.

Some argue that present airport facilities in the area can expand to meet predicted aviation needs and that new facilities or even significantly expanded facilities are, or will be. needed in the next 20 years. The final draft of the Virginia Air Transportation System Plan has projected that a new general utility airport for the northern peninsula area is teasible. ${ }^{33}$ Also the Peninsula Airport Commission has contracted for the preparation of a master plan studying the feasibility of a new airport.

At present there exists a privately owned general aviation airport in Williamsburg (Figure 4-9). One justification which is being cited for the constructinn of new airport facilities is the possible lack of premanency of that airport. since private airports can be sold at any time at the discretion of their owners (although no evidence of possible sale exists at the present tıme).

Three basic questions will be dzalt with in connection with air transportation facilities on the peninsula: (1) What is the community attitude toward the need for new general aviation facilities? (2) What factors lead to the various conclusions about need? (3) What are the possible ways of meeting such a need? 


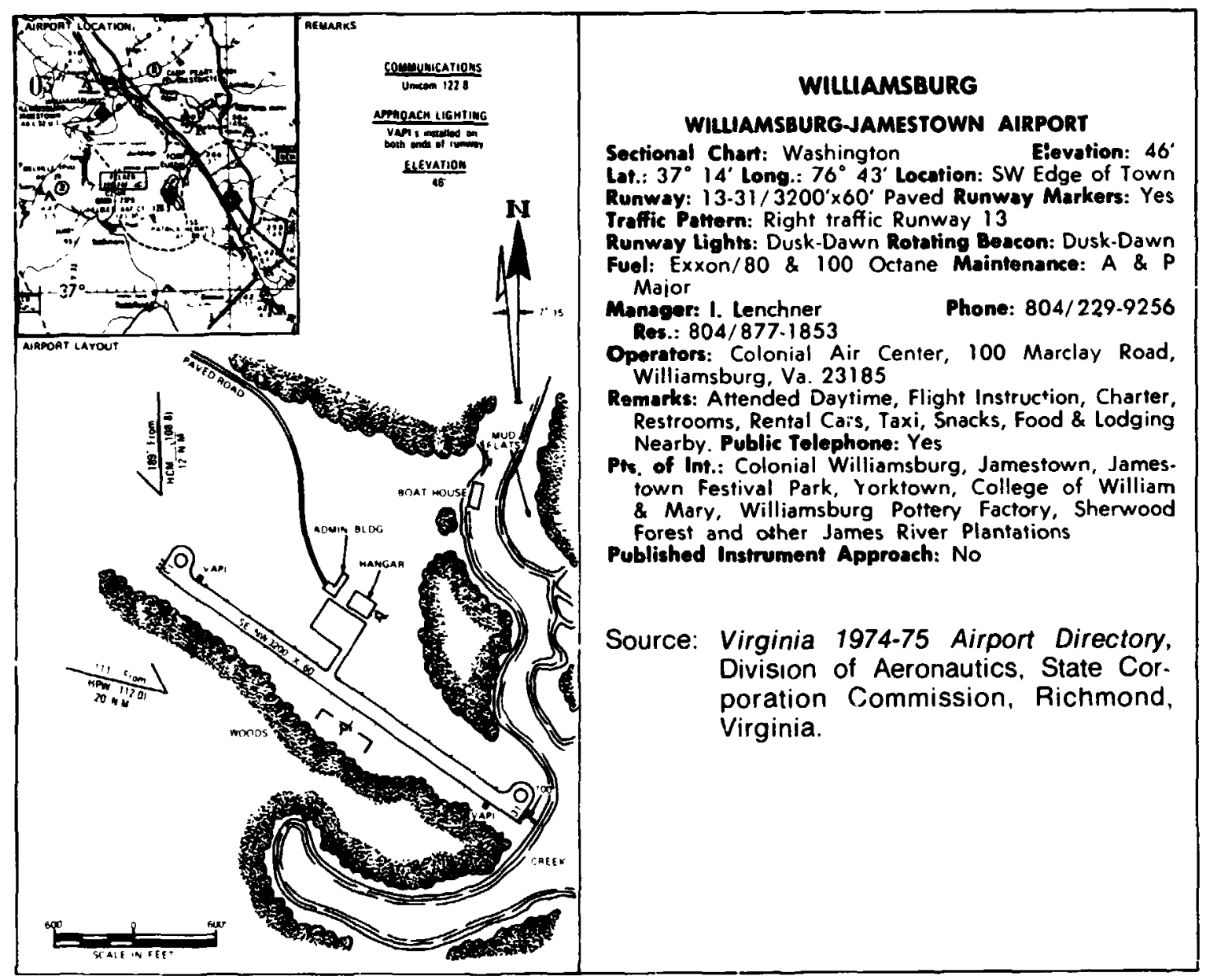

WILLIAMSBURG-JAMESTOWN AIRPORT

FIGURE 4-9

\section{Community Characteristics}

Williamsburg is located in the upper Virginia peninsula. Table IV-IV summarizes the socio-economic characteristics of York and James City Counties, and the City of Williamsburg. Since land is scarce in Williamsburg, the highest rates of growth have occurred in York and James City Counties. Due to the tourist industry, the localities hope to establish orderly growth patterns to support continued tourist appeal. James City County has recently articulated its goals in a document which, stated that these goals include the promotion of "sound, long-term, and balanced economic development." and the adoption of "necessary controls so as to limit the population of James City County to no more than

"James City County Community Goals and Objectives

"Tie Comprehensive Plan. Williamsburg Virginia 1968

* Willaamsturg Council is Opposed to Name Site of New Airport. Newport News Daily Press, June 9. 1967
75,000 persons by the year $2000 .{ }^{.34}$ In the area of transportation facilities. the document encouraged the developmient of a regional plan, with emphasis on the buffering of transportation facilities from adjacent neighborhoods. There was no specific menticn of an airport.

Williamsburq is currently revising its 5omprehensive Plan, which was develcped in 1968. In a brief section of that report. Williamsburg's inactive Central Airport was mentioned as a good location for a new airport, with both the size of the site and the lengths of the runways noted as adequate. ${ }^{35}$ At the time this plan was published. the Willaamsburg-Jamestown Airport was being developed in the midst of a heated controversy. ${ }^{36}$ Both of these airports are shown in Figure 4-10.

Seeking greater Industrialization. York County recognizes the importance of a general aviation facility in the upper peninsula. A revised comprehensive land-use plan for the 


\section{TABLE IV-IV DEMOGRAPHIC CHARACTERISTICS OF THE UPPER PENINSULA}

\begin{tabular}{lccc}
\multicolumn{1}{c}{ Item } & York County & James City County & Williamsburg \\
Population & 33,203 & 17,853 & 9,069 \\
Density (No./Sq. Mi.) & 257.4 & 117.5 & $1,813.8$ \\
Median age & 24.5 & 27.6 & 23.1 \\
Median family income & 9,902 & 8,835 & 10.266 \\
$\%$ with income \$15.000+ & 21.7 & 15.9 & 28.0 \\
Median School year finished & 12.1 & 11.4 & 13.3 \\
Persons/Household & 3.58 & 3.38 & 2.47 \\
$\%$ in Manufacturing & 17.5 & 9.5 & 4.4 \\
$\%$ in White Collar & 49.5 & 44.5 & 61.6 \\
$\%$ Government Workers & 38.7 & 33.7 & 42.8 \\
Total Employed & 10,277 & 6,083 & 3,676 \\
\% Rural Farmland & 5.6 & 2.6 & -
\end{tabular}

Source: 1970 U.S. Census Data.

county is currently under consideration. In the plan, some parts of the upper county which are close to Williamsburg are to be opened to light industry. ${ }^{37}$ The proximity of a general aviation facility has been noted as a factor in industrial development.

The major industry in the area is tourism. with Colonial Williamsturg. Busch Gardens, Jamestown Festival Pa.k, Jamestown Island, and the Yorktown Battlefield as points of interest. Other principal employers include the College of William and Mary, and Eastern State Hospital. The following major manufacturing establishments are located within the area served by the airport: Dow Badische (synthetic fibers); Anheuser-Busch, Inc. (malt liquors); American Oil Company, Inc. (petroleum refinery); Jeffco Manufacturing Company (aluminum cans): Synthe-Tex Corporation (carpet yarns); and. the seafood industries in York County (packaged seafoods).

\section{History and Development of Williamsburg Aviation Facilities}

In February 1967, the Central Airport owned by the College of William and Mary, and serving the Williamsburg area was closed to the public. This left the upper peninsula without general aviation facilities at a time when the tourist business in the area was growing. Shortly thereafter, the construction of a new pri-

"Mary B Edwards. "York Commission Votes Land Use Plan Approval. "Newport News Daily Fress," September 10, 1970

" "Airport Using City Name May Disturb Willamsburg." Newport News T:mes Herald, September 10, 1970 vate airport on a fifty-acre site on College Creek was proposed. The new general aviation airport was to relieve Patrick Henry International Airport in Newport News by attracting general aviation planes to the upper peninsula. The airport would eventually handle as many as 250 general aviation planes and construction of a hangar large enough to accommodate 10 light planes was planned. ${ }^{36}$

Almost immediately there was opposition to the proposed airport. coming mainly from residents of the Birchwood Park and Marlboro subdivisions, and from the parents of youngsters attending Rawis Byrd Elementary School. These groups opposed the site on the grounds that planes would pass too close to Byrd Elementary School and to a city water tower in the vicinity, thus creating safety and noise problems. The airport, however, was to be designed so that planes taking off would be no closer than three-fourths of a mile from the elementary school.

A hearing was held by the State Corporation Commission (SCC) in Richmond on July 3. 1967 to act on the application for the new airport. Neither the James City County Planning Commission nor the Board of Supervisors could have stopped construction of the facility since the county had no applicable zoning ordinance.

Federal and state agencies were not convinced that the proposed site was unsafe or that it would result in high noise levels in the surrounding communities, especially it the flight 


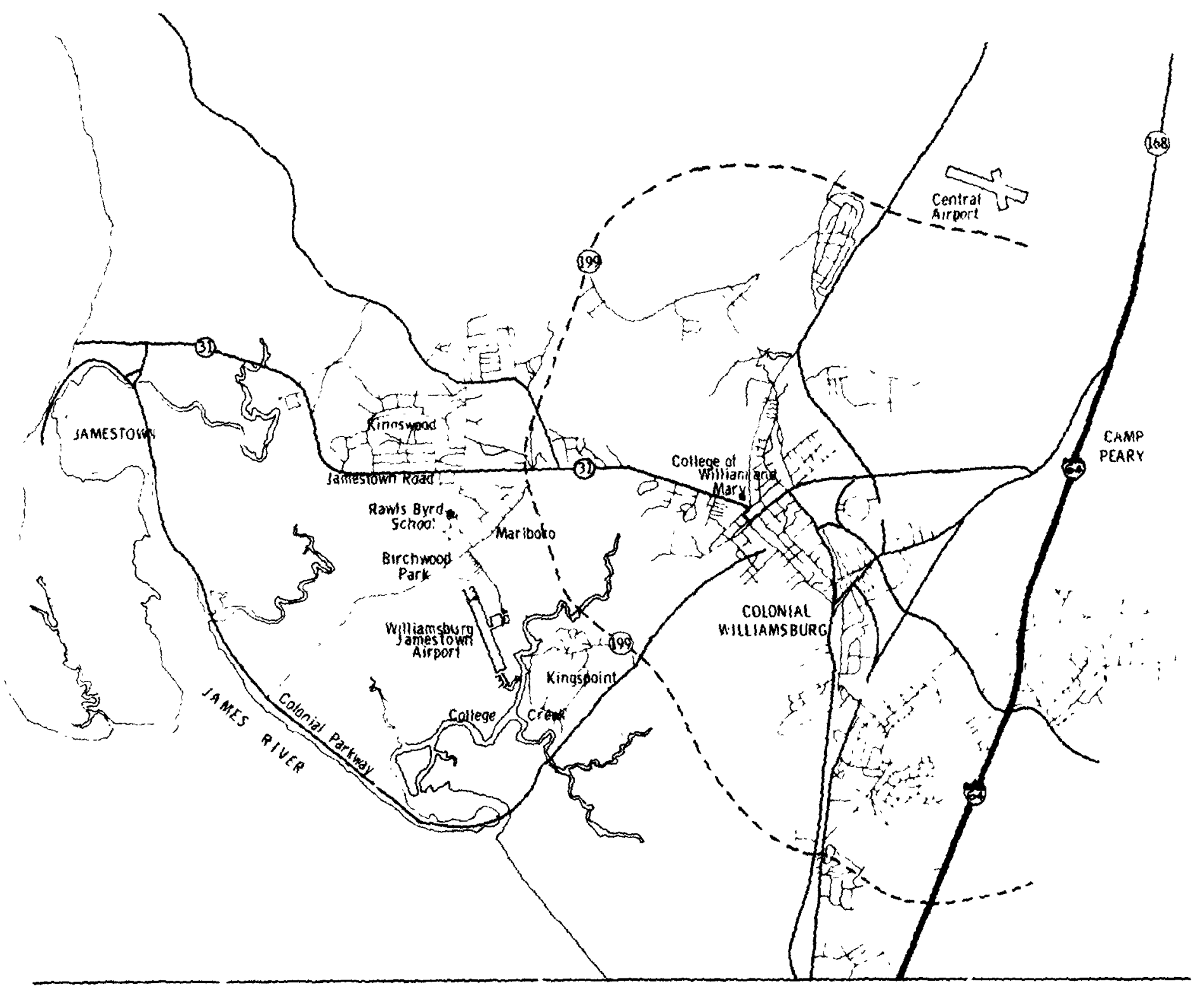

THE WILLIAMSBURG AREA

FIGURE 4-10 
patterns for the airport kept most of the air traffic on the James River (south) side of the airport. The SCC approved the airport and the decision was appealed immediately to the State Supreme Court of Appeals (Virginia Supreme Court). Opponents of the proposed airport argued that the SCC had applied wrong standards to the evidence presented at an October 1967 hearing when permission was originally granted for construction. They asked that the case be sent back to the SCC for a second hearing, at which time additional evidence could be presented. In June 1969 the State Supreme Court of Appeals affirmed an action by the SCC licensing the Williamsburg-Jamestown Airport. The cou'rt's ruling confirmed the Commission's decision which found that the proposed arport "met or exceeded all safety criteria of the Virginia code and commission rules and regulations." 39

In September 1970, the airport was dedicated officially with the words "this county is the thırd fastest growing county in the state and this airport is one good example of the type of progress James City County has made in the past 15 years. "40

Williamsburg-Jamestown Airport was open for only a short time when many concerned indiviciuals and interes ${ }^{+}$yroups which had originally opposed it began to complain that airplanes were flying too low over residential areas. A representative of the State Division of Aeronautics visited the airport to investigate these complaints. and to interview residents of the nearby Birchwood subdivision. Later, a General Aviation Operations Inspector for the Federal Aviation Administration was also consulted and said that he did not "consider the airport hazardous if pilots would adhere to the traffic pattern. Of course there are all kinds of pilots just as there are all kinds of automobile drivers. But I think the directions being taken are good-putting all the traffic on the southern side of the field."

Despite the findings of the State Division of

" "Jamestown Airport Licensing Affirmed. Newport News Daily Press. July 17, 1969

- "Williamsburg-Jamestown Airport OHicially Dedicated Newpon News Dally Press. September 211970

- Opponents of Airport Fall to Sugc 'st Improvements. Newpor News Daily Press, August 30. 1970

-2 Supervisors to Seek Irivestigation of Air Traffic Pattern Violations. Newport News Daily Press, May 1, 1971

" Ibia

" Ibra

is "No Violations Found in Probe of Area Airpon. Newpor News Daily Press. May 261971 30. 197
Aeronautics and the FAA inspector, complaints continued. The James City County Board of Supervisors eventually agreed to look into the matter of reported violations of the air traffic pattern at the airport. A list of 10 planes which reportedly violated the traffic pattern and fiew too low over residential districts was compiled by the residents of the area in April of 1971. The identification numbers of several airplanes had been copied by Birchwood residents and were reported to the County Board of Supervisors. Though he had spoken favorably about the airport at its dedicatior, a community leader who has previously led the appeal of the SCC decision to license the airport, has continued his leadership of those dissatisfied with the airport. He looked into the role of the State in enforcing the aviation laws of Virginia and concluded that "for all practical purposes, there are no laws." "42 "If the State Division of Aeronautics is to enforce the law," he said. "then they should come down here and enforce them. I'm not saying it is the airport manager's fault-it's the pilots fault and we need to get someone down here to enforce the traffic pattern." 43 The Division of Aeronautics did investigate complaints a year earlier but no action was taken on the matter.

In telegrams to the SCC, The State Division of Aeronautics, and the FAA, a candidate for the house of delegates in the Democratic primary asked that he be informed as to who has regulatory authority. "Many citizens in the Birchwood. Kingswood and Kingspoint reas are desperately concerned about the failure of aircratt to follow prescribed traffic patterns. thereby endangering school children," he said in his telegram. ${ }^{44}$ A new investigation did not turn up any pilot-violators. The FAA Inspector told the chairman of the James City County Board of Supervisors that, after careful in. vestigation, no violators were found but that there was a plan :o educate pilots further on the required traffic patterns. He suggested that a sign ir dicating the traffic pattern be "posted in a more conspicuous place." ${ }^{45}$

Objections to the Williamsburg-Jamestown Airport from nearby residents have subsided in recent years. Some of the airport's neighbors still refer to it as a nuisance, but its existence has been accepted.

Various air shows have been held at the Williamsburg-Jamestown Airport. These shows provide community entertainment, and generate revenue for local businessmen from the money spent by air show participants. Over 5.000 persons attended the first air show in 1971 and were offered a variety of skysuard and cround entertainment. ${ }^{46}$ The Flying Dentist As- 
sociation flew in 100 planes to the airport for their annual meeting in Williamsburg. ${ }^{\circ 7}$ Thirty experimental and antique airplanes participated in the second annual Colonial "Fly-In," drawing a crowd of 200 persons in $1973 .^{.8}$

\section{Existing Aviation Facilities}

The Virginia Peninsula is presently served by three airports in addition to Williamsburg. Jamestown. ${ }^{49}$ These are:

(1) Patrick Henry Airport at Newport News, 15 miles southeast $(25$ minutes by Interstate 64). This is the air carrier airport serving the peninsula area. It presently has adequate facilities for general aviation:

(2) Gloucester Airoort at Gloucester, 15 miles northeast (not $c$. ) the peninsula or readily accessible from Williamsburg due to its location across the York River). This is a general aviation airport with facilities comparable to Williamsburg-Jamestown airport; and, arid.

(3) West Point Municipal Airport at West Point, 19 miles north. This is a general aviation airport with better runway facilities (three 5000-foot runways) but is not attended and is too distant to serve the peninsula area effectively.

The Williamsburg-Jamestown Airport is currently classified in the NASP as a "feeder," low-density facility, serving up to the general utility class of aircraft. ${ }^{\text {so }}$ The final draft document of the VATS Plan projects that the airport will play a local service role during the next 15 . year period. ${ }^{51}$ The reason for this classification. reflecting a reduced operational role, is the proposed addition of a second airport to serve the area. The proposal will be discussed in a subsequent section of this case study.

The Williamsburg-Jamestown Airport is

- PICture caption in The Virginia Gazette, June 23. 1972

- Ed Offley. 'Thirty Home-Built Planes Swoop into 'Fly-In'. The Virginia Gazelty. November 91973

- Virginia Airport Directory. Division of Aeronautics. State Corporation Commissiori. Richmond. Virginia. 1974

so 1972 National Airport System Plan. Federal Aviation Administration, 1972 Computer update February, 19:5

s. Virginia Air Transportation System Plan. Final Draft. op

"Airport Master Record, Willamsburg. Federal Aviation Administration August 1972

"Magnefic direction 130 (Southeast) and 310 (Northwest)

s* Foreign Exchange provides for no-toll calls trom airpon

"Personal inspection of facilities on July 15 and 19. 1975 equipped to serve general aviation with the following facilities: ${ }^{52}$

(1) One runway: Asphalt. 3,200 feet $x$ 60 feet, 13-31. ${ }^{\text {s3 }}$

(2) Runway lights: Low intensity, operating during hours of darkness.

(3) Rotating Beacon, operating during hours of darkness.

(4) Wind Indicator: Tetrahedron and segmented circle (to show right hand trattic for Runway 13).

(5) L'nicom: Radio advisory service is offered on frequency 122.8 .

(6) Weather Information: FAA Flight Service Station, Newport News through telephone foreign ex. change. ${ }^{54}$

(7) Surface access and parking: Twolane paved access road and 7,000 square yards of auto parking.

The general aviation services and associated activity on the airport can be grouped in three categories as indicated by the firms offering the services.

The Williamsburg-Jamestown Airport, Inc., provides airport services (fuel sales, aircraft tiedown, and routine services) for visiting pilots. Two full-time employees and the following facilities are used for these services: ${ }^{\text {s5 }}$

(1) Aircraft parking and tie-down: Capacity for 60 aircraft with space for approximately 12 on paved ramp area.

(2) Aircraft Fuel Sales: Two 8,000gallon tanks provide storage capacity for 80 and 100 octane fuel through contract with the Exxon Oil Corporation.

(3) Customer lounge/office area: located in a portion of a 20-foot by 60 foot structure that was a hunting lodge.

Colonial Aviation, Inc. IEuses a portion of the facilities and operates a flight school and aircraft rental facility. The firn: is an FAA approved agency for the training of pilots with Private. Commercial, and Flight Instructor airplane ratings. The school also holds approval by the Veterans Administration for the training of veterans. Approximaiely 40 students are in training at any given time and receive their instruction in three. single-engine Cessna aircraft which are also available for rental. The 
owner-manager is also an FAA Pilot Examiner for certification flight checks and is assisted by three flight instructors. ${ }^{56}$

The third operation is Colonial Aviation Services which operates as a maintenance facility through leasing a portion of the 950square-yard hangar. The firm provides major and minor repairs to aircraft, utilizing two mechanics in addition to the owner. ${ }^{57}$

In the area of aircraft activity, the Williamsburg-Jamestown Airport falls into the low density category, based on an estimated 70,000 operations of which 40,000 are due to the 23 locally based aircraft and 30,000 are due to itinerant aircraft. ${ }^{\text {se }}$ The airport is currently operating at 36 percent of its capacity. ${ }^{59}$

An evaluation of the Williamsburg-Jarnestown Airport can be made by an assessment of the facility in comparison to others serving comparable communities. The following evaluation (based on the scheme presented in Appendix F) has been computed for the airport: $: 0$

$\begin{array}{lrr}\text { Air Transportation } & \text { Rating } & \text { Possible } \\ \text { Services } & 1 & 5 \\ \text { Operational Capability } & 2 & 5 \\ \text { Aircraft Capacity } & 1 & 5 \\ \text { General Avic tion Services } & 4 & 4 \\ \text { Ground Transportation } & 3 & 3 \\ \quad \text { Total } & 11 & 22\end{array}$

Based upon the above evaluation the airport is strong in the area of general aviation services and ground transportation. The low rating in air transportation services is due to the lack of air-taxi services. The lack of an instrument approach and the short runway limit the operational and aircraft capacity ratings of the airport.

An assessment of the facility by selected tenants and users is summarized as follows: ${ }^{: 1}$

(1) The existing airport should be developed in preference to constructing a new airport, even if such development would require public

- Interview with Mr Tom Johnson and Mr Carl MacConnell of Williamsburg-Jamestown Airport. July 16. 1975

$s$

2 ibud

so Arrport Master Record. Williamsburg. op cit

* Virginia Air Transportation System Study. Final Draft, Technical Supplement. Vol II. Part 2. June 1975, p 51

- See Appendix $F$ for code of airport evaluation criteria 1975

- Interviews ol selected tenants and users on Julv 14 and 16 ownership. It was generally agreeo that the area could not support two airports.

(2) The airfort is fulfilling a definite aeronautical requirement for the area.

(3) The runways and approaches are adequate for existing based aircraft but runway extension would provide expanded capacity for larger business-type aircraft.

(4) A taxiway to serve runway 13-31 is needed along with additional paved parking and tie-down facilities.

(5) T-hangars are needed for aircraft storage.

(6) Maintenance of the airpo + lighting system could be improved.

(7) The existing services offered are rated as "good" to "excellent."

(8) The cost of service is generally considered fair. One owner stated tiiat he saves about $\$ 400$ per year in personal property taxes and tiedown charges by being based at Williamsburg-Jamestown rather than at Patrick Henry Airport.

Wiiliamsburg-Jamestown Airport, Inc. has invested $\$ 500,000$ in time, equipment, and land. When the airport was under construction, the state provided $\$ 75,000$ in matciling funds for runway construction. This sum is amortized over a 20-year period, during which the airport must stay open or pay back the remaining portion of the loan.

Extensive improvements to the airport have been considered and the state has offered to match funds witn the airport owner for the development of additional aircraft parking facilities. The need for this expansion is determined from the expected increase in traffic due to the Bicentennial activities in 1976. As of this date, no development plans have been finalized.

\section{Support}

In 1974, interest was initiated in the development of a new facility with the argument that Patrick Henry was crowded and that Williamsburg-Jamestown had reacned capacity. The Peninsula Airport Commission subsequently obtained funds for a study of the feasibility of the new genera! aviation airport. Two-thirds of the cost of the study came from 
the FAA Planning Grants Program, with the rest coming from state and local matching funds. ${ }^{62}$

Possible support for the construction of a new general aviation facility in the peninsula also came from the final dratt of the VATS plan which projected a new airport for the northern peninsula eventually to become a reliever for Patrick Henry's overflow of general aviation traffic. "By 1990 however, it will take both Patrick Henry and its reliever, WilliamsburgJamestown, to accommodate the almost 600,000 annual GA operations projected for Planning District 21. By developing Williamsburg-Jamestown as a high capacity reliever, it would be possible to accommodate this GA demand and the more than 33,000 annual air carrier operations projected for 1990." "63 Designation by the VATS plan as a "reliever" is important since it implies a high priority status not accorded all proposed new airports.

The bases on which the new Williamsburg Airport has been designated as a reliever for Patrick Henry by the VATS plan are that: (1) Norfolk Regional Airport cannot expand its air carrier facilities much beyond their existing level; (2) Patrick Henry, the only other air carrier airport in the region and currently operating at 50 percent capacity, will thus be forced to expand its air carrier operation; and. (3) Patrick Henry is also an international airport and its international operations are expected to grow. Thus the VATS plan draws the preliminary conclusion that by 1990 Patrick Henry will need a reliever facility. ${ }^{64}$

\section{Opposition}

In addition to variations in the estimates of the numbers of aircraft which will be based in the peninsula in future years, another item where differences in opinion exist relates to the adequacy of existing aviation facilities. While some describe existing facilities as inadequate for accommodating projections of future need. the FBOs at both the Williamsburg-Jamestown and Patrick Henry Airports say that they have ample room for expansion in the future. and that a new airport is not really necessary. (It should be observed that the Williamsburg-

"The cost to a locality of having a master plan drawn up is relatively small in this case the $12.1,2$ percent not tijnded by the tederal and state governments was prorated among the cities of Willamsburg Newport News and Hampton, and York and James City counties according to population

" Virginia Air Transportation System Study, Final Draft, Voi II. Part 3 July 1975. Appendix F. D 10

" 1 bud

"Johnson and MacConneil interview July 16. 1975 at Wiltrasmburg-Jamestown Airport
Jamestown operators admitted that a new general utility airport in the northern part of the peninsula possibly would attract owners of small aircraft to base their planes there and would seriously hurt business at the present Williamsburg airport. $)^{65}$

If taxiways were constructed and tie-down areas were expanded as planned, the Williamsburg-Jamestown Airport would be capable of accommodating at least 30 additional airplanes. The general aviation facilities at Patrick Henry Airport are also capable of handling a large increase in both traffic and based aircraft. With a 3,200-foot runway, the Williamsburg-Jamestown Airport cannot accommodatc business jets, while Patrick Henry can. When Route 199 is opened to traffic, the driving time between Patrick Henry and Williamsburg will be reduced to about 25 minutes, thus making it more convenient for the residents of the northern peninsula to use Patrick Henry.

As for the objection that the WilliamsburgJamestown Airport could be sold at any time because it is a private facility, some say this is not too likely to happen. They point to the acceptance of a state matching grant by that airport for improvements, as a sign of permanence. The matching grant is conditional upon the airport staying in operation for 20 years or paying back all or part of the matching funds.

There is another objection to the construction of a new facility in the northern peninsula based on the argument that general aviation serves only a limited portion of the community. Admittedly, there are community-wide services provided by general aviation-such as air rescue or pest control-but a large portior of general aviation is concerned either with business flying or pleasure flying and as such, it should rank far behind other services which are more widely used by the community. Persons who argue in this way object to the allocation of public resources for the construction of new general aviation airports, which serve a selected few. This type of objection is not unique to the peninsula area. Persons of this school of thought argue that airport development should be funded mainly by the local com. munity desıring it, and that a community should not have such developments if it cannot support them financially.

\section{Future Developments}

Although the firsi phase of the Master Plan is still under study, speculation is already under way, as to where the new airpo:t will be located. Several possible locations are being discussed 
informally. One is the cirfield at Camp Peary in the upper peninsula. While the use of an, existing facility seems to be preferable to building a new airport in some cases, a joint-use agreement between the public and the military at Camp Paary might not be a good idea. Camp Peary, for example, is in the process of becoming a central storage area for munitions, which may not be compatible with an increase in airport activity.

Another possible site for a new general utility airport in the peninsula is the old abandoned Cen'ral Airport which is located on land owned by ine College of William and Mary. In the mid-1960's the airport manager died and the College decided to close the airport and use the land for building married students' housing; however, the housing was never built and the airport site remains in disrepair. After Central was closed, a motel was built some distance from the end of one of the major runways. but if it should interiere with flight patterns, that runway could be extended in the opposite direction so that required altitudes could be reached well before planes were over the motel.

There are two other possibulities for the location of a general utility airport on the peninsula. One is to buy and expand the present Willianısburg-Jamestown Airport which would Involve paying the fair market price and being certain that the runway would be expandable to the length needed to handle business jet aircraft. College Creek limits expansion to the nurth, and a southerr extension would mean that air traffic would be taking off much closer to the Rawls Byrd Elementary School-site of the earlier civic protests and public concern about noise and safety. Also land to the west of the present runway is not possessed by the airport owners and there night be some difficulty in buying additional land for the purpose of buliding a second iunway

A final possibility would be the purchase of farm land well to the north of Williamsburg and building a new airport there. This might result in an advarse environmental impact on the area. In any event, the question of site selection is not an immediate one. since the Peninsula Airport Commission in its monthly meeting of July 17, 1975 returned Phase I of the Master Plan to the consultants for further work. ${ }^{66}$

The future of air transportation on the

". "Satellite Airport Dratt is Rejected," Newport News Daily Pross, July 181975

- Commonwtalth of Virginia Division of Aeronautics. Divi. sion of State Planning and Community Affairs. Preliminary Drath of the Plan for the Virginia Air Transportation System, December 1974 peninsula depends to a great extent on whose projections prove to be most accurate in the coming 10 to 20 years. When Patrick Henry and Williamsburg-Jamestown begin to find that more persons want to base aircraft at those fields than there is room; when T-hangars are built and there are long waiting lists for their use; and, when the number of operations at these airports begins to reach the maximum safety limit, then the need for expanded or new airport facilities will become apparent to an increasingly larger segment of the interested public. The problem is how to forecast the timing and extent of this aviation growth accur stely.

\section{Introduction}

\section{Virginia Beach}

The City of Virginia Beach provides a unique opportunity to study the relationship of general aviation to community development for the following reasons: (1) the current status of general aviation in the city; (2) the recummendations of the Virginia Division of Aeronautics for aviation facilities in the area; (3) the demographic, geographic, and socio-economic characteristics ol the comm Inity; and, (4) the status of aviation-relicted planning in the city

(1) Current Status. The City of Virginia Beach has no active general aviation facility 10cated within its jurisdiction; therefore, the level of general aviation activity from a "within-thecity" perspective is nonexistent. City residents who require general aviation services must use the facilities located in adjacent communities.

The city does have a great deal of aviation activity located within its bounclaries as a result of the existence of Naval Air 'itation (NAS) Oceana. the Navy's largest master jet base. Because of a possible new gereral aviation airport and the existence : a inilitary airport, an opportunity was provided :u study the needs of groups with potentia!!y conflicting uses of the area's air space.

(2) Preliminary VATS PIan Recommendations. The Preliminary Draft of the Plan for The Virginia Air Transportation System ${ }^{67}$ recommended the development of two airports in Virginia Beach, one in the northern section (Fort Story) and one in the southern section (New Creeds), as shown in Figure 4-11. Apparently. state level aviation planners see a requirement for additional aviation facilities to serve the citizens of Virginia Beach.

(3) Community Characteristics. Demographically, the city's population stands about 220,000 and has been increasing at a very rapid rate, which will probably lead it to be 


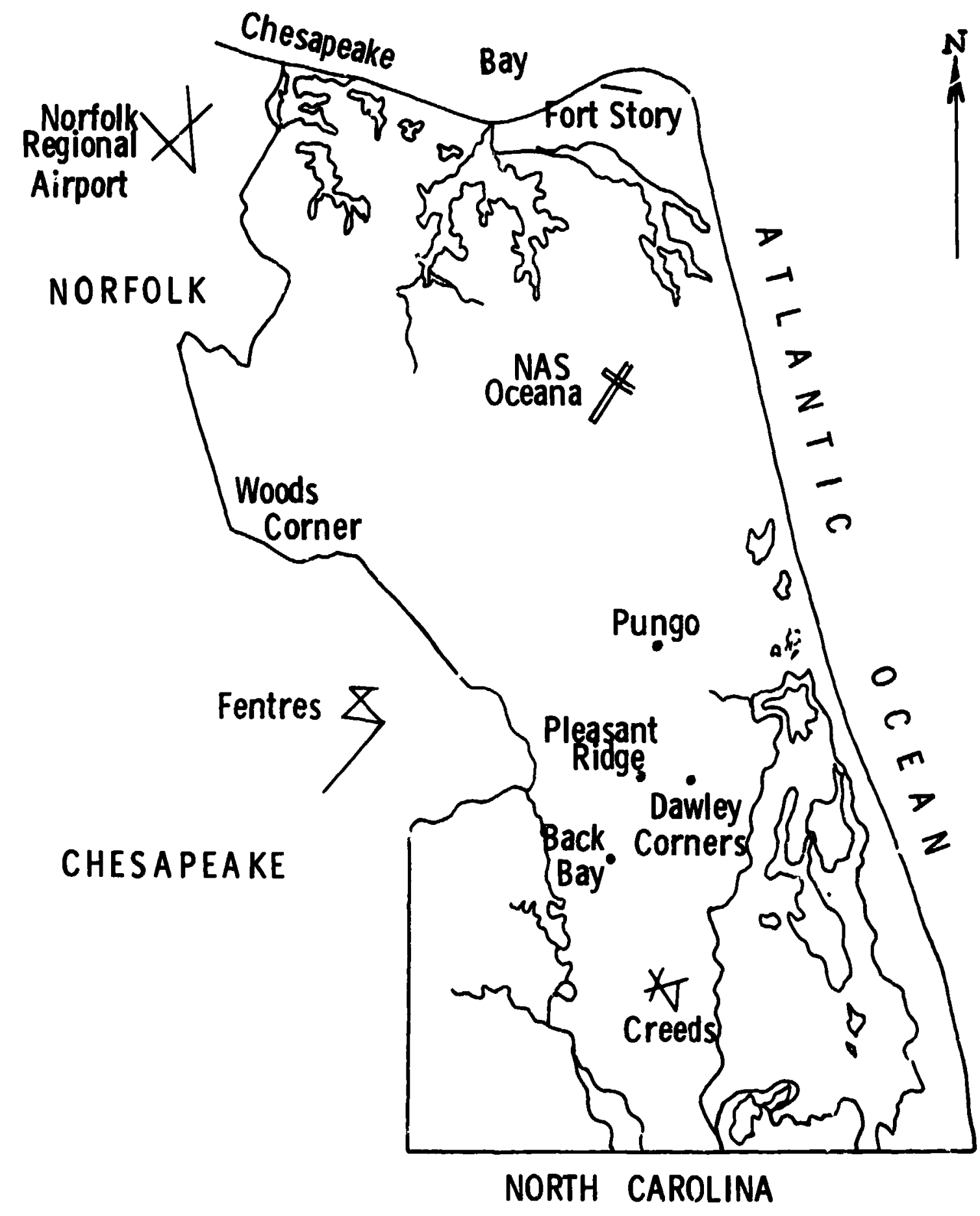


Virginia's largest city in the very near future. In socic-economic terms, the vity has a predominantly middle-to-upper class population. Geographically, the city has a and aiea of 259 square miles. ${ }^{68}$ Thus, by many of the usual indicators, the city is expected to be able to generate and support a high leve! of general aviation activity.

(4) Related Planning. Virginia Beach already has an abandoned city airport which. when considered with past airport site planning studies, macie ii apparent that decision-makers within the city have attempted to deal with the problem of existing and potential general aviation airport sites.

\section{Community Characteristics}

Virginia Beach. which calls itself the world's largest resort city, is located $i_{i}$ the southeastern corner of Virginia and is part of the Norfolk-Portsmouth-Chesapeake SMSA. It is 90 miles southeast of Richmond and 200 miles south of Washington. D.C. It is a city of 259 square miles bordering 51 square miles of water and is located at an elevation of six feet above se \& level. ${ }^{69}$ Virginia Beach was iricorporated as a town in 1906 and in 1952 it tecame a city. In 1963. the city merged with Princess Anne County and was greatly enlarged.

The total population of Virgin:a Beach has been growing rapidly. It has grown from a population of 42.000 in 1950 to 172.000 in 1970 . The 1974 city population stood at 219,285 , according to studies conducted by the Virginia Beach Planning Department. The population of the city is distriouted unevenly throughout its seven boroughs and ranges in size from 70,639 in the Lynnhaven Borough to 871 in the Blackwater Borough. The most rapid population growth is concentrated in the city's larger boroughs although population movement and development is aiso expected to increase in the southern part of the city which is relatively unpopulated and undeveloped.

An anal;'sis of the city's labor market, pre-

st These datd are based on information contained in a community data publication prepared by the V'irginia Beach Department of Economic Development January 1975 and on a Development in. formation Package picpared by the City of Virginia Beach Department of Planning on April 24. 1975

$$
s 16, d
$$

- Internal memo from George Tinnes. Assistant to the City Menager of Virginia Beach to City Manager Robert Scott entitled. - Chronological report of the city s general aviation airport develop. ment efforts. Jainary 14,1972 The history of development discussed in inis section is based on ine memo nited above and on interviews conducted by the research team with Mr Tinnes Ali rijotailons also appear as quotations in the Mr Tinnes memo Hereafter. relerred to as the Tinnes memo

ibid pared by the city's Department of Economic Development, indicates that most of the residents of the city are employed in either professional/technical industries or in management/administrative positions. Few employees are classified as laborers, and non-manufacturing sectors of the city's economy provide the largest source of employment, particularly in the service and retail trade areas. The city's major industries are Guille Steel (steel joists), Nepatrix (fabric dying), Snark Boat Products, J.C. Penney (regional distribution center). Eastern Elec!ric Wire and Cable Company (natioral distribution center), Cooper Bearing Coinpany (split roller bearings), and Stihl, Inc. (chain saws). A large number of the sity's resicents are service personnel and civilians employed by the military.

The city is served by a variety of transportation facilities: 1-64 connects with both I-95 and 1-85. The Penn Central Transportation Company. the Southern Railway System, and 50 truck lines, including common and contract carriers in the SMSA, serve the city. The waterway serving the city is the Port of Hampton Roads wnich is 25 square miles in size, handles about 70 million tons of cargo, and has channels up to 45 feet deep. The nearest airport is Norfolk Regional which has air carrier service provided by Allegheny, National, Piedmont, and United Airlines.

The city currently has three major industrial park properties available-Oceana West (1.000 acres). Little Creek (26 acres). and the Airport Industrial Park (202 acres) directly east of Norfolk Regional Airport. Other industrial park sites are being planned.

\section{History and Development}

Virginıa Beach's general aviation airport development efforts began on April 16. 1963 when the city manager, at the request of City Council, appointed a three-member committee to determine the feasibility of the city's using the airport facilities at Fort Story for general aviation (see Figure 4-11). ${ }^{70}$ In September, 1963 the city's request for joint use of the Fort Story airsraft facilities was endorsed by the Director of the Virginia Division of Aeronautics. At the same time, the Report of the Aviation Commission to the Governor and the General Assembly of Virgınıa identified Vırginia Beach as one of the airport projects in Virginia in need of state aid. On March 4, 1964 the Army denied the city's request for joint use of the Fort Story aircraft facilities due to certain restrictive areas in the flight pattern at Fort Story." Two months later the city's need for a general aviation air- 
prrt was again endorsed by the Director of the Virginia Division of Aeronautics. On October 9 , 1967 the City Council appointed an Airport Study Committee which once again led to a request by the city manager to establish a general aviation facilitiy at the Fort Story site. The Army denied this request and also a later request for reconsideration made by Congresiman Thomas N. Downing on December 18, 1967. ${ }^{72}$

In 1968 several significant events affecting the development of general aviation in Virginia Beach occurred. The city was listed in the $\mathrm{Na}$ tional Airport System Plan. The airport study committee presented reports to the Sity Council on the economic benefits that occur to communities as a result of general aviation and on the Army's objections to the city's requests to use the Fort Story site. ${ }^{13}$ The Airport Study Committee reached the following conclusions about the city's general iviation needs: ${ }^{74}$

(1) That the immediate need of the city with respect to an airport exists, primarily for tourism. In this conjunction such an cirpo.t would only be of value if located in, or ad, acent to the Beach Borough. Considering the air space requirements for Oceana Naval Air Station, the only area in or adjacent to the Beach Boruugh would lie in the vicinity of Seashore State Park.

(2) It is proposed that prior to the development of urban housing in the southern portion of our city, that acquisition of land be undertaken, such to be sufficient for the location of an airpor. to be developed in conjunction with industrial use.

The Industrial Development Authroity received a presentation made by the president of a realty company on its proposed plans for an airport and industrial park in the southern part of the city between NAS Oceana and Auxiliary Landing Field (ALF) Fentress. This request was deried by the FAA because of its proximity to operations occurring at both of these military

\footnotetext{
"Ibid

"Ibid

- Dewberry. Nealon and Davis. Airport Site Evaluation and

Selection. Farrfax. Virginıa 1970

- Tinnes merno

$16,1 d$

"Dewberry of al

- Letter from the FAA to Dewberry Nealon and Davis. dated $N$ arch 31. 1970

- Letter from City Manager Robert Scott to thu FAA, dated May 24. 1971

- Letter from Dewberry. Nealor and Davis. to Mr James Sader. chiairman of the Virginia Beach Airport Study Committee. dated June 25. 1971

- Tinnes memo
}

airports. At about the same time first community opposition to airport development emerged in a resolution transmitted to the City Council by the Board of Directors of the North Virginia Beach Improvement League which requested the council to "resist all efforts to place an airport at Fort Story, State Park, or North Virginia Beach."75

In January, 1969, the realty company once again renewed its efforts to obtain space for a public use airport in the vicinity of Oceana and Fentress. The Virginia Division of Aeronautics then sent a letter to th. FAA requesting that the company be required to gain approval from the City of Virginia Beach. In Anril. 1969 the company withdrew its request for an aviation facility because it had not been able to obtain the necessary zoning and use permit from the city. This was because the city was considering the establisi., nent of a public use airport and might be pre-errpted by Virginia Beach Aviation Sales Limı.ed. ${ }^{76}$

The city thien retained the firm of Dewberry. Nealon and Davis for an airport planning study. Subsequent to its initiai planning study, the firm conducted a Site Evaluation and Selection Study which 1: as submitted to the city manager on July 9, 170. In conducting this study the consultanis looked at a variety of factors includirg: size and type of airport required. meteorological analysis, accessibility. compatible land use, engineering feasibility, construction costs, and real estate costs. ${ }^{77}$ In March, 1970 the consultants received a letter from the FAA rejecting the proposed airport site locations at Fort Story. Pungo, and Woods Corner for "airspace utilization" reasons. The FAA indicated that it would continue to assist the city in locating a suitable site for the proposed Virginia Beach airport. ${ }^{78}$

In May. 1971 the City Manager rec, Jested FAA approval for an airport located at the Bacix Bay site "inasmuch as the project conforms to the guidance furnished by your office in the course of site selection." 79 In June the city's Airport Study Committee received a letter from Dewberry, Nealon and Davis repoting that the Navy has indicated that it was its opinion that serious aircraft operaiional safety problems would arise in the proposed site area. This, however, is contrary to their position of May, 1969.80 The Navy indicated at that time that "there would be a possibility' of rerouting their southern operations to accommodate a general aviation airport in the general vicinity of the Back Bay site. ${ }^{\text {'1 }}$ The FAA responded to the Navy's objection by indicating that its regional 

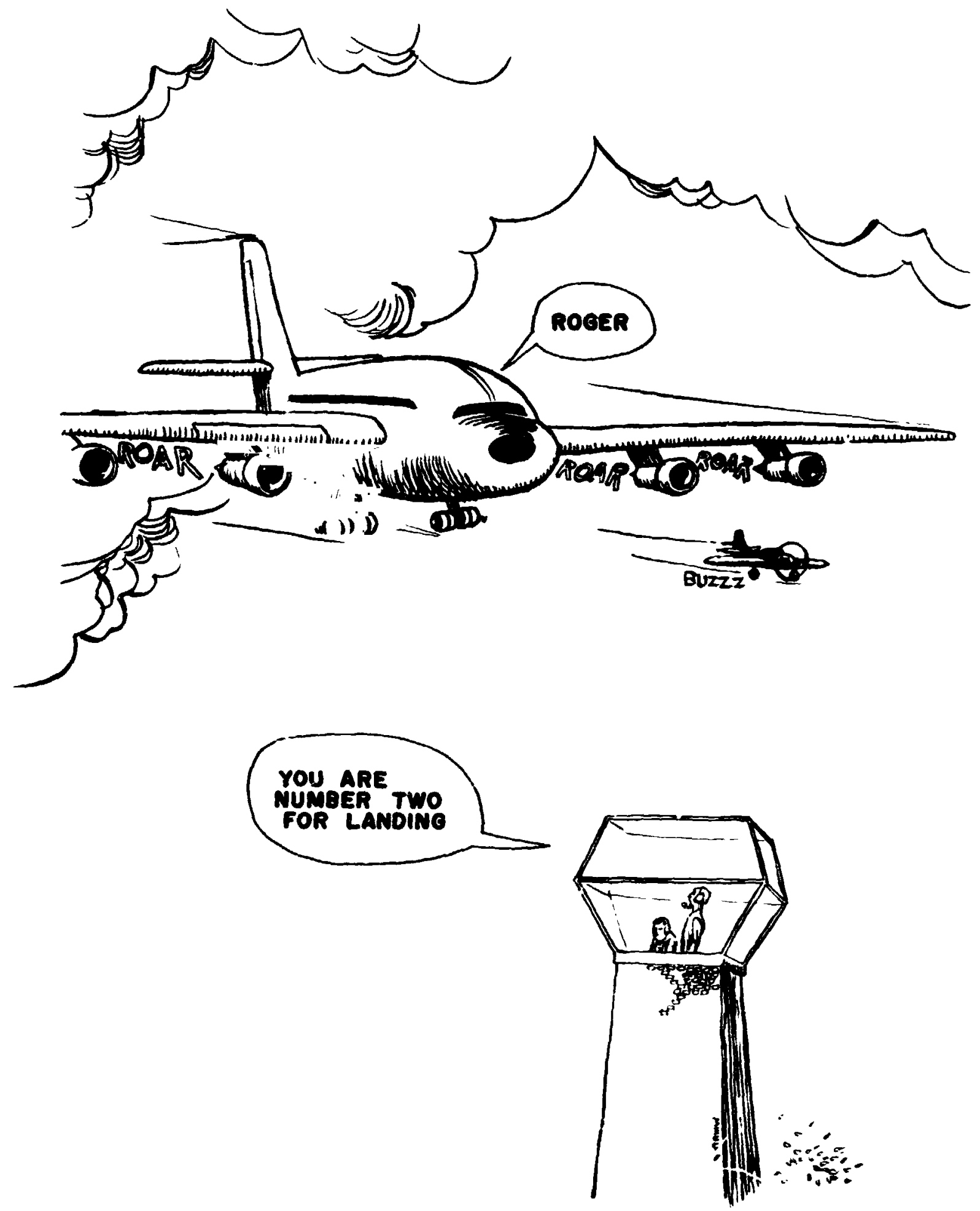
office would "restudy the entire Navy dominance of airspace in the Virginia Beach area and reaffirm the urgent requirement to place a general aviation airport on the west side of the peninsula." 2 2 The city then attempted to obtain the Navy's permission for joint use of NASOceana. This request was denied.

On November 4, 1971, the City Manager received a letter from the FAA ini.icating that "inasmuch as the (Back Bay) site had been selected based upon a 'search area' recommended by the Air Traffic People, we returned the airspace finding for further review to our regional office. The region suggested that the Fort Story area, previously rejected, appeared to possess the best potential for the general aviatic.l airport from an airspace utilization viewpoint." 83 At a December meeting, during which the city solicited the Navy's assistance in locating a general aviation airport site within the city. the NAS Oceana Base Commander suggested that the city use the Fort Story site for a joint civilian/military air facility. At a December 9. 1971. FAA airspace meeting with the City of Virginia Beach. action was postponed indefinitely at the city's request due to the Navy's airspace objections.

On February 14. 1973 the city contacted Congressmar. William Whitehurst to meet with him on the city's airport difficulties in a project with a history which was "long and fraught with disappointment." The city's director of economic Jevelopment, emphasized that after many meetings "we are no further toward a positive decision than we were when the Airport Study Committee nas established five or six years ago." "ss In response to Congressman Whitehurst's interest he then indicated that "the Fort Story location is one that everyone

\footnotetext{
- Letter trom Dewberry. el al. oo ctl.

"Letter frem the FAA to Cliy Manager Robert Scott. dated November 41971

- Lettef from A James De Ecillis Director of the Virginia Beach Department of Economic Development to Congressman $G$ William Whitehurst, dated February 14. 1973

is lbid

- Letter from A James De Belis to Congressman G Willian Whitehurst dated May 8. 1973

- Interviews conducted with Mr Harold Galluo-Industrial Development Coordinator. Mr Jerry Broadway-Administrative Alde Ken Knight-Comprenensive Planner, and Mr Lee EstinCivil Detense Coordinator on July 16. 1975

- The following information is based on an Internal memo to Mr George L. Hanbury. Assistant City Manager. dated July 8. 1974

- Internal memo from Mr Jerry Broadway to Mr A James De Beliıs reporting on the FAA Heanngs on the Creeds Activation. dated October 16. 1974

$\infty$ loid

- Internal memo from Mr Jerry Broadway to Mr Ken Knight. Depanment ol City Planning. datad March 6. 1975
}

can best live with, especially Oceana, since it would not unduly interfere with air traffic," and that "we should feel the need of an aiport to serve our city. and in the effort to establish one we do not want to leave any stone unturned." ${ }^{86}$

At this point, the city lost interest in Fort Story. The following reasons were given by city officials: (1) difficulties expected in obtaining A my approval for the use of Fort Story location; (2) meteorological problems associated with the site; and. (3) a changing view of the city toward the Fort Story location because the city was now viewing the area as a possible recreational site and felt that the needs of general aviation might be incompatible with the needs of recreation. ${ }^{\text {B }}$

In late 1973 the city began to autively pursue the Creeds Airport location as the "best" site. On November 2, the city requested a "Private classification for Creeds indicating no aircraft operations at present and none anticipated." After a series of meetings with representatives of NAS Oceana, who still objected to this site. the city filed a second form 7480-1 witt, the FAA and now requested a "Private Restricted Use Only" classification for the Creeds Airport. In June the city was notified that the FAA was conducting an aeronautical study of the reactivation of Creeds Airport.

On October 16, 1974 the FAA conducted a hearıng on the Creeds Airfield situation to enable the proponents and the opponents of the proposed reactivation to voice their opinion."9 The proponents included two members of the State Corporation Commissicn and a representative from the Virginia Beach Department of Economic Development. Opposition to the reactivation was voiced by several Navy officials, the President of the Back Bay Civic, League, and the Manager of the Back Bay National Wildlife Refuge.

The Navy's and the Civic League's main objection was based on the danger of midair collisions and of limited approach and departure avenues over the southern part of Virginia Beach. A representative from the State Division of Aeronautics countered this argument by saying that "the Navy does not own the airspace over or around Creeds, and that anyone has the right io fly in this airspace." ${ }^{90}$ In addition, the state representative argued that "with proper controls, high performance and low performance aircraft use the same airspace every day at numerous airports throughout the country without midair collisions." The meeting resulted in a compromise in which the Navy in- 
dicated that it would not object to the reactivation of Creeds as a heliport.

More recently, comments have centered on the Preliminary Draft of The Virginia Air Transportation System Plan. The plan was reviewed by a representative of the Department of Economic Development who noted that: (1) the inclusion of the Creeds Airport in the State Plan and the National Aiport Systems Plan "lends much support to our application which is presently before the FAA to activate the airport at Creeds:" (2) the reactivation of Creeds Airport might make that area an excellent location for an industrial park; (3) Creeds would provide air access to the False Cape State Park recreational area. ${ }^{92}$ In addition he noted that the Department of Economic Development had no plans for an airport at the Fort Story location. Similar views were contained in the city's comments on the VATS plan transmitted to the Division of State Planning and Community Affairs. ${ }^{93}$ These comments indicated that the city supports the Creeds Airfield and that the Virginia Beach Planning Department had no plans to develop the proposed Fort Story facility. Therefore the city concluded "if not enough federal funds are available for ADAP support of general aviation facilities. it may be wise to concentrate federal funds in only one facility in Virginia Beach."

The Assistant to the City Manager for Human Resources. commented that the VATS plan in reality anticipates three airports serving Virginia Beach by 1990: Fort Strny, a facility in the southern part of the city, and Norfolk Regional. He recalled the story of the "Tortoise and the Hare" and suggested that "with perseverance the city will obtain general aviation facilities in the southeastern and the northeastern parts of the city by the tir:. 1990 rolls around." In addition he indicated that the city could work most productively toward establish. ing better access and utilization of the general aviation facilities located at the Norfolk Regional Airport.9"

\section{Existing and Proposed Aviation Facilities}

Two of the five sites discussed in the Airport Site Evaluation and Selection report prepared for the City of Virginia Beach in July 1970

"10id

- Letter from Mr Ken Knıght Virginia Beacn Comprehen. sive Planner to Mr Robert S De Mauri Division of State Planning and Community Aftairs Transportation and Public Sdfety Section dated March 10. 1975

- Letter from Mi George Tinnes Assistani to the City Man ager ftuman Resources to Mr James P Sadler Virginia Beach Air port Committee. March 271975

"Dewberry Nealon and Dav's, up cIl were visited. The sites discussed and evaluated in the form of "consultants 1st choice, 2nd choice, etc." were: Back Bay (visited), Dawley Corners, Pleasant Ridge, Woods Corner, and Creeds (visited).

In addition, the sites at Fort Story, Pungo airfield (abandoned), and NAS Oceana were visited to aid in evaluating their applicability as general aviation airport sites. This enabled the researchers to gain a better understanding of the envirormental conditions which had been discussed w'ith officials from the City of Virginia Beach. Woods Corner, Pleasant Ridge, and Dawley Corners were not visited because these locales were dropped early in the city's site selection study and no present consideration was given to them by any of the people contacted for this case study.

Fentress is an auxiliary landing field used by the United States Navy for simulated carrier landing practice for their high performance jets. Fentress, with an 8,000-foot single runway, has approximately 80,000 to 100,000 operations per year and acts as a reliever field for NAS Oceana which has over 150.000 operations annually. The Virginia Beach Airport Site Evaluation and Selection report did not consider Fentress in the plan. It was stated in the letter of transmittal with the report that "Fentress... is not only in another jurisdiction. but is poorly situated from an access standpoint." 9

Pungo Field. Back Bay. and Creeds extend south from NAS Oceana in that order and are approximately $6.8,11.9$ and 15.9 miles respectively from the center of Oceana.

Major objections to these three sites came from the Navy because of conflict with the traffic patterns at NAS Oceana. Over 50 percent of the time, runways $5 \mathrm{~L}$ and $5 . R$ at Oceana are active while runways $23 \mathrm{~L}$ and $23 \mathrm{R}$ are used about 35 percent of the time (see Figure 4-12 for a layout of NAS Oceana). Problems were discussed with Navy personnel who provided drawings showing their ground control approach (GCA) pattern. Approach to the GCA pattern for runway $5 R$ (which is the instrument :anding runway) would normally pass directly over or very close to Creeds. which is also in Oceana's VFR approach zone. Back Bay would be further from this pattern but is still within the approach zone of runways $5 \mathrm{~L}$ and $5 R$. Pungo Field does not appear to be in the approach zone of $5 L$ and $5 R$, but its close proximity to NAS Oceana could present a VFR traffic problem.

Opening a general aviation airport in the Pungo-Back Bay-Creeds area presents another 


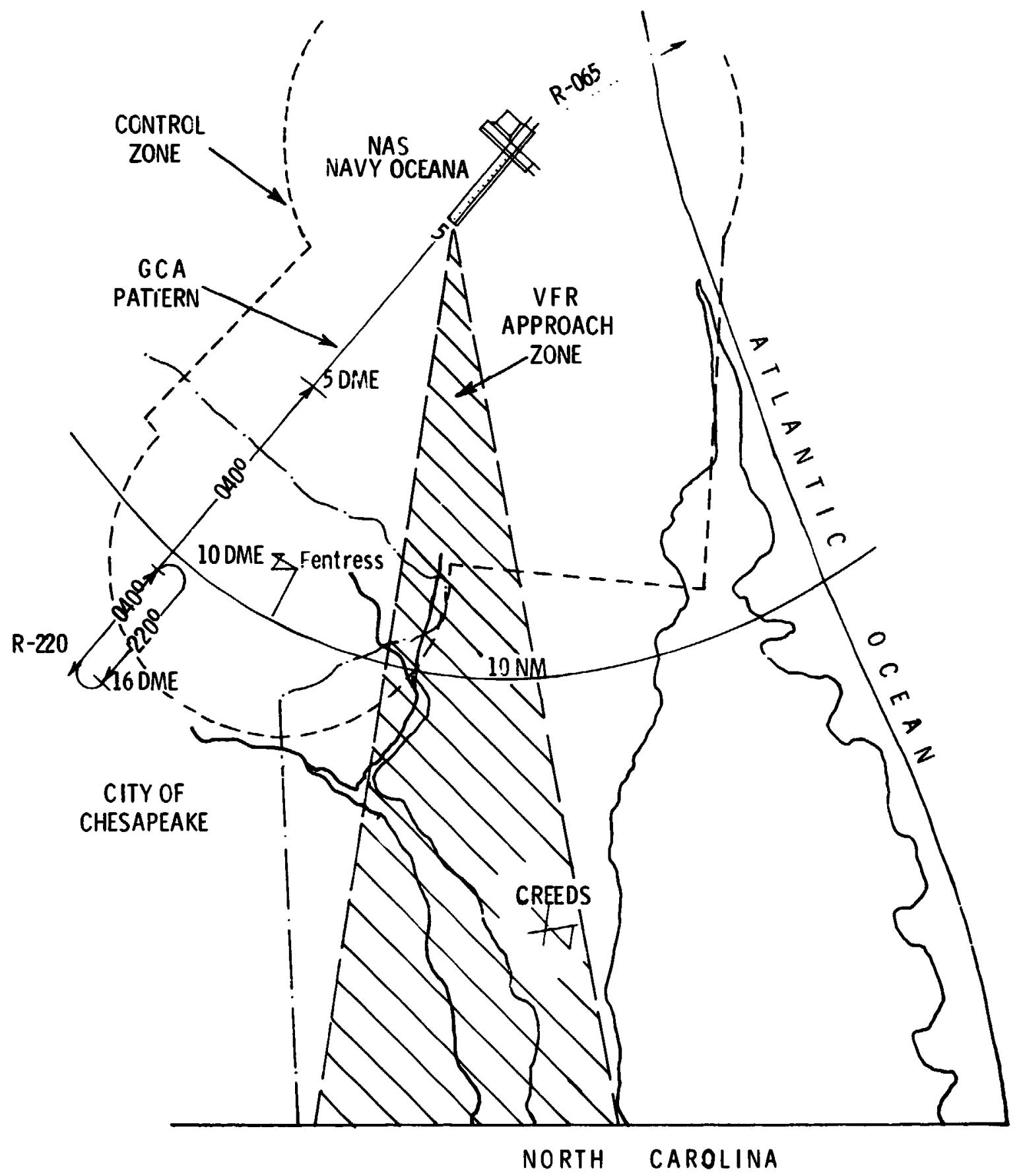

NAS OCEANA AIRSPACE UTILIZATION

FIGURE 4-12 
potential problem to NAS Oceana traffic. NAS Oceana has an established control zone and according to Federal Aviation Regulations, any aircraft flying in this airspace up to 3,000 feet above the ground must be under the control of NAS Oceana. Above 3,000 feet, if the aircraft is VFR, there is no requirement to contact NAS Oceana. High performance mi,itary aircraft will be under direct control while civil aircraft may or may not be, which presents a potential safety problem. An additional general aviation airport in the area would pose a potential safety problem. It appears that the FAA should make a detailed study of this problem. A possible solution would be the establishment of a Terminal Control Area to handle the expected high density traffic.

Creeds field is 15 miles from the City Hall complex of Virginia Beach City and it takes approximately 23 minutes to make the trip by automobile. This large distance is somewhat objectionable, but anything closer would create greater air traffic conflicts with NAS Oceana. The remaiıing area to be considered is at Fort Story, located in the extreme northeast corner of the City of Virginia Beach. This land is presently owned by the United States Army and from an air traffic point-Jf-view presents the least amount of conflic! as long as one runway is oriented in a general east-west direction. A review of the documentation and talks with Virginia Beach officials indicated that Fort Story personne!, and possibly the residents of Virginia Beach in the Fort Story area, appear to be the only persons opposed to this location. It is not clear why aviation-knowledgeable people have recommended the Fort Story location since the runway length appears limited. the runway is oriented such that it is about $90^{\circ}$ to the prevailing wind (a runway into the prevailing winds would conflict with Norfolk Municipal Airport and NAS Oceana), and the salt air and aand envirunment are very detrimental to aircraft. The Fort Story airport is located at the edge of the NAS Oceana control zone.

The old runway at Fort Story was approximately 3.500 feet in length and constructed of pierced steel plank (PSP). The runway has been abandoned for all practical purposes and would have to be reconstructed completely, although sufficient room appears to exist to lengthen it. There is another very small, hard surface located at Fort Story which appears to be a road and doubles as a landing strip. This strip is

\footnotetext{
- Interview conducted with Mr George Callis. Councilman--City of Virginia Beach on July $22 \quad 1975$

- Interviews conducted with members of the Virginia Beach department of economic development and city planning
}

limited, due to size, to aircraft with STOL capabilities.

\section{Support}

It is difficult to talk in terms of proponents in the Virginia Beach case because the city has not placed a great deal of emphasis on having its own general aviation facility. This is not to say that the city does not desire the services provided by general aviation but indicates :hat the city officials interviewed felt that the facilities at Norfolk Regional cculd be changed and upgraded to serve Virginia Beach's needs.

The city's source of support for access to general aviation facilities seem to be interests related to economic development. But even here, city officials indicated that an airport does not in itself lead to economic development. One city council member commented that he had seen no convincing evidence that would lead him to support the use of local tax funds for the development of a general aviation airport. He seriously questioned the supposed benefits to the community although at the same time he indicated that the users of general aviation should have the facilities available but not necessarily within the city limits of Virginia Beach. ${ }^{96}$

The Creeds site is supported by the Department of Economic Development for three reasons. First, because of the expected population and industrial growth in the southern part of the city. Secon $t$. the department believed that an airport at Creeds would be used by certain technical and research and development industries which it hopes will be located near the Oceana Naval Air Station. Third, Creeds would receive some use once False Cape State Park is opened as a day facility with expected use by approximately 25,000 visitors daily. ${ }^{97}$

Additional support by city officials for the development of a general aviation facility in Virgınia Beach is given by the city manager's office. The City Manager and ar assistant to the City Manager both see the need for additional industrial development in the city. At the same time, the former is also interested in locating a convention center in Virginia Beach. A general aviation facility is a desired component of the planned industrial and the convention cenier development. It should be noted, however, that the key problem will be in gaining access to a genera! aviation facility and not necessarily triiding one within the city limits in the $\mathrm{im}$ mediate fuiure.

Additional internal support for general aviation is found among the three members of the city's Airport Committee, individuals ap- 
pointed by the City Manager at the request of the City Council. Their major role has been to conduct studies on the aviation needs of the city and to report to the appropriate city officials on the city's aviation needs. They seem to be the only organized group currently supporting general aviation developments in the city.

At the present, Virginia Beach's second airport site at Fort Story seems to be supported by very few, if any, individuals within the city because of the generally held belief that the best way to use the Fort Story land, if available. is for recreational purposes. Past support for the Fort Story site came primarily from the industrial development interests in the city

An additional source of support for the development of general aviation facilities in Virginia Beach could be aircraft owners residing in the city. In 1970. FAA aircraft registratıons for the city show 56 aircraft whose owners have Virginia Beach addresses. ${ }^{98}$ Discussions with the city officials interviewed would leac one to believe that this number had increased substantially as a result of the type of population growth the city has experienced. No evidence was obtained to show that these aircraft owners have lobbied actively in their own behalf

Of at least equal importance in obtaining general aviation services in a given community are external sources of support. In the case of Virginia Beach these include members of the State Corporation Commission, Division of Aeronautics; the Federal Aviatıon Admınıstration which has included an aviation facility for Virginia Beach in its National Air System Plan; and. Congressman William Whitehurst whose district includes the City of Virginıa Beach.

The State Division of Aeronautics has endorsed aircraft facilities in Virginia Beach since 1963 when it supported the joint use proposal at Fort Story. In 1969 it endorsed the city's Advance Airport Planning Proposal. In 1971 the city received $\$ 5,000$ in state funds as a reim. bursement for airport planning in connection with Virgınıa Beach Municipal Airport. Most re. cently the Commonwealth has supported the city in hearings conducted by the FAA on the proposed reactivation of Creeds airfield

The FAA has supported the development of

* Dewberry et al, p 7

" Leter from A lames De Bellis Direcior Virginia Beach Department of Economic Development to Congressman William Whitehurst dated May 81973 Letter from Congressman Whitehurst to James De Bellis dated May 30 1973 Letter from James De Bellis to Major General Jack Fuson Commanding Officer US Army Transportation Center Fort Eustıs. Virginia. dated June 6. 1973 aviation facilities in Virginia Beach since 1968 when the city was first listed in the National Airport System Plan (NASP). Recognition of the population center in the NASP adds imprtus to an airport program because it indicates that potentially federal funds are available to assist in the planning and development of an airport. This recognition also indicates that federal officials believe that an airport is viable in that particular area, adding support to the proponents of an airport who would perceive a powerful ally in the form of the federal government. With this implied support they may become more vocal and active in their recommendations for an airport.

A third source of external support is Congressman William Whitehurst, who has played a cooperative role in attempting to obtain land at the Fort Story site. Mr. Whitehurst has contacter the Commanding Officer at the United States Army Transportation Center at Fort Eustis regarding the use of that site. In addition Congressman Whitehurst has corresponded with Virginia Beach's Director of the Department of Economic Development regarding the development of an aviation facility near the Oceana Naval Air Station. ${ }^{99}$

\section{Opposition}

Opposition to the development of a gereral aviation facility has come from two principal sources: (1) certain local civic and environmental interests and (2) the Navy The local interests have exrressed opposition to the Fort Story site because they would like it to be used for recreational purposes. Opposition to the Creeds site was expressed by both the Pres1dent of the Bajk Bay Civic Leaque who Nas concerned with the danger of micalr collisions. and the Manager of the Back Bay National Wildlife Refuge who was concerned about the environmental effects of the proposed development. One could conclude without surprise. given the low level of aviation activity within the city. that local citizen group opposition is not strong.

Continuous opposition to the development of an aviation facility at the Creeds site has come from officials representing the Oceana Naval Air Station. Since the reasons for this opposition hive been discussed in the aviation environment section of this case study they need not be repeated here. Results of interviews conducted with the Commanding Officer and the air traffic control officer of NAS Oceana clearly indicated the Navy's concern about the air space available to Oceana and the diffıcultıes inherent in mixıng high performance 
military aircraft with low performance general aviation aircraft. ${ }^{100}$

in summary, except for the opposition expressed by Navy officials, few individuals op. pose the development of an aviation facility in Virginia Beach. Nevertheless, one should remember that opposition to policy decisions does not nenerally develop at the early planning stage, a present characteristic of the Virginia Beach situation.

\section{Future Developments}

The City of Virginia Beach appears to have long range plans which include aviation requirements. One of the problems the city has encountered is the slow response of the Federa! Aviation Administration. An initial application to open Creeds Field for the city's private use was submitted to the FAA in 1973. The most recent application is dated May 20, 1974. As of July 16, 1975, the FAA has not given the city a response.

The city's emphasis has been, and will continue to be, placed upon the reactivation of Creeds airfield. The associated costs of equipment, maintenance, and insurance for the development of a "Private Restricted Use On!y" facility would be relatively small. ${ }^{101}$

Another vision of the future airport needs of the City of Virginia Beach is held by the General Manager of Piedmont Aviation at Norfolk Regional Airport, who is also a member of the Virginia Advisory Committee on Aviation. ${ }^{102}$ He believes that the proposed Fort Story airport should be upgraded from a General Utility facility to a Basic Transport facility. He reasons that the demands of Virginia Beach's convention business and the requirements of corporate pilots clearly show the need to develop an upgraded facility

The future of general aviation in Virginia Beach is perhaps described best with these statements: Virginia Beach might succeed in obtaining a general aviation facility, probably at the Creeds site, at some point in the future. UntIl that occurs, the city will be able to gain access to the services being provided to general aviation through the proposed expansion of the facilities at Norfolk Regional Airport.

${ }^{100}$ Interview conducted with Capt Knutson. U S Navy Commanding Oflicer. NAS Oceana and Commander J Morrison. US Navy. Air Traffic Control Officer. NAS Oceana. on July 18 1975

is. Internal memo from Jerry $W$ Broadway. Department of Economic Development to R Scott Tyler dated April 29. 1974

- Letter from TC Ferguson Member of Virginia Advisory Commission on Aviation, to the Director of the Virginia Division of Aeronautics. dated March 7, 1975

\section{Chesapeake}

Introduction

The proposed Chesapeake Municipal Airport represents an attempt to develop a new general aviation airport with the eventual purpose of becoming an air freight center for industrial development. With 2,000 acres of developable land, it is hoped that light industries will locate in the immediate area. The airport, in planning for eight years, has been approved for development by federal, state, and local officials. Construction is scheduled to begin in the fall of 1975. Coincidentally, the VATS Plan projects the need for a general utility airport for this region.

The proposed new airport has surmounted the initial problems associated with a rew airport development program, and for this reason was selected for study, even though the project is noncontroversial in almost every respect.

\section{City Characteristics}

Chesapeake is a large, sprawling city, located in the Tidewater region of southeastern Virginia. It is bounded by Suffolk County on the west. the cities of Portsmouth and Norfolk on the north, the City of Virginia Beach on the east. and the State of North Carolina on the south. Having incorporated in the mid-1960's, Chesapeake is now the state's largest city with an area of 361 square miles. Over two-thirds of the city is rural in character with most of its population of 91,400 (1971) concentrated in the northern section around the port areas. In 1972. there were more than 69,000 farm acres in production covering over one-third of the city's area. The Great Dismal Swamp National Wildlife Refuge is located in the southwest corner of the city.

In the past, major industries have located along the waterfront. These include ttie largest employers: Lone Star Industries, Inc., and Evans Products Company, both dealing in the manufacture and sale of building and construction materials, and having about 670 and 625 employees, respectively. A study of the area indicates, however, that industry is beginning to locate around 1-64 outside the center city. The impetus to this pattern has been given by Volvo of America. Inc., which has begun construction of a plant with an eventual employment of 3500 people.

The 1974 annual report of the Chesapeake Industrial Development Authority reported an expectation of more than $\$ 165.4$ million in new industry and 4,517 additional jobs. Of these 
totals, $\$ 150$ million and 3,500 employees are expected to be from Volvo. ${ }^{103}$

\section{Existing Avlation Facilitios}

Currently, there are three airports in the City of Chesapeake (see Figure 4-13): (1) Chesapeake-Portsmouth, a privately owned general aviation airport located eight miles southwest of the city center; (2) South Norfolk. a privately owned general aviation facility located four miles south of the city center; and, (3) Auxiliary Landing Field (ALF) Fentress, owned and operated by the United States Navy as a training proficiency field. A private airport. Suffolk, is in near proximity. Several other existing and proposed airports within a 50-mile rasilus of the new airport site, including Virginia Beach and Williamsburg-Jamestown, have been reviewed previously in this chapter.

The major air carrier airport for the region south of Hampton Roads is Norfolk Regional Airport, a primary, medium density airport serving general transport category aircraft. It has a large general aviation facility which is presently near capacity. In order for Norfolk Regional to expand, it must obtain land outside the present municipal boundaries of Norfolk. Airport planners for Norfoli Pegional and Virginia Beach officials are presently discussing expansion plans for property directly east of the airport and located within the corporate boundary of Virginia Beach.

Of the three private airports near the proposed site, Chesapeake-Portsmoutt, with 125 based aircraft is by far the busiest and largest with 60,000 operations annually. It is readily accessible by six-lane highwav and rail (Norfolk and Western) transportation, and covers an area of 1,200 acres. At present, although little residential or commercial activity impinges on the site, several radio and television antennas north of the airport represent a potential airspace hazard.

At Chesapeake-Portsmouth there are two 3.500-foot asphalt runways, one of which is being expanded to 4,500 feet. A third runway is proposed and could be extended up to 7,500 feet without difficulty. At present, the runways are considered to be of marginal length and bearing capasity, and capable of handling only the smallest $j \in t s$. Dry wells and canals are used for drainage, in a way similar to that proposed for the site of the Chesapeake Municipal Airport.

On the Chesapeake-Portsmouth Airport,

"Annual Report of Chesapeake Industrlal Development Commission. January 1975 there are several FBOs which provide air taxi service, and aircraft and avionics maintenance, employing a total of 15 full-time individuals. One of two fish-spotting companies in the Peninsula area has a based airplane on the field. The airport appareritly operates at a loss even though the FBOs appear to be successful. The retired airport manager has indicated that this location is a perfect site for development as there is ample space for industry to develop in the area.

The South Norfolk Airport is presently congested although it has some capacity for expansion. It is near the major highway intersection of 1-64 and Virginia Route 168, and opposite the new Volvo plant. There are a numher of residences in the vicinity and the land seems well suited for airfields. The airport is a family operation with marginal facilities. The owners are not interested in selling the land.

\section{History and Development of the Proposed Facility}

Unofficial planning for a public airport was begun in the mid-1960's by members of the aviation community in search of better facilities. It was also hoped that the new facility would act as a reliever for Norfolk Regional where general aviation activity must vie with certıfıcated air carrier traffic. Many owners of private aircraft prefer being based at an uncontrolled field to avoid restrictions placed on them at a hub airport. Also, the cost of keeping a plane at a major airport is higher than that of basing it at a small general aviation facility.

In 1968, official action was taken by city council approval to establish a publicly owned general aviation airuort. As planning progressed it becam.e apparent that Chesapeake was in a position to attract addıtional industry and cargo operations. This was considered in the overall airport plan, by providing for an industrial park and for runways which will be strong enough to handle cargo operations. A local consulting firm was hired to recommend possible sites and to prepare an airport layout plan, in order to satisty the minimum requirements for application for federal funds. The eligibility for such funds was established, since the airport was included in the National Airport System Plan.

The geographic location of the proposed Chesapeake Municipal Ariport seems suitable. The area is a forest just opposite the Dismal Swamp. It is owned by a wood products company and used as a tree farm. Trees in this area are 40 to 50 years old and are ready for harvestIng. After the necessary clearing takes place. 


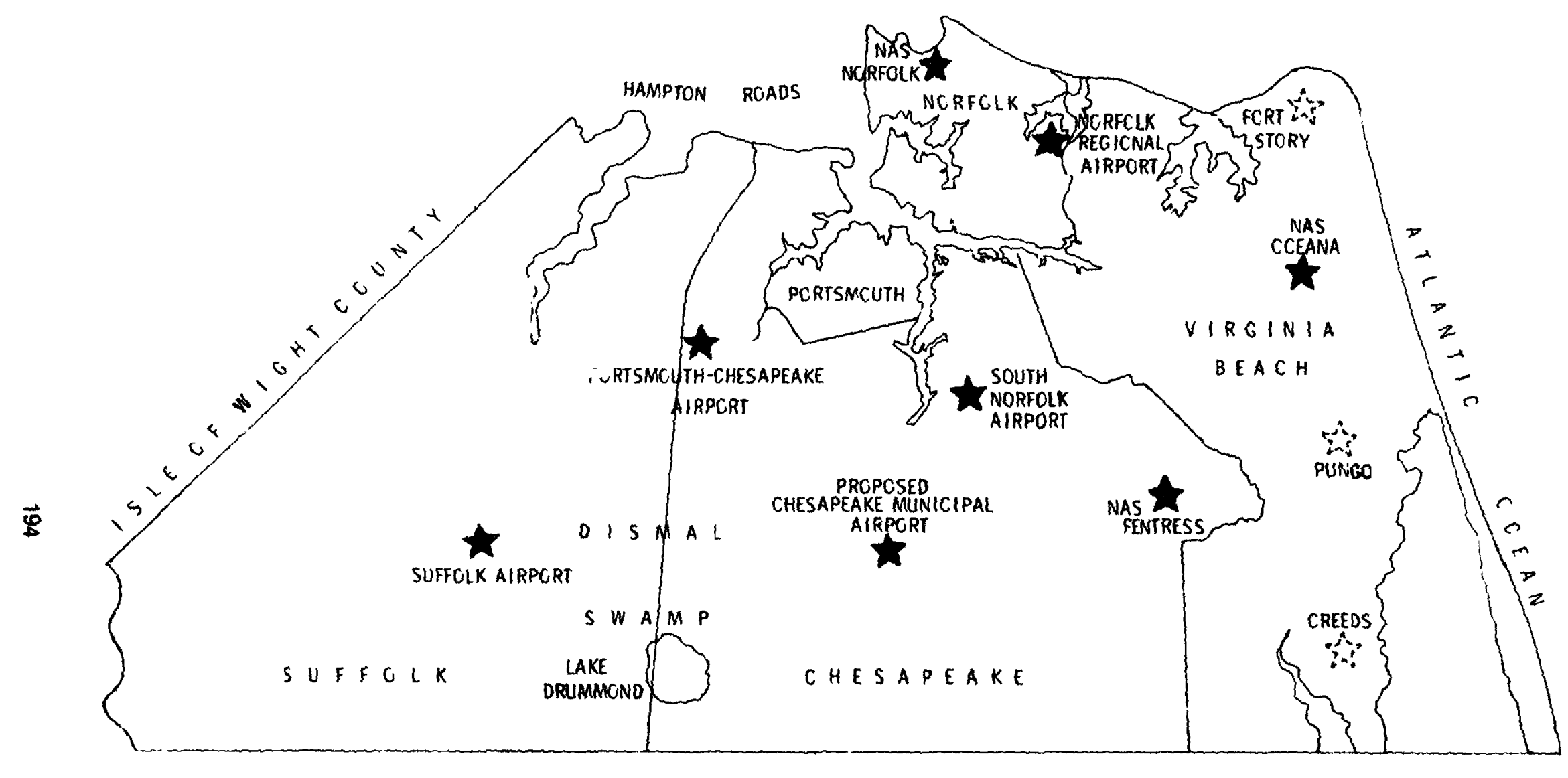

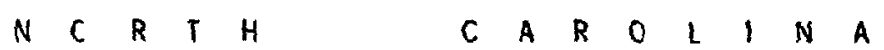

AIRPORTS IN CITIES SOUTH

OF HAMPTON ROADS

FIGURE 4-13 
the company will sell the land to Chesapeake. There are only a few residences to the north and none to the south. The land itself is wet, however, and both runway and building construction might result in problems. Access to the site by railroad is non-existent and road access is minimal. In its favor is the fact that the other airports in the region are general aviation facilities with short runways, not strong enough to accommodate iarger cargo and business air Jlanes.

The proposed airport is located close to, but outside, the control zones of ALF Fentress, Norfolk Regional Airport, and NAS Norfolk (Chambers). It should thus have very little effect, if any, on aircraft operations at any of the other airports in the area. Initial phases of the airport's development do not include an instrument approach, but this is included in subsequent phases.

After development plans for both siting and layout were developed and submitted to the necessary federal agencies, an Environmental Impact Statement was prepared and submitted. An attempt was made to determine if any of the 28 endangered species would be affected by the establishment of the airport. This is understandable since the location is adjacent to the Dismal Swamp and the area is one which is ecologically delicate. The Environmental Impact Statement has met federal approval.

After approximately seven years of work to obtain Federal funds for such a project, the City of Chesapeake was notified on May 1, 1975 that it had to have all of its plans and specifications prepared, and contractors selected, prior to June 10,1975, if it expected to receive any of the 1974-1975 ADAP funds. (ADAP expired on July 1. 1975; at this writing its renewal is being considered by Congress.) Such short notice for response undoubtedly placed the City of Chesapeake in a poor position for a detailed price negotiation with tentative contractors. The first of three stages for development of the Chesapeake Municipal Airport, however, has now been approved for ADAP funding.

It is intended that Stage I will consist of a 3.600-foot by 60 -foot runway with taxiway turnarounds and no terminal navigation aids. Runway strengths will be designed to support aircraft of up to 12,000 pounds with medium intensity runway lights.

Stage II will upgrade the airport from general utility to basic transport by extending

ir Find Draft Environmental Impact Statement for Chesapeake IMunicipal Airport. 1974 the runway to 4,600 feet by ' 10 feet and adding a full length taxiway. In addition, the runway will be able to handle aircraft weighing up to 30,000 pounds and will have both taxiway and runway lights, a VASI approach system, and runway end identification lights (REIL).

Stage III will involve making the airport meet the general transport category by extending the runways to 7,500 feet by 150 feet and establishing precision approach caapability.

\section{Support}

The proposed airport has strong support from those interested in general aviation planning and is included in the NASP and VATS plans. The Chesapeake City Manager, City Council. Airport Authority, and the Industrial Development Authority have all given their fuli support to the airport development effort. Besides the approval of ADAP funds for 75 per. cent of the total $\$ 1.2$ million Stage I construction costs, a commitment of $\$ 200,000$ has been made by both the city and the state. The city intends to borrow money from general funds with. a commitrnent to pay it back. Any other funds needed will be generated by the Airport Authority through the issue of revenue bonds. There is no intent to levy a tax. Interviews at the existing Chesapeake-Portsmouth airport indicated a belief that existing businesses will probably not be nurt by a new airport, but they do perceive that a new airport in Virginia Beach would provide serious competition.

\section{Opposition}

According to the Environmental Impact Statement, at least one public hearing was held on November 7, 1972 and announcement for reviewing the final draft was made in early 1974. It is not known how many citizens re" is wed the firial draft. The initial public hearing was conducted primarily to discuss the environmental effects of the airport project.

Opponents who spoke at this meeting consisted of an outdoorsman concerned about the Dismal Swamp, a resident who lives close to the new airport, and a member of the Virginia Beach School Board who opposed the time of the hearing rather than the building of the airport. Also at this meeting, a petition. containing 57 signatures, was submitted which "opposed. . . the construction of an industrial park and airport in the Shillelagh Road/West Road area [ becz'sse] such a facility would adversely affect property values and introduce elements incompatible with the peaceful and quiet enjoyment of the area. ${ }^{104}$

On contacting two of the petıtıoners. it was 
tound that their attitude indicated a hopelessness concerning the ability of small numbers of residents to achieve success in any dispute with the city. in addition, their major complaints were directed toward jet traffic and not necessarily small general aviation planes. The other nearby communities of Norfolk, Portsmouth, and Virginia Beach are neutral, with no interest in funding the airport in Chesapeake. Several people stated that they think Virginia Beach will not build an airport but if it did, the airport will have some effect on the level of general aviation activity in Chesapeake.

\section{Conclusions}

Compared with other communities which are considering the expansion of their air transportation facilities, the prospect of putting in a new airport in Chesapeake has been greeted with relatively little community opposition.

As far as the selected site is concerned. there seems to be minimal opposition in the community, with the exception of a few farmers living in the vicinity of the proposed site. The location is fairly isolated and the planes will make approaches over the Dismal Swamp which is uninhabited by people.

Furthermore, indirect suppoit for this airport development is expected to result from good labor relations in the area (Virginia is a right-to-work state), climise, general area facilities and the port lucation in the community. Also a number of industries have made oral commitments to the facility and several FBOs have also expressed interest. These FBOs, however, would have to construct their own facilities. since the city will only construct a small administration building on the site.

\section{SUMMARY AND CONCLUSIONS}

The study of transportation and general aviation in Virginia is summarized as follows:

(1) Virginia has a comprehensive system of highway, rail, bus, and air carrier modes with excellent common carrier service between larger cities.

(2) The role of air transportation and general aviation airports in community develomment is recognized in the Virginia A $r$ Transportation System Plan which projects expanded general aviation service for Virginia primarily thrrough the expansion of existing lacilities and the adaition of 19 new iacilities.

(3) Pagional and local studies in 1 inia have identified the complex and oifficult nature of thie airport planning process. The following factors appear to be essential considerations in this process:

(a) Local and regional planners must consider the comprehensive transportation planning procoss as well as statewide aviatior plans.

(b) Accurate input data are needed in the planning process and at present there is some problem in acquiring certain information, particularly at non-tower-controlled airports.

(c) Forecasting must be done realistically, with a consideration of all factors impacting on aviation.

(d) Naticral and State plans can serve is general guides from which local communities can develop final plans.

(e) The execution of all plans is dependent upon their acceptance by the communities involved.

(i) Inter-as well as intra-community forces play a major role in the final outcome of any aviation facility development. 


\section{AVIATION SERVICE ANALYSIS :}

\section{A GUIDEBOOK}
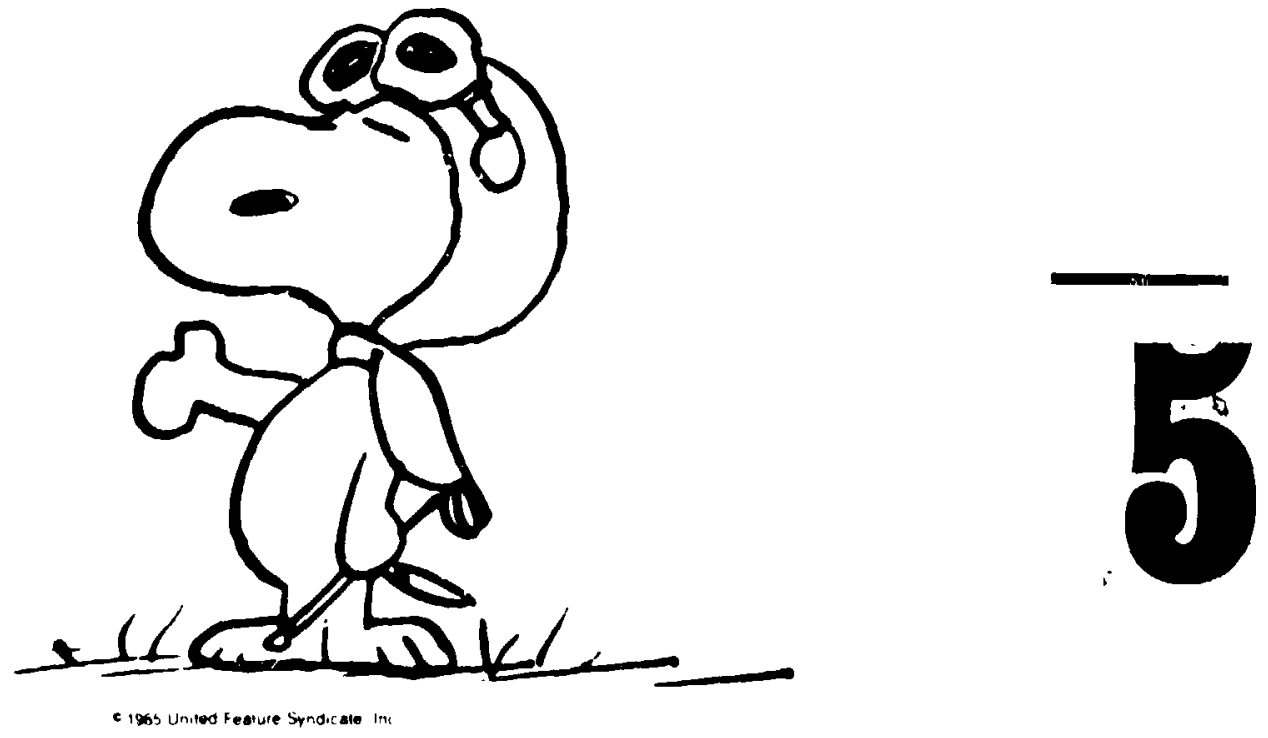


\section{CHAPTER V \\ AVIATION SERVICE ANALYSIS: A GUIDEBOOK \\ INTRODUCTION}

This guidebook is designed to assist local decision-makers-elected and appointed officials. and other interested individuals in a community - in the process of determining whether or not aviation senices are required to fulfill the needs of the residents of their communities. The use of this guidebook clearly implies that: (1) local communities must make a choice about the level and kind of aviation services they want; (2) this choice must be made with the involvement of the public throughout the process; and, (3) the process of making the choice relating to obtaining access to aviation services may be terminated at many different stages of the choice process.

The guidebook is organized in a flow chart pattern with an accompanying text at various stages of the flow chart. The users of the guidebook must be careful to follow through the steps in the flow chart in the sequence presented. An " $X$ " after a topic number indicates that the particular sequence is completed. At times appropriate cross-references are made to previous positions in the flow chart. These must also be used where they are indicated. Finally, it is best to think of this guidebook as an outline of the steps one must follow, and the items one must consider, in establishing access to aviation services for the residents of a local community.

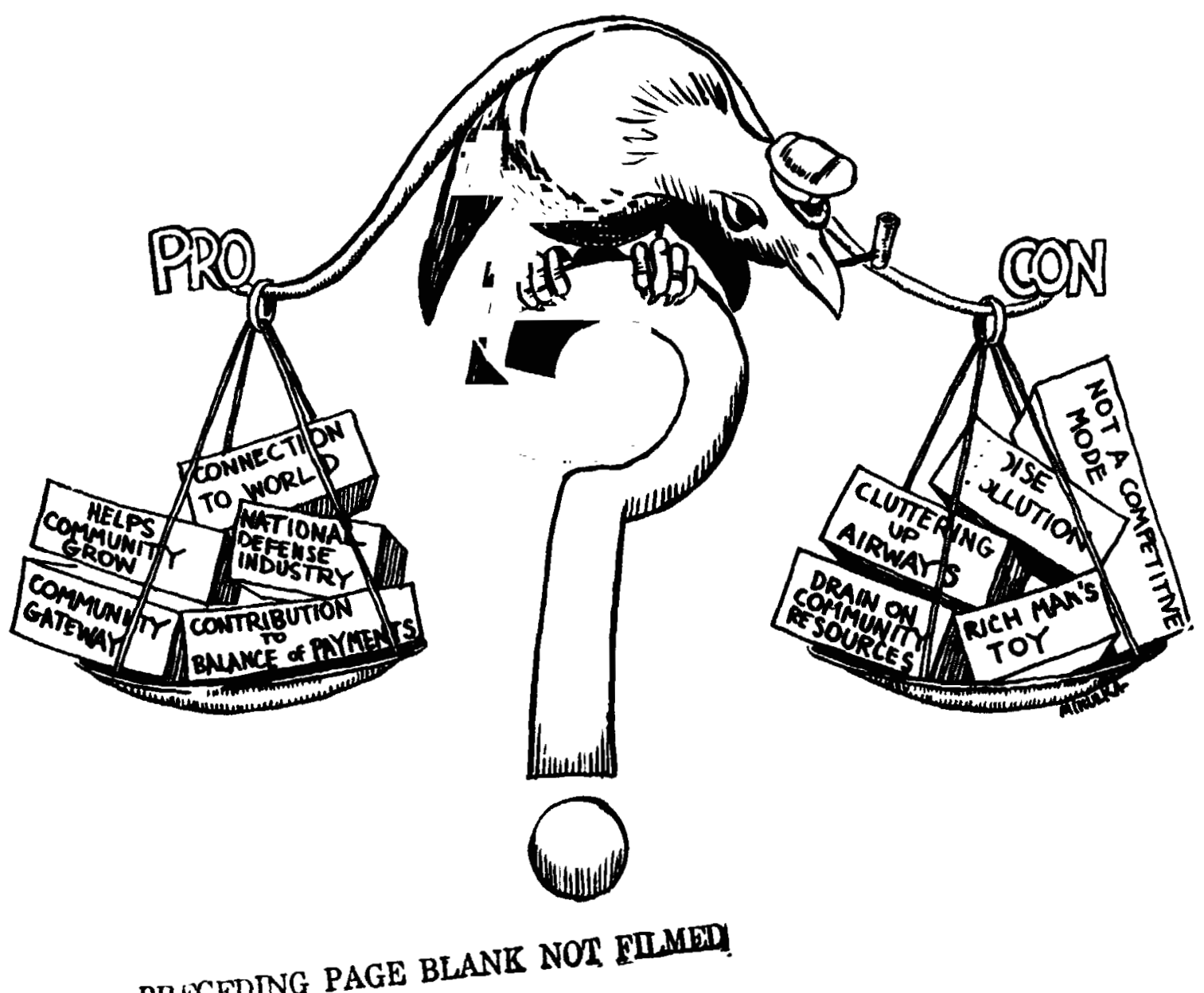


START

t

(1)

1

(2)

$-(3) x$
$-(4) x$
$-(5) x$
$-(6) x$
(1) Community Goals

Consider: external influences

internal influences

community characteristics

(2) Inventory of Transportation Services-Consider the modes of transportation available to the population center in terms of provider costs and user costs. Figure 5-1 helps to determine the trade-offs available between the types of transportation and the distance traveled.

(3) Automobile-Consider types (interstate, arterial, primary, and secondary) and number of highways available. How far do your people usually travel? If the automobile meets your total transportation requirements, there is no need to continue the analysis.

(4) Bus and Truck-What intercity bus services are available? What is the trucking ability (number of tons/year) in your area? Do the bus and truck services meet the remaining needs of your population center? If yes, there is no need to continue the analysis.

(5) Rail-What freight andior passenger services are available? Do they serve the remaining transportation needs of your population center? If yes, there is no need to continue the analysis.

(6) Water-What water transportation services are available? Do they serve the remaining transportation needs of your population center? If yes, there is no need to continue the analysis.

TO TOPIC 7. 
FROM TOPIC 2.

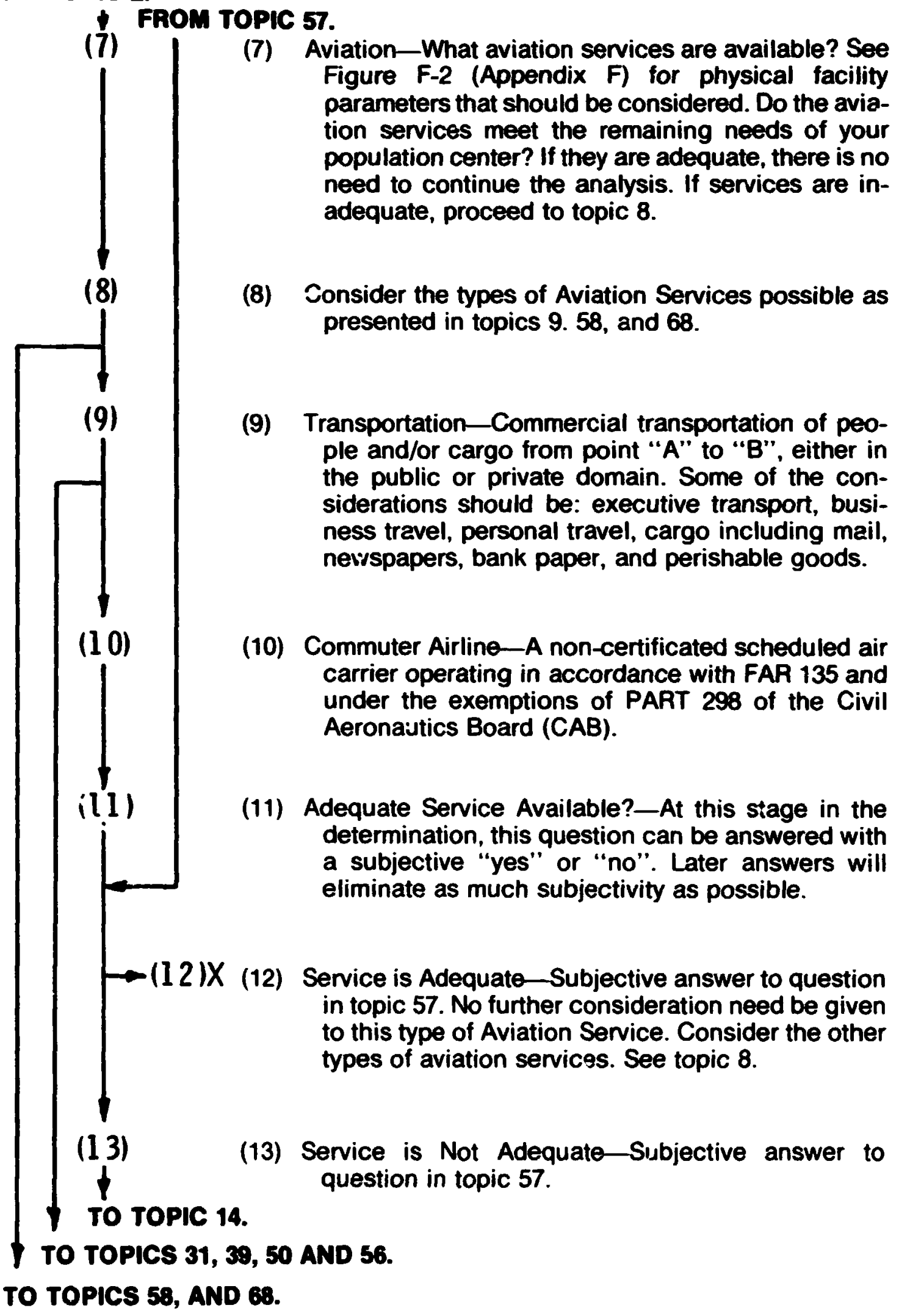


FROM TOPIC 13.

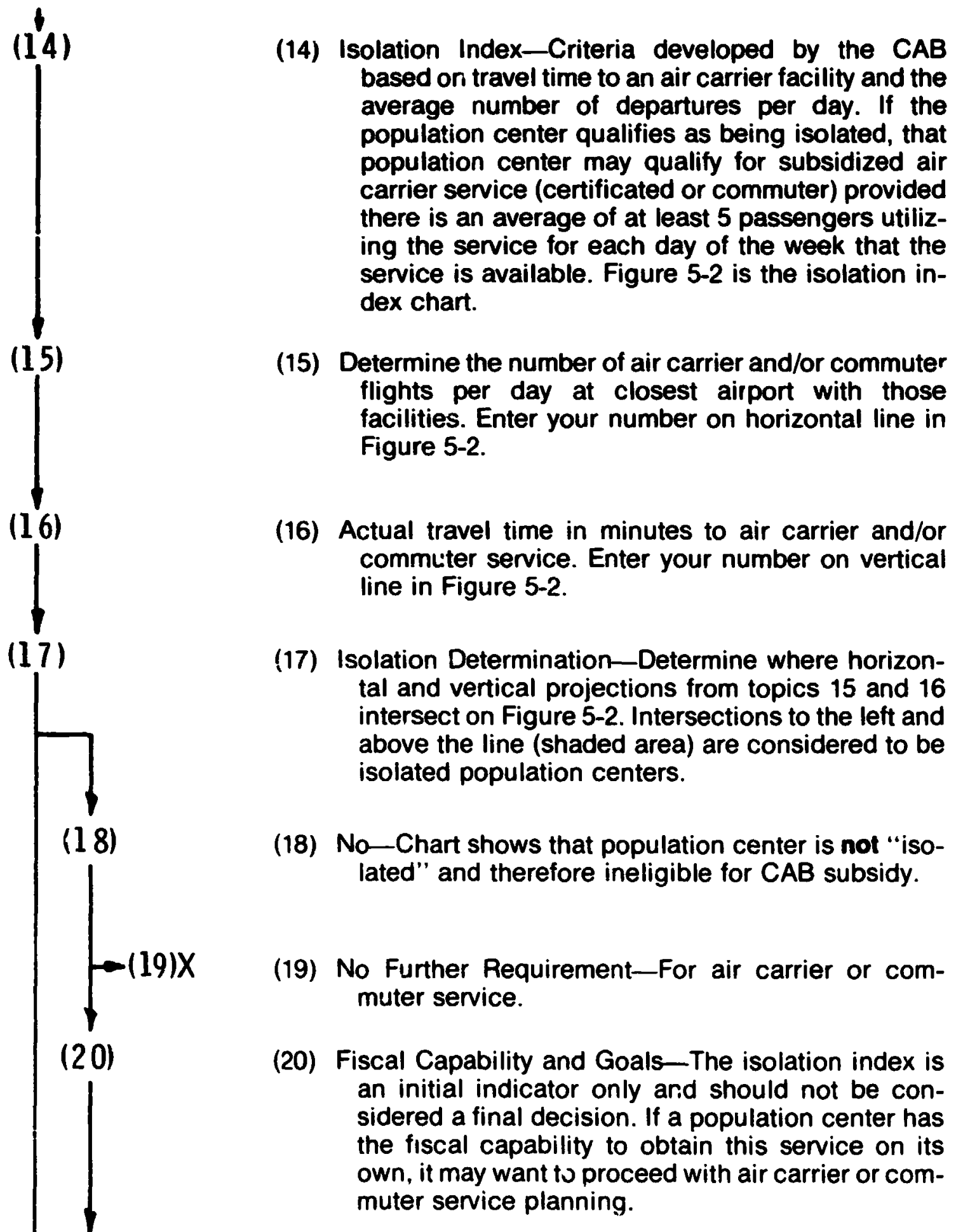

TO TOPIC 22.

TO TOPIC 21. 
FROM TOPIC 20.

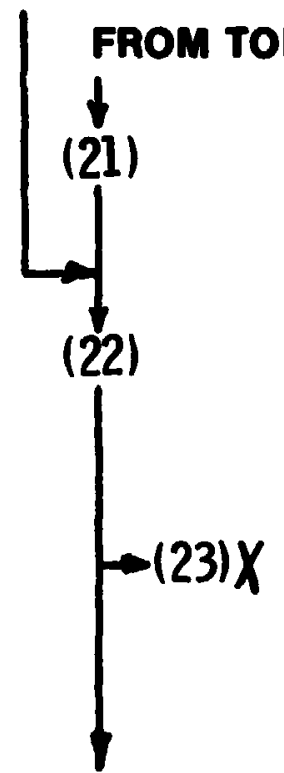

(24)

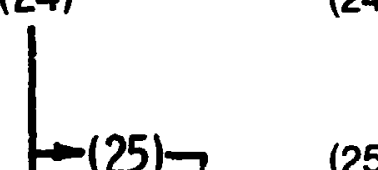

(25)

Geographic Considerations-Are there terrain features that may or may not support the requirement for commuter services? Can the terrain and soil base support an airport with orientation to local winds and anticipated aircraft weights? Are the potential airport sites accessible for ground and air transportation? Is the travel time to the potential sites reasonable? Is there a serviceable airport located nearby?

(26)

Industrial Base-The type of industry in an area influences the amount and type of air transportation. Primary industries (such as agriculture and mining) generate less air travel than service type industries (such as insuranco, banking, and marketing).

(27) Community Goals-How do commuter services relate to the developmental goals of your community? 
FROM TOPICS 25, 26, 27, 35, 36, 37, 38, 48, 49, 54, 55, 60, 61, 62, 63, 64, 66, 67, $69,70,71$, AND 72.

\section{FROM TOPIC 24.}

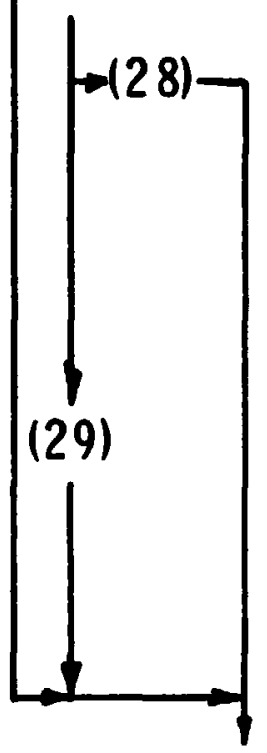

(28) Demographic - Is there a sufficient size population to justify commuter service? Is the population density sufficient to justify commuter services? What is the age distribution of the population center? How mobile is the population-both short and long term?

(29) Transportation Objectives-Has the population center considered comfort, safety, minimum loss to the users, maintenance of environmental quality, general public satisfaction, and monetary costs for the transportation objective?

(30)

(30) Airport Facilities_-Perform an inventory of existing airport facilities and forecast anticipated use of the facility. Methods for predicting based aircraft, annual operations, travel demand, and cargo demand are shown in Tables V-I, V-II, V-III, and V-IV.

TO TOPIC 73. 
FROM TOPIC 9.

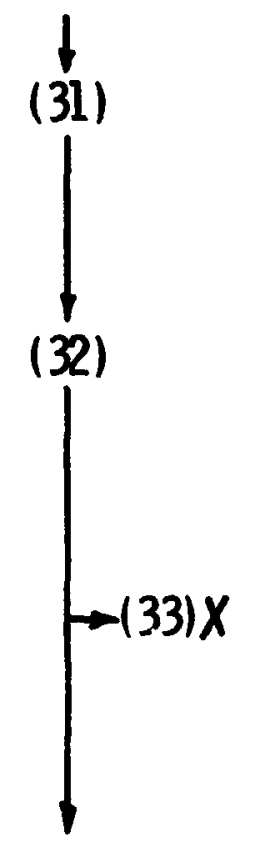

(34)

$\left[\begin{array}{l}-(35) \\ -(36)-1 \\ -(37)-1 \\ -(38)-\end{array}\right]$

(31) Air Taxi-A non-certificated, non-scheduled service operated in accordance with FAR 135 and under the exemption of PART 298 of the CAB.

(32) Adequate Air Service Available?-At this stage in the determination, this question can be answered with a subjective "yes" or "no." Later answers will eliminate as much subjectivity as possible.

(33) Service is Adequate_-Subjective answer to question in topic 11. No further consideration needs to to given to this type of aviation service. Consider the other types of aviation services. See topic 2.

(34) Service is Not Adequate-At the time of the inventory.

(35) Geographic Characteristics_Does the location of the population center (island, etc.)influence the need for air taxi service? Is there a geographic limitation that may prevent the establishment of an airport? Would another airport be closer than the proposed airport?

(36) Population Size-Are there enough pecole in the population center to support the needs of an air taxi service?

(37) Industrial Base-List the industries in your area and determine their dependence or lack of it on aviation.

(38) Community Goals - List the goals of the community and determine if an air taxi operation fits into the goal pattern.

TO TOPIC 30. 


\section{FROM TOPIC 9.}

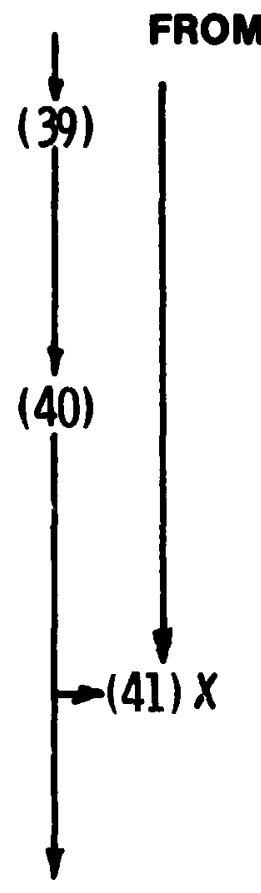

(42)

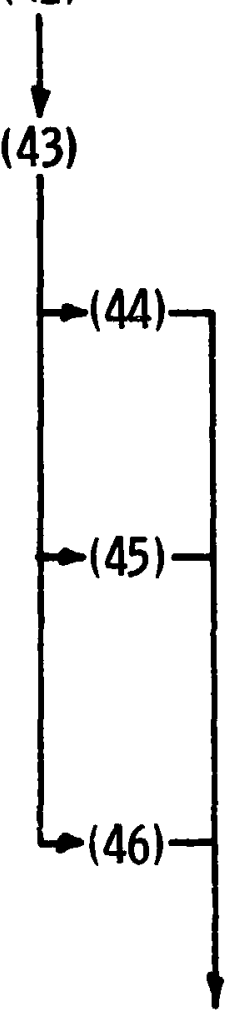

(39)

Business and Corporate Aviation-That part of general aviation which uses aircraft in the pursuit of its own business and corporate function, but does not "hold out to the public."

(40)

Adequate Service Available?-At this stage in the determination, this question can be answered with a subjective "yes" or "no." Later answers will eliminate as much subjectivity as possible.

(41)

Service is Adequate-Subjective answer to the question in topic 40 or 51 . No further consideration needs to be given to this type of aviation service.

(42)

Service is Not Adequate-This service was not adequate at the time that an inventory of services was developed.

(43) Type of Industry - List the industries in your area and determine their dependence or lack of it on aviation.

(4i) Minirig and Primary Industries-These industries have historically used few aircraft in their business. Typical industries in this category are raw material mining companies, and agriculture, other than spray application.

(45) Industrial-These industries usually occupy a position between the industries of topics 44 and 46 in the amount of dependence on aviation services. Typical industries in this category are appliance manufacturers and automotive equipment manufacturers.

(46) Service-Traditionally, these businesses utilize business aircraft the most. Typical industries are sales firms, marketing firms, insurance companies, and banking institutions.

TO TOPIC 47. 
FROM TOPICS 44, 45, AND 46.

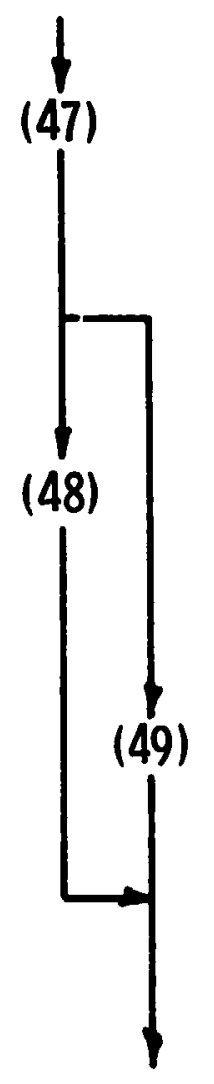

(47) Needed Aviation Services-Based on the inventory of existing businesses, a determination should be made of what types of aviation services will be needed. What size and type aircraft are the companies using? How does this affect the airport facility? What services will be necessary at the airport? (fuel, maintenance, tie-down, hangar, offices, flight personnel)

(48) Transient Only - If the aviation services are for transient aircraft only, then there wili be fower facilities required and less revenue derived from the airport.

TO TOPIC 30.

(49) Aircraft Primary Base_- If business aircraft are based at the airport, there is a higher renuirement for facilities and also a potentially highs. income from the airport. 
FROM TOPIC 9.

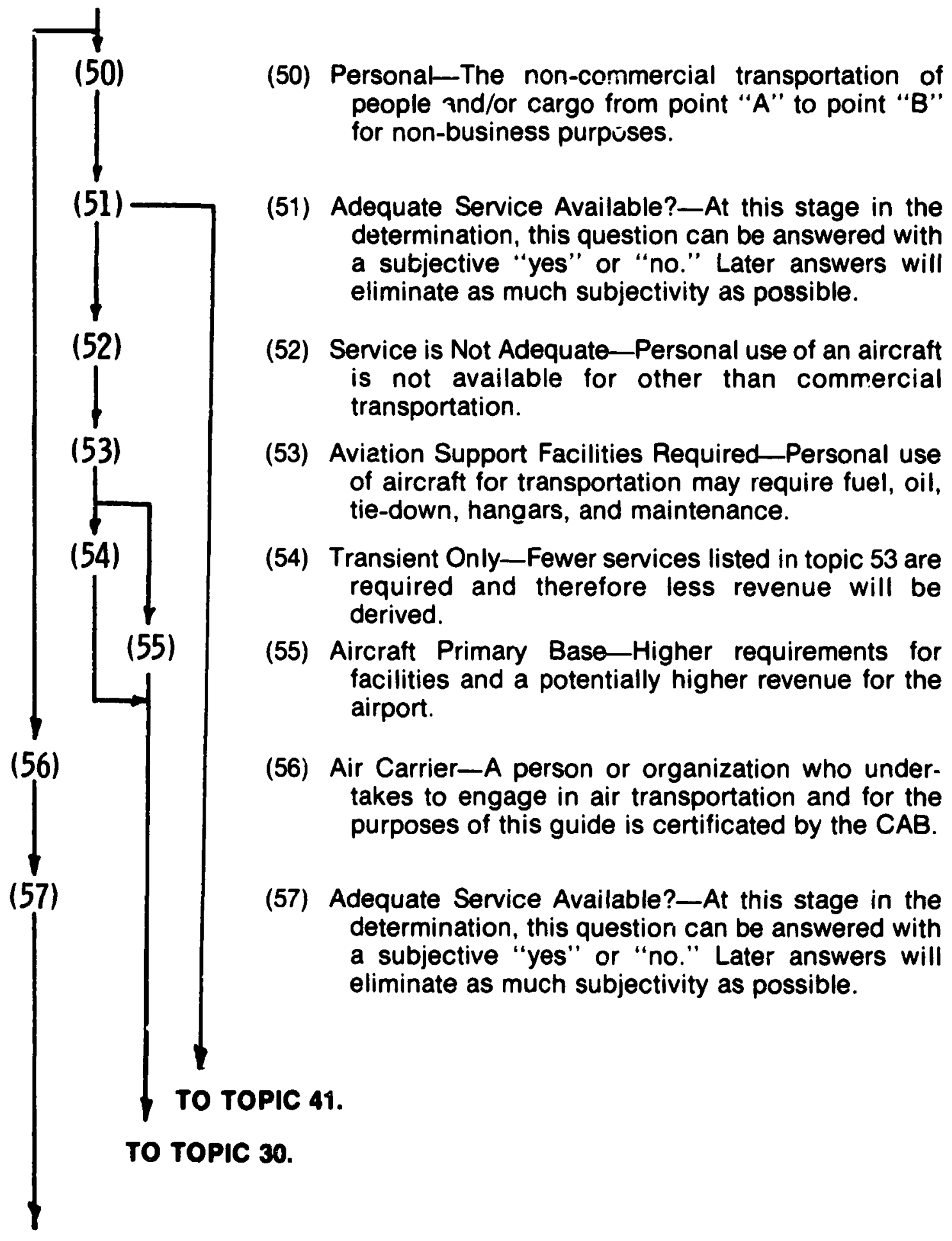

TO TOPICS 12 AND 13. 


\section{FROM TOPIC 8.}

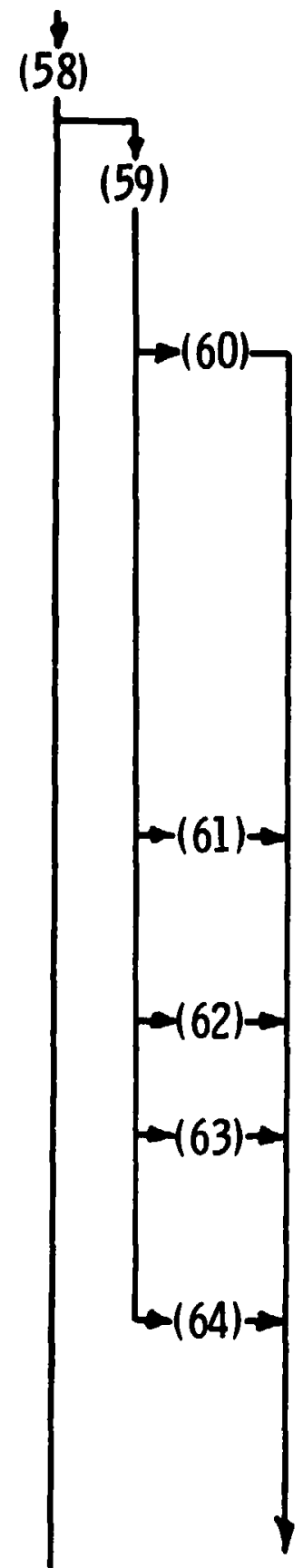

(58) Services_-Services provided in support of other primary community functions.

(59) Industrial Services_Services such as: aerial photography; advertising; agricultural management; utility patrols; construction; and flight training.

(60) Geographic Considerations - Is there a geographic uniqueness that is compatible with aviation? For example: large agricultural area for spray applications, fish spotting along coastal areas, logging with helicspters in rough terrain. Is there a geographic limitation that may prevent the establishment of an airport? For example: no available airspace that would not conflict with present aviation functions; terrain is too rough to establish an airport; available land does not align well with winds in the area.

(61) Industrial Base-Does your community have an industrial base that will support aircraft services silch as: aerial photography, fishing, mining, ac riculture, or large forestry operations.

(62) Population-Is there sufficient population to make these aircraft services economical?

(63) Types of Industry-Certain types of industries rely more heavily on aviation than other types. List the industries in your area and determine their dependence or lack of it on aviation.

(64) Community Objectives-Does the community want development in those areas where aircraft services are normally used?

TO TOPIC 30.

\section{TO TOPIC 65.}


FROM TOPIC 58.

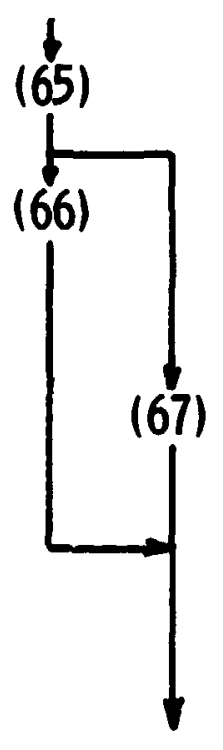

(65) Special Community Services-Services in the police, fire, and medical emergency areas.

(66) Geographic Considerations-1s the terrain relatively inaccessible for rescue purposes with other than a helicopter? Is wildlife management required?

(67) Public Welfare Requirements-How can aircraft be used to improve the welfare of the public? Examples: some types of traffic control, shark patrol, water safety patrols, fire fighting, ambulance service.

TO TOPIC so. 
FROM TOPIC 8.

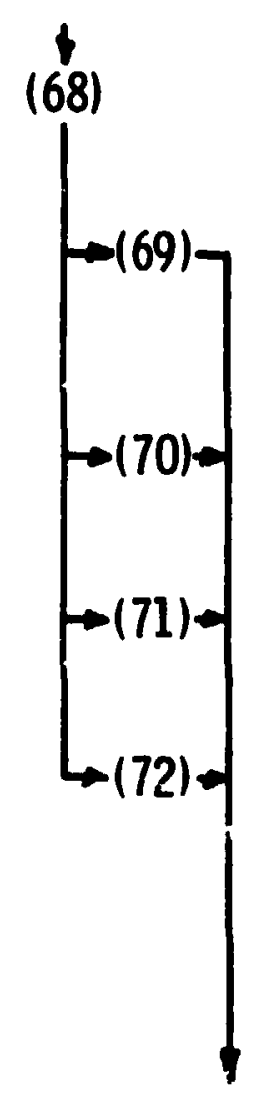

(68) Recreational Flying-Non-revenue flying that does not involve transportation (topic 9) or services (topic 58).

(69) Geographic Considerations - Is there a geographic limitation that may prever.t the establishment of an airport? Would another airport be closer than the proposed airport?

(70) Population Size-Are there enough people in the population center to support the needs of recreational flying?

(71) Average Income-ls the average income in the population center large enough to support recreational aviation?

(72) Aircraft Owners-How many aircraft owners are there in the area who will be willing to base their aircraft at the airport? What type of aircraft do they have and how many hours does each - ccraft fly annually?

TO TOPIC 30. 
FROM TOPIC 30.

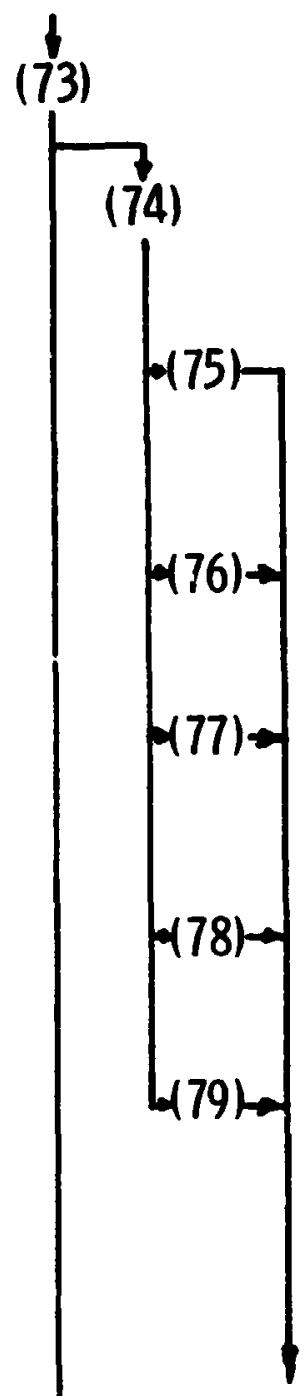

(73) Type of Sponsors-Determine the type of sponsor desired, based on the topics that follow.

(74) Private-A community may make an agreement with a private airport developer for the airport to be open for public use.

(75) Funding-The developer may borrow at a low interest rate, incorporate and sell stock, or use available funds. No community funds would be necessary.

(76) Common Law Liability-No community liability, the owner or operator of the airport would be responsible.

(77) State Regulations_Some states license airports. If your state does, the airport owner may need to obtain a license. State funds may be available for development.

(78) Federal Regulations_FAA and CAB should be checked for possible regulation of the aviation service(s).

(79) Community Control-The airport can be controlled through zoning laws regulating its location and surrounding development. However, the airport may be closed at any time by its owners.

TO TOPICS 111 AND 112.

TO TOPICS 80, 99, AND 105. 


\section{FROM TOPIC 73.}

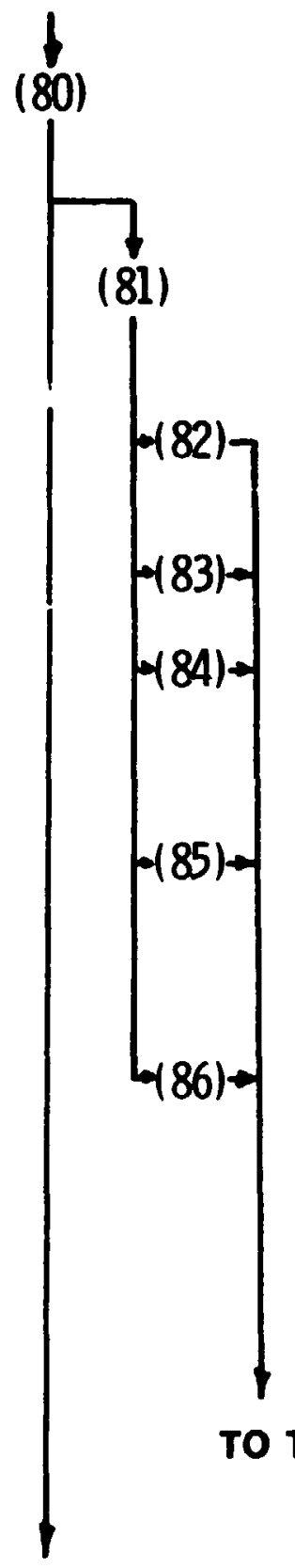

(80) Local Community-The community may have the means to sponsor an airport. Zoning laws are necessary. The power of eminent domain to acquire land is helpful.

(81) Direct Ownership-One or more communities may own and operate an airport as part of their regular government function.

(82) Funding-Financing is available through property taxes or a bond issue. The bond issue may have to be approved by a general referendum.

(83) Common Law Liability - The community is liable.

(84) State Regulations_States may license airports. State funds may be available for airport development. Most states approve applications for federal funding.

(85) Federal Regulations-FAA has regulations depending on the type of airport. CAB controls certificated air carrier service. Community may request federal aid for developing master plan and constructing the airport.

(86) Community Control-Community ownership gives the locality the greatest degree of control possibie. Revenues returned to the general fund may be hard to use for airport improvements.

TO TOPICS 87 AND 93. 
FROM TOPIC 80.

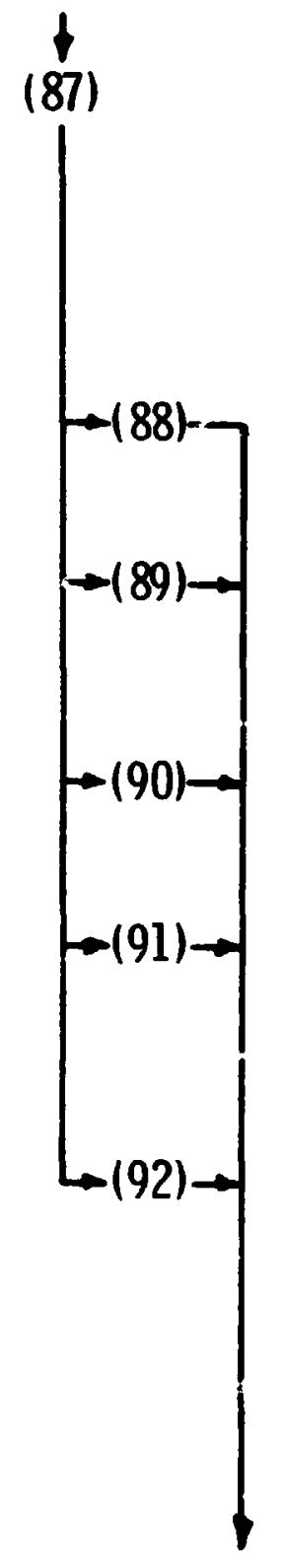

(87) Airport Commission or Authority-May own and/or operate the airport. Members are usually appointed from communities involved. Determine if a commission or authority already exists or if one is available to join. The state may have an enabling act which allows a community to set up such a body.

(88) Funding-The airport body may issue revenue bonds, which are redeemed by income from the airport.

(89) Common Law Liability-The commission or authority is liable. The community may be vicariously liable, depending on the degree of control it exercises over the commission or authority.

(90) State Regulations_Possible licensing of airports, funding through state, and approval of federal fund requests.

(91) Federal Regulations_FAA has airport safety regulations, $C A B$ controis certificated air carrier service. The community may request aid for developing master plan and constructing an airport.

(92) Community Control-Depends upon the enabling act: the community may appoint officials to an independent body, the state may appoint them, or they may be elected by the voters of the community. The cornmission or authority may act as the champion of the airport.

TO TOPICS 111 AND 112. 
FROM TOPIC 80.

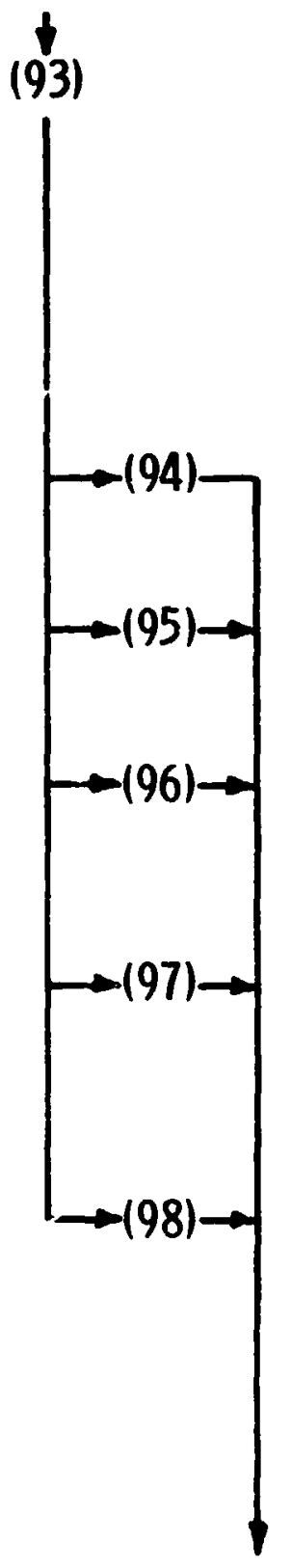

(93) Port Authority-May own and/or operate all transportation facilities withir, member communities. Members are appointed from the communities involved. State enabling acts may allow formation of an authority by a community. If the authority is to be composed of two or more states, an act of Congress is required. Determine if an authority already exists for the area.

(94) Funding-Authority issues revenue bonds which are redeemed by income from the systems in the authority.

(95) Common Law Liability-Authority is liable. Responsibility of members depends on their degree of control over the authority.

(96) State Regulations - If composed of states, the members may have the control. The states may license airports, provide funding, or approve the request for federal funds.

(97) Federal Regulations-FAA has airport safety regulations. $C A B$ controls certificated air carrier service. The Port Authority may request aid for developing the master plan and constructing the airport.

(98) Community Control-Provides the best coordination of transportation facilities. As the number of communities increases, the control by an individual community decreases. Authority may be completely independent, depending on the enabling act.

TO TOPICS 111 AND 112. 
FROM TOPIC 73.

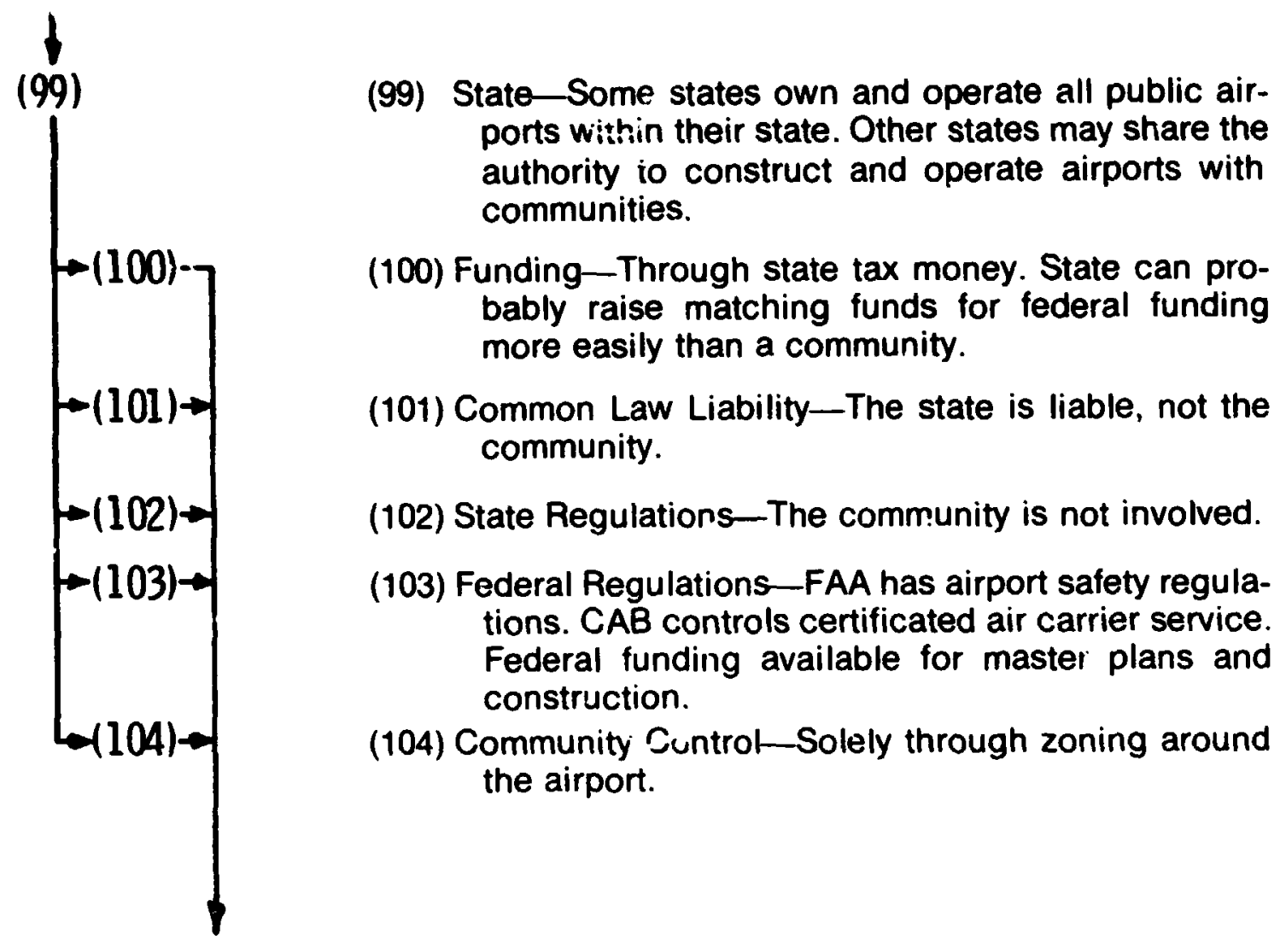

TO TOPICS 111 AND 112. 
FROM TOPICS 75, 76, 77, 78, 79, 82, 83, 84, 85, 86, 88, 89, 90, 91, 92, 94, 95, 96, 97, AND 98.

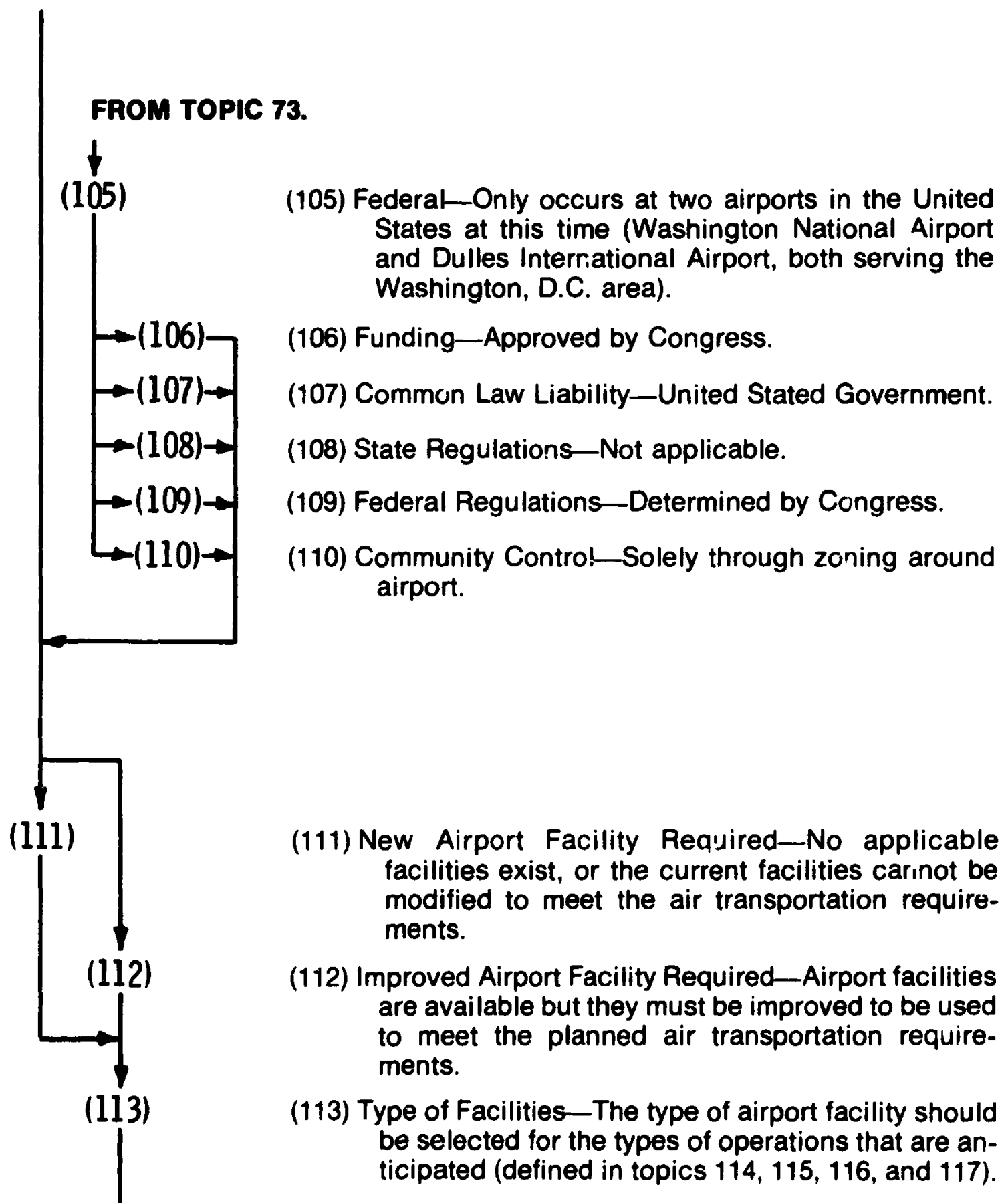

TO TOPICS 114, 115, 116, AND 117. 
FROM TOPIC 113.

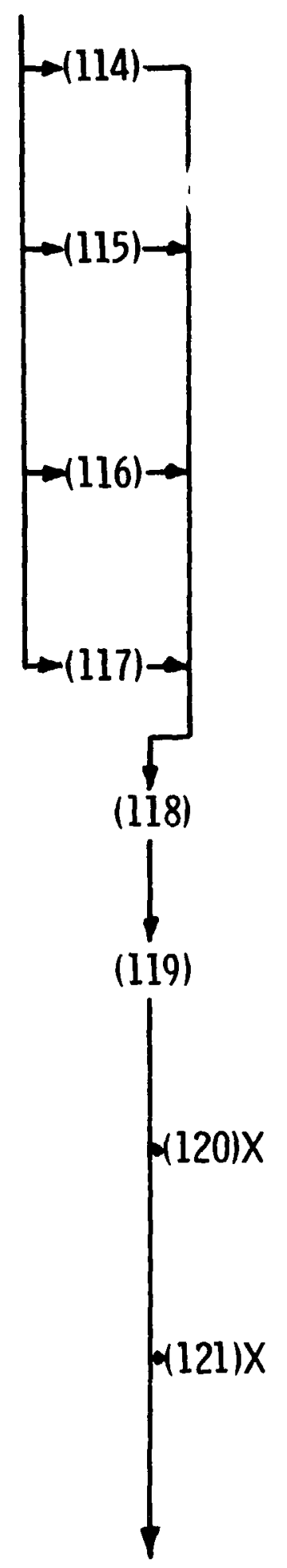

(114) Basic Utility-Airport accommodating 95\% 0: general aviation propeller aircraft under 12,500 pounds (FAA AC 150/5300-4A, 11-68).

(115) General Utility-Airport accommodating substantially all general aviation propeller aircraft under 12,500 pounds. Airport should have at least 500 annual itinerant operations between 8,000 and 12,000 pounds (FAA AC 150/5300-4A, 11-68).

(116) Basic Transport-Airport accommodating all general aviation aircraft up to 60,000 pounds gross weight. Should have at least 500 annual itinerant operations between 12,500 and 60,000 pounds (FAA AC 150/5300-4A, 11-68).

(117) General Transport-Airport accommodating transport category aircraft up to 175,000 pounds gross weight. Shuuld have at least 10 itinerant departures per week (FAA AC 150/5300-4A, 11-68).

(118) Funding Support-The population center must decide what type of funding is ai:ailable, what type it prefers to use, and for what purposes the funding may be used.

(119) Local-Funding support must start at the local population center level. The five choices listed in topics $119,120,121,124$, and 123 exist.

(120) Private Funding-Funds for the airport may be provided entirely from private sources. In this case the airport belongs to that private source and is not eligible for federal funds. In some states, it may receive limited support with state funds.

(121) $100 \%$ Local Public Funds-Airport will be funded wholly by the local population center. It may be eligible for state and federal funds for future development. Bonds, tax levies and donations may be used to fund the facility.

TO TOPICS 122, 124, AND 125. 
FROM TOPIC 119.

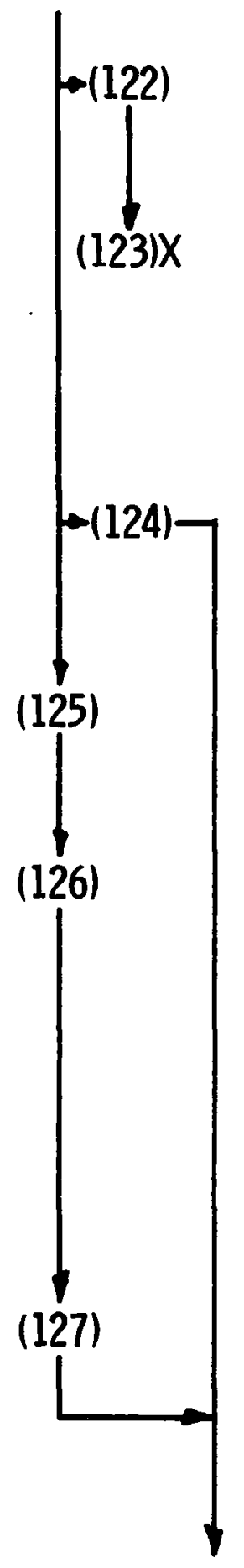

(122) $50 \%$ Local Funds_-If only local and state funds are used, the local population center is usually expected to fund $50 \%$ or more of the program.

(123) $50 \%$ State Funds-If only local and state funds are used, the state is usually expected to fund up t', $50 \%$ of the program cost. Local population center should determine what amount of assistancs the state is able to provide. Future action depends on the state regulations that relate to airport funding and development.

(124) $25 \%$ Local Funds-Unless a public agency's powers are limited by state law or state funds are not available, the local population center may elect to use only local and federal funds. In that case, the local share will be $25 \%$.

(125) $12.5 \%$ Local Funds - If state and federal funds are anticipated, the local population center is usually expected to fund $12.5 \%$ of the program costs.

(126) Airport is Part of the National Airport System PlanThis is a requirement in order to obtain federal funds. If the proposed airport is not part of the NASP, local action should be initiated to place the airport in the NASP. Application for a planning grant is made on FAA Form 5100-101, Application for Federal Assistance (Nonconstruction Programs), signed by an authorized local authority and transmitted to the appropriate FAA field office. (See FhA advisory circular 150/5900-1A.)

(127) State-If the state is involved in the funding, the local population center should check state requirements. The state's share of the funding is usually $12.5 \%$.

TO TOPIC 128. 
FROM TOPICS 124 AND 127.

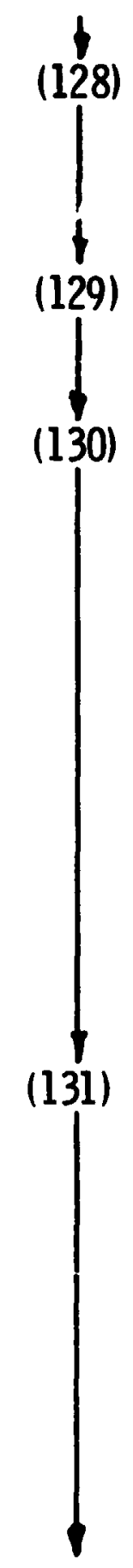

(128) $75 \%$ Federal Funds-The maximum subsidy that the local population center can expect from the Federal Government under ADAP. Funds may only be used for federally designated purposes.

(129) Planning Grant--ADAP Sec. 13 [ 84 Stat 224] limits federal grants for planning to $2 / 3$ of the planning cost. Inclusion of Environmental Impact Statement is optional.

(130) Public Agency Submits Project Application-Required by Sec. 16 [ 84 Stat 226] . Inclusion of environmental impact statement is required. Environmental impact statement should include:

(1.)Environmental Impact-noise, air quality, water quality, hydrology, wildlife, scenic assets, recreational assets.

(2) Unavoidable adverse effects.

(3) Alternatives to the action.

(4) Relationship between short-term uses and maintenance and enhancement of long-term productivity.

(5) Any irreversible or irretrievable commitment of resources.

(See DOT P 5600.1, Airports and Their Environment.)

(131) Develop Phase I Airport Requirements_This is the first step in the development of the airport master plan in accordance with FAA advisory circular 150/5070-6. Topics to be included are: inventory; forecasts of aviation demand; demand/capacity analysis; facility requirement determination; and, environmental study. In the evenironment study, the following impacts are to be considered: aircraft noise, land use, air pollution, water pollution, hydrology, and ecology.

TO TOPICS 132 AND 133. 
FROM TOPIC 131.

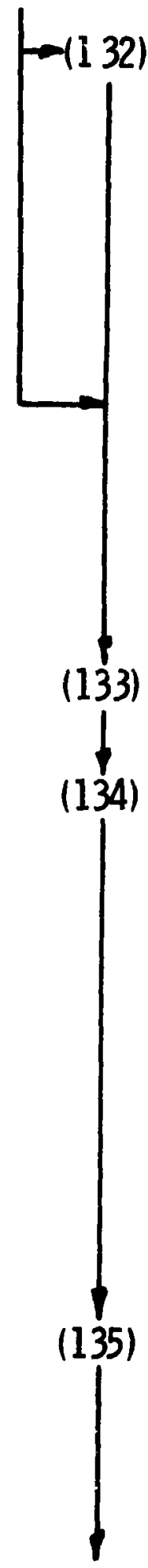

i-32) Public Hearing-It is not mandatory that a public hearing be held at this time, but experience has indicated that the more opportunity the public has to be informed, the less likely it is that the public will oppose the facility in its later stages of development. Federal regulations require that airport sponsors and planners should seek out and consider the views of interested parties, including those of federal, state, or local agencies, or the public at large. The preliminary environmental impact statement must be made available to the public at least 30 days before a public hearing. A transcript of the hearing must be prepared and a summary of it must accompany the environmental impact statement. (See FAA advisory circular 150/5100-7A for further details.)

(133) Submit the Phase I Plan to the State and Federal Government for Approval.

(134) Develop Phase II, Site Selection Plan-After approval of Phase I, the Phase II plan should be prepared in accordance with FAA advisory circular 150/5070-6. Topics to be included are: airspace requirements; environmental factors; community growth patterns; airport access; availability of utilities; land costs, site development costs; and, political considerations. Environmentai impact statements are required for all major federal airport development actions significantly affecting the quality of the environment. "Significant" in the previous sentence is defined in DOT order 5610.1A, attachment 1, page 2. A negative declaration is required if there is no significant impact.

(135) Public Hearings-Required at this time by the FAA. ADAP requires a public hearing some time after topic 45 and before federal approval is received.

TO TOPICS 136 AND 137. 
FROM TOPIC 135.

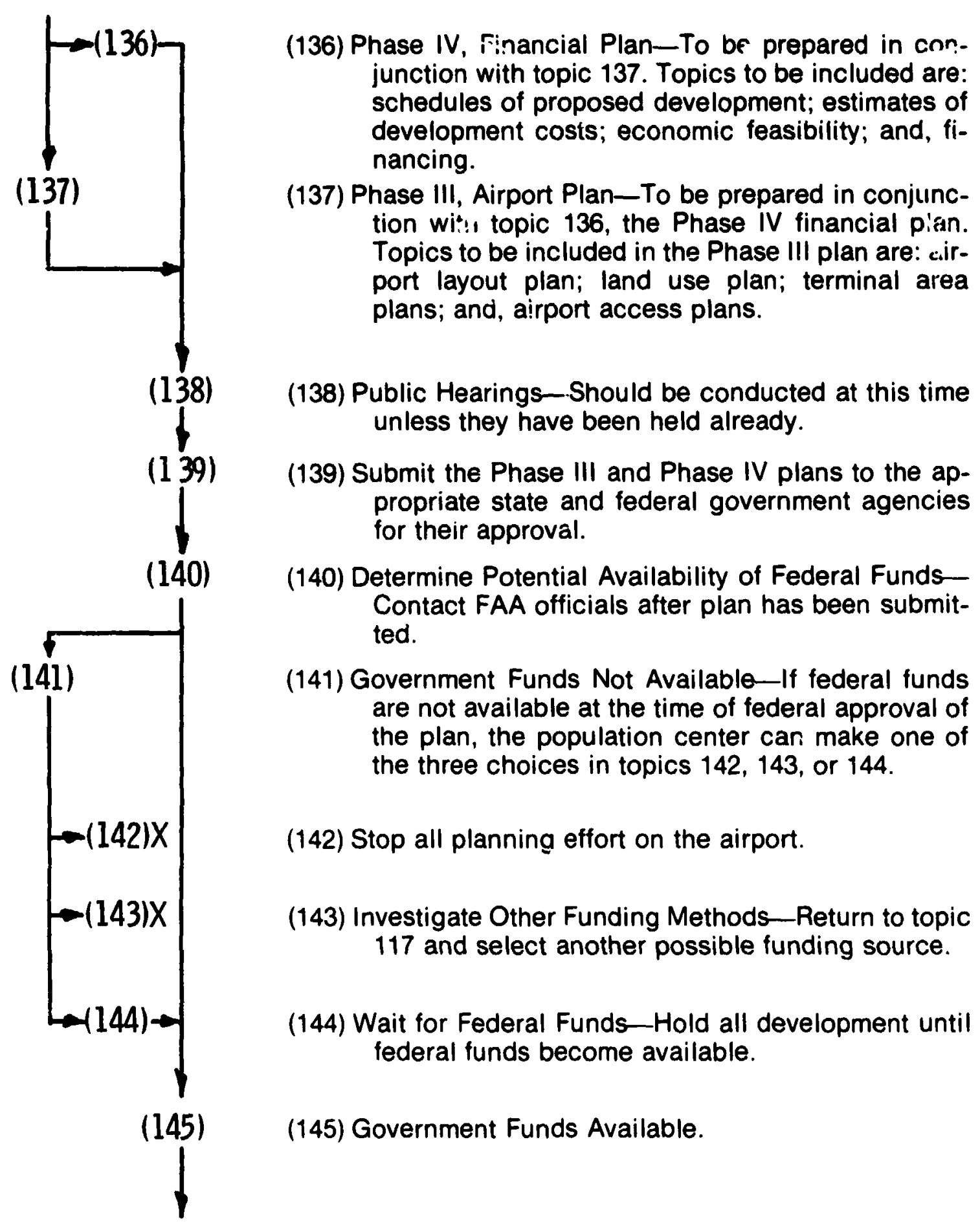

TO TOPIC 146. 
FROM TOPIC 145.

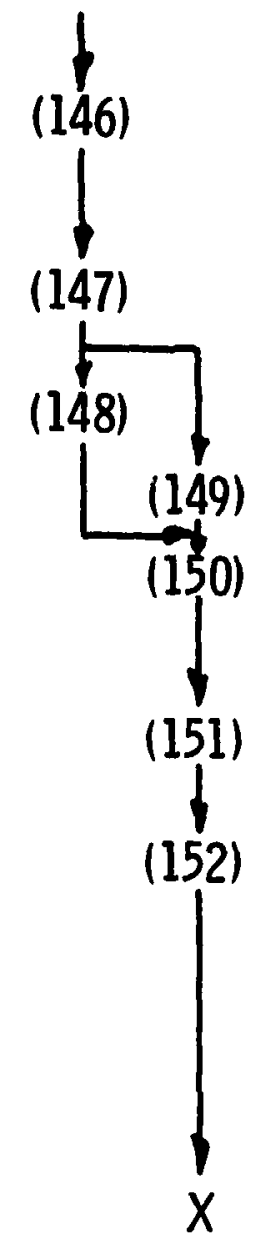

(146) Receive notice from the FAA to obtain firm financial data for justification of specific federal funds.

(147) Develop invitations to bid for submission to potential contractors.

(148) Site Procurement Bid.

(149) Contractor Bids.

(150) Receive quotes from all potential bic sources. Select the best bids and prepare financial data for submission to FAA.

(151) Submit financial data to FA.A in the format requested.

(152) Receive notification from FAA and the state that funds are available and that the construction can proceed.

THE END. 


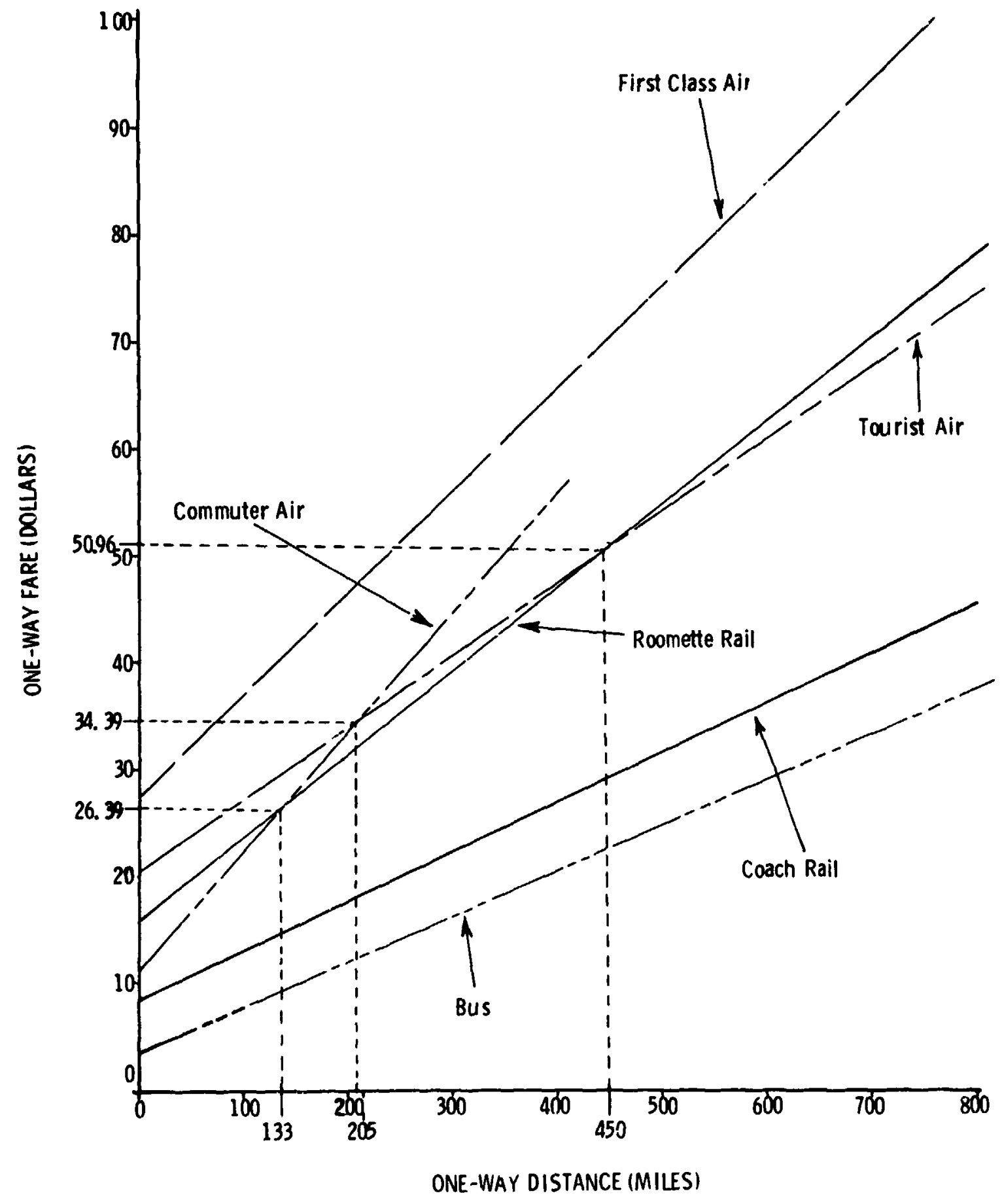

TRANSPORTATION TRADEOFFS

FIGURE 5-1 


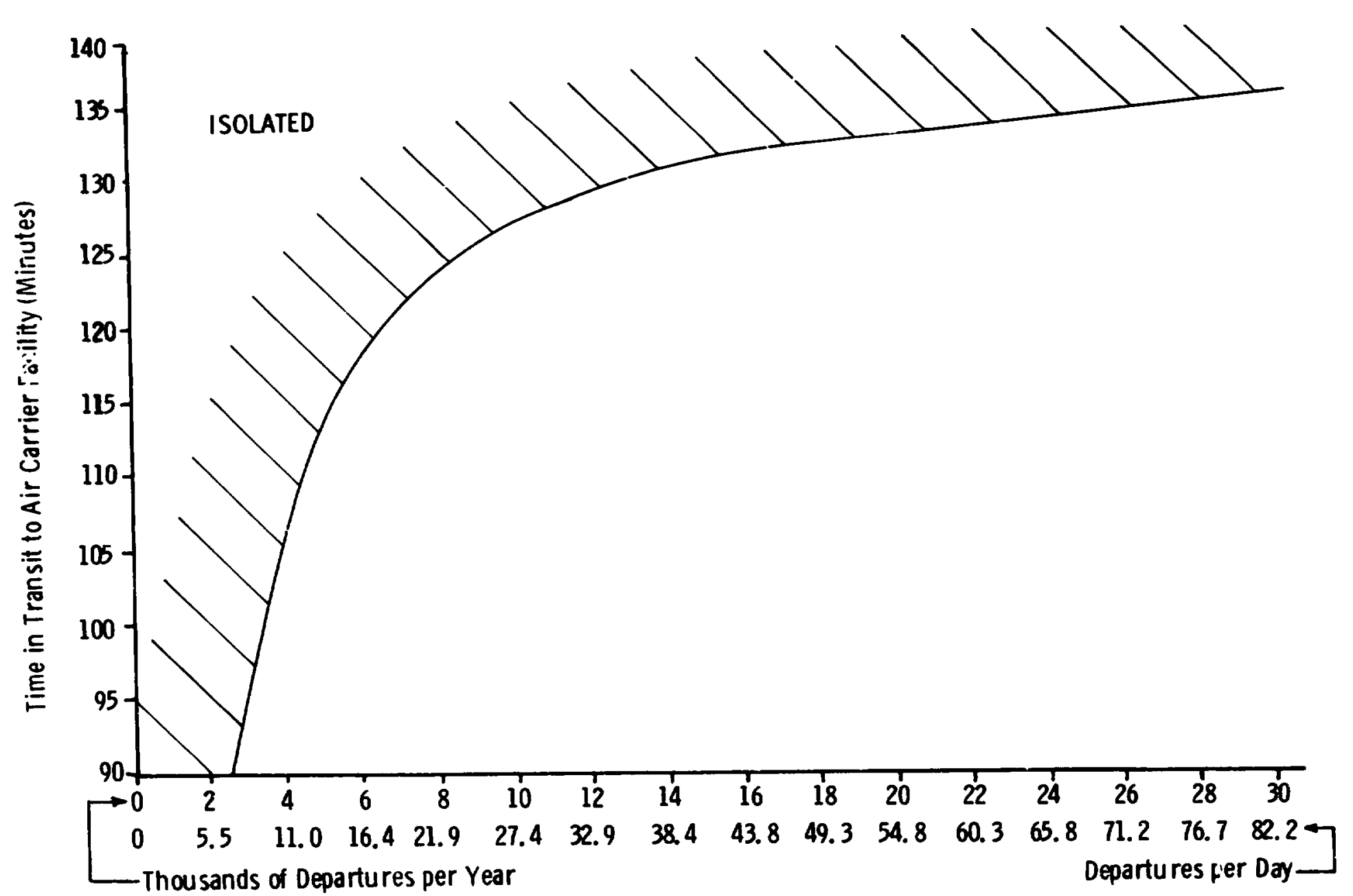

Source. Service to Small Communities, Part III Policy Alternatives and Recommendations.

A staff study of the BUREAU GF OPERATING RIGHTS, Civil Aeronautics Board, 1972

ISOLATION INDES

FIGURE 5-2 


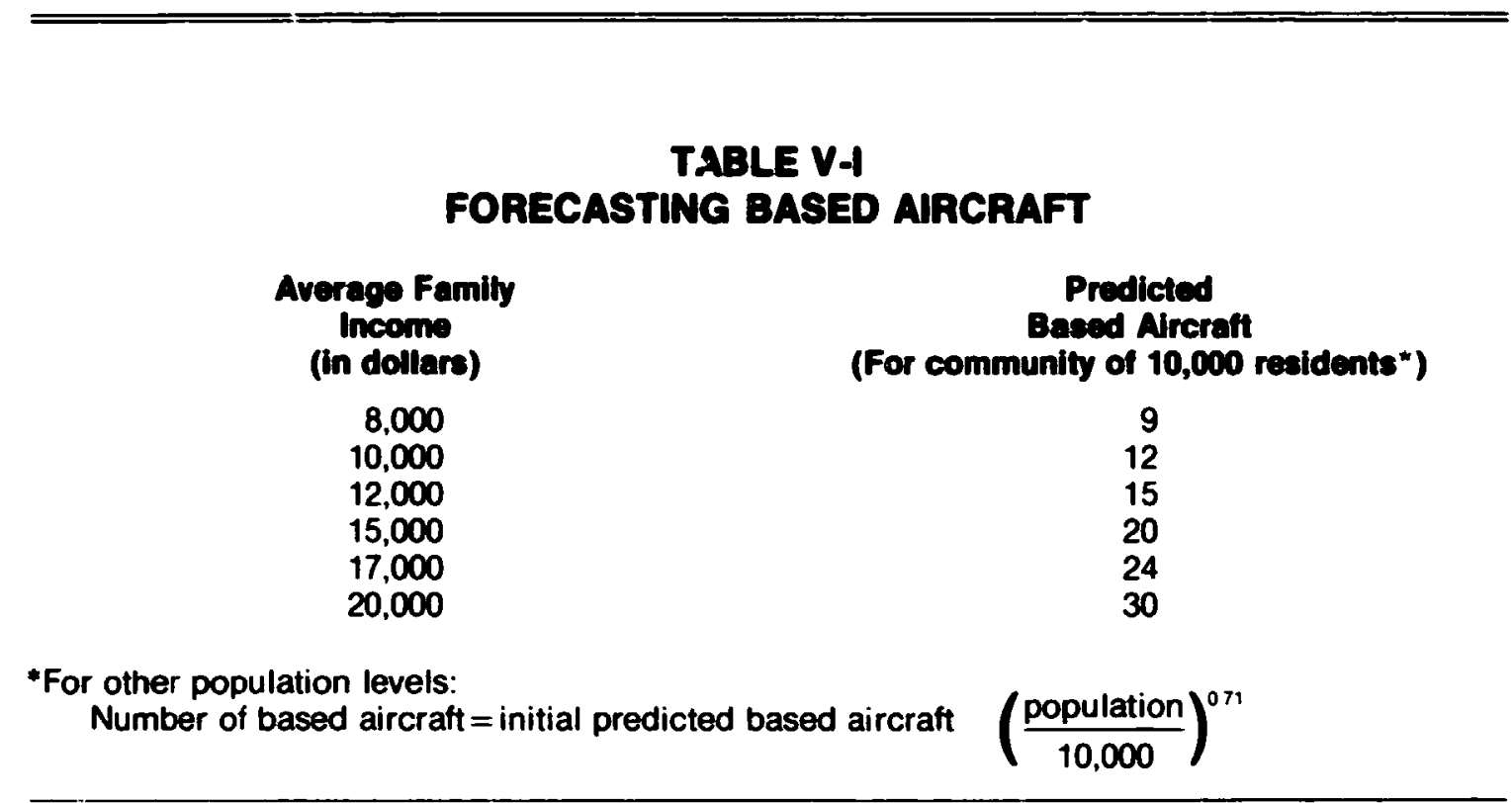

Source: Based on data obtained from the Final Dratt of the Virginia Air Transportation System Study and also from Chapter !! of this Report.

TABLE V-II

FORECASTING AIRPORT OPERATIONS

Per Capita Income

(in dollars)

$$
\begin{aligned}
& 1,500 \\
& 1,750 \\
& 2,000 \\
& 2,250 \\
& 2,500 \\
& 2,750 \\
& 3.000 \\
& 3,250 \\
& 3,500
\end{aligned}
$$

Annual

Aircraft

Operations

(for community of 10,000 residents*)

5,200

6,200

7,300

3,400

9,500

10.600

11,700

12.900

14,000

* For other population levels:

Annual Aircraft Opperations $=$ initial annual aircraft operations

$\left(\frac{\text { population }}{10,000}\right)^{0.57}$

Source: Based on data obtained from the Final Draft of the Virginia Air Transportation System Study and also from Chapter II of this Report. 


\begin{tabular}{|c|c|c|c|}
\hline \multicolumn{4}{|c|}{ TABLE V-III } \\
\hline \multicolumn{4}{|c|}{ FORECASTING REVENUE PASSENGER MUEES } \\
\hline $\begin{array}{l}\text { Per Capita ! reome } \\
\text { (in dol! } m, x)\end{array}$ & & Passenger! & $\begin{array}{l}\text { Revenue } \\
\text { :filles/Capita/Year }\end{array}$ \\
\hline $\begin{array}{l}1.500 \\
1,750 \\
2,000 \\
2,250 \\
2.500 \\
2750 \\
3,000 \\
3.250 \\
3,500\end{array}$ & & & $\begin{array}{r}.58 \\
.72 \\
.87 \\
1.02 \\
1.19 \\
1.36 \\
1.54 \\
1.72 \\
1.91\end{array}$ \\
\hline$\left\{\begin{array}{l}\text { Annu.3l } \\
\text { Pevenue } \\
\text { derived } \\
\text { by Commuter }\end{array}\right\}=$ & $\left(1.163^{*}\right)$ & $\left(\begin{array}{l}\text { Revenue } \\
\text { Passenger } \\
\text { Miles/Capita/Year }\end{array}\right)$ & (Population) \\
\hline
\end{tabular}

* \$1.163 is based on an average commuter fare per passenger mile. For fares other than $\$ 1.163$, multiply the revenue passenger mile by $\left(\frac{1.163}{f a r e}\right)^{0172}$ Use the value obtained instead of the $\$ 1.163$ in the equation above.

$\left(\frac{163}{\text { fare }}\right)$

Source: Based on data obtained from the Final Draft of the Virginia Air Transportation System Study and also from Chapter II of this Report.

TABLE V-IV

FORECASTING REVENUE CARGO TON-MILES

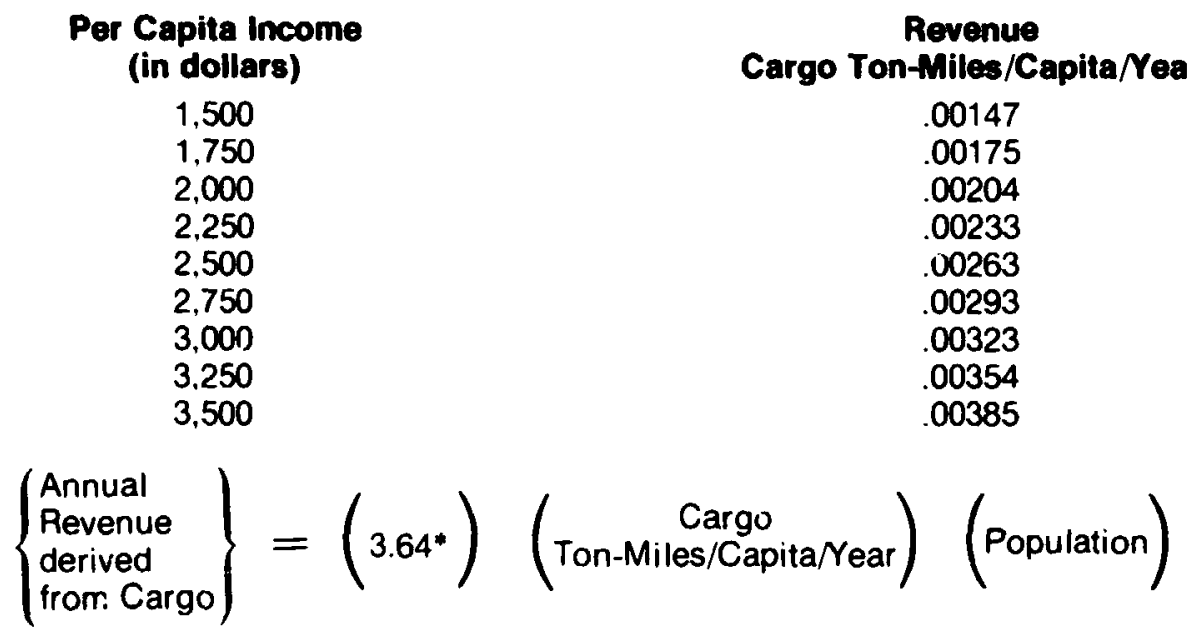

* $\$ 3.64$ is based on an average air-cargo rate per ton-mile. For rates other than $\$ 3.64$, multiply the per capita cargo ton-miles by $\left(\frac{3.64}{\text { rate }}\right)^{002}$ Use this new value instead of the $\$ 3.64$ in the equation above.

Source: Based on data obtained from the Final Draft of the Virginia Virginia Air Transportation System Study and also from Chapter II of this Report. 


\section{APPENDIXES}

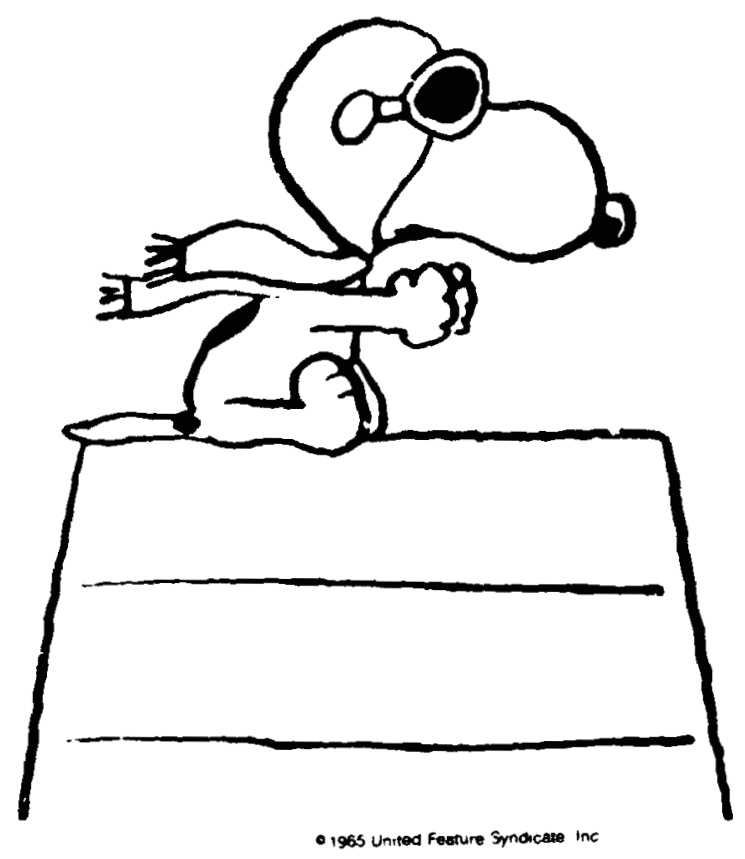

PRECEDINO PACE YANE NOT FHMMD 


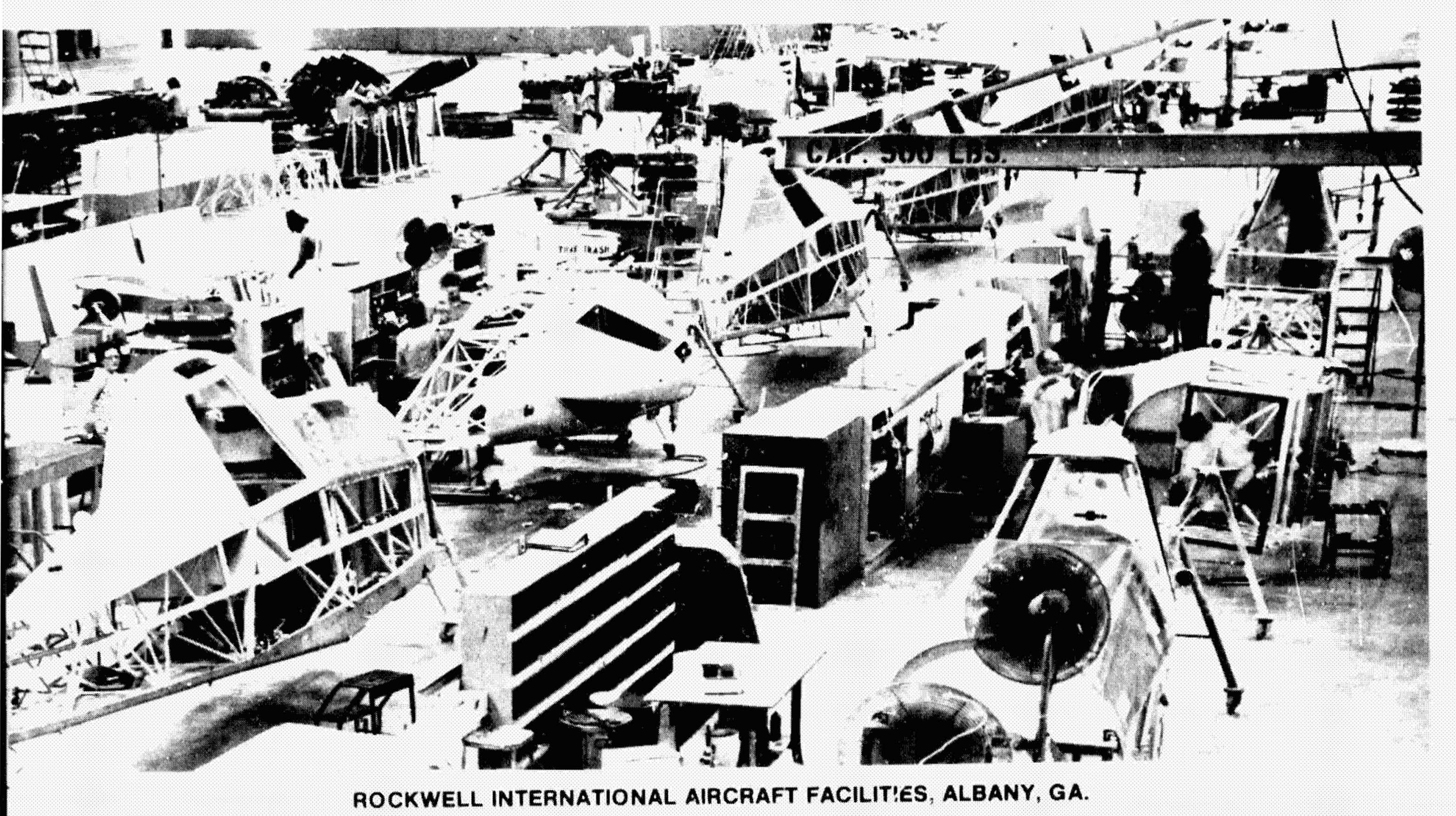




\section{APPENDIX A \\ FACULTY FELLOWS AND ASSOCLTES nAsA-AsEz ENGINEERING SYSTEMS DESIGN PROGRAM SUMMMA 1975}

Project Director:

Michaol Z. Sincoff

B.A. M.A. University of Maryland

Ph.D.. Purdue University

Area of Expertise: Interpersonal/Organizational

Communication

Associate Professor of Interpersonal Communication

and Director. Center for Communication Studies

School of Interpersonal Communication

Ohio University

Athens. Onı

Aesietant Project Director:

Jarir S. Dajanı

B.Eng. American University of Beirut

M.Sc . Stanford University

Ph.D. Northwestern University

Area of Expertise: Transportation and Systems

Planning

Associate Professor of Civil Engineeri.1g and Policy

Sciences

Department of Civil Engineering and the Institute of

Policy Sciences and Public Affairs

Duke University

Durham. North Carolina

\section{Participants:}

Kay L Antoniewicz

B A J D (in progress). University of Virginia

Area of Expertise Environmental Law

Law Student

University of Virgınıa

Charlottesville. Virginia

John J Bernardo

B.S. Pennsylvania State University

M.B A Duquesne University

M S.. Ph.D. Purdue University

Area of Expentise Operations Research

Assistant Professor of Management

Department of Management

University of Notre Dame

Notre Dame. Indiana

Bernard F Byrne

B S.C E. Carnegie Institute of Technology

M.S E.. University of California

Pn D University of Pennsylvania

Area of Expertise' Transportation Engineering

Assistant Professor of Civil Engineering

Department of Civil Engineering

West Virginia University

Morgantown, West Virginıa

Alexis Cenko

B S. Pennsylvanıa State University

$M E$. Cornell University

$P h D$. West Virginia University

Area of Expertise 'Aerodynamics

Assistant Professor of Aeronautics

Department of Aeronautics

Dowling College

Oakdale. New York
Sybil de Groot

B.A., M.A. Ph.D Ohio State University

Area of Expertise- Engineering Psychology

Associate Prolessor of Industrial Technology

School of Technology

Florida International University

Miamı, Florıda

Robert M. Eastman

A.B., Antioch College

M.S. Ohio State University

Ph.D., Pennsylvania State University

Area of Expertise: Operations Research/Systems

Analysis

Professor of Industrial Engineering

Department of Industrial Engineering

University of Missour!

Columbia Missour

Joan Franklın

B.A., Reed Cullege

M.A. University of Oregon

Ph D. Washington University

Area of Expertise: Political Science

As sistant Protesscr of Political Science

Political Science Department

Bowling Green State University

Bowling Green, Ohıo

Sander B Friedman

B.S.M E . Purdue University

M S. Northern Illinois University

Ph D. University of Waterloo

Area of Expertise Automation/Automatic Contro

Systems. Manufacturing

Associate Profesor of Engineering Technology

Department of Engineering Technology

Miamı University

Oxford. Ohio

Gary W Kiteley

B S.. University of Minnesota

M S . Purdue University

Area of Expertise: Aviation Management and Operations

Associate Professor of Aviation Management and

Director. School of Aviation

Department of Aerospace Engineering

Auburn University

Auburn. Alabama

Clare F Kosbab

BS M A Ohıo State University

Area of Expertise Aviation Maintenance and Operations

Director of Engineering Technologies

Engineering Division

Columbus Technical Insitute

Columbus. Onıo 
Timothy J. Kubiak

B.A. Univesrity of Toledo

M.A., Ph.D., Michigan State University

Area of Expertise: Community Resource Development

Assistant Professor of Geography

Department of Geography

Easiern Kentucky University

Richmond, Kentucky

Inwin B. Levinstein

A.B. University of Chicago

M. 1. University of Pittsburgh

Ph.D.. I'n..,ersity of Chicago

Area of Expertise: Social Thought

Assistant Professor and Director, Interdisciplinary

Studies

Department of Interdisciplinary Studies

Old Domınıon University

Nortolk, Virgınia

Henry L. Livas

B.S. Hampton Institute

M.S., Pennsylvania State University

Area of Expertise: Architectural Engineering

Associate Professor of Architecture and Engineering

Studies in Engıneerıng

Hampton Institute

Hampton, Virgınıa

Charles L. Menges

B.A., College of Willıam and, Aany

J.D. (In progress), University of Virgınıa

Area of Expertise: Environmer al Law

Law Student

University of Virgını

Charlottesville, Vırgınıa

Morris H. Mericle

B.S., M.S., Pn.D., lowa State Unive.sity

Area of Expertise: Systems and Cr ntrol

Associate Professor of Electrica. Engineerıng

Department of Electrical Engineering

lowa State University

Ames, lowa

Wolfgang Pindur

B.A. Ohio State University

M.A., Ph.D., Wayne State University

Area of Expertise: Urban Policies and Administration

Associate Professor of Urban Studies and Public

Administration

Institute of Uman Studies and Public Admınistratıon

Old Domınıon University

Norfolk, Vırgınıa

Robert L. Scott

A.B. Union Coliege

L.L.B., J.D., Si Johns University

Area of Expertise: Air Transportation/Aviation Law and

Regulation

Adjunct Professor of Air Transportation

Department of Policy, Marketing and Environment

School of Business and Organization Science

Florida Internatıonal University

Miamı, Florida
John J. Uhran, Jr

B.E.E., Manhattan College

M.S.E.E., Ph.D., Purdue University

Area of Expertise: Systems Studies/Communication

Theory

Associate Professor of Electrical Engineerıng

Department of Electrical Engineering

University of Notre Dame

Notre Dame. Indiana

Robert K. Wattson, Jr.

B.S. Oklahoma State University

S.M., Massachusetts Institute of Technology

Area of Expertise: Low-speed Aerodynamics and

Preliminary Airplane Design

Professor of Mechanical and Aeronautical

Engineering and Associate Chairman

Department of Mechar'ical and Aeronautical

Engineering

Tri-State College

Angola, Indiana

Perry B. Wigley

B.S., Birmingham-Southern College

M.S., Ph.D., Virgınia Polytechnic Instıtute and State University

Area of Expertise: Geology

Associate Protessor of Geology

Department of Geology

Eastern Kentucky University

Richmond, Kentucky

Iliustrator:

R. J. Rrvindranath

B.E. Bangalore University

M.S (in progress). Old Dominion University

Mechanical Engıneering

Secrotarial Staff:

Deborah F. Moore

B.S., M B.A. (In progress), Old Dominion University Busıness Admınıstratıon

Sandy E. Sealey

B S. (in progress). Old Dominion University

Business Education

Linda M Shifflette

B.S., M.Bus.Ed (in progress), Old Dominion University Business Education

Typiats:

Reba Hudspeth

Pembroke High School, Class of 1975

Mary Sandy

B.A., Radford College (Englısh and Spanish)

M.P A (in progress). George Washington University

Public Administration 


\section{APPENDIX B \\ GUEST LECTURERS}

Date

June 2

June 3

June 9

June 10

June 12

June 13

June 18

June 19

\section{Speaker/Affillation/Topic}

Mr Joseph Stickle

Assistant Chief, Flight Research Division

NASA-Langley Research Center

Hampton. Virgınıa 23665

"Current Research in General Aviation"

Mr Stanley J. Green

Vice-President and General Counsel

General Aviation Manulacturers Association

1025 Connecticut Avenue, N.W.

Washington, D.C., 20036

"Overview of General Aviatıon"

Mr. William J. Wood

Assistant to the President;

General Aviation Manufacturers Association

1025 Connectıcut Avenue, N W.

Washington, D.C , 20036

"Overview of General Aviatıon"

Mr James H Gray. Chief

Envir'onmental and Community Affairs

State Corporation Commission

Division of Aeronautics

Richmond. Virginia 23231

"Virgınıa Air Transportation System"

Mr Robert E. Nozıglia, Chief

Plannıng and Programs

State Corporation Commission

Division of Aeronautics

Richmond, Virginia 2:23s1

"Virginia Air Transtortation System"

Mr Robın K. Ransone

Engıneering and Science Systems

Univesrity of Virginia

Charlottesville. Virgınia 22901

"Proposal for an Air Transportation Model"

Mr Norman $\rfloor$ Crabtree. Deputy Director

Division of Aviation

Ohıo Department of Transportation

2829 W. Granville Road

Columbus. Ohio 43085

"The General Aviation System in Ohıo"

Dr Louis Mayo. Vice-Presiderit

Policy Studies and Special Projects

The George Washington University

Washington, D.C

"Aviation Policy Studies

Mr F Lee Bailey. Attorney

c/o Wayne Smith Company

500 - 12th Street. S W.

Washington. D C 20024

"General Aviatıon"

Mr William J Snyder

Chief Project Engineer. Civiı Helicopters

FRD Rotor Systems Section

NASA.Langley Research Center

Hampton. Virginia 23665

"Helicopter Role in General Aviation.

Mr Walter J Robınson. Jr. Vice-President

R Dixon Speas Associates

1001 International Blvd. Suite 1111

Atlanta, Georgra 30354

"Aviation System Planning" 
June 24

June 27

July 7

July 11

July 15

July 28

July 29

Mr Thomas S. Miles. Presıdent

National Air Transportation Associations

1156 - 15th Street. N.W

Washington. D C. 20005

"Commuter Airlınes"

Mr P Kenneth Pierpont, Head

Airfoıl Research Section

NASA-Langley Research Center

Hampton. Virginia 23665

"Supercritical and Low Speed Airfoil Research"

Dr Jeremy Wartord

Public Utılities Economist

The WVorld Bank

Washington. D C.

"Subsidies to General Aviatıon"

Mr James H. Gray, Chief

Environmental and Community Affairs

State Corporation Commission

Division of Aeronautics

Richmond. Virginia 23231

"The Virginia Alr Transportation System Plan"

Mr Fletcher Bartholomew

Howard. Needles. Tammen \& Bergendoff

P O Box 186. $130 \mathrm{~N}$ Royal Street

Alexandraa. Virginıa 22313

"Development of the Vırgınıa Aır Transportatıon System Plan"

Joan E Caldwell

President. Northwest Greenwich Association

364 Riverville Road

Greenw!ch, Connectıcut 06830

"The Westchester. New York Airport Controversy"

Willam A Whittle

FAA Airpsit District Office

$900 \mathrm{~S}$ Washington Stree:

Falis Church Virgınıa 22046

"FAA Comments on the Virgınia Air Transpor,ation System Plan" 


\section{APPENDIX C \\ ACKNOWLEDGMENTS}

Appreciation is expressed to the following persons and organizations for providing material, information, and assistance. These individuals and organizations are not responsible for any inconsistencies or reportorial er-cis that might be found in this document.

\begin{tabular}{|c|c|}
\hline Name & Organization/City \\
\hline Alvin F. Balaban & $\begin{array}{l}\text { Public Relations } \\
\text { General Aviation Division } \\
\text { Rockwell International } \\
\text { Bethany, Oklahoma } 73008\end{array}$ \\
\hline Nadine Batkins & $\begin{array}{l}\text { General Reference \& Cataloging } \\
\text { NASA-Langley Research Center } \\
\text { Hampton, Virginia } 23665\end{array}$ \\
\hline Virgınia Bıggıns & $\begin{array}{l}\text { Reporter } \\
\text { Daily Press } \\
\text { Newport News, Virgını } 23602\end{array}$ \\
\hline James Bland & $\begin{array}{l}\text { Aurpurt Engineer } \\
\text { State Corporatıon Commission } \\
\text { Division of Aeronautıcs } \\
\text { Ricrimond. Virginıa } 23231\end{array}$ \\
\hline Sandra Blow & $\begin{array}{l}\text { Subject \& Reference Bibliography } \\
\text { NASA-Langley Research Center } \\
\text { Hampton, Virginıa } 23665\end{array}$ \\
\hline Letha Brelt & $\begin{array}{l}\text { Beech Aircraft Corporation } \\
\text { Wichita. Kansas } 67201\end{array}$ \\
\hline Jerry Broadway & $\begin{array}{l}\text { Administratıve Aıde } \\
\text { Virgınia Beach. Virgınıa } 23451\end{array}$ \\
\hline Gordon M. Clark & $\begin{array}{l}\text { System Research Group } \\
\text { The Ohio State University } \\
\text { Columbus, Ohio } 43215\end{array}$ \\
\hline Billy E Commander & $\begin{array}{l}\text { Chief. Norfolk ATC Tower } \\
\text { Norfolk Regıonal Aırpon } \\
\text { Norfolk. Virgınia } 23518\end{array}$ \\
\hline Comprehensıve Plannıng Team & $\begin{array}{l}\text { uames City County } \\
\text { P O. Box J C. } \\
\text { Williamsburg. Virginia } 23185\end{array}$ \\
\hline Norman J Crabtree & $\begin{array}{l}\text { Deputy Director. Division of Aviation } \\
\text { Ohio Department of Transportation } \\
\text { Columbus. Ohio } 43085\end{array}$ \\
\hline Joseph R. Crotti & $\begin{array}{l}\text { Assistai Director. Aviation Planning \& Research } \\
\text { Department of Transportation } \\
\text { Division of Aeronautics } \\
\text { Sacramento. California } 95822\end{array}$ \\
\hline Willie Curtis & $\begin{array}{l}\text { General Reíerence \& Catalogıng } \\
\text { NASA-Langley Research Center } \\
\text { Hampton. Virgınıa } 23665\end{array}$ \\
\hline A. James DeBellıs & $\begin{array}{l}\text { Director. Department of Economic Development } \\
\text { Virgınıa Beach, Virgınıa } 23451\end{array}$ \\
\hline Joseph B. Emerson & $\begin{array}{l}\text { Flight Service Office } \\
\text { Flight Research Divisior } \\
\text { NASA-Langley Reseaich Center } \\
\text { Hampton. Virginia } 23665\end{array}$ \\
\hline Lee Eskın & $\begin{array}{l}\text { Civil Detense Coordinator } \\
\text { Virginia Beach Virginia } 23451\end{array}$ \\
\hline Raymond Fassell & $\begin{array}{l}\text { Assistant Director } \\
\text { lowa State University Press } \\
\text { S State Avenue } \\
\text { Ames. lowa } 50010\end{array}$ \\
\hline Thomas Ferguson & $\begin{array}{l}\text { Piejmont Aviatıon. Inc } \\
\text { Norfolk Regional Airport } \\
\text { Norfolk. Virgınıa } 23518\end{array}$ \\
\hline
\end{tabular}




\begin{tabular}{|c|c|}
\hline Harold Gallup & $\begin{array}{l}\text { Coordinator, Industrial Development } \\
\text { Virginia Beach, Virginıa } 23451\end{array}$ \\
\hline James H. Gray & $\begin{array}{l}\text { Chief, Environmental and Community Affairs } \\
\text { State Corporatio.n Commission } \\
\text { Divisıon of Aeronautıcs } \\
\text { Aichmond, Virginia } 23231\end{array}$ \\
\hline Stanley J. Green & $\begin{array}{l}\text { Vice-President and General Counsel } \\
\text { General Aviation Manufacturers Association } \\
\text { Washington, D.C. } 20036\end{array}$ \\
\hline Jane Hess & $\begin{array}{l}\text { General Reference \& Cataloging, Section Head } \\
\text { NASA-Langley Research Center } \\
\text { Hampton. Virginia } 23665\end{array}$ \\
\hline Carl Holland & $\begin{array}{l}\text { Piper Aircraft Corporation } \\
\text { Lock Haven, Pennsylvania } 17745\end{array}$ \\
\hline Aichard I. Hornbeck & $\begin{array}{l}\text { Manager, Air Transport Operations } \\
\text { General Electric Company } \\
\text { Westchester County Airport } \\
\text { Hangar E } \\
\text { White Plains, New York } 10604\end{array}$ \\
\hline Tom Johnson & $\begin{array}{l}\text { Willıamsburg-Jamestuwn Aırport } \\
100 \text { Marclay Road } \\
\text { Willıamsburg. Virginıa } 23185\end{array}$ \\
\hline Ken Knight & $\begin{array}{l}\text { Comprehensıve Planner } \\
\text { Virgınia Beach. Virgınıa } 23451\end{array}$ \\
\hline Capt. Knutson & $\begin{array}{l}\text { Commanding Officer } \\
\text { NAS Oceana } \\
\text { Virginıa Beach, Virgınıa } 23460\end{array}$ \\
\hline Richard E. Kuhn & $\begin{array}{l}\text { Chief, Subsonic-Transonic Aerodynamics Division } \\
\text { NASA-Langley Research Center } \\
\text { Hampton, Virginia } 23065\end{array}$ \\
\hline In Lenchner & $\begin{array}{l}\text { Patrick Henry Internatıonal Airport } \\
\text { Newport News, Virginia } 23602\end{array}$ \\
\hline Carl MacConnell & $\begin{array}{l}\text { Willamsburg-Jamestown Alrport } \\
100 \text { Marclay Road } \\
\text { W'llamsburg. Virginıa } 23185\end{array}$ \\
\hline Charles Preston Mangum. Jr. & $\begin{array}{l}\text { Manager, Norfolk Regional Aırport } \\
\text { Norfolk. Virgınia } 23518\end{array}$ \\
\hline Eugene Marlın & $\begin{array}{l}\text { Executıve Director } \\
\text { Peninsula Airf or Commission } \\
\text { Patrick Henry International Airport } \\
\text { Newport News. Virgınıa } 23602\end{array}$ \\
\hline Peter Mikulka & $\begin{array}{l}\text { Department of Psychology } \\
\text { Old Dominion University } \\
\text { Norfolk. Virginıa } 23508\end{array}$ \\
\hline Thomas $\subseteq$. Miles & $\begin{array}{l}\text { President. National Air Transportation Associations } \\
\text { Washington. D.C } 20025\end{array}$ \\
\hline Commander J. Morrison & $\begin{array}{l}\text { ATC Offıcer } \\
\text { NAS Oceana } \\
\text { Virgınıa Beach, Virginıa } 23460\end{array}$ \\
\hline H Eugene Myers & $\begin{array}{l}\text { Gulfstream Sales } \\
\text { Grumman American Aviation Corporation } \\
\text { P O Box } 2206 \\
\text { Savannah. Georgia } 31402\end{array}$ \\
\hline Mr Nonnelly & $\begin{array}{l}\text { State Corporatioiı Commission } \\
\text { Richmond, Virginia }\end{array}$ \\
\hline Robert E. Nozıglia & $\begin{array}{l}\text { Chief. Planning and Programs } \\
\text { State Corporation Commission } \\
\text { Division of Aeronautıcs } \\
\text { Richmond. Virginia } 23231\end{array}$ \\
\hline P Ken Pierpont & $\begin{array}{l}\text { Airfoil Research Section } \\
\text { Subsonic-Transonic Aerodynamics Division } \\
\text { NASA-Langley Research Center } \\
\text { Hampton, Virginia } 23665\end{array}$ \\
\hline
\end{tabular}




\begin{tabular}{|c|c|}
\hline Betty Pope & $\begin{array}{l}\text { General References \& Cataloging } \\
\text { NASA-Langley Research Center } \\
\text { Hainpton, Virginia } 23665\end{array}$ \\
\hline Magg। Pritchard & $\begin{array}{l}\text { Advertising } \\
\text { Cessna Aircraft Company } \\
\text { Wichita, Kansas } 67201\end{array}$ \\
\hline Public Relatıons Department & $\begin{array}{l}\text { Gates Learjet } \\
\text { Midcontinent Airport } \\
\text { P O. Box } 1280 \\
\text { Wichita, Kansas } 67201\end{array}$ \\
\hline Sgt John Rasner & Font Eustıs. Virginıa 23604 \\
\hline Brian T. Ratchford & $\begin{array}{l}\text { Department of Operations Analysis } \\
\text { SUNY-Buffalo } \\
\text { Buffalo. New York } 14214\end{array}$ \\
\hline Willam Ravenscroft & $\begin{array}{l}\text { United Feature Syndicate, Inc. } \\
220 \text { E. 42nd Street } \\
\text { New York. New York } 10017\end{array}$ \\
\hline Mr. Richardson & $\begin{array}{l}\text { State Corporation Commission } \\
\text { Richmond, Virginia }\end{array}$ \\
\hline Walter J. Robınson. Jr. & $\begin{array}{l}\text { Vice President } \\
\text { R. Dixon Speas Associates } \\
\text { Atlenta. Georgia } 30354\end{array}$ \\
\hline J.P Royer, Jr & $\begin{array}{l}\text { Director of Planning } \\
\text { Commonwealth of Virgınıa } \\
\text { Department of Highways and Transportation } \\
\text { Richmond. Virgınıa }\end{array}$ \\
\hline Sue Seward & $\begin{array}{l}\text { Subject \& Reference Bıbliography } \\
\text { NASA-Langley Research Center } \\
\text { Hampton, Virginia } 23665\end{array}$ \\
\hline Spyridon N. Sideris & $\begin{array}{l}\text { Chief. Aviation Planning \& Research } \\
\text { Department of Transportation } \\
\text { Division of Aeronautics } \\
\text { Sacramento. California } 95822\end{array}$ \\
\hline Richard J Sincolf & $\begin{array}{l}\text { Attorney } \\
401 \mathrm{~N} \text { Washington Stree:. Sulte } 207 \\
\text { Rockville, Maryland } 20950\end{array}$ \\
\hline William J Snyder & $\begin{array}{l}\text { Chief Project Engineer. Civil Helicopters } \\
\text { FRD Rotor System Section } \\
\text { NASA-Langley Research Center } \\
\text { Hampton. Virginıa } 23665\end{array}$ \\
\hline John H. Spencer & $\begin{array}{l}\text { Department of Architeclure. Chaırman } \\
\text { Hampton Institute } \\
\text { Hampton. Virginia } 23668\end{array}$ \\
\hline George Tirines & $\begin{array}{l}\text { Assist ant to the City Manager } \\
\text { Virginia Beach. Virginia } 23451\end{array}$ \\
\hline Marie Tuttle & $\begin{array}{l}\text { Subject \& Reference Bibl:ugraphy, Section Head } \\
\text { NASA-Langley Research Center } \\
\text { Hampton. Virginia } 23665\end{array}$ \\
\hline Harry A Verstynen. Jr. & $\begin{array}{l}\text { Aviation Safety Technology Branch } \\
\text { NASA-Headquarrers } \\
\text { Washington. D C. } 20546\end{array}$ \\
\hline Virginia Gazette & $\begin{array}{l}\text { P O Box } 419 \\
\text { Willamsburg. Virgınıa } 23185\end{array}$ \\
\hline C G Voyles & $\begin{array}{l}\text { Senior Vice-President } \\
\text { Grumman American Aviation Corporation } \\
\text { P O Box } 2206 \\
\text { Savannah. Georgia } 31402\end{array}$ \\
\hline Jane Wagenfeld & $\begin{array}{l}\text { Circulation \& Acquisition Section } \\
\text { NASA-Langley Research Center } \\
\text { Hampton. Virginia } 23665\end{array}$ \\
\hline Katherıne Walker & $\begin{array}{l}\text { Newport News Board of Education } \\
\text { Newport News. Virginia } 23602\end{array}$ \\
\hline
\end{tabular}


Mr. \& Mrs. Larry Waltrip

Dennis Warner

Lt. Thomas M. Weaver
Williamsburg-Jamestown Airport

100 Marclay Road

Williamsburg, Virginia 23185

President

Public Systems Associates, Inc.

Durham, North Carolina 27707

United States Army Transportation Museum

Fort Eustis, Virginia 23604 


\section{APPENDIX D \\ ORGANIZATION OF THE DESION TEAM}

\section{A. Prellminary Study}

To attain the goals of the project within an etevenweek period, the design study was organized into various phases. Initially, participants were divided into three basic groups for preliminary study:

Group A (Eupply)

Group 8 (Demand)

B. F. Byrne, Chairman

W. Pindur, Chairman

J. L. Franklin

G. W. Kiteley

K. L. Antoniewicz

C. F. Kosbab

J J. Bernardc

R. L. Scott

A. Ceriko

J. J. Uhran, Jr.

S. G. de Groot

R. M. Eastman

M. H. Mericle

Group C (Community Impact)

$S$ B. Friedman, Chairman

T. J. Kubiak

I B Levinstein

H L. Livas

C. L Menges

R. $\mathrm{K}$ Wattson

P. B. Wigley

\section{Eection Coordinatora}

In the sixth week yaction coordinators were selected. They are primarily responsible for preparation and presentation of information centained therein.

Chaptor I, Cenoral Aviation Compononts

R. M. Eastman

Chapter Hi, General Aiviation Environmont

P. B Wigley

Chapter III, Community Perapectives

I. B. Levinstein

Chapler N, Virginia Traneponation System

B. F. Byrne

G. W. Kiteley

Chaptor V. Aviation Seryice Anabyois: A Guldobook W. Pindur

Appendix E, Gloceary

R. K. Wattson, Jr.

\section{E. Other Committees}

\section{B. Group Assionments}

Following two weks of prelıminary investigation, a Task Outline Committee was formed to determine the Design Tearr.'s direction for the remainder of the study Tack Outline

G. W. Kiteley, Chai, man

S. G. de Groot

T. J. Kubiak

\section{In-Depth Study}

During weeks four through seven, the desig.l team functioned in the following study groups:

\section{General Ayiation \\ B F Byrne \\ R M Eastman \\ H L Livas \\ $M H$ Mericle \\ R L Scott \\ R K Wattson, Jr \\ P B Wigley}

III. Data Collection

S. G. de Groot

A Cenko

G. W. Kiteley

C. L. Menges

\section{Community Anabyais}

$K L$ Antoniewicz

J J Bernardo

$J$ L Franklın

$S$ B Friedman

C F Kosbab

$T$ J Kubiak

I d Levinstein

W Pindur

I J Uhran, Jr

\section{Caes studies}

K L. Antoniewicz

$J L$ Franklin

G W. nitteicy

C. F. Kosbab

I B Levinstein

$H$ L Livas

$C$ L. Menges

W. Pindur

A L. Scot

J. J. Uhran, Jr.
During the final four weeks of the study, two additional committees were formed

\section{Editorial Committeo}

$M$ Z. Sincoff

J S. Cajani

Oral Presentathn/lluastration Commiltes

S. B Friedman

G. W. Kiteley

T J Kublak

W. Pindur

R L. Scott

J. J. Uhran, Jr

R. K. Wattson Jr. 


\section{APPENDIX E GLOSSARY}

ADAP (Airport Development Aid Frogram)

Established by the Airport and Airway Development Act of 1970 for ine puipose of developing a nationwide system of public airports Section 14 of the Act empowers the Secretary of Transportation to make specific grants for airpont development, and to obligate funds for aimay development Title ll of tha Act provides for taxes to be col. lected on fuel, air travel by persons and property, and the use of civil aircraft it also established an Airport and Airway Trust Fund (a v)

\section{ADF (Automatic Direction Finder)}

A general purpose. low frequency beacon or radio station provides a s'gnal to aircraft instruments. enabling the pilot to home on the beacon

\section{Administrator, The} tration

The Admınistrator of the Federal Avation Admınıs-

\section{Aerodynamice}

The portion of the science of physics which deals with the study of the flow patterns of moving air. and the forces created on objects past which it moves The force exerted by air on. for example, an airplane can be thought of as split up into several contributions The magnifudes of these contributions depend on the shape and size of the aircraft. on its orientation to the airstraam. on the deflections of its movable control surfaces, and on the power or thrust level at which its engines are operating

\section{Air Commerce}

Carriage by aircraft of persons or propeny for hire carriage of mail by aircraft, or operation sf aircraft in the conduct cf a business or vocation Classified as iriterstate. overseas. and foreign

\section{Aircraft}

A flight vehicle sustained by the atmosphere It may be "lighter-than-air. and thus sustained at least partly and sometimes wholly by aerostatic (displacement) forces, or "hejvier-than-air," and thus sustained by arodynamic torces (due to motion through the air) Lighter-than-arr vehicles are balloons and airships Heavier-than-air vehi. cles are airplanes (fixed-wing) helicopters (powered ro. tary-wing), and a few subordinate types

\section{Aircrofl Category (Airworthinoss) (Fined Wing)}

Normal, Utility, and Acrobatic-Small Airplanes. aircraft under 12.500 ID (FAR 23)

Tranepont Category-AIrcraft over $12.500 \mathrm{lb}$ (FAR 23). must be mulitenginged (FAR 121) Some other minor categories exist

\section{Aircraft Repair Station}

Cenificated activity employing certificated personnel quailfied to repair aircraft and equipment A Fixed Base Or arato (FBO, q v) may operate a repair station

\section{Aintrame}

Structural framework or shell of an aircraft What is commonly thought of as an "airplane manufacturer." is an aitrame manufacturer An aiframe manufacturer may. however. make other components besides structure, and asserrbles both his own and purchased parts to form the aircraft
Air foll

The shape of the cross-section of a surface, of body. such as a wing or propeller The crnss-section is normally taken perpendicular to the wingspan or propeller blade diameter The special shapes of airfolls are called airfoil sections; geometric and aerodynamic characteristics of many such sections are available in various publications

\section{Alleron}

A hinged surface on the trailing edge (rear portion) of a wing used for roll control in operation allerons work like boat rudders laid on their sides. but one moves up and the other down The altarons are connected to the control wheel in the cockpit Turning the wheel to the right causes the right alleron to deflect upward, the left downward, thus rolling the airplane to the right

\section{Airman}

FAA certificated personnel engaged in operation and maintenance of aircraft, and in operation of airway facilities The following categories exist (1) crew member engaged in navigation of aircraft while underway: (2) in. dividual in direci charge of aircraft. engine or propeller. maintenance. overhaul. or repairs, and. (3) arrcraft dis. patcher or air traffic control operator

\section{Airplene}

A particular type of aircraft it is propelled through the air by a powerplant which exerts its force preponderantly forward. and sustained in the air mainly by differential air pressures set up on fixed wing surfaces by its inotion thrcugh the air

\section{Airplene Flight Manual}

The FAA requires thai ctrtain information on the operatıng characteristics of eac 7 type-cenificated aircraft be displayed in the aircraft in 3 forr. suitable for use by the pilot For small airplanes this information is displayed on placards and in an owner's manual For airplanes over 6.000 pounds. an Airplane Flight Manual is prepared One pan of the flight manual must be approved by the FAA This part contains a generai description of the aircraft, operating limitations. operatıng proceduies, and pertormance in. formation To this "approved" seciton of the Airplane Fitght Manual the manufacturer will add an "unapproved" section containing further information he judges will be of use to pilots flying the airplane All "operational" performance. ior instance. will be in this section range/payload/ield length tradeotfs, luel consumption data. effect of speed. altitude. and reserves on range etc "Unapproved" means simply that the section is outside FAA's charter

\section{Airport}

A landing area for aurcraft The Federal Aviation Act of 1958 adds the words. "used regularly by aircraft for receiving or discharging passengers or cargo

\section{Airport and Airway Truat Fund}

Established by Section 208 of the Airport and Airway

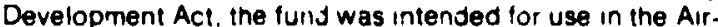
port and Ainway Devglopment Program The fund was to be created from the taxes on fuel. travel, and aircraft collected under provisions of Title II of the Airport and Airway Development Act The Secretary of the Treasury holds the Trust Fund and reports jearly to Congress of the financial conditions and results of operation of the fund dur.ng the fiscal year and on the outlook for the succeeding five fiscal years 


\section{Arepend}

S. sed of aircraft relative to the air. The airspeed measuring iristrumeni of an airplane is typically an alrpressure-actuated device. which subtracts the ordinary barometric pressure from the so-called "tota:" alr pressure. which is sensitive to forward speed. The remander is the "dynanic" pressure, and this is displayed to the pilot on an "airspeed indicator" which is graduated in knots or miles per hour instead of in pressure units This is the so-called "Indicated airspeed, ' and is not equal to the true speed of the aircraft througn the air. The correction is (for low speeds and a perfect ıneasuring system)

True airspeed $=$ Indicated airspeed $X$

$\sqrt{\frac{\text { Air Density }}{\text { Standard sea level aır density }}}$

Since at altitude the air density is usualiy less than that at sea level. the airspeed indicator will read lower than t ue airspeed.

\section{Air Toxi}

Operation complying with F:R Part 135 and CAB Economic Regulation Part 298 Two kinds: Unscheduled and Scheduled or "Commuter"

\section{Air Tran tation}

Carriage by aurcraft of persons or property as a com. mon carrier for compensation. or carriage of mail by aircraft Referred to in the Federal Aviation Act of 1958 as being. "interstate, overseas, or foreign."

\section{Ainway}

A fed rral aimay is a portion of the navigable airspace of the United States designated by Administrator as a federal dırway Jet aırway routes c e between the altitudes of 18,000 feet and 48,000 feet Lower ainway structure extenc's down to 1,0 o feet above the ground

\section{Airworthiness Certificate}

Documt.it carried in each aircraft deciaring it to be of a type design which has be sn classified hy FAA as airworthy it does not mean tha: ... ie specific airciaft is arnorthy but only that at the time it was issuec the airplane was in conformity with the type design Referer.ces to the actual aitworthiness condition of the arrcraft will be frund in its losbook The certificate must be renewed annuallv. based upor inspection of the air craf,

\section{Arworthiness Regulation.}

Parts of Federai Aviation Regulations controliıng design and performance aspects of new aircraft designs Part 23. for example covers small aırplanes in normal. utılity and acrobatic categor.es: Part 25 covers transport category Contents of the regulations for alrcraft are typıcally (1) applicability limite. (2) definitions. (3) fight por. formance (takeoff, landing. cliınbs, stalls. handling), (4) applied loads (flight, ground or water). (5) proof of structure. (6) design and construction. (7) equipment requirements. arid. (8) information to be furnished Other airworthıness regulations cover $e$. ines. propellers. and components

\section{ALPA}

Airline Pilots' Association.

\section{Altitude} sea level.

Usually taken to mean the height of an arrcraft above

\section{Approach}

The descending path by whicil an airplane closes the distance tetween it and the runway on which it is being landed. A VFR approach may have three coisecutive legs at right angles io each other: (1) Jownwind-approxImately 800-foot height; (2) Bese-descending, course at right angles to runway; and (3) Find_descending, aligned with runway. IFR approaches may lack downwind and base legs if the localizer beam is approached at an angle and the airplane turned directly into it for final approach.

\section{Approved}

Approved by the FiA Administrator. May pertain to aircraft type certificates, parts, reports (e $\mathrm{g}$. the "approvec" section of an airplane flight manual), agencies.

ARTCC

Air Route Traffic Control Center

ATA

Air Transport Association.

ATC

Air Traffic Contro:

\section{Avaltable Seat miles}

On each inter-airuort flight. the product of aircraft miles flown multiplied by seats available. The seats availa. ble are not necessanly the se ats instalied. since for some trips some seats may have to remain unfilled to keep the arrcraft below its certificated gross weight.

\section{Avionics} in aircraft

Aviation electronic equipment made for installation

Balanced Field Length (BFL) (ref. airport and airplane design)

Airplane takcoff run length for a transport categon; airplane as determıned by the following measurements

-Distance frcm brake release to attainment of a height of $\mathbf{5 0}$ feet ( 35 feet for turbine aırcraft). one engine having stopped at a decision speed $v_{1}$ ( $q v$.)

-Distance from brake release to stop. one engıne having stopped at a decision speed $V_{1}$

Proper choice of $V_{1}$ makes thes? distances equal. and the single resulting distance is kn $w n$ as the balanced field length

\section{See also FAR Landing Field Length.}

\section{Breakeven}

Load factor at which revenues equal total operating cost A function of aircraft size and type. and fare structure

\section{Business}

Banks. corporations. etc . which engage in markating and finence as distınct from manufacturing.

\section{CAB (CIvil aronautics Board)}

Indersindent of FAA Purview-Economic develcsment of ayıation Umbrella includes-route granting (cer. tified carriers), schedulıng. fare settıng. (See Economic Regulations.)

Category (of landing when operatiıg (FR)

Cat $\longleftarrow 200$ foot celling. 2.600 foot runway visual range. Cat If 100 and 1.200 , and. Cat IIf -0 and 0 To land IFR requires qualified (IFR-rated) pilot. properly equipped aircraft and airport 


\section{Catezories of Scheduled Air Transport}

(1) Certificated-trunk, regional. supplemental and cargo, and (2) Non-certificated_Commuter/small troight and mail

\section{Celling}

Height of cloud cover above weather reporting station it is measured when one-half or mcre of the sky is covered by clouds.

Also, the maximum altitude at which an airplane can clımb it certain specific rates General aviatıon aırplanes. except business jets, seldom cruse near their ceiling altitudes

Certilicete FAA.

The following types of certificates are issued by the

(1) Alrman Certificates

Pilots

Mechanics

Aur Traftic Controllers

(2) Aircraft Certificates

Aircraft

Engine

Propeller

Experimental

ivpe

Production

Ainworthıness

(3) Alr Carrier Operatıng Certil, zate (this is not the Cerfificate of Public Convenience and Necessity)

Certified carrier

Non-certificated carrier

Supplemental carrier

(4) Air Navigation Facility

(5) Air Agency Ratıng

Fiıght and ground Training Schools

Aırcraft Repaır and Mauntenance Stations

City Pair

The terminal communities in an air trip: the origin and cestination on a one-way basis. This is cnly coincidentally the same as a sector (q.v.).

Civil Aircraft (of the United States)

Any aircraft registered under the provisions of the Federal Aviation Act of 1958.

\section{Common Carrior}

public hire

A transportation business that offers its services for

\section{Community}

City, town. or rezion under study The community is made up of a group of individuals posse ssing a "feelıng" of or. In fact. having a common objective or economic. social. or political bond.

\section{Commuter}

Subdivision of Air Taxi Operator Air Taxi Operators engage in direct air tran:sportation within the $\mathbf{4 8}$ contıguous states which do not utilize large aircraft They are registered with the CAB. but do not hold cartificates of public convenience and necessity Pursuant to published schedules. a commuter makes at least five round trips per week between two or more points.

- Control (Aır Traffic)

Services offered by FAA to expedite traffic flow As seen by pilot these take the form of maps and charts. tower service (departure control, approach control, local control and ground control), air route traffic cuntrol center radio and radar flight service (weather information and flight plans)

\section{Controlled Airspace}

Airspace within which movement of aircraft is controlled by FAA. Control may apply to some or all aircraft, and may restrict either route or speed.

(1) Control ares-airspace designated by FAA from an altitude of 700 feet above defined surtace area of ground

(2) Control zone-includes all airspace designated by FAA above and around one or more aurports

(3) Continental contro! aree-all airspace over the 48 contiguous states. abowe 14.500 leet. VFR traffic prohibited when visibility is below 5 miles.

\section{Control Surfeces (of aircraft)}

Movable flap-type hinged portions of the wings and tail surfaces of an airplane. or of the fins of an airship. used by the pilot to maneuver it or to control its direction of flight On a conventional airplane the three types of surfaces are. (1) allerons ( $q v$ ), one on each wing. (2) elevators. On the horizontal tall (the fixed portion is the "stabilizer"): anc. (3) rudder, on the vertical tail (the fixed portion is the "vertical fin")

\section{Cost-Benefit}

A ratıo between gains and losses. both in the social and economic reaims. as a result of the reallocation of resources The ratio is determined by the actual comparison of known and projected dollar costs and benefits arising due to the reallocation The cost-benefit analysis assumes, however, that all costs and benefits can be measured in the market (i.e.. with dollar values)

\section{Course}

The intended direction of fligtit in a horizontal plane The course is not necessarily the direction in which the aircraft is pointed (see heading).

\section{Cruise, Cruise Flight}

A "cruising" aircraft is in level. unaccelerated fl:ght at any speed at which such flight can be maintaineo. The cruise speeds usually chosen are much nearer the aircratt's top speed than its stalling speed

An economy crules is flowr at or very near the speed for which the aircraft's fuel consumption per ground mile traversed is a mınımum

A cruise altitude is the altitude authorized by $A_{11}$ Traffic Control in a flight plan clearance: the pilot may normally fly at any altitude between the minimum er, route altituce or the minimum obstacle clearance altitude for the route, and the altitude specified in the clearance. The cruise altitude is taken to be the height of the aircraft above sea level

\section{CTOL (Conventional Takeoff and Landing)}

A catch-all term which includes all aircraft with no devices other than flaps, and perhaps leading edge cevices. specifically devised to shorten the takeoff and randing field lengths required If. however. due to the extreme sophistication of its flaps and leading edge devices, an airplane can achieve substantially shorter takeoffs and landings than other contemporary airplanes of its weight. speed, and general class, it could be considered a STOL or RTOL airplane rather inan a CTOL airplane

There is no "official" cesignation of airplanes as CTOL, RTOL, OI STOL 


\section{Deciation Mcloht}

Height at which decision must be reached. during an instrument approach, on whether to land or "execute missed approach "

\section{Development}

Utilization of human and natural resource base for the maximization of social and economic benefits throughout the "community."

\section{DME (Distance Measunng Equipment.)}

Aurborne and ground equipment used to mzasure, in nautical miles. the distance of an zircraft from a vavigation and.

\section{DOC_see Operating Coet.}

DOT-Department of Transportation.

\section{Economic Factors}

Trade area. income (per capita or median), lahor force. employment/unemployment. industnal mix. retill and wholesale trade. population. tax base. and employment sectors.

\section{Empty Woight}

Aircratt with normal operational equipment but with 10 liquids except actuating systems. Empty weight is 55-65 percent TOGW for small aurplanes.

\section{Experimental Certificate}

Document issued by FAA, under which one specific airplane may be flown using an experimental flight test crew only. Homebuilts presently operate under experimental certificates

\section{FAA (Federal Aviation Admınıstratıon)}

Presently part of Department of Transportation Pur. view-safety aspects of aviation under which FAA certifies pilots. mechanics, other operators, repair stations. aircraft. instruments and equipment: airports (zertificated traffic only). airlines, manufacturing facilities (through issuance of production certificates to manufacturing companies building type-centified aircraft) FAA operates arwey equipment (radio and radar). flight service stations. FAA regulates all of the above

\section{FAR (Federal Aviation Regulations)}

Documents having the force of law (part of U S Code) prescribing technical and procedural aspects of the conduct of the aviation community.

\section{FAR Landing Fiela Length}

167 times actual landing distence of a type arrcraft under given environment (altitude and temperature) An aircraft operatıng under Part 121 may not be dispatched to a destination at which it cannot be brought to a stop within the first 60 percent of an active runway Caiculated landing field lengths are used in desiy.. of airports and aircraft

Fare

Tariff paid bv passenger for privilege of riding Usually on an average fare structure will consist by implication of a boarding fee and a mileage rate Must be approved by CAB for certificated ca riers. sector by sector Commuter fares are generally compatible except for effects of airplane size and performance on fares requireu to make a profit
F80 (Fixed base operator)

An FBO may offer a variety of services on an a'roort --Aurcraft storage and parking

-Fuel sales

- Arrcraft. engine, and accessory maintenance and mpair

-Aircralt sales (new, used) and rental

-Flight and ground instruc in

- Aurcraft parts and accessory sales

- Specialized services (e.g. air ambulance)

An FBO may also be the airport owner.

\section{Federal Avintion Act of 1958}

"An act to continue the Civil Aeronautics Board as an Agency of the United States, to create a tederal Aviation Agency. to provide for the regulation and promotion of cIvil aviation in such a manner as to best foster its development and safety, and to provide for the safe and etficient use of the airspace by both civil and military aircraft, and for other purposes

As originally written, the act provided for the FAA to be an independent agency responsibie only to the Prest dent. and for the CAB to be charged with accident investigation as well as economic regulation The Department of Transportation Act of 1966 placed the FAA under the Depanment of Transportation and removed the accident investıgative function from the $\mathrm{CAB}$ and placed it under the National Transportation Safety Board A controversy exists as to whether these changes benefited aviation

\section{Fiold Elovation}

Height of airport runways above sea level

Filght Level

Pressure altitude related to standard sea level pres sure. given in hundreds of feet Flight levels are cailed by this name starting at 18.000 feet altitude

\section{Flight Plan}

Data on a single proposed IFR flight. filed with FAA Flight Service by the pilot before departure. Includes type registration number. and color of aircraft. pilot's name. number of passengers aboard. destınation and alternate. amount of fuel on board. routing.

\section{FSS (Flight Service Station)}

ihis activity relays traffic control messages, briefs pilots. dissemınates weather infoimation, and monitors navigational aids

Fual

All aircraft of the present day use petroleum pro ducts as fuels

Aviation Gasoline ("Avgas") is used by the piston-engine fleet Small airplanes use a product in the general octane-number range of "Ethyl" automobile gasoline Large pıston-engined aircraft use gasoline with octane ratıngs in excess of 100 The piston engine in its present form will not digest other fuels

Kerosene is used by some of the turbine engine fleet. others use a fuel which has no single commercial designation but is known to the militan as JP-4, and is comparable to a wide-cut gasoline Turbıne engınes confıgured for "jet fuels" such as the above will accept aviation gasoline only for very short periods of running. so the use of avgas in turbine engines is restricted to emergencies. 
G

The ac: leration of gravity at the tarth's surface (32.17 leet per second per second) is frequently referred to as "one ' $g$ '" Any other acceleration, expressed in the same units, can be referred to as "so many g's" by dividing that acceleration by the acceieration of gravity For example. an acceteration of 64.34 feet per second, or twice that of gravity, becomes " 2 g's " Aircraft accelerations, such as in pullups or turns. are so expressed; the general name for the quotient acceleration/acceleration-of-gravity is the "load factor" (q.v. for another definition) In aurcraft d gn applied structural loads are obtained first as load $t_{2}$.urs ( 1 e, accelerations experienced by the aircraft or aircraft component in flight) and then converted to their force equivalents by introducing the component masses.

\section{Heading}

The direction in which the nose of an aircraft is pointed. viewed on a horizontal plane Headings are typically expressed in degrees. measured clockwise from magnetic nortn. Since the air mass in which the airplane is operating may be moving sideways across the desired course of flight, the heading of the aircraft may not be the same as the course as laid out on a map. but will be off toward the side of the course from which the air mass is approaching

Helicopter

A particular type of aircraft it is both propelied and sustained in the air substantıally by the differentıal air pressures set up on rotary wings. hinged :0 a powered axis

\section{Homobuilh}

Aircraft. 51 percent of which is built by the in dividual owner May not be flown as an air carrier Homebuilts are all small and mostly primitive with respect to radio equipment Antique restorations can come unde homebuilt category Not certificable as a type-must be individually FAA inspected and approved

\section{Mot Atmoephere}

Fictitious atmosphere representing a typical mid summer day in warmer areas Begins at $103^{\circ}$ at sea level

Housing

Buildings and services intended for providing dwell ing. Including private homes, high-rise units and housing propects

10C-see Operating Cost.

IFA (instrument Flight Rules)

IFR conditions prevall when the weather is not good enough for flight by visual reference to the ground

ILS (Instrument Landing System)

Provides electrical signals forming a cross-shaped pattern along the glide path (The glide path is the line of intersection of the two signals. the "glide slope and "localizer") Aurcraft control systems can be slaved to these signals to control the approach automatically.

Impact

The effect upon the various community systems or sub-systems produces by the introduction of a new sub system (e $\mathrm{g}$. new airport) or a change in an existıng system (e $g$. extending services)

\section{Interline Agreement}

Agreement between airlines covering ticket servicIng, baggage handing. and miscelianeous services All trunk and regional airlines and some commuters participate

Knot

One nautical mile per hour Standard airspeed unit worlowide. See "nautıcal mile."

\section{Limiting Woights}

Maximum weight at which an aırplane can take off at a given field under given environment. Weight may be limited by runway length or climb capability. Used by al certificated airlines and by most commuters. they are part of FAA-required information in an airplane fight manual.

\section{Load Factor}

(1) "Flight '-structural definitions, not pertinent here. (2) "Passenger"- number of passengers being carried'number of passenger seats avallable; and (3) "Overall" - -ratıo of actual or assumed payload to total payload of aircraft.

\section{Local Service Carrier ("Regional")}

Certificated domestic route air morners operatıng routes of lesser density and average length between small and principal traffic centers.

\section{Mach Number}

True airspeed/speed of sound in air in local free stream Usually referred to as, e g.. "Mach 08

\section{Manuals}

Each airplane over 6,000 pounds maximum certificated yross weight must be provided with an approved Airplane Flight Manual. Airplanes below 6.000 pounds will have Owner's Manuals. Each domestic and flag carrier must provide a manual for the use of flight and ground operations personnel (and for management peisonnel in the case of supplemental carriers) These manuals are divided into sections containing information for each category of personnel Some typical topics are policies. personnel duties and responsibilities. types of aircraft and operations authorized for each route. crew requirements. normal and emergency operating procedures. inspections. weight and balance procedures. and safety information and instructions The aircrat manufacturer provides a maintenance manual for his aircraft. which includes such things as

System descriptions

Lubrication instructions

Pressures and electncal loads

Tolerances and adjustment

Methods of leveling, raising. and towing

Control surface balaricing

Inspection, repair, special tools

The manufacturer will also provide a parts catalog

Merker

An electronic signal generated by an instrument landing system to form a "milepost" or a landing approach path Two usually referred to "outer" and "middle "Outer marker may be a reporting point on an approach. and usually is 4-7 miles from runway threshold.

\section{Maximum Landing Woight}

Not less than 5 percent under TOGW unless fuel jettison is provided (FAR)

\section{Metrosolitan} sons

Urban area with - -entral city of at least 50,000 per. 


\section{Mlased Approsech}

An IFR approach to a landing which is sborted prior to reaching the touchdown point, and the airplane climbed out to try again or to fly to an alternative destination. The missed approach must be decided on at or before a minimum decision height.

\section{Nautical Mile}

One minute of arc at sea level on the earth's surface at the equator (about 1.15 statute miles). See "knot."

NTSB (National Transportation Safety Board)

Part of DOT. Purview-investigative aspects of safety (NTSB and FAA commonly both investigate alrcraft accidents, but NTSB is empowered to determine the probable causes).

OAG_Official Airine Guide.

$O$ and $D$ - Origin and Destınatıon Reports

Reports of passenger traffic required by $C A B$ of all certificated carriers, possibly in future of all commuters.

Omni

Nickname for VOR (q.v.).

Operating Cost (of arrcraft and arrlines)

DOC (direct)

Flight operations

Crew

Fuel and oll

Traıning

Depreciation (of a/c and spares)

Insurance (hull, of a/c'

Maintenance (of $a / c$ ar d equ,pment)

vizintenance burden

IOC (direct)

Station operating cost

Administration

Advertising

Equipment (except station)

Insurance (except a/c)

\section{Operating Regulations}

Parts of Federal Aviation Regulations Part 91 covers general aviation: Part 121 covers certificated air transport. Part 125 covers air taxi operators The rules govern the manner in which aircratt may be operated and include sect:ons on manuals required. operating and crew imitations. arworthiness and instrumentation requirements. records and reports Part 121 also contains certification rules, approved rules for routes. aurcrew flight time limitarions. and dispatch rules

Operation (from arport)

One takeoft or one landing

\section{Operator}

A company or individual who owns or leases aircraft for various uses: the pilot of an airplane.

\section{Overrun}

Unpaved extension of paved runway suitable for emergency stops Consists of "clearway" and "stopway"

\section{Payload}

Revenue-producing portion of the useful load of an aircraft Some small airplane manufacturers include crew and crew's baggage in the rayload for engineering purposes.
Pitch flight.

Nose-up or nose-down attitude of the arcraft in

Primary/Alternate (destınation)

Intended destination of flight, and destination to which diversion may occur if necessany (e.g, for weather)

\section{Profftability}

Difference between net passenger tıcket plus/or cargo revenues, and total operating costs. Can be predicted for sector or route if fare structure and demand are known, or lor design if they are assumed.

\section{Proftt Potontial}

All combinations of stage length and payload. using whic $h$ a specific type of arcraft can concelvably make muney under a given fare structure.

Rader

A system for locating an object such as an airplane by displaying on a screen or scope a bright soot representing the airplane, generated by ultra high frequency radio waves reflected to a receiver by the aurplane

\section{Recreation}

Facilities for carrying out specific recreational activities parks, movie theaters, opera houses, concert halls. arenas, gymnasiums, and recreatıon centers

\section{Regiatration}

FAA or state license declaring one specific arrcratt to be in existence and owned by one specific person. Is not a permit for the arrcraft to be cperated

\section{Reservas}

Difference between total fuel on board at start of flight and estimated fuel used during mission Reserves are prescribed by FAR 91 (general aviation operatıng rules) and 121 (air transport operatıng rules). Generally taken to be allowances for holding and flight to alternate destinatiori. but for design frequently taken to include also desceiti. missed approach and climbout from missec approach Fol talking purposes 200 nautical miles plus 15 minutes is usually used to portray fuel reserves

\section{RNAV (Area Navigation)}

A method of navigation that permits aircraft operaIIons on any desired course within the coverage of stationreferenced navigation signals or withın the limits of selfcontained system capability Using RNAV, it is not necessany to be on the established ainways between OMNI sta. tlons in order to receive "on-course" signals Inslead. using the on-board RNAV' equipment. fictitious "airways" may be set up using the signals from actual OMNI stations and the airplane flown on these "ainways"

Roll

Motion of an aircrait in flight about a generally foreand-aft axis through its center of -ravity

\section{Route}

A defined path, consisting of one or more courses. which an aircraft traverses over the ground. viewed on a horizontal plane

ATOL (Reduced Takeoff and Landing)

A type of airplane whose takeoff ard landing performance is better than a CTOL airplane but not as good as a STOL airplane Technically an PTOL airplane would incorporate a very low wing loading or some form of powered 
lift Oparationally the field lengths are thought of as 3,500-4,000 feet.

Note. Since in practice large airplanes have longer field performance than small aırplánes incorporating sımilar technical features (e g. kınds of flaps), an airplane size bracket should be attached both to the fefinition of RTOL and of STOL)

Rural

Places of less than 2,500 persons or diffuse population with an employment base primarily in agriculture.

RVR (Runway Visual Range)

The horizontal distance along a runway at which a pilot about to land can see the high intensity runway lights.

Sector (referred to as "stage" in design)

Length of a scheduled route, between two cities at which takeoff and landing are made consecutively.

Segment (climb)

Portion of takeoff or landing climbout performed in a specific flight configuration

Ist segment-gear down, flaps down, cowl flaps open, engines at takeoff power or thrus

and segment-gear up. flaps down, engines a! maxımum contınuous power or thrust

En route-gear and flaps up, engines at maxImum contınuous power or thrust

Approachtıons, engines at $:$ ixımum contınuous power or thrust

Balked Landing-gear down. flaps at landing settıng. engines at takeoff power or thruat This is an all engine climb.

Minımum standards for airplanes are set by FAR Parts 23 and 25 For purposes of setting up takeoff flight paths at airports, multı-engıned aırplanes of transport category e.g. business jets. are assumed to have one engine failed during all climbs except balked-landing climb As presently prescribed. and eerment climb usualty is critical for establishing takeoff flight paths and limiting weights

\section{Shrouded Fropeller}

A propeller with a ring-shaped wing surrounding the propeller disc or plane of motion The central axis of the ring wing is the same as that of the propeller The ring wing. If pronerly designed. increases the static and lowspeed thrust of the unit for the same power input, but usually lowers the unit efficiency in cruising flight

Slat

A small auxiliary aifoil which can be deployed from the leading edge of a wing to improve its high lift capability

Sliputream:

The cyliridrical stream of fast-moving air behind the propeller of an airplane in flight, or beneath the rotor of a hovering helicopter

\section{Small Aircrat}

Aircraft under 12,500-pound TOGW

\section{Social Fsctors}

Hous'ng. education, government services and ex penditures, reireation. public assistance health services. life styles, and cuality of life - a measured or perceived phenomenon based upon any or all social, economic. and bio-physical factors (e.g., improved housing, recreation. etc. or citızen attitude concerning improved social environment).

\section{Special Condtions}

Additions or modifications for FARs, negotiated between FAA and aintrame manufacturer prior to start of an ai "rame development program These are not "Amend. ments" for the FAR in that they govern only the specific model type to be developed.

\section{Spoilers}

Movable, hinged surfaces on the top of a wing. The most common form looks like a small, upside-down wing flap When raised, the device "spoils" the lift on part of the wing (breaks up the smooth air flow). Spoilers can be used one-side-at-a-time for roll control or all at once for steep emergency descents at high speed.

\section{Sport Aviation}

Segment of the aviation community devoted in large part to flyıng for pleasure and building individual aırcraf for pleasure

\section{Stalling Speed $\left(V_{S}\right)$}

Airspeed below which an airplane cannot maintain horizontal flight due to the decay of lift on its wings. The stalling speed is highest with wing flaps retracted. lowest with flaps fully extended. The stalling speed is also inverseIy proportional to the square root of the air density and directly proportional to the square root of the iving loading (q.v) Some aırplanes have a "mınımum flyıng speed" below which their powerplants do not have enough power to maintain level flight, but which is above the stalling speed

\section{STOL (Short Takeoff and Landing)}

Two definitions (1) Operational: not firm but thought of as 1,000-2,000 foot balanced field length. (2) Technical: Series of technologica! developments which can be applied to aircraft of any size (e 9 . Boeing 727 is a "mild" STOL airplane) These developments include multıple-element airfoils. spoiler controls, boundary layer control (various types), and combined lift-thrust systems

Penaity of Incorporating "severe" STOL technology can range from 2 percent (big airplane) to 10 percent (small airplane) of gross weighi This is usually intolerable for revenue-producing types

\section{Survaillance Rader}

A long range (about 200 miles) radar for trackıng en route aircraft along an aınvay, is known as "en route" ASR Aır Surveillance Radar provides for termınal area air traffic control and aircraft location information to tower operators

\section{Takeoff Flight Path}

Computed $p$, h of an airplane takeoff from 50 feet (35 feet for turbinc-powered aircraft) to in feet height above ground Used in airport development w.ork to set maximum permissible obstacle heights near approach and departure paths

\section{Technical s' dard Order}

Performance and quality control standard for com ponents (airplanes, engines, and props are not "TSO d." I e., presented for determination that they comply with the standard) A properly functioning component of a TSO'd type may be installed on any airplare capable of utilizing it Components may also te "approved" specisically for installation in an airplane of a specific type 
Tetrahedron in vicinity

Wind indicator on airport, visible to pilots of aircratt

Threshold (of runway)

"Near" end of runway for approaching aircraft

Toc (Total Gperating Cost)

The sum of DOC (Direct Operatıng Cost) and IOC (Indirect Operatıng Cost)

\section{Togw}

Literally "takeoft gross weight"-The maximum weight, at takeoff brake release, for which an airplane is centificated. There may be a "ramp weight" at engıne start above TOGW

Trafile

Aircraft operatıng in air or on ground

Transponder

An airborne radar beacon receiver-transmitter which automatically receives radio signals from all interrogators on the ground and which selectively replies with a specific reply pulse or pulse group. only to those interrogations being recelved on the mode to which it is set to respond The modes vary with the purpose for which the transponder is being used (Identification, altitude reporting, emeraency)

\section{Transportation}

With respect to control public and private Mass transportation has recently become considered in a specia category, but is generally thought of in a public-utility framework.

\section{Turbofan}

Similar to turbojet except that not all the air ingested is run through the combustion chamber Some is "bypassed."

\section{Turbojet}

Airbreathing reactivi' engine, which compresses air using rotatıng machınery. adds fuel burns and exhausts the fuel-air mixture to create thrust, in a generally straight path and contınuously

\section{Turboprop}

Similar to turbojet except that substantially al avarlable excess energy from fuel compression and burning is used to drive a conventional propeller

Technically, a turboprop is a bypass engine which routes through the propeller about 48 times the airmass it routes through the compression/combustion/expansion cy cle.

\section{Type Cortilicate}

Certificate under which all airplanes of a given generai model are declared technically airworthy if in conformity with the FAA-approved manufacturer's plans

\section{Unicom}

Primitive radio facility at small airports Can com. municate with airplanes, but does not control traffic.

\section{Usolul lond}

Takeoff gross weight minus empty weight Usable for passengers, crew, baggage and cargo, liquids and extra furnishings, and equipment

vy

Airspeed, during takeott run, at which an cengine is assumed to fail. At this point the pilot must decide whether to stop or to continue the takeotf run The value of $\because 1$ published in an Airplane Flight Manual is that for which the "go" and "stop" distances required are equal In theory this gives the pilot a means of deciding whether to oo or stop, $1 e$, if an engine fáls at a speed below $v_{1}$, he should stop, if above $V_{1}$, he should go.

$V_{\mathbf{m c}}$

Minimum Control Speed_Airspeed below which an airplane cannot be controlled as to direction of path, either ir. air or on ground. $V_{m c}$ must be no grf tter than $12 V_{s}$ at some minimum weight May control limitıng weight for takeoff

VASI (Visual Approach Slope Indicator)

A system of lights at the sides of a runway that gives visual descent guidance during the approsch Each light unit projects toward the approachıng aircraft a beam of "lght having a white seginent in the upper part of the beam and a red segment in the lower part if the pilot of an airplane on approach sees red lights. he is undershooting. If wiite, he is overshooting

VFR (Visual Flight Rules)

In general, VFR conditions for flight exist when the weather is good enough for the arrcraft to be operated by visual reference to the ground

\section{VOR ("Omni")}

Very high frequency omni-directional radio range $A$ ground rat.o station which provides an aircrat, equipped with a suitable receiver, with location information Works like triangulation in surveying. (Two stations required for accurac; urless aircraft is specially equipped )

\section{VORTAC}

VORTAC incorporates VOR and Tactical Air Navigation equipment into a single system

\section{VTOL (Vertical Takeott and Landing)}

Only operational civil type now is the helicopter Other concepts have been ifred All types. Including helicovier. are expensive to operate and maintain relative to fixed-wing conventiona! a:-craft

Weight Restrictions (on aurcraft category)

(1) Arworthinese FAR 23. 25. etc.)

- $\quad 12.500$ Part 23

- 12.500 (Tra sport category) Part 25

(2) Economic Regs:ation (CAB 298)

Alr Tax $-7,500$ to । ayload or 30 passenger seats Wing Loading

Weight. $W$. of an airplarie Jivided uy its wing area $S$ Since some small proportion of the weight of the airplane in flight is sustained by the fuselage, a conventionally defined wirig arga is used. usually obtained by prolonging the outline of "ne wing panels through the fuselage to the arrplane centerline

The stalling speed of an airplane of given geometry is proportional to $\sqrt{W / S}$

Work

Workers (professional level. skılled and unskilled labor), and Facilities (special factories)

Yaw

Angular motion of an aircraft in flight. about an axis passing through its center of gravity. the axis being approximately vertical when the airplane is in straight-ano. level flight Yaw is seen from the cockpit as a "nose-right" or "nose-left" swing 


\section{APPENDIX F \\ VIRGINIA AIRPORT DATA BANK}

To gain insight into the relationship between the variuus factors important in airport development, an extensive amount of data ware collected for each airport in Virginia and recorded on a separate short form devised for that purpose. A sample data sheet is shown in Figure F-1 The data included such items as facilities available. development potential, vegree of utilization, altemative modes of transportation and demographic data. The data collected for each of these categories and the coding system used are described in this appendix. On the form. categories are designated by capital letters (A, B, C, D, and E). Sections describing the dsta in each category are designated by the same letter 1 ie section labeled " $A$ ", for instance, describes the Physical Facility Parameters

Descriptor and Locator Information

In the top right hand corner of the sheet. a number has been assigned to each airport, based on an a!phabetical listıng of the nearest city. as indicated in the "near city" line. The airport name is given in the "airport" line. The "county/unit" Indicates the county or independent unit in which the airport is located The "planning district" line indicates the number of the planning districts in which the airport is located. Public or private ownership is indicated by a check mark beside either the "public" or "private" line. The "airport operator" indicales the fixed base operator (FBO) at the airport and his phone number.

\section{A. Physical Feciltity Paramotera}

In this section are included those parameters which describe the facilities and services available at each airport These have been coded and a scale generated to differentiate between the level of facilities at each airport Figure F-2 shows the scale and the point value assigned to each level of the scale In general. the scale is self-explanatory The values of the scale for the aircraft capacity are based on FAA standards for airport runway lengths as shown in Table F-I

\section{B. Development Potential}

In this section the potential for future development and 'he resources for such are shown The first line--"plan inclusion"-is coded as follows

4-included in FAA and/or Virginıa Air Transporta. tion System Plan for significant development

3-included in FAA or VATS for some development

2 -included in FAA or VATS for no major changes

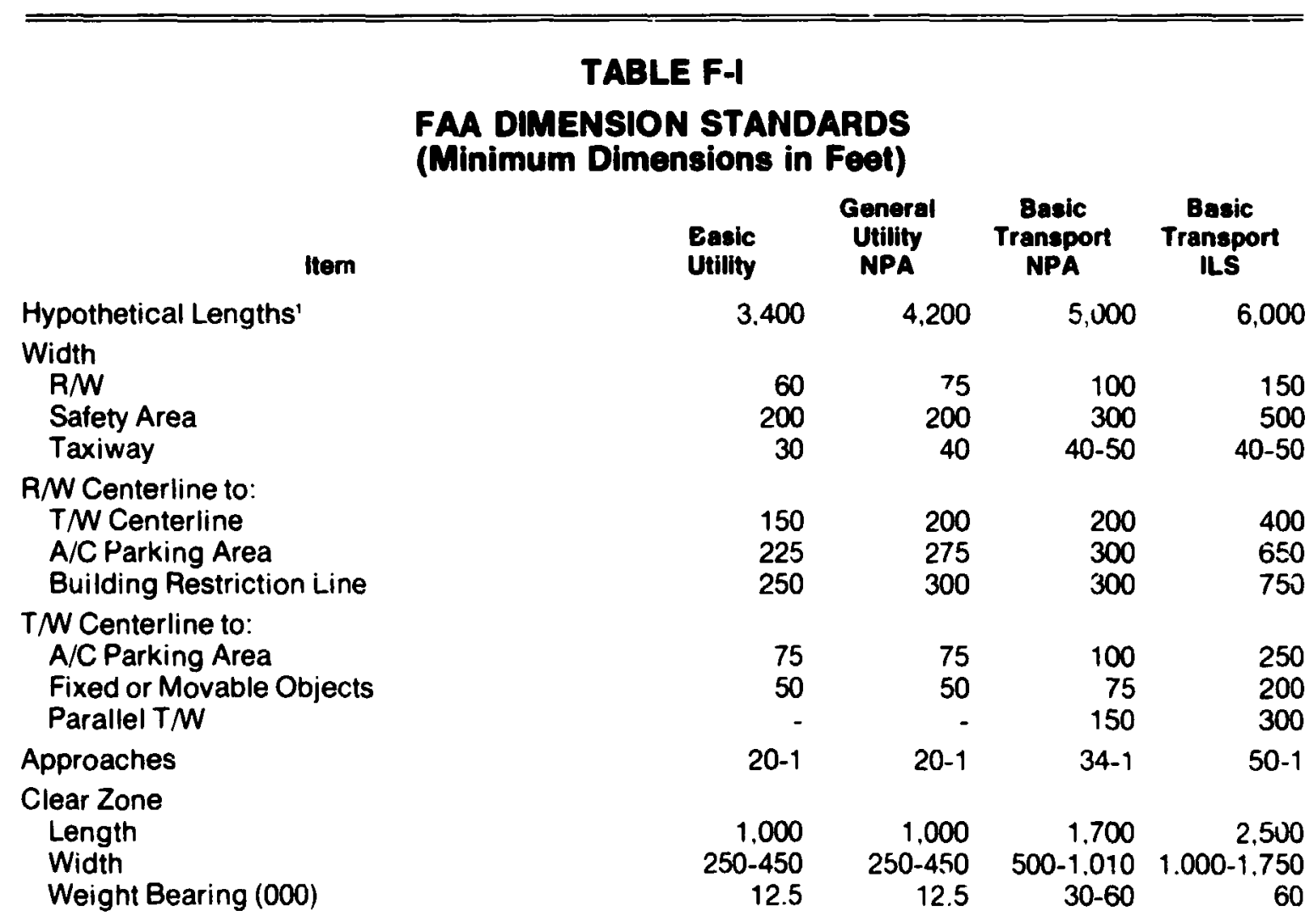

' Lengths are determined by temperature, al.itude and effective RM gradient.

Source: from FAA Advisory Circulars, 150/5300-4A and 150/5300-6. and FAR Part 77 as comipiled by R. Dixon Speas Associates. 


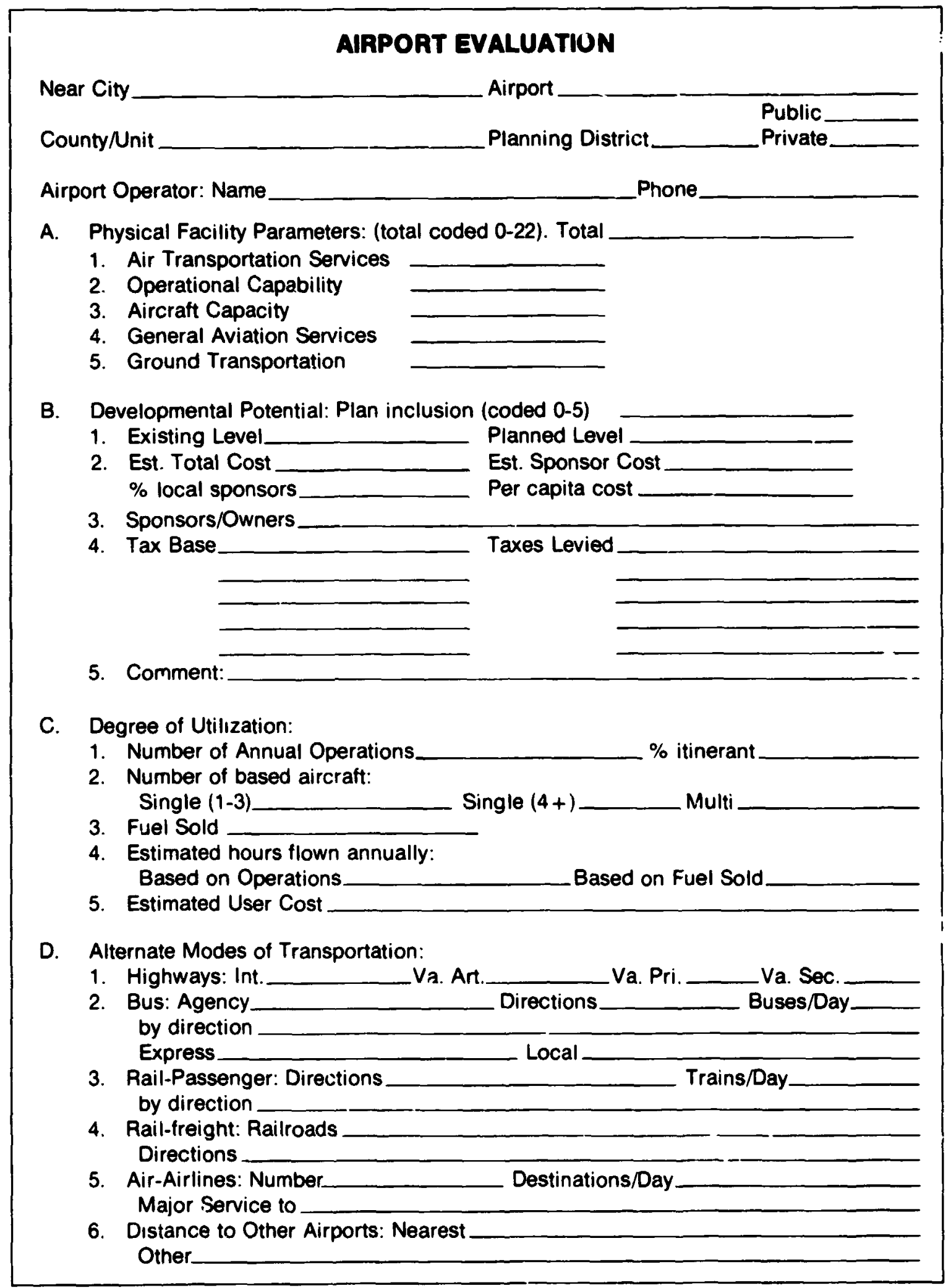

AIRPORT EVALUATION FORM

FIGURE F-1 


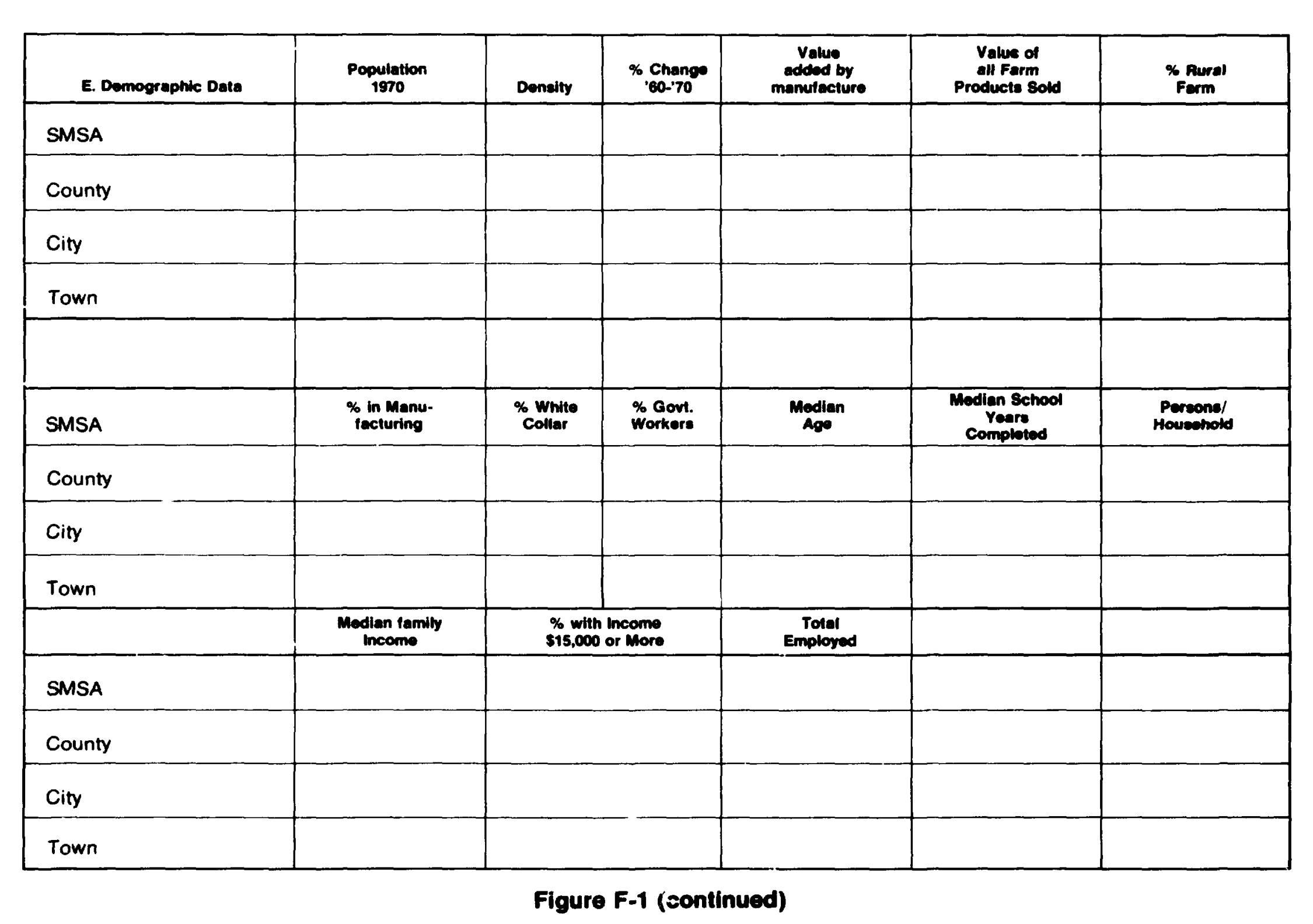


1-limited service potential or not included in FAA or VATS plan

Line number B-1 in Figure F-1 indicates the change in level, as described in Figure 4-4 of the text of this report. The existing arid planned levels are shown. On Line B-2, the, total cost of the planned improvements is shown. The percent that the local sponsor must put up is shown in this category. The per capita cost is shown for all the local units involved. In Line B-3, the name of the sponsor or owner is given.
Line B-4 shows both the tax base and the amount of taxes levied. In general, the tax data were included as an indication of the financial resources of the governmental unit responsible for the airport and thus of its ability to finance the construction and/or maintenance of the facility. The "tax base" was obtained by adding the true value of the municipality's real and public service corporation property with the assessed value of its personal property. The municipality in each case was the political subdivision or subdivisions (in the case of joint ventures) that contributed

\section{SCALING SYSTEM}

This is a 22-Point Scale. Total Scores are the sum of individual scores on each of 5 Physical Facility Dimensions as follows:

1. Air Transportation Services

5. International Air Carrier

4. Certificated Air Carrier (Trunk or national carrier)

3. Certificated Local Service Carrier (Regional carrier)

2. Commuter Air Line (Scheduled air taxi) or Intra-state Airline.

1. Charter or unscheduled air taxi available.

0 . None.

\section{Operational Capabilities}

5. Instrument Landing System (precision: ILS with localizer)

4. Instrument approach (non-precision: ILS)

3. Runway lights, beacon, and approved or published instrument approach.

2. Two of the above.

1. One of the above.

0. None.

\section{Airceraft Capacity}

5. Up through and including transport aircraft of $175,000 \mathrm{lbs}$., hypothetical runway $=$ 6,000 feet, runway width - 150 feet. (ST, AC, or GT classifications)

4. Transport aircraft up to $60,000 \mathrm{lbs}$., hypothetical runway $=5,000$ feet, runway width $=$ $100 \mathrm{ft}$. (BT classification)

3. Paved runway longer than hypothetical value of $4,200 \mathrm{feet}$, width $=75 \mathrm{ft}$., handling general aviation aircraft up through and including 12,500 lbs. (generally, GU classification)

2. Paved runway between 3,400 and 4,199 feet handling gerieral aviation aircraft up to 12,500 .

1. Paved runways between 2,000 and 3,399 feet.

0 . Paved runways less than 2,000 feet or any sod runway.

\section{General Aviation Services}

4. Major repairs, fuel, rental and flight instruction (unless banned)

3. Minor repairs, fuel, rental and flight instruction

2. Fuel and either rental or flight instruction

1. Fuel only

0 . None

\section{Ground Transportation}

3. Taxi, car rental and bus or limousine

2. Taxi and car rental

1. Taxi or courtesy car only

c. None 
to the support of the airport through public funds. Although the assessed value of personal property is not itentical to the true value, the former was chosen as a reliable api:aximation thereot since true value data were not avalable. "Taxes levied" were simply the sum of the real estate and personal property taxes levied in the appropriate municipalities.

Line B.5 is labeled "Comment," and allows the recording of any additional relevant li.icrmation that might be useful in explaining the possible impact ihat the airprt may have on the community. This includes items such as proximity to metropolitan areas, existence of an industria airpark, types of industry in the community. and so forth. Especially considered were any peculiar characteristics of the airport or community which did not appear in other data but which wcisld influence the development of aviation in that region.

\section{Degree of Utillzation}

Airport utilization is generally measured in terms of annual operations and the number of based aircraft Neither figure. however, is an accurate reflection of the economic impact of aviation at the airport. A multi-engine aircraft performing two operations at an aifield will probably have greater impact than a single seat airplane doing ten touch-and-go landings Ar attempt was made therefore to estimate the actual economic impact of air activity at the airport included in the VATS study'

For most airports included in the VATS study, data on the annual number of operations were obtained from the FAA ${ }^{2}$ Virginia registration forms provided data on the number and type of aircraft based at each Virginia airport' At airports for which the FAA provided no estimates for the number of annual operations the VATS Plan consultar's' projection for 1976 were used, adjusted for the actual number of aircraft based at that airpon' At airports with no based aircraft, all operations were assumed :o have been conducted by a single engine aircraft seatıng four

All aircraft based at an airport were divided into three categories single-engine seating three or less. single-engine seating four or more. and multi-engine The total operations at an airport were assinned to the three aircraft types based on the number of each aircraft type and the relative frequency of operation by that type of aircraft The number of operations pertormed by aircraft type was then multiplied by the average number of

Virginia Air Transportation System Study. Phase III, General Aviation Forecasts. April 1974 Dratt prepared by Virginia Division of State Planning and Community Aftairs, and Virginia Division of Aeronautics. Richmond Virginia

2Airport Facilities Annual Record Statistical Report, FAA flle updated to December 1974 Washington. DC

'Annual Aircratt Survey. Virginia Division of Aeronaufics. Richmond. Virginia, April 1975

- Preliminary Dratt of the Plan for the Virginia Air Transportairon System, Division nf Aeronautics. Pichmond. Virginia. Decem. ber 1974

- Air Traflic Control Aavisory Committee Aeport of the Air Traffic Control, Advisory Committee Vol 2 Department of Transportation. Washington D C, July. 1972 (Appendix G. Tables G 1.4 used to determine average annual hours flown)

- Wartord J J. Public Policy Towards General Aviation. Brookings Institution, Washington, D C. 1971

- Department of Highways Virginia 1974-OHicial State Highway Map. Commonwealth of Virginia Rand MeNally. Chicago. Illinois. 1974

- Russalrs Official National Motor Coach Guide. Russell s Guides. Inc . Cedar Rapids. lowa, Volume 47. No 8. May 1975 hours/operation performed by that aircraft type to deterriline the total hours flown by all aircraft of that type at the airport" The hours flown were then multiplied by the average hourly operating cost to determine the usor cost for each aircraft type * A sample calculation is given in $\mathrm{Ta}$. ble F-II. The user costs for the three aircraft types were then added to arrive at a figure for the total user cost at the airport

Although the preceding analysis was developed from data avallable tor 1967 and 1968, the relative break. down between aircraft tyues does not change significantly in the two years and should hold to the present (Table F-II) Furthermore, the figures expressing total user cost. although generated in terms of 1967 dollars, is felt to be a better estimate of the economic impact of aircratt activity at an airport than data on operations and number of based aircrat alone. since it not only distinguishes between aircratt types and their frequency of operation, but also takes into account the differences in their operating expenses.

\section{Alternative Modes}

The service provided by the alternative modes of transportation has been coded on the airport evaluation sheets The point considered for the evaluation is the nearest city or town served by the airport in question The facilities and services are those user. ir intercity transportation. which include highways. Ir'erc.ty buses, rail passenger services, and air carrier services

In the sections to follow, the coding for alternative modes is presented in the order in which the modes are presented in the evaluation sheets $A$ label appearing in many of them is "directions" - which refers to the number of directions one can travel from the evaluation point

1 Highways.' In this sertion the rumber of direc. tions one can travel from the evaluation point has been coded for four classes of higitway. The highway clazses are:

Int. (Interstete)-National sy 3tem of Interstate and defense highways All such highways are completely grade spearated multilane and have geometric characteristics permittıng $70 \mathrm{mph}$ travel

Va. Art. (Virginia Arterial)_A system of high. ways designated by the Virginıa Department of Highways to provide multi-lane facilities between points and in areas not served by the Interstate system Most of these highways have U.S number designa. tions (but do not include all U S highways) and are typically grade separated within urban areas and have at grade intersections in rural arees

Va. Pri. (Virginia Parimary)-This includes all L , highways not inciuded in the arterial systems plus all other Virgınia numbered highways desıgnated primary by the Highway Department High ways coded for this section include only those not paralleled by interstate or Virginia arterial highways

Va. sec. (Virginie secondery)-This includes all Virgınıa numbered highways desıgnated as sec. ondary by the Virginia Highway Department Only those highways not paralleled by the above three classes have been included

2 Bus.' Information coded in this section includes the presence or absence of an agency station where tickets may be purchased and to which express and baggage may be checked The number of directions served and the number of buses a day are also included in the line designatec "by direction" is included the number of buses coming from each direction 


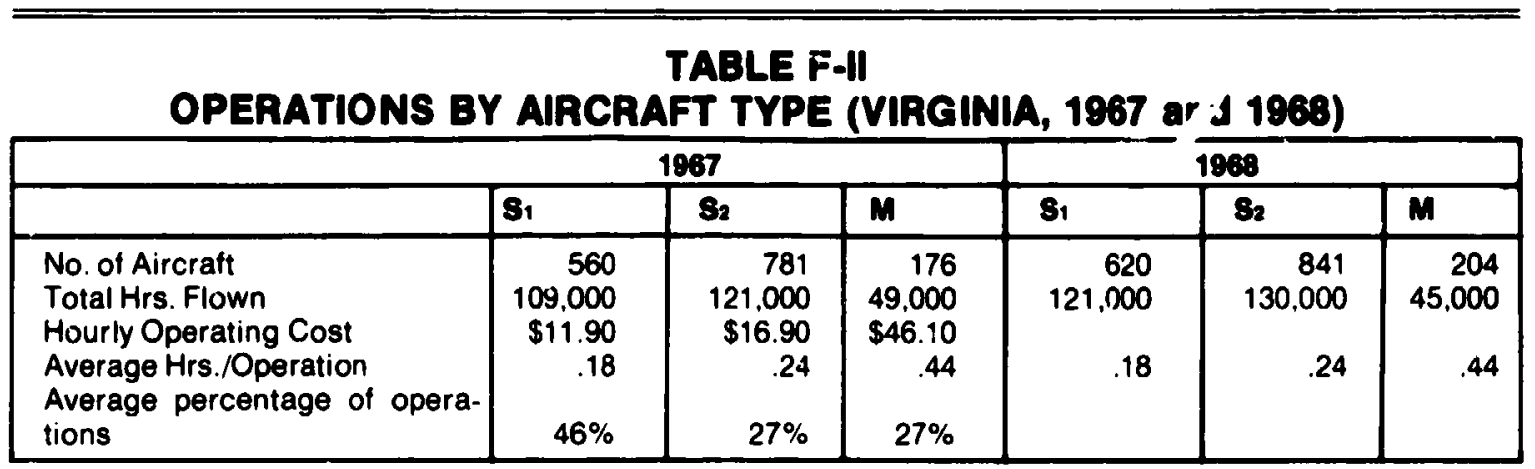

To estimate the total operations performed by each aircraft type the following procedure was used:

$$
\begin{aligned}
& N\left(S_{1}\right)=\frac{\left[.46 n\left(S_{1}\right)\right] N}{\left[.46 n\left(S_{1}\right)+.27 n\left(S_{2}\right)+.27 n(M)\right]} \\
& N\left(S_{2}\right)=-\frac{\left[.27 n\left(S_{2}\right)\right] N}{\left[.46 n\left(S_{1}\right)+.27 n\left(S_{2}\right)+.27 N(M)\right]} \\
& N(M)=\frac{[.27 n(M)] N}{\left[.46 n\left(S_{1}\right)+.27 n\left(S_{2}\right)+.27 n(M)\right]}
\end{aligned}
$$

Where $\quad \mathrm{N}$ - total operations at an airport

$S_{1}$ - Single engine aircraft seating three or less

$\mathrm{S}_{2}$ - Single engine aircraft seating four or more

M - Multi-ençine aircraft

$N($ ) - Operatioils performed by aircraft type ( )

$n i$ ) - Number of based aircraft of type ( )

3 Rall Pasesenger.' This information is very similar to that given for intercity buses The number of directions served. the number of trains per day, and the number of trains coming from each direction.

4 Rall Frolght. ${ }^{0,1}$ As an indication of potential rail passenger service and development potential of the community. the number of directions and level of freight service is given in this section The first part indicates the railroads serving the evaluation point The second pa indicates the level of services rendered and the number of directions served for each level of service for each railroad The railroads are indicated by initials as follows.

Sou Southern

$N \& W$ Nortolk and Western

$C \& O$ Chesapeake and Ohı

R F \& P Richmond, Fredricksburg and Potomac

- Amtrak. Alt-America Schedule, May 15, 1975

'US Department of Transportation Rall Senvice in the Midwest and Northeast Region, Local Rall Service Zone Reports. Washing.un. D C . Volume II Part 2. Fobruary 1974

- Otficial Rainway Buide, North American Freight Senvice Edition. National Ratway Publication Company. Now York. Now York, Volume 107, No 5 March/Aprll, 1975

- Onicial Airline Guide, (OAG). North American Edition. Reuben H Donnelly Fublisners, Oak Brook, Illinols, May 15, 1975

$\begin{array}{ll}\text { PC } & \text { Penn Ccntral } \\ \text { B \& O } & \text { Baltimore and Ohio } \\ \text { SCL } & \text { Seaboard Coast Line } \\ \text { L \& N } & \text { Louisville and Nashville } \\ \text { CLIN } & \text { Slinchfield } \\ \text { NS } & \text { Norfolk Soi:thern }\end{array}$

NF \& D Nortolk, Franklın, and Danville

The rail freight service level is indicated after each railroad by a parenthesized expression of the form $(x, y)$ The indicator $x$ shows the level of service and $y$ the number "directions the rail lines with $x$ level of service go. The $x$ levels of service are indicated as follows
(1) 0 - 9 million gross ton miles
(2) 1 - 49 million gross ton miles
(3) 5 - 99 million gross ton miles
(4) $10 \cdot 19.9$ million gross ton miks
(5) 20.299 million gross ton miles
(6) $30-39.9$ million gross tor miles
(7) 40 . million gross ion miles

5 Arlines." Indicated in this section cre the number of airlines, the number of destinations reached per day by direcl flights from the airport, and the major destinations served from the airport These major destinations are indicated by the three-letter aurlıne code. The common ones are

DCA Washington Natıonal

IHD Dulles 


\section{ROA Roanoke \\ ORF Nortolk \\ RIC Richmond \\ LGA Laguardia \\ EWR Nowark \\ PHL Philadelphia \\ BAL Baltımore}

6. Distance to other Airporte. The distance to the nearest airport is indicated. The distance to other close airports is also included.

\section{E. Domographic Data}

In order to understand the socio-economic environment surrounding each airport. demographic data were compiled on all nearty towns, cities, and counties that were likely to use the aurport Standard Metropolitan Statıstical Areas (SMSAS) were also included if the facility was located within one The SMSAs used in these tabula. tions have since been enlarged to include additional counties and cities, but data for these larger SMSAs were not avallable as this report went to press

"Value added by manufacture" was derived by subtracting the total cost of materials (including materials. supplies, fuel, electric energy, cost of resales and miscellaneous rereipts) from the value of shipments (in- cluding resales) and other receipts, and adjusting the resulting amount by the nei change in finished products and work-in-progress inventories between the beginning and end of the year "Percent rural farm" includes all rural residents living on farms. farms being defined as places of 10 or more acres froll which sales of farm products amounted to $\mathbf{\$ 5 0}$ or more in the preceding calendar year or as places of less than 10 acres from which sales of farm prc Jucls amounted to $\$ 250$ or more in the preceding year. "Persons per nousehold" were obtained by dividing the population in households by the number of housenold heads The percentages for manufacturing. white collar, and government workers were based on the total number of employed persons in the municipality. All other calegories are self-explanatory.

With the exception of "Value of all farm products sold, " which was ohtained from Division of State Planning and Community Affairs, Data Summary Series, (Richmond. Va ), 1971-1972 all the demographic data were compiled from the following $\cup S$ Census publications Number of inhabitants, Virginia, PC(1)-A48. (August, 1971): General Sucial and Economic Characteristics, Virginia, PC(1)-C48. (February. 1972): General Population Characteristics, Virginia, PC(1)-B48, (October, 1971), Dotailed Characteristics. Virginia, F(D(1)-D48. (Novembar, 1972): 1972 Consus of Manufacturers, Virginia, MC72(3)-4?. (May, 1975) 